Bakers and Bakeries in the Roman Empire: Production, Power, and Prestige

\author{
Jared Thomas Benton \\ Denver, Colorado
}

Master's Degree, University of Arizona 2005

Bachelor's Degree, University of Colorado, 2002

A Dissertation presented to the Graduate Faculty of the University of Virginia in Candidacy for the Degree of

Doctor of Philosophy

Department of Art and Art History

University of Virginia

January 2014, Ph.D.

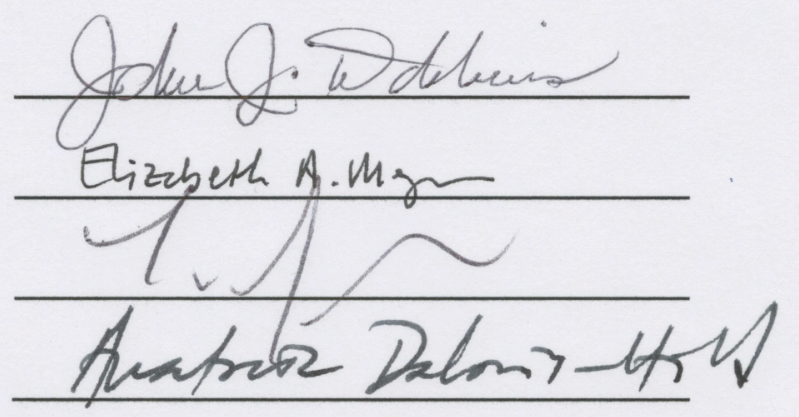


CHAPTER 1 METHOD AND THEORY 28

CHAÎNES OPÉRATOIRES AND SOCIALly Constructed SPACE

CHAPTER 2 THE DEVELOPMENT OF ROMAN COMMERCIAL BAKING 62 Specialization, Product Dependence, AND ‘New Work'

CHAPTER 3 REVENUE AND PROFITS 114

CHAPTER 4 SOCIAL STATUS AND SOCIAL RELATIONSHIPS 136 IN ROMAN PISTRINA

CHAPTER 5 THE STRATEGIES OF ROMAN BAKERS' ASSOCIATIONS: 169 POLITICS, PRICES, AND RIOTS 
APPENDIX CATALOG OF BAKERIES

232

FIGURES

369

BIBLIOGRAPHY

415 
I would like to thank the many friends and family who have supported me over the years, but especially Dr. Dan Weiss, Dr. Kevin Cole, and Gertrude Benton for talking me through some of the more difficult times and for being such good company while backpacking through the George Washington National Forest. I owe much to Dr. Noel Lenski, who set me on the right track. Thanks to the entire Classics department at the University of Arizona, but particularly Dr. David Soren and Dr. Eleni Hasaki. Dr. Bernard Frischer has influenced the direction of my life since my time at the Intercollegiate Center of Classical Studies in Rome. I am heavily indebted epistemologically to Dr. Anastasia Dakouri-Hild who helped me navigate the treacherous world of archaeological theory. Thank you to Dr. Tyler Jo Smith for graciously stepping in at the end and giving me the tools to finish. Dr. Jon E. Lendon and Dr. Elizabeth A. Meyer have taught me what it truly means to be an educator, for which I will be eternally thankful, but I must especially thank Dr. Meyer for reading every word that I ever wrote. Thanks to Dr. John J. Dobbins who has supported me in so many ways it defies enumeration and whom I count among my friends. My parents never questioned why I would choose this path in life (though maybe they should have), but I thank them nonetheless. Above all, without Anne, my best friend and fiancé, I would never have graduated. 


\section{INTRODUCTION}

The importance of bread to the ancient Roman diet is hard to overstate. It not only accompanied most meals, but for many in Roman society it was the foundation of their diet. ${ }^{1}$ As the producers of such a staple, one would expect pistores (Roman miller-bakers) to hold a position or some power in society. Yet traditional scholarship on bakers - and Roman craftsmen in general - lends them little if any agency. Craftsmen are canonically considered a poor and marginalized group who not only failed to unify, but were completely reliant on their social and financial superiors for any status or stability that they might have achieved. This model of craftsmen has been formed almost completely upon ancient literature and epigraphy. A contrary vein of scholarship, typically consisting of more material-based research, lends more agency to tradespeople. But such studies emphasize the subversive behaviors and economic agendas of craftsmen, often drawing conclusions that are not entirely supported by the evidence. Both perspectives on Roman craftsmen are driven more by their need to maintain a broader model of the ancient economy than they are by an interest to explore the productive and social capabilities and interests of Roman craftsmen. Moreover, such studies rarely engage the actual evidence left by the craftsmen themselves. Scholarship that marginalizes craftsmen is grounded in textual evidence produced by and for an elite population that was pre-disposed against

\footnotetext{
${ }^{1}$ One need only think of the rations for working slaves ascribed by Cato (de Agricultura 1.56). Familiae cibaria. Qui opus facient per hiemem tritici modios IIII, per aestatem modios IIII S, vilico, vilicae, epistatae, opilioni modios III, conpeditis per hiemem panis P. IIII, ubi vineam fodere coeperint, panis P. V, usque adeo dum ficos esse coeperint, deinde ad P. IIII redito. "Rations for the hands: Four modii of wheat in winter, and in summer four and a half for the field hands. The overseer, the housekeeper, the foreman, and the shepherd should receive three. The chain-gang should have a ration of four pounds of bread through the winter, increasing to five when they begin to work the vines, and dropping back to four when the figs ripen."
} 
practitioners of all trades; that which over-emphasizes the power and importance of craftsmen is often based on modern economic theory and a few scant pieces of evidence. This study forms a model of Roman craftsmanship that is grounded first and foremost in the evidence, exhausting not only the architectural remains of bakeries, but also the art, epigraphy, and papyri of Roman bakers. From that evidence, a picture of a complex industry emerges. The Empire's urban population relied so completely on bakers for its bread, that the craftsmen, as a group, were often afforded a surprising degree of power in certain social and economic matters. But the defining trait of Roman bakers was their restraint in employing their power.

The marginalization of Roman craftsmen is not a construct of modern scholarships; it has its roots even in antiquity. There was a certain elite disdain evident in Roman literature for craftsmen and economic activity in general. A specific passage from Cicero's De officiis is often cited and is sometimes used to generalize about the perception of craftsmen in general.

Now in regard to trades and other means of livelihood, which ones are to be considered becoming to a gentleman and which ones are vulgar, we have been taught, in general, as follows. First, those means of livelihood are rejected as undesirable which incur people's ill-will, as those of tax-gatherers and usurers. Unbecoming to a gentleman, too, and vulgar are the means of livelihood of all hired workmen whom we pay for mere manual labour, not for artistic skill; for in their case the very wage they receive is a pledge of their slavery. Vulgar we must consider those also who buy from wholesale merchants to retail immediately; for they would get no profits without a great deal of downright lying; and verily, there is no action that is meaner than misrepresentation. And all mechanics are engaged in vulgar trades; for no workshop can have anything liberal about it. Least respectable of all are those trades which cater for sensual pleasures: fishmongers, butchers, cooks, and poulterers, and fishermen, as Terence says. Add to these, if you please, the perfumers, dancers, and the whole corps de ballet.

But the professions in which either a higher degree of intelligence is required or from which no small benefit to society is derived - 
medicine and architecture, for example, and teaching — these are proper for those whose social position they become. Trade, if it is on a small scale, is to be considered vulgar; but if wholesale and on a large scale, importing large quantities from all parts of the world and distributing to many without misrepresentation, it is not to be greatly disparaged. Nay, it even seems to deserve the highest respect, if those who are engaged in it, satiated, or rather, I should say, satisfied with the fortunes they have made, make their way from the port to a country estate, as they have often made it from the sea into port. But of all the occupations by which gain is secured, none is better than agriculture, none more profitable, none more delightful, none more becoming to a freeman. But since I have discussed this quite fully in my Cato Major, you will find there the material that applies to this point. ${ }^{2}$

Superficially, Cicero's distinction between good occupations and bad ones is the "intelligence" required (prudentia) or the "benefit to society" (utilitas). But he applies those principles inconsistently. The contributions of a fisherman differ little from those of a farmer; both occupations are responsible for the production or harvesting of food stuffs and they both require skill. Such inconsistencies indicate the extent to which the perception of ancient craftsmen was ideologically defined and socially informed.

Such ideological objections to craftsmen and craftsmanship have defined how modern scholars have perceived Roman craftsmen for the last half century. M. I. Finley, in his seminal study The Ancient Economy, uses Cicero's assessment of craftsmen to generalize not only about the ancient world, but also the importance of craftsmen to the Roman economy and society. ${ }^{3}$ Finley posits that the elite aversion to occupations and craftsmanship prevented them from engaging in such activities. He writes that, "the citizen-elite were not prepared, in sufficient numbers, to carry on those branches of the economy without which neither they nor their communities could live at the level to which they were accustomed. The elite possessed the resources and the political power,

${ }^{2}$ Cicero De Officiis 1.150-151. Trans. Walter Miller 1913.

${ }^{3}$ Finley 1973, 41-2. 
they could also command a large personnel. They lacked the will; that is to say, they were inhibited, as a group (whatever the responses of a minority), by over-riding values."4 Thus craftsmanship was "in the hands either of men of low status or of men like the wealthy metics of Athens, who were more respectable socially but outsiders politically." Few would argue against this position. We never hear of craftsmen rising to the equestrian order and they would surely have advertised their socially mobility had they obtained it. But Finley's study is an elite prosopography; his intent is to show that those with money and power were not investing in economic activity in the modern sense. This has led to a dichotomous choice for scholars. In most scholarship on the Roman economy, industries were only important if they were massive production centers of the sort that provided bricks for the Imperial building program or exported vast amounts of Arretine ware. Small-scale craftsmen were not only passive in the cultural and economic changes of the ancient Mediterranean region; they were also not even part of Roman culture. In such thinking, they were outsiders politically, as Finley observes, but also outsiders socially, having no place in the elite culture that Finley believes comprised Roman society.

Recent scholarship similarly marginalizes craftsmen by neglecting them in the analyses of Roman social systems and mechanisms of culture change. Andrew WallaceHadrill's influential work Rome's Cultural Revolution explores the nature of Roman society and mechanisms of culture change. ${ }^{5}$ The driving forces of culture change in Wallace-Hadrill's model of Roman society are elite competition and emulation of elite

\footnotetext{
${ }^{4}$ Finley 1973, 60.

${ }^{5}$ Wallace-Hadrill 2008.
} 
behaviors. ${ }^{6}$ As other groups adopted certain practices, elites, who had a social need to differentiate themselves from the rest of society, were forced to seek new practices and different types of prestige goods. Despite constant reference to craft-production and the importance of prestige goods, craftsmen are not mentioned once in his book.

Additionally, Wallace-Hadrill only tangentially addresses one of the defining attributes of Roman material culture: its cities. It is hard to imagine that the large urban centers that developed under the early and middle Empire could have matured without craftsmen. Certainly cities developed without large numbers of craftsmen and high levels of specialization, particularly in the pre-Hellenistic periods. In his survey of Olynthus, Nicholas Cahill finds evidence for only two millers and one baker. ${ }^{7}$ Yet he estimates the population of the city at 1,050 people, possibly tripling in size to 3,000 by $332 \mathrm{BC}$. The lowest estimate for the population of Pompeii in AD 79 is twice that of Olynthus at its peak and most estimates for the Campanian city approach twelve thousand, nearly four times that of its Hellenistic counterpart. Conversely, Ostia may have had a population as large as 60,000 though most current estimates are around 30,000, still ten-times the population of Olynthus. Such concentrations of people would have required constant supply of food and a greater degree of social complexity and specialization than their smaller and earlier counterparts.

\footnotetext{
${ }^{6}$ Wallace-Hadrill 1994, 146 fig. 7.1.

${ }^{7}$ Cahill's evidence for such craftsmen is tenuous at best. His identification of A viii 8 as a baker's house (Cahill 2002, 348) is based on the discovery of one millstone and a few basins in the house. He further identifies houses A 4 and A 6 as the domiciles of millers based on the large number millstones found in them, though he expresses confusion at the use of saddle querns rather than the more productive hopperrubber.
} 
The view of craftsmen as poor and impotent was not always the canonical one.

Early scholars tended to view craftsmen as upwardly mobile and agents of change in

Roman society. Mikhael Rostovtzeff and Tenney Frank viewed Roman craftsmen as a

group who could lift themselves from humble origins to form something of a nouveau

riche. Herbert Hill, in The Roman Middle Class in the Republican Period, forms the first

coherent position on the possibility of a Roman middle class. For Hill, the equites

represented the likeliest candidates. He presents evidence that the wealthy group just

below the patricians was upwardly mobile and actively involved in commercial activity.

Hill overlooks the landed wealth of the equites, their remarkably few numbers, and the

small percentage of them involved in commercial activity. ${ }^{8}$

Hill fails to account for several critical aspects of the equestrian order, not the

least of which is the minimum property requirement. Finley summarizes well the

criticisms levelled against Hill's work.

An influential book on the Roman equites was published in 1952 (by

H. Hill) under the title, The Roman Middle Class, and the middle class, we all know are businessmen. Nothing has bedeviled the history of the later Roman Republic more than this false image of the equites, called businessmen, capitalists, the new moneyed class, ad lib., resting on the large, deeply entrenched assumption that there must have been a powerful capitalist class between the land-owning aristocracy and the poor. We have already seen that the equites were an order in the strict sense, and it has been proved that the overwhelming majority of them were landowners. There was, it is true, a small but important section among them, the publicans, who engaged in public contracts, taxfarming and large-scale moneylending, chiefly to communities in the provinces who were in difficulties over the taxes these same publicans were collecting for the Roman state. I do not underestimate these men, but they were neither a class - they were required to offer land as security for their contracts, it is important to note - nor were they engaged in large-scale manufacture and commerce, nor was there a class struggle between them and the senators. A vast fictitious edifice,

\footnotetext{
${ }^{8}$ Hill 1952.
} 
erected on a single false assumption about classes, still passes for Roman history in too many books. ${ }^{9}$

Hill's overreach in applying the term middle class to the equites and Finley's reaction to his work only contribute to the scholarly marginalization of craftsmen and the gains that could be made from craftsmanship. Emanuel Mayer's recent book, published exactly 60 years after Hill's work and sharing a title with it, is a more sophisticated treatment of the idea of a middle class in the Roman world, but suffers from similar problems. Rather than look for it among the equites, as was Hill's folly, Mayer attaches the label to "the plurality of middle classes" that were dependent "on their sales and not on working their land or that of others." ${ }^{10}$ Mayer notes that such groups vary widely in their status, geography, or even religion and to aggregate them under the single moniker of 'middle class' is to neglect their eclectic nature. In many ways, Mayer's work is a response to the work of Wallace-Hadrill. Mayer disagrees with Wallace-Hadrill's perception of Roman culture as completely elite and he points to the many "workshops and associated businesses" without which the urbanism and accomplishments of Rome would not have existed. $^{11}$

Yet the faults of Mayer's work prevent it from being a coherent alternative to Wallace-Hadrill's comprehensive study. Miko Flohr observes that Mayer never explicitly defines his vague conceptualization of 'middle classes' or how such groups of people manifest in the material evidence, other than their artistic tastes. ${ }^{12}$ Unique aesthetic preferences and wall paintings with original subject matter in medium sized houses

\footnotetext{
${ }^{9}$ Finley $1973,49-50$.

${ }^{10}$ Mayer 2012, 5 and 19.

11 Mayer 2012, 19 and 220.

12 Flohr 2013, 308-9.
} 
suggest to Mayer a middle-class aesthetic, but Flohr notes that such a group would "deprive the Roman world of most of its local urban élites, and reduce most cities to, essentially, middle-class communities. Ultimately, this means that the book fails to make a convincing case that the controversial concept 'middle class' is very useful in discussing Roman urban communities." 13

The weaknesses in Mayer's methods and his goals deprive the sentiment behind Mayer's work of the attention it deserves. A challenge is necessary to the notions that Roman culture was intrinsically elite and that culture change in Roman society was entirely 'top-down.' Indeed, a growing number of archaeologists are beginning to question the canonical position on Roman craftsmen and Roman society in general. Common among this group is the belief that Roman craftsmen were more than Cicero's contemptible description of them. Mark Bradley explores the lives of Roman fullers, rejecting the condescension toward craftsmen evident in the literature. He observes that fullers provided an essential service to society and were proud of their contributions. ${ }^{14}$ Flohr, also studying Roman fullonica (fulleries), not only rejects "the primacy of literary and epigraphic evidence over material remains" but also the asking of "wrong questions." Rather than ascertain the social class or status of fullones, he proposes exploring how they lived their lives. In order to do so, he 'populates' Roman fullonica and explores their behavior by networking their activities through the architecture they inhabited. ${ }^{15}$

\footnotetext{
${ }^{13}$ Flohr 2013, 309.

${ }^{14}$ Bradley 2002, 38-40.

15 The primacy to which Flohr refers is a common held belief that the sole avenue to understanding social components of ancient societies is through the texts and inscriptions, but material culture is just as much a product of social processes as the epigraphy of freedmen or the elegy of Catullus. It would be a mistake, however to abandon the textual and epigraphic evidence. They are too valuable as evidence into the daily
} 
Furthermore, he notes a difference between fulling in Pompeii and that of Rome, Ostia, and Florence. He argues that the small-scale Pompeian producers were less alienated from their work, in the Marxist sense, than the complex workforce on which large-scale production centers relied. Flohr concludes that "the public craftsmanship of the fuller of Pompeii formed a solid basis for a sound dose of occupational pride."16

One finds the conclusion that craftsmen were proud somewhat unsatisfying. Although trades people did not share the elite condescension towards them, it is not entirely clear what that means for their place in Roman society. Were they proud of their craft in spite of - or in opposition to - the elite condescension towards them? What was the actual productive capacity of the craftsmen? Did product dependence change their socio-economic standing in Roman society? If so, what power did the craftsmen wield and to what ends did they implement it? These are the questions that this study addresses through the architectural, artistic, and written evidence for commercial baking in the ancient Roman world.

\section{Previous Archaeological Studies of Roman Commercial Baking}

The earliest work on the Roman baking industry either focuses entirely on artistic evidence or it concerns specific technologies (like millstones) regardless of their specific archaeological context. Hugo Blümner gathers and catalogs the artistic representations of

lives of Romans and just because it is difficult to reconcile them with the material evidence, does not mean that it is impossible.

${ }^{16}$ Flohr 2013, 348-349. 
commercial baking, among other industries. ${ }^{17}$ It is a remarkable resource for further studies, such as Paola Ciancio Rosetto's study of the tomb of the baker, Eurysaces, in Rome or Andrew Wilson and Katia Schorle's analysis of a previously unknown frieze depicting the production of bread. ${ }^{18} \mathrm{~L}$. A. Moritz conducted the first extensive study of Roman millstones. ${ }^{19}$ His work focused primarily on the morphology and the typology of milling technologies, but it also explored issues of baking as a natural extension of flour production. Although specific bakeries are occasionally referenced, Moritz does not incorporate the context of milling technology into his study.

The touchstone for any study of actual Roman bakeries is Betty Jo Mayeske's 1973 doctoral dissertation, Bakeries, Bakers, and Bread at Pompeii: A Study in Social and Economic History. Mayeske surveys the literary evidence for commercial bakeries, catalogs the bakeries in Pompeii, divides them according to their morphology, and uses the decoration in them to argue for religious unity among the bakers of Pompeii.

Jan Theo Bakker's edited volume on the bakeries of Ostia contains one chapter dedicated to each of the eight bakeries in the city. ${ }^{20}$ Each author investigated a different bakery, but used the same methods. The walls of the bakeries were sequenced to assess construction history and the features associated with various processes in the production of bread are located. Unlike Mayeske, Bakker and the other authors explored the interior of the bakeries in detail with a specific focus on production and the function of individual spaces.

\footnotetext{
${ }^{17}$ Blümner 1875.

${ }^{18}$ Ciancio Rosetto 1973; Wilson and Schorle 2009.

19 Moritz 1958.

${ }^{20}$ Bakker 1999.
} 
Mathieu Leduc has conducted the only study of the bakeries at Volubilis. He explores the locations of the bakeries in the built environment, finding that bakeries are well distributed throughout the city but that those of the southern quarter of the city are poorly constructed and less well preserved. ${ }^{21}$ In addition to these more general analyses, Leduc estimates how many people could have been fed by the bakeries in the city by using the volume of the kneading machines. ${ }^{22}$ His research continues in Volubilis, but his interests have extending into ethnoarchaeology as a means of interpreting material remains of bakeries in the ancient city.

Building on Mayeske's work, Nicolas Monteix's recent work on Pompeii's baking industry updates the catalogue of the city's bakeries and creates a " typochronologie", a diachronic typology of bakeries based on the technical construction of their permanent features. ${ }^{23}$ He infers from the different oven-types a diachronic progression of innovation. Monteix is particularly interested in chronological variation and technological innovation. While his work is on-going, he is finding that during the course of the $1^{\text {st }}$ century AD Pompeii's bakers were innovating and standardizing their oven technology. ${ }^{24}$ Ultimately, his work on the wear patterns on baking equipment, such as kneaders and millstones, should prove very relevant to issues of production and productivity.

With the exception of the early work on the artistic and technological components of the commercial baking industry, all of the studies of Roman bakeries have focused on

\footnotetext{
${ }^{21}$ Leduc 2008; 2011.

${ }^{22}$ Leduc 2008, 488-94.

${ }^{23}$ Monteix 2009, 322-323.

${ }^{24}$ Monteix 2009, 234-235
} 
the evidence from a single city. Such myopia has prevented most archaeological studies of Roman industries from addressing broad socio-economic trends. This dissertation was intended, from its inception, to address relevant issues in the study of the Roman world. As such, data was gathered from every available source.

\section{Architectural Remains of Bakeries}

There are six Roman cities that contain bakeries, all in the western half of the Empire (fig. 1). This is not to say that there were no bakeries in the eastern half of the Empire. In fact we know that there were from epigraphic and literary sources. What, then, could explain the absence of bakeries in the east? To some degree, excavation bias must be a factor in preventing the discovery of the Roman bakeries of the eastern Mediterranean basin. Excavations in Greece and the eastern Mediterranean region often focus on pre-Hellenistic periods, before specialization intensified. But Roman cities abound in the east and still no bakeries have been found. The Roman cities of the west were frequently excavated with the goal of exposing the entire site, often motivated by a desire to understand Roman urbanism. Continuity of inhabitation is probably the greatest culprit. While the cities of the western Mediterranean were frequently abandoned by the end of Antiquity, like Ostia or Augusta Raurica, the cities of the east were often continuously inhabited to the present.

Another issue with the architectural remains of bakeries is that thirty-five of the fifty-six bakeries in the dataset are located in Pompeii. This phenomenon in the evidence is in part a product of the nature of craftsmanship in Pompeii. The city's baking industry 
consisted of producers of a smaller scale than the massive bread factories found at Ostia. But the baking industries of other communities, such as Volubilis or Italica, also relied primarily on small-scale producers. Preservation and site-formation of Pompeii must be considered. The city's unique demise is well known, but it is also a topic of debate. Some have perceived Pompeii as a "snapshot" of Roman daily life, while others have noted that residents had twelve hours to escape the city, making it an example of exodus and human response to disaster. In either case, the material remains of bakeries - and the city in general - are significantly better preserved than most of the sites in the dataset of this study. Thus it is not surprising that Pompeii would have more bakeries preserved.

This city of Pompeii is strategically located near the coast and the Sarno River, atop a promontory created by a prehistoric lava flow from Vesuvius. The history of Pompeii begins as early as the Neolithic period, though the first significant settlement of the area occurred during the Bronze Age, possibly near the Porta Nocera. The earliest standing remains date to the sixth century BC, as evidenced by the early Archaic walls. From its foundation, Pompeii appears to have been a multicultural center, with evidence for Greek, Etruscan, and Italic populations. The bulk of the population appears to have spoken Oscan, a central Italian language belonging to the Sabellic language family. Pompeii took on new importance in the first century BC, when it was made a colony and a number of veterans were settled there. With the influx of Romans, the city took on a different physical form. By the principate of Augustus, the city's center had begun to 
formalize into an identifiably Roman forum. ${ }^{25}$ The last chapter of Pompeii's ancient history is defined by tragedy and natural disasters. In AD 62, an earthquake devastated the city and left it in ruins. Following the earthquake, the city rebounded and rebuilt many of the damaged structures, such as the Temple of Isis and the entire east side of the forum. ${ }^{26}$ Despite the revitalization of Pompeii after AD 62, life in the city came to an end the morning of August $24^{\text {th }}$, AD 79 when Vesuvius erupted. The volcano sent incalculable amounts of ash, stone, and gas into the air. As the day progressed, the heavier particles in the air (large and small stones) began raining down onto the city. The city and people of Pompeii more or less survived the hail of so-called lapilli (small volcanic rocks). The true demise of the city began in the night as the smaller particles and ash began to fall. When the column of debris towering above the volcano collapsed, it sent wave after wave of fast moving ash and poisonous gas. The waves, known as pyroclastic flows, leveled any structure not already covered by layers of ash and stone. The gasses asphyxiated the residents of the city that had not already fled as they clambered over layers of stone and ash.

The Pompeian bakeries are distributed fairly evenly throughout the city, although they show a tendency to be located on streets that lead to gates (fig. 2). Many are located in the western half of the city, a fact that has been noted by Ray Laurence. ${ }^{27}$ But only about one third of the eastern half of Pompeii is excavated and there are surely more

\footnotetext{
${ }^{25}$ Although Mau and Maiuri argue for significantly earlier dates for the public structures around the forum, J.J. Dobbins convincingly demonstrates that most of that construction dates to the principate of Augustus and later. Dobbins 1994; 2007.

${ }^{26}$ The inscription outside the temenos of the temple of Isis records the rebuilding of the sanctuary after the earthquake. Dobbins 1994.

${ }^{27}$ Laurence 1994, 55-7.
} 
bakeries to be found under the ash and lapilli. Obviously, the bakeries must date to before AD 79, but they probably took their current form after the earthquakes that must have preceded the eruption.

Like Pompeii, Herculaneum's excellent preservation is owed to the eruption of Vesuvius in AD 79. Unlike Pompeii, the city was not entombed in falling ash and lapilli, but rather quickly consumed by hot pyroclastic flows. ${ }^{28}$ The mud poured into every window and filled every room, covering the city in anywhere from 7 to 25 meters (23 to 80 feet) of mire. Over the centuries, the mud hardened into a stone-like substance or what Maiuri calls 'tufa'.

Herculaneum's two bakeries are both located in the city's insula orientalis, an area characterized by commercial and public spaces (fig. 3). Excavation of the insula's façade began in 1932, under the direction of Amedeo Maiuri. The area was the focus of intense investigation from 1933 to 1937 , when both bakeries were unearthed. The proximity of the bakeries to the Grand Palaestra is frequently noted and the insula orientalis is thought to be a commercial zone.

According to Roman canon, Ostia was founded by the legendary king of Rome, Ancus Marcius. ${ }^{29}$ The earliest remains evident in the city date to the fourth century BC, when the site may have been an early colonia of Rome. Ostia took on a new significance in the Punic wars, during which it served as an important naval base. In the following centuries, as Rome grew, so did Ostia in terms of population and importance. Rome's needs eventually necessitated the construction of harbors to accommodate the many ships

\footnotetext{
${ }^{28}$ Sigurdsson et al. 1982, 43.

${ }^{29}$ Ennius, Annales 143; Cicero, De Re Publica 18, 33.
} 
supplying the two cities. Claudius had the first of the city's harbors built just to the north at Portus. Trajan's construction of the famous hexagonal harbor heralded Ostia's greatest period of prosperity and growth. But by the end of the third century, the grand city began falling into disrepair. Its population declined and its commerce all but halted. Many factors may have played a role in Ostia's fate, including nearby swamps and the silting of the harbor. From the third century onward, emperors began living elsewhere and other urban centers took on greater political, mercantile, and military significance.

Similar to Pompeii, large portions of the city are excavated, roughly 35 hectares, but Ostia has a fundamentally different urban fabric. While the cityscapes of Pompeii and Herculaneum are defined by large atrium-style houses, Ostia's streets are lined with horrea and massive insulae (apartment complexes). Additionally, Pompeii and Herculaneum were destroyed in a single event that allowed for uncharacteristically well preserved features, like carbonized loaves still in an oven. Ostia, on the other hand, was not suddenly covered by ash or mud, but rather experienced slow abandonment and eventual silting. The city ceased to be Rome's primary port by the fourth century AD and the population declined over subsequent centuries until Ostia was completely abandoned in the ninth century AD.

The long period of decline and eventual abandonment manifests as a lack of certain features in Ostia's bakeries. Many of the technologies found in Pompeii's bakeries are missing in Ostia. The millstones and kneading machines have vanished in all but two of the city's bakeries. All that remains in most ovens are the base plate and the 
first few courses of the dome. Like their Pompeian counterparts, Ostia's bakeries tend be located on large streets that lead to gates (fig. 4).

Italica was a Roman colony in the province of Baetica along the Baetis river, now called the Guadalquivir in modern Spain. According to Roman legend, it was founded at the end of the third century BC by Scipio Africanus. ${ }^{30}$ Full colonization, however, did not begin until the second century BC. ${ }^{31}$ Certainly the town was well established by $153 \mathrm{BC}$, when the victor of Corinth, Lucius Mummius, dedicated an inscription and monument to the people of Italica. ${ }^{32}$ It was in the late first century and early second century AD when the town reached the height of its power and prosperity. Both Emperors Trajan and Hadrian hailed from Italica. The town expanded to the northwest, more than doubling in size. Both of the bakeries that have been found in Italica are located in the new portion of the town (fig. 5). One is on the same block as the House of the Birds, while the other is on the same insula as the House of the Planetarium.

Volubilis, a Roman city near modern Fes in Morocco, is considerably less well preserved than the other sites in this study. It was not protected by the debris from a volcanic eruption, as Pompeii was, or covered over by silt by a nearby river, like Ostia. The city was continuously inhabited for centuries after the fall of the Roman Empire and was only fully abandoned with the arrival of Idris I in the 8th century, though the center of occupation in the city gradually shifted and the size of the population varied. The unoccupied city, particularly the ancient center of the city surrounding the forum in the

\footnotetext{
${ }^{30}$ Appian, Iberica, 38.

${ }^{31}$ Bandelli 2002, 123.

${ }^{32}$ CIL II 1119: L MVMMIVS L F IMP COS CORINTHO CAPTA POPVLO ITALICENSI. Much of the inscription is now lost.
} 
southeast and the main cardo in the northwest, remain exposed to the elements. The walls are often only a few feet high and never display their original decoration. Moreover, the site is largely overgrown with vegetation, although recent efforts have remodeled the museum and increased Volubilis' exposure to academics and the public alike. The state of preservation at Volubilis presents several problems for the study of its industries. Many of the diagnostic features that one finds in bakeries at other sites, such as supports for tables or post-holes for shelves have vanished with the upper portion of the walls. Moveable features, such as millstones and kneading machines are often ex situ or are of questionable provenance. Fixed features, like ovens, are often discernible but in such poor condition that their attributes cannot be quantified or assessed.

Despite such challenges, Volubilis contains eight identifiable bakeries scattered throughout the city (fig. 6). They vary in the state of their preservation; the Forum Bakery (Bakery 3 in Volubilis) has millstones and kneading machines in situ and a relatively well-preserved oven, but the bakery in the Maison au Bassin Trefle (Bakery 8 in Volubilis) is nothing more than a kneading machine and the few tiles that remain from the oven. Mathieu Leduc identifies a total of fourteen bakeries, but only eight with ovens. The other six in Leduc's dataset are workshop-like spaces in which either millstones or kneading machines were found. In certain cases, both milstones and kneading machines were found. The moveable nature of millstones or kneading machines combined with the long period of decline and abandonment, make the identification of such spaces as bakeries difficult, if not impossible. This study's dataset of bakeries in Volubilis is limited to those that contain ovens, which are not moveable. 
Augusta Raurica takes its name from the tribe of Rauraci that inhabited the region prior to Roman intrusion. Like many of the cities across the Alps, the Augusta Raurica has its origins in the late Republic. Lucius Munatius Plancus, a Roman senator and consul in $42 \mathrm{BC}$, records that he founded two colonies for Rome: Lugdunum and Raurica. ${ }^{33}$ The colony had to be re-founded or otherwise altered a generation later under the principate of Augustus, earning it the imperial prefix.

The theater at Augusta Raurica was always partially above ground, leading to its mistaken identification as a castle, called the $\mathrm{Zu}$ den neun Thurmen (The Nine Towers) by locals. Investigations at the site began as early as 1590, with the unearthing of the theater. Excavation of the rest of the city began in 1966 when a suburban developer began building in the area. ${ }^{34}$ There were a number of ovens found just west of the theater, including a remarkably intact baking oven (fig. 7). The clustering of the ovens near the city's theater (insula 5, 9, and 5/9), including a number of stones that might have been presses or slaughter floors for a butcher, has drawn speculation that the theater, as a place of public gathering, attracted commercial activity. ${ }^{35}$

\section{Artistic Depictions of Commercial Baking}

The depiction of industries and production was a common practice in Roman society, particularly as a component of funerary rituals. Craftsmen would display the tools and processes of their occupation on their tombs and on altars. Such industrial

\footnotetext{
${ }^{33}$ CIL X 6087.

${ }^{34}$ Berger 1977, 29.

${ }^{35}$ Amman and Schwarz 2002, 275-318.
} 
imagery was a celebration of the deceased's identity in life and contributions to society. As such, the images of commercial production are part of iconographic programs that are designed to communicate something about the individual craftsman and his craft.

Depictions of baking are thus imbued with symbolic meaning, from which one can infer aspects of the craftsman's identity and the identity of his profession.

The images are also important to our understanding of commercial baking. In the celebration of the craftsman's occupation, the technologies of the baking profession are frequently depicted on the funerary monuments. Sometimes the technologies appear in isolation, but in other cases they are shown in their productive context. Such representations of commercial baking provide the critical interpretive link between the material remains of Roman bakeries and the processes that they once housed. In terms of the production they show, depictions of commercial baking can be divided into two categories: continuous narratives of production and isolated scenes of process or technology.

One of the earliest Roman depictions of commercial baking - and unquestionably the most famous - is the Tomb of the Baker, Eurysaces, in Rome (fig. 8). The tomb is located just outside the Porta Maggiore (formerly the Porta Praenestina), at the nexus of the via Labicana and the via Praenestina. The date of the monument is Augustan, but the tomb and Eurysaces are otherwise unknown, preventing a more precise attribution of date. The tomb's bizarre form has been a topic of frequent speculation. Some have hypothesized that the cylinders comprising the bottom of the tomb represent grain 
measures (fig. 9). ${ }^{36}$ The recessed cylinders above them, however, suggest that they represent kneading machines. The depths of the cylinders are adorned with squares in the center, as are the kneading machines from Pompeii's bakeries (figs. 10-11). The most recognizable part of the tomb is the frieze, which extends around the monument just below the cornice. Continuous in narrative, it shows the production of bread from the transportation of grain to the weighing of loaves after baking (fig. 12). A similar relief sculpture, possibly of a similar date, adorns the oven in the Ristorante Romolo in Trastevere (fig. 13). The relief, only recently published, shows a series of production scenes, using some similar motifs to those in the frieze from the tomb of Eurysaces. Andrew Wilson and Katia Schorle speculate that the relief may have originally come from a tomb in the area of restaurant, noting the nearby discovery of the tomb of the Platorini, though they acknowledge the possibility that the relief may have come from farther away. ${ }^{37}$ The sarcophagus of Lucius Annius Octavius Valerianus is dated by its inscription to the later second or early third century AD (fig. 14). ${ }^{38}$ It was found near Casal Rotondo on the Appian Way, south of Rome, though it is currently in Vatican Museums. ${ }^{39}$ The sarcophagus consists of two registers. The upper register shows the harvest of grain and the lower register shows its transportation and manufacture into bread. Specifically, it shows milling and baking. Octavius Valerianus himself is shown as a large central figure around whom the other activities occur. Fragments of a marble plaque now in the Museo Civico Archeologico di Bologna date to the late third or early

\footnotetext{
${ }^{36}$ Blake 1947, 182; Magi 1965, 882; Toynbee 1971, 128; Rosetto 1973, 34-5.

${ }^{37}$ Wilson and Schorle 2009, 101.

${ }^{38}$ CIL VI 11743; Rostovtzeff 1926, pl. 26; Moritz 1958, pl. 8; Hope 2007, 48; Wilson and Schorle 2009, fig. 21.

${ }^{39}$ Smith $1904,444-5$.
} 
fourth century AD (fig. 15). They show men and donkeys milling grain, forming loaves, and baking bread.

Not all depictions of commercial baking show a continuous narrative of breadproduction. Sometimes a single process - or even just a single technology - is shown. The funerary monument of P. Nonnius Zethus from Rome, now in the Vatican Museums, consists of a central inscription, flanked by depictions of a millstone on the left and sieves and grain measures (modii) on the right (fig. 16). Although a donkey is shown with the millstone, the scene is not part of a larger production with kneading, loaf-formation, and baking. The sieves are simply displayed, unaccompanied by figural representation. The first-century AD funerary monument of Marcus Careius Asina shows a similar scene, with a millstone and a donkey (fig. 17). A dog looks on from the right with a funerary altar in the background, an obvious allusion to the monument's function.

\section{Chapter Summaries}

The architectural and artistic evidence, combined with epigraphic and other forms of written evidence, is used to explore three broad topics concerning the lives of Roman bakers: production, hierarchy, and power. A careful quantification of production is critical to assessing the level of dependence on commercially produced bread in the Roman world. The same evidence for production in Roman bakeries expands our understanding of the importance of specialization in the Roman economy. Workshops, such as bakeries, are frequently discussed in terms of status, but it is their owners and 
operators that have status, not the buildings. ${ }^{40}$ These individuals comprise hierarchies, the study of which elucidates the details of the bakeries' operation in terms of labor, management, and finance. Power inside bakeries was obviously distributed asymmetrically throughout the hierarchy, but outside the workshop pistores' primary avenue to power was through unification, with or without formal craft associations or collegia. An analysis of unity among Roman bakers reveals not only their ability to wield power, but also their intentions in doing so. In sum, the examination of production, hierarchy, and power in the Roman baking industry exposes the place of bakers in Roman society and their ability to effect change in the socio-economic environment around them.

The theoretical and methodological problems facing the material study of bakeries are explored in Chapter One. Current methods and approaches to the identification of workshops, the status of craftsmen, and professional associations are analyzed. In the discussion, specific flaws in our approach to Roman craftsmen are isolated. Solutions to these problems are sought in the theoretical approaches from other disciplines, such as anthropology and sociology, to industries and material evidence in general. Specifically, the concept of materiality (human object interrelations) and chaînes opératoires (operating sequences) are adopted from the field of anthropology and adapted to suit the evidence particular to Roman culture. The benefit of applying operating sequences or process chains (as a concept) to Roman bakeries is shown through an exploration of the issues facing the identification bakeries, the study of hierarchy in bakeries, and the assessment of unity among bakers.

\footnotetext{
${ }^{40}$ This philosophy derives largely from Andrew Wallace-Hadrill's (1994) linkage of socio-economic status with house size. The same principles are subsequently applied by Damian Robinson (2005) to Pompeian workshops.
} 
Chapter Two is grounded in a quantification of production in each bakery. The production is estimated from a process known as 'packing', the quantification of the number of circles that can fit into a larger circle without overlapping. The breadproduction is estimated for each city in the dataset with a large enough sample of bakeries. The results are compared to population estimates and estimates of demand in the cities to assess product dependence: how much bread did the community require and were the bakers capable of meeting those needs? The technologies and features in bakeries are further used to isolate two different types of specialization: sub-industries and spin-off industries.

In Chapter Three the estimates of production and the price of bread are used to estimate revenue and profits for the bakeries. The costs of operating the bakeries, like the price of wheat or labor costs, are estimated and subtracted from the revenue to arrive at profit. Finally, the estimated profits are compared to various the salaries of soldiers or the prerequisites for admittance to the equestrian order to place the money earned by commercial bakers in its socio-economic context.

Chapter Four investigates the social statuses of people who participated in the Roman baking industry. This is done at first through the architectural remains of the Roman bakeries are categorized based on the different ways that the chaînes opératoires integrated with other social processes in Roman houses and workshops. The epigraphic, literary and papyrological evidence, provides specific details about the various statuses and foles of individuals in the commercial production of bread. The varying types of 
bakeries are linked with the different systems of operation identified in the written sources of evidence.

Finally, Chapter Five is an exploration of the unity and agenda of Roman bakers. First, the architectural remains of different bakeries and their individual chaînes opératoires are compared and similarities are isolated. Some degree of communication, and potentially regulation, is inferred from such similarities. Iconographic depictions of baking are explored both as indicators of commercial practices and as symbols meaningful both to individual bakers and bakers as groups. Most of the art is from funerary contexts, but millstones also appear on signet rings and shop signs, implying the existence of a shared identity, summarized and symbolized by the images. Finally, inscriptions and papyri from around the Empire indicate that bakers were pursuing patrons, self-regulating, and pursuing an independent economic agenda. Their relationship with the state, however, was founded in mutual restraint. The bakers, for fear of reprisals from authorities, did not seek to unreasonable augment their profits. And the state, for its part, repeatedly shows reluctance to regulate or otherwise interfere with the activities of the bakers, acknowledging their importance to the provisioning of Roman cities.

The chapters are followed by the Appendix, which consists of an illustrated catalog of the bakeries. The catalog is sub-divided according to the cities in which the bakeries were found. The subdivisions are ordered according to the date of the evidence from each city: Pompeii and Herculaneum (first century AD), Ostia and Italica (second century AD), and Volubilis and Augusta Raurica (third century AD). The bakeries are 
numbered sequentially, but they begin anew for each city. In the main body of this study, the bakeries are referenced by their catalog designation in bold. The number followed by their city (Bakery 3 in Ostia).

\section{Preliminary Conclusions}

One simple question drives this study: did Roman craftsmen have the ability to change the socio-economic conditions in which they lived? This study attempts to answer that question by exploring Roman bakers' ability to produce, organize, and push an agenda. From the evidence presented above - and some introduced later - the answer must be a qualified yes. Roman bakers could affect their socio-economic realities, but they were also limited by the social and financial ties that linked them to patrons, former masters, landlords, and lenders.

Roman bakers were extremely adept producers who quickly adopted new technologies allowing them to turn much of the Empire's urban population into customers. Such production earned significant profits for them, not enough to elevate them to one of the higher Roman orders, but certainly above wage labor. Some of that money, however, was owed to proprietors and lenders who wielded both financial and social power over craftsmen, sometimes even owning them as slaves. Even independent craftsmen were beholden to former masters, proprietors, or lenders.

Some pistores formed horizontal bonds with the fellow craftsmen, creating

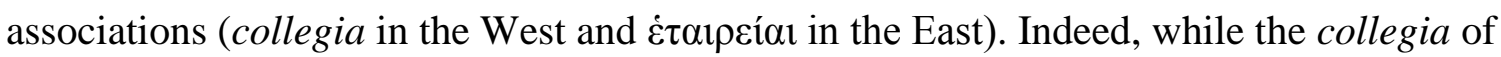
Rome and Ostia were defined by their relationship with the state, the associations of 
craftsmen in other parts of the Empire were characterized more by their affiliations to one another. The bakers appear to have regulated their industry, setting prices and possibly controlling certain aspects of production. Nevertheless, the bakers were frequently afforded special exceptions to certain social obligations, even avoiding punishment after two riots that they had a hand in causing. It is such exemptions that provide the best evidence that Roman bakers had power. Despite this power, we never hear of Roman bakers becoming senators or even equites. They earned modest incomes, but they showed no efforts to maximize profits or fight price-controls. Although they had a monopoly on bread production, one never finds the price-gouging or avarice that came to characterize the guilds of the Middle Ages. What is most striking is not that Roman bakers had power, but that they appear not to have used it very often or to much effect. 


\section{CHAPTER ONE}

\section{Method and Theory: Chaînes Opératoires and Socially Constructed Space}

Despite calls for interdisciplinary studies and new approaches, the study of Roman industries has failed to keep pace with other disciplines, both in method and theory. For most of the twentieth century, the field of Roman studies relied on logical positivism to identify and interpret ancient industrial activity. ${ }^{1}$ As a result, many archaeological and material based studies of Roman industries struggle to make their work relevant to contemporary debates. ${ }^{2}$ If Roman archaeology is to begin addressing broader socio-economic issues - such as specialization in Roman cities or the distribution of social power in industrial hierarchies - then some theoretical framework is essential. But theoretical approaches from other disciplines are tailored to each field's specific evidence and epistemology. Thus theory from anthropology, sociology, and other fields must be adapted - not adopted - to suit the idiosyncrasies of the Roman built environment, especially industries which frequently use technologies and procedures that are unattested in other time periods and in other cultures.

This chapter accomplishes three objectives. First, the problems facing the study of Roman industries are isolated in the scholarship on the subject. Second, the theories of inference from other fields of study, such as anthropology and sociology, are explored for

\footnotetext{
1 Allison 1999, 59.

${ }^{2}$ A June, 2012 conference, aimed at integrating archaeological studies on Pompeii into the debates of economic history, was held at Oxford University: Structure and Scale of Roman Urban Economies: the Case of Pompeii.
} 
methods to improve our understanding of Roman industries. Third, the final section of this chapter shows how such theories from other fields are adapted and applied in this this study.

Epistemologically, this study is grounded in the 'materiality' strain of archaeological thought and ontological approaches to architecture. Materiality is a concept that often defies qualification. Chris Gosden, an anthropological archaeologist whose work pertains to the human perception of objects, defines 'materiality' as "human relations with the material world." He contrasts it with 'mutuality', which he defines as 'human inter-relations." 3 While contrasting the two concepts, Gosden clearly views them as integrated and co-constitutive. Gosden's intent is a balance between materiality and mutuality, but the majority of similar studies place disproportionate emphasis on mutuality. Some research, like the anthropologist Daniel Miller's work on the material world, treats materiality as the medium through which one studies mutuality. ${ }^{4}$ Other, more ethereal studies completely avoid defining materiality as a concept and rarely integrate material culture in their analyses. ${ }^{5}$ For the purposes of this study, materiality is the complex and often reflexive relationship between human action and the material world that surrounds it.

Human and artifact interrelations, or materiality, are often conceptualized through chaînes opératoires, sometimes translated as operating sequences. The application of chaînes opératoires is grounded in the belief that knowing the necessary processes and their order facilitates an understanding of production. Such sequences of operations,

\footnotetext{
${ }^{3}$ Gosden 1994, 82 .

${ }^{4}$ Miller 2005.

${ }^{5}$ Godelier 1986; Miller 1998; Toren 1999; Graves-Brown 2000.
} 
when linked to specific features or technologies, can provide a critical link between industrial processes and the spaces that hosted them. With commercial production of bread spatially located in houses and workshops, one can begin to explore topics such as who was performing the labor and what their relationships were with other participants in the baking industry.

\section{Approaches to Roman Industrial Space:}

Three topics are explored in Roman bakeries: production, social status of bakers, and professional bakers' associations. Such issues have been investigated through the architectural remains of Roman industries, but with limited success. Inadequate methods have played a significant role in limiting - or otherwise impairing - the conclusions derived from material evidence for Roman craftsmanship. The identification of industries remains rooted in logical positivism, uninformed by issues of production or scale. Status, on the other hand, is frequently equated with area or size; the larger the workshop or house, the higher the status. The study of Roman trade-associations, in their many forms, has primarily been based on epigraphy and legal evidence. Archaeological approaches to unity and association among craftsmen have focused on the isolation of guild halls and shared religious practices, neglecting professional and productive cooperation evident in the workshops. 


\section{Identification of Workshops}

Walter Moeller provides one of the first archaeological studies of an industry. In his work on the ancient wool industry of Pompeii, he identifies a series of establishments which he associates with the different processes in wool production. ${ }^{6}$ Moeller's method begins with an analysis of wool terminology derived from literature and epigraphy. He determines what tasks were associated with the different terms based on their etymology. In the case of lanifricarius, the word literally means 'wool-scrubber'. Moeller then compares this to Pliny's, and others', description of ancient wool manufacture. He links the lanifricarius with the initial wool cleansing that involved washing and scrubbing the wool to remove impurities. Finally, he applies the term officina lanifricaria to establishments that he associates with that profession. There are two problems in Moeller's methods. First, there is no self-assessment: he never explicitly examines or explains his methods in his scholarship. Moeller simply states which workshops he identifies as officina lanifricaria, the presence of a series of vats his only criterion. Second, he argues that Pompeii's wool industry produced more than the city could consume and exported the surplus, but he makes no effort to quantify either the city's production or consumption.

In a similar vein, Betty Jo Mayeske's 1972 dissertation was the first to study Pompeii's bakeries. ${ }^{7}$ She posits that any space with an oven was a commercial bakery and as a result she includes in her study a number of small spaces, often in large houses, with a small oven. Mayekse also includes small workshops, clearly commercial in nature,

${ }^{6}$ Moeller 1966, 493-6; 1976.

${ }^{7}$ Mayeske 1972. 
but with only a large oven. Not all of these spaces are necessarily bakeries. Some could be kitchens and other industries could made use of similar oven-technology. Jan Theo Bakker, in an edited volume on the bakeries of Ostia, provides a study better grounded in the actual material remains of the industries. ${ }^{8}$ The touchstone for any further study on Ostia's baking industry, each chapter and author explores one bakery in the ancient city. Methodologically, the walls of the bakeries are sequenced to assess construction history and the various technological attributes of the bakeries are described. The features associated with the production of bread (such as millstones, paving stones, kneading machines, or ovens) are cataloged to indicate the nature of production in the workshops.

\section{The Social Status of Craftsmen}

Moeller's work on the wool industry of Pompeii is among the first archaeological studies to address the socio-economic status of Roman craftsmen. He constructs a complicated argument based on supposition and argues that Pompeii's wool industry was run by "boss fullers" who earned significant wealth from their commercial activities. Moeller arbitrarily sets the number of workers in each establishment at thirteen: twelve workers and one foreman. ${ }^{9}$ Moeller then estimates that seven hundred to a thousand Pompeians were involved in the wool industry, between five and ten percent of the city's population. He infers from this that the industry was producing more wool than Pompeii required and that the surplus was exported. The exports of wool, surmises Moeller,

\footnotetext{
${ }^{8}$ Bakker 1999.

${ }^{9}$ Moeller 1976, 81.
} 
generated significant wealth that was reaped by "fuller bosses." ${ }^{10}$ Moeller uses the names of certain individuals, whom he believes participated in the wool industry, to argue that fullers were primarily freedmen. ${ }^{11}$ Moeller ultimately concludes that a group of self-made entrepreneurs drove the wool industry of Pompeii.

Mayeske infers the socio-economic status of the bakers from the physical relationship of bakeries to large houses, concluding that bakers were primarily elites but not exclusively so. Her research is based on two erroneous assumptions. First, she assumes that the spatial relationships between bakeries and elite domestic spaces are a direct reflection of the socio-economic status of bakers, and second, that people actively participating in a bakery were from the same social background.

Although not a study of Pompeian industries, Andrew Wallace-Hadrill's seminal work, Houses and Society in Pompeii and Herculaneum, provides a method for addressing wealth and socio-economic status that was adopted by many subsequent scholars. He uses house size and form to divide Pompeian domūs into four categories, termed quartiles. ${ }^{12}$ The underlying philosophy is that house-size is determined by socioeconomic status. In other words, the larger the house is in terms of area, the wealthier the resident. Scholarship on Roman houses is important to the study of industries in two ways. First, many of the bakeries were linked with - or doubled as - domestic space. Second, industries conformed to the social needs of society just as houses did. Yet the study of Roman industries has focused primarily on the workshop's exterior, such as the locations of workshops within the built environment of a city or the relationships of

\footnotetext{
${ }^{10}$ Moeller 1976, 92 and 99.

${ }^{11}$ Moeller 1976, 98-104.

12 Wallace-Hadrill 1994, 81.
} 
workshops with other structures. ${ }^{13}$ Scholarship in this vein tends to infer the status of craftsmen from the relationship of the workshop to elite domestic space. ${ }^{14}$ Damian Robinson, relying on Wallace-Hadrill's quartile system, divides the bakeries of Pompeii according to their size and their relationship to large houses. He determines that participants in commercial baking occupied positions across the full spectrum of Pompeian socio-economic statuses, but that the actual production was hidden in the largest houses assumed to be the most elite homes. Robinson argues that elites sought to conceal commercial activity to "give the impression to a viewing public that the owner of the property was engaged in a toil-free life through disguising the extent of the owner's participation in industry." 15 Miko Flohr observes that Robinson's methods and hypothesis fail "to do justice to the archaeological material" and are "based on ideas about social status and human behavior that, unfortunately, are never tested by a detailed analysis of the material evidence." 16

Moving in new directions, Flohr's recent writing on domestic and industrial space assesses the social complexity behind Pompeii's industries. He accepts Wallace-Hadrill's assumption that house size, in general, equates to socioeconomic status, but he adopts Felix Pirson's use of number of rooms rather than total area in meters. Flohr adapts this assumption with an architectural distinction between the domus and the taberna.${ }^{17}$ Flohr's

\footnotetext{
${ }^{13}$ Laurence 1994, 55-69.

${ }^{14}$ The initial study of the bakeries in Pompeii by Betty Jo Mayeske (1973) subdivided bakeries according to their relationship with nearby large houses. Walter Moeller's creation of 'fuller-bosses' from the officina lanifricaria he found in Pompeii. Neither of these studies found much acceptance in terms of their interpretation, but they were the foundation of other studies. They composed the first catalogs of the city's industries and summarized the previous and relevant scholarship.

${ }^{15}$ Robinson 2005, 88-105.

${ }^{16}$ Flohr 2007, 130.

${ }^{17}$ Flohr 2007, 136-142.
} 
dichotomy distinguishes large atrium-style houses (the domus) from industries with no link to a large house (the taberna). His data show that workshops can be found in every sort of house, large and small. Like Robinson, Flohr finds that industrial space in the domus tends to be less visible from the street, but argues that this is due to the practical needs of the household and the industry itself. In opposition to Robinson's hypothesis that Roman elites held an aversion to commercial activity, Flohr prefers a functionalist interpretation, arguing that if any concealment took place, it was "related to the internal organization of the complex and had little to do with the relation between workshop and the outside world." 18

In every case, Flohr argues that the evidence demonstrates a significant amount of independence among craftsmen. They may have rented space from elites, but their dayto-day activities were not controlled. Moreover, he uses this to support Finley's position that elites derived their wealth primarily from their land, in this case in the form of rent, but had little hand in economic activities. Flohr rightly observes that the nature of ten rooms surrounding a courtyard is fundamentally different from that of ten rooms in a row linked by a corridor. ${ }^{19}$ His meaning is simple: space is more than the sum of its parts. Flohr knows this intuitively, but struggles to make typologies reflective of that reality. His distinction between the domus and the taberna is an attempt to address the problem, but the resulting analysis comes off as an oversimplification of an extremely complex and intertwined relationship between domestic activity and commercial production.

\footnotetext{
18 Flohr 2007, 135.

${ }^{19}$ Flohr 2007, 136.
} 
Although Flohr's methods and conceptualization of Roman industrial architecture are more sophisticated than Robinson's, the functionalism he employs neglects social aspects of life in the workshop. Robinson, on the other hand, views workshops as having status. Workshops cannot have status themselves nor do they simply or accurately represent it. People who worked in a workshop have status and they were assuredly not of the same background. Indeed, we have already seen that bakeries relied on social structures and institutions, not homogenous social groups. Any assessment of peoples' status as they practiced their craft in bakeries must be grounded in processes or behaviors that are attested in these spaces, not in house morphology as such.

\section{Associations of Craftsmen}

The material study of Roman craft associations has relied mostly on epigraphic evidence for communal behaviors. Inscriptions do provide an abundance of evidence for the group activities of craftsmen. But epigraphy is rarely a way of preserving financial agreements or fiscal policies; the inscribing of stone is a tradition steeped in practices such as elite display and euergatism. Naturally, overreliance on this source of evidence focuses the study of collegia and other craft-based associations on their social behaviors, like dining or funerary rights. When architectural evidence is employed, it is usually in the context of guild halls or the search for them. Rarely are the remains of workshops or productive spaces explored for similarities or differences that might indicate the types of professional behaviors that the craftsmen shared. 
Moeller argues that Pompeii's fullers were organized into a collegium, or some into an association based on common craft. He cites two sources of evidence for this. First, abundant epigraphic evidence implies at least political unity through the support of specific candidates. ${ }^{20}$ Second, the fullones of Pompeii erected a statue in the Eumachia building and dedicated it to her. ${ }^{21}$ This is the only evidence tying the fullers or any other industry to the building or to Eumachia. From this, Moeller interprets the entire structure as the meeting place of a collegium fullonum (an association of fullers) and an auction house for wool products. $^{22}$

Other scholars infer the existence of an association or some form of unity, though stopping short of identifying a formal collegium. Mayeske turns to religious iconography in Pompeii's bakeries, noting the repeated occurrence of Vesta in such contexts. From this, Mayeske identifies a shared religious devotion to Vesta and the Vestalia among pistores, although she avoids stating that there was a collegium pistorum (an association of bakers). ${ }^{23}$ Matthieu Leduc notes that the distribution of the bakeries in Volubilis is rather diffuse, but he interprets the similar types of technologies in the workshops as a form of unity. ${ }^{24}$ Flohr is even more cautious, although he notes that the absence of epigraphic evidence attesting craft associations of fullones is not convincing evidence that such institutions did not exist or that the craftsmen were not pursuing economic agendas as a group. ${ }^{25}$

\footnotetext{
${ }^{20}$ Moeller 1976, 83-97.

${ }^{21}$ CIL X 813.

${ }^{22}$ Moeller 1976, 57-71.

${ }^{23}$ Mayeske 1972, 144-165.

${ }^{24}$ Leduc 2008, 497-503.

${ }^{25}$ Flohr 2013, 333-5.
} 


\section{Theories of Inference}

In some ways, the problems facing the study of Roman industries are the same that have plagued archaeology in general for the last fifty years. How do we interpret the patterns we find in the material record? Answering this question has been the focus of archaeological thought since the 1960s and much work has addressed the topic. Anthropological approaches to industry abound, yet most of them developed for application to prehistoric contexts. Certainly the Mediterranean culture of the first century AD differed greatly from prehistoric peoples in a number of factors such as social complexity, technological capacity, or population size and density. Among our sources of evidence, architecture abounds for Roman communities in a way that it does not for prehistoric sites. Yet the last major contribution to archaeological thought on architecture came in 1994, with the edited volume by Michael Parker Pearson and Colin Richards.

Lewis Binford's 1962 call to arms, Archaeology as Anthropology, ushered in the 'New Archaeology', a period of rapid advancement in archaeological thought. ${ }^{26}$ The New Archaeology was characterized by determinism and objective positivism. Its dominant means of inference was middle-range theory, which proposes to bridge the 'static' material evidence with the 'dynamic' processes that circumscribed its formation. ${ }^{27}$ In other words, inferences are made about the processes based on their material consequences. A middle-ranging device - often an experimental or ethnoarchaeological study - reveals the relationship between the material and the

${ }^{26}$ Binford 1962.

${ }^{27}$ Binford 1977, 1978. 
processes. Middle-range theory bridges the divide between the material and the immaterial, generating data, but a more general theory is required to make that data relevant to major issues facing archaeologists. During the heyday of processual archaeology, that role was often filled by Systems theory. ${ }^{28}$ More recently behavioral archaeology radiated into that niche. James O'Connell urges the formation of a general theory of human behavior, adopting approaches from behavioral ecology. Essentially O’Connell proposes the formation of hypothetical scenarios derived from ethnoarchaeology, then the testing of such scenarios against the material evidence available. $^{29}$

Ethnoarchaeology, middle-range theory and behavioral archaeology comprise a powerful system of inference, but they are not without their flaws. The use of ethnoarchaeology limits, by its very nature, inferences to observable and extant phenomena. Extinct or inconceivable behaviors are invisible to the ethnoarchaeologist. ${ }^{30}$ Middle-range theory, because it relies so heavily on observation and extant phenomena, is subject to the same criticism. Similarly, behavioral archaeology is reliant on data generated by ethnography, ethnoarchaeology and middle-range theory. Another problem is the assumed direct relationship between the material and the immaterial. Middle-range theory is predicated on the idea that actions have material consequences; thus action can be inferred from those material consequences if one understands the relationship between the two. What happens when an action has no perceivable material consequence or when

\footnotetext{
${ }^{28}$ Flannery 1968, 1973.

${ }^{29}$ O'Connell 1995.

${ }^{30}$ Hodder 1986, 194.
} 
multiple processes result in identical material consequences? ${ }^{31}$ Moreover, the observation of direct material consequences originated in the study of 'site-formation processes', which sought to identify how material enters the archaeological record. Such a focus on interment succeeds, in part, for prehistoric contexts, but interment of artifact assemblages is less applicable to contexts with permanent architecture, long-term reuse, and complex technological accoutrements. Architecture and technology are not material consequences, but their forms and spatial arrangements are essential to understanding and enabling - ancient processes, particularly in the proto-industrial society of Imperial Rome.

Bridging empirical data and theory is the defining problem of archaeological thought and has been so since the advent of the New Archaeology. Middle-range theory's sole purpose was to address this very issue. More recently, the concept of 'materiality' has come to dominate the discourse on material evidence and inference. While middlerange theory assumed a simple causal relationship between processes and material evidence, approaches concerned with materiality take an ontological bent. For studies operating under the umbrella of materiality, the complex relationship between humans and their physical environment is essential to inference.

Some recent scholars have begun to lament the absence of materials in the study of materiality. Tim Ingold, an anthropologist and ethnographer whose work focuses on husbandry in northern Scandinavia, points out that such conceptualization of materiality marginalizes material culture. He describes such scholarship as not engaged "with the

\footnotetext{
${ }^{31}$ Multiple processes can often have similar or identical material consequences, which James O’ Connell labels ‘equifinality'. O’Connell 1995.
} 
tangible stuff of craftsmen and manufacturers but with the abstract ruminations of philosophers and theorists. To understand materiality, it seems, we need to get as far away from materials as possible." ${ }^{, 32}$ Ingold further criticizes such approaches for their complete divorce from actual materials. He does not see material and cognitive approaches as mutually exclusive, but rather as potentially stronger if integrated. Nicole Boivin, an archaeologist whose work is based in southeast Asia, corroborates Ingold's position, arguing that material engagement theorists reduce "artifacts to reified thoughts." ${ }^{33}$ Furthermore, she argues that it is in fact the 'physicality of matter' that provides objects with functionality, symbolism, and ultimately agency. Boivin's definition of 'materiality' must be a union of Gosden's material relations and human inter-relations. For Boivin, "what is important is not just materiality, but the coming together of materiality and embodied humans engaged in particular activities." ${ }^{\prime 34}$

Despite the ontological focus on human/material relations, the quintessential problem facing adherents of 'materiality' is the same as the one that faced the New Archaeology in its nascence: how does one bridge material culture and the immaterial actions with which it was once associated? Carl Knappett identifies two inferential frameworks from within 'materiality' studies: behavioral chains and chaînes opératoires. Knappett sees the distinction between the two schools of thought as breaking down on geographic (and linguistic) lines. Behavior chains dominate in the Anglophone literature of the United States and chaînes opératoires, as the name might suggest, is the product of

\footnotetext{
${ }^{32}$ Ingold 2007, 2.

${ }^{33}$ Boivin 2008, 129.

${ }^{34}$ Boivin 2008, 167.
} 
Francophone scholarship in France. ${ }^{35}$ David and Kramer, on the other hand, see the difference between behavioral chains and chaînes opératoires as an epistemological difference. $^{36}$ Behavioral chains emerge from the James O’Connell's 'behavioral ecology', more in the determinist camp of archaeology, while chaînes opératoires comprise part of the French school of technologie culturelle, a somewhat more relativist tradition. Both are probably correct.

Using behavioral chains, Schiffer and Skibo explore the factors in artifact design in terms of behavioral archaeology. ${ }^{37}$ They reject traditional classifications of artifacts, such as style and function, and attempt to explain variation in artifacts in terms of artisan behavior, such as procurement of raw materials, skill level, and performance characteristics. Schiffer and Skibo base their analysis on 'behavioral chains', the series of procedures involved in the conversion of raw materials into manufactured goods. They characterize craftsmen as highly adaptable problem-solvers, who respond to changing conditions by innovating and altering their existing practices. Schiffer and Skibo’s explanation of artifact variability along with O'Connell's behavioral ecology offer a framework for archaeologists to integrate ethnographic data into their analyses, but both deliberately ignore cultural factors in artifact design. David and Kramer criticize Schiffer and Skibo's approach as setting forth "an unrealistic and ethnocentric image of artisan as engineer-handyman adjusting design in light of feedback regarding any or all activities on an artifact's 'behavioral chain' in order to attain weightings of performance characteristics that approximate a culturally determined ideal (or, in socially

\footnotetext{
${ }^{35}$ Knappett 2012, 196-7.

${ }^{36}$ David and Kramer 2001, 140-1.

37 Schiffer and Skibo 1997.
} 
heterogeneous contexts, ideals).” In other words, Schiffer and Skibo create an archetypal artisan and prescribe it to the evidence, often identifying variance as rational adaptation.

Schiffer and Skibo's behavioral chains are similar to, and likely derived from chaînes opératoires, a conceptualization of industrial practices that has recently witnessed a renaissance. The French archaeologist, André Leroi-Gourhan first began exploring ancient behavior in terms of chaînes opératoires during the 1960s. Cresswell defines the term as "a series of operations which brings a raw material from a natural state to a manufactured state." 38 This indeed coincides with how Leroi-Gourhan conceived chaînes opératoires. The most common anglicized form of this concept is 'operating sequences'. The knowledge of the order of operations facilitates the isolation of manufacture in the material remains, while also providing an interpretive framework for linking material remains to procedural. Many studies, ranging from historical archaeology of the early United States to primatology, use such an approach with great success. ${ }^{39}$ Most of these studies follow Cresswell's definition and tend to adopt a rather linear linking of the chains, most commonly in terms of industrial production. Olivier Gosselain assesses stylistic choices at each stage in the chain of African pottery production. ${ }^{40}$ He finds that social identity is expressed in the technique and stylistic choices of African potters, but it is not static; it is subject to interactions of the potters with other humans, both inside and outside of their social group.

\footnotetext{
${ }^{38}$ Cresswell 1976, 6.

${ }^{39}$ A recent study uses chaînes opératoires to explain and understand resource exploitation and tool use among wild chimpanzees Carvalho, Cunha, Sousa, and Matsuzawa 2008.

${ }^{40}$ Gosselain 2000.
} 
The use of 'sequence' or 'series' to translate chaînes opératoires implies a linear relationship between processes and prevents horizontal links in the chaîne or any conceptualization of industrial practices as linked to other spheres of life. David and Kramer point out that the English translations fail to capture the polysemic nature of the French term and propose a translation of chaîne as 'enchainment'. ${ }^{41}$ Similarly, Skibo and Schiffer have revised their earlier position, replacing 'behavioral chains' with the Spanish word 'cadena' ${ }^{42}$ The shift in terminology is a laudable attempt to include all social and cultural aspects of an object's history. The use of Spanish rather than the original French is an obvious attempt to differentiate behavioral archaeology's use of the idea from the relativist school of technologie culturelle that produced it. Pierre Lemonnier defines a chaîne opératoire as "the series of operations involved in any transformation of matter (including our own body) by human beings." 43 Lemonnier recasts the chaînes opératoires approach as an exploration of all factors influencing production to aid ethnographers and ethnoarchaeologists in designing a research plan and observation list. For the application of chaînes opératoires in archaeology, Lemonnier's definition expands a chain into other areas of human activity, including social behaviors and even human cognition.

Recent studies apply chaînes opératoires to explore invention, innovation, and decision making from the part of the producer/craftsman. Sander van der Leeuw observes that Lemonnier's conceptualization of chaînes opératoires "permit[s] the investigator to come to grips with their variants and thus with both their invariant 'backbones', those strategic components which cannot be modified without jeopardizing the entire chain,

\footnotetext{
${ }^{41}$.David and Kramer 2001, 140.

${ }^{42}$ Skibo and Schiffer 2008, chapter 2.

${ }^{43}$ Lemonnier 1992, 26.
} 
and with the degrees of freedom and the choices which the actors can afford themselves." 44 In other words, some processes are essential to the production of certain items, but at other points in production the producer could achieve the same end through multiple means. It is at these points of freedom that van der Leeuw sees the greatest opportunity to isolate 'choice' (which path the producer chose from the available options). The work of Sander van der Leeuw demonstrates the strengths of chaînes opératoires as a means of inference, particularly concerning human decisions. By tracking individual process through the material evidence for them, one can effectively assess productivity and isolate technological choices of agents in production. Yet choices are informed by the experiences and identity of the one making the decisions. Moreover, the focus on choice in the reconstruction of chaînes opératoires neglects mutuality, as Gosden conceives it. This is the product of a weakness in the chaînes opératoires approach: it restricts production to inflexible paths. Ludovic Coupaye rightly notes that such rigid formulations of the chaînes limit production to a single formulation each time it occurs. ${ }^{45}$ Single option models of production fail to account for change. In such a model, materials and action have routes that they follow without variation. Van der Leeuw notes that human behavior constantly varies and such variation is the actual source of invention. ${ }^{46}$ Through experimentation, whether intentional or not, one arrives at the new. Coupaye advises conceiving of linked processes in terms of a material 'flux', a continuum of technical activities and social behaviors. ${ }^{47}$ Coupaye's flux extends chaînes

\footnotetext{
${ }^{44}$ van der Leeuw 1993, 240-241.

45 Coupaye 2009, 441.

46 van der Leeuw 2009.

${ }^{47}$ Coupaye 2009, 450.
} 
opératoires to include social behaviors. In his study of yam production in Papua New Guinea, he expands the definition of chaîne opératoire from the industrial operating sequences to include other processes, such as the decoration of maabutap (yams). ${ }^{48}$ Productivity, argues Coupaye, comprises more than technical activities and technologies; ritual and aesthetic display can affect production by 'prompting people's emotions and evaluations'. ${ }^{49}$

Similarly, David and Kramer observe that chaînes opératoires are more than the series of procedures comprising industrial production, but can be extended into other spheres of life. ${ }^{50}$ In addition to Coupaye's ritual and aesthetic production, industrial production is integrated into a meshwork of processes that range from domestic mode production to social interaction. All production is carried out by people that have an identity and a socio-economic status. Their industrial activities are part of their daily life and integrated into patterns of behavior that exist outside commercial activity. Thus every chaîne opératoire has social and economic links that extend horizontally from the linear sequence of procedures. Such horizontal, social links in the chaîne are critical to the integration of mutuality into the study of industries, but isolating them is more difficult than identifying a sequence of industrial procedures. Industrial manufacture consists of for the most part - known processes in a familiar order. Social processes are less circumscribed by constants and have fewer material consequences. The issue is one of scope: is it possible to incorporate social and industrial processes into the same theoretical model?

\footnotetext{
${ }^{48}$ Coupaye 2009, 441-449.

${ }^{49}$ Coupaye 2009, 452.

${ }^{50}$ David and Kramer 2001, 140.
} 
One of the advantages of reconstructing chaînes opératoires is the ability to adjust scope while maintaining the same theoretical framework. James Elkins notes that the use of materiality in art history lacks this ability: one is often too focused on a single process in the production of art or the scope is so broad that the study becomes completely divorced from the evidence. ${ }^{51}$ But in the context of architectural evidence and commercial production, one can apply chaînes opératoires on a small scale or a large one. One can trace the sequence of procedures within one establishment to assess the productivity and ascertain the choices of the individual craftsman. Reconstructing the social links in the chaîne allows for an exploration of sociality within industries by 'zooming out' to view the integration of industrial operational sequences in their sociocultural context. Expanding the scope outside individual workshops, comparison of different chaînes of the same industry characterizes the spread of innovative technologies and procedures. Moreover, such comparisons reveal commonalities in practice, which suggest communication between craftsmen and contribute to the reconstruction of the shared identity of tradespeople based on common craft.

Conceiving of architecture in terms of chaînes opératoires and materiality is not new. Christopher Tilley, following his previous work on phenomenology and landscape, applies the concept of materiality to various structures, from Neolithic temples on Malta to barrows in southern Sweden. ${ }^{52}$ Seemingly in response to Ingold's complaint that materials were conspicuously absent in the study of materiality, Tilley explores the form and tactile aspects of building materials as symbolic of cognitive processes. Like much of

${ }^{51}$ Elkins 2008.

52 Tilley 2004. 
Tilley's work, his phenomenological approach is more inspiring than it is a convincing framework for inference about architectonic forms or the cognitive and social processes that produced them.

\section{Identifying Bakeries}

One of the goals of this study is to investigate the roles of specialization and product-dependence in the ancient economy through an assessment of production in bakeries. Although the frequent absence of certain technologies in bakeries makes quantification of production largely based on oven size, chaînes opératoires contribute by ensuring a healthy dataset. Previous studies have identified anything with an oven as a bakery. In some cases, the supposed workshops are clearly domestic kitchens. In other cases, the workshops have ovens and are commercial, but appear to have belonged to a different industry altogether. Exploring the individual processes in the production of bread - the isolation of those processes in the architectural remains - allows one to distinguish production areas that were definitively producing bread and those that were not necessarily doing so. For the quantification of production for each city, the careful identification of bakeries prevents the inclusion of non-bakeries in the calculations that might skew the results.

How do we know what the patterns in material evidence mean? Chaînes opératoires are very well suited to serve as a framework for providing context between technologies. They give visual and spatial expression to the progression of industrial processes, acknowledging their order and direction. But a chaîne opératoire is merely a 
framework for organization production; it does not intrinsically include information about the necessary processes in the production of bread. Nor do chaînes opératoires account for the role of social structures in determining operation time or division of labor. These types of information require some form of comparanda. Textual evidence for baking exists, but only in the form of recipes and domestic mode production. Nor do chaînes opératoires account for the role of social structures in determining operation time or division of labor. These types of information require some form of comparanda. Artistic evidence is well-suited to explicate the relationship between industrial processes and the culturally specific technologies with which they were associated. Iconographic representation of commercial baking, however, is not a visual documentation of commercial baking practices intended for the benefit of posterity; such depictions are a matter of performance in which the patron chooses how to have his or her profession portrayed and ultimately artists give them expression. But such visual comparanda not only indicate the purpose of individual technologies and the order in which they were used. They attest the extent to which bakers and society in general shared a common notion of what comprised a bakery or what kinds of people and activities were associated with it. In this regard, iconographic representations of commercial baking, like the frieze from the Tomb of the Baker, Eurysaces, in Rome, contribute a critical emic element to an otherwise etic analysis of production. They provide a sense of how bakers and Romans in general perceived commercial activity and industrial production. Roman depictions of ancient baking are used to indicate the physical features and technologies that facilitated the production of bread. These features and technologies serve as points of reference with 
which one can link the chaînes opératoires with the spaces that were associated with them.

At the first stage of reconstructing the meshwork of processes, the operational sequence in bread production is reduced to the essential processes that comprise it. Second, contemporaneous depictions of ancient baking are used to indicate the physical features and technologies that facilitated the production of bread. Finally, these features and technologies serve as points of reference in isolating the industrial chaîne opératoire in each bakery. The resulting series of procedures is displayed visually by networks in GIS. In the second stage, the operational sequence is expanded to include the more broadly defined chaîne opératoire, including social processes such as domestic production, dining, donkey stabling, and elite display.

Modern baking has developed many ways to produce bread. W.P. Edwards divides the different methods into five groups: sourdough, bulk fermentation, sponge batter, continuous mixer, and Chorleywood. ${ }^{53}$ Chorleywood requires artificial chemicals and the continuous mixer method needs an electrical high speed mixer, so they cannot serve as analogs for Roman baking. The sponge batter method involves two mixing and fermenting stages, in which the mixture is nearly liquid at first, requiring an impermeable mixer (which the Romans could have made but did not). The remaining methods, sourdough and bulk fermentation, are largely the same with regard to their processes; the difference between the two is that bulk fermentation uses a yeast as a leavening agent, which the sourdough method replaces with a starter (leftover dough highly fermented).

${ }^{53}$ Edwards 2007, 168. 
Edwards reduces bulk fermentation - and the sourdough method - to the processes that comprised them, in essence the sequence of operations or chaîne opératoire (table 1). His sequence is mixing, kneading, bulk fermentation, dividing, molding, panning, proving, and baking. Yet the use of these principles as interpretive tools imposes a modern and fundamentally etic perspective on ancient baking practices. Ancient bakers may have initiated such chemical processes, but they certainly had no knowledge of them on a molecular level, and processes such as molding or panning are not essential to bread production and are culturally specific. Edwards' sequence of operation can be further reduced to four processes: mixing and kneading, loaf-formation, proving, and baking. Furthermore, ancient bakers milled their own grain, compelling the inclusion of milling and sifting to the operational sequence. Thus the chaîne opératoire in ancient bread production is: (1) the grain is milled into flour; (2) the flour is sifted to remove impurities; (3) flour, water, and a leavening agent are mixed and kneaded into dough; (4) the dough is formed into loaves; (5) the loaves are left to leaven or rise, ideally at a controlled and rather warm temperature; (6) and finally, the loaves are baked into bread.

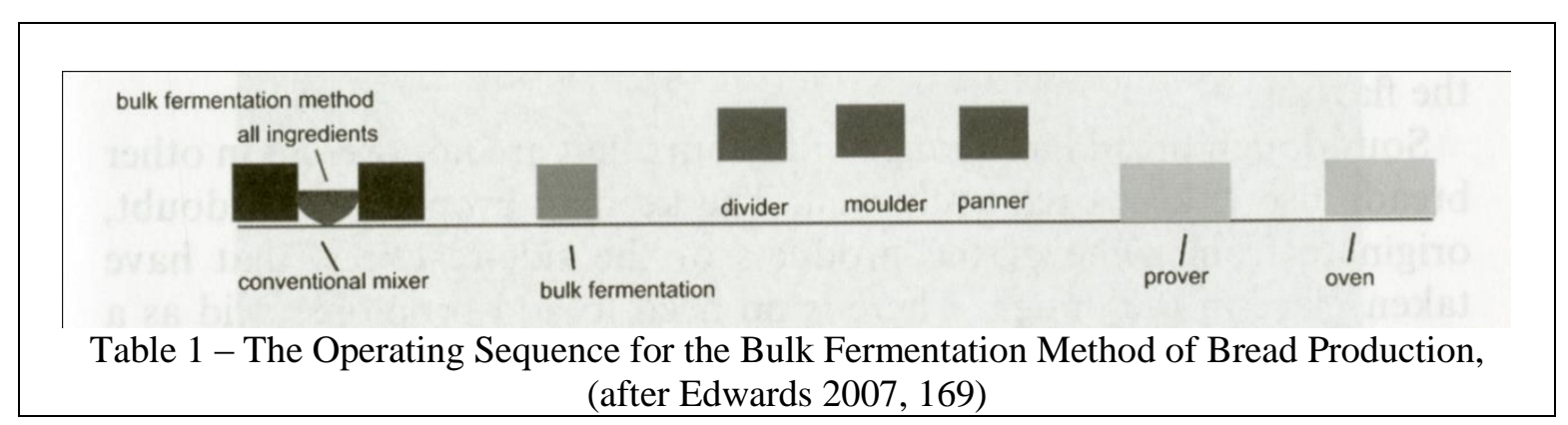


Although modern baking practices can indicate an operating sequence, they cannot indicate the culturally specific technologies used by ancient bakers or how the ancient mind conceived of a bakery. Fortunately, ancient bakers had a tradition of depicting their craft on their tombs and shop-signs. The best known and most detailed depiction of ancient bread production dates to the principate of Augustus and appears as a frieze on the Tomb of the Baker, Eurysaces. The tomb, just outside the Porta Maggiore in Rome, originally had four sides, though only three remain extant in fragmentary form. ${ }^{54}$ The frieze, although incomplete, depicts most of the processes involved in the production of bread and the technologies that facilitated them. Robert Curtis, in his work on ancient food technology, reduces the frieze on Eurysaces' tomb to its basic elements, from which he derives the processes in the production of Roman bread. ${ }^{55}$ The frieze depicts milling through large hourglass millstones, rotated by a donkey and supervised by a human. Two men, using sieves, sift the flour of impurities. The flour is mixed with water and kneaded into dough in what Moritz calls a kneading machine. ${ }^{56}$ The dough is formed into loaves on a table and the loaves are then baked into bread in a masonry oven.

Leavening, the process by which yeast converts sugars into carbon dioxide giving bread its spongy consistency, does not appear on Eurysaces' tomb, or in any other work of Roman art, probably due to the static and rather tedious nature of its depiction. Pliny discusses methods for leavening bread and states that the most popular in his day was to use a fermented mixture of bread and water from the days before, commonly called a

\footnotetext{
${ }^{54}$ Petersen 2006, 87.

${ }^{55}$ Curtis 2001, 358-9 fig. 28.

${ }^{56}$ Moritz 1958, 82 and 216.
} 
starter. ${ }^{57}$ But Pliny's description focuses on ingredients, not processes, and he offers no indication of what features were associated with leavening.

Medieval and early modern depictions of baking do depict leavening and offer some indication of what features might have facilitated this process. The medieval tradition of handbooks often addresses various trades, like baking and milling. Manuscript illuminations frequently accompany textual descriptions of the trades. One such handbook was the Tacuinum Sanitatis, the Maintenance of Health. The Tacuinum suggests, visually and textually, different types of food and activities that promote healthy living. These images often depict the production of the foods in question. Two scenes from Latinus 9333, a manuscript of the Tacuinum in Paris, show men and women making bread. Already baked bread is stacked in baskets and depicted with a slightly darker hue. In both baking images from Latinus 9333, the unbaked bread resides near the oven on shelves or tables.

The features and technologies evident in the artistic depiction of commercial baking serve as points of reference in reconstructing the chaînes opératoires in ancient Roman bakeries (table 2). Large hourglass shaped millstones grind grain into flour. The sifting of the flour to remove impurities is nearly invisible in the archaeological record because it requires no permanent fixtures and uses technologies made of ephemeral materials. Mixing and kneading is done by a stone vat, known as a kneading machine, which functions like a standing mixer. More kneading and loaf-formation occurred on

${ }^{57}$ Pliny Naturalis Historia XVII.xxvi.102-4. Pliny (Naturalis Historia XVIII.xii.68) also describes the use of foam from the production of beer to leaven bread in Gaul and Hispania. 
tables. Shelves served as locations for proving or leavening of the loaves and ovens baked them into bread.

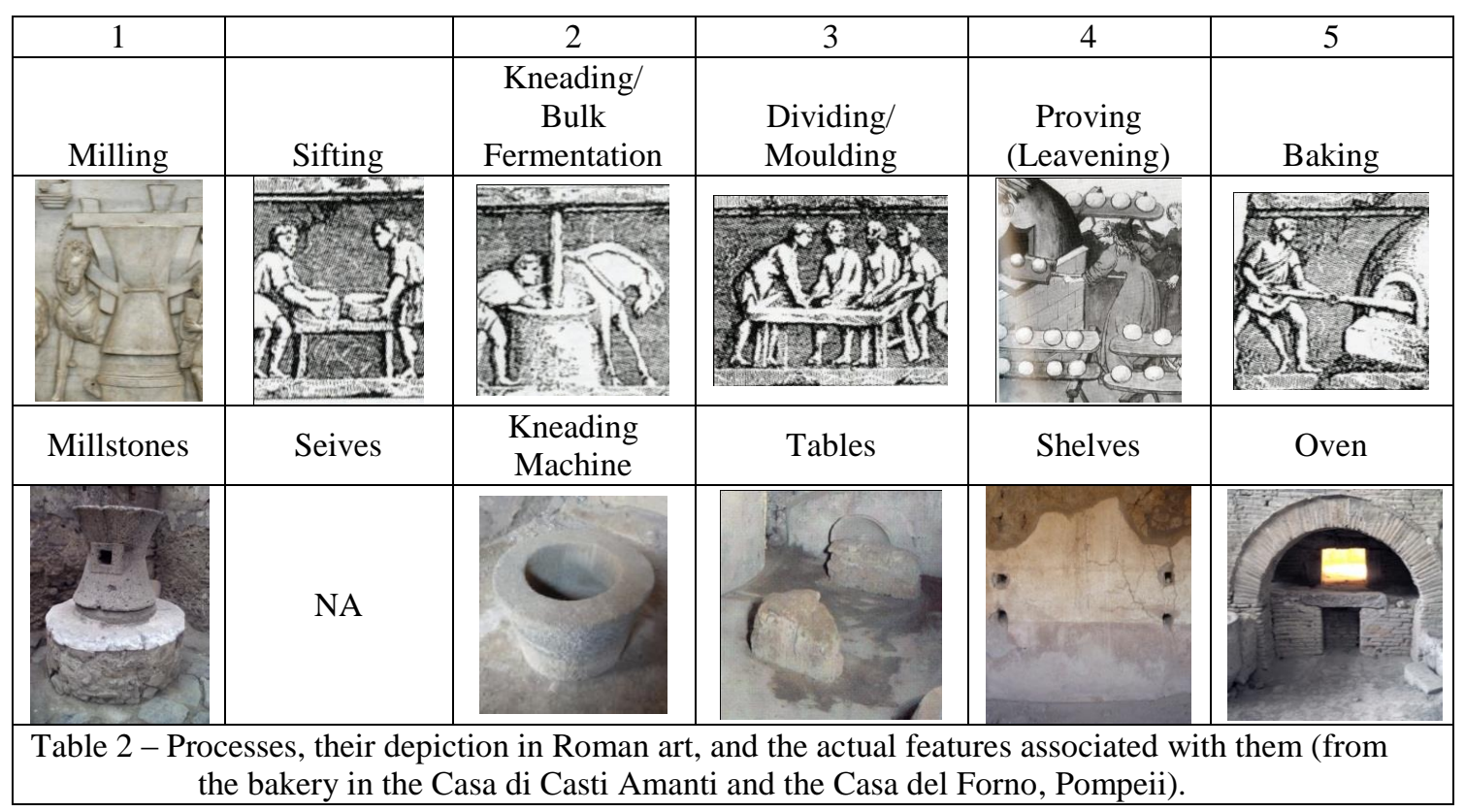

The application of chaînes opératoires in isolating the production of bread has two advantageous effects on the analysis of production in Roman bakeries. First, it ensures that the estimates of bread-production for each city are derived exclusively from workshops that were demonstrably producing bread, displaying all or part of the chaîne opératoire of bread production. Second, those spaces excluded from analysis contain information about specialization and its impact on the economy. Certain workshops are clearly commercial in nature; they have wide doorways and are only a single room with large ovens. Yet they have none of the other features and technologies associated with the process involved in producing bread. The existence of these breadless bakeries suggests 
the specialization of a separate industry, derived from the commercial production of bread.

\section{Social and Industrial Hierarchies}

Who was responsible for making the bread is another important question and the status of participants in economic activity is a topic of frequent discussion in the study of Roman industries. Previously scholarship has frequently framed the topic in terms of the social status of bakers. Yet workshops, such as bakeries, are not operated by a single individual whose status can be assessed. Bakeries relied on hierarchies of people, who varied both in their socio-economic background and in the level of their compensation for their participation. Any understanding of craftsmen and their socio-economic status in society must be grounded in an exploration of the relationships between people who worked in bakeries.

Coupaye's research shows that industrial production could be engrained in social practices. Even the product, in his case yams, could take on symbolism and meaning beyond their nutritional value. Yet Coupaye studies production and social processes in living cultures. The same types of behaviors are much more difficult to isolate in the physical world from ancient and extinct cultures. Moreover social behaviors have an indirect relationship with the material world. Unlike industrial processes, social behaviors rarely have direct material consequences nor do they require physical technologies. They have a reflexive relationship with the architecture around them. Thus they must be inferred from the architectural forms which defined them and which in turn they helped 
to define. One must have, therefore, criteria or factors through which the baking spaces might be evaluated. Traditionally, domestic and industrial space in Pompeii has been assessed based on size (area in $\mathrm{m}^{2}$ ), morphology (the presence of certain architectural forms such as atria or peristyles), or decoration (the presence of art such as wallpainting). The size of a house or bakery and its decoration carry obvious significance for the status of associated people, but reliance on any single factor would, inevitably, lead to misconceptions. Equating house size to social status or wealth risks conflating a very large house containing a small bakery with a very large bakery with no domestic space contained within. In this regard, conceiving of production in terms of operating sequences and locating associated technologies inside workshops and houses prevents such conflation. But this merely allows for a distinction to be made between commercial baking spaces and other spaces within the same structure; it does not shed light on the relationship of the other activities to the actual production in the workshop.

The space and architecture are, however, more than the area they occupy or their other quantifiable attributes. This point is made clear by Henri Lefebvre who distinguishes between the physicality of space and the 'truth of space', the social realities that shape the built environment and are in turn shaped by the built environment. ${ }^{58}$ For Lefebvre, architecture is just as much an implement of social control as a product of social processes. As such, social relationships and power dynamics are evident, if latent, in architectural forms and the nature of spaces. Two ways that architecture shapes - or is used to manipulate - human perception is through the control of access and visibility.

\footnotetext{
${ }^{58}$ Lefebvre 1991, 397-400.
} 
Such factors can be assessed and even quantified for different spaces and such analyses are facilitated by Geographic Information Systems (GIS).

The bakeries are assessed according to a variety of factors: size, percentage of space occupied by commercial baking, visibility, and the relationship of the production to the other spaces around it. Some bakeries, exclusively in Pompeii, are characterized by their location hidden in the inaccessible backs of very large houses. Bakery 13 in Pompeii, the Casa del Labirinto, is an example of this sort of bakery. ${ }^{59}$ Similarly, some bakeries are also confined to large houses, but it occupies a larger portion of them. Other bakeries are easily distinguished from the domestic space to which they are linked often displaying a separation so distinct as to make the bakery/house appear as two different establishments. Bakery 15 in Pompeii is an example of this sort. ${ }^{60}$

While these bakeries are characterized by a clear separation of industrial activity from domestic space, but within large houses, other bakeries are more integrated into the spaces around them. One cannot access any room in these bakeries without seeing or engaging the commercial activity that occurred within. Commercial production in bakeries of this sort is integrated with the domestic space around it. Bakery $\mathbf{3 5}$ in Pompeii is an example of this sort of bakery. ${ }^{61}$ Other bakeries of a similar sort are small and have little indication of elite domestic activity, but often have stairwells to upper stories. Bakery 22 in Pompeii is an example of this type of bakery. ${ }^{62}$ Other bakeries are principally characterized by their large size, but they are probably better considered bread

\footnotetext{
${ }^{59}$ VI.11.9.

${ }^{60}$ VI.14.34.

${ }^{61}$ IX.12.6-7.

${ }^{62}$ VII.12.7.
} 
factories than bakeries in houses, because of the amount of their space dedicated to commercial baking and the lack of demonstrably domestic features. They are dominated by space dedicated to the production of bread and its sale. Bakery 3 in Pompeii is an example of the bakeries of this sort. ${ }^{63}$

These differ sorts of bakeries are taken to be representative of different types of social hierarchy in Roman bakeries. The small bakeries hidden in large houses implies strong vertical relationships between those producing the bread the elite residents of the large house. The bakeries in the smaller establishments imply a group of craftsmen who are more independent from such vertical relationships, such as patronage or manumission. But here one reaches the limits of what the material evidence can tell us. Textual evidence, such as epigraphy and legal corpora, provide the details concerning the social relationships on which Roman industries relied for their labor and operation. The textual evidence, however, cannot provide any indication of scale or extent. How common was one type of baking operation over other types of operations? Do the baking operations in Rome and large urban centers differ from those of smaller communities such as Volubilis or Pompeii? Only through a combination of the textual and material evidence can these questions be answered. Linking social hierarchies isolated in textual evidence with the different sorts of bakeries indicates the chronological and geographic prevalence of any one model of bakery operation.

${ }^{63}$ I.4.12-17. 


\section{Standardization and Unity}

Roman collegia and other forms of craft associations are a topic of frequent study, commonly through epigraphic and legal evidence. These sources of evidence are employed also in this study, but the archaeological evidence is also incorporated. While earlier studies primarily searched for guild halls, this study employs the evidence from inside actual workshops and artistic depictions of commercial activity. In the case of the architectural evidence, the bakeries in each community are analyzed for standardization. While the identification of the bakeries and the exploration of hierarchy in them focuses on differences, the investigations into standardization and professional relationships between bakers emphasizes the similarities.

Viewsheds model the ability to see from specific points given ideal conditions and no obstructions. Ephemeral objects, such as doors or curtains, are almost invisible in the material evidence, but they could curtail visibility. Thus the results of the viewshed analyses are not interpreted as what one would see, but rather as indications of how exposed one would be to the different processes in the production of bread. The different levels of exposure for each process are interpreted as part of an intentional design in the layout of the bakeries. Similarities in design are considered indicative of shared notions of what comprised a bakery and how it should operate.

The chaînes opératoires in the production of bread are, in many ways, linear. One process, such as milling, is necessarily followed by the next process, in this case sifting. There are, however, a number of corollary chaînes that intersect the primary production chaîne. For example, donkeys participate in the process of milling, but they also need to 
be stabled. The relationship between the primary production chaîne and the routes between the millstones and the stables are taken as part of the deliberate design. How the different chaînes intersect or are kept separate indicate the considerations that bakers had in performing their craft. Thus similarities between bakeries in the relationships between different operating sequences can indicate concerns shared by bakers and possibly indicate self-imposed regulations from a bakers' association. Even if bakers are only pursuing best practices, thus accounting for any similarities in the layout of their bakeries, highly similar forms and organizations must indicate at the very least communication.

\section{Conclusion}

The absence of an intellectual framework for the inferences made about Roman craftsmen and workshops has led to a failure to effectively understand them. Domestic production is frequently equated with commercial production and different industries are often conflated. Formal attributes, such as house-size or accessibility, are taken as simple expressions of status or class. Finally, the study of the communal behaviors of craftsmen is limited to epigraphic traditions, which emphasize social cooperation, and guild halls, which are not a necessity for craft-based associations.

There is a vast body of anthropological thought on the relationship between humans and the material world. It contains a number of insightful ways of approaching industries, particularly where artifact assemblages are concerned. Yet much of the Roman evidence for commercial baking is architectural. Adapted to suit architectonic evidence, 
materiality and specifically chaînes opératoires offer an elegant way of approaching production and space in Roman industrial contexts. Moreover, operating sequences can be applied strictly to production, or they can have horizontal links in the chain, allowing for an understanding of how commercial production intersects social processes. 


\section{The Development of Roman Commercial Baking: Specialization, Product Dependence, and 'New Work'}

Recent scholarship on commercial production, like baking, has settled into two diametrically opposed positions: both strong and weak readings of the evidence.

Interpreting the evidence strongly, Peter Temin argues that "ancient Rome managed to achieve a high standard of living through the combined operation of moderately stable political conditions and markets for goods, labor and capital, which allowed specialization and efficiency." ${ }^{1}$ Emanuel Mayer similarly views specialization as one of the driving forces of the ancient Roman economy, arguing that the wealth generated and earned by specialist producers elevated them to a higher socio-economic status, the Roman equivalent of a middle class. ${ }^{2}$ Preferring a weak reading of the evidence, Helmut Schneider argues that craftsmen specialized in certain products, but a failure to incorporate new technologies at the craft level resulted in static productivity and a lack of further specialization. ${ }^{3}$ In a similar study, Richard Saller argues that initial specialization was beneficial where it occurred, but could only have contributed to further economic growth if 'new work' was created. In other words, did 'old work' previously conducted domestically just shift into the hands of a few specialists or did the consolidation of work free people to pursue other specialized and productive activities? Saller equivocates on

\footnotetext{
${ }^{1}$ Temin 2006, 134.

${ }^{2}$ Mayer 2012.

${ }^{3}$ Schneider 2007.
} 
this point, proposing it as a possible avenue of future research. ${ }^{4}$ The arguments on both sides are model-driven, often showing more concern with maintaining the integrity of the larger argument than they are with exploring the issue. Moreover, studies addressing specialization generally neglect material evidence, which in many ways is more adept at address issues of production and craftsmanship, The actual material evidence for commercial baking indicates a high level of dependence on commercial goods and that suggests the specialization of one industry (in this case commercial baking) created new work for other industries, even leading to the creation of new industries.

This chapter explores the topics of specialization, reliance on specialist production, and their effect on the economy by using the evidence from commercial bakeries to answer three essential questions. (1) How reliant was the urban population of the Western Roman Empire on commercial bakers for their bread? (2) Did the high level specialization or dependence on the specialist production of bread under the Early Empire create 'new work', with the formation of sub-industries (secondary craftsmen whose work was essential to the primary specialist producer) or branch-industries (craftsmen adapting the skills and technology of commercial bakers to serve a new and different industry)? (3) If so, was there a regression to a simpler industrial infrastructure during periods of instability and collapse, such as the third century crisis or the fall of the Roman Empire? Did such a regression, if it existed, impede the bakers' ability to meet the needs of the populations of which they were a part, contributing to decline and collapse?

\footnotetext{
4 "This seems to me to be an area that would repay further research... In what sectors does 'new work' appear?” Saller 2012,81.
} 
Specialization has been seen mostly as a positive economic force. Plato provides one of the first assessments of specialization, in the form of divisions of labor, which he believed were the origin of class distinctions and ultimately of the formation of a state. ${ }^{5}$ Centuries later, proto-capitalists and economists, such as Adam Smith, tended to link specialization with productivity; the more specialized an industry, the more efficient its production. ${ }^{6}$ Yet Smith also saw specialization as damaging the integrity of men's minds through the repetition of a few simple, mindless tasks. ${ }^{7}$ Marxists, on the other hand, took a more negative view of specialization. Like Plato, Marx saw specialization as the origin of iniquity, but he also believed that specialized workers suffered from alienation (Entfremdung) through their own efforts because they rarely saw the end product of their labor. ${ }^{8}$ Marx's vision of the alienation of the worker is very similar to Smith's view of the effects of specialization, but while Smith believed the positive results of specialization out-weighed the negative ones, Marx saw the positive results as benefiting only the wealthy elite. ${ }^{9}$

With regard to the modern economy, whether in neo-Classical or endogenous economic models, specialization is viewed as a positive force. ${ }^{10}$ Its role in economic growth is tied to its effect on productivity. In concept, specialization occurs when one producer has an absolute or comparative advantage over other producers, eventually

\footnotetext{
${ }^{5}$ Plato, Republic, II.369.

${ }^{6}$ Smith, Wealth of Nations, I.

${ }^{7}$ Smith, Wealth of Nations, V.1.178.

${ }^{8}$ Marx, Economic and Philosophic Manuscripts of 1844, $1^{\text {st }}$ Manuscript, 22.

${ }^{9}$ Marx, Economic and Philosophic Manuscripts of 1844, $2^{\text {nd }}$ Manuscript, 14-28.

${ }^{10}$ Neo-Classical economic thought often marginalizes the role of specialization in economic growth by aggregating it with other factors into 'total-factor productivity'. Endogenous growth models tend to attribute greater importance to specialization as an internal economic force that can be influenced by public policy. Solow 1956; Mankiw 2007, 250-1.
} 
replacing them and assuming their workload. ${ }^{11}$ The process has several economically beneficial results. First, the most efficient producer is now responsible for all such production, increasing overall productivity. Second, those whose time was once occupied by one type of production are now freed to pursue other activities, decreasing overall opportunity costs.

The role of specialization in fueling economic growth often leads to a positive perception of specialization. While the field of economics focuses on specialization as an agent of growth, as a topic of archaeological study, specialization is a catalyst of social stratification, a factor in state-formation, and even a tool of social power. ${ }^{12}$ In some cases, specialization can even have a negative characterization. In scholarship on periods of decline and collapse, specialization is frequently seen as a liability. Colin Renfrew, in an effort to construct a quantitative approach to systems collapse, posits that socio-economic complexity (which he uses synonymously with specialization) serves as a precursor to and cause of - collapse. Adopting an evolutionary model, Renfrew writes that, "To adapt too well, too fully, and too effectively to present conditions may be to restrict the flexibility of response available to cope with a future change in those conditions."13 Despite the vast body of thought in the fields of both economics and anthropological archaeology, specialization did not factor significantly in the scholarship of Classical Archaeology or in the study of the ancient economy until relatively recently. M.I. Finley, who dictated the direction of economic history of the ancient Mediterranean

\footnotetext{
${ }^{11}$ Neo-Classical economists use absolute advantage to describe the superiority in efficiency of one producer over another; comparative advantage, on the other hand, is grounded in the opportunity cost (what one has to give up) to the producers. Mankiw 2007, 52-8.

${ }^{12}$ For a summary of work on specialization, see Brumfiel and Earle 1987, 1-9; Wailes 1996.

${ }^{13}$ Renfrew 1979, 487.
} 
for more than thirty years, only addresses specialization with regard to its rare occurrence in 'isolated self-sufficient communities' and the lack of concern with it in making economic decisions. ${ }^{14}$ Willem Jongman admits that "where trade and division of labour occurred, they were advantageous," but he disregards specialization as a force in the ancient economy by questioning the level to which it occurred. ${ }^{15}$

As strict primitivists, both Finley and Jongman had a vested interest in ignoring specialization and its effects, but a jaundiced view of specialization persists in most scholarship on the ancient economy. Schneider notes the advances of technology in certain areas of production, such as large water-mill complexes, but he sees a lack of technological innovation at the craft level. ${ }^{16}$ For Schneider, this failure to incorporate innovative technologies and thereby reduce the cost of labor prevented greater craft specialization. ${ }^{17}$ Richard Saller takes a less definitive view; he acknowledges certain occupational specialists, but equivocates on what impact they would have had. Saller admits that specialization increases efficiency and that it can free other producers to pursue 'new work', but notes that there is no assurance that those freed by specialist production will pursue other activities. ${ }^{18}$

Not all work on the ancient economy views ancient specialization as non-existent or under-developed; studies grounded in material evidence often discern significant social and economic effects from specialization, both positive and negative. In an early - albeit

\footnotetext{
${ }^{14}$ Finley 1973,113 and 128.

${ }^{15}$ He believes that the high costs of transport and travel made more specialization inefficient and unnecessary, Jongman 1988, 53.

16 Schneider 2007, 168.

${ }^{17}$ Schneider 2007, 169.

18 Saller 2012, 81.
} 
poorly received - study, Walter Moeller argues that the wool industry of Pompeii had hyper-specialized into distinct officinae and that the production of these workshops was intended for long-distance trade. ${ }^{19}$ D.P.S Peacock, in a more sophisticated study, uses pottery types and provenances to argue that there were indeed domestic producers, but that production also occurred on the workshop- and industrial-scale. ${ }^{20}$ In both of these cases, increased specialization in the industry is considered to have intensified production and augmented productivity. Such intensified production implies increased product dependence in Roman communities and in that sense specialization would have contributed to economic growth, but it does not necessarily mean that those liberated from pottery- or wool-production were out pursuing other activities and creating new work.

Studies of economic collapse at the end of Antiquity argue that specialization had resulted product dependence, but also imply that such specialization created new work, that would ultimately contribute to the severity of collapse. K.R. Dark investigates the transition of the economy of Britain from the period of late antiquity into the Middle Ages. He identifies centers of intense production, fabricae, which he distinguishes from craftsmen workshops. ${ }^{21} \mathrm{He}$ uses this evidence to suggest that, while the ancient economy was not 'industrial' (in the sense that it had not undergone an industrial revolution), it was 'proto-industrial'. ${ }^{22}$ Adopting a model similar to Renfrew, Dark suggests that specialization of proto-industrial complexes, and a reliance on the goods they produced,

\footnotetext{
${ }^{19}$ Moeller 1976, 29-56.

${ }^{20}$ Peacock 1982, 6-11, 25-41.

${ }^{21}$ Dark 1996, 16-17.

${ }^{22}$ Dark 1996, 4-7.
} 
created the opportunity for a 'catastrophic collapse'. ${ }^{23}$ Bryan Ward-Perkins also sees specialization as having significantly contributed to the growth in the economy and improvements in the quality of life. He argues that the level of dependence on specialist production was so high that, at the end of antiquity, it exacerbated the severity of the impact when craftsmen like bakers ceased to produce. ${ }^{24}$ Ward-Perkins' 'despecialization' hypothesis offers a powerful model with which to explain some phenomena of late antiquity: the depopulation of certain cities, higher infant mortality rates, and the decreased quality of the specialist production. But such phenomena can also be explained by other catalysts, like war and political instability. Ward-Perkins' assertion is grounded on two assumptions: first, that dependence on specialized Roman producers was very high and, second, that the same specialists failed to meet the needs of their communities as the Empire crumbled. Moving forward, the product dependence of Roman communities on commercial baking is assessed by comparing production estimates of the bakeries with demand in the cities. The possibility that new work was generated by specialization is explored through the relationship between commercial baking and other industries.

\section{Roman Bakers and Product Dependence}

Pliny the Elder writes that there were no bakers in Rome before $171 \mathrm{BC}$ (the accuracy of this claim is discussed on page 21). Before that, explains Pliny, women did such work much as they did in his own time amongst barbarous peoples and in the

${ }^{23}$ Dark 1996, 20.

${ }^{24}$ Ward-Perkins 2005, 136-7. 
countryside. $^{25}$ Two important facts can be inferred from his statement. First, in Pliny's own time, people outside major cities - or among populations without urban centers produced their own bread. Second, his suggestion that women used to produce bread implies that in his own time, roughly contemporaneous with the operation of Pompeii's bakeries, they did not. It is possible that Pliny means that women produced bread domestically, but now men do it. Yet he clearly links this statement with the advent of specialized bakers, implying not only a shift in the division of labor between genders, but also a shift from domestic to commercial production.

Pliny’s statement implies a degree of dependence on commercial bakers, but he may have been referring strictly to Rome or perhaps just to the Italian Peninsula. Moreover, his statement can only really account for the situation in the first century AD. Here material evidence can test his generalization and make a significant contribution by broadening the scope both geographically and chronologically. Only three cities in this study contain enough evidence for an estimate of both population and production: Pompeii, Ostia, and Volubilis. While not a diachronic data set, they do represent three different time periods and two or three different regions. ${ }^{26}$

The evidence for domestic production of bread in cities consistently shows that this method of production could not have met the needs of an urban population. Ovens are a feature in very few homes in Pompeii and Ostia and those homes are only the largest. ${ }^{27}$ Volubilis, on the other hand, has no discernible ovens in any context other than

\footnotetext{
${ }^{25}$ Pliny, Naturalis Historia, XVIII 109

${ }^{26}$ Pompeii and Ostia are both in Italy, but Ostia's proximity to Rome would have made it uncharacteristic of other Italic urban centers.

${ }^{27}$ Holleran 2012, 135.
} 
commercial baking. ${ }^{28}$ Of the sixty-nine Pompeian non-bakery establishments sampled by Pedar William Foss, only one had a small oven for domestic production. ${ }^{29}$ Foss, in his survey of domestic culinary practices in Pompeii, identifies two others throughout the city and misinterprets another two installations as bakeries, giving Pompeii a total of five domestic ovens. ${ }^{30}$ The average diameter of these ovens is $1.1 \mathrm{~m}$; their maximum daily production could not have exceeded 600 loaves, somewhere around 5\% of the total demand for bread. Even if all of the domestic ovens were operating at full capacity, which they almost certainly were not, they could not have made a significant contribution to meeting the demand for bread in the city.

One can bake bread without an oven; there existed in antiquity several types of terracotta covers in which one could effectively bake, the testum and the clibanus. Cato refers to the process as sub testu (under brick) and Frayn uses literary accounts of their use to attempt to interpret the material remains of such devices. ${ }^{31}$ In a more recent study, Cubberley, Lloyd and Roberts arrive at the same essential conclusions as Frayn. ${ }^{32}$ First, the use of the sub testu method was prevalent in both town and country during the periods before the first century $\mathrm{AD}$ and continued to be the primary method of baking in rural contexts for the rest of antiquity. Literary and ceramic evidence of portable baking devices in urban contexts is sporadic during the first century AD and no evidence exists during later periods. While noting that a fine ware alternative may have replaced the

\footnotetext{
${ }^{28}$ Mathieu Leduc (2008, 480-81) notes the conspicuous absence of ovens in houses and the paucity of millstones. Only thirty rotary querns were found in all of Volubilis.

${ }^{29}$ Foss 1994, 82-3.

${ }^{30}$ Foss almost surely missed a few domestic ovens that were not in his sample, but even so there are not many more and the rarity of domestic ovens in the city is frequently commented on.

${ }^{31}$ Frayn 1978, 28-33.

32 Cubberley, Lloyd, and Roberts 1988, 101.
} 
course ware baking covers, Cubberly et al. also conclude that "If the decline [in portable baking devices] is real, however, it may be tied up with changes in the socio-economic structure of the city in the early Empire, which led, for example, to greater commercialisation (including, notably, the development of large bakeries), less selfsufficiency and the development of tenement housing." 33

Despite the lack of evidence for portable baking in Roman urban contexts after the first century BC, it is worth asking if a city could meet its own needs through domestic production using such devices. Andrew Wallace-Hadrill estimates that there were between 1200 and 1300 households in Pompeii; these would need to produce between 8,000 and 10,000 loaves of bread daily. If we imagine that every household had one ceramic baking device capable of baking three loaves of bread simultaneously, then each household would need to dedicate an average of two to two and a half hours each day to the production of bread. While not an efficient and rational approach to opportunity costs, it was well within the means of a household to provide for itself. Nevertheless, the sheer number of such items required to meet a city of tens of thousands would surely have been found in considerable numbers if they had existed. Even if there was only one per household, Pompeii should have had between 1,200 and 1,300 operating at the time of the eruption and the debris of thousands more in its fills and dumps. No portable baking covers were found in such numbers at Pompeii, and in Ostia they were not found at all. The lack of ovens, large or small, and the paucity of baking

\footnotetext{
${ }^{33}$ Cubberley, Lloyd, and Roberts 1988, 115.
} 
covers from urban contexts strongly suggests that domestic production did not significantly contribute to daily bread-making.

The evidence for domestic production of bread in Volubilis and Morocco is less well studied. The houses in Volubilis contain no masonry ovens, but the ceramic evidence at the site has not been studied to the extent that the evidence of Pompeii and Ostia has. Nevertheless, the absence of domestic ovens, the low production yield of the portable baking technologies, and the number of bakeries in the city support the conclusion that domestic production of bread in Volubilis was similarly insignificant. At least in Italy, domestically produced bread was not contributing to the urban demand, but the evidence points to a similar situation in Volubilis.

Because domestic production could not - or did not - make a significant contribution to the production of bread in cities, the question becomes: could the baking industry in each city meet the needs of the entire urban population? In the modern economy, issues of supply, demand, and gross domestic product are counted and calculated. ${ }^{34}$ For the ancient world, one cannot observe production rates or calculate total production. It is impossible to count how many people in a community made bread at home or bought it from a baker. One must estimate those statistics using proxy-data, extant physical evidence that can be quantified and that has a relationship - causal or other - with the sought-after statistic. Two specific statistics are taken as indicative of demand for bread and commercial supply: population estimates and the estimated production capacity of Roman ovens. The potential demand is inferred from the

\footnotetext{
${ }^{34}$ Mankiw 2007, 206-208.
} 
population estimates for each community multiplied by the amount of bread consumed daily, a number derived from ancient literary accounts. The production for all bakeries in the dataset is estimated from the capacity of their ovens. With the two statistics (estimated overall need and estimated commercial bread-production), the general level of dependence on commercially produced bread is inferred.

Walter Scheidel warns against the casual use of proxy-data, like shipwrecks and lead pollution, urging caution in any inferences drawn from such data. He observes that trends in the material evidence may not be the product of the desired processes. ${ }^{35}$ For example, the number of shipwrecks is often taken as evidence of trade levels. Scheidel notes that the same trend could be the product of a change in seafaring practices. The navigation of riskier albeit shorter routes could increase the number of naval disasters. Scheidel suggests a distinction between 'strong' and 'weak' readings of the data. ${ }^{36}$ In a strong reading, the numbers of shipwrecks are not only interpreted as indicative of trade levels, but their increasing numbers are taken as evidence of growth sustained by endogenous factors like investment by the state and education. ${ }^{37}$ In a weak reading, the same data and trends are taken as evidence of 'one-off' growth, a product of spreading urbanism in the Western Mediterranean as it caught up with the East in terms of technology and population. ${ }^{38}$

The issue isolated by Scheidel is one quite familiar to archaeologists and one discussed at length in chapter two. One would imagine that Scheidel would look at oven

\footnotetext{
${ }^{35}$ Scheidel 2009b, 49

${ }^{36}$ Scheidel 2009b, 51-53

${ }^{37}$ Scheidel 2006, 54-59

${ }^{38}$ Scheidel 2009b, 64
} 
size and argue that products other than bread might have been baked in the oven or that the ovens were never fully packed with loaves by the bakers. Scheidel's concerns are addressed in two ways in this dissertation. First, the commercial manufacture of bread is grounded in a complete understanding of the entire chain of operations, with an account of each process and its associated features, which alleviates concerns that the bakery or its ovens might have served in other functions. But more important, production is modeled with high productivity and low productivity to achieve an upper boundary estimate of production and a lower boundary estimate, which mitigates the danger of interpreting the data too strongly or too weakly.

The daily ration of bread for the average resident of an ancient city surely depended on wealth and status. Cato the Elder famously addressed the issue of rations for slaves, albeit a few centuries before the earliest bakery in the dataset. He prescribed for field-hands four modii of wheat (triticum) for the winter and four and a half for the summer. ${ }^{39}$ His use of the word triticum would imply that the grain was not yet separated from the hardened glumes, thus requiring further processing, probably pounding and milling. Cato rations four pounds of bread for the chain-gang in the winter and five pounds when working in the vineyards, then four again when the figs come in. These must be monthly distributions, but it would still be an exceptionally small amount.

Cato's numbers are hard to interpret. How much bread could be made from four modii of triticum? Did the chain-gang receive four pounds of bread for the whole winter or was it a monthly distribution? In a passage from the Satyricon, Petronius provides

${ }^{39}$ Cato, De Agricultura, 55-56 
more concrete numbers. Ganymede (Petronius' champion of the oppressed) announces his distrust for the bakers and recalls earlier days when a loaf of bread cost only an as and could feed two people. ${ }^{40}$ Scheidel takes this as an indication of the price and a daily portion of bread, but Ganymede's description is nostalgic. ${ }^{41}$ His need to state the earlier price and size of the bread implies that the cost of bread had increased beyond an as and that a loaf could not feed two people. Moreover, Petronius is an author prone to using hyperbole for comic effect, suggesting that the idea of bread so cheap or so large was unthinkable. Pricing aside, it would seem from Ganymede's lament that one loaf of bread would feed no more than one person daily.

The population estimates for Pompeii range from 6,400 to 20,000 , the rather large differential a product of differing methodologies. Fiorelli, using the house as the basic unit of calculation, arrived at a number of 12,000 inhabitants. ${ }^{42}$ Nissen observes that Fiorelli did not include the upper stories of Pompeii in his calculation and thus doubles the number, arriving at the canonical 20,000. ${ }^{43}$ Beloch, the consummate demographer of the ancient world, felt the number too high and reduced it to $15,000 .{ }^{44}$ In a more recent study, Russell derives urban population densities from medieval towns, which range widely from 40 people per hectare to 289 people per hectare. He then applies them to Pompeii arriving at a range of 2,500 to 18,000 inhabitants, though he prefers a population

\footnotetext{
${ }^{40}$ Petronius, Satyricon, 44.11

${ }^{41}$ Scheidel (2004) compiled a list of references in ancient literature to foodstuffs and other goods from which he derives costs and measures.

${ }^{42}$ Fiorelli 1873, 10.

${ }^{43}$ Nissen 1877, 374-379.

${ }^{44}$ Beloch 1898, 274.
} 
range between 6,400 and 6,700. ${ }^{45}$ Wallace-Hadrill, citing Ian Hodder, notes that population density cannot be a constant among all cultures; it is a product of habits, social structures, power dynamics, and senses of propriety that are specific to each culture. He advises a bottom-up solution in which the numbers of inhabitants are assessed for each house based on our knowledge of Roman society and then tallied. Wallace-Hadrill assigns sensibilities of space based on socio-economic status inferred from house size, assuming that elites require more space and non-elites are afforded less. Despite this, Wallace-Hadrill refrains from offering an estimate, content with identifying the number of households and a now-improved understanding of their sense of privacy. ${ }^{46}$ In recent years, consensus has fallen in the 8,000 to 10,000 range. $^{47}$

As is true of Pompeii, so too large portions of Ostia are excavated, roughly 35 hectares, but the city has a fundamentally different urban fabric. While the cityscapes of Pompeii and Herculaneum are defined by large atrium-style houses, Ostia's streets are lined with horrea and massive insulae (apartment complexes). In one of the earliest studies of the city, Calza estimates the population of Ostia at 36,000. Russell Meiggs rightly concludes that Ostia must have had a significantly higher population density than many other Roman cities and estimates a population of 60,000 people. ${ }^{48}$ Packer, in his study of the houses of Ostia, suggests that such estimates overvalue the importance of the insulae, arriving at an estimate between twenty and twenty-five thousand. ${ }^{49}$

\footnotetext{
${ }^{45}$ Russell 1977.

${ }^{46}$ Wallace-Hadrill 1991, 204; 1994, 102-3.

${ }^{47}$ Ling 2007, 97-99; Ling further points out that all of the estimates are based solely on the area within the walls, overlooking the possibility that some inhabitants lived outside the city.

${ }^{48}$ Meiggs 1973, 532-34.

${ }^{49}$ Packer 1967, 86.
} 
Volubilis has received less attention than the other two cities, but the city is roughly 44 hectares, about two-thirds the size of Pompeii. ${ }^{50}$ Andrew Wilson uses a ratio of 200 people/ha to estimate a population of 8000 people. ${ }^{51}$ Assuming a population density similar to that of Pompeii, Volubilis could have had a population range between 6,500 and 8,000 .

If one loaf of bread a day is a reasonable ration for one person, then the range of each city's daily need for bread would correspond to its maximum and minimum population estimates. For Pompeii, the range of estimated bread need is between 8000 and 10,000 loaves. In Ostia, the estimated need for bread ranges from 20,000 to 25,000 a day. Volubilis' estimated bread requirements range from 6,500 to 8,000 loaves, daily.

Production of flour and bread has most commonly been estimated based on millstones. Jan Theo Bakker argues that a single millstone could produce enough grain to feed approximately 90 people. There were 81 millstones operating in the Pompeii's bakeries (usually three or four millstones per bakery, though some have fewer). According to Bakker's 90-person constant, Pompeii's baking industry could have fed approximately 7,300 people. But there are some significant reasons why millstones are not the ideal option for estimating production. First, there are no good comparanda for their use. Medieval and modern bakers did not include milling in their repertoire and millers in those periods most commonly used some sort of natural energy source to drive their mills, such as water or wind. ${ }^{52}$ Furthermore, many of the millstones that were located in the bakery during excavation are now robbed out. Their bases are there, so we

\footnotetext{
${ }^{50}$ Fentress et al 2001, 36.

${ }^{51}$ Wilson 2011, 184.

${ }^{52}$ For a full discussion of the history of milling, see Moritz 1958 and Williams and Peacock 2011.
} 
can assess the number of millstones in each bakery, but without the millstones themselves one can only guess their size and productivity. There is also evidence (the existence of bakeries without millstones altogether) that there was a source of flour other than that which was milled by the bakery.

Matthiew Leduc quantifies production through kneading machines, estimating the total number of people that Volubilis bakeries could supply. ${ }^{53} \mathrm{He}$ calculates the volume of each kneading machine and estimates the number of times a device would be operated in a day, arriving at a maximum output of dough. Leduc estimates that the kneading machines in Volubilis could produce enough dough for bread to feed between 2200 and 3800 people. Yet many of the same criticisms of millstones also apply to the kneading machines. To arrive at his estimate, Leduc has to use all the kneading machines, including those well out of their use-context. Furthermore, we have no clear comparanda for this technology. Medieval bakers used troughs, mixing dough by hand. The kneading machine is a technology culturally specific to Europe and the Mediterranean under the Roman Empire. Finally, not all bakeries have kneading machines. They may have been robbed out, but some bakeries may have found other solutions for the process of mixing and kneading.

Ovens provide the most ideal evidence for production. Every bakery has one and they survive relatively well, even if their domes have collapsed. There are essentially two types of ovens in the Roman world, the beehive or 'black' oven and the continuously fired dual chamber oven. The beehive ovens, like those of Pompeii, are direct-fired, but

\footnotetext{
${ }^{53}$ Leduc 2008, 494.
} 
the masonry insulation and the iron doors on the city's ovens indicate a multi-load retained heat method: fuel is burned inside the baking chamber to heat the interior masonry and the smoke exits through the opening and up a flue sooting the front of the oven, earning them the name 'black' ovens. The oven is then swept clean and the loaves are inserted to be baked by the well-heated masonry. The oven takes about two and a half to three hours to reach the ideal surface temperature (between 550 and $570^{\circ} \mathrm{F}$ ) and a single load of bread takes 45 minutes. An experienced baker can make two rounds of loaves before needing to re-fire the oven; thus two oven loads of bread requires roughly four hours. ${ }^{54}$ The re-fire needs less time because the oven is already hot, but between fires the oven must be allowed to cool sufficiently to prevent damage to its masonry. ${ }^{55}$ In total, baking four oven-loads of bread in a masonry black oven would require about seven hours, or ten hours for six loads.

The number of loaves in a load obviously depends on the size of the oven. Carbonized loaves have been found in many bakeries and they are on average about 22 $\mathrm{cm}$ in diameter. ${ }^{56}$ The calculation of how many circular objects can fit into a larger circular object without overlapping is a process commonly called 'packing'. Packing cannot be reduced to a simple equation; each scenario (large circle with $x$ diameter can

\footnotetext{
${ }^{54}$ Wing and Scott 1999, 13.

55 Wing and Scott 1999, 131.

56 This is based partially on the baking tins found in Baker One in Herculaneum, but also on personal measurements of carbonized loaves, Maiuri 1958, 457-458.
} 
contain $y$ number of non-overlapping smaller circles with the diameter $z$ ) requires its own solution and formula. ${ }^{57}$

But bakers are not mathematicians and one would want some space between individual loaves inside the oven. Fortunately, excavators of the bakery at VII.1.36 in Pompeii found the oven still containing a load of loaves. They found 81 carbonized loaves in the oven, which has a diameter of $2.55 \mathrm{~m}$. The oven could accommodate about 109 loaves, but the baker only loaded the oven to about $75 \%$ of its full capacity. This provides a way of resolving the rigid theoretical packing scenario with the reality of a baker's practices. The total capacity for each oven, in the discussion that follows, is reduced by $25 \%$ to arrive at a single load of bread, multiplied by the number of firings and loads per fire.

The second type of oven, specific to Ostia, is more difficult to assess. They are much larger ovens, implying greater productivity, but they are also continuously fired, alleviating the need for a wait time between firings. The two limiting factors are the time necessary to bake loaves into bread and the length of time the oven was in operation. For continuously fired ovens, the same hours are applied, subdivided by bake time. A fortyfive minute bake time plus the time to insert the bread and extract it results in about one load per hour, over a seven to ten hour period.

Although the ovens serve here as the basis of estimating production for each bakery, the entire chaîne opératoire in the Pompeian bakeries factors into the assessment through the exclusion of bakeries that have no indication of the entire process (see

\footnotetext{
${ }^{57}$ Eckhardt Sprecht, a professor of fluid dynamics at Otto von Guericke University, has compiled the solutions to all packing scenarios and created an online application that allows for quick assessment of number of loaves in a circle. http://hydra.nat.uni-magdeburg.de/packing/cci/\#Results.
} 
chapter two). This is less of an issue for Ostia where the large ovens, deliberate design, and street paving stones in the interior of the establishment clearly delineate the commercial bakeries from any domestic production. In Pompeii, many of the bakeries are in houses and some houses have small ovens. The commercial bakeries are distinguished from what little domestic production existed and similar but separate industries through the presence of the operating sequence, shown to be specific to the production of bread, as manifested by certain features such as millstones, kneading machines, tables, shelves and ovens.

The estimates for the production of bread in Pompeii, Ostia, and Volubilis indicate that the baking industry in each city could have met the needs of the entire urban population. In Pompeii, the need is estimated at 8,000 to 10,000 loaves a day; the Pompeian baking industry was capable of producing between 7,600 and 11,300 loaves each day (table 3). The Ostia population would have required 20,000 to 25,000 loaves a day and the baking industry producing an estimated 14,000 to 20,000 loaves a day with only six bakeries (table 4). The Ostian oven may, however, been capable of producing up to twice that amount with its large ovens and the indications of trays inside the oven. ${ }^{58}$ In Volubilis, the need for bread is estimated at 6,500 to 8,000 loaves a day and the excavated ovens of the city could produce between 2,500 and 3,500 (table 5). The population estimates are based on the entire area of the city, not just its excavated areas. The city is roughly 44 ha in area, but only 20 ha are excavated, ca. $45 \%$ of the city.

\footnotetext{
${ }^{58}$ The Ostian oven is discussed in the section of this chapter on sub-industries.
} 
Doubling the estimated production levels arrives at 5,500 and 7,700 loaves a day, nearly the same as the population estimates.

These statistics are just estimates, but they suggest that the baking industries of Pompeii, Ostia, and Volubilis were capable of meeting the needs of their city's population. On the other hand, just because the industry could meet the demand of the city does not mean that it did. Each estimate is a maximum production based on the number of worked hours and the sizes of the ovens. Each bakery could have also produced much lower quantities as needed. But the combination of high production estimates for urban baking industries and the lack of evidence for domestic production (low numbers of masonry ovens in houses and the conspicuous absence of portable baking technologies) imply that the needs of the urban population could only have been met commercially. In other words, the residents of Pompeii, Ostia and Volubilis were very reliant on bakers for their daily bread. 


\begin{tabular}{|c|c|c|c|c|c|}
\hline Bakery & $\begin{array}{c}\text { Load } \\
\text { Capacity }\end{array}$ & $\begin{array}{l}\text { Seven-hour } \\
\text { Estimate }\end{array}$ & $\begin{array}{l}\text { Ten-hour } \\
\text { Estimate }\end{array}$ & $\begin{array}{c}\text { Average } \\
\text { Diameter (m) }\end{array}$ & Area $\left(m^{2}\right)$ \\
\hline Pompeii2 & 79 & 316 & 474 & 2.5 & 4.91 \\
\hline Pompeii3a & 49 & 196 & 294 & 2.0 & 3.14 \\
\hline Pompeii3b & 72 & 288 & 432 & 2.4 & 4.52 \\
\hline Pompeii4 & 72 & 288 & 432 & 2.4 & 4.52 \\
\hline Pompeii6 & 55 & 220 & 330 & 2.1 & 3.46 \\
\hline Pompeii7 & 86 & 344 & 516 & 2.6 & 5.31 \\
\hline Pompeii8 & 55 & 220 & 330 & 2.1 & 3.46 \\
\hline Pompeii9 & 86 & 344 & 516 & 2.6 & 5.31 \\
\hline Pompeii10 & 49 & 196 & 294 & 2.0 & 3.14 \\
\hline Pompeii12 & 60 & 240 & 360 & 2.2 & 3.80 \\
\hline Pompeii13 & 66 & 264 & 396 & 2.3 & 4.15 \\
\hline Pompeii14 & 66 & 264 & 396 & 2.3 & 4.15 \\
\hline Pompeii15 & 66 & 264 & 396 & 2.3 & 4.15 \\
\hline Pompeii16 & 81 & 324 & 486 & 2.55 & 5.11 \\
\hline Pompeii17 & 86 & 344 & 516 & 2.6 & 5.31 \\
\hline Pompeii18 & 86 & 344 & 516 & 2.6 & 5.31 \\
\hline Pompeii22 & 60 & 240 & 360 & 2.2 & 3.80 \\
\hline Pompeii23 & 72 & 288 & 432 & 2.4 & 4.52 \\
\hline Pompeii24 & 86 & 344 & 516 & 2.6 & 5.31 \\
\hline Pompeii26 & 60 & 240 & 360 & 2.2 & 3.80 \\
\hline Pompeii27 & 31 & 124 & 186 & 1.6 & 2.01 \\
\hline Pompeii28 & 55 & 220 & 330 & 2.1 & 3.46 \\
\hline Pompeii29 & 79 & 316 & 474 & 2.5 & 4.91 \\
\hline Pompeii30 & 72 & 288 & 432 & 2.4 & 4.52 \\
\hline Pompeii31 & 40 & 160 & 240 & 1.8 & 2.54 \\
\hline Pompeii32 & 66 & 264 & 396 & 2.3 & 4.15 \\
\hline Pompeii33 & 55 & 220 & 330 & 2.1 & 3.46 \\
\hline Pompeii34 & 55 & 220 & 330 & 2.1 & 3.46 \\
\hline \multirow[t]{2}{*}{ Pompeii35 } & 60 & 240 & 360 & 2.2 & 3.80 \\
\hline & TOTALS & 7620 & 11430 & & \\
\hline
\end{tabular}




\begin{tabular}{|c|c|c|c|c|c|}
\hline Bakery & $\begin{array}{c}\text { Load } \\
\text { Capacity }\end{array}$ & $\begin{array}{l}\text { Seven-hour } \\
\text { Estimate }\end{array}$ & $\begin{array}{l}\text { Ten-hour } \\
\text { Estimate }\end{array}$ & $\begin{array}{c}\text { Average } \\
\text { Diameter }(\mathrm{m})\end{array}$ & Area $\left(\mathrm{m}^{2}\right)$ \\
\hline Ostia1 & 345 & 3105 & 4485 & 5.1 & 20.43 \\
\hline Ostia2 & 290 & 2610 & 3770 & 4.7 & 17.35 \\
\hline Ostia4 & 145 & 1305 & 1885 & 3.35 & 8.81 \\
\hline Ostia5 & 220 & 1980 & 2860 & 4.1 & 13.20 \\
\hline Ostia6 & 330 & 2970 & 4290 & 5 & 19.63 \\
\hline Ostia8a & 79 & 711 & 474 & 2.5 & 4.91 \\
\hline \multirow[t]{2}{*}{ Ostia8b } & 178 & 1602 & 2314 & 3.7 & 10.75 \\
\hline & Totals & 14283 & 20078 & & \\
\hline
\end{tabular}

Table 4 - Daily Production Estimate (in loaves) for the Baking Industry in Ostia

\begin{tabular}{|c|c|c|c|c|c|}
\hline Bakery & $\begin{array}{c}\text { Load } \\
\text { Capacity }\end{array}$ & $\begin{array}{l}\text { Seven-hour } \\
\text { Estimate }\end{array}$ & $\begin{array}{l}\text { Ten-hour } \\
\text { Estimate }\end{array}$ & $\begin{array}{c}\text { Average } \\
\text { Diameter }(\mathrm{m})\end{array}$ & Area $\left(\mathrm{m}^{2}\right)$ \\
\hline Volubilis1 & 73 & 292 & 438 & 2.4 & 4.52 \\
\hline Volubilis2 & 86 & 344 & 516 & 2.6 & 5.31 \\
\hline Volubilis3 & 79 & 316 & 474 & 2.5 & 4.91 \\
\hline Volubilis4 & 76 & 304 & 456 & 2.45 & 4.71 \\
\hline Volubilis5 & 66 & 264 & 396 & 2.3 & 4.15 \\
\hline Volubilis6 & 82 & 328 & 492 & 2.55 & 5.11 \\
\hline Volubilis7 & 66 & 264 & 396 & 2.3 & 4.15 \\
\hline \multirow[t]{2}{*}{ Volubilis8 } & 79 & 316 & 474 & 2.5 & 4.91 \\
\hline & Totals & 2428 & 3642 & & \\
\hline
\end{tabular}

Table 5 - Daily Production Estimate (in loaves) for the Baking Industry in Volubilis 


\section{The Creation of 'New Work':}

\section{Sub-Industries and Branch-Industries}

There is general consensus that an intensification of production and an expansion of product dependence occurred in almost every sector of the ancient economy, at least for urban populations, from the third century BC to the first century AD. Such phenomena were fueled by the initial specialization of craftsmen and later technological, procedural, and institutional innovations. Furthermore, the expansion and intensification of commercial baking into the western half of the Roman Empire would certainly precipitate economic growth, but everything from the second century BC to the first century AD fits pre-existing notions of specialization. The expansion of specialist producers into the West fits with the so-called Romanization of those areas and with Scheidel's model of 'catch-up' economics. ${ }^{59}$ The eastern Mediterranean had been economically more sophisticated than the West since the Hellenistic period, but Roman dominion over Gaul, Hispania, and North Africa brought economic opportunities that were quickly exploited and that caught those provinces up (to some extent) with their cousins in the East.

The more fundamental issue - and the one posed by Saller - is whether specialization continued in some form in the first century AD, creating 'new work' rather than simply shifting the production of 10,000 loaves of bread from 1500 households to a few specialist producers. We have already seen that dependence on the commercial production of bread mush have been very high, approaching complete in three major

\footnotetext{
${ }^{59}$ Scheidel 2009, 68.
} 
cities. But Saller will only allow that such specialization consolidated 'old work' into the hands of a few specialist producers. There is some evidence that the commercial baking industry had sub-divided or hyper-specialized into different professions. A Greek inscription from Side, dating to the first half of the third century AD, records the occupational titles of two different groups that appear to be based on individual processes in the production of bread. ${ }^{60}$ The first profession mentioned, the $\alpha \lambda \varepsilon v \rho{ }^{\prime} \alpha \alpha \theta \dot{\alpha} \rho \tau \varepsilon \varsigma$, is a combination of $\alpha \dot{\lambda} \varepsilon v \rho \circ \varsigma$ (flour) and $\kappa \alpha \theta \alpha \rho \tau \eta \dot{s}$ (cleanser). They must have performed the process of sifting flour seen in the various depictions of commercial baking (figs. 18-19). The second derives from àßákıov (slab) and $\sigma \tau \alpha \tilde{\iota} \varsigma$ (dough), probably the individuals shown forming loaves in artistic depictions of bread production (figs. 20-22). But the two groups probably do not represent separate associations of craftsmen, but rather some sort of association between laborers. It is hard to imagine that a dough shop existed where a craftsman sold dough to commercial bakers. Equally implausible is a workshop that specialized in sifting flour. Indeed, there is no archaeological or epigraphic evidence that the processes kneading or loaf-formation occurred at separate locations.

There is, however, evidence in baking technologies and procedures for the growth of both sub-industries and branch-industries. The relationship between the commercial baking industry and its various sub-industries has largely been overlooked because of the common tendency to neglect the context of commercial technologies. Millstones are frequently subjected to material analysis, as we shall see, but rarely analyzed in their productive contexts. One of the advantages of the chaîne opératoire approach is that it

\footnotetext{
${ }^{60}$ SEG 33, 1165. Nollé 1983. This inscription is discussed in greater detail in Chapter Five.
} 
binds the various processes of bread-production into one sequence of operations with a single goal. The result is that technologies are not viewed as separate from each other or the human actions that defined them, but rather as part of single industrial entity. Thus ovens that belong to the commercial baking industry can be distinguished from those that were belonged in a different context. Although a minor point, this allows for the isolation industries that produced technologies specifically for the commercial baking industry. The application of chaînes opératoires also facilitates the distinction between different industries. Evidence from commercial bakeries indicates that the bakers were reliant on at least two other sub-industries, millstone-producers and builders specializing in the construction of ovens and work-spaces. Furthermore, by defining a bakery through the presence of the full range of processes in the production of bread, rather than through a single feature, a possible branch-industry emerges from the evidence: oven-letting (the baking of pre-prepared items for a fee). Whatever industry the shops with ovens represent, it is not only distinct from commercial baking, but it was also founded in the same technological tradition. Both the sub-industries and the branch-industry represent the creation of 'new work' that was only possible after the initial specialization of commercial bakers.

Although the focus of this section is the first century AD and the centuries that followed, it is worth reviewing the evidence for the initial specialization of commercial baking in the last few centuries BC. The Roman baking industry had its roots in the third century BC, although there is evidence for millstone production on a large scale as early 
as the fourth century BC. ${ }^{61}$ Pliny records that there were no bakers in Rome until the war with the King Perseus (171 BC). ${ }^{62}$ The earliest epigraphic evidence in Latin, dating to late in the second century BC and found at Capua, would seem to corroborate Pliny's assertion, ${ }^{63}$ but the first mention of the word pistor (miller-baker) in the collected body of Latin literature occurs in Plautus' Asinaria, ca. 200 BC, some 30 years earlier than Pliny's account. ${ }^{64}$ The discrepancy remains unexplained, but Fujisawa suggests that Pliny was referring to pistores as he knew them, miller-bakers, while the early incidence of the word in the Asinaria reflects an older definition suggested by the etymology of the word pistor, which derives from the word pisere or pinsere (to grind or mill). ${ }^{65}$ Although attractive, this interpretation is refuted by the fact that Plautus writes, " $a$ pistore panem petimus", indicating that at least some pistores had already incorporated the production of bread into their repertoire. In either case, the general scarcity of evidence and the lack of architectural or artistic material would suggest that there were commercial bakers in the western Mediterranean region during the second century BC, but few of them.

It is probably also during this time that the first rotary mills, millstones that grind through rotation rather than lateral motion, begin to be made. The number of different types of rotary millstones varies widely in both their morphology and their operation. Some are quite small and operated by humans, while others are quite large and are operated by donkeys. The earliest known large rotary millstones date to the late fourth or

\footnotetext{
${ }^{61}$ Arribas 1987; Williams-Thorpe and Thorpe 1990.

62 Pliny, Naturalis Historia 18, 107-8.

${ }^{63}$ It attests a certain M. Ocratius Marcus, a freedman and pistor. CIL X 3779, dated to 106 BC by Boak 1916, 28.

${ }^{64}$ Plautus, Asinaria, 200.

${ }^{65}$ Fujisawa 1995, 175; “in pistrino pisetur”, Varro, De Re Rustica, 1.63.
} 
third century BC, often referred to as the Morgantina mill (figs. 23-4). ${ }^{66}$ They are made of basalt quarried from the region of Etna or on the island of Sardinia, usually in the hourglass shape common in Pompeii, though much smaller and human-operated. They consisted of a catillus, the upper hour-glass shaped portion that rotated, and the meta, the lower conical and stationary portion. There is some speculation that the advent of a rotary mill made of basalt is a combination of Greek stone technology and Punic exposure to the small rotary millstones found as early as the fourth century on the Iberian Peninsula. Beginning in the second century $\mathrm{BC}$, a different type of rotary millstone (the mola asinaria) begins to make appearances in the textual evidence, which is probably the same as the Pompeii millstone (fig. 25). ${ }^{67}$ Earlier rotary millstones were pushed by humans, but the asinaria was driven by donkeys, which allowed the millstones to be much larger and probably increased the length of time they could be operated. The invention and proliferation of new technologies, like the mola asinaria, implies greater production and expansion into new markets of clientele, in the sense that more people were shifting from domestic production to dependence on commercial bakers. Nonetheless, the vast majority of people, both urban and rural, still made their own bread, probably also milling their own grain. ${ }^{68}$

\footnotetext{
${ }^{66}$ White 1963, 203-206, pl. 47 and 48.

${ }^{67}$ Cato mentions the mola asinaria five times in book five, advising its use not only for milling grain but also in the production of olive oil and wine. There are some indications that the grain mill was also used at mines for crushing certain ores.

${ }^{68}$ Cato's suggestion to provide slaves with wheat would imply that they were responsible for the pounding, milling, and baking of their own bread.
} 
The first century BC yields significantly more evidence for commercial baking. Five inscriptions attest a pistor, all funerary. ${ }^{69}$ One is from Ostia, another from Aquileia, and the other four are from Rome. The most famous inscription from the first century AD attesting a pistor, CIL VI 1958a, comes from the tomb of the baker in Rome. It describes Eurysaces, the permanent resident of the tomb, as a pistor redemptor. The meaning of redemptor is debated, but it has generally been accepted that he was a contract baker, potentially for the military or for the annona, though the latter was distributed as grain until the third century AD. ${ }^{70}$ Chapter Four addresses the social importance of the tomb and the inscriptions in greater depth. In terms of specialization and 'new work', however, a contract baker represents significant increases in production, demanding new technology and increased productivity. Whatever redemptor entails, the scale of production evident in the frieze of the tomb indicates a significant increase over the small shops found in Pompeii, Italica, and Volubilis.

Another inscription found near the Porta Maggiore, CIL VI 1958c, labels Ogulnius a PISTOR SIMI and AMICVS, presumably a pistor of similago (flour made from standard wheat). ${ }^{71}$ One is tempted to interpret the inscription as evidence of a pistor who only mills, but does not bake, and it is probably right not to link pistor too closely with either miller or baker; it is entirely possible that Latin speakers had no trouble

\footnotetext{
${ }^{69}$ CIL V 1046 (Aquileia); CIL VI 1958a (Rome); CIL VI 1958c (Rome); CIL VI 6687 (Rome); CIL VI 9000 (Rome); SO III, 63 (Ostia).

${ }^{70}$ Rossetto 1973; Brandt 1993, 14-15; Curtis 2001, 358-60; Petersen 2006, 87-88.

${ }^{71}$ The contracted word SIMI is taken as similaginarius, though the word is attested nowhere else and would be a hapax. I prefer similaginis, a baker who mills this particular type of flour and makes it into bread.
} 
assigning bakers, millers, and miller-bakers the same title. ${ }^{72}$ Pliny the Elder offers another explanation for the use of similago. He provides the prices of different types of flour; given an average supply, farina costs 40 asses, similago costs 8 asses more, and sifted similago twice as much as farina (80 asses). ${ }^{73}$ In life, Ogulnius may have specialized in the production of finer types of flour that he either sold or made into bread, and his friend honored him by including this fact on his gravestone. For the purposes of specialization, it is interesting that bakers not only focused on specific types of products, but also different levels of quality. It suggests that the clientele were stratifying: the wealthy were no longer the only people who could buy their bread, or at least their grain, pre-milled. Such stratification suggests an expansion into new markets, possibly a product of technological advances and increased productivity, which in itself entails 'new work'.

There is possible archaeological evidence for one bakery in the first century BC. It is just outside the Porta Maggiore in Rome, near the tomb of Eurysaces, but almost nothing remains of it. ${ }^{74}$ More abundant is the artistic evidence. The most famous is the frieze from Eurysaces' tomb that originally wrapped around the entire monument, of which frieze only three sides remain extant (fig. 12). Despite its incompleteness, the frieze depicts nearly all the processes in the manufacture of bread (discussed at length in chapter two). Robert Curtis deftly identifies the different processes and technologies (fig.

\footnotetext{
${ }^{72}$ This is supported by the presence of bakeries in Pompeii, Ostia, Italica, and Augusta Raurica that have no millstones.

${ }^{73}$ Pliny, Naturalis Historia, 18.20.90.

${ }^{74}$ Coates-Stephens (2004, 21-31) assigns a first century BC date, primarily through association with the tomb of Eurysaces, although it was no longer operating when the Aqua Claudia was constructed, so the bakery must pre-date AD 38.
} 
26). Of interest here is the evidence for technological innovation and scale of production. The mola asinaria, as Cato calls it, is clearly still in use, but new technologies also appear. The portable terracotta domes and small floor ovens of the second century BC are replaced with a large masonry oven. Moreover, the size of the oven not only increases capacity and production, but also requires procedural innovation in terms of the oven's operation.

Andrew Wilson and Katia Schorle identify the recently rediscovered and published Romolo relief as dating to the first century BC (fig. 13). ${ }^{75}$ They place the relief stylistically in the same time period as the frieze from Eurysaces' tomb, but tentatively assign an earlier date based on the absence of kneading machines. The presence of the kneading machine on Eurysaces' tomb and its absence on the Romolo relief suggest that the technology was recently developed or just now beginning to spread. Either way, the effect on the economy is the same. Mechanized technology further suggests increases in production. Such innovations may be tied to Eurysaces' status as a contractor: providing services to the army or to the city of Rome would require significant increases in production, which would in turn demand technological and procedural innovation.

An increase in production is also suggested by the number of individuals depicted on the two friezes. Forty-one people appear on the (incomplete) frieze from Eurysaces' tomb, half of whom are occupied with the production of the bread in some way. The Romolo relief shows ten individuals, all in the act of delivering grain, milling, kneading, forming loaves, or baking. There is a linear sequence to the friezes, moving from one

\footnotetext{
75 The frieze is now located over the old oven in Romolo restaurant in Trastevere. Wilson and Schorle 2009, 101 and 122-123.
} 
process to the next, so the intent may be to show the various processes rather than different individuals or the number of workers. Certainly continuous narrative appears elsewhere in Roman art, such as the Perseus and Andromeda fresco from Boscotrecase (ca. 10 BC) and the funerary relief from Ostia showing a circus scene (AD 110). ${ }^{76}$ Nevertheless, the production depicted by both baking reliefs is not that of domestic production converted to mom-and-pop scale production. There are a considerable number of participants engaged in large-scale production. The status the various individuals is discussed in greater detail in Chapter Four, but it suffices to say that large numbers of slaves are doing all the work and, in the case of Eurysaces' tomb, togate individuals oversee the labor who may themselves have been free or slave. ${ }^{77}$ Such hierarchical structures suggest that institutional innovation was also a response to increased production. A small familia with few or no slaves could not have met the needs of an imperial or military contract; a much larger hierarchical structure was necessary.

The technological, procedural, and institutional innovations of the first century $\mathrm{BC}$ suggest an expansion of production through increased productivity. Such increases in production surely meant that the industry was serving an expanded clientele, as is also suggested by a differentiation in the quality of products. While most people - if not all in small towns and in rural areas still made their own bread, bakers in Rome were providing a variety of flours and thus also breads to an expanded and more stratified clientele. In addition to increased product-dependence, one already begins to see evidence for sub-industries, particularly in the technological advances of the first century

\footnotetext{
${ }^{76}$ Kleiner 2007, 77 and 169.

77 Zimmer 1982, 21.
} 
BC. The millstones on the tomb of Eurysaces are well carved and large. The basalt would have to be quarried and a specialist would have to carve the millstones into shape. It is worth nothing, however, that all the inscriptions, artistic evidence, and archaeological remains for commercial baking in the first century $\mathrm{BC}$ come from Rome or Ostia, with the exception of one inscription from Aquileia. Surely the expansion of clientele and the advent of sub-industries did not extend to rural areas, where craft specialization never occurred. But the other cities in the western Mediterranean probably also lagged behind Rome. Growth into new markets, such as new clientele or contract baking, and the necessity of sub-industries were a product of the demand for bread that Rome and Ostia had over other communities in the first century BC because of their large populations.

The evidence for the first century AD is far more widespread and abundant with inscriptions found in Hispania, Mauretania, Campania, and Latium. ${ }^{78}$ Artistic depictions of commercial baking, both funerary and commercial in nature, range from Italy to southern France (fig. 16-17). Archaeological remains of bakeries exist at Pompeii and Herculaneum. The expansion of specialist producers into other areas in the western Mediterranean certainly contributed to economic growth, but it still falls into the category of initial specialization and fits pre-existing notions of 'catch-up' economics and so-

\footnotetext{
${ }^{78}$ AE 1913 116, CIL IV 875, CIL IV 886, CIL IV 7273, CIL IV 10150 (Campania); CartNova 154, EE IX 345 (Hispania); AE 1985906 (Mauretania); CIL VI 6338, CIL VI 9462a, CIL XIV 2302 (Rome). Among the inscriptions attesting pistor or pistores, CIL XIV 2302 refers to a pistor candidarius, a baker who makes white flour or bread from white flour. Cato lists many types of bread, but one trait that is valued highly is whiteness, so much so that chalk (creta) was added to certain types of wheat to whiten the bread. Pliny, Naturalis Historia, 18.29.113-114. Three of the inscriptions are political programmata from Pompeii in which the pistores, as a group, call for the election of one person or another. The significance of such cooperation for later professional associations is discussed at greater length in chapter five. $A E 1913$ 116; CIL IV 886, 7273.
} 
called Romanization, not constituting new work in the sense that new occupations were being created.

\section{The Millstone Sub-Industry}

In the eastern Mediterranean, the trade of millstones extends as far back as the Neolithic, though the vast majority of millstones were still of local stone where available. ${ }^{79}$ The trade of millstones intensified in the sixth and fifth centuries BC, with stones travelling up to $800 \mathrm{~km}$ (nearly 500 miles), but most millstones were still of a local material. ${ }^{80} \mathrm{~A}$ mounting body of evidence has pointed to the invention of the rotary quern in the western Mediterranean area sometime in the fifth, possibly even the sixth century $\mathrm{BC}$, with the earliest examples disparately scattered throughout Spain, Britain, and one in Carthage. ${ }^{81}$ Despite the invention and diffusion of new millstone types, the vast majority of continued to be locally sourced. ${ }^{82}$ The Sec wreck provides the first evidence for longrange trade of millstones in the western Mediterranean. Though Greek in origin, the ship held two Sardinian millstones of a similar form to mills found at Morgantina suggesting a western origin for that technology (fig. 23). ${ }^{83}$ The sourcing of early examples of the hourglass shaped millstone to the islands of Sardinia and Sicily leads Frankel to

\footnotetext{
${ }^{79}$ Cyprus appears to be the exception. Its lack of volcanic rock suitable for milling seems to have compelled early trade, particularly with the Levant. Hasegawa 2012, 106.

${ }^{80}$ Williams-Thorpe and Thorpe 1993, 293.

${ }^{81}$ Stefanie Wefers $(2011,72)$ prefers a Punic and Mediterranean origin, but Peacock and Cutler $(2011,79)$ have doubts about a Mediterranean.

${ }^{82}$ Alonso 2011, 57. Green 2011, 123. The material was simple limestone hewn from nearby outcroppings. Yet such millstones appear in significant numbers and display considerable standardization; it is unlikely that they were the production of individual millstone makers. For example, the sheer number of puddingstone mills at Herdfortshire in Britain, indicates the existence of a specialized millstone producer even for very simple rotary mills.

${ }^{83}$ Fig. 6 and 10; White 1963; Williams-Thorpe and Thorpe 1990, 18-19.
} 
hypothesize that the meeting of the local-stone rotary quern and the east Greek basalt hopper-rubbers in the central Mediterranean islands led to the innovation of the Pompeii or Morgantina style millstone. ${ }^{84}$

As commercial baking intensified and expanded westward in the last few centuries $\mathrm{BC}$, the millstone trade took on a new character. In the eastern Mediterranean, first-century BC millstones have been found as far as $1300 \mathrm{~km}$ (over 800 miles) from their source. ${ }^{85}$ Specific quarries began specializing in particular types of millstones, some producing only rotary querns and others the larger Pompeii-style millstones. ${ }^{86}$ In the West, the continuous export of millstones from Orvieto over almost a thousand years offers a look into the development of the industry. Orvieto first became a prized source of stone as early as the seventh century BC, as evidenced by saddle-querns found throughout central Italy. ${ }^{87}$ The Etruscans later exploited the igneous rock near Orvieto for their own millstones, modeling them on the Greek hopper-rubber and exporting them as far away as Monte Bibele in northern Italy ${ }^{88}$ In the first century BC the Orvieto quarries specialized in the Pompeii-style millstones, sending them to North Africa, Sicily, and locations throughout the Italian peninsula. ${ }^{89}$

In the first century $\mathrm{AD}$, millstones from Orvieto were being transported throughout the western Mediterranean region, now including the Iberian peninsula and

\footnotetext{
${ }^{84}$ Frankel 2003, 18-19. A line in Pliny's Natural Histories might suggest that the Pompeii millstone was invented at Orvieto. Pliny refers to Volsinii as the site of invention for the mola versatilis, though his meaning of this is unclear. Some scholars believe Old Volsinii is not modern Bolsena, but actually Orvieto. Pliny, Naturalis Historia XXXVI.29.135.

${ }^{85}$ Williams-Thorpe and Thorpe 1993, 294.

${ }^{86}$ Williams-Thorpe and Thorpe 1993, 295.

${ }^{87}$ Antonelli et al. 2000.

${ }^{88}$ Renzulli et al. 2002, 181.

${ }^{89}$ Peacock 1980, 50-51.
} 
the interior of Gaul. Luc Jaccottey and Samuel Longepierre, in their survey of millstones from France, isolate a pattern in their distribution. The millstones of southeastern France are almost entirely from Orvieto, while the millstones from southwest and central France are a combination of millstones from local sources and from Orvieto. In Northern France, away from the rivers leading to the Mediterranean, no millstones from Orvieto were found. Based on their description of them, all the millstones in France fit Peacock's types three or four, suggesting that the import of Italian millstones to Gaul began in the first century AD and persisted for several hundred years.

The level of production and distribution of millstones parallels the developments in the Roman baking industry. Both intensified production from the second century BC to the second century AD. Complexity within the millstone industry also increased in the first centuries $\mathrm{BC}$ and $\mathrm{AD}$, just as it had in the Roman baking industry. Although they do not focus on them in their study, Jaccottey and Longepierre find a number of inscriptions on their millstones and show them in their diagrams (figs. 27-28). These inscriptions must be relevant to the production or distribution of the millstones. G.B. de Rossi hypothesizes that the inscriptions are in fact makers' marks. De Rossi found a meta and catillus in 1855 on the Aventine in Rome inscribed with the letters AEAH (fig. 29). ${ }^{90} \mathrm{He}$ argues that the letters on certain millstones were in the Greek alphabet, because of the curvilinear E, and actually represent "una fabbrica di molini" rather than the owner of the bakery. ${ }^{91}$ But de Rossi laments the lack of other inscription of this sort, with which to compare the catillus from the Aventine. He notes that one cannot conduct a full study of

\footnotetext{
${ }^{90}$ De Rossi 1857, 277.

${ }^{91}$ De Rossi 1857, 278-79.
} 
workshops and the meaning of the inscriptions on the millstones. L.A. Moritz in his seminal work on milling technology in Classical antiquity increases our corpus of millstone inscriptions, finding several in Pompeii and Ostia (figs. 29-31). ${ }^{92}$ Moritz posits that the inscriptions are probably makers' marks, while avoiding de Rossi's millstonefactory hypothesis. The precise meaning of the inscriptions is still unknown and they have received less attention than millstone petrology. They must represent some component of their production or distribution, possibly makers' marks as de Rossi and Moritz suggest. ${ }^{93}$

In addition to increased production and infrastructural complexity, millstone producers seem to have added the kneading machine to their repertoire. Kneading machines need not be of one specific material or another. The millstones tend to be made of hard porous stones or stones with inclusions so that they will prove resilient to wear and have an edge. Kneading machines do not require those traits, but they are still made from basalt. The millstones producers certainly had the requisite skills to produce the kneading machines: the catilli are far more complex than kneading machines. Moreover, there may be some indication that the first kneading machines were actually basins created out of upside down metae (fig. 32).

Certainly there was trade in millstones before the specialization of bakers, but it was localized and thus at comparatively low levels. The parallel trajectories of the millstone production and the commercial baking industry (in terms of production,

\footnotetext{
${ }_{92}$ Moritz 1958, 77 and 94.

93 Jodry 2011, 88-89. Inscriptions on millstones from military contexts attest tents and names, suggesting that ownership was the important factor in their engraving, though this model does not apply to bakeries, where several different inscriptions on diffferent millstones might coexist in the same bakery.
} 
distribution, and complexity) imply a coeval development, even if a causal relationship cannot be proved. Both were clearly products of urbanization in the western Mediterranean region, but domestic production of grain never required millstone technology as complicated, large, or costly as the commercial bakeries did. Additionally, the Roman bakeries generated new technologies, like the kneading machine, that millstone producers were already equipped to supply. Nor did the market for simpler domestic milling technologies, such as rotary querns, cease in the rural areas and to some extent in the towns. The complicated, large, and numerous millstones required by the commercial baking industry represented a new market for millstone suppliers and their labor to meet the needs of that new market constituted 'new work'.

\section{Specialist Builders}

The production of ancient millstones has received significant attention over the last thirty years, providing an abundance of data. Other technologies, relied on by Roman bakers to make their bread, were similarly complex, requiring a specialist producer. Yet such technologies or features have received little attention. The kneading machine has

only recently become a focus of scholarly discussion, but in many ways the production of millstones and kneading machines comprise a single industry. The neglect of other technologies in the bakers' repertoire, such as ovens, tables, and shelves, is in part a result of the poor state of preservation in which one usually finds them. Millstones and kneading machines are durable and identifiable even as fragments; the greatest threat to their continued existence is reuse. Ovens and tables, on the other hand, erode over time, 
often leaving nothing more than a floor of large tiles or a cluster of stones. Nevertheless, ample evidence for both exists at Pompeii and Ostia. Another sub-industry, in the form of builders specializing in bakery construction, can be inferred from the standardization evident in the construction and layout of the workspaces in bakeries.

The ovens depicted by the frieze on Eurysaces' tomb and by the Romolo relief are masonry, but simple domes lifted on platforms. Such ovens appear in Pompeii in the first century AD, but twenty-one of Pompeii's thirty-five bakeries of a larger, more complex type. Unlike the bee-hive-shaped ovens depicted on the tombs, the Pompeian oven engages the surrounding architecture (fig. 33). The front of the oven, which Fiorelli calls the praefurnium, is framed by an arch and leads to the flu above, channeling the smoke through the building and out the roof. Below the praefurnium is a small cavity, formed by the platform of the oven and a slab of stone above. ${ }^{94}$ The arch is built from ceramic bricks, layered and mortared in such a way that the bricks on the sides are perfectly horizontal and the keystone brick at the top of the arch is perfectly vertical. Lining the arch is often a lip made of tiles laid flat on the arch. The praefurnium in most cases, doubles as a chute from a nearby workroom. The aperture to the oven is constructed out of some sort of lava-stone, potentially broken millstones and kneading machines, with two stones serving as posts and a third as a lintel. Twenty-one of the thirty commercial ovens in Pompeii have the same design and are nearly indistinguishable (fig. 34).

The chute in the praefurnium always leads from an adjacent room (figs. 35-37), which Fiorelli describes as the paneficium (bread-making space). The so-called paneficia

\footnotetext{
94 This cavity can still be found on wood-fired ovens in Italy. The cavity is most commonly used to store fuel for the oven.
} 
differ widely in their state of conservation, but their layout is remarkably consistent throughout the city. Two masonry podia, one positioned near a wall and the other in the center of the room, served as table supports (figs. 38-40). The kneading machine is positioned beyond the table at the other end of the room. Along the sides, usually near the oven, post holes for shelves extend in lines into the walls. Connecting the room to the praefurnium, a chute slopes downward to the front of the oven. Twenty-six of Pompeii's bakeries display this layout, or a derivation of it, in their paneficium.

The nearly identical ovens and the consistency in the layout of the paneficia in Pompeii suggest that one builder or firm of builders was responsible for the construction of the workspaces in the city's bakeries. The ancient bakers needed millstones, ovens and workrooms. Their need was an opportunity for a specialized builder to exploit, thus creating new work. But unlike the producers of millstones, the specialized builders appear to be localized to one city. The two bakeries at Herculaneum, only a short distance from Pompeii and contemporaneous with it, have ovens of a very different type, more akin to the oven on Eurysaces' tomb. One is almost completely destroyed, but the other is undamaged. Neither bakery contains a masonry oven of the Pompeian type; the ovens and paneficia are not laid out in the Pompeian fashion. The builder - or builders specializing in the construction of certain parts of bakeries in Pompeii appear to have not served Herculaneum. ${ }^{95}$

There is evidence for a similar sub-industry specializing in the construction of ovens at Ostia. The Ostian oven is an archaeological hapax; no oven built before or after

\footnotetext{
95 Though they may have served other nearby communities for which we have no evidence.
} 
shares its distinctive traits or the manner in which it was operated. While the larges oven in Pompeii is just over $2.6 \mathrm{~m}$ in diameter, Ostia's largest oven has an average diameter of $5.6 \mathrm{~m}$. The difficulty in operating such a large oven, at least in terms of utilizing the space at the very back, leads Bakker to suggest that the ovens might have contained rotating grates, which would allow the baker to exploit the entire area of the oven surface. ${ }^{96} \mathrm{He}$ cites as evidence the wear marks on the sides of the oven, which he interprets as wear from the rotation of the lazy-Susan. There are several reasons why this cannot be the case. First, most ovens in Ostia are oval, meaning that nothing could rotate within them and still make use of the entire oven-surface. Second, the wear marks tend to slope upward towards the back of the oven. Finally, the grates proposed by Bakker would trap ash from the oven's fire, preventing the baker from cleaning his oven efficiently and potentially ruining his bread.

If the ovens did not contain some revolving device, how did the baker utilize space at the back of the oven, five meters away? The Caseggiato dei Molini, perhaps the best preserved bakery in Ostia, suggests an answer. The oven is located in a small room just east of the northwest corner of the bakery. The oven, with an average diameter of 4.7 $\mathrm{m}$, occupies three quarters of the space. Even with a rotating grate, as suggested by Bakker, the baker would still need a long spatula. The two apertures in the wall at the entrance to the oven-room point to the solution. At first I thought they were chutes, in the manner of Pompeii, but then decided that they were too low to the ground. I then suspected that they were vents to allow warmth near the leavening shelves. After Daniel

\footnotetext{
${ }^{96}$ Bakker 1999, 111.
} 
Wing, a professional oven-builder, pointed out the need for spatula or some sort of long rod, I realized that the apertures were there to accommodate the end of the pole as the front moved back and forth in the oven, manipulating the bread.

The lines, however, could not have been produced by a tool with a broad flat end like the spatula. The spatula would leave marks at the very base of the oven sides, just above the floor surface. The grooves in the Ostian ovens are 10 and $20 \mathrm{~cm}$ above the surface of tiles flooring the oven. Wing hypothesizes that Ostian bakers used multilayered trays that they inserted and removed with a long rod with a hook on the end. The trays themselves could have had hoops for the rod to catch, facilitating the removal of the trays from the very back of the $5 \mathrm{~m}$ ovens. The apertures east of the oven in Ostia's bakery two could have been inserted to allow the rod to extend back and forth without being limited by the wall. The use of the apertures to accommodate the pole of the spatula is corroborated by the wear-lines in the oven. They extend most of the way toward the front of the oven, but not the entire way. There are no lines on either side of the oven-opening for about one meter, which would naturally be the place where the end of the pole would have the hardest time reaching. Another explanation for the absence of wear-lines at the front of the oven is provided by the fire damage evident on either side of the oven-opening. The tufa blocks that comprise the side of the oven turn a reddish brown when they are burned. The only burnt blocks in the oven at bakery two are those closest to the oven-opening. This would further suggest that the movement of the rod was not only limited by the angle of its insertion, but also by the fires on either side of the 
opening. This is important because it shows that the Ostian oven did not use the retained heat method, but was continuously fired.

There are two types of ovens in Ostia. The first type is a masonry oven made mostly with bricks, probably dating to the third century AD; only one type-one oven exists at Ostia. ${ }^{97}$ It is smaller and simpler than the other ovens and a century later than the other type. Type-two ovens are larger and have a surface of large terracotta tiles. The cupola of the type-two oven is made from tufa blocks, in which the wear grooves are etched (figs. 41 and 42). They are rather simple, compared to the masonry ovens of Pompeii, but their size made their construction complex. Their large size would have required a master builder with the requisite knowledge to build a dome that would not collapse after their first use. The large tufa blocks probably served as solid foundations that could stand the intense heat from the fires high enough to heat the enormous ovens.

The specialized baker did not invent the oven nor did the advent of commercial baking beget the specialist builder. But the specialization of commercial bakers created a market for larger and more efficient technologies, which preexisting industries were willing to fulfill, as we have seen with the millstones and kneading machines. The ovens and work-rooms of Pompeii's bakeries offer another example. A single builder or firm of builders provides a possible explanation for the standardization evident in the design of the ovens and the layout of tables and shelves. The workshop may have built in other contexts as well, but it had as part of its business a specialization in building ovens and work spaces for commercial bakers of Pompeii. Similarly, the massive ovens of Ostia

\footnotetext{
${ }^{97}$ Ostia Bakery 8 (II.8.9).
} 
required enough skill that a professional builder must have been responsible for their construction. Unlike the millstone industry, contract building for the baking industry does not seem to have extended beyond the bounds of the city, as evidenced by the different layouts of Pompeii and Herculaneum. The ancient baking industry therefore contributed to the work of two other industries (millstone production and building) and very probably leading to a sub-specialization within the millstone industry. Such increases in specialization and subsequent contributions to the work-load of other industries strongly suggest that the emergence of commercial baking generated 'new work'.

\section{Oven-Letting: A Spinoff of the Commercial Baking Industry}

Throughout medieval and early modern Europe, particularly in the Mediterranean region, people took their items, bread or other, to their local baker or communal oven to be bake. A modest fee rented space in the oven at its next firing. This practice is well attested in later periods, but it is unclear if it occurred also in antiquity. ${ }^{98}$ Mayeske speculates that it was a possibility, but the textual sources are conspicuously silent on the issue. Paul Erdkamp suggests that "people made their own dough and brought it to professionals who baked it in their ovens, as was a widespread custom in Mediterranean lands in medieval times." 99 Yet he acknowledges that such a phenomenon is only a possibility and the extent of its practice during antiquity remains unknown. Nevertheless,

${ }^{98}$ Francois Desportes $(1999,277)$ traces the shift from medieval oven-letting to early modern commercial baking. Paul Newman $(2001,16)$ describes the economic advantages that oven-letting and communal ovens offered. By sharing or outsourcing the baking, communities collectively negotiated the opportunity costs of firing an oven, in terms of both fuel and time.

${ }^{99}$ Erdkamp 2005, 252. 
there is some archaeological evidence that oven-letting did occur and that certain shops may have specialized in the practice, thus constituting a separate industry altogether.

There are certain bakeries in Pompeii, Ostia, and Italica that have ovens larger than all - or nearly all - other ovens at the site. These bakeries have no indication of the chaîne opératoire, none of the other features typically associated with Roman bread production such as millstones, kneading machines, tables, or shelves. Bakeries 1 and 21 in Pompeii consist of a room or two and an oven. Bakery 5 in Pompeii is a converted home with two ovens, but no millstones, no kneading machines, and no shelves. ${ }^{100}$ The corresponding bakeries in Ostia and Italica (Bakeries 3 and 7 in Ostia and Bakery 1 in Italica) are little more than a room with a gigantic oven.

Fiorelli tends to refer to such bakeries as the workshops of pistores placentarii, or pastry-bakers, but even a pistor placentarius would require millstones for flour. I hypothesize that these are bakeries that specialized in oven-letting. Those who lacked the means or desire to buy their bread could make it at home and bring it to these specialized bakers and for a modest fee have their bread baked. But bread need not be the only thing that these large ovens baked; people in the Middle Ages and even as recently as the twentieth century brought their Sunday dinner to a baker, which might entail meats or other dishes.

Some confirmation of this hypothesis might come from the use of bread-stamps. Claire Holleran speculates that stamping ones name in the bread may have served to

\footnotetext{
${ }^{100}$ It is worth nothing that bakery five in Pompeii was heavily damaged in the 1943-Allied bombing raid. Some features that could shed light on its operation are now gone.
} 
distinguish different people's bread in a communal or professional oven. ${ }^{101}$ The traditional view of bread stamps, however, has been that they represent the identity of the baker, not his clientele. The association between bread and person might serve the baker as means of advertisement. There is another possibility as well. Ovens of the sort found at Pompeii, Ostia, and Italica could roast just about anything. The operator of these establishments may have focused on roasting meats or other goods, and never actually practiced oven-letting. Whether or not these bakeries actually let their ovens does not detract from the fact that, while related, these establishments represent a fundamentally different industry. The adaptation of technologies developed for the baking industry to a new industry, however related, also constitutes 'new work'.

The branch-industry of oven-letters is different from that of the millstone producers and the specialized builders; oven-letting was pre-dated by - or was at least coeval with - the development of commercial baking. The oven-letting industry was something that grew specifically out of the commercial production of bread. In modern economics, such phenomena are categorized as hyper-specialization. But in contrast to modern hyper-specialization, the distinct industries of commercial bread production and oven-letting were defined by their product, not by their task. In modern economies, a producer in the steel industry might focus solely on casting and another on galvanizing, never actually seeing the end product of their focused labors. Ancient bakers, on the other hand, seem to have remained focused on the product, not the task. Despite the existence of water-mills, which would be far more efficient than the mola asinaria, they continued

${ }^{101}$ Holleran 2012, 135. 
to mill their own flour. Although Ostia's bakeries might be considered proto-industrial bread factories, their specialization remained limited by a focus on product rather than task.

\section{Instability and Collapse: Reversion to More Simple Modes of Production}

For the first part of the third century commercial baking persists much as it had during the second century, at least on the Italian Peninsula. The artistic evidence, while not as elaborate or grandiose as either Eurysaces' tomb or the Romolo relief, still depicts the same technologies, hour-glass millstones, ovens, and kneading machines (figs. 1415). The epigraphic evidence is similarly consistent. Those pistores, to whom the term applied, shed the status-marker libertus (a phenomenon discussed further in chapter four), but, like the second-century inscriptions, late antique epigraphy is rife with allusions to collegia and corpora pistorum (discussed at length in chapter five) ${ }^{102}$

Despite such consistency, the third century was a period of turmoil; so much so that certain parts of the Empire were abandoned and never reincorporated. In AD 285 the bulk of the province of Mauretania Tingitana was abandoned, including the site of Volubilis. There had been some occupation of the area as early as the second century BC and Carthage may even have had a presence at the site. The city became a colonia in the $40 \mathrm{~s} \mathrm{AD}$, though it reached its peak of wealth and population at the end of the second century or the beginning of the third and much of the architectural remains date to this period. Despite its abandonment by the Empire, Volubilis remained vibrant well into the

${ }^{102} A E$ 1913, 189; $A E$ 1915, 102; CIL III 2328; CIL VI 2109; CIL VI 10235; CIL VIII 4585; CIL XIV 4452 . 
fourth century and the old city remained inhabited until the fifth century when much of it was converted into a cemetery and occupation shifted to the southwest near the Khourmane River.

The bakeries with their millstones and ovens must date to one of the last phases of occupation in the area of the old city, probably between 285 and 400 AD. Compared to their second-century counterparts at Ostia and Italica, Volubilis' bakeries are much smaller, though their ovens are comparable in size. The construction of the ovens is of a much lower quality and the standardization evident in Pompeii's praefurnia and Ostia's massive ovens is not present. Each oven has different characteristics, as though building was ad hoc. It is possible that the bakers were themselves responsible for the construction of ovens, though it could also be that the builder simply worked with whatever materials were available. The small size of the bakeries, the simple ovens, and the lack of standardization suggests a lack of institutional complexity in both the operation and outfitting of the bakeries.

In response to such conditions, the bakers of Volubilis did something interesting. They chose a less efficient technology, but one that better suited their needs. Millstones of the Pompeian type exist at Volubilis, but usually as building material. The last millstones used at the site were of a new type, dubbed the 'annular mill' (fig. 43). This type is lightweight, and thin, but can be operated by humans. With limited space, no access to the millstone-trade, and apparently a dearth of donkeys, ${ }^{103}$ the annular millstones gave Volubilis' bakers flexibility. They could move the millstones into place

\footnotetext{
${ }^{103}$ Leduc 2008, 480-485.
} 
when they were needed and put them away when they were not. They were less complex to make, meaning local producers using local stones could make them. Perhaps most important, they could be operated without having to buy, feed, and stable donkeys. Certainly productivity decreased, but not necessarily production. An annular millstone can produce just as much flour as a donkey-driven mill; it just requires more time. From the second century $\mathrm{BC}$ to the second century $\mathrm{AD}$, every innovation in the Roman baking industry was a response to increased demand and the need to increase production. Innovation at Volubilis in third or fourth century AD served more as an adaptation to external stresses.

A similar phenomenon seems to have occurred at Augusta Raurica. The late thirdcentury establishment with an oven, initially thought to be a bakery, was actually a conglomerate of bakery, tavern, inn, and house (Bakery 1 in Augusta Raurica). The bakery-tavern was destroyed in such a way that it preserved the find-assemblages for both the ground floor and the top floor. Sandra Amman and Peter-Andrew Schwarz closely analyze the assemblages, noting tools, large quantities of chicken bones, lares, and cookware. ${ }^{104}$ As was true of the bakeries at Volubilis, the construction of the oven at Augusta Raurica is less sophisticated, but Amman rightly observes that this cannot be taken as evidence of gross deterioration, a process she refers to as 'slumification' (transformation en bidonville). ${ }^{105}$ The substantial military presence in the area may have buffered Augusta Raurica from economic down-turn, as evidenced by the militaria, such as swords, and other high quality objects found in the assemblage associated with the

${ }^{104}$ Amman and Schwarz 2011, 99-273.

${ }^{105}$ Amman and Schwarz 2011, 402 and 406. 
second floor. The lack of sophistication evident in the construction of the oven does not amount to 'slumification', but like the commercial baking at Volubilis; it does imply significantly less complexity within the industry.

While bakers weathered decline and political instability rather well, even proving resourceful in their adaptation to adverse conditions, they could not withstand a complete collapse of the political, social, and economic systems of which they were a part.

Inscriptions attesting pistores persist on the Italian peninsula until the sixth century AD. ${ }^{106}$ The last inscription attesting pistor not from Italy appears at Sitifis (modern Setif) in Mauretania Sitifensis in the late fourth century AD. ${ }^{107}$

\section{Conclusions}

A narrative of specialization within the Roman commercial baking industry can be constructed from the available evidence. The first specialized bakers appeared in the western half of the Mediterranean region toward the end of the third century BC. These early bakers may have primarily focused on milling, but at least some sold bread as well. Their clientele probably consisted of a small portion of society. Over the course of the next century and a half, bakers expanded their consumer base, meeting the new demand of a growing urban population increasingly dependent on commercially produced bread. The strain of producing surely led to increased numbers of specialist bakers, but it also compelled them to innovate and incorporate new technologies, such as the donkey-mill and the kneading machine. Additionally, the increased production also forced the bakers

${ }^{106}$ CIL XI 317.

${ }^{107}$ CIL VIII 8480. 
to augment their labor force, leading to institutional innovation and an emergence of a hierarchical structure within the baking industry.

By the end of the first century BC, the majority of the urban population of Italy and even communities farther west were highly dependent on commercial bakeries for their bread. Bakers' markets continued to expand, but only insofar as the population was growing. This did not halt innovation. New types of ovens were being built and larger millstones were being quarried. The specialist bakers generated 'new work' by providing a new market for millstone producers and specialized builders. The technologies and practices of commercial baking also generated new industries in other ways. Ovenletting, as a separate industry, grew out of the baking industry, but its technology and practices were derivative, thus offering another example of how specialized bakers led to 'new work'.

Where Roman specialization stopped was the hyper-specialization based on task rather than product. One of Gideon Sjoberg's criteria for an industrialized city is a workforce specialized in tasks, not products. Despite the invention of watermills and the absence of millstones in certain bakeries, the commercial pistor was both miller and baker until the Middle Ages. During periods of instability, political or economic, bakers proved resourceful. The bakers of Volubilis continued to innovate and prosper even after the abandonment of the province in AD 285. But the innovation in these periods takes on a new character. While the advent of the mola asinaria, kneading-machine, or Ostian oven resulted from the pressures of meeting increased demand, the innovations evident at Volubilis were adaptations to decreased resources and declining infrastructure. 
Nevertheless, bakers were resilient and persisted. They could not endure, however, complete collapse. Even Volubilis surely benefitted from proximity to the Empire, even if it was not part of it. As the Empire collapsed, commercial baking occurred on a much smaller scale and those who practiced it were doubling as innkeepers and restaurateurs. Despite the less than ideal conditions at the end of antiquity, Roman bakers successfully maintained high levels of production for over three centuries, maybe more in certain areas. The urban population of the western Roman Empire was nearly completely dependent on them from the beginning of the first century AD to the fourth century. The topic of the next chapter, is the extent to which Roman bakers benefitted financially from their productive success. 


\title{
CHAPTER THREE
}

\section{$\underline{\text { Revenue and Profits }}$}

\author{
LABORA ASELLE \\ QVOMODO EGO LABORAVI \\ ET PRODERIT TIBI \\ Work, little ass, \\ as I have worked \\ and you shall profit. ${ }^{1}$
}

Chapter three showed that Roman bakers were successful at meeting the needs of the urban population of the Empire and at consistently adopting innovative technologies, but such productive success did not necessarily translate into financial gain. Moreover, the estimates for revenue in the bakeries show that such regional producers were well compensated for their efforts. The high producing bakeries, such as those of Ostia, could generate annual revenues in the hundreds of thousands of sestertii. The less productive bakeries, which pervade at Pompeii and the other sites sampled in this study, make significantly lower revenues, but their profits exceeded the basic salaries of unskilled labor by tens of thousands of sestertii every year.

The goal of this chapter is singular: determine the extent to which wealth was created by commercial baking. M.I. Finley posits a similar question, "whether or not urban manufacture and trade generated wealth in the ancient world to any significant extent or whether they merely took a share of the consumption fund created by the

\footnotetext{
${ }^{1}$ Graffito from the palatine hill, accompanied by a drawing of a donkey driving a millstone, fig. 160.
} 
agrarian and mining sectors." In attempts to answer this question, it is often assumed that the financial rewards for commercial activity were limited, thus preventing craftsmen from causing much of an impact on the economy, society, or even their own socioeconomic status. ${ }^{2}$ This is the first actual attempt to quantify the possible revenue and profit generated by an industry. The production estimates from Chapter Two are used to estimate the revenue of the bakeries. Profits are derivded from the revenues reduced by estimates for the operating costs of the bakeries. The results of the analysis show that wealth was generated by commercial baking. But to answer Finley's question, only the bakeries in Ostia could generate revenues that would constitute significant wealth. The other bakeries were making more money than is commonly thought, but they were not commercial enterprises that could effectively and quickly elevate someone to the upper eschelons of Roman society. The profits of small-scale bakers could, however, elevate them above much of Roman society, affording them some comfort, stability, and possibly even power.

\footnotetext{
${ }^{2}$ MacMullen $(1974,22)$ sees craftsmanship as not profitable on account of the "absentee landlords" who siphoned off the entire surplus. He says this about agriculture, but in the context of craftsmen and social mobility. Jongman $(1988,198)$ groups craftsmen with slaves and unskilled labor, often disregarding the activity of craftsmen as nothing more than the production of luxury goods for elite consumption. Helmuth Schneider $(2007,169)$ argues that "the chances of obtaining high returns from craft-based production were clearly lower than in agriculture or in money-lending. Even Temin $(2013,116)$ says that, "craftsmen and some agricultural workers had competencies that did not depend on literacy and would receive a higher wage in a rural labor market for them. But these skills would not earn much, if anything, in urban areas."
} 


\section{Estimated Revenue of the Bakeries}

Revenue is the money received for goods or services. For Roman bakeries, it is the money made from the sale of bread (and possibly other products and services). ${ }^{3}$ Estimating revenue requires knowledge of production levels and the cost of bread. The first is estimated in chapter three from the archaeological remains of the bakeries. The second is grounded in textual and epigraphic evidence for prices, for which we have evidence only from the first and second centuries AD and before. We do not have evidence for prices in the third century AD, and Diocletian's Edict on Maximum Prices is conspicuously silent of the price of bread. Any assessment of revenue for Volubilis' bakeries is impossible, not only because of the lack of prices during the third century AD, but also because at the time of their operation they were technically not part of the Empire. ${ }^{4}$ Whatever monetary system they were using, we have no records for the prices of bread or the costs of operation and raw materials. Similarly, the bakery/tavern of Augusta Raurica provided services that exceed the basic pistrinum, which prevents a reasonable estimate of its revenue because it may have been significantly augmented by non-bread baking activities which were not estimated in this study. ${ }^{5}$ Thus the estimation of revenue and profit is limited to Pompeii, Herculaneum, Ostia, and Italica.

The prices of bread vary both geographically and chronologically. That said, the price of bread remained remarkably stable for long periods of time. Kenneth Harl writes:

Most Romans enjoyed stability in daily purchases of bread during the 250 years from the principate of Augustus to Severan

\footnotetext{
${ }^{3}$ The possibility of oven-letting is discussed in detail in Chapter Two.

4 The inland portions of Mauretania Tingitana were abandoned in AD 285, though a Latin speaking population persisted until the arrival an Arab army in AD 708 (Fentress et al. 2001, 36-37).

${ }^{5}$ Ammann and Schwarz 2011, 404-406.
} 
dynasty. They employed primarily middle-sized base metal denominations that were fractions of a thick brass or bronze prime denominations, whether the brass Roman sestertius, the bronze civic six-assaria piece, or the Alexandrine drachma. The prime denomination of uncial weight ( $25 \mathrm{gm}$.), whatever its tariffing, inspired confidence, proved a handy multiple of considerable value, and was conveniently exchanged against silver coins. At Rome or Pompeii in ca. 50, wheat bread weighing one or one and one-half pounds sold on average 2 asses, so that a Roman paid out either a shiny brass dupondius (12.5 g) or two reddish copper asses (11 g each). In smaller Italian towns bread went for one-half this price. ${ }^{6}$

The evidence for the price of bread in Pompeii during the first century AD exists in both literary and epigraphic form, at least for the Italian peninsula. In a passage from the Satyricon, Ganymede remembers a time when a loaf of bread cost only an as and could feed two people. ${ }^{7}$ The implication of this backward-looking lament is that the cost of bread had exceeded an as in Ganymede's own time (the middle of the first century AD). Two inscriptions from Pompeii, both found on the $18^{\text {th }}$ column of the Large Palaestra (II.7), corroborate that assessment, recording the price of bread at two asses. ${ }^{8}$ Their location and the other items mentioned suggest a price list, possibly even a menu. A third inscription, found in the atrium of the so-called Hospitium of Fabius Memor and Celer (IX.7.25), records food stuffs either bought or sold and also gives a price of two asses. ${ }^{9}$ Another inscription with an unknown provenance reads more as a shopping list, giving the price of one libra of bread as one and a half asses. ${ }^{10}$ The calculation of bread in pounds presents a problem. It may be another way of saying one loaf, if one loaf were to

\footnotetext{
${ }^{6}$ Harl 1996, 278.

${ }^{7}$ Petronius, Satyricon, 44.11.

${ }^{8}$ CIL IV 8561, 8566.

${ }^{9}$ Cooley 2004, 163.

${ }^{10}$ CIL IV 4227.
} 
weigh roughly one pound. A loaf of bread made from modern flour, in the same dimensions as those found carbonized in Pompeii, weighs slightly more than a modern pound. ${ }^{11}$ The assessment of bread in pounds is not specific to this inscription. Cato rations four pounds of bread for the chain-gang in the winter and five pounds when working in the vineyards, then four again when the figs are ripe. ${ }^{12}$ There are two possibilities. First, quantities of bread might have been calculated by the loaf for small purchases, but in bulk they were weighed. This is corroborated by the scales evident in the baking frieze on Eurysaces' tomb, which shows grain weighed as it enters the bakery and bread weighed again as it leaves. The second possibility is that the two-as price is what a secondary vendor charges, while the purchase of bread directly from the baker costs only 1.5 as. This would be supported by the discovery of the two-as price in locations where bread might be sold by a secondary vendor (a palaestra and a hotel), while the inscription attesting the 1.5-as price seems more like a shopping list. In either case, we are left with two prices for bread.

There is less evidence for the price of bread in Ostia and Rome. A public inscription recording the food given by the magistrate from his own funds to the collegium salutare Dianae for a banquet, found at Lanuvium near Ostia and dating to AD 136, gives a price of two asses per loaf. ${ }^{13}$ A second inscription, found on Caseggiato degli Aurighi (III.10.1) in Ostia, links bread with a price of eight asses, but it is unclear whether one loaf cost eight asses, or eight asses worth of bread were bought or sold

\footnotetext{
${ }^{11}$ I tested this myself, making bread similar in diameter and height to the carbonized loaves found in Pompeii and Herculaneum. They do weigh just over a modern US pound, about the same as 1.5 Roman pounds ( 1 Roman pound $=.725$ US pounds).

${ }^{12}$ Cato, De Agricultura, 56.

${ }^{13}$ Ratti 1925, 435-62; CIL XIV 2112.
} 
(possibly 4 loaves). ${ }^{14}$ As Harl notes, the prices of bread stayed fairly consistent for several centuries. Despite the eight-as price from Ostia, there are really only two numbers given for a price of bread, 1.5 and two. While seemingly inconsequential with regard to a single loaf, the $33 \%$ difference in price can result in a difference of hundreds of asses in a single day's revenue. For a bakery making 500 loaves a day, the two prices result in revenues differing by 250 asses (1000 and 750 asses). But for the purposes of estimating revenue, the two prices allow for a high and low estimate of maximum revenue.

Table 6 shows the estimated production of bread in the bakeries of Pompeii, Herculaneum, Ostia, and Italica. The average daily revenue for the pistrina of Pompeii, Herculaneum and Italica ranges from 611 to 815 asses. For Ostia, the numbers are significantly higher, as are their production levels, ranging from 5,000 to 6,700 asses. Amounts of money and salaries in the Roman world were usually calculated in sestertii $(H S)$. The maximum yearly revenue for the average bakery in Pompeii is estimated between 55,000 and 75,000 HS. The average bakery in Ostia could achieve revenue between 456,000 and 611,000 HS. To put matters in perspective, the estimated revenue of Pompeii's bakeries is comparable to the pay of the highest ranks of the military and the estimated revenue of Ostian bakeries exceeds the Augustan requirement for admittance to both the equites and senate. ${ }^{15}$ These estimates suggest that even small workshops dealt in

\footnotetext{
${ }^{14}$ Panem a(sses) VIII / (a)xu[i]ng(i)a a(sses) V, IParOst 10. The location of the inscription in a ground floor apartment complex might suggest a domestic shopping list, in which case the price the price to quantity relationship would be unclear.This might be supported by the seemingly unrelated items: bread and axel grease (axuingia). It is also possible that the eight asses, recorded in IParOst 10, represents the increasing price of bread in the years between 100 and $300 \mathrm{AD}$. Evidence for the price of bread reappears in the fourth century, after the reorganization for the currency by Diocletian. In 398 Theodorus issued a proclamation that the price of bread in Ostia be reduced by one nummus, but there is no indication what bread originally cost before its reduction. ${ }^{14}$

${ }^{15}$ Augustus set the financial requirements for the equites at 100,000 denarii and 250,000 for the senate.
} 
large amounts of money and the large Ostian bakeries were dealing in fortunes, in terms of their revenues.

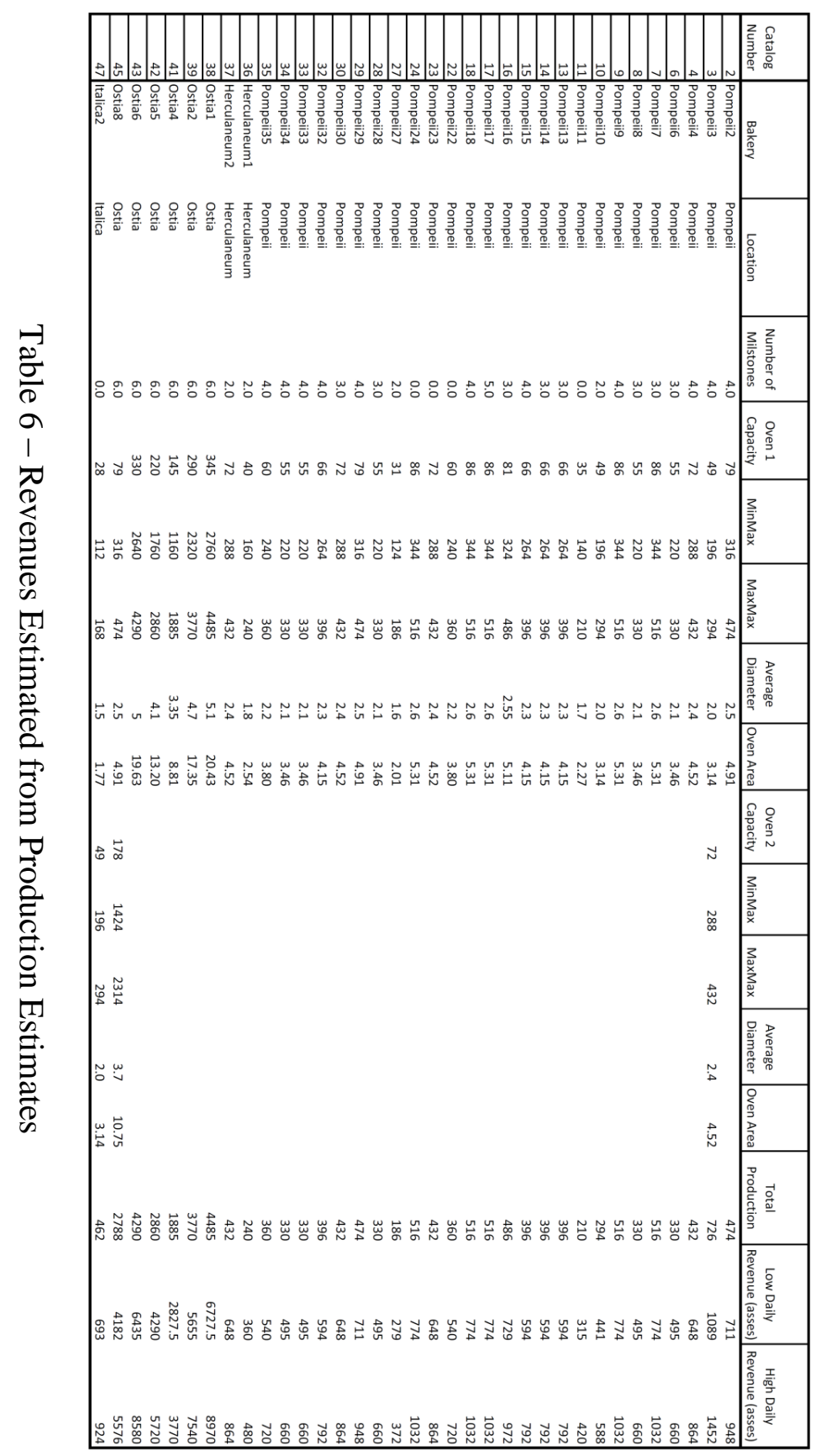




\section{Estimated Gross Profit: The Costs of Grain}

Roman bakeries, despite differences in scale, dealt in massive sums of money, but generating revenue differs from making a profit. Revenue is the amount of money created from products sold or services rendered; profit is the amount of revenue less the costs of production and operation. Unlike that of bread, the price of grain varied geographically and fluctuated with the socio-economic realities of the time. Nevertheless grain prices stayed relatively consistent over long durations, though they varied geographically depending on regional supply and demand.

The cost of wheat to bakeries is, on the surface, a simple assessment; it is the amount needed multiplied by the price paid per unit. Pliny says that one modius $(8.62$ liters) of wheat can produce between 30 (XXX) and 35 (XXXV) Roman pounds of bread. At 1.5 Roman pounds per loaf, as is suggested by the passage in Petronius and the inscription from Pompeii, Pliny's figures would indicate that one modius of wheat yielded between 20 and 24 loaves of bread. Naum Jasny and L.A. Moritz both correctly reject these numbers. Even if extraction of flour from wheat were $100 \%$, to achieve the amount of bread described by Pliny, water would have to comprise more than half of the bread even after baking. Jasny and Moritz suggest a corruption of the text from 20 (XX) and $25(\mathrm{XXV})$ to the higher numbers by the accidental inclusion of an additional ' $\mathrm{X}$ ', which would mean that a modius of wheat would yield between 13 and 17 loaves of bread. Moritz finds the 25-pound bread yield fairly convincing, comparing it to modern 
production figures of flour to bread ratios. Thus one modius of wheat could produce about 16.6 loaves of Roman bread. ${ }^{16}$

Three graffiti from Pompeii list the price of a modius of wheat: CIL IV 4811, CIL IV 4000, and CIL IV 1858. Gilles Bransbourg takes the first graffito, TRICI MODIOS XXX MODIOS AMPHRAS AV, as a clear indication of 30 asses per modius of wheat. ${ }^{17}$ He bases his interpretation on modios being an alternative nominative singular, with $\mathrm{O}$ replacing $\mathrm{U}$, and $\mathrm{XXX}$ representing the price in asses. But unlike the other inscriptions with prices, we have no indication of denomination. If the $\mathrm{XXX}$ does represent asses, modios could be plural and the price of one modius of wheat would be 15 asses. On the other hand, 30 might be the number of modii bought or sold. The second inscription provides a clearer price list. Fiorelli records the discovery of a graffito in the paneficium of bakery two in Pompeii (I.3.27): ${ }^{18}$

$\begin{array}{lcc}\text { OLLIIVM L } & \text { A } & \text { IV } \\ \text { PALIIA } & \text { A } & \text { V } \\ \text { I AIINVM } & \text { A } & \text { XVI } \\ \text { DIARIA } & \text { A } & \text { IV } \\ \text { I VRI VRII } & \text { A } & \text { VI } \\ \text { VIRGAI } & \mathrm{A} & \text { IV } \\ \text { OLIIVM } & \mathrm{A} & \text { VI }\end{array}$

Moving left to right, the three columns list items, followed by an $A$ and numerals. Koenraad Verboeven concludes that the 'A' stands for as and the numerals stand for prices and Mayeske identifies faenum (third down) as wheat. ${ }^{19}$ If the faenum means

\footnotetext{
${ }^{16}$ Jasny 1944, 156.

${ }^{17}$ Bransbourg 2012.

${ }^{18}$ CIL IV, 4000 .

${ }^{19}$ Mrozek 1975, 22: oleum l (olive oil), palea (chaff), faenum (hay, wheat?), diaria (slave rations), furfure (bran), virgae (stalks?), and oleum (olive oil). The second ' $L$ ' after the first 'oleum' has not been explained, perhapts to indicates a different type of oil or a different grade of olive oil.
} 
wheat and the $A$ stands for price of asses per modius, then cost is 16 asses for a modius. Duncan-Jones finds the same price in other parts of Italy (excluding Rome). ${ }^{20}$ The third graffito attests a lower price: FRVMIINTV M H A XIIX. Ernst Diehl identifies the M as representing modius and $\mathrm{H}$ as IS (one and a half). ${ }^{21}$ Thus the price is 18 asses for 1.5 modii of wheat. Bransbourg interprets the inscription as a 12-as price for a modius. The epigraphic evidence thus indicates a price for a modius between 12 and 16 asses for the Campanian cities, and an inscription from Baetica implies a similar range for Hispania as late as the end of the second century AD. ${ }^{22}$

The price of wheat at Ostia is a more complex situation, so much so that the actual cost of wheat for the cities bakeries are probably inestimable. Nevertheless, the difficulties in assessing the costs of wheat highlight some of the more interesting complexities inherent to commercial activity in Ostia and Rome. Stanislaw Mrozek cites an inscription found in Forum Sempronii, dating to the end of the first century AD, in which Lucius Maesius Rufus touts his sale of wheat at one denarius, which must mean 16 asses were lower than the usual price paid at least during the period Rufus made his wares available for purchase. ${ }^{23}$ Naum Jasny, who conducted the first comprehensive study of wheat prices and milling costs under the Roman Empire, arrives at an average price between eight to ten $H S$ (32 to 40 asses) per modius for Rome and Ostia. ${ }^{24}$ Richard Duncan-Jones disagrees, noting that Jasny's numbers were grounded in the assumption that milling costs would be one sestertius per modius because of the low cost of wheat in

\footnotetext{
${ }^{20}$ Duncan-Jones 1982, 50-1.

${ }^{21}$ Diehl 1910, 391.

${ }^{22}$ CIL II 1573.

${ }^{23}$ CIL XI 6117; Mrozek 1975, 15.

24 Jasny 1944, 166.
} 
Egypt. ${ }^{25}$ He prefers an average cost of six HS (24 asses) per modius. Duncan-Jones' 24

asses and Jasny's 32 asses provide a low and high price of a modius of wheat for Rome and Ostia during the second century AD.

At the prices proposed by Duncan-Jones and Jasny, Ostia's bakeries would have operated at a loss, even without the other costs of operating a pistrinum. It may be that the bakeries did operate at a loss, which might explain the state-offered social concessions to freedmen for their participation. ${ }^{26}$ Still, it seems a tall price to invest hundreds of thousands of sestertii every year for an excusatio from certain legal restrictions. It is more likely that Duncan-Jones' and Jasny's price-estimates represent the typical price paid by consumers, but not the prices paid by the bakeries. There are several factors that could lead to a difference between the price paid by a consumer and that paid by a producer. Certainly the distribution of free wheat to the public alleviated a portion of the cost; some of that wheat surely found its way into the bakeries from the recipients of the dole. ${ }^{27}$ In fact, they may have even received free grain from the city, as suggested by an early second century contract between the state and the bakers of Oxyrhynchus. ${ }^{28}$ Bakeries may have also had access to cheaper wheat than the general public though social relationships with merchants. The same might be accomplished by a baker who was actively involved in the importation of wheat. The latter is attested by CIL XIV 4234, in

\footnotetext{
${ }^{25}$ Duncan Jones 1982, 346.

${ }^{26}$ The state-concessions to freedmen for service are discussed further at the end of this chapter in the section on liberti. Though the emperors had previously made similar offers for other industries, the first intercessions in the baking industry came in the principate of Trajan.

${ }^{27}$ Sirks also does not discount the possibility even at a very early time that pistores were receiving subsidized grain in Rome and Ostia.

${ }^{28}$ P.Oxy. XII 145. The bakers agree to provide certain amounts of bread from the specified amount of wheat supplied to them. Certainly the eastern Mediterranean is a fundamentally different situation and each city in the Empire had a distinct strategy with regard to their craftsmen, but the papyrus at least indicates that the practice existed in Roman contexts.
} 
which Marcus Caerellius Iazemus is labeled both a pistor and a mercator frumentarius. As such, Iazemus may have had access to wheat at prices lower than the general public. ${ }^{29}$ With the price of wheat for Pompeii, Herculaneum, and Italica, one needs only to calculate the amount of requisite wheat for each bakery. It is reverse engineered from the maximum bread production for each bakery (Table 7). If the average bakery in Pompeii could produce 395 loaves and one modius yielded 16.6 loaves, the pistrinum would require approximately 24 modii of wheat. At a price of 12 to 16 asses ( 3 to $4 H S$ ) per modius, the estimated daily cost of wheat would range from 310 and 420 asses for an average bakery in Pompeii. Although the estimated revenue of bakeries in Pompeii, Herculaneum, and Italica is quite high, nearly $50 \%$ covers the cost of wheat. The average estimated annual revenue of such bakeries is between 54,000 and 73,000 HS. With cost of wheat subtracted, the estimated annual gross profits for the bakeries are between 27,000 and 37,000 HS, significantly lower than the massive estimates for their revenue, but still quite high.

\footnotetext{
${ }^{29}$ Jasny $(1944,166)$ suggests something similar, asking if the prices of flour mentioned by Pliny were
} 'wholesale' or 'retail'. He concludes that they must have been retail due to their surprisingly high cost. 


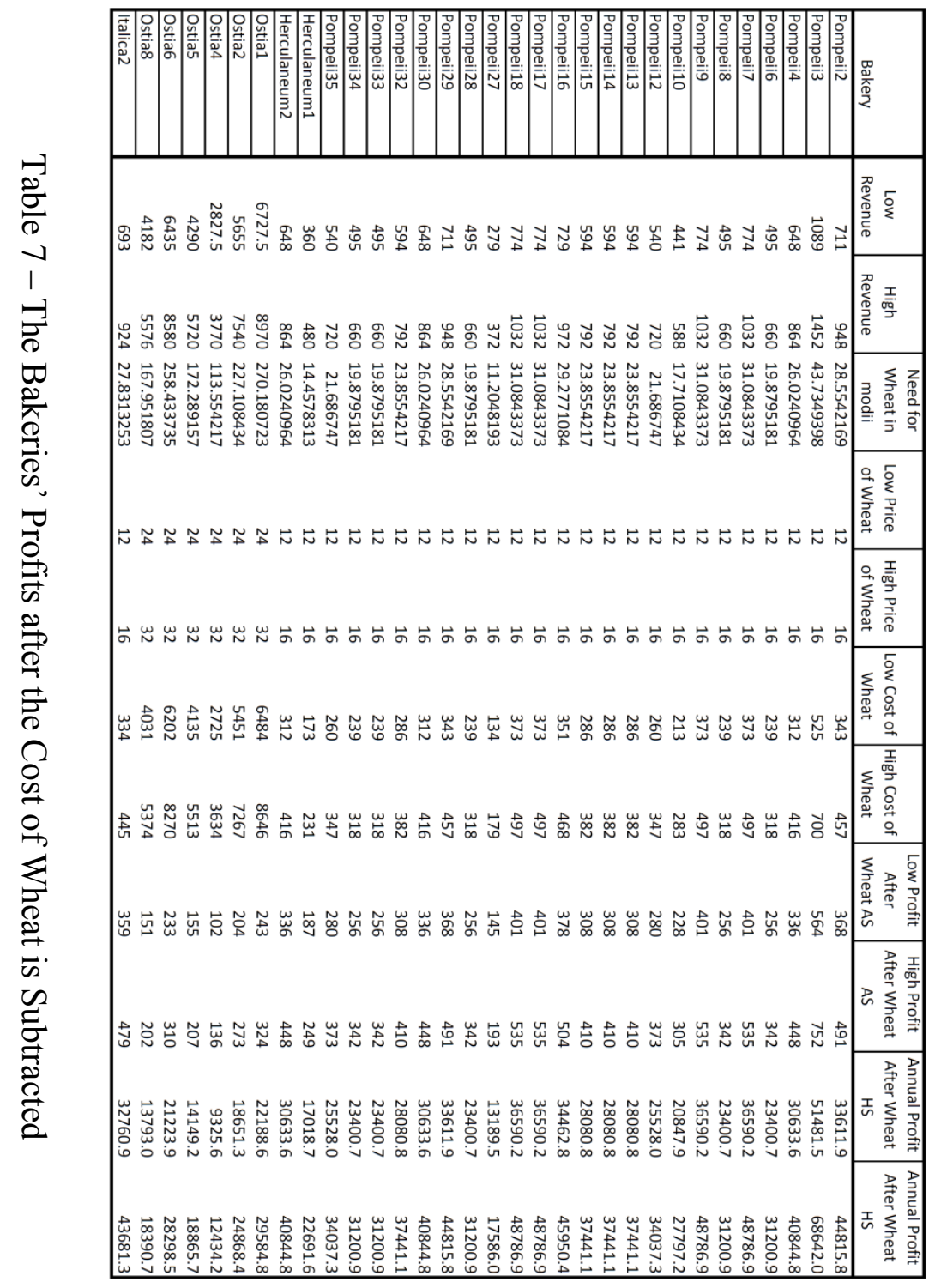




\section{Estimated Gross Profit: The Costs of Equipment, Power, and Labor}

Although wheat comprised the bulk of a bakery's costs, it was not the only expenditure. There was upkeep of the mills, fuel for the fire, payment to employees, rations for the slaves, and feed for the donkeys. Ethnoarchaeological studies of millstones suggest that basic saddle-querns could last generations because of their use strictly in domestic production, but rotary querns last only 10 years when operating in a commercial capacity. ${ }^{30}$ The implication is that increasing complexity in milling technology and intensification of production was accompanied by decreasing durability. Thus the large complex millstones of Pompeii and Ostia might last only a few years. Cato provides a total price for the installation of a millstone amounting to $629 \mathrm{HS}, 393$ times the price of a modius of wheat during the second century BC. ${ }^{31}$ Diocletian's Edict of Maximum Prices, on the other hand, limits the price of a millstone including installation costs to 1250 denarii, 19 times the given price of a modius of wheat. There are two explanations for this remarkable discrepancy. First, the price of millstones decreased relative to the prices of other merchandise; such phenomena frequently occur as industries gain better infrastructure and initial demand decreases. Second, the price of grain may have increased relative to price of other items, which may have been the product of inflation or population growth. Both explanations are possible and they are not mutually exclusive.

\footnotetext{
${ }^{30}$ Hamon and Le Gall $(2011,19-21)$ find that basic saddle querns in Mali are used in exclusively domestic contexts and can last a life-time, but the craftsmen of such objects stay in business because the millstones are given as dowries for a marriage. Holly Parton's study of milling on the Greek island of Olymbos (2011, 33-41) shows that domestic rotary querns could last generations, but that the more intensive milling of wind-mills and water-mills using the same technology produced much lower durability.

${ }^{31}$ Cato, De agricultura, 22.3.
} 
For the sake of argument, assuming somewhere in between these two ratios, ca. 200 times the cost of a modius of wheat, a millstone might cost about 3200 asses. If each millstone in a bakery needed to be replaced every two years, the estimated annual cost to a bakery would be $400 H S$ multiplied by the number of millstones in the workshop.

Diocletian's Edict of maximum prices sets the price for one cart of wood at 150 denarii, approximately double the cost of a modius of wheat. ${ }^{32}$ Although the edict was promulgated hundreds of years after the destruction of Pompeii and was never fully adhered to, the prices do offer a comparative model on which to estimate the cost of fuel. The cost of a modius of wheat in Pompeii was 16 asses, thus a cart of wood should cost around 24 asses. Firing a 'black' oven, like those in Pompeii, consumes no more than 13 $\mathrm{kg}$ of fuel. ${ }^{33}$ The estimates for maximum production assume three firings a day, requiring $39 \mathrm{~kg}$ of wood. Even if a cart of wood only amounted to half a cord (4ft by $2 \mathrm{ft}$ by $8 \mathrm{ft}$ ), the weight would be $900 \mathrm{~kg} .{ }^{34}$ If half of the wood purchases by wagon (32 asses) was used a day, each bakery in Pompeii spent about 16 asses a day. In Ostia, the very large ovens were continuously fired and their size would require more fuel. No modern comparanda exist with which to compare Ostia's ovens, but we can well imagine a hefty price. The average production estimate for Ostia's ovens is ten times the same number for Pompeii's bakeries. If the ration of fuel to baked loaves were consistent, then one would imagine that ten times the fuel was necessary, ca. 160 asses a day worth of fuel.

\footnotetext{
${ }^{32}$ The modius castrensis was set at 100 denarii, but the Italian modius was roughly $2 / 3$ the size of the former. Duncan-Jones 1976.

${ }^{33}$ Wing and Scott 1999, 195-6 and personal conversations with Daniel Wing.

${ }^{34} \mathrm{~A}$ cord is a unit of measurement that measures the dry volume of wood equal to 128 cubic feet or 3.62 cubic meters.
} 
Labor could come in two forms: slaves and hired workers. The cost differential between hiring free labor and keeping slaves is somewhat debated. Skydsgaard argues that the difference between free and servile labor would be a financial wash. ${ }^{35}$ Holleran refutes this assertion, noting that slaves were fed and clothed at private expense, while the free poor sent money into circulation. ${ }^{36}$ Holleran, however, addresses the issue within the context of public construction in the city of Rome. Pompeii's bakeries are primarily a private affair, which would mean that the bakery was responsible for rationing and accommodating any slaves. Accepting for the moment that Skydsgaard is correct in equating the two types of labor, estimating the cost to a bakery requires the number of hired laborers and their pay. Every depiction of millstones, which would have to have been continuously operated, shows a worker tending the donkeys. Kneading, forming loaves, and proving would also require at least one worker. Finally, a fornax (oven operator) was needed to operate the oven. In total, a bakery would need one workman for the millstones, one fornax for every oven, and at least one workman per kneading machine for kneading and forming loaves. In Pompeii, Herculaneum, and Italica, three workers would surely suffice for most of the bakeries and if slave labor were any cheaper it would further lower their costs. An inscription in Pompeii, CIL IV 6877, records the price of a workman at a denarius a day (16 asses), plus one loaf of bread (2 asses in lost revenue), for a total of 18 asses a day per workman. ${ }^{37}$

\footnotetext{
${ }^{35}$ Skydsgaard 1983, 225.

${ }^{36}$ Holleran 2011, 171.

${ }^{37}$ OPERARI(s) PANE(m) DENARIV(m).
} 
Donkeys represent twofold costs for a bakery: their upkeep and their replacement. An undated inscription from Aesernia labels the food for mules as faenum (in this case hay), for which one paid two asses. ${ }^{38}$

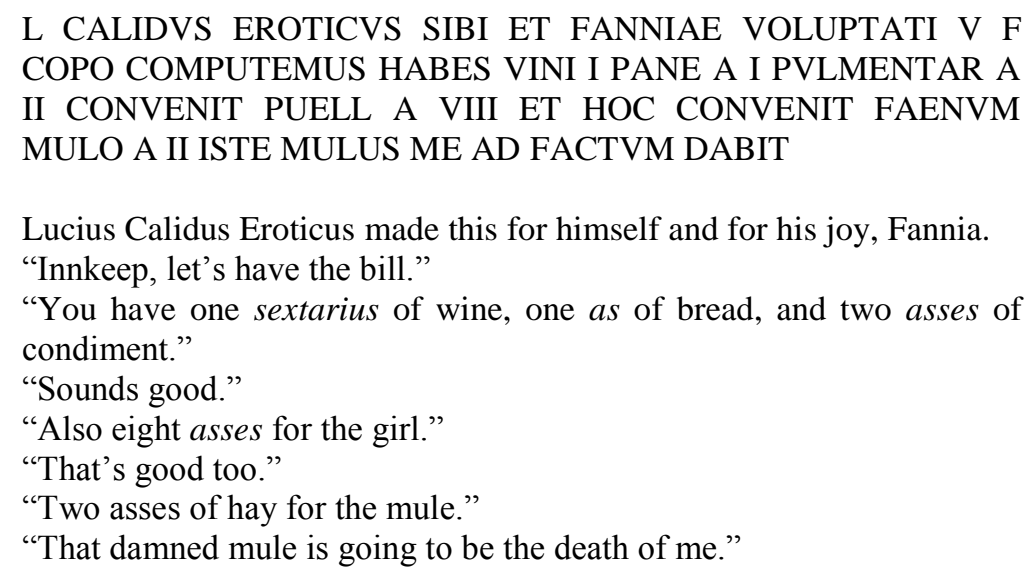

The quantity of hay received for two asses is unclear and the joking nature of the inscription might suggest that the price is not realistic. Additionally, the ratio of feed for a mule in stables must be different than that of a mule at labor. Roth and Roth use military field manuals to estimate the needs of donkeys in the Roman army. They estimate about $6.5 \mathrm{~kg}$ of feed for a donkey. Four donkeys would thus require about $26 \mathrm{~kg}$ of feed, or 57 pounds. ${ }^{39}$ A legal contract between Sarapion and the Eutheniarchs (P. Oxy. 908) stipulates that each man must supply the feed for donkeys, specified as grass and barley. ${ }^{40}$ Grass is a difficult item to assess. It might be indicated in CIL IV 4000 as virgae, the price of which is set at four asses for an indeterminable amount. The price of barley is

\footnotetext{
${ }^{38}$ CIL IX 2689; The inscription is funerary in nature, but is framed by a dialogue between an innkeeper and a traveler. One senses a joke in the text, perhaps a pun on mulus, but the idiom is lost. The price for feed for the mule is set at two asses.

${ }^{39}$ Roth and Roth 1999, 65.

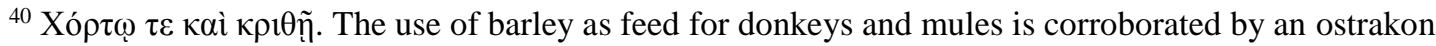
from Africa Proconsularis, OBuNjem 72.
} 
typically valued at $50 \%$ of the price of wheat. ${ }^{41}$ Barley weighs $.54 \mathrm{~kg}$ per liter and there are 8.62 liters in a modius; thus one donkey at labor would consume approximately 1.4 modii of barley a day. With the cost of barley set at eight asses per modius for Pompeii and ten asses for Ostia, feeding a single donkey would cost about 11 asses and 14 asses a day respectively.

Pliny says that female donkeys are the best for labor and can start at 13 months and can breed until they are 30 years old. ${ }^{42}$ This is consistent with modern knowledge of donkeys living in good conditions, but donkeys living in third-world countries and worked hard tend to live only 12 to 15 years. ${ }^{43}$ By all accounts, the labor of turning the millstones was brutal and the shorter lifespan suits both the conditions of the ancient world and the ancient bakery. Using four donkeys with a life span of roughly 12 years, the average Pompeian bakery would need to buy a new donkey every three years, or one third of a donkey every year. Both Varro and Pliny record the purchase of donkeys for extraordinary amounts of money, as much as 400,000 HS. ${ }^{44}$ While acknowledging the benefits of such beasts, Pliny is clearly perplexed at the expenditure. Apuleius' protagonist in the Metamorphoses, although written a century later than the demise of Pompeii, is frequently bought and sold, for prices ranging from 170 to 700 asses $^{45}$ The lower prices all appear in cases that should serve further to humble Lucius. In this reasoning, the annual cost of owning a donkey would be one-twelfth of 700 asses per

\footnotetext{
${ }^{41}$ Polybius 2.15.1, 34.8.7; Cicero, In Verrem, 3.188.

${ }^{42}$ Pliny, Natural History, VIII.68.168.

${ }^{43}$ Pearson and Ouassat 1996, 228-33.

${ }^{44}$ Varro, Res Rustica, 2.1.14; 3.2.7; Pliny, Naturalis Historia, VIII.68.167 “Asinum CCCC nummum emptum Q. Axio senatori auctor est M. Varro, haut scio an omnium pretio animalium victo. opera sine dubio generi munifica, arando quoque, sed mularum maxime progeneratione."

45 Apuleius, Metamoprhoses, 10.13.1 and 10.17.1.
} 
donkey (assuming a 12-year lifespan for the beasts): 58 asses. The Casa dei Casti Amanti has five donkey skeletons, but only four millstones. Using this as the ratio for donkeys to millstones, the number of beasts needed for each bakery is the number of millstones plus $25 \%$ the number of millstones.

In sum, the operating costs of the bakeries in Pompeii, Herculaneum, and Italica further reduce their profits (Table 8). The average estimated daily cost to a pistrinum in these cities is 126 asses. The total estimated daily cost of operating an average bakery in these communities, with the price of wheat included, is 570 and 725 asses, 88 to $93 \%$ of the estimated revenue of the average Roman bakey. The cost of wheat occupies $73 \%$ of the total costs (Table 9). The next highest cost for the bakeries is labor, which occupies $14 \%$ of the overall costs. This is interesting because the legislation of the sencond century and later is exclusively concerned with these two factors. Millstones and fuel comprise 3 and $4 \%$, respectively. The donkeys occupy $1 \%$ or less, but their feed occupied an estimated $6 \%$ of a bakery's costs. Beasts of burden were not daily costs and we should not underestimate the sudden difficulties arising from the unexpected death of a donkey. That said, if a pistor planned carefully, annual costs should not have been too much of a detriment to the finances of the pistrinum particularly considering the large sums of money they could accumulate in short amounts of time from their revenue. After all costs are accounted for, the daily net profit for the average pistrinum in Pompeii, Herculaneum, and Italica is estimated between 170 and 285 asses. The yearly estimated profit for such bakeries is between 17,000 and $27,000 H S$. 


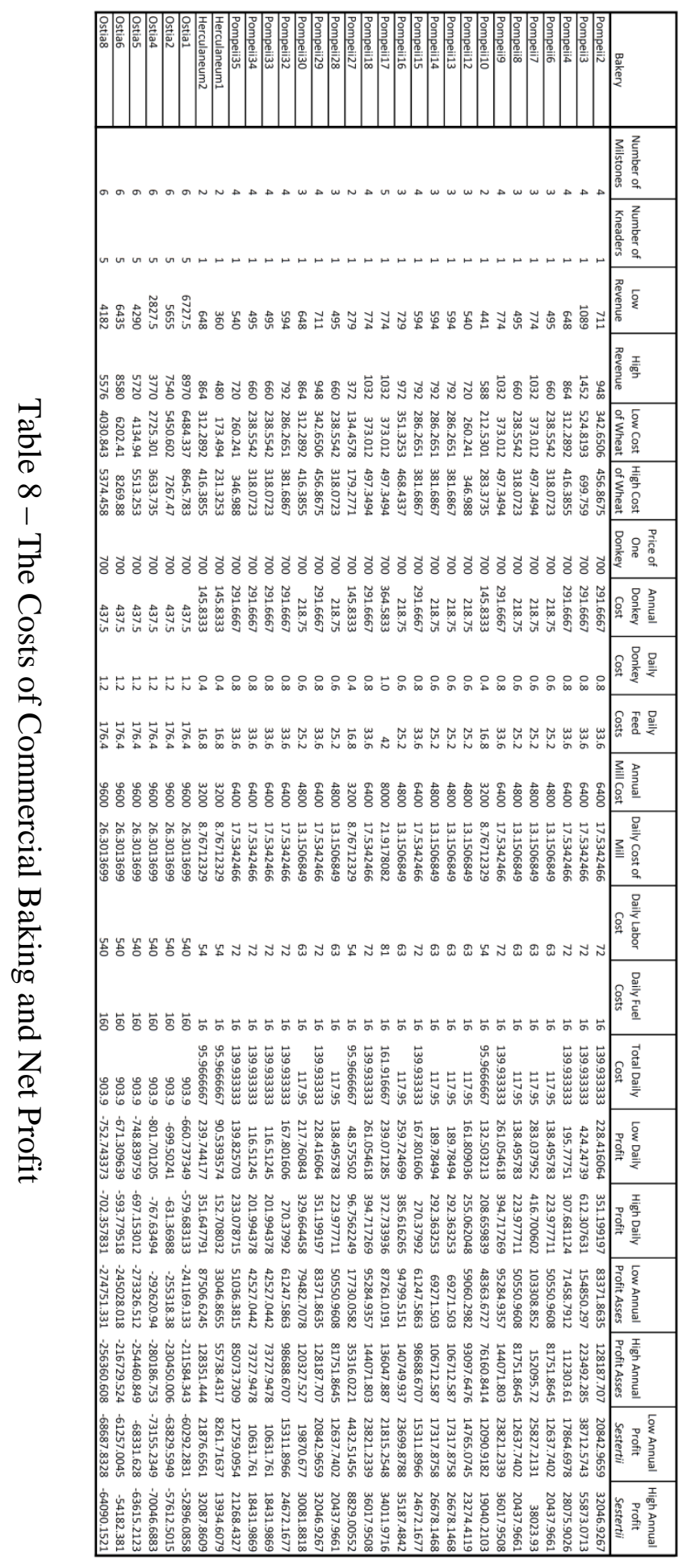




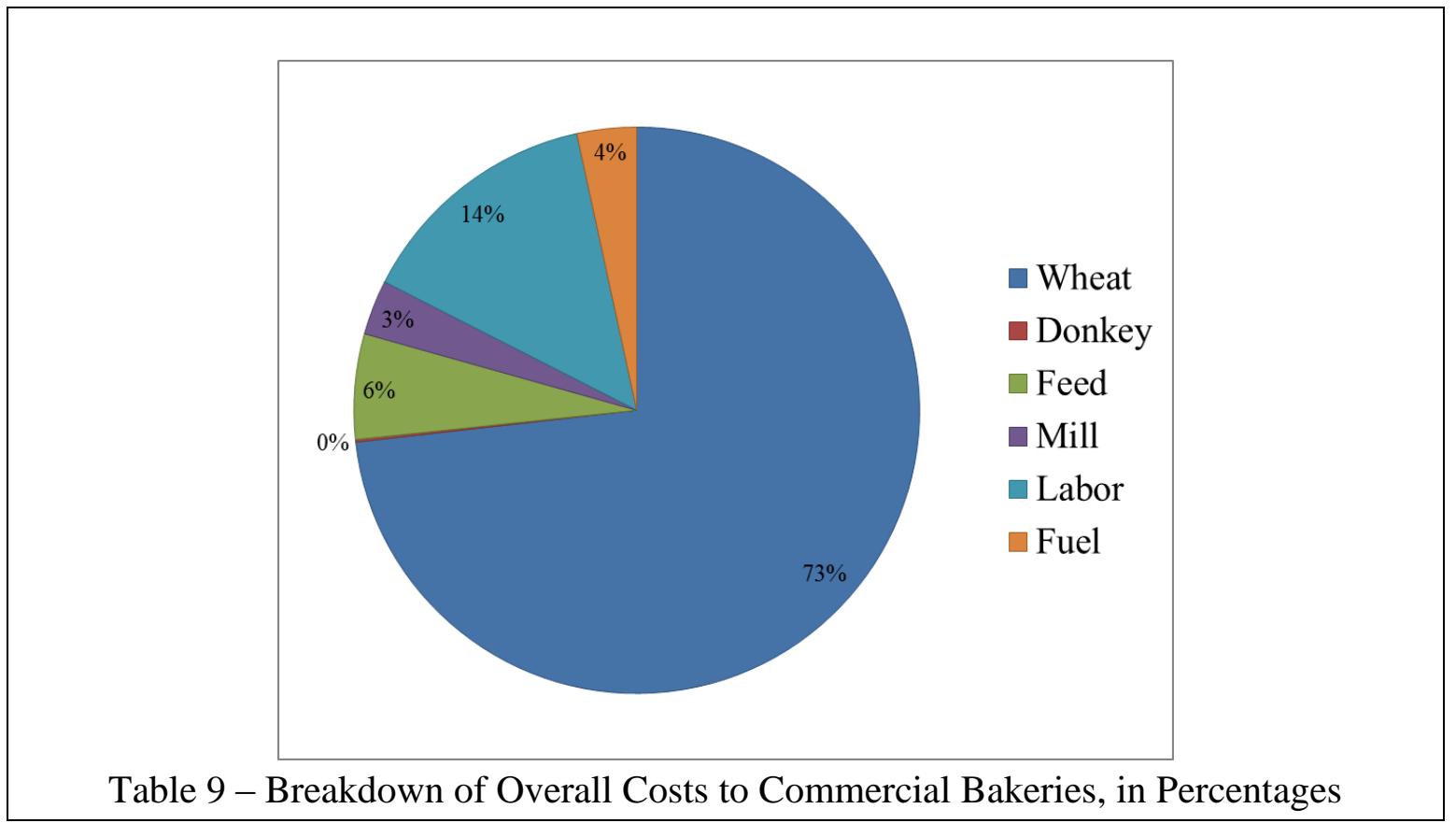

\section{Assessment of Incomes}

The income of bakers is estimated from the daily estimated profits, totaled for a year. Taxes comprised further costs, but they are not uniform either geographically or chronologically. It is important to remember that the profit estimates are based on the maximum possible income, using the maximum production estimates. To put the matter in perspective, in Tacitus' description of the mutiny in AD 14, the soldiers complain that 10 asses a day was insufficient. ${ }^{46}$ Their annual salary would thus amount to $912 \mathrm{HS}$ and 2 asses. Later in the same episode, the soldiers' pay is cited as one denarius a day, or 1460 $H S{ }^{47}$ In either case, the pistores of Pompeii well surpassed that amount. The basic soldier

46 Tacitus Annales 1.17.

${ }^{47}$ Harl 1996, 275. 
is probably more akin to civilian unskilled labor; centurions and primipili might offer a better comparison for skilled craftsmen like pistores. Duncan-Jones estimates the annual salary of a centurion at $15,000 H S$ and 60,000 to 80,000 for a primipilaris.

Although low than the pay of the pimipilares, the pistrina in Pompeii, Herculaneum and Italica generated unexpectedly large amounts of money. If one were to rely entirely on the commercial sale of bread for the financial stability, there were risks, but it was not only possible to live a comfortable life, but also afford some luxury. Indeed, Harl calculates the cost of the basic nutritional needs at six asses a day, per person, about $547 \mathrm{HS}$ annually. ${ }^{48}$ With the profit from an average Pompeian pistrinum, one could afford to rent a house and a bakery (on the order of the ones rented by Caecilius Iucundus) and still have considerable amounts remaining. Although not enough to elevate them to equestrian status, and probably not enough even for admittance among the decurions, the money from commercial baking was enough to distinguish participants from other "poor" people through the comfort and stability it afforded them. More important to the issues at hand, the profits of the Roman bakeries indicate that pistores were not the impoverished craftsmen, lacking sufficient resources to play an important role in Roman society and the economy, as has been suggested. This, however, is predicated on the idea that craftsmen were actually the ones profiting from commercial baking, which we shall see, was not always the case.

\footnotetext{
${ }^{48}$ Harl 1996, 274.
} 


\section{CHAPTER FOUR}

\section{$\underline{\text { Social Status and Social Relations in Roman Pistrina }}$}

Chapters Two and Three demonstrated that the urban population of the Roman Empire was highly dependent on commercially produced bread and that the bakers earned reasonable sums of money. The level of wealth created by the sale of bread evokes notions of a bourgeoisie or a middle class. But the traditional understanding of Roman society - and its economy - is that it defies class analysis, consisting more of vertical ties than horizontal ones. Indeed, the architectural remains of some of our earliest bakeries indicate that Roman commercial baking had origins rooted in the elite domus and by extension the elite familia. The large bread factories of Ostia suggest a reliance on complex social systems for their extensive production and operation. Textual evidence indicates that both the bakeries in elite domūs and Ostia's bread factories were manned by people who related to one another through vertical bonds that defined Roman society, such as master-slave, master-freedman, and patron-client. Less evidence about social relations exists for the bakers operating the smaller pistrina, which prevailed in other parts of Italy and in the provinces. These bakeries, and the bakers who manned them, comprised the bulk of all extant Roman bakeries. Such bakers were likely also reliant on vertical relationships; bound to their patrons and reliant on their slaves. But at the heart of most commercial bread production in the Roman world was the small humble family, not the large familia or the complex social systems of bread factories. 
The aims of this chapter are twofold: (1) to identify the social hierarchies in the architectural evidence for actual bakeries and, (2), to use the artistic, literary, epigraphic, and papyrological evidence to model the social status and social relations on which commercial baking relied. These two goals are achieved by synthesizing the different types of evidence rather than by treating them separately, allowing this study to benefit from the unique strengths of each type. The material evidence can point to the existence of social groups who are relatively invisible in the texts. Moreover, the archaeological evidence can provide scope - with respect to the prevalence of specific practices geographically and chronologically - where textual evidence cannot. The written sources are often anecdotal and discrete in the sense that they contain information that, strictly understood, pertains to one instance, while the material evidence, once compiled, can cover a greater chronological and geographic range, approaching a continuous data-set. Similarly, the written sources of evidence contain details that archaeological methods cannot provide.

Any exploration of status and social relations, with regard to the economy or Roman craftsmen, must begin with Moses I. Finley’s seminal work, The Ancient Economy. ${ }^{1}$ Finley's interests lay not so much with Roman craftsmen as with the lack of economic activity displayed by those with wealth and status. In this way, his work is more of an exploration of elite proclivities and aversions than an actual study of who performed Roman society's economic activity. Finley believes that elites refrained from economic activity because they "lacked the will; that is to say they were inhibited, as a

\footnotetext{
${ }^{1}$ Finley 1973.
} 
group (whatever the responses of a minority), by overriding values."2 When Finley does address craftsmen specifically he tends to marginalize their importance. To summarize Finley's position: those actively participating in economic activity were both rich and poor, but always of low birth. "Someone had to import food, metals, slaves and luxuries, construct houses, temples and roads, and manufacture a wide range of goods... a very large part of that activity was in the hands of either men of low status or of men like the

wealthy metics of Athens, who were more respectable socially but outsiders politically." 3 Scholars have sought evidence that contradicts or supports Finley's suppositions, a search that has often compelled them to focus on commercial enterprises that display extensive financial investment, large-scale production, and technological innovations toward mechanization. ${ }^{4}$ However worthy, such a focus neglects the smaller scale producers, both in their ability to produce and their importance to the ancient economy. Moreover, the few bread factories give the false impression that the Roman economy benefitted from industrialized bread producers, while the vast majority of bakeries throughout the Empire worked on a much smaller scale and relied on a much simpler social structure.

\section{Social Status and Hierarchy in Roman Bakeries: The Archaeological Evidence}

As discussed in Chapter One, issues of social status and hierarchy have traditionally been explored, with regard to craftsmen, through the relationship of

\footnotetext{
${ }^{2}$ Finley 1973, 60.

${ }^{3}$ Finley 1973, 59.

${ }^{4}$ Morel 1993, 229-30; Dark 1996, 1-21; Ward-Perkins 2005, 87-110.
} 
workshops to large houses. The basic assumption is that the size of the house indicates the status of the craftsman and the closer the workshop is tied to the house, the higher the status of the craftsman. Linking socio-economic status too closely to house size conflates fundamentally different spaces. For example, Wallace-Hadrill would place Bakery 3 in Pompeii (I.4.12-17) and Bakery 35 in Pompeii (IX.12.6-7) in the same quartile. Yet despite being comparable in size, the two have obvious differences in their layout. One of the ways to normalize area and make it a more effective factor on which to categorize the bakeries (at least in part) is to quantify the amount of space occupied by commercial baking within the entire building. Bakery 3 has two ovens and 57\% of its space is dedicated to the commercial production of bread, with the remaining $43 \%$ allocated to shop spaces). Bakery 35, on the other hand, has a single oven and only $35 \%$ of the building is occupied by the production of bread. The former has six entrances and the latter has two. The two bakeries are obviously fundamentally different and grouping them together on the basis of size alone neglects those differences. Nevertheless, size does matter, even if it is not taken as an indication of eliteness.

Atria and peristyles have also been interpreted as evidence of the social status or wealth of a house's residents. ${ }^{5}$ Excluding the small ovens in clearly domestic contexts, just over $40 \%$ of Pompeii's definitively commercial bakeries are in some way linked to spaces containing an atrium or peristyle. Yet Flohr notes that "a complex of ten rooms around a garden is fundamentally different from one of ten rooms in a row behind each

\footnotetext{
${ }^{5}$ This was one of the factors on which Wallace-Hadrill formed his quartiles. Fiorelli uses atria as indications of "abitazioni", the number of which he uses to estimate the population of Pompeii. WallaceHadrill 1991, 204; 1994, 102-3; Fiorelli 1873, 10.
} 
other." The use of atria and peristyles as the sole measure of 'eliteness' can exclude many elite houses and conflates spaces that are obviously different, but happen to share a single aspect. Bakery 2 in Herculaneum, for instance, lacks an atrium or peristyle, but it has such elaborate decoration (figs. 44-45) that both Amedeo Maiuri and Domenico Esposito identify it as an "abitazione signorile."7 Furthermore, aggregating all atria or peristyles into a single category fails to qualify nuances, and fails to account for the possibility that some atria once served as elite architectural elements for display, but were later appropriated to serve other functions. Bakery 6 and Bakery 29 in Pompeii, among others, contain atria that have millstones and kneading machines in them, for instance. The atrium and the peristyle may not define a space in its entirety or, necessarily, signify 'eliteness', but they are defining attributes of Roman domestic architecture, by both modern and ancient standards, and thus cannot be disregarded so easily. ${ }^{8}$

Rather than dividing the bakeries into types, the social hierarchies in bakeries are explored through meaningful distinctions - such as visible-obscured, accessibleinaccessible, or separated-integrated. Areas of space dedicated to commercial baking and concealed in the backs of large houses, combined with elite markers such as atria and peristyles, characterize one group of bakeries exclusively found in Pompeii. From this is inferred a close relationship between the commercial activity and the domestic activities of the elite Roman familia. A second group of bakeries, found primarily in Ostia, are massive in size, with a near complete dedication of building space to the production of

\footnotetext{
${ }^{6}$ Flohr 2007, 136.

${ }^{7}$ Maiuri 1958, 451-455; Esposito 2012, 183-189.

${ }^{8}$ Vitruvius de Architectura VI.2-4; Clarke 1991; Wallace-Hadrill 1994.
} 
bread, with the remaining minute space kept for shops. Similar to the small bakeries in big houses found exclusively in Pompeii, the layout of these Ostian bread factories implies a separation of commercial activity from all domestic spaces. Finally, a third group is characterized by bakeries that are smaller than the aforementioned types, but vary in size within their range. The chaîne opératoire in each one of these bakeries is integrated into spaces under the same roof but not dedicated to commercial baking. These shared spaces often contain indications of domestic activity, such as dining or food preparation of a non-commercial sort.

\section{Small Bakeries in Big Houses}

A group of four bakeries in Pompeii are distinguished by the enormity of the houses in which they are located and the very small portion of the household space that they occupy: the Casa del Labirinto, the Casa del Marinaio, the Casa di Epidio Sabino, and the Casa di Terentio Proculo (figs. 46, 47, 48, and 49). ${ }^{9}$ Each of the first three houses has an area over $1000 \mathrm{~m}^{2}$, of which less than $10 \%$ is dedicated to the production of bread. Despite the rather large amount of baking space and its smaller size, the Casa di Terentio Proculo probably also belongs in this group (fig. 47). The location of the baking spaces in these houses is such that they would be completely invisible to the outside world. Moreover, a resident of the house could move about and be completely shielded from the commercial activity occurring only meters away.

\footnotetext{
${ }^{9}$ Pompeii Bakeries 13, 26, and 31 (VI.11.9; VII.15.15; IX.1.22/29)
} 
Another group of bakeries also exists only in Pompeii. Their baking spaces tend to be located inside houses with an area between 200 and $500 \mathrm{~m}^{2}$, with only 20 to $50 \%$ of the house dedicated to commercial baking (figs. 50-59). ${ }^{10}$ As in the very large houses, the industrial space is carefully kept separate from the parts of the house that have atria or peristyles and are often well-decorated. Unlike the small bakeries in larger houses, the commercial space is not relegated to back areas with narrow access, although it is frequently shielded from outside scrutiny. The house and bakery often appear as two separate entities existing within a single communicating space. The commercial half is hidden and inaccessible while the non-baking spaces are visible and highly accessible. The pistrinum of Sotericus, Bakery 3 in Pompeii (figs. 50-51), is in a building split almost in two with the eastern half of the space dedicated to commercial baking and the western half decorated with a peristyle and extensive fourth style wall painting (figs. 6061). The Casa di Aemilio Gallico presents a similar case (figs. 58-59). The house features two atria, but one is converted into a mill and oven room. The other is surrounded by well-decorated rooms with a small bath complex below. Such houses still fall in WallaceHadrill's third and fourth quartiles. Five of the eight houses of this sort have atria or peristyles.

We can infer two things from the architectural and material remains about the social relations among the people working in these bakeries in big houses. First, the attachment of the commercial spaces to the domestic spaces suggests a link between those who operated the bakery and the Roman familia and, second, the size of these

\footnotetext{
${ }^{10}$ Pompeii Bakery 4 (I.12.1-2); Bakery 9 (VI.2.2\&27); Bakery 15 (VI.14.34); Bakery 28 (VIII.4.26);
} Bakery 29 (VIII.6.1). 
houses suggests that the familiae with which these bakeries were associated were wealthy.

The existence of these small bakeries in large houses only at Pompeii might imply a geographic limitation, but the city represents our only material evidence for commercial baking in the first century AD, with the exception of Herculaneum's two bakeries. The complete absence of such bakeries at Ostia, Italica, Volubilis, and Augusta Raurica might indicate that they were a phenomenon of the first century AD and possibly before, but the material evidence alone is not extensive enough to support this conclusion. As we shall see, however, the epigraphic, textual, and artistic evidence do corroborate a disappearance of these bakeries with close relationships to elite familiae after the first century AD. It is profitable, then, to briefly explore the origins of the Roman pistor and the social relationships that defined commercial baking in the periods leading up to and including the first century AD.

The origin of the term pistor is linked to the actual operation of the pistrinum. Citing Varro, Pliny tells us that the words pistor, pistrix, and pistrinum derive from the verb pinsere, to grind or mill. ${ }^{11}$ Pliny deduces from this that the early craftsmen milled, but did not bake. Varro's inclusion of pistrix and Pliny's assertion that women performed the baking before $171 \mathrm{BC}$ might mean that the earliest commercial producers of bread were female. ${ }^{12}$ The first-century BC Roman jurist Trebatius Testa, quoted by Ulpian, casts baking under the purview of female slaves in rustic estates.

\footnotetext{
${ }^{11}$ Varro, De Lingua Latina, V.31; Pliny the Elder, Naturalis Historia, 18.28.108.

12 The only other mention of the word pistrix occurs centuries later in North Africa in the province of Numidia. CIL VIII 2889.
} 
Trebatius amplius etiam pistorem et tonsorem, qui familiae rusticae causa parati sunt, putat contineri, item fabrum, qui villae reficiendae causa paratus sit, et mulieres quae panem coquant quaeque villam servent: item molitores, si ad usum rusticum parati sunt: item focariam et vilicam, si modo aliquo officio virum adiuvet: item lanificas quae familiam rusticam vestiunt, et quae pulmentaria rusticis coquant. ${ }^{13}$

Trebatius further thinks that a baker and barber, intended to serve the needs of the rural household, are included; likewise, the mason, who is intended to repair the villa, and the women who cook bread and look after the villa; likewise, the millers, if they are intended for use on the estate; likewise, the kitchen maid and the steward's wife, provided she assists her husband in some duty; likewise, the wool makers who make clothes for the rural household and those women who cook relishes for the rural slaves. ${ }^{14}$

If the earliest specialization grew out of a situation similar to later rural baking, as Pliny suggests, one may infer from this that women were the earliest pistores. There is very little evidence for female participants in the commercial baking industry after the first century BC. It may be that as commercial baking became increasingly profitable, men pushed women from the occupation.

Our first evidence for slaves in the pistrinum comes from Plautus, dating to the early second century BC. He uses the term mola (millstone) eight times ${ }^{15}$ and mentions pistrina (bakeries or mill-houses) ten times. ${ }^{16}$ The most common context in which either term appears is as a threat to petulant slaves, a place to be sent for misbehaving. ${ }^{17}$

Indeed, the notion that the pistrinum was a place with negative connotations persisted into the $2^{\text {nd }}$ and $3^{\text {rd }}$ centuries AD. Apuleius' description of a bakery in his Metamorphoses

${ }^{13}$ Dig. XXXIII.7.12.5 (Ulpian)

${ }^{14}$ Watson 1985 v. 3.

${ }^{15}$ Compiled by Moritz 1958, 67. Bacchides 2; Menaechmi 975; Persa 22; Poenulus 1152; Pseudolus 1100.

${ }^{16}$ Compiled by Moritz 1958, 67. Bacchides 781; Captivi 808; Epidicus 145; Mostellaria 17; Poenulus 827; Pseudolus 494, 499, 500, 534, 1060.

${ }^{17}$ Plautus, Asinaria, 709. "Postidea ad pistores dabo, ut ibi cruciere currens," "Afterwards I will give you to the bakers, so that they might whip you as you run." 
corroborates the poor working conditions of slaves in pistrina. Lucius, Apuleius'

protagonist, describes the poor wretches he sees while working in a bakery.

Dii boni, quales illic homunculi vibicibus lividis totam cutem depicti dorsumque plagosum scissili centunculo magis inumbrati quam obtecti, nonnulli exiguo tegili tantum modo pubem iniecti, cuncti tamen sic tunicati ut essent per pannulos manifesti, frontes litterati et capillum semirasi et pedes anulati, tum lurore deformes et fumosis tenebris vaporosae caliginis palpebras adesi atque adeo male luminanti et in modum pugilum, qui pulvisculo perspersi dimicant, farinulenta cinere sordide candidati. ${ }^{18}$

Ye gods, what a pack of runts the poor creatures were who looked after us! Their skins were seamed all over with the marks of old floggings, as you could easily see through the holes in their ragged shirts that shaded rather than covered their scarred backs; but some wore only loin-cloths. They had letters branded on their foreheads, and half-shaved heads and irons on their legs. Their complexions were frightfully yellow, their eyelids caked with the smoke from the baking ovens, their eyes so bleary and inflamed that they could hardly see out of them, and they were powdered like athletes in the arena, but with dirty flour, not dust. ${ }^{19}$

These were the slaves who worked the ovens (evidenced by their soot) and milled the flour (evidenced by their flour). Apuleius' characterization is obviously hyperbolic, but the working conditions for the slaves were clearly bad. Not only were these slaves dirty, they were shackled, branded, and jaundiced. Boudewijn Sirks notes Apuleius' placement of the bakery scene immediately after the capture of the bandits who held the donkey Lucius, ${ }^{20}$ and identifies the association of the two passages as possible evidence for forced labor in Roman pistrina imposed as punishment on criminals.

Such negative connotations for labor in the pistrinum is also hinted at in the legal evidence, but there we see a greater concern for the owner's rights. For example, with

\footnotetext{
${ }^{18}$ Apuleius, Metamorphoses, 9.12.

${ }^{19}$ Translation by Robert Graves 1951.

${ }^{20}$ Sirks 1991, 414 and appendix 1.
} 
regard to the defendant liable if suit is brought on account of the mistreatment of a slave entrusted to another for safekeeping, Ulpian outlines how one might bring lawsuit:

Si quis servum custodiendum coniecerit forte in pistrinum, si quidem merces intervenit custodiae, puto esse actionem adversus pistrinarium ex conducto: si vero mercedem accipiebam ego pro hoc servo, quem in pistrinum accipiebat, ex locato me agere posse: quod si operae eius servi cum custodia pensabantur, quasi genus locati et conducti intervenit, sed quia pecunia non datur, praescriptis verbis datur actio: si vero nihil aliud quam cibaria praestabat nec de operis quicquam convenit, depositi actio est. $^{21}$

If anyone compels a slave held for safekeeping to work in a mill, I think that there is an action on hire against him if he received payment for the safekeeping. However, if it was I who received payment for this slave whom he took into the mill, I can bring action on the leasing. But if the work of the slave was payment for the safekeeping, this is as if it were a kind of leasing and hiring but, because money is not paid, an action praescriptis verbis is given. Indeed, if nothing other than food was supplied and nothing was agreed concerning the work, the action is on deposit. $^{22}$

The setting of the scenario in a pistrinum might imply that it was a negative experience that demanded action, but Ulpian's primary concern is that the owner be properly compensated for the unauthorized use of the slave as labor. In fact, discussions of inheritance make it clear that in the passing of a bakery from one person to an heir, the slaves were considered part of the equipment. ${ }^{23}$ Slaves did not merely work in the pistrinum; they could be, legally, part of it.

Despite their status as property, not all slaves performed menial labor. Some slaves actually receive the title pistor. Three inscriptions, found in the columbarium of Livia Augusta, commemorate pistores who may have been free or freed, but who are

${ }^{21}$ Dig. XVI.3.1.9 (Ulpian).

${ }^{22}$ Watson 1985 v. 2. Ulpian uses the word pistrinarius for baker, which may mean that the proprietor, whether or not the operator, of the bakery was liable.

${ }^{23}$ Dig. XXXIII.7.18.1 (Paulus), see page 35 n. 123. 
grouped in with the servi Caesaris (slaves of the imperial household). ${ }^{24}$ Another inscription, CIL VI 9000, seems to corroborate slave bakers having a close relationship to elite familiae. ${ }^{25}$ A certain Faustus is identified as the pistor of Marcella and Paullus. ${ }^{26}$ The combination of some individuals in the genitive with another in the nominative implies ownership. In each of these cases the servi-pistores appear to be associated with a large household. They may simply represent the domestic autarchy of elite familiae. ${ }^{27}$ Autarchy, the self-governance often espoused by aristocrats with the means to consider such a practice, could explain the small bakeries in the very large houses, such as the Casa del Labirinto, in which the household could include hundreds of people. But the same explanation seems less convincing for the bakeries in large houses where nearly half of the space is given over to the production of bread, such as the Casa di Aemilio Gallico.

The direct evidence for servi-pistores disappears by the end of the first century AD. They are mentioned again by the second- and third-century jurists, referred to as pistores in five sections of the Digest of Justinian. ${ }^{28}$ But the jurist in each case was quoting a previous scholar's work from either the first century $\mathrm{BC}$ or $\mathrm{AD}$. In one

\footnotetext{
${ }^{24}$ CIL VI 4010, 4011, 4012; Hasegawa 2005, 45.

${ }^{25}$ FAVSTUS / MARCELLAE PAVLLI / PISTOR.

${ }^{26}$ It is frequently assumed that this inscription refers to a well-known Roman noble couple of the first century BC, Claudia Marcella Minor and Paullus Aemilius Lepidus, who was consul in 34 BC (Cosi 1996, 264; Fusco and Gregori 1996, 226-232).

${ }^{27}$ Excellent bakers for houses were apparently much sought after, Gellius Aulus, quoting a lost work of Varro, describes the potential purchase of a baker at 100,000 HS. Gellius Aulus XV.19.2 "Si, quantum operae sumpsisti, ut tuus pistor bonum faceret panem, eius duodecimam philosophiae dedisses, ipse bonus iampridem esses factus. Nunc illum qui norunt volunt emere milibus centum, te qui novit nemo centussis." ${ }^{28}$ Dig. XXXII.73.3; XXXIII.7.12.5; XXXIII.7.15; XXXIII.7.18.1; XXXIV.5.28.
} 
remarkable instance, the third-century AD jurist and politician Javolenus Priscus records

a legal case from the time of Marcus Antistius Labeo, that is, some time before AD 10.

Qui habebat Flaccum fullonem et Philonicum pistorem, uxori Flaccum pistorem legaverat: qui eorum et num uterque deberetur? Placuit primo eum legatum esse, quem testator legare sensisset. Quod si non appareret, primum inspiciendum esse, an nomina servorum dominus nota habuisset: quod si habuisset, eum deberi, qui nominatus esset, tametsi in artificio erratum esset. Sin autem ignota nomina servorum essent, pistorem legatum videri perinde ac si nomen ei adiectum non esset. ${ }^{29}$

A man who owned a fuller called Flaccus and a baker called Philonicus legated "Flaccus the baker" to his wife. Is only one of them to be delivered and, if so, which one? Or are both to be delivered? It was decided that in the first instance that slave was legated whom the testator though he was legating, but that if this was not clear, the first thing to consider was whether the owner knew the names of his slaves. If he did, then it is the slave who is named that should be delivered, the error being supposed to lie in the description of his trade. But if he did not, then it is the baker who should be deemed to have been legated just as if no name had been given to him. ${ }^{30}$

In Dig. XXXII.73.3, Ulpian quotes Sabinus, a first-century AD jurist. In Dig.

XXXIII.7.12.5, he quotes Trebatius, a first-century BC jurist. In Dig. XXXIII.7.15,

Pomponius quotes Sabinus. In Dig. XXXIII.7.18.1, Paulus quotes Vitellius, a first-

century $\mathrm{AD}$ jurist. When they are not quoting earlier sources, the later jurists never once

refer to a slave as a pistor. Even when they mention slaves working in pistrina, the pistor is clearly distinguished as someone other than the slaves.

Whatever their duties in the pistrinum, slaves were an integral part of commercial baking, often operating within the household as a whole and, in such cases, receiving the pistor. Such slave bakers provide the link between the baking industry and the elite familia missing in the archaeological record. Slaves were part of the Roman household, much as the small commercial spaces were linked to the domestic spaces in the big

${ }^{29}$ Dig. XXXIV.5.28 (Javolenus).

${ }^{30}$ Watson 1985, v. 3. 
houses; like the baking spaces, slaves were located in back spaces because of their low social standing in Roman society and within the familia. The disappearance of any literary evidence for such slaves after the first century AD parallels the absence of small bakeries in large houses in the evidence for commercial baking in the second century AD and after.

The small bakery in a large house, however, accounts for only a small portion of all bakeries and only a fraction of those found at Pompeii. One is tempted to conclude that these bakeries represent the origins of Roman commercial baking: domestic production of bread, that of large elite domīs and familiae, that was then adapted for commercial purposes. Barring the discovery of Republican bakeries before the first century BC, such a conclusion must remain only speculation. Nevertheless, the small bakeries in large houses represent some of our earliest architectural evidence for commercial baking and they disappear in the centuries following the eruption of Vesuvius in AD 79.

\section{Bread Factories}

While the small bakeries in large houses disappeared, a different type of pistrinum emerged, perhaps as early as the end of the first century BC. These bakeries have no physical relationship to elite houses and no indications of domesticity of any sort, although that does not preclude them from serving in that function. The amount of space dedicated to the production of bread, the size of the ovens, and the number of millstones and kneading machines all indicate an emphasis on production (figs. 62-75). Six of the 
seven bakeries fitting this profile are located in Ostia, and only one is in Pompeii (Bakery 3 in Pompeii, I.4.12-17). In terms of production, Bakery 3 in Pompeii lacks some of the technological innovations of similar bakeries in Ostia, such as the large ovens. But its size and the high percentage of the space it occupies dedicated to commercial activity places it in the same category as the other massive bakeries from Ostia. ${ }^{31}$ Moreover, the high levels of visibility throughout much of Bakery 3 are consistent with the visibility of most bread factories. Jan Theo Bakker observes that all of the bakeries in Ostia appear to have been either purpose-built or inserted into structures originally intended to be shops. ${ }^{32}$ Each bakery consists of standardized and compartmentalized rooms, often extending in rows. There are staircases in all of the bakeries and domestic space may have existed in an upper floor. But the standardization and compartmentalization of the rooms suggest structures purpose-built for commercial activity.

Without a direct relationship with domestic space, the social hierarchies and the relationships between participants in these large bakeries are less immediately evident. The concentration of such bread factories in Ostia (and once, probably, in Pompeii) suggests an evolution beginning in the first century $\mathrm{AD}$ and blossoming in the second century AD. The emphasis on production in the frieze on the tomb of the baker Eurysaces could indicate that the origins of bread factories might lie in the last quarter of the first century BC. In either case, the bread factory appears to have been a phenomenon

\footnotetext{
${ }^{31}$ Bakery three in Pompeii lacks the massive ovens of the city to the north, but compensates for its less productive technology by having two ovens. It also has few millstones (4) and fewer kneading machines (1, possibly 2).

${ }^{32}$ Bakker 1999.
} 
geographically restricted to Ostia, or at least Italy. ${ }^{33}$ The single large bakery of this sort in Pompeii might suggest that, had the city persisted into the second century AD, the bakeries there would have evolved into the type of industry evident in Ostia. Similarly, one might infer that Ostia's baking industry, the evidence for which dates to the second and early third centuries AD, resembled Pompeii's during the first century AD. Yet the two cities have differences that extend beyond the chronological divide between them. Pompeii has a reasonably large population by ancient standards, but otherwise is exceptional only for its preservation. Ostia, on the other hand, was the port city of the Empire's capital. It exceeded Pompeii in the scale of its economy, its infrastructure, and its population size throughout the city's history. We should not be quick to assume that Pompeii and Ostia represent two different points on the same developmental trajectory. The bread factories are, as far as we can tell, chiefly a phenomenon of Ostia and possibly Rome.

Legal texts, which pertain primarily to Rome and Ostia, reflect a similar preoccupation with production. Indeed, legal and artistic evidence from Rome attest a branch of the commercial baking industry that was preoccupied with high productivity and ways of increasing that productivity. Trajan offered rights as full Roman citizens to men of Latin status who would mill at least 100 bushels (modii) of grain a day for at least three years. ${ }^{34}$

\footnotetext{
${ }^{33}$ Without evidence from the large urban centers of the eastern Mediterranean, such as Antioch or Alexandria, it is impossible to say that bread factories existed exclusively on the Italian peninsula. ${ }^{34}$ A precedent for Trajan's concession occurred during the principate of Claudius, who gave concessions to those who built merchant ships (naves mercaturae), each according to their status. He gave Roman citizens a vacatio from the lex Papia Poppaea, which prevented low-born Roman citizens from marrying into the Senate or equites. Clausius gave to Junian Latins protection under the ius Quiritium, the law protecting the rights of citizens. And to women, reprieve from the ius quattuor liberorum (Suetonius, De Claris
} 
Denique Traianus constituit, ut si Latinus in urbe triennio pistrinum exercuerit, in quo in dies singulos non minus quam centenos modios frumenti pinseret, ad ius Quiritium perveniat. ${ }^{35}$

Lastly, Trajan enacted that if a Latin carry on the business of miller in Rome for three years, and grinds each day not less than a hundred measures of wheat, he shall attain Roman citizenship. ${ }^{36}$

This text, prima facie, would seem to suggest that at least some Roman bakers were freedmen, that is, Junian Latins. ${ }^{37}$ Indeed, liberti are frequently attested as pistores. The earliest epigraphic evidence for a pistor in the second century BC labels a certain Marcus Ocratius a pistor and libertus. ${ }^{38}$ Inscriptions from the first century BC also name a number of pistores who are liberti. ${ }^{39}$ Prominent among them is Marcus Vergilius Eurysaces, who is sometimes considered a freedman because of his name. ${ }^{40}$ By the second century AD, however liberti ceased to self-identify as freedmen in their epigraphy, making them almost indistinguishable from freeborn participants in the commercial baking industry.

Rhetoribus, 18.4.19). See Mouritsen (2011, 81-91) for a full discussion of whether disenfranchised freedmen would even have accepted such an offer.

${ }^{35}$ Gaius, Institutiones, 1.34 .

${ }^{36}$ Poste 1890, 52.

${ }^{37}$ Latinus in the city of Rome had ceased to refer to an actual ethnic or geographic distinction. Junian Latins were slaves manumitted in a way that did not conform to the lex Aelia Sentia on manumission. The most common breach of the law was the manumission of a slave before his or her 30th year. Following their manumission, Junian Latins lacked certain rights enjoyed by standard liberti. Mouritsen 2011, 87. ${ }^{38}$ CIL X 3779.

${ }^{39}$ CIL V 1046; CIL VI 6687; SO III, 63, 143-144.

${ }^{40}$ Hackworth Petersen $(2006,88)$ summarizes the arguments that Eurysaces was a libertus: "In brief, Eurysaces' identity as a libertinus is deduced for the following reasons. The name Eurysaces, a Greek rather than a Latin one, has led some to conclude that he had been a slave. In addition, work in and of itself, not to mention the labor-intensive activities of baking, was typically associated with slaves and freed slaves rather than with ingenui. Finally, and perhaps most problematically, the monument's remarkable appearance has suggested to more than a few a naive ostentation specifically associated with a freedman's taste (or lack thereof). Whether consciously or not, throughout the scholarship on the tomb, historians' belief in Eurysaces' identity as a wealthy (nouveau riche) ex-slave has been used to explain this monument's nontraditional appearance." 
Much scholarship addresses the awkward status of Latini Iuniani and the concessions made to them during the first and second centuries $\mathrm{AD}$ for service in various sectors, even successful procreation. Much of this scholarship centers on the social programs instituted by Augustus and the later concessions, such as that of Trajan. Suetonius himself believed that Augustus' laws were motivated by racism. ${ }^{41}$ This idea manifests itself more recently in the idea that Augustus intended to limit the number of freedmen in Roman society because they posed some threat to society, perhaps increases to the dole or general unrest. ${ }^{42}$ Henrik Mouritsen observes that such scholarship fails to articulate what the specific threat was that could have compelled the emperor to take action. ${ }^{43}$ Moreover, he calls most of the Augustan laws 'half-hearted' and notes that in the case of Junian Latins Augustus' laws probably had the opposite effect: even more freedmen. ${ }^{44}$ Mouritsen instead posits that the existence of a multi-tiered hierarchy of freedmen served to protect the notion of citizenship. ${ }^{45}$ With the transformation of Roman citizenship from a privilege mostly held by the free residents of the city of Rome and Italy to that of a geographically nonspecific citizenry, the state had to insure that the privilege was not too easy to obtain. As such, the avenue to citizenship through slavery and manumission had to be made more difficult to navigate so that potential candidates could be vetted. The ensuing system through which slaves and outsiders might achieve

\footnotetext{
${ }^{41}$ Suetonius Augustus 40.3. "Magni praeterea existimans sincerum atque ab omni colluvione peregrine ac servilis sanguinis incorruptum servare populum, et civitates Romanas parcissime dedit et manumittendi modum terminavit." "Considering it also of great importance to keep the people pure and unsullied by any taint of foreign or servile blood, he was most chary of conferring Roman citizenship and set a limit to manumission" (trans. Rolfe 1913.)

${ }^{42}$ Most recently by Sarace 2006, 67. See Mouritsen 2011, 80, n. 62 for a full account.

${ }^{43}$ Mouritsen 2011, 81-82.

${ }^{44}$ Mouritsen 2011, 85-86.

${ }^{45}$ Mouritsen 2011, 91.
} 
citizenship had the effect, intended or not, of encouraging certain behaviors. Citizenship and various rights became incentives, something to be earned, that encouraged the liberti (and provincials) to service. It is through this lens that we should view the relationship of the state and freedmen bakers of Rome and Ostia. The Latini Iuniani and other freedmen were probably already practicing pistores, having learned their craft possibly as slaves, but were encouraged by the prospect of certain rights or even citizenship to increase their production of bread (or at least to mill no less than 100 modii a day).

Trajan's conditional extension of rights under the ius Quiritium to the Junian Latins suggests that liberti already played an important role in the commercial baking industry, especially in large bakeries, such as those at Ostia. But the freedmen who might benefit from Trajan's concession were not the sort of men who turned the millstones or operated the ovens. Much of the labor in the large bakeries was surely done by slaves, or potentially the free poor who occupied Ostia's massive apartment complexes. The frieze on the tomb of the baker, Eurysaces, is often cited as evidence of slaves in the bakeries of Rome. The frieze emphasizes the scale of production (an interesting parallel to Ostia's massive bread factories) showing large numbers of people at work, bundles of bread being weighed, and possibly two ovens. The frieze depicts not only the production of bread, but also the participants, perhaps providing some indication of the social hierarchy that existed inside bread factories, since the various individuals and their activities model the roles people could play in large bakeries. Three specific responsibilities emerge from the frieze: labor, oversight, and accounting. There are forty-two individuals shown in the frieze, but only fifteen are directly involved in the production of bread. Another eleven 
are transporting either grain or bread. The other sixteen are involved in various types of management, including eleven togate individuals depicted on the frieze. A single figure from this frieze on the Tomb of the Baker in Rome, often identified as Eurysaces himself, stands between two tables on which eight men are kneading dough into loaves. He motions with his hands while the working men attentively watch; the togate man is probably teaching them or ensuring proper technique. ${ }^{46}$ Five other togate men anticipating the arrival of wheat sit around a table on which there are several poorly defined objects that might be ledgers of some sort. Curtis identifies these men as government officials recording the amount of wheat given to the bakery, much as officials recorded the weight of pure metals issued to mints. ${ }^{47}$ Three more togate men control the weight of bread as it leaves the bakery in baskets. Two are checking sifted flour, making sure it is of adequate quality and fineness. We need not necessarily assume that these are government officials, although it does fit with Eurysaces' status as pistor redemptor (contract baker). Furthermore, not all pistores had contracts with the state. The task of maintaining quality within these private bakeries surely fell to the operators, whether freeborn or freed. Togate men cluster at the receipt of the wheat and departure of the bread from the bakery. These men stand near tables, ledgers, and scales. Their participation hints at the other side of commercial activity: accounting.

One is tempted to assume that the fifteen laborers and eleven transporters are slaves. Lauren Hackworth Petersen identifies two types of people in the frieze, "workers

\footnotetext{
${ }^{46}$ Kneading is one of the more skill-requiring tasks in the production of Roman bread; one needs familiarity with the proper consistency. Too much kneading can over align the glutens, preventing gasses from leaving the dough, and not enough kneading can allow the gasses to leave too easily.

${ }^{47}$ Curtis 2001, 360; Harl 1996, 46.
} 
in short tunics and official-looking togate figures." 48 But not all of the workers are in tunics or togas; some are entirely bare-chested with only modest loincloths to clothe them. Similarly, all the men working on the Romolo relief are clothed in a tunic or a simple girdle; many are bare-chested. Andrew Wilson and Katia Schorle interpret the lack of shirts as a product of both the heat in the bakery and the status of the individuals as slaves. ${ }^{49}$ But there is no reason these individuals could not be free poor, hired to labor in the bakeries. Moreover, the togate individuals on the frieze from the tomb of Eurysaces need not be officials, elites, or even freeborn. There is nothing about these individuals to suggest their specific social status.

Indeed there is ample evidence, particularly from the legal texts, that slaves served not only as labor but also in more managerial positions. The jurist Marcus Antistius Labeo frequently addressed the activity of slaves in the pistrinum, in this case outside of it.

Idem Labeo ait: si quis pistor servum suum solitus fuit in certum locum mittere ad panem vendendum, deinde is pecunia accepta praesenti, ut per dies singulos eis panem praestaret, conturbaverit, dubitari non oportet, quin, si permisit ei ita dari summas, teneri debeat. ${ }^{50}$

Labeo says, too, that a baker who regularly sends a slave to sell bread in a particular place will certainly be liable if with his consent the slave takes payment in advance for the daily delivery of bread and then becomes insolvent. ${ }^{51}$

Labeo says that if a pistor sends a slave to sell bread elsewhere or if he makes arrangements for regular deliveries, accepting payment for these services, then the pistor

\footnotetext{
${ }^{48}$ Hackworth Petersen 2006, 106.

${ }^{49}$ Wilson and Schorle 2009, 104.

${ }^{50}$ Dig. XIV.3.5.9 (Ulpian).

${ }^{51}$ Watson 1985, v.1.
} 
is liable if the product does not arrive. The slave is, then, actively involved in distribution; he or she sells bread and makes deliveries.

Even though slaves could operate as proxies, their responsibilities were not limited to running errands. Indeed, when the jurist Ulpian addresses liability when discipuli were left in charge of a workshop, in this case a fullonica, he is clearly referring to slaves.

\begin{abstract}
Sed et cum fullo peregre proficiscens rogasset, ut discipulis suis, quibus tabernam instructam tradiderat, imperaret, post cuius profectionem vestimenta discipulus accepisset et fugisset, fullonem non teneri, si quasi procurator fuit relictus: sin vero quasi institor, teneri eum. Plane si adfirmaverit mihi recte me credere operariis suis, non institoria, sed ex locato tenebitur. ${ }^{52}$

Suppose that a person setting out on a voyage leaves his whole laundry business in the hands of his apprentices to whom he asks his customers to give their orders and that after he has gone, an apprentice takes in clothes and makes off with them. The launderer will be liable if the apprentice was left as a business manager, but not if he was left as a kind of personal agent. Of course, if he had warranted that I could trust his staff, he can be sued on the contract of work, not on the business manager's conduct. ${ }^{53}$
\end{abstract}

The discipulus left in charge by the fullo could be freeborn, but Ulpian's use of the word institor implies subordination of some sort, possibly the son or slave of the craftsman. Institor was the generic term for any kind of agent employed to manage the economic affairs of a superior. The use of proxies such as these was a common practice among slave-owners and the term institutor is frequently associated with slaves. ${ }^{54}$ There were two broadly defined types of such agents: the exercitor and the institor. Exercitores were legal agents in shipping, while institores were agents in the area of sale of products or

\footnotetext{
${ }^{52}$ Dig. XIV.3.5.10 (Ulpian).

${ }^{53}$ Watson 1985, v.1.

${ }^{54}$ Aubert 1993; Aubert 1994, 210-321; Verboven 2002, 29. Although Holleran (2012, 229-30) observes that institores might also have been independent distributors.
} 
rendering of services, though not necessarily with a specific location. ${ }^{55}$ The names of the proxies are usually suited to the specific type of economic activity in which they were involved. ${ }^{56}$ In the agricultural world, Roman masters would often appoint vilici to manage their affairs in their absence. Agents managing workshops were called officinatores, from the word for workshop (officina) ${ }^{57}$ Aaron Kirschenbaum shows that such proxies were bound to their superior in a legal bond he calls the "principal-agent relationship. $" 58$ This might take the form of the paterfamilias' relationship to his sons, but it has its origins in the influx of slaves and the economic complexity that came with them. $^{59}$

Liberti and clientes may have also served in this function. Freedmen, in most cases, were bound to their former masters even after manumission. The standard freedman relationship with a former master was defined by patronage and, as such, the freedmen/clients may have been used in a fashion similar to the institores ${ }^{60}$ Such a relationship manifested in the commercial baking industry might be indicated by two inscriptions from Ostia. CIL XIV 4234 records a certain Marcus Caerellius Iazemus as quinquennalis pistorum, codicarius, and mercator frumentarius. ${ }^{61}$ Another inscription,

\footnotetext{
55 Kirschenbaum 1987, 93.

${ }^{56}$ Aubert 1993, 173.

57 Vilicus, sometimes spelled villicus, is derived from villa, the name for the rural dwelling on an agricultural estate (fundus).

58 Kirschenbaum 1987, 99.

${ }^{59}$ Kirschenbaum 1987, 89-95.

${ }^{60}$ Mouritsen $(2011,38)$ notes that patronus is derived from pater and that the freed slave is technically part of the familia. The former master becomes, in affect, a quasi-father.

${ }^{61}$ Quinquennalis, perhaps an authority within the corpus pistorum elected at 5-year intervals, implies some hierarchy within the collegium. In Iazemus' case, he held the office three times and for life. Codicarius, or caudicarius, is a lighterman, a person responsible for the transfer of goods from ship to ship. In early modern London, lightermen used flat-bottom rafts to transfer merchandise to go up river. Mercator frumentarius must either be a merchant involved in the production, transportation, or importation of grain.
} 
CIL VI 1002, records another member of the corpus pistorum, Marcus Caerellius

Zmaragdus. Iazemus probably denotes a previous association with a German tribe in the Black Forest area, the Iazemi. ${ }^{62}$ Zmaragdus is the Greek word for an emerald, but borrowed into Latin. Sirks hypothesizes that the two were freedmen of the Caerellii, a known family of equites of the second and third centuries AD. He cites them as possible evidence that equites and other elites may have used their social ties to slaves, freedmen, and freeborn clients to participate indirectly in commercial baking. Sirks writes that, "Wealthy Romans often allowed their freedmen and slaves, or family members with no political aspirations, to look after their commercial affairs. Such a dispersal was also necessary at a time in which communications were relatively good, yet (of course) slower than in our own time. It was part of this dispersal that wealthy Romans deposited money with freedmen which was given back to them later on." 63

Such indirect participation in commercial baking is confirmed by a discussion of the legacy of pistrina by the jurist Paullus in the Digest of Justinian:

Instrumento legato aliquando etiam personas legantium necesse est inspici. Ut ecce pistorio instrumento legato ita ipsi pistores inesse videri possunt, si pater familias pistrinum exercuit: nam plurimum interest, instrumentum pistoribus an pistrino paratum sit. ${ }^{64}$

When instrumentum is legated, it is sometimes also necessary to consider the person of the testator, as, when the instrumentum of a mill is legated, the millers themselves can be regarded as included only if the head of the household ran the mill. For it makes a very great difference whether the instrumentum referred to the millers or to the mill. ${ }^{65}$

\footnotetext{
${ }^{62}$ Sirks 1991, 276.

${ }^{63}$ Sirks 1991, 65.

${ }^{64}$ Dig. XXXIII.7.18.1 (Paulus).

${ }^{65}$ Watson 1985, v. 3.
} 
Participation was clearly a legal concern to Romans. Paulus indicates that inheritance of skilled slaves integral to a bakery's operation could hinge on whether the "pater familias pistrinum exercuit." The implication is that some owners were actively involved in production, but that others were merely owners of the workshop. Those who were not actively involved, but owned the pistrinum, must have used some sort of agent (servile, freed, or freeborn) to attend to their affairs in the bakery.

To sum up, the textual and artistic evidence for commercial baking in Rome and Ostia presents a three-tiered hierarchy: labor, management, and investors. Despite such stratification, the roles of participants of the same status range vertically. Slaves were employed as labor, but could also serve as managers in their masters' stead. Free people, liberti among them, may have served as labor, but appear more prominently in the evidence as the pistores themselves. A third group of moneyed participants was mostly engaged as investors, either funding the enterprises of their freedmen or clientes or using their slaves as proxies to carry out the business of running a bakery, although owners could also be active in running the bakeries themselves.

\section{Small Bakeries not in Large Houses}

While the bakeries in Ostia were characterized by their productivity and some bakeries in Pompeii were defined by their location in - and delineation from - large, elite domestic spaces, the majority of Roman bakeries existed in much smaller buildings (such as those already discussed at Pompeii) and had no direct connection to elite houses (like 
the bread factories at Ostia) (figs. 76-135). ${ }^{66}$ This is not to say that these bakeries had no relationship with domestic space, but rather that they are characterized more by the greater integration of the commercial activity into whatever domestic spaces surrounded them. These small-time producers account for all the bakeries at Herculaneum, Italica, Volubilis, and Augusta Raurica. They also comprise more than half of all the bakeries in Pompeii.

The bakeries of this sort vary greatly in their size and their decoration, but in each of them the chaîne opératoire is integrated with the other activity patterns in the house in ways that prevent a resident from moving through the house without exposure to commercial activity. Some of the smaller bakeries have elaborate decoration that evokes the adornment in elite houses, but they lack the characteristic atria and peristyles. For example, in Bakery 35 in Pompeii, one's path from the triclinium to the kitchen and toilet overlaps with the donkey's route from the mills to the stalls (figs. 86). There is no entrance to bypass areas dedicated to bread production. The workroom south of the oven, often called the paneficium by Fiorelli, is undecorated except for a central painting of Venus with Cupid on the west wall (fig. 94). A tessellated design of an animal is located on the wall north of the millstones (fig. 95). The enmeshment of bread production with the other domestic routines indicates that baking was not merely occurring in the house; it was integrated into the lives of the residents. Furthermore, the production of bread is more visible to the outside world relative to the other types. Viewshed analyses of

\footnotetext{
${ }^{66}$ Pompeii Bakery 2 (I.3.27); Bakery 6 (V.3.8); Bakery 16 (VII.1.36); Bakery 32 (IX.3.10-12); Bakery 33 (IX.3.19\&20); Bakery 34 (IX.5.4); Bakery 35(IX.12.6\&7); and Herculaneum Bakery 2 (Insula Orientalis II.1a \& 3); Volubilis Bakery 4; Bakery 5
} 
Bakery 35, Casa dei Casti Amanti (IX.13.12), and Bakery 2 (I.3.27) suggest high levels of potential visibility into the smaller bakeries independent of large houses (figs. 87 and 97).

While some of the smaller pistrina have elaborate decoration, they contain no atria and no triclinia. ${ }^{67}$ This is not to say that they were not also serving in some domestic capacity, merely that their domestic components lacked the markers of eliteness. They frequently contain interior staircases to upper floors, where operators of the bakeries may have resided. Wallace-Hadrill observes that any space may have served a domestic function, although he notes that in small spaces such as these the person-to-room density would be considerably higher than in larger houses. ${ }^{68}$

Compared to the Ostian bread factories and the small bakeries in large houses, much less evidence exists for the inner workings of small bakeries not in large houses. To some extent, this is the product of the (deduced) lower status of such small-time bakers and the lighter material and textual footprint they left. The juridical sources focus on the highly productive bakeries (milling at least 100 modii a day) or on bakeries where issues of investment and ownership are concerned. The ever-useful tomb of the baker reveals much about highly productive bakeries, but the smaller monuments erected by or for pistores (presumably operating more humble workshops) often show only a millstone and a donkey. The textual and epigraphic evidence for slave bakers in Roman households exists because of the close relationship between the pistores and the elites to whom they

\footnotetext{
${ }^{67}$ Pompeii Bakery 8 (VI.2.6); Bakery 10 (VI.5.15): Bakery 12 (VI.6.17); Bakery 18 (VII.2.22); Bakery 27 (VII.16.6); Bakery 30 (IX.1.3); Herculaneum Bakery 1 (Insula Orientalis II.8); Volubilis Bakery 1; Bakery 2; Bakery 3; Bakery 6; Bakery 7; Bakery 8.

${ }^{68}$ Wallace-Hadrill 1994, 102.
} 
were beholden: the columbarium of Livia Augusta or the monument erected by Marcella and Paullus for their pistor Faustus exists because the masters provided them for their slaves.

Nevertheless, if we associate the less grand funerary monuments for pistores found throughout the Empire with the smaller workshops independent from the elite domus, then there are a few things that one might say. Many of the funerary inscriptions in both Rome and in other parts of the Empire were written by or for pistores who are also liberti. The status of the bakers as freedmen might suggest that the system of vertical relationships evident in juridical evidence from Rome was at work also in the smaller bakeries, but on a reduced scale (fewer slaves and fewer intermediaries). The number of pistores who were also liberti would certainly imply that slavery and manumission played an integral role in the baking industry in general. There were also, however, freeborn pistores. One Numidian inscription, CIL VIII 27867, records the erection of a funerary monument for a baker by his parents. One wants to see a shared trade between the pistor and his father, who would then have taught him how to bake, but there is no direct evidence to support this. We certainly can say that this pistor was freeborn and that he could not have learned his craft while a slave.

Another difference between the bakeries of Ostia and the smaller, integrated bakeries at Pompeii, Herculaneum, Italica, Volubilis and Augusta Raurica is that people actually lived in these smaller bakeries. This, combined with the distinction between these small bakeries and the small bakeries in large houses, makes one want to infer a class of independent craftsmen, detached from the influences of the wealthy or elite. 
Indeed, Mathieu Leduc notes repeatedly the "indépendance totale vis-à-vis des habitations dans lesquelles elles sont situées; la dissociation entre l'espace domestique et l'espace artisanal." ${ }^{69}$ Leduc adeptly avoids directly identifying this dissociation in the built environment as a product of social independence of the bakers of Volubilis, yet it is clear that he is thinking in those terms as he discusses artisan quarters and the relationships of the pistrina with the rest of their insulae. ${ }^{70}$ The tacit implication is that the bakers are socially independent, an inference supported by the structural independence of the bakeries from large homes. Yet structural independence is not necessarily a sign of social independence: craftsmen with money to invest could still find ways to profit from the commercial sale of bread. They could lend money or rent properties they owned.

Inscriptions attest the payment of rents in Pompeii, though unfortunately none addresses the lease of a bakery. There is no direct evidence for the cost of rent of a bakery before the $6^{\text {th }}$ century $\mathrm{AD}$, but we do have some evidence for rents in general. We know, for instance, that one of Pompeii's insulae with bakeries in it (VI.6) had properties for rent. The proprietor, Gnaeus Alleus Nigidus, offers tabernae cum pergulis (shops with upper stories), cenacula equestria (upscale apartments), and domūs (houses).

$$
\begin{gathered}
\text { INSVLA ARRIANA } \\
\text { POLLIANA (C)N AL(LE)I NIGIDI MAI } \\
\text { LOCANTVR EX (K) IVLIS PRIMIS TABERNAE } \\
\text { CVM PERGVLIS SVIS ET C(E)NACVLA } \\
\text { EQUESTRIA ET DOMVS CONDVCTOR } \\
\text { CONVENITO PRIMVM (C)N AL(LE)I } \\
\text { NIGIDI MAI SER }{ }^{71}
\end{gathered}
$$

\footnotetext{
${ }^{69}$ Leduc 2011, 181.

${ }^{70}$ Leduc 2011, $185-7$.

${ }^{71}$ CIL IV 138.
} 
One wants to see these small-time producers in the tabernae cum pergulis: commercial spaces located below domestic spaces. Another inscription from the Praedia Iuliae Felicis records the rental of a bath, tabernae, and multiple cenacula over a domus. ${ }^{72}$ Rents could serve as a financial (and horizontal) bond between operators of bakeries and local elites.

Unfortunately, none of the advertisements in Rome or Pompeii contain information about the rental value in money for the different properties. This information could be found in wax tablets clearly used as financial records found in the house of Lucius Caecilius Iucundus. In addition to the properties he owned, the local aristocrat rented a large house and a fullonica (fullery). Fulleries make excellent comparanda for pistrina: just as the millstones and ovens of bakeries required ample space, so did the massive vats of the fuller necessitate a large workshop. Iucundus' annual rent paid for the domus was recorded in the tablets as 6,000 HS; the annual rent paid for the fullery was $1,652 H S .^{73}$ Iucundus, however, was not a fuller; he was an auctioneer and banker. ${ }^{74} \mathrm{He}$ rented the fullery, but the inscription does not record why he rented the fullonica or whether he maintained its commercial function. If the fullery did continue to function under Iucundus' tenancy, he almost certainly was not himself the fullo and one is tempted to imagine that he ran the business by using his proxies (possibly called institores). If we accept Iucundus' tenancy of the fullery as a possible parallel for elite participation in the commercial baking industry, the pistores operating small bakeries not in large houses could still have social obligations that would mitigate their financial gain while

\footnotetext{
${ }^{72}$ CIL IV 1136; Pirson 1997.

${ }^{73}$ CIL IV 3340, 141.

${ }^{74}$ Andreau 1974, 25-30.
} 
simultaneously providing wealthy elites with an avenue to profit from activities in which they were not actively involved.

There is, in short, much less that we can say about the lives of the bakers in these small workshops distinct from large houses, although these small-time bakeries comprise the largest number in the data-set. The variation in their size and decoration implies a range of wealth, probably depending in part on the success of the individual baker as a producer and vendor. But, as with much of Roman society, the fortunes of the poorer and more humble segments of society probably hung on the favor of those socially and financially above them. Indeed, we have seen some hints of vertical relationships at work in the functioning of the small-time bakeries. Many bakers were freedmen, though we have no sense of what percentage of pistores were liberti. Although we have no direct evidence for how much on would pay to rent a bakery, we do see rent or loans in other trades and for other types of properties. Such financial relationships, might represent vertical bonds, like patronage, but may simply be between to strangers as the need for advertisement might suggest.

\section{Conclusions}

The material and textual evidence for Roman commercial bakers allows for a general sketch of social relations within bakeries. The small bakeries in large houses are limited to Pompeii and the first century AD. Similarly, the textual and epigraphic evidence for servi pistores, such as Varro or the columbarium of Livia Augusta, disappears after the middle of the first century AD. The direct - and intra-familial - 
relationship of the slave baker to his master was replaced by less direct relationships, but they were no less vertical. The social and commercial systems that replaced the family at the heart of the baking industry travelled down two different paths: the massive bread factories of major urban centers and the small-time producers scattered throughout the Empire.

The bakeries in Ostia (and presumably Rome as well) were fundamentally different from those in the other cities. In the second century AD the bakeries at Ostia were industrialized producers, with quasi-mechanized technology. Most of their space was consumed by commercial production and the rest was dedicated to shops for the sale of bread. In addition to those productive differences, the people who were associated with the Ostian bakeries likely differed from their counterparts elsewhere. The operation of the commercial bakeries at Ostia was characterized by greater social complexity. At Rome and Ostia, elites consolidated production and profit into large bread factories, but likely used indirect social relationships such as proxies and freedmen to do so. These bakeries relied heavily on the relationships created by slavery, manumission, and patronage for their operation.

The true workhorses of the Roman baking industry were the small bakeries independent of large houses, found in Pompeii and throughout the Empire. Over half of all the bakeries in the data-set are of this sort. Although there is much less epigraphic or textual evidence for how these bakeries operated or who operated them, there are hints that they, like their giant Ostian counterparts, relied on vertical relationships to operate. Compared to the social complexity required by the bread factories, the social hierarchies 
of the smaller bakeries were much simpler. The presence of liberti among the small-scale bakers strongly suggests the existence of vertical relationships and potentially a reliance on slaves and freedmen for labor. There are some indications of freeborn craftsmen, which would also suggest that the production in these bakeries was centered on the family unit more narrowly defined; fathers and sons and mothers and daughters were producing for the good of the family, probably aided by the few slaves such craftsmen could afford. 


\section{The Strategies of Roman Bakers' Associations: Politics, Prices, and Riots}

Roman pistores were exceptionally adept producers; they successfully supplied bread to entire communities and had considerable resources at their disposal, but their gains were probably mitigated by the asymmetrical distribution of profit along strong vertical relationships. Were they content with the prosperity afforded them or did they use what power they had, their economic clout and social ties, to push an agenda? If so, what types of objectives were important to them and how did they go about achieving these ends? Unlike performers of inessential services, commercial bakers were often afforded the right to associate. The special exceptions permitted to them by the Emperor and various other authorities suggests that their importance to the provisioning of cities earned them a degree of power. Indeed, they even appear to have escaped punishment in cases where they resisted the wishes of local authorities. But the threat of reprisals from the state, also appears to have restrained the bakers. We have no evidence that they attempted to strike or leverage the state with the dependence of Roman cities on their product. Indeed, although the bakers self-regulated the price at which bread was sold, they did so with a focus on equity rather than profiteering. 
The recent work of Jinyu Liu has shown that Roman collegia and other tradeassociations were not all alike. ${ }^{1}$ Associations, even those of the same trade, could be very different from one another, and adapted to local social and economic realities. Indeed, bakers' associations were not uniform across the Roman Empire; those of Rome and Ostia had a much more direct relationship with the state and even the Emperor than their counterparts in other areas. Geographic variation can account for some inconsistencies in our evidence, but in other cases there are simple contradictions. Further investigation suggests, however, that the evidence is not as contradictory as it first appears. Rome and Ostia emerge as the outliers, with the state involved directly with the commercial activities of collegia pistorum in those cities by providing incentives for higher productivity. Consistency in the use of iconography and similarities in bakery layout suggest a degree of homogeneity in commercial baking practices across, at least, the western half of the Roman Empire, although such consistencies or similarities could be the product of shared practices without the existence of a collegium pistorum or some other form of association. Closer analysis of the epigraphic and papyrological evidence for craft associations reveals the same concern for provisioning the community that was evident in Rome and Ostia, but the authorities remained uninvolved in the matters of the bakers' associations until the supply was threatened in some way. In cases where intervention was necessary, the authorities used fines and other punishments to discourage whatever behavior was causing the problem. We have, however, only scant evidence for subversive behavior among bakers or their subsequent punishments. Perhaps

\footnotetext{
${ }^{1}$ Liu 2009, 4-11.
} 
the threat of force dissuaded them, but even in cases when bakers do cause riots, they successfully escape punishment. From the evidence emerges a balance between the needs of the craftsman and the needs of society, a balance sustained by a reactive state and the importance of bakers to the provisioning of Rome's cities.

\section{Uniformity in the Material Culture of Bakers The Iconographic Evidence}

There are, unfortunately, no definitive examples of imagery produced for - or by - a collegium pistorum. But the iconography produced for individual bakers sheds light on their shared practices in two ways. First, the images depict common procedures and reflect common concerns, which probably shows some transmission of information on a professional level. Second, the images often appear in contexts and in scenes that are not commercial in nature, which implies a link to the craftsman's identity and might suggest a symbolism of membership. In some cases, bakers are communicating the location of their establishment to their potential consumers through shop signs. In other cases, the iconography communicates the trade of the deceased. It is an announcement of who one was in life, and a celebration of his contributions to society. In yet other cases, the depictions of commercial baking are statements of identity, neither commercial nor funerary in nature. Like the expressions of identity and craft seen on bakers' tombs, they celebrate one's contributions to society, in this case, while the person still lives. In at least one case a millstone on a signet ring seem to be used specifically to communicate identity 
as a baker and membership in a craft. All these ways of communicating show that there was a shared visual language known, and meaningful, to its audience.

The fornax is probably the motif most familiar to the modern viewer. Ovens changed little from the first century BC to the nineteenth century AD. A man inserts bread into the oven with a long utensil. The earliest of such depictions, the frieze from the tomb of Eurysaces and the Romolo relief, show the oven-operator lunging into the action with one leg extending forward and the other stretching backward (figs. 136-137). The late second- or early third-century sarcophagus of Lucius Annius Octavius Valerianus is much less elegant in terms of style and technique, but clearly shows the same motif of the fornax extending his body and the spatula into the oven (fig. 138). ${ }^{2}$ At some point during the third century AD, the ovens in such scenes shift from simple domes to masonry. The oven on a sarcophagus found in Rome from the middle of the third century is depicted not as a free-standing dome, but rather as a masonry oven akin to those in Pompeii (fig. 139). ${ }^{3}$ The masonry oven appears again on a funerary plaque from the end of the third century AD, now in the Museo Archeologico di Bologna, but the striding oven-operator is replaced by a man with pants and a short tunic. He is more likely the pistor than the oven-operator (fig. 140). ${ }^{4}$

All of these oven-motifs are elements of larger production scenes that come from funerary contexts with proveniences in Rome or nearby. The same motif, however, also appears in an early third-century mosaic from Gaul, in which the fornax is part of a rustic

\footnotetext{
${ }^{2}$ Rostovtzeff 1926, pl. 26; Moritz 1958, pl. 8; Hope 2007, 48; Wilson and Schorle 2009, fig. 21.

${ }^{3}$ Blümner 1912, 72. See chapter three for a discussion of the masonry ovens in Pompeii.

${ }^{4}$ Wilson and Schorle 2009, 120.
} 
calendar in a large house (fig. 141). ${ }^{5}$ The central portion of the mosaic is occupied by personifications of the four seasons riding animals and the panels radiating outward show rustic scenes associated with the seasons. The image of the fornax conforms to the motif in the other works, but its association with autumn and rusticity suggests that it is not a depiction of commercial baking. The similarities between the mosaic from Gaul and the scenes of commercial bakers are probably a product of the artist's familiarity with pattern books and the artistic traditions of depicting baking.

The motifs of loaf-formation and kneading are found only in funerary contexts. The tomb of Eurysaces, the Romolo relief, and the Bologna plaque all show a group of men forming dough into loaves (figs. 20-22). On the Bologna plaque, the scene is so carefully carved that one can discern the manipulation of the dough into loaves. ${ }^{6}$ The number of people involved in loaf-formation on the tomb of Eurysaces is significantly greater than in the other two depictions. Here there are two tables and eight participants, while the Romolo relief and the Bologna plaque show only one table and three men. Despite such minor differences, the scenes are remarkably consistent. Each scene has a table and the men are bare-chested. Moreover, on both the tomb of Eurysaces and the Bologna plaque, one togate individual controls the quality of the loaves. He is central on the tomb, apparently instructing the workers, but on the plaque the figure (on the right), although fragmentary, seems to lean over to inspect a loaf in his hand.

In spite of the ubiquitous use of kneaders, particularly in the western Roman Empire, the tomb of Eurysaces offers the only known depiction of the device (fig. 142).

\footnotetext{
${ }^{5}$ Dunbabin 1999, 76 fig. 80.

${ }^{6}$ Blümner 1912, 44-5; Wilson and Schorle 2009, 104-114, fig. 22.
} 
A donkey operates the machine while a man reaches in to facilitate the mixing of dough and water and the subsequent kneading. The other depictions of kneading show a vat or barrel serving in the same function, except that mixing and kneading are the product of human action rather than of a donkey or a mechanism. Three men in the Romolo relief reach into a vat, presumably to form the dough (fig. 143). Similarly, two individuals in a clipeus on the relief from the Villa Medici in Rome are shown reaching into a large barrel (fig. 144). The barrel is shaped like a modius, circular with sides tapering to the top, but it is too large to be one. The lines on the side and the bands at the top, middle, and bottom imply wooden planks held together by some sort of strap, not unlike a modern barrel. The size might indicate that the barrel is too deep for kneading, in which case it is unclear what is being depicted. Hugo Blumner identified the men as workers and calls the barrel a Bottich, a vat or tub. ${ }^{7}$ He clearly saw this scene as one of kneading. This would be supported by the fact that the worker on the left lacks a shirt. Much like their colleagues in the loaf-gang, the kneaders in all three depictions are bare-chested and wear only a short loincloth. The three depictions of kneading are too different to constitute a motif, but they do share certain traits like the act of reaching into a vessel of some sort and the bare chests of the workers. Such similarities are not the product of a single iconographic prototype on which later depictions rely; they are the result of shared procedural habits and the necessities of the process. The act of kneading requires reaching into a container (and apparently also partial nudity). Hygiene must have been a concern; dough was

\footnotetext{
${ }^{7}$ Blümner 1912, 40.
} 
particularly susceptible to contamination during kneading and forming loaves. Having semi-nude workers would minimize any such contamination. ${ }^{8}$

While the depictions of the loaf-gang are similar enough to constitute a motif, the scenes of sifting differ so widely that they cannot be considered a motif. Moreover, the manner of depicting sifting varies widely. In some cases the actual action is shown; in other cases it is merely alluded to. All the scenes of sifting, however, show a shared pride in quality and an interest in advertising that quality even in death. The action of sifting is one familiar to archaeologists. On the tomb of Eurysaces, two men (both clothed in short tunics) sift flour on either side of a low table (fig. 18). The Bologna plaque, on the other hand, shows a different component of sifting, but one still easily recognizable to archaeologists: dumping the excess material left in the sieve (fig. 19). A partially nude man lifts the sieve up and turns it on its side to allow the unwanted material to fall wherever he is putting it, perhaps in a container to be milled again. The other two scenes do not show sifting, but they allude to it through the display of sieves along with other processes or technologies associated with the production of bread. The cinerary urn holder of P. Nonius Zethus shows on one side of its inscription a donkey and millstone (fig. 145). ${ }^{9}$ On the other side, there are various accoutrement of commercial milling: modii, baskets, and a sieve. Similarly, a funerary plaque from Isola Sacra near Ostia shows the sale of bread (fig. 146). ${ }^{10}$ Above the vendor two sieves hang, presumably on a

\footnotetext{
${ }^{8}$ The phenomenon of nude workers is familiar from any number of drug scenes in modern movies. Stealing may have also been a concern. Wilson and Schorle $(2009,104)$ suggest that the nudity is a product of slavery or the heat from the ovens. The latter seems more likely than the former. The operators of millstones would surely also have been slaves, yet they are more fully clothed.

${ }^{9}$ Curtis 2001, 362, pl. 28; Wilson and Schorle 2009, fig. 18.

${ }^{10}$ Ciancio Rossetto 1973, 47 fig. 34; Zimmer, 1982, 113-14 no. 24; Wilson and Schorle 2009, 112 fig. 13.
} 
wall. The proud display of the sieve is the visual equivalent of the term pistor similaginarius (similago was a high-quality flour); it is an announcement of the quality of one's product. ${ }^{11}$ But a satisfaction in one's craft need not necessarily indicate communication between pistores. Pride could grow in each pistor independently and, indeed, prideful displays were characteristic of funerary depiction. ${ }^{12}$

The same tradition of advertising one's life on a funerary monument is also evident in the depiction of milling and millstones. Two of the fourteen depictions of commercial milling, both from Pompeii, are shop-signs (figs. 157-158). Ten of the fourteen are from funerary contexts, just over $70 \%$ (figs. 147-156). The other two are from contexts that are neither funerary nor advertisement: one is a graffito and the other a signet ring (figs. 159-160). Most of these depictions fit into one of two motifs. The two earliest depictions of Roman commercial milling, the frieze on Eurysaces' tomb and the Romolo relief, form the prototypes to which all subsequent depictions of milling adhere. The frieze on Eurysaces' tomb shows two millstones, each turned by a donkey (fig. 147). Each equine stands behind the millstone to which it is tethered. The donkeys extend one leg, as though suggesting motion as a kouros might. The Romolo relief shows only a single donkey, also behind the mill (fig. 148). The position of the beast suggests circular motion, for its head is rotating to a frontal position as though the donkey were preparing to turn around the millstone. This motif, which I call "type-one", first attested on the tomb of Eurysaces, appears frequently on funerary monuments and altars from the first century AD. The cinerary urn holder of P. Nonius Zethus from Ostia, but now in the

\footnotetext{
${ }^{11}$ The pistor Ogulnius in CIL VI 1958 touts the quality of his flour, see chapter three for a discussion of this inscription.

${ }^{12}$ Hackworth Pedersen 2006, 99-120.
} 
Vatican Museums, shows a donkey standing behind the millstone, simply extending its foreleg to indicate movement (fig. 149). Similarly, the funerary stele of Marcus Careius Asina from Narbonne, Gaul shows a donkey behind a millstone facing right (fig. 150). ${ }^{13}$

After the first century AD, the second type of milling scene pervades. A crude and schematic depiction of milling on a funerary terracotta plaque from the Isola Sacra near Ostia shows a horse turning a millstone (fig. 151). While the donkey on the Romolo relief rotates his head and inclines it downward, the horse's head on the terracotta plaque is turned upward. The equine lifts his inside front leg in a not entirely successful attempt to negotiate the shift in perspective. Although in a more classical and elegantly rendered style, the relief the Villa delle Tre Madonne near Rome shows a near-identical depiction of a horse with millstone (fig. 152). The head is in frontal perspective while the body remains in profile. The artist of the Tre Madonne relief resolves the problem of depicting the legs of the horse as it turns by showing the horse lift its inside leg as though taking a step. The head tilt and stepping leg are repeated in a Bologna plaque (fig. 153). Here the head of the horse is, however, almost in profile, but facing in an opposite direction from its body. The same awkward combination of opposite profiles appears also on a fragment of a sarcophagus from the Vigna Sassi in Rome, now in the Museo delle Terme, but this time with a donkey, evidenced by his pointy ears (fig. 154).

There are, of course, exceptions to these generalizations about the motifs used to depict commercial milling. The millstone on the sarcophagus of Lucius Annius Octavius Valerianus shows a millstone more akin to a rotary quern than the Pompeii-style

\footnotetext{
${ }^{13}$ Esperandieu 1925, 190-1
} 
millstones in the other depictions (fig. 155). Robert Curtis expressed doubt that the scene shows a millstone, suggesting instead that it might be a kneader. He acknowledged that it could be a rotary quern, but objected that they had been eclipsed by the Pompeii-style millstones by the first century AD. ${ }^{14}$ But the object is clearly bipartite like a millstone, not monolithic like the kneading machines. ${ }^{15}$ The sarcophagus from the Villa Medici combines types one and two (fig. 156). The horse extends behind the millstone, facing right and entirely in one coherent profile, but he lifts his leg. Despite these anomalies, all from the later third century $\mathrm{AD}$, the coherence of the milling motifs generally extends throughout the region around Rome and even as far as southern France.

Certainly the artists played their role in establishing such homogeneity, but the use of millstones as symbols is not solely determined by the artist's familiarity with the object. Nothing indicates that more than the appropriation of the motifs cultivated in funerary iconography to serve in other contexts and to convey other meanings. A shop sign, now lost, from Pompeii shows a geometric representation of a donkey and millstone (fig. 157). This image, at least, shows a typical type-one depiction of milling. A more spectacular and unconventional use of the millstone was found in a fresco in the macellum at Pompeii (fig. 158). ${ }^{16}$ Cupids garland donkeys and partake of beverages around an abstracted millstone at the fresco's center. One is tempted to see in this scene a reference to the responsibility of a collegium to hold convivia for its members. Indeed,

\footnotetext{
14 The evidence for actual millstones indicates that even when a more efficient technology exists, less productive technologies persist, often in rural areas, but also in cities. Williams-Thorpe and Thorpe 1993, 270

${ }^{15}$ Curtis 2001, 358 pl. 30.

${ }^{16}$ Wolfgang Helbig (1868, 154 n. 777) said the fresco was found in the Pantheon, which is what the early excavators of Pompeii called the city's macellum, because of its shape. Mau first re-identified the structure as the macellum.
} 
Blümner called the scene a "Mühlenfest" (mill festival) and identifies it as a celebration of the Vestalia. ${ }^{17}$ The location of the fresco in the macellum likely suggests an association with the commercial sale of bread, thus its current categorization as a shop-sign, although it could be more plausibly called a statement - or possibly a celebration - of craft. Both this scene and the humbler shop sign indicate that the depiction of millstones would be introduced into contexts other than those of sepulchral decoration.

The symbolic importance of milling scenes does not extend only to shop-signs. A gemstone from a signet ring, found in Pompeii, shows a donkey tethered to a millstone in a variant of the type-one milling motif (fig. 159). Unlike any of the other depictions, the millstone has a conical base that extends downward. It is perhaps a subterranean anchor, like a caisson, as Blümner suggested, although no millstones of that sort have ever been found. ${ }^{18}$ More likely such a depiction is an abstraction. A ring bearing a millstone would naturally communicate one's craft. The choice of a symbol from one's craft as an identifier would also suggest pride in that craft. Rings of this sort were infused with great importance in the Roman world. They could communicate status; in the Republic, only certain class groups could wear a gold ring, including senators and military tribunes. ${ }^{19}$ Rings became associated with marriage as early as the first century AD. Rings could also signal that one was acting as an agent for a superior; emperors frequently used rings to indicate who partook of imperial authority or who had free access to the imperial court. In each case, the ring symbolizes something greater than its superficial meaning. The gold rings were not just symbols of wealth, they were statements of privilege, power, and

\footnotetext{
${ }^{17}$ Blümner 1912, 46.

${ }^{18}$ Blümner 1912, 45.

${ }^{19}$ Sebesta and Bonfonte 1994, 78.
} 
- above all - belonging to the right group of people. Similarly, the wedding ring was a symbol of belonging to a marriage. The select few who had an Emperor's ring belonged to an extremely elite and exclusive group. The signet rings consistently serve as indicators of membership. A signet with a millstone would be a symbol of membership in the craft of baking, but it may also have been a symbol of membership in a bakers' association. This is corroborated, in a way, by the use of the type-one motif of milling in a graffito from the Palatine in Rome (fig. 160). The sketched donkey and millstone appear almost comical. The inscriber advises the donkey to work, as he has worked, and the beast shall profit. ${ }^{20}$ The joke, discussed at length in chapter four, is that the beast cannot profit. Thus by extension, the man did not profit either, despite his hard work. It may be just a joke, but the depiction of the millstone and donkey and their comical rendering express sentiments opposite that of the signet ring; the latter is an expression of pride and membership while the former represents, at best, exhaustion, at worst, alienation.

The commonalities in the representation of processes in the production of bread, despite motifs and the agency of artists, show an obvious shared pride in the quality of one's work. The depiction of milling, unlike the other scenes, sometimes appears in contexts other than funerary and even serves as expressions of identity, as in the case of the signet ring. The consistent use of the millstone as a symbol in the iconography of the bakers suggests a degree of uniformity in the practices of bakers.

${ }^{20}$ GraffPalatino-1, 289. 


\section{Uniformity in the Material Culture of Bakers The Architectural Evidence}

In chapter four, the differences in the bakeries were equated with different utilizations of the social hierarchies on which the commercial baking relied. But bakeries in the same city frequently display similar layouts and identical technologies. In chapter three, a sub-industry in the form of building contractors in Pompeii and possibly Ostia could even be deduced from the similarities in the construction of ovens. The existence of this sub-industry, however, can only explain the built or immobile components of commercial bakeries. There are additional attributes of a bakery that would have been the choice of the owners and operators of the pistrina rather than the builders. Ovens and millstones are fixed, but their relationship to moveable technologies and other processes such as kneading and sieving produces a layout or pattern in the chaîne opératoire that is dynamic, the consequence not of a builder but of a producer. The similarities arising from choice, rather than necessity, in layout and operation of the pistrina indicate shared notions of propriety and hygiene that in turn suggest some communication between pistores.

Two different types of commonalities in each city's bakeries can be seen: their layout and their operation. The first is detected architecturally, in terms of bakery-design and the placement of technologies within the spatial environment, and here will be assessed through viewshed analyses. This method was introduced in Chapter Four, where it was used to understand the integration of commercial baking into domestic patterns in Roman houses. While in chapter four the viewsheds were used to assess the visibility of 
the entire chaîne opératoire, here the visibility of each component of the process is considered separately. The results of viewshed analysis are not intended to show just what a passerby might see; instead they are interpreted as the level of exposure that society had to certain processes. Certainly there could be doors or other obstructions to visibility that are no longer extant; thus from the viewshed analyses I infer which processes the bakers were more willing to have seen and which they were more likely to hide. Patterns in how all pistores in a city managed visibility in pistrina suggests some form of shared practices and, by extension, shared attitudes about which activities were acceptable and which unacceptable. The pistrinum is conceived as a network of processes. While in chapter four operating sequences were used to explore the relationship between commercial production and Roman domesticity, here they are the basis for an investigation into procedural commonalities. Certain patterns of behavior intersect - or avoid - other patterns. From these patterns one can isolate certain decisions on the part of the bakers.

Some portion of the commercial production of bread is visible in 19 of Pompeii's 25 pistrina with millstones (figs. 161-179) $)^{21}$ and millstones are visible from the outside in 17 of the 19 bakeries. $^{22}$ Ovens come in second, with visibility in 14 of the 19 pistrina. $^{23}$

\footnotetext{
${ }^{21}$ Three of the nine not included here are the pistrina with no millstones. The other six are bakeries which do not have any part of the production of bread exposed to the outside world. All six are of the smallbakery-in-large-house sort (see chapter four).

${ }^{22}$ Pompeii Bakery 2 (I.3.27), Bakery 3 (I.4.12), Bakery 6 (V.3.8), Bakery 8 (VI.2.6), Bakery 9 (VI.3.3), Bakery 11 (VI.6.4), Bakery 12 (VI.6.17), Bakery 14 (VI.14.28), Bakery 16 (VII.1.36), Bakery 27 (VII.16.6), Bakery 28 (VIII.4.26), Bakery 29 (VIII.6.1), Bakery 30 (IX.1.3), Bakery 32 (IX.3.10), Bakery 33 (IX.3.19), Bakery 34 (IX.5.4), Bakery 35 (IX.12.6).

${ }^{23}$ Pompeii Bakery 3 (I.4.12), Bakery 7 (V.4.1), Bakery 8 (VI.2.6), Bakery 9 (VI.3.3), Bakery 11 (VI.6.4), Bakery 14 (VI.14.28), Bakery 16 (VII.1.36), Bakery 18 (VII.2.22), Bakery 27 (VII.16.6), Bakery 28 (VIII.4.26), Bakery 30 (IX.1.3), Bakery 32 (IX.3.10), Bakery 33 (IX.3.19), Bakery 35 (IX.12.6).
} 
There are kneading machines in eight of the 19 pistrina, but only two are visible to the outside. ${ }^{24}$ The kneading machine is the most visible feature in only one bakery; ovens are the most visible in only four. ${ }^{25}$ Millstones, and milling, are the most visible feature in 14 of the 19 Pompeian pistrina in which any part of the production is visible.

Volubilis' bakeries can be divided into two categories. Some of them have ovens near entrances with kneaders and millstones in back rooms (figs. 180-2). The others conform to the pattern set by the pistrina of Pompeii; they have millstones in highly visible areas and the other processes in less visible areas (figs. 183-7). Moreover, this division into two categories is reinforced by geographic separation; the three bakeries that have the ovens upfront are all located in the southern half of the city (fig. 188). This division could have multiple explanations. There might be some chronological divide that is not immediately evident or the different zones might suggest differing neighborhoods, which may have been delineated on ethnic or socio-economic lines. Such divisive factors as ethnicity or socio-economic status are not mutually exclusive, for one ethnicity could have had an advantage over another, producing a socio-economic disparity not only in wealth, but also in geography.

There is obvious standardization in how bakeries were organized, but the forces that produced such homogeneity are not immediately obvious. Were bakers driven to similar layouts in their pistrina by the needs of their production or were they conforming to a shared notion of what comprised a bakery? To some extent, it must be the former. The industrial needs of the pistrina (access to grain, the replacement of broken mills, or

${ }^{24}$ Pompeii Bakery 6 (V.3.8), Bakery 19 (VII.2.51).

${ }^{25}$ Pompeii Bakery 6 (V.3.8). 
the mobility of the donkeys) might explain the location of the millstones near entrances. Ovens, the second most visible feature in the bakeries, are also well suited to be placed near entrances. They represent the final process in the production of bread, as well as the most pleasant to smell. The lack of visibility for kneading, loaf formation, and leavening might similarly be a result of industrial needs. A secluded space near an oven would facilitate the mixing and leavening of dough because such spaces would be warm but their temperatures regulated. But in Volubilis half of the pistrina have different layouts. The ovens are upfront, but so are the kneaders and so were, presumably, loaf-formation and leavening. The existence of alternative layouts, even in Pompeii, suggests that there was no single layout that would work best or even was thought to work best. Indeed, such functional determinism has been shown to be, in general, a poor explanation for architectural forms. ${ }^{26}$ Thus the commonalities must have been, at least to a certain extent, culturally determined. This implies that Romans had notions of what comprised a bakery, but more than that, it suggests that Roman bakers had a shared culture of their own.

The shared notion of what constituted bakeries extended beyond their physical layout and into their operation. In Pompeii, nine of the bakeries have stables that are identifiable from their troughs or from the donkey skeletons found in them (fig. 189). ${ }^{27}$ In every single case, the path the donkeys walked from the millstones to their stalls (figs. 190-197) is carefully kept separate from the production of the bread. In the case of

\footnotetext{
${ }^{26}$ Such was also the conclusion arrived at by Amos Rapoport (1969a and 1969b) in a comparison of the house forms of the Navajo and Pueblo peoples.

${ }^{27}$ Pompeii Bakery 2 (I.3.27 Bakery 3 (I.4.12), Bakery 9 (VI.3.3), Bakery 13, Bakery 14 (VI.14.28), Bakery 15, Bakery 28 (VIII.4.26), Bakery 34 (IX.5.4), Bakery 35 (IX.12.6).
} 
Bakery 28 in Pompeii (VIII.4.26), the stables are not evident but there is only one path from the mill-room and it does not intersect with the bread-production. The donkeys are always kept separate, albeit in a different way in each bakery. Most bakeries simply place the stables in an area away from millstones and oven. But for the long narrow pistrina, this is not an option. In an extreme case, Bakery 34 (IX.5.4), the entire pistrinum is divided into two halves. The production takes place on the east side of the bakery and the path of the donkeys from the mills to the stable at the back of the bakery is separated from production by a wall.

Pompeian bakers had a tendency to keep donkeys as far away from the production of bread as they could. As potential sources of contamination, it makes sense that the donkeys would need to be kept away from the flour, dough, and bread. But much as the layouts were probably culturally determined, so too were, most likely, the procedures the pistores chose to follow. The consistent separation of the two processes, production and stabling, in all the pistrina represents a shared sense of hygiene. A similar phenomenon is evident in the artistic depictions of sifting, kneading, and loaf-formation. The people depicted performing those tasks are always shown semi-nude. Such care to prevent contamination of the products is shared by all the pistores and suggests a shared concept of hygiene and possibly communication between them. Common operating practices and notions of hygiene could only result from communication, but might also suggest some form of regulation, perhaps from a bakers-association. The existence of such procedural uniformity, and the near unanimous presence of millstones at the front of bakeries, 
further suggests not only a connection between bakers in the same city, but across greater geographic boundaries.

\section{Conflicting Evidence}

The material evidence suggests certain behaviors, evident in the iconography of bakers and remains of bakeries, which may be attributable to the existence of collegia. But common use of symbols or shared hygienic practices are not necessarily the products of collegia. The textual evidence provides more details about the function of collegia pistorum in Roman society and, in doing so, offer some explanation for the patterns identified in the iconographic and architectural evidence.

The written evidence, however, is not without its complications. There is a fair amount of conflicting evidence. Three texts embody the seemingly contradictory nature of the evidence for collegia pistorum - and craft associations in general - in the Roman world. The first, a passage from book three of the jurist Gaius' Provincial Edict, outlines the rights and privileges of legally sanctioned collegia in Rome and around the Empire. The second is a contract, recorded on papyrus, between salt merchants and members of a trade association in the Egyptian town of Tebtynis. The third is an inscription from Ephesus recording a bread riot somehow incited by the city's bakers and the subsequent actions taken by the authorities to resolve the situation. Each of these pieces of evidence portray a different type of craft association.

Roman juridical literature, as a body of writing concerned with the legal opinions of elite jurists and emperors, is naturally focused on the state's relationship with craft- 
associations and the aspects of collegia that concerned the state. As such, the Roman

jurists of the second century and later focus on imperial concessions to the collegium

pistorum (discussed at length in Chapter Four) or the corporate capacity of the

association. The collegium pistorum apparently received this capacity sometime before

the middle of the second century AD, when the jurist Gaius lived and wrote.

\section{Gaius libro tertio ad edictum provinciale}

pr. Neque societas neque collegium neque huiusmodi corpus passim omnibus habere conceditur: nam et legibus et senatus consultis et principalibus constitutionibus ea res coercetur. Paucis admodum in causis concessa sunt huiusmodi corpora: ut ecce vectigalium publicorum sociis permissum est corpus habere vel aurifodinarum vel argentifodinarum et salinarum. Item collegia Romae certa sunt, quorum corpus senatus consultis atque constitutionibus principalibus confirmatum est, veluti pistorum et quorundam aliorum, et naviculariorum, qui et in provinciis sunt.

1. Quibus autem permissum est corpus habere collegii societatis sive cuiusque alterius eorum nomine, proprium est ad exemplum rei publicae habere res communes, arcam communem et actorem sive syndicum, per quem tamquam in re publica, quod communiter agi fierique oporteat, agatur fiat.

2. Quod si nemo eos defendat, quod eorum commune erit possideri et, si admoniti non excitentur ad sui defensionem, venire se iussurum proconsul ait. Et quidem non esse actorem vel syndicum tunc quoque intellegimus, cum is absit aut valetudine impedietur aut inhabilis sit ad agendum.

3. Et si extraneus defendere velit universitatem, permittit proconsul, sicut in privatorum defensionibus observatur, quia eo modo melior condicio universitatis fit. ${ }^{28}$

Gaius, Provincial Edict, book 3: Partnerships, collegia, and bodies of this sort may not be formed by everybody at will; for this right is restricted by statutes, senatus consulta, and imperial constitutions. In a few cases only are bodies of this sort permitted. For example, partners in tax farming, gold mines, silver mines, and saltworks are allowed to form corporations. Likewise, there are certain collegia at Rome whose corporate status has been established by senatus consulta and imperial constitutiones, for example, those of the bakers and certain others and of the shipowners, who are found in the provinces too.

1. Those permitted to form a corporate body consisting of a collegium or partnership or specifically one or the other of these have the right on pattern of the state to have common property, a common treasury, and an attorney or syndic through whom, as in a state, what should be transacted and done in common is transacted and done.

${ }^{28}$ Dig. 3.4.1 - 3.4.1.3 (Gaius). 
2. For if no one defends them, the proconsul says that he will order what they have in common to be seized and, if after warning they are not roused to defend their property, to be sold. Furthermore, we consider that there is no attorney or syndic on occasions also when he is away or prevented by ill-health or not qualified to act.

3. And if an outsider wants to defend the corporations, the proconsul allows it, as is the practice in the defense of individuals, because this improves the position of a corporation. ${ }^{29}$

Gaius discusses more than one type of collegium, including "partners in tax farming, gold mines, silver mines, and saltworks," as well as shipowners and bakers. The first group, partners in various types of raw-material extraction, cannot be considered craftsmen.

They are owners and investors in the exploitation of a natural resource, not the refinement of that resource. Shipowners, similarly, are invested in the transportation of materials; they are not men involved in the crafting of that material. Bakers, alone in the professions listed by Gaius, are craftsmen, although it is worth noting that he mentions "certain others."

There are two explanations for the pistores' inclusion in Gaius' list. First, the pistores were not craftsmen but rather the owners of large establishments such as those at Ostia or, second, they were craftsmen but ones who were responsible for the supply of essential materials, which earned them the right to form an association. But this passage belongs in the Gaian edict concerning the provinces, where we have no evidence for the massive bread factories of the sort in Ostia. Indeed, one can look at this list and note that each group is responsible for something essential to daily existence of a city such as Rome: food, precious metals, salt, bread, and the transportation of these goods. Whether or not the pistores mentioned by Gaius were the craftsmen or the owners, we will

\footnotetext{
${ }^{29}$ Watson 1985 v. 1.
} 
probably never know, but we can say that their inclusion here seems more a product of legal attempts to ensure the supply of Rome than a concession solely to owners of things rather than makers of things.

Additionally, the subject of Digesta 3.4.1 is the corporate capacity of the collegium. Gaius notes that those permitted such an institution could "have common property, a common treasury, and an attorney or syndic through whom, as in a state, what should be transacted and done in common is transacted and done." The focus of the passage, however, is on the ability of the members of a collegium to take on an attorney or syndic for their common defense. Koenraad Verboven conceives of such agents in terms of direct and indirect representation. ${ }^{30} \mathrm{He}$ writes that "claims and obligations should preferably be transferable with the network" (in other words, direct representation), "but it would be counterproductive for the network as a whole if its members could not acquire or contract personal obligations when acting on behalf of other members, since this liability in fact reflects and is implied by their formal independence." 31 In a world where the social relationships between people were paramount, limiting an agent's ability to form personal obligations while acting as a representative limited his effectiveness in that role. To this end, collegia (as corporate bodies) often took on patrons, whose greater power and prestige almost certainly increased their effectiveness as representatives.

On the other hand, Gaius specifies that outsiders were possible candidates as syndics as well, implying the some representatives - if not most - were members of the

\footnotetext{
${ }^{30}$ Verboven 2002, 260-4.

${ }^{31}$ Verboven 2002, 262.
} 
collegium. A member of a craft association serving as the representative of the entire

body, in the capacity to pay taxes, is recorded in a contract drawn up in AD 47 by the

salt-merchants ( $\dot{\alpha} \lambda o \pi \omega ́ \lambda o i)$ of Tibtunis, Egypt.

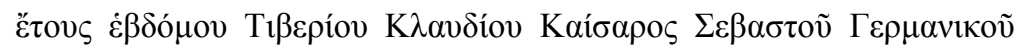

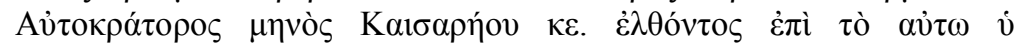

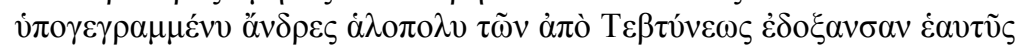

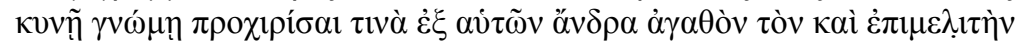

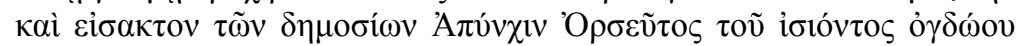

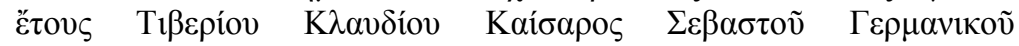

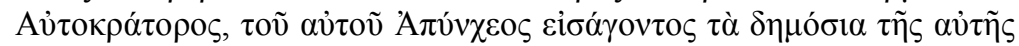

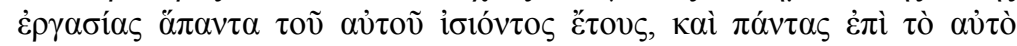

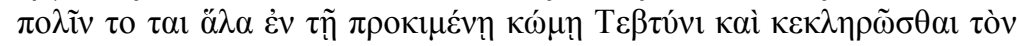

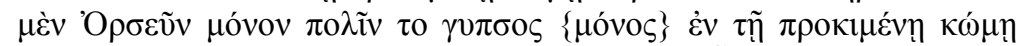

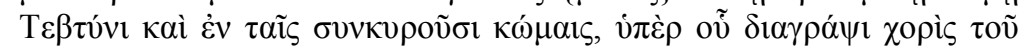

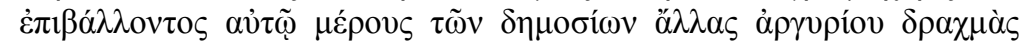

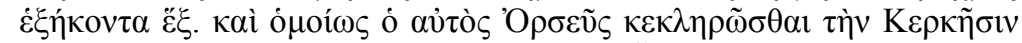

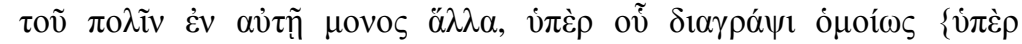

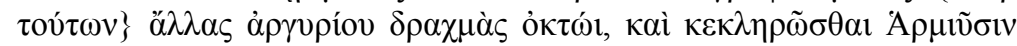

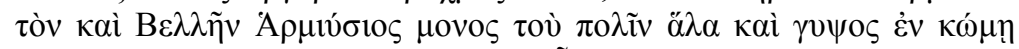

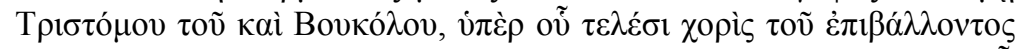

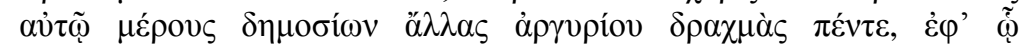

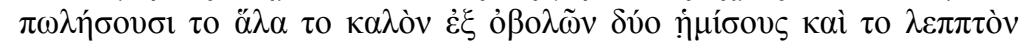

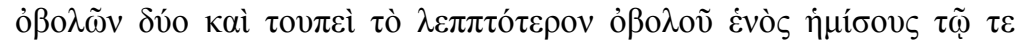

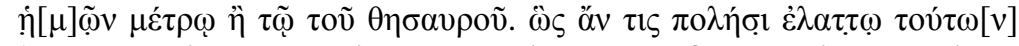

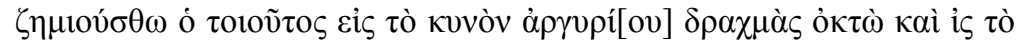

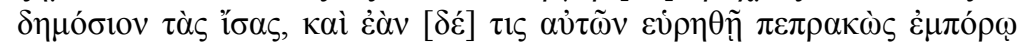

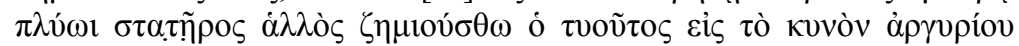

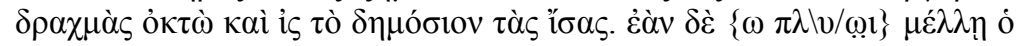

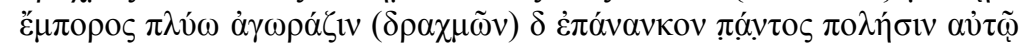

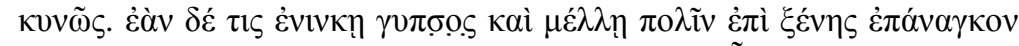

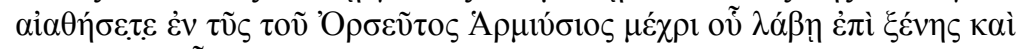

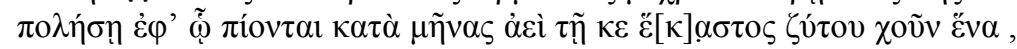

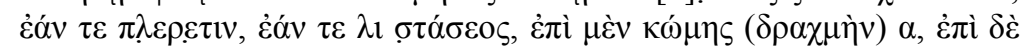

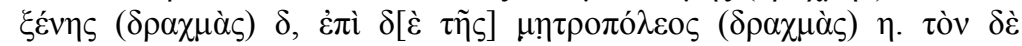

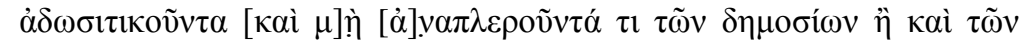

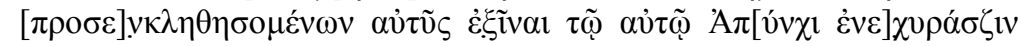

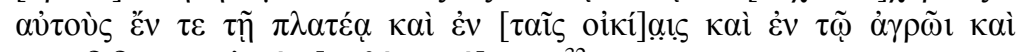

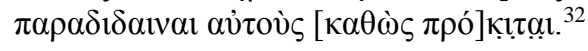

In the seventh year of Tiberius Claudius Caesar Augustus Germanicus Imperator, the 25th of the month Kaisareios. The undersigned men, salt merchants of Tebtynis, meeting together have decided by common consent to elect one of their number, a good man, Apynchis, son of Orseus, both supervisor and collector of the public taxes for the coming eighth year of Tiberius Claudius Caesar Augustus Germanicus Imperator, the said Apynchis to pay in all the public taxes for the same trade for the same coming year, and (they have decided) that all alike

${ }^{32}$ P. Mich. 5, 245. 
shall sell salt in the aforesaid village of Tebtynis, and that Orseus alone has obtained by lot the sole right to sell gypsum in the aforesaid village of Tebtynis and in the adjacent villages, for which he shall pay, apart from the share of the public taxes which falls to him, an additional sixty-six drachmai in silver; and that the said Orseus has likewise obtained by lot Kerkesis, alone to sell salt therein, for which he shall likewise pay an additional eight drachmai in silver. And that Harmiysis also called Belles, son of Harmiysis, has obtained by lot the sole right to sell salt and gypsum in the village of Tristomos also called Boukolos, for which he shall contribute, apart from the share of the public taxes which falls to him, five additional drachmai in silver; upon condition that they shall sell the good salt at the rate of two and onehalf obols, the light salt at two obols, and the lighter salt at one and one-half obol, by our measure or that of the warehouse. And if anyone shall sell at a lower price than these, let him be fined eight drachmai in silver for the common fund and the same for the public treasury; and if any of them shall be found to have sold more than a stater's worth of salt to a merchant, let him be fined eight drachmai in silver for the common fund and the same for the public treasury; but if the merchant shall intend to buy more than four drachmai's worth, all must sell to him jointly. And if anyone shall bring in gypsum and shall intend to sell it outside, it must be left on the premises of Orseus, son of Harmiysis, until he takes it outside and sells it. It is a condition that they shall drink regularly on the 25 th of each month each one a chous of beer . . . in the village one drachme, outside four drachmai, and in the metropolis eight drachmai. But if anyone is in default and fails to satisfy any of the public obligations, or any of the claims that shall be made against him, it shall be permissible for the same Apynchis to arrest him in the main street or in his house or in the field, and to hand him over as aforesaid. ${ }^{33}$

The salt merchants elected Apynchis, one of their own ( $\tau$ เv̀े $\dot{\xi} \xi \alpha \dot{\tau} \tilde{\omega} v)$, the supervisor

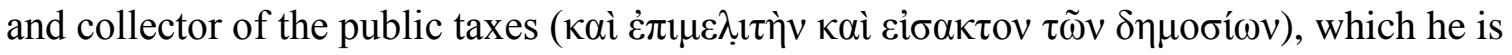
charged to pay collectively for them all. His ability to do so implies the corporate capacity of the association.

But unlike the passage from Gaius' Provincial Edict, the focus of this contract is not the corporate capacity or indirect representation of the association, it is selfregulation. The salt-merchants, through their association, take three important regulatory actions: non-competition agreements, price-setting, and the establishment of penalties for

\footnotetext{
${ }^{33}$ Trans. Advanced Papyrological Information System (APIS) papyri.info.
} 
breach of contract. ${ }^{34}$ The salt merchants agree to a non-competition pact in which sole individuals are given the right to sell gypsum in three communities. Second, they limit the price at which the salt can be sold and the way in which gypsum could be transported and sold. Third, the salt-merchants display a willingness to enforce their agreement, establishing fines for breach of contract.

The focus of the price-setting and non-competition, however, is in no way subversive, but rather a means to ensure that each of them shares equally in the profits.

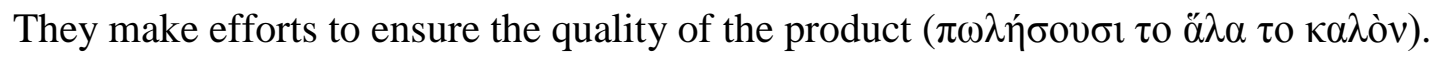
Their agreement concerning prices is not to increase them, padding their profit margins, but rather to prevent one merchant from undercutting the rest by selling a price lower than the others' or selling more than a stater's worth of salt to a single merchant. Any sale exceeding a certain amount must be conducted by all. The sale of salt and the commercial baking industry had, obviously, different concerns. Indeed, we can easily imagine that bakers would have a greater interest, as far as their self-regulation is concerned, in production. The salt merchants would have no such concern. Nevertheless, the contract from Tebtynis does suggest two things about possible activities of bakers' associations: first, they probably self-implemented price controls and, second, used such controls to reduce competition and spread profits, rather than augment them.

The state is conspicuously absent in the contract of the salt-merchants of Tebtynis, implying a policy of mutual non-intervention between bakers' associations and authorities. Some evidence, however, suggests that associations of bakers had an

\footnotetext{
${ }^{34}$ It is worth noting up front that while the economic components of this contract receive most of the attention, the trade association also stipulated the frequency of its members' conviviality, even specifying the amount of beer to be drunk.
} 
adversarial relationship with the state and were actively pursuing an agenda separate from

the interests of the state and the community. A first-century AD Greek inscription found

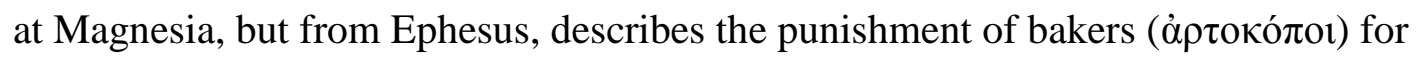

inciting stasis. There is clear indication that they were operating as a single entity when

they committed the bakers' crime.

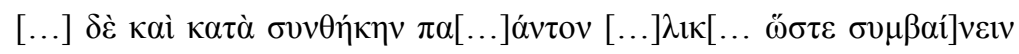

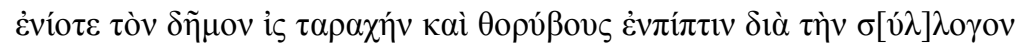

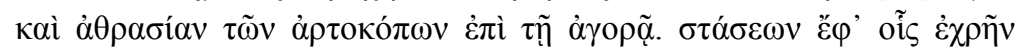

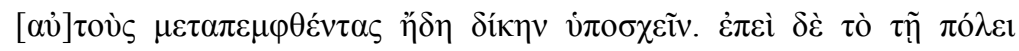

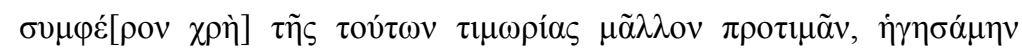

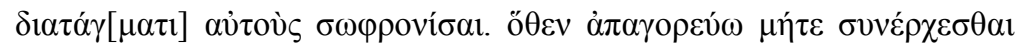

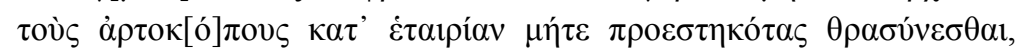

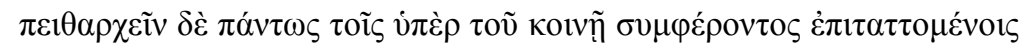

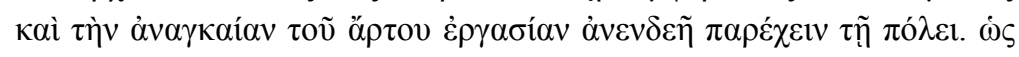

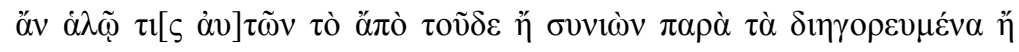

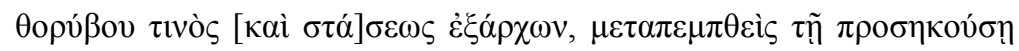

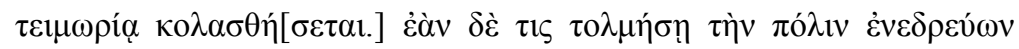

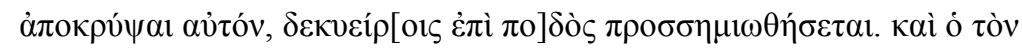

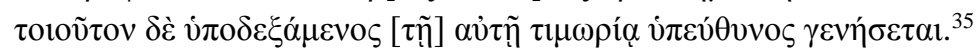

and according to the contract ... in as much as a force sometimes assaults the people to raise up disorder and confusion on account of the tumult and insolence of the bakers against the market. They should, for their sedition, have already come and undergone a trial, but because it is necessary to place the common good of the city above the punishments they deserve, I see fit through edict to bring them back to reason. That is why I forbid the bakers to assemble under a $\dot{\varepsilon} \tau \alpha \iota p \varepsilon i ́ \alpha$ and to grow over-bold in their feasts. They must be obedient in every way to those with authority over the public good and they must perform the work necessary to provide bread for the city. Thus from this day forward if any one of them either holds a meeting against my proclamations or takes the lead in any disorder and sedition, he shall be called forth and punished according to the appropriate penalties. If anyone contriving a reckless act keeps it secret from the city, he shall be branded on the feet by the decurions, and anyone welcoming one such as this into their home shall be submitted to the same punishment.

Here we are told that bakers played some part in a riot, the cause of which was their

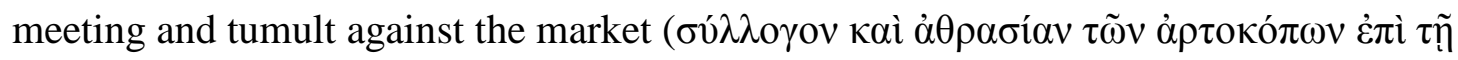

${ }^{35}$ I.Ephesus II 215; SEG IV 512 - Identified as a letter from a Roman magistrate. 
$\dot{\alpha} \gamma o \rho \tilde{\alpha})$. Any speculation about the bakers' actual actions hinges on one's interpretation of

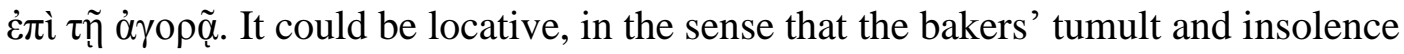
occurred in the agora, or it could be figurative in that the bakers were taking actions that ran contrary to the commercial needs of the city. We are never told specifically that they have an association or $\dot{\varepsilon} \tau \alpha \rho \varepsilon i \alpha$, only that they are henceforth prohibited from forming one. This might suggest that they were operating in such an organization when the strikes occur, but this is not necessarily so. We can learn from this inscription that the bakers

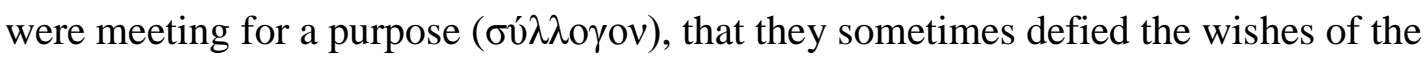
state ( $\dot{\alpha} \theta \rho \alpha \sigma i \alpha v)$, and that they were important enough to the existence of the city that

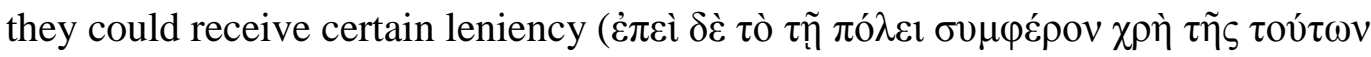

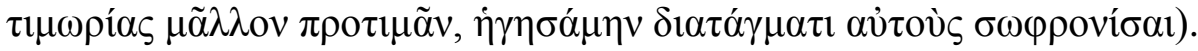

The evidence above (Gaius' Provincial Edict, the contract of the salt merchants of Tebtynis, and the inscription of the bakers' riot of Ephesus) presents three distinct depictions of craft associations in the Roman world. The conflicting nature of collegia depicted by these three pieces of evidence raise several questions. First, how important was attracting a patron to a bakers' association? Second, was the collective economic agenda of bakers' associations designed to share profits or to increase them? Similarly, was the relationship between associations and the state cooperative, through corporate bargaining and contracts, or adversarial, stoked by subversion and subsequent punishment? 


\section{Patronage and the Collegium Pistorum}

The passage from Gaius alludes to the need for social relationships between the collegium, as a corporate body, and external individuals who might be able to defend or otherwise aid it. This is not surprising. Roman society was - and had long been - held together by vertical relationships, chiefly patronage. Individuals could have a patron. Cities could have a patron. We know that Roman craft associations and associations in general frequently took on patrons. ${ }^{36}$ Having a patron benefitted collegia in a number of ways. Occasionally a patron, presumably one without an heir, left his entire estate to a collegium. ${ }^{37}$ In other cases, patrons established perpetual endowments for the collegia. ${ }^{38}$ Patrons also performed non-monetary forms of benefaction. The corpus of the pescatores (fishermen) and the urinatores (divers) set up a monument in AD 206 to their patron, Tiberius Claudius Severus. Severus had given the corpus 10,000 HS as an endowment, he paid for statues of the emperor Caracalla and his wife, and he saw to it that they received some sort of special boating right (navigatio scapharum). ${ }^{39}$ Liu noted the frequent services of tutela (protection) and defensio (defense, probably in the legal sense) in the epigraphic evidence for collegia centonariorum. ${ }^{40}$

The remunerations to the patron for the beneficence to the collegia are less clear. Paul Veyne noted that elites received no material benefits from the patronage of craft associations. ${ }^{41}$ Veyne proposed instead that the benefits were personal, the pleasure

\footnotetext{
${ }^{36}$ van Nijf 1997, 77-81; Liu 2009, 213-45.

${ }^{37}$ Such was the case with a collegium fabrum in Gabboneta in northern Italy, CIL V 4122.

${ }^{38}$ Liu 2009, 223.

${ }^{39}$ CIL VI 1872, see van Nijf 1997, 99; Verboven 2007, 886; Liu 2009, 225.

${ }^{40}$ Liu 2009, 225.

${ }^{41}$ Veyne 1990, 18.
} 
derived from good deeds. Van Nijf observed that elites reaped symbolic benefits from the honorific actions that members of the collegium took, like erecting monuments to them or performing regular funerary rights after their death. Notably absent from the duties of the collegial members is political support.

Although there is no direct evidence for a patron of a collegium pistorum, there are a few examples of a pater corporis pistorum, a comes pistorum, and a contrascriptor pistorum, but the earliest dates to $\mathrm{AD} 249$ and only one, dating to the $6^{\text {th }}$ century $\mathrm{AD}$, is outside Rome. ${ }^{42}$ Two other inscriptions from Rome, of uncertain date, record liberti Augusti each of whom was praepositus (placed in charge of) the pistores. ${ }^{43}$ These men were almost certainly not the patrons of the collegia because they were placed in charge of it, rather than voluntarily assuming that role. Patres, comites, and contrascriptores may be the patrons of the collegia, but Liu observes that one person may be patron of one collegium and pater or mater of another, implying a distinction. ${ }^{44}$ Unfortunately, no dipinti of the inscriptions specify the beneficence of such men to the collegia with which they were associated.

We have, perhaps, more evidence for what the pistores owed their patron. A number of Pompeian painted dipinti indicate that the city's bakers, or at least some of them, cooperated politically by announcing their support for specific candidates. This evidence is specific to Pompeii. Even in Herculaneum, its Campanian neighbor, no programmata or political participation are found from any craftsmen. But the pistores' political participation is always communicated through fragile dipinti, not inscribed in

${ }^{42}$ Pater: CIL XIV 4452; CIL XI 317; comes: ILCV 1906a; contrascriptor: CIL VI 8999.

${ }^{43}$ AE 1923, 76; CIL VI 8998.

${ }^{44}$ Liu 2009, 221. 
stone or etched in plaster, and even the programmata discussed in this chapter no longer exist. If such a practice existed elsewhere, and I think we can safely assume that it did, it is unlikely that the evidence for it would survive. Even in Herculaneum, only a small portion of the city has been excavated and it would be presumptuous to assume that none existed from such a small data sample.

These dipinti follow a formula that Henrik Mouritsen called 'rogantes', a group asking for the election of an individual. ${ }^{45}$ Two politicians were specifically supported by the city’s bakers: Gnaeus Helvius Sabinus and Gaius Julius Polybius. In the case of Sabinus, the pistores team up with the vicini (the neighbors, presumably of Polybius):

CN(aeum) HELVIVM SABINVM AED(ilem) / PIST(ores) ROG(ant) ET CUPIVNT CVM VICINIS ${ }^{46}$

The bakers, with their neighbors, ask and wish that you make Gnaeus Helvius Sabinus an aedile.

Another dipinto from Pompeii, one that does not actually mention the pistores, might suggest another explanation for the bakers' political support of C. Iulius Polybius:

C(aium) IVLIVM POLYBIVM AED(ilem) O(ro) V(os) $\mathrm{F}$ (aciatis) PANEM BONVM FERT ${ }^{47}$

I ask that you make Gaius Iulius Polybius Aedile; he brings good bread.

The supporter remains unnamed, but he explains to the viewer that Julius Polybius brings the good bread. This may be a reminder of previous beneficence or a promise of future generosity. ${ }^{48}$ Distributions of bread were common, even before Aurelian converted the dole from grain to bread. The famous depiction of the bread-vendor in Pompeii is now

\footnotetext{
${ }^{45}$ Mouritsen 1988, 60-64.

${ }^{46}$ CIL IV 7273.

${ }^{47}$ CIL IV 429.

${ }^{48}$ Cooley and Cooley 2004, 114.
} 
largely thought to be a depiction of such a distribution (fig. 198). ${ }^{49}$ The pistores would no doubt have benefitted significantly from a large commission of bread.

And yet such a quid pro quo relationship is nothing new. Patrons could always expect support, political or otherwise, from their clients, who in turn were rewarded with certain limited beneficence. Mouritsen observed that the dipinti need not necessarily indicate the existence of an association of bakers in Pompeii. The use of the plural with pistores need not imply all the bakers, merely more than one. ${ }^{50}$ Certainly the implication is a group, but there is no assurance that the group was universal or a collegium. Indeed, Julius Polybius enjoyed the support not only of the pistores, or at least some of them, but also that of a single ardently supportive pistor.

\section{C(aium) IVLIVM POLYBIVM IIVIR(um) O(ro) V(os) F(aciatis) / PISTORES ROGANT ${ }^{51}$}

I ask that you make Gaius Iulius Polybius Duumvir; the bakers ask it.

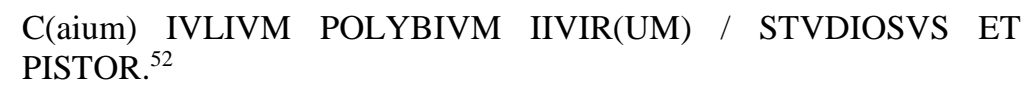

I, hard working and a baker, ask that you make Gaius Iulius Polybius Duumvir. $^{53}$

\footnotetext{
${ }^{49}$ The painting is from VII.3.30. Fiorelli initially interpreted the scene as the municipal distribution of bread. Helbig, on the other hand, identified the man distributing the bread as a baker selling his product, an idea that proliferated for most of the twentieth century. In the past 20 years, that position has been challenged. The rejection of the individual as a baker is largely based on the work of Frolich, who argued that the modest, but proud house and the vendor's toga suggest a magistrate rather than a craftsman. We have seen in chapter four that bakers probably could afford modest houses, at least to rent. Moreover, we know from the tomb of Eurysaces and other depictions of pistores that men in togas could be associated with the production of bread. This is not to say that the fresco is a depiction of a baker, only that the meaning of the imagery probably deserves revisiting. Fiorelli 1875. 208; Helbig 1864, 119-220; Thomas Frolich 1991, 236-41.

${ }^{50}$ Liu 2008, 57-8.

${ }^{51}$ CIL IV 886.

${ }^{52}$ CIL IV 875.

${ }^{53}$ The O.V.F is taken as implied or no longer extant.
} 
And yet, whoever the hardworking pistor was, his individual efforts for Gaius Julius Polybius mirror the collective efforts of his fellow bakers. One is tempted to interpret his independent actions as separate from the actions of the other pistores, but there is no reason to assume that the author of the dipinto was not also among those bakers who had expressed support for Polybius in other cases.

Mouritsen argued that "the rogator inscriptions were posted on the initiative of the electoral agents and were not the expression of any particularly strong interest in the election among individual voters." ${ }^{, 54}$ He observed that women, craftsmen, liberti, and clientes comprised a significant portion of the rogatores. ${ }^{55} \mathrm{He}$ concluded from the "lowstatus" of such rogatores that they would have had an "undesirable effect" on the campaign and election. ${ }^{56}$ From this perceived undesirable effect and the low numbers of such dipinti he concludes that the rogatores had a previous relationship with the candidate and speculates that a patron-client relationship was the source of their support. Yet there is no direct evidence that a preexisting relationship existed between Polybius and the bakers; it is merely surmised from a postulated undesirability of their participation. The proclamations of support from the pistores - and from many of other rogatores - may instead be an example of individuals or corporate entities trying to attract a patron. Someone, like Polybius, who held an important position in Pompeian society would probably do nicely.

The statements of political support of Pompeii's pistores for men of political life is, probably, a component of their duties as a corporate client. We can probably assume

\footnotetext{
54 Mouritsen 1988, 59.

${ }^{55}$ Mouritsen 1988, 63.

${ }^{56}$ Mouritsen 1988, 64.
} 
that such duties were an aspect of at least some of the baker's associations in other parts of the Roman Empire. Despite the lack of evidence, the collegia pistorum were probably also responsible for other funerary and honorific duties. Conspicuously absent in the evidence is any formalized mechanism whereby a patron invests in the commercial activities of collegial members or commits to mitigating professional risks through financial support during the lean times. Nor is there evidence that a patron of a collegium shared in the profits of its constituent members. The major benefit to both sides was the prestige of their reciprocal, albeit asymmetrical, relationship. Patronage of this sort was prestigious for the patron and collegium alike, explaining the epigraphic tradition of boasting of such relationships.

\section{The Economic and Professional Agenda of Collegia Pistorum}

Although collegia pistorum as a whole benefitted from the patron/client relationship, the contract of the salt merchants of Tebtynis suggests that professional and fiscal policy was handled internally. The raison d'être of Roman craft and trade associations - as well as their roles in the professional lives of their members - has traditionally been explored through comparison of the collegium with the medieval guild. Waltzing isolated a number of similarities, such as confraternity, religious devotion, and funerary trusts. ${ }^{57}$ But he also noted certain differences: Roman collegia, according to Waltzing, pursued none of the self-regulation and collective economic interests that characterized medieval guilds. Finley concurred with the last point, giving a verdict of a

\footnotetext{
${ }^{57}$ Waltzing 1896-1900 v. 1, 161-333.
} 
largely social function for Roman collegia, but disagreed with any argument or implication of continuity or much similarity between the ancient and medieval institutions. On the issue of collegia, he wrote:

The communal activity was restricted to religious, social and benevolent affairs; in no sense were they gilds trying to foster or protect the economic interests of their members, nor did they reveal a trace of the hierarchical pattern of apprentice, journeyman and master that characterized the medieval and early modern guilds. Slaves and free men (chiefly free independent craftsmen) could be fellowmembers of a society, precisely because of the absence of any feeling of competition. ${ }^{58}$

Ramsay MacMullen, on the other hand, saw the origins of trade associations in the conviviality of local commerce: "a great deal suggests that a friendly, gossipy atmosphere prevailed among people who saw each other every day, worked at the same job in the same neighborhood, and shared all the same ups and downs. Trade associations were the result." ${ }^{\prime 59}$ With regard to the nature of such associations, MacMullen acknowledged the inaccuracy of modern trade unions as an analogy for Roman collegia, but he further argued that "crafts associations do indeed act as a larger, more influential whole to protect [craftsmen's] economic interests. ${ }^{{ }^{60}}$ Yet MacMullen expressed shock not at the ability of craft associations to push an economic agenda, but at how infrequently they pursued one. ${ }^{61}$

In part, the view that ancient and medieval guilds have little in common has deteriorated as recent work has shown that even early modern craft-associations served religious and convivial functions. Moreover, the ancient evidence increasingly suggests

\footnotetext{
${ }^{58}$ Finley $1999,81$.

${ }^{59}$ MacMullen 1974, 72-73.

${ }^{60}$ MacMullen 1974, 74.

${ }^{61}$ MacMullen 1974, 77.
} 
that, in part, Roman collegia were also concerned with economic matters. Certainly a concern for prices and the incitement of riots suggest economic preoccupations. As such, Finley's assertion that associations of craftsmen were "restricted to religious, social and benevolent affairs" is probably an over-simplification of a more complex relationship between collegia and the professional lives of their members. Matt Gibbs observes that, while ostensibly voluntary in terms of membership, certain associations could wield enough influence to make membership the only viable option. ${ }^{62}$ Indeed, it is hard to imagine that the salt merchants of Tebtynis, given their concern for competition and willingness to impose their policies by force, would tolerate a rogue merchant undercutting their prices. But bakers would not have shared the urgency felt by the salt merchants in dealing with competition. No single pistor could have met the needs of a community.

Collegia and similar associations probably also attracted members passively. Wim Broekaert used modern analyses of costs and profits to argue that craft associations could confer economic advantages to their members through communication and cooperation between professionals and the shared cost-burdens ${ }^{63} \mathrm{He}$ divided the burdens that would have faced transporters of goods into three categories: transaction costs, transportation costs, and financing costs. Using naval merchants who supplied Rome and the other urban centers of the western Mediterranean as a test case, Broekaert found that the navigatores and negotiatores faced significant obstacles if they acted alone, but that the right social ties and personal relationships could facilitate both the mobilization and

${ }^{62}$ Gibbs 2011, 299-300.

${ }^{63}$ Broekaert 2011, 222-4. 
importation of resources. ${ }^{64}$ The types of problems that confronted these merchants, such as the costs of transport or the delay in recouping investments until the sale of the merchandise, could easily be overcome through cooperation (i.e. sharing costs or expediting the sale of merchandise). Collegia, according to Broekaert, would naturally confer these benefits to members through the relationships implicit in them.

Just as the bakers would probably not have shared the salt merchants' concern with non-competition pacts, the long-range transportation of goods, as an economic endeavor, provides a poor analogy for Roman commercial baking, because bread, as a perishable good, could not be exported. Nevertheless, Broekaert's work shows that association conferred benefits per se. That cooperation was the natural result of communications between agents in the economy. Bakers could mitigate costs by importing in bulk as a group or manage risk by sharing resources. Moreover, Gibbs' point is well taken; such advantages would have made working outside the collegium nearly impossible for a rogue salt merchant or independent baker.

If they were not overly concerned with competition or long-distance trade, what economic issues were important to ancient Roman bakers? To review, the merchants agreed to a non-competition pact, set their prices, and established punishments for breach of contract. The architectural remains of bakeries might further suggest that such selfregulation extended also to hygienic practices. Indeed, such regulations would naturally not appear in a contract between salt merchants, who were not themselves craftsmen

${ }^{64}$ Broekaert (2011) cites the extraordinary case of Gaius Vestorius and Marcus Tuccius Galeo, whom Cicero repeatedly describes as having a close social and economic relationship. Cicero Ad Atticum, VI.2.3, XIV.9.1, XIV.12.3. John D'Arms (1981, 50-55) speculates that the two men formed a societas. He cites as evidence a sunken ship of unknown date found in the 1960s near Marseilles, with the merchandise aboard bearing the names both men. Tchernia 1968, 51-82. 
concerned with issues of production; bakers would have needed different regulations. But without a contract between bakers, of the sort made by the salt merchants, we have no direct evidence for their regulations or what issues concerned them. We must infer those concerns from the actions they took.

Here the second-century Greek inscription from Magnesia provides some insight. ${ }^{65}$ It records a riot of the Ephesians somehow caused by the bakers of the city. The

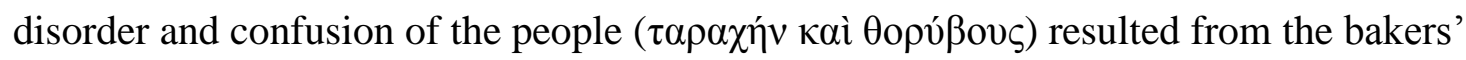

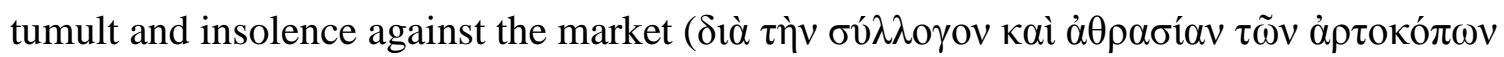

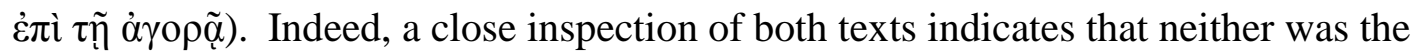
product of a strike. The specific words used to describe the crimes of the Ephesian bakers

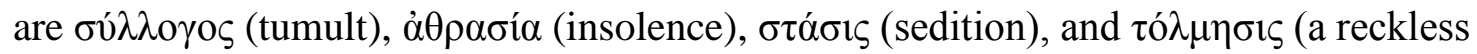

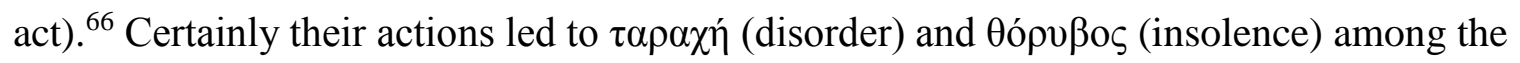
people. The troubles resulted from their tumult and insolence, but the inscription never explicitly states what the bakers did or if they were the leaders of the riot. Nor is there any indication that the bakers had stopped producing bread. The words for the actions of the bakers are vague, but, as stated above, any interpretation of them hinges of how one

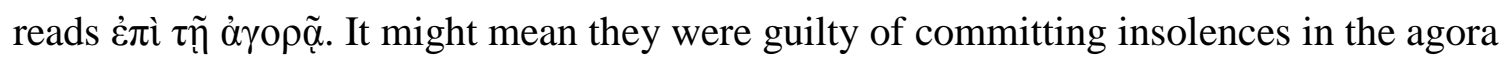
or that they did so against the market. If, for the sake of argument, we assume that it was the latter, then it might suggest that the bakers were charging prices for their bread led to the disorder and confusion. Indeed bread riots were common in the Middle Ages and

\footnotetext{
65 I.Ephesus II 215; SEG IV 512, identified as a letter of a Roman magistrate.

66 There is another component to this to which the inscription only alludes: conviviality. The bakers' had "grown haughty in their feasting." Conviviality appears also in the contract of the salt merchants and generally throughout the evidence for the activities of collegia in general.
} 
right up to modern times. The causes of these disturbances were sometimes shortages of

bread and at other times prices too high for the common man to pay.

Support for price-setting among bakers may be found in Libanius' Orationes. He

describes a fourth-century riot, the cause of which he ascribes to the city of Antioch's

bakers. The fourth-century rhetor describes his time at the eastern city and tells of a riot

during which he arbitrated a disagreement between the mob and the governor.

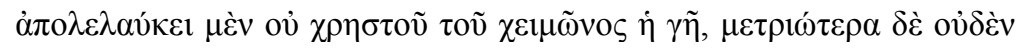

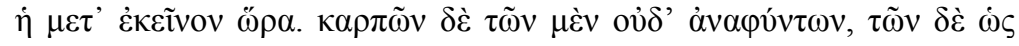

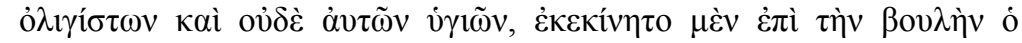

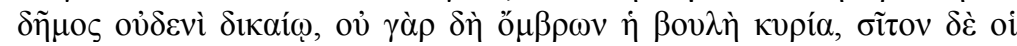

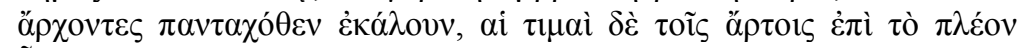

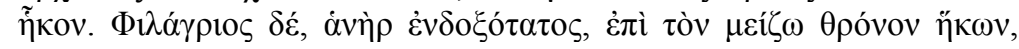

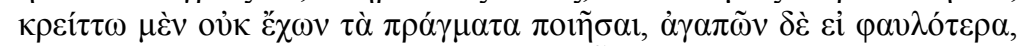

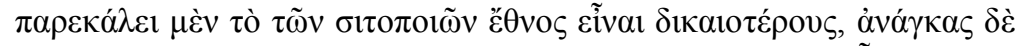

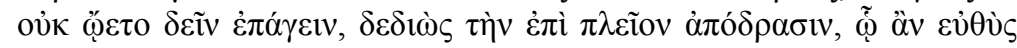

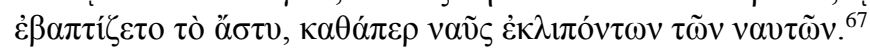

The countryside had experienced a bad winter, and the following summer was no better. Part of the corn had not even germinated, the rest was sparse, and even this was blighted. In consequence, the populace created disturbances against the city council, quite unreasonably since the council could not control the weather. Though the governors tried to get corn from every possible source, the price of bread rose higher and higher. The renowned Philagrius, having reached a higher office, though unable to improve the situations, was content if it got no worse. He kept urging the bakers' group (" $\left.{ }^{\prime} \theta v o \varsigma\right)$ to be more reasonable, but was reluctant to enforce his demands, for he was afraid of the increasing desertion, which would have left the city shipwrecked, abandoned by its crew. ${ }^{68}$

The bakers' actual role in the disturbance was grounded in the prices they were charging, but the high prices were actually a product of bad weather and a poor harvest. This, at least, fits with the evidence from the contract between the salt merchants of Tebtynis. They were not interested in raising the prices for financial gain; their efforts to control prices were attempts to ensure that each member of the association shared in the profits.

${ }^{67}$ Libanius Orationes I.205-10.

${ }^{68}$ Norman 1992, 267. 
The price of grain had gone up with the poor harvest and the bakers, to remain solvent, were forced to raise their prices beyond the means of the ordinary Antiochene, leading to the riot.

Unlike the salt merchants, Roman bakers appear not to have concerned themselves with non-competition, but why would they when entire cities were dependent on their product (see Chapter Two)? The architectural evidence may suggest that bakers' associations regulated the hygiene of bakers, but the separation of donkeys and bread production may simply be the product of independent logical reasoning: each craftsman arriving at the logical conclusion that the donkeys should not be around the food. If our sparse evidence for bread riots in antiquity are any indication, the main concern for bakers' associations, with regard to their self-regulation, was price-setting, and their greatest risk was the availability and cost of their grain.

\section{The Collegium Pistorum and the State}

Perhaps the greatest crime committed by the bakers of Ephesus and Antioch was their insolence. Presumably local authorities urged them to lower their prices, but the bakers did not. To some extent this was a necessity, at least in the case of the bakers of Antioch. Exogenous constraints (weather) cause supply to fall and prices to rise. On the other hand, we have no evidence that the bakers conceded to the authorities and, furthermore, both groups of bakers appear to have escaped with limited punishment. The issuing authority of the inscription from Ephesus states that the bakers "should, for their sedition, have already come and undergone a trial, but because it is necessary to place the 
common good of the city above the punishments they deserve, I see fit through edict to

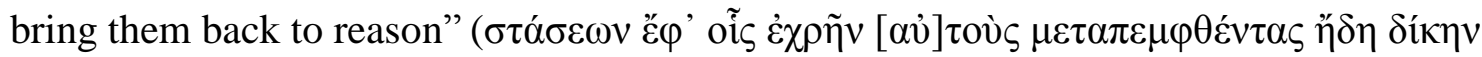
نં

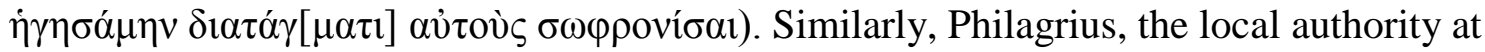
Antioch was "reluctant to enforce his demands, for he was afraid of the increasing

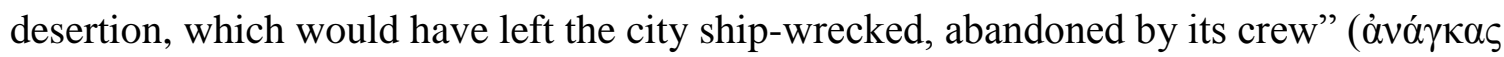

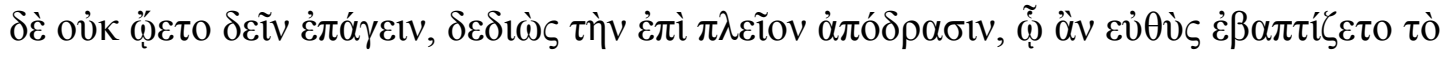

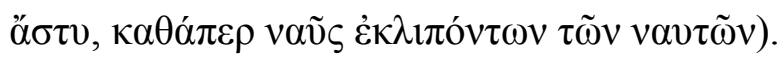

There are, however, examples of bakers being punished. The bakers of Ephesus lost the ability to form an association (implying that they had that right previously). They could also be fined. A recently published inscription, dating to the late second century $\mathrm{AD}$ and found near Seville (ancient Italica in Baetica) records the construction of a dedication by the duumviri from the fines levied on a group of pistores (fig. 199).

\section{Q L OPTATVS ET Q C OPTATVS IIVIṚ EX MVLTIȘ PISTORVM POSVERVNT ${ }^{6}$}

The duumvirs Q. L. Optatus and Q. C. Optatus built this from the fines of the pistores.

It is truly unfortunate that the infractions of the pistores are not recorded. Additionally, we do not know if the pistores were fined as a corporation, with a fine paid from a common treasury or as individuals. But Salvador Ordóñez Agulla and José Carlos Saquete Chamizo identify the types of reasons that bakers might be penalized and speculate that it was probably for some form of collective price increase. ${ }^{70}$ It perhaps does not need to be anything quite so nefarious (although it could be); the price-setting

${ }^{69}$ Ordóñez and Chamizo 2009, 199-200. Multis = mulctis.

${ }^{70}$ Ordóñez and Chamizo 2009, 201-2. 
employed by pistores, as we have seen, was probably aimed at sharing profits, not increasing prices, and the lack of any accusation in the inscription means that the bakers might have committed any number of minor infractions.

In practice, the threat of force may have served the state better than actual punishment. By not punishing the bakers, one allows them to continue producing the community's primary foodstuff. But insolence cannot go unpunished and the state had an interest in preventing improprieties among the bakers and thus also riots in the streets. Indeed, not only does the authority at Ephesus show concern for continued production, he sets the punishment for illicit meetings or otherwise seditious behavior. A baker acting contrarily to this edict shall be called forth and punished according to the appropriate penalties. If anyone contriving a reckless act keeps it secret from the city, he shall be branded on the feet by the decurions, and anyone welcoming one such as this into his

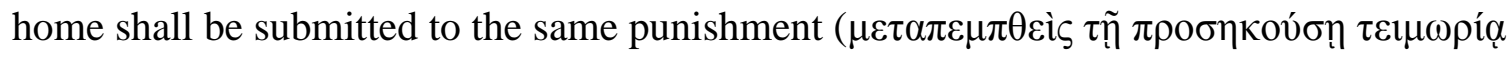

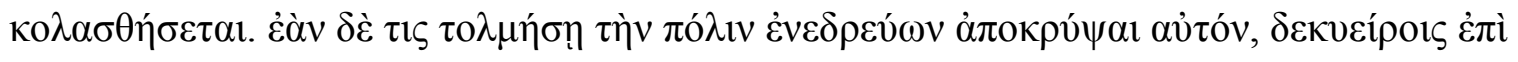

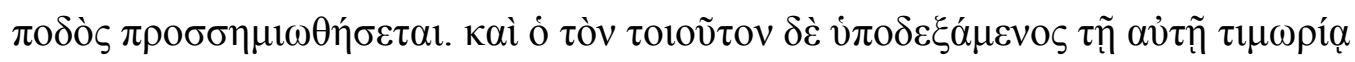

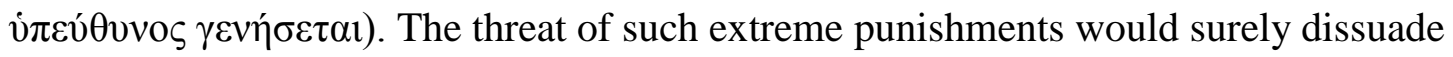
bakers from acting mischievously in the future, or at least motivate someone to inform on them. With the threat of force, the state could keep the bakers producing while still achieving its goals. Such threats of force may, in fact, provide an explanation for why the salt merchants and, probably, the bakers of Antioch were not raising their prices to inflate their profits. 
The two inscriptions, from Ephesus and Italica, and Libanius' description of the events at Antioch indicate a relationship between collegia and the state that is (or can be) adversarial, balanced only by the moderation of craftsmen and the threat of reprisals from authorities. The body of juridical evidence concerning the collegia pistorum in Rome and Ostia, however, suggests a more cooperative and complimentary relationship. Rather than using threats and punishments to restrain collegia pistorum, authorities employed incentives urge bakers into conforming with the wishes of the state and meeting the needs of the cities. There is also evidence that the authorities in Rome and Ostia used the corporate capacity of the bakers to contract with the entire collegium.

The legal and literary sources tell us that a collegium pistorum was formed - or reformed - during the principate of Trajan. ${ }^{71}$ But the first direct evidence for an association of bakers is found in an Ostian inscription dating to $\mathrm{AD} 140$ and the association is called a corpus, not a collegium. ${ }^{72}$ Corpus, rather than collegium, appears to have been the preferred nomenclature for the association of bakers in Ostia and Rome until the fourth century AD. Every inscription attesting an association of pistores during the second and third century AD uses the word corpus. ${ }^{73}$ Jean-Pierre Waltzing hypothesized that the collegium pistorum had previously existed, but the corpus was

\footnotetext{
${ }^{71}$ Romans themselves canonically attributed the origin of collegia to the Rome's regal past. Plutarch (Numa, 17) writes that Numa Pompilius introduced collegia to Rome as a way of organizing the people that soothed the tensions between the Sabines and Romulus's original people. There was little, if any, specialization and the few craftsmen who might have existed could hardly have constituted a trade association. Another possible origin for Roman collegia lies in the Twelve Tables, the legal compromise between the patricians and plebeians (ca. $450 \mathrm{BC}$ ). The jurist Gaius records a passage from the Twelve Tables in which members (sodales) of associations (collegii) are afforded the right to make contracts with whomever they want so long as they do not break the law (Dig. 47.22.4 Ulpian).

${ }^{72}$ CIL XIV 4359.

${ }^{73} A E$ 1994, 197; $A E$ 1996, 309; CIL VI 22; CIL VI 1002; CIL VI 40607; CIL XI 3517a.
} 
created by imperial decree in the second century AD. ${ }^{74}$ Boudewijn Sirks, on the other hand, focused more on the nature of the corpus as a legal entity. He observed that a corpus was not necessarily a separate entity; a collegium could have a corpus. For Sirks, the corpus was the legal entity that allows groups of craftsmen and merchants to hold a common treasury, contract as a group, and take common representation.

The manner in which Trajan first sanctioned an association for the bakers might support Waltzing's hypothesis that a collegium pistorum existed at some point prior to that emperor's reign. Aurelius Victor, writing in the mid-fourth century AD, tells us that Trajan revived (reperto) and strengthened (firmato) the collegium pistorum.

\begin{abstract}
Adhunc a Domitiano coepta, forum atque alia multa plus quam magnifice coluit ornavitque, et annonae perpetuo mire consultum, reperto firmatoque pistorum collegio. ${ }^{75}$

Furthermore at Rome he improved and decorated in a more than magnificent fashion a forum and many other structures begun by Domitian, and showed admirable concern for the permanent grain supply by reviving and strengthening the guild of bakers. ${ }^{76}$
\end{abstract}

The use of the word reperto, which could mean 'found' or 'revived', implies that Trajan's collegium pistorum was not the first iteration of the association. Aurelius Victor's use of firmato (strengthened) further complicates our understanding of Trajan's sanctioning of the collegium pistorum, indicating that the new form was stronger in some fashion. This may be a reference to certain concessions given by Trajan to the bakers. For the emperor proclaimed that any Junian Latin assuming responsibility for a pistrinum milling at least 100 modii of grain for no shorter period of time than three years would henceforth have the rights of citizens. The importance of freedmen and the Latini Iuniani

\footnotetext{
${ }^{74}$ Waltzing 1896-1900 v.1, 140.

${ }^{75}$ Aurelius Victor, de Caesaribus, 13.5.

${ }^{76}$ Bird 1994, 15.
} 
are discussed at length in chapter four, but for the study of the collegium pistorum and their relationship with the state, the more important component is Trajan's bipartite allowance. He furnished a way for certain bakers to improve the social status, but he did so on the condition that the pistores produce at a certain levels. This certainly fits Sirks' hypothesis that the purpose of the corpus and collegium was to compel greater production. ${ }^{77}$

This hypothesis is also supported by the allowance of vacationes (exemptions) to other, non-liberti pistores sometime before $107 \mathrm{AD} .{ }^{78}$ Another concession, recorded in the Fragmenta Vaticana, grants an excusatio tutelae (exemption from the duty of guardianship) to members of the collegium pistorum provided that they operated a bakery of at least 100,000 HS.

Ulpianus de officio praetoris tutelaris. Sed qui in collegio pistorum sunt a tutelis excusantur, si modo per semet ipsos pistrinum exerceant; sed non alios puto excusandos, quam intra numerum constituti centenarium pistrinum secundum litteras divi Traiani ad Sulpicium Similem exerceant; quae omnia litteris praefecti annonae significanda sunt, ${ }^{79}$

Ulpian, in his commentary on the duty of the praetor tutelaris. Yet those in the collegium pistorum are exempted from guardianship if only they themselves operate a pistrinum, but I believe that no others can be released apart from those among their number who operate a pistrinum of 100,000 sesterces in accordance with the letter of the late Trajan to Sulpicius Similis. And all these matters are given in the letter (to) the Prefect of the Annona. ${ }^{80}$

Sirks translates pistrinum centenarium as a bakery worth 100,000 sestertii. Given the requirement in Gaius Institutiones 1.34, it seems more likely that centenarium refers to

\footnotetext{
${ }^{77}$ Sirks 1991, 406.

78 This action must have occurred before the vacatio to the Junian Latins. The letter mentioned in FV 233 is to Sulpicius Similis, who ceased to be Prefect of the Annona in 107 AD. D'Escurac 1976, 334. Sirks 1991, 315.

${ }^{79}$ FV 233.

${ }^{80}$ Trans. Sirks 1991, 315. Centenarium could mean worth 100,000 sesterces, as Sirks suggests, but it could also mean that the pistores had to mill at least 100 measures of grain to receive the excusatio.
} 
modii than sestertii. Here again we see a concern for the productivity of the bakery. The Emperor used his power to grant benefactions to encourage increased production. This may explain Trajan's strengthening (firmato) of the collegium pistorum. He made the collegium stronger by increasing the productivity of its constituent members.

Another possible explanation for the strengthening of the collegium pistorum is the special grant to it of corporate capacity. The passage from Gaius' Provincial Edict lists the sort of corporate rights afforded to, among others, the collegium pistorum. "Those permitted to form a corporate body consisting of a collegium or partnership or specifically one or the other of these have the right on pattern of the state to have common property, a common treasury, and an attorney or syndic through whom, as in a state, what should be transacted and done in common is transacted and done" (Quibus autem permissum est corpus habere collegii societatis sive cuiusque alterius eorum nomine, proprium est ad exemplum rei publicae habere res communes, arcam communem et actorem sive syndicum, per quem tamquam in re publica, quod communiter agi fierique oporteat, agatur fiat). Thus the corporate capacity of the collegium pistorum allowed its members to hold common property and to have a common treasury, a fact evident in the contract of the salt merchants of Tebtynis. But the edict also says that the collegia can be represented, as a collective, by a single individual in transaction. It may be that the corporate capacity of the collegia served as a way for the state to contract with a large number of bakeries at once. An inscription on the tomb of the baker Eurysaces describes him as pistor redemptor, frequently translated as contract baker. ${ }^{81}$ It suggests

${ }^{81}$ CIL VI 1958a. 
that the state could contract with an individual baker as early as the first century BC. The corporate capacity of the collegium pistorum would have allowed it to contract, as an entity with many individual members, with the state.

But we have no evidence that the state contracted, on a regular basis, with Rome's corpus pistorum during the second and third centuries AD. Keith Hopkins noted that a general lack of corporate capacity in the Roman world limited investment and thus also the possible scale of industrial and agricultural production. ${ }^{82}$ On the other hand, Koenraad Verboven acknowledged the corporate capacity of the collegium pistorum, but cautions that such rare examples should not be considered a first step "towards a generalization of incorporated societates." 83 Verboven further noted that corporations were extremely rare in the early modern period until the nineteenth century and even then only came into existence when the costs of a particular commercial endeavor exceeded the ability of a single family to meet those costs. ${ }^{84}$ The issue, according to Verboven, was a matter of aspiration; Roman producers and investors lacked the requisite economic thought - or at least desire - to pursue greater production and profits. Without such pursuits, and with a strong state interest in maintaining production in certain sectors (including baking), corporate capacity never developed the complexities of investment evident in modern corporations. The only purposes of the corporate capacity of Rome's collegia appears to have been common property, common treasury, and common representation in legal affairs.

\footnotetext{
${ }^{82}$ Hopkins 1978, 53.

${ }^{83}$ Verboven 2002, 278, 284-85.

${ }^{84}$ Verboven 2002, 286.
} 
The relationship between the state and collegia pistorum is, therefore, a perplexing one. On the one hand, there is evidence for significant friction between the two institutions. Only with leave from the state could such associations exist, but their importance to the provisioning of Roman cities afforded them some immunity to some restrictions and, in some cases, punishments. On the other hand, the state regularly allowed the formation of collegia and, at least in Rome, used incentives to motivate - and probably manipulate - collegia pistorum. More than anything, restraint characterizes the relationship between the two institutions. The state was reluctant to interfere directly with the bakers and the bakers refrained from more aggressive economic policies that could have earned them greater prices, such as strikes or price-hikes.

\section{Conclusions}

Certainly Roman bakers were actively pursuing professional and economic agendas. In part, they achieved their goals by attracting a good patron who could ensure they be granted certain rights or exemptions from certain social burdens. The pistores of Pompeii used official and sanctioned channels to promote their interests: attempting to attract patrons, fulfilling the obligations of clientela, and receiving in return the benefits of the patron's largess and access to resources.

Parallels from other trades suggest that the active pursuit of an economic agenda occurred internally, among the members of a craft association. Although they did not concern themselves with cornering markets, they do appear to have set their prices. But the delicate relationship with the state probably prevented them from gouging their prices 
to increase their profits. Bakers were singularly important to the provisioning of Roman cities, earning them certain allowances from authorities, but the state also had an interest in keeping residents fed and happy. The threat of reprisals from the state may have provided the incentive to keep bread-prices low. Nowhere in the epigraphy or papyri is there evidence for the collegium regulating the productive practices of its members, suggesting that the shared hygienic concerns evident in the bakeries was not a product of a craft association. On the other hand, our best evidence for self-regulation comes from the contract of the salt merchants of Tebtynis, who were not craftsmen and were unconcerned with matters of production.

The punishments and fines incurred by the bakers at Italica and Ephesus might prima facie suggest that the bakers were unsuccessful in their strategies. A closer inspection indicates, however, that this might not have been the case. First, the inscription found near Italica never specifies the amount of the fines incurred or the bakers' transgressions. In fact, no crime may have been committed at all. The contract between the salt merchants from Tebtunis provides another explanation. The merchants agree to a minimum price and to certain regulations on how their product can be sold. The punishment for breaking these rules was a fine, half paid to the collective treasury of the salt merchants and half paid to the public treasury. The fines at Italica could therefore actually represent a success on the part of the bakers. If they self-regulated through fines, the erection of a monument from that money would represent successful enforcement of the association's by-laws. 
The same cannot be said of the punishments placed on the bakers of Ephesos; they are definitively being punished for an action they took. Whatever the Ephesian bakers did to incite the disturbance, it incurred repercussions from the state limiting their activities. They could not meet as a hetaireia or have feasts, whether they were able to before or not. If the bakers had an economic agenda, it is not mentioned in the inscription, but profit, we have seen, was one of the primary motivators for the 'insolence' of bakers and indeed there is also no indication that their goals, whatever they were, were not met. Given who had the inscription set up, the representative of the state, it makes sense that he would emphasize the steps that were taken to prevent future incidents. In fact, the inscription specifically says the bakers would not be punished by litigation because of the important service they provided to the city.

This is probably the best evidence that bakers were successful in pushing whatever modest agenda they pursued. Commercial baking was so critical to the existence of Roman cities that bakers enjoyed a certain power. This phenomenon is evident in nearly all the evidence. The bakers of Rome and Ostia, unlike some other industries, were allowed a collegium and the legal status of some bakers was improved if they continued to produce. No matter the reason for the bakers' fines near Italica, the duumviri are emphasizing that the money came from them. The bakers of Ephesus were not prosecuted, despite having played some part in a riot. The bakers at Antioch could resist the wishes of local authorities and maintain higher-than-normal prices. We have already seen in chapter two that commercial bakers supplied the bread to entire 
communities, supplemented very little by domestic production. Such product dependence gave the bakers a certain power.

And yet they refrained from using that power. Despite the disorder and confusion they caused, probably through their price-setting, there is no evidence that they engaged in strikes or aggressive price hikes to increase their profits. The threat of reprisals from the state probably dissuaded them. Local - and possible imperial - authorities had to weigh the needs of the community against the importance of bakers to the provisioning of cities. In other cases, mostly in Rome and Ostia where the commercial baking industries could attract the attention of emperors, incentives were employed to keep the collegia pistorum in line. The one consistent attribute that characterizes the relationship between the state and bakers' associations is the mutual use of restraint. 


\section{CONCLUSION}

At its core, this study explores with the place of commercial bakers in Roman society and their relationship with the world around them. These issues are cast in a number of different ways. First, the product-dependence of Roman cities and the importance of specialization to Roman urbanism were established. Although the profits and financial resources generated by the commercial production and sale of bread were significant, such profits were distributed asymmetrically throughout the social hierarchy within Roman bakeries and along vertical social bonds outside them, such as masterslave, master-freedman, or patron-client. Such productive success, particularly the near complete dependence of Roman cities on commercial bakers, put them in a position of importance and power. Indeed, Roman authorities, jurists and magistrates alike, acknowledged the importance of bakers to provisioning of Roman cities and the craftsmen were often allowed an immunity to certain social obligations and even punishments. But when bakers formed associations, their actions were never subversive or even avaricious. They controlled prices, as a group, and perhaps self-regulated certain productive matters, but they did so with the intent to share profits, rather than augment them.

In the exploration of each issue - in each chapter - the material and written evidences were woven together to support, supplement, or complement one another. The remains of actual bakeries were central to every component of this study. As such, a way was needed to conceptualize the production of bread and bridge the gap between the 
industrial and the social. Chaîne opératoires (operating sequences) provided the necessary interpretive framework with which to identify bakeries and quantify production. The chaînes also offered a way to link action with space, which allowed the commercial activity to be contextualized within the social processes evident in the houses and workshops.

The production of bread in each bakery is estimated by quantifying how many loaves could fit in the oven and how many times in a day each oven could produce a full load of bread. The estimates for the demand and commercial production of bread in Pompeii, Ostia, and Volubilis suggest that the urban population of the Roman Empire was highly dependent on commercial bakers as opposed to domestic production. Although the baker and the miller never hyper-specialized during antiquity, under the early Empire sub-specialists, such as millstone suppliers and possibly even oven letters, developed as a result of the commercial baking industry's increasing productivity.

Estimates of production and the prices of bread recorded in inscriptions were used to estimate the revenues of the bakeries. The revenues of the bakeries were reduced by the operating costs to arrive at the profits that the bakers could expect to earn. From their productive success, Roman bakers earned relatively high amounts of money, even after the operating costs. Some bakeries, like those of Ostia, might have generated profits numbering in the hundreds of thousands of sestertii every year, although it is difficult to assess the costs of such bakeries. High profits would help explain the consolidation of bread production in six extremely large bakeries at Ostia. Moreover, the epigraphic and legal evidence from Rome and Ostia indicates that there were strong vertical bonds and 
proxies that facilitated elite participation in the baking industry. The estimates for the profits earned by the smaller bakeries that dominated the cities of Pompeii, Herculaneum, Italica, Volubilis, and Augusta Raurica ranged from ten to twenty thousand sestertii each year. Such sums of money would not have provided the wealth needed for bakers to join the equites, but they were much higher than the income of unskilled laborers. In fact, such profits were high enough for the earner to rent a decent home and support a small familia.

Profits, however, are not always distributed fairly or evenly among participants in a craft. The compensation that one reaped from participation in a craft surely depended on one's status both in the workshop and in society at large. The way that the chaines opératoires integrate into houses and workshops indicates that there were three broadly defined groups of bakeries: small bakeries in large houses, bread factories, and small bakeries not in large houses. Inscriptions and juridical evidence indicates that during the first century $\mathrm{AD}$ - and probably before - there were a number servi-pistores (slave bakers) who worked for elite families, perhaps even the imperial family. This phenomenon aligns chronologically with the small bakeries in large houses, which exist only in Pompeii. Much of the juridical evidence for bread production in Rome and Ostia shows a preoccupation with productivity and large-scale production. Indeed, the bakeries of Ostia are massive bread factories and the legal and epigraphic evidence for commercial baking in Rome and Ostia attests strong vertical relationships between operators of the pistrinum and elites in the community. The vast majority of commercial baking was done in small bakeries not in large houses. For these bakers we have much 
less evidence. There are some hints at vertical relationships and a reliance on slavery for labor. The integration of the commercial production of bread into the spaces suggest that the activity was a daily part of the inhabitants lives. I have proposed that the primary social unit responsible for the commercial production of bread throughout the Empire was the small familia, the core family and what few slaves modest craftsmen could afford.

It is in their group behaviors that Roman bakers achieved their greatest degree of success and power. The bakers of Rome and Ostia, we know, formed collegia that were made into legal bodies as corpora. There are indications, including Gaius' Provincial Edict, that bakers' associations existed elsewhere in the Empire. Some of the discrepancies in the evidence for collegia pistorum is probably due to regional variation; what worked for Rome might not work for Ephesus. But the seemingly contradictory nature of the evidence for commercial baking is the product of the precariousness and delicate balance that defined the relationship between such associations and the state. The one consistent attribute of associations and cooperation among bakers is that they could expect special treatment, sometimes receiving concessions from certain social obligations or avoiding punishment after acting contrary to the wishes of authorities. These privileges were afforded to them because of the integral role that the bakers played in the provisioning of the city. On the other hand, they never push for greater profits and only act contrary to the wishes of the state when calamity strikes and they are forced to raise prices. In normal economic climes, bakers appear to have been kept in check by a state 
that would rather use the threat of force than force itself. Thus, the relationship between bakers and the state is primarily characterized by restraint.

The analyses in this dissertation have obvious importance to the study of Roman commercial baking, but the implications of the study extend into other areas of inquiry. Both the growing dependence on commercial baking and the subsequent sub-industries and spin-off industries show that specialization was a major component of the ancient economy and one of the contributing factors in economic growth. Most craftsmen were not industrialists, but rather small-scale producers. As such, the social mobility they could achieve through the practice of their trade was limited. Additionally, Roman craftsmanship is most frequently thought to have been perpetuated through the institution of slavery.

\section{The Adaptation of Anthropological Theory to Roman Archaeology}

In Chapter One, I proposed adapting theory from Anthropological Archaeology rather than simply adopting it. Indeed, much of modern archaeological theory was developed for - and constructed by - prehistoric archaeologists. Prehistory, typically, does not have associated with it the built environments which were central to Roman society. Nevertheless, chaînes opératoires provide a conceptual framework to link (industrial) activity to space. From there, one can explore the relationship of society to that space through physical relationships.

The application of the chaînes-opératoires approach to Roman commercial baking yielded results relevant to the related field of archaeological theory. First, the 
ephemeral nature of flour and bread, unlike lithic production, necessitates a certain degree of linear progression in the sequence of operations. A stone can picked up, worked, and then dropped. Later the same stone can be picked up again and modified in a new way. Thus the production of lithics is not always linear; nor is the order of operations strictly enforced. The production of bread, on the other hand, is restricted by the inability of the processed material to return to the state of the raw material. Flour cannot become grain. Dough cannot become flour. At certain steps, one cannot go backwards. There are also aspects of food that make its production different from the production of processed materials that are less susceptible to entropy. The sequence of the procedures in the production of bread must occur in short order. One cannot begin the process, abandon it, and then return to complete days, months, or years later. In short, the application of operating sequences as the conceptual framework for understanding production has focused mostly on stone and pottery. Its application to Roman commercial baking reveals that the nature of the chaîne opératoire largely depends on the physical attributes of the raw and processed materials, such as ephemerality or edibility.

\section{The Ancient Economy and Economic Growth}

It is often assumed that M. I. Finley believed that there was no economic growth in antiquity. While it is true that Finley viewed the economy as qualitatively static through most of antiquity, he also acknowledged that there were quantitative differences between the Mediterranean economy of Classical Athens and that of the Roman Empire. Indeed, Willem Jongman described such economic growth as the subsistence economy 
pushed to the limits of its productive capability and restrained by Malthusian constraints. ${ }^{1}$ Thus, in such a model of the ancient economy, growth was the result of increases in population size.

The predominance of this model for the ancient economy began to erode as early as the 1980s with work such as that of John D'Arms. ${ }^{2}$ Further questions were raised about the ancient economy, among them the existence of economic growth. Scholars began quantifying material remains to answer some of these questions. Such studies are called quantitative because they use material evidence as proxy data for ancient economic activity. In other words, the levels of material evidence serve as an indication of the actual economic activity with which they were associated. A classic example of this kind of study is that of A.J. Parker, who inferred trade levels where from the number of shipwrecks. ${ }^{3}$ A trend repeatedly emerged from the data derived from the shipwrecks and other evidence. The data levels increase for the evidence dating to the last few centuries BC and begin to decline for the evidence from the subsequent periods. Such proxy-data, whatever processes lead to their formation, indicate economic growth peaking toward the end of the first century BC or the beginning of the first century AD.

The existence of economic growth may not be debatable, but its significance and causes are still disputed. Richard Saller, and economic historian who was central to the discussion in chapter two, frames his discussion of economic growth in two ways. First, he raises the issue of whether growth in the ancient economy was aggregate or per

\footnotetext{
${ }^{1}$ Jongman 1988.

2 D'Arms 1981.

${ }^{3}$ Parker 1992.
} 
capita. ${ }^{4}$ Second, in terms of scale, he questions the significance of such growth. ${ }^{5}$ In the search to explain and understand growth in the ancient economy, many scholars turned to modern economic thought and models. For much of the last century, the neoclassical growth model has been preeminent. In neoclassical growth theory, three factors are important to changes in an economy: population size, invested capital, and total factor productivity. ${ }^{6}$ The third of the three is a conglomerate of any factor that affects production levels, including weather and technological innovation. The application of the neoclassical growth model to antiquity resulted in much scholarship focused on demography, investment, specialization, and innovation (as it pertains to productivity). ${ }^{7}$ Education has also been considered as an important factor and other endogenous factors will probably be added to the causes of economic growth under the Hellenistic Kingdoms and the Roman Empire. ${ }^{8}$

This study can now add specialization to the list of factors in the economic growth evident during antiquity. The increasing dependence on commercial bakers and other similar craftsmen producing essential goods, generated wealth and freed customers to pursue other activities. The importance of specialization to the ancient economy is perhaps the most important economic issue that is raised by the study of craftsmen like

\footnotetext{
${ }^{4}$ Saller 2002, 265.

${ }^{5}$ Saller 2002, 257-60.

${ }^{6}$ The Solow-Swan Growth Model is the dominant explanatory equation in neoclassical economics. Changes in observed growth are rationalized as the sum of changes in committed labor, invested capital, and total factor productivity. The last of these, total factor productivity is a residual, meaning that it is not observed like the hours of overall labor or investment. Total factor productivity consists of anything that can affect output, like bad weather or technological innovation.

${ }^{7}$ Ecological determinants must be a consideration, but are underrepresented in the literature on economic growth and decline. A recent study of ancient weather patterns (Lubick 2011, 8-11) based on data from tree rings suggest that increased rain and decreased temperatures created unsuitable conditions for wheat production, leading to food-shortages and political instability. Similar claims can and have be made about disease (Sallares 2002).

${ }^{8}$ Saller 2002, 262-6.
} 
bakers; did the specialization of craftsmen, like bakers, create 'new work'? In other words, were people freed by craftsmen only to idle their time away or did they actually pursue other ends that increased overall productivity of society? The standardization of ovens in Pompeii and Ostia and the complexity of millstones throughout the Empire strongly suggest the existence of sub-industries that were reliant on the commercial baking industry for their very existence. New work was created in the sense that specialization in the baking industry created opportunities for new craftsmen (oven builders and millstone producers). Moreover, the specialization of bakers and the subsequent new technologies were also possibly employed in a 'spin-off' industry, that of oven-letters. Certain bakeries in Pompeii, Ostia, and Italica have ovens, but lack the other technologies (such as millstones, kneading machines, tables, or shelves). Moreover, they tend to be ovens in a single-room shop. These bakeries may represent a separate industry in which baking was offered as a service. Food might have been brought to the shop and baked there for a fee. The emergence of new industries, dependent upon the commercial baking industry, indicates that new work was being created as a result of specialization.

\section{Social Mobility}

Social mobility is a popular topic in scholarship of Roman history, and one that deserves further attention, particularly mobility between subdivisions at the lowest levels of society. Moreover, it is a topic that has not adequately utilized the material evidence. Most of the work on social mobility has been rooted in textual evidence. Paul Weaver 
defines social mobility in the Roman world as the "process of status dissonance by which persons rate highly on some criteria of status, such as ability, achievement, wealth, but low on others, such as birth or legal condition." Weaver's 'status dissonance', incongruity between one's birth and one's wealth, provides him with a way to explore social mobility in ways that do not actually affect status. He can identify social mobility in people who had "ability, achievement, and wealth," even if they were deficient in birth and status. ${ }^{9}$ Thus Roman social categories, such as slaves, were vertical components in society; some members of their ranks extended all the way to the top, such as servi Caesaris, and others were at the very bottom, such as the poor laborers working in the bakeries.

The view of social mobility as separate from social status is position not shared by all. Ramsay MacMullen, whose seminal work Roman Social Relations remains the touchstone for almost every issue to the study of the Roman world, believed that social mobility did not exist and cited as evidence the supreme importance of land as wealth in the ancient world:

It governed the relation, generally one of absentee-ownership, between
country and city, peasant and Decurion... Moreover, it diminished
social mobility; for where wealth held the key to advancement, the
more slowly it changed hands, the more slowly people changed status.
Class hardened almost to the point of caste, at least in the late Empire.
Finally, it gave other kinds of investment a bad name. Industry and
commerce were not for gentlemen. ${ }^{10}$
In many ways Weaver and MacMullen agreed on the major points. Roman social categories are characterized by their verticality and some people - even if exceptionally few - could attain significant wealth despite their low birth or status. The two scholars

\footnotetext{
${ }^{9}$ Weaver $1967,3$.

${ }^{10}$ MacMullen 1974, 25-26.
} 
differ, however, in their definition of social mobility. For Weaver, attaining wealth and power despite low birth constituted social mobility, or at least 'social dissonance'. MacMullen, on the other hand, perceived social status as the fundamental trait that must change for social mobility to exist. ${ }^{11}$ Both scholars focused primarily on mobility into the wealthiest minority of Roman society, which MacMullen separated into two classes: "the rich and the poor."12

This dichotomous view of Roman society persists among many contemporary scholars. Dennis Kehoe, writing much more recently, notes that late-antique Rome society was divided into honestiores and humiliores, the first consisting of senators, equestrians, decurions, and members of the military, the second comprising everyone else. ${ }^{13}$ The simplistic division adopted by Kehoe creates between honestiores and humiliores prevents him from seeing social mobility. He nearly quotes MacMullen, citing also Trimalchio as an example of the potential wealth a former slave (libertus) could obtain, but also as an example of how a slave could never fully escape his birth or be fully enfranchised in Roman society. ${ }^{14}$ Other recent scholarship does not adopt this dichotomous view entirely, although it is often present as a tacit assumption. Josiah Osgood, in his exploration of the Roman familia, discusses women, slaves, children, and craftsmen. With regard to inter-mobility, he notes that sons often followed their fathers into the same trades. Social mobility was possible, acknowledges Osgood, but only rarely

\footnotetext{
${ }^{11}$ MacMullen $(1974,107)$ points to Trimalchio as the example of this.

${ }^{12}$ This is much the same as Peter Garnsey's (1970) distinction between honestiores and humiliores.

13 Kehoe 2011, 153.

${ }^{14}$ Kehoe 2011, 147-148.
} 
and it is impossible to quantify. ${ }^{15}$ He clearly sees social mobility strictly as admittance to the upper echelons of society.

Splitting Roman society into two categories, 'rich and poor', is intrinsically elitist and a product of over-reliance on textual and epigraphic evidence. It is not surprising that the literature of antiquity, almost entirely elite in its perspective, should aggregate the majority of society economically and socially below them into a single group, "them, not us" ${ }^{16}$ Certainly the vast majority of wealth, landed or other, resided in the hands of the few, so functionally the dichotomy of rich and poor in Roman society was not merely a fiction of elite perspective. But the concept of social mobility, in such a model, is exclusively the ability to move from the poor to the rich. Such a conceptualization of Roman society and social mobility neglects the nuance and diversity of the vast majority of people living under Roman rule and their ability to change their own lives while still not attaining admittance to the equites.

The available evidence indicates that small-scale producers dominated breadproduction in Pompeii, Herculaneum, Italica, Volubilis, and Augusta Raurica. The wealth estimated to have been generated by such small-scale production was not enough to lift bakers to one of the higher-level social orders. In this sense, social mobility was not attainable by Roman craftsmen. On the other hand, the estimated revenues of Roman bakers do indicate that such craftsmen were afforded a certain level of comfort in their finances that would have distanced them from much of society. In this sense, craftsmen could elevate themselves in society, at least financially, if not socially.

\footnotetext{
15 Osgood 2011, 75.

16 There are, of course, exceptions to this. Horace was not Roman nor was he a member of the provincial decurion class. He was the son of a coactor, some sort of auctioneer.
} 


\section{Roman Craftsmanship}

This dissertation began by observing that studies of Roman craftsmen usually fall into one of two categories. Craftsmen have previously been considered either impotent and poor, or powerful and proud. I proposed founding an the study of social relationships and avenues to power for craftsmen in the actual evidence of their activities. The evidence for commercial bakers shows them to have been adept producers, upon whom the bulk of the Roman Empire's urban population relied, at least from the first century AD onward.

The dependence on commercial baking evident in Roman cities might extend to other industries. The customers who did not bake their own bread probably did not scour their own wool. The level of product dependence in Roman cities likely relied on the type and cost of the product. Basic goods of low cost, like bread or cloth, must have had a broader consumer base than elaborate goods of high cost, such as silverware or wall painting. Similarly, the revenues of craftsmen would probably also fluctuate based on their product and their skill.

Although the search for economic growth or technological innovation has frequently focused our attention on the presence - or absence - of large-scale producers such as the bread factories of Ostia, the vast majority of commercial baking was done by small familia, including a few slaves, in what was very likely their home. These smallscale producers were integral to the existence and stability of the Empire's urban population. The very existence of craftsmen, such as the pistores, not only freed people to 
pursue other activities, but it also spurred production in other sectors and provided technologies for new industries. For their productive success, bakers were wellcompensated financially, but not enough to make them major players in Roman society's political affairs, at least not as individuals. But as a group, they were much more powerful. Their combined success and importance could attract patrons that any individual baker could not have expected. Their combined importance to the provisioning of Roman cities earned them a degree of power that the state was happy to let them have, just so long as they did not use it. 


\section{Catalog of the Bakeries}

The bakeries in this catalog are divided into groups according to the cities in which they were found. The cities are ordered chronologically by the date of the evidence found at them. Bakeries from six cities are included: Pompeii, Herculaneum, Ostia, Italica, Volubilis, and Augusta Raurica. At Pompeii and Herculaneum, the evidence dates to the first century AD. The evidence at Ostia and Italica is dated to the second century AD. The bakeries at Volubilis and Augusta Raurica are third-century in date.

All possible bakeries are included in the catalog, even those that are considered kitchens for domestic production or some other industry in the body of the text. These are compiled from the catalogs or identifications of previous scholars.

The catalog is illustrated with plans, photographs, and images from secondary sources. The focus of the illustrations is the productive aspects of the bakeries, indicating the location of various technologies. These technologies are indicated on the plans with numbers ( 1 - millstones, 2 - kneading machines, 3 - tables, 4 - postholes for shelves, and 5 - ovens). 


\section{Pompeii}

\section{Bakery 1 - I.3.1}

The establishment at I.3.1 is one of Pompeii's most anomalous bakeries, due to its lack of millstones and large oven. Most bakeries without millstones are located along the same street, the via degli Augustali. The bakery consists of four spaces. The large front room gives access to two spaces, a small room to the southeast and the oven to the northwest. The area of the oven has several supports for tables or counters. The oven itself is $2.5 \mathrm{~m}$ wide and $3.0 \mathrm{~m}$ long. The oven forms the northwestern wall of a room to its east. Fiorelli records a ladder in this room, potentially leading to a loft space on a second story.

Fiorelli suggests that it may have been the workshop for a pistor dulcarius, a type of baker attested in Latin literature, apparently some sort of pastry chef. No evidence exists to support this hypothesis, but Fiorelli frequently associates bakeries that lack millstones with this type of baker. Mayeske interprets the front space as a shop and the small room as a preparation space. She does not mention the table supports, but notes the wide entrance of the oven and a now disappeared amphora serving as a flue. Mayeske also identifies the room in the back next to the oven as a preparation space, but makes no mention of Fiorelli’s loft.

Fiorelli 1861, 70; Fiorelli 1875, 50; Fluvio 1879, 285; Mayeske 1973, 82-83; Flohr 2007, 135. 
234

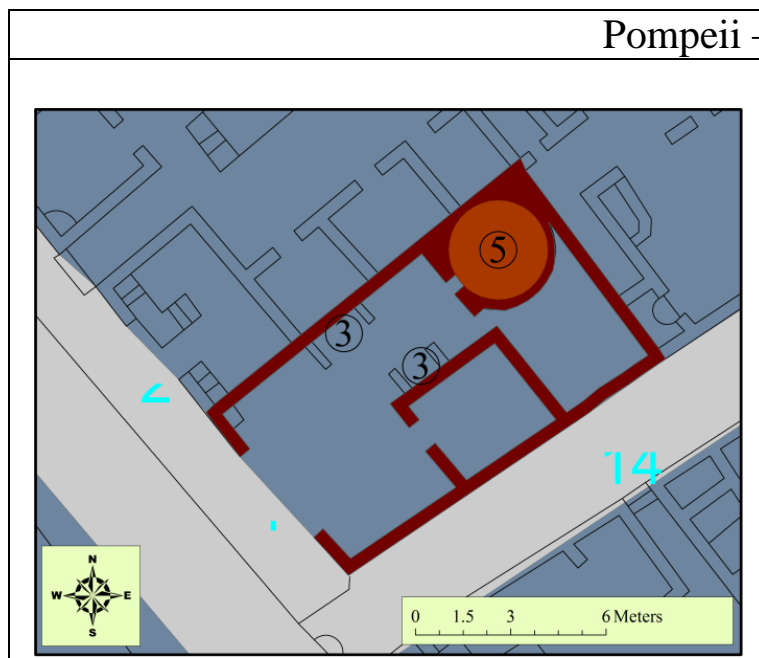

Plan of Bakery One

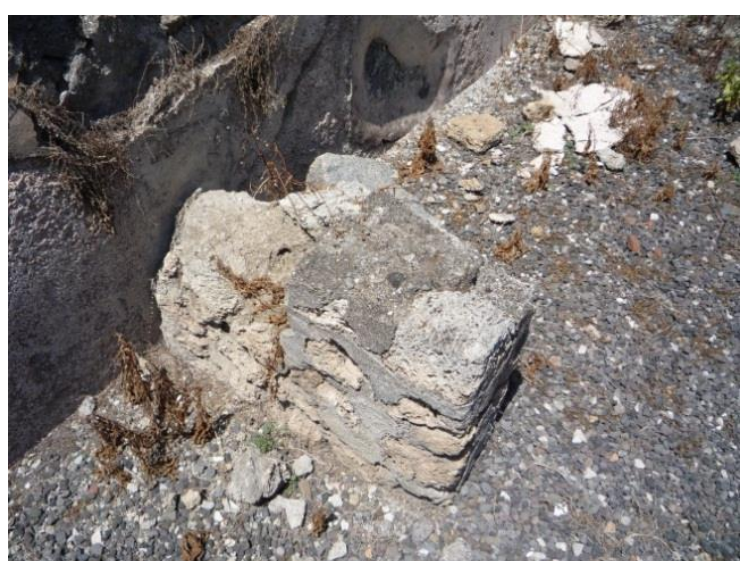

(3) Table Supports

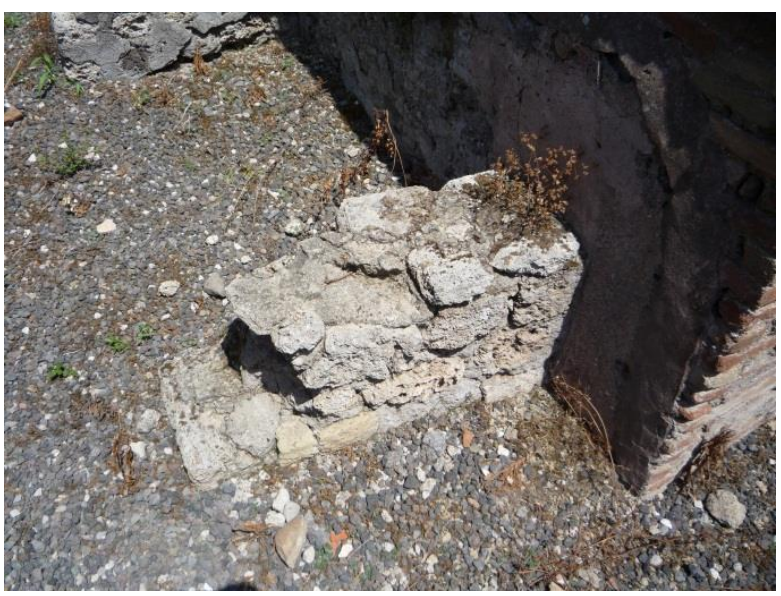

(3) Table Supports

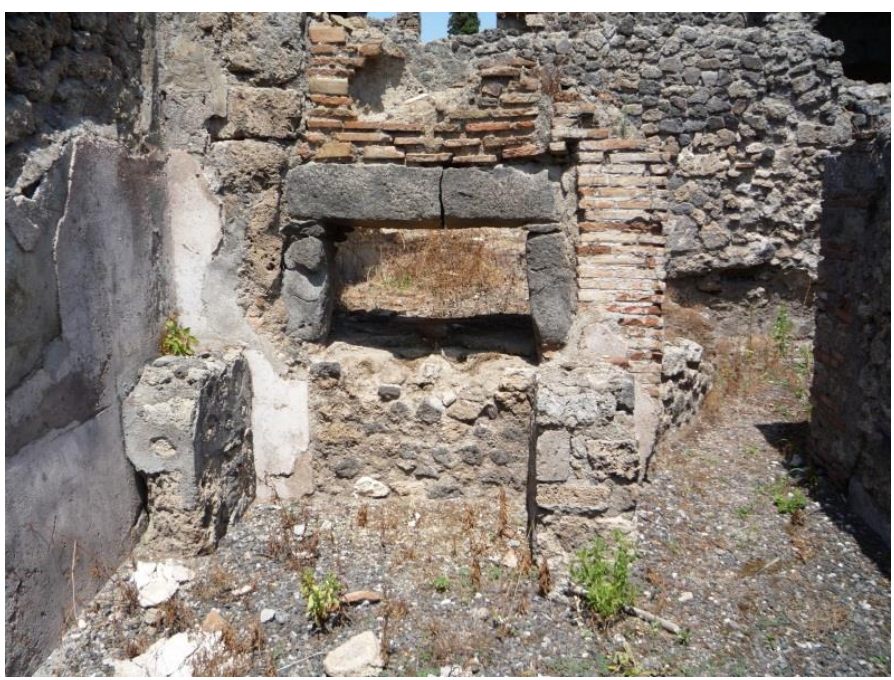

(5) Oven 
Bakery 2 - I.3.27

Excavated in 1869, bakery two is one of the largest in the city, but does not communicate with any of the large houses in the area. Just inside the entrance, a small room resides to the northwest. In the main chamber are the bases for five millstones, robbed out sometime after excavation. Fiorelli records the existence of a lararium, of which only two painted snakes remained. A series of four rooms line the main chamber to the southeast. The eastern most room in the series contains a kneading machine and postholes for shelves. Fiorelli records a graffito (CIL IV 4000) found in the same room as the kneading machine:

$\begin{array}{llc}\text { OLLIIVM L } & \text { A } & \text { IV } \\ \text { PALIIA } & \text { A } & \text { V } \\ \text { I AIINVM } & \text { A } & \text { XVI } \\ \text { DIARIA } & \text { A } & \text { IV } \\ \text { I VRI VRII } & \text { A } & \text { VI } \\ \text { VIRGAI } & \text { A } & \text { IV } \\ \text { OLIIVM } & \text { A } & \text { VI }\end{array}$

The same room links to the next room in the series, in which the oven resides. The oven is $2.5 \mathrm{~m}$ in diameter. A chute connects the front of the oven to the room with the kneading machine. Fiorelli says that there were four platforms in front of the oven which no longer survive. The room just west of the oven does not contain any baking technologies, but it did have a similar chute that was filled in during antiquity. The eastern most room is a toilet. Finally, two rooms extend eastward from the main chamber. The smaller and southern most of the two contained a staircase that no longer exists and the larger has a vat and a long trough. A

Both Mayeske and Fiorelli make comment on the graffito from the room with the kneading machine, but neither speculate as to its meaning. Mayeske offers transliterations 
of oleum l (olive oil), palea (chaff), faenum (wheat), diaria, furfure, virgae, and oleum (olive oil). Koenraad Verboeven indicates that the 'A' stands for as and the numerals stand for prices.

Mayeske interprets the room just north of the entrance as a storage space, as well as the room west of the oven. Both Mayeske and Fiorelli agree that the room east of the oven as the panificium, a place for the preparation of bread. Fiorelli records the bases of four millstones, though five were found there in 2008. Mayeseke and Fiorelli also agree that the eastern most room was the stables for the donkeys.

Fiorelli 1861, 75; Fiorelli 1875, 110; Nicollini 1854, 78; Boyce 1937, 24; Schefold 1957, 14; Mayeske 1973, 83-4; Verboven 2002, 110. 


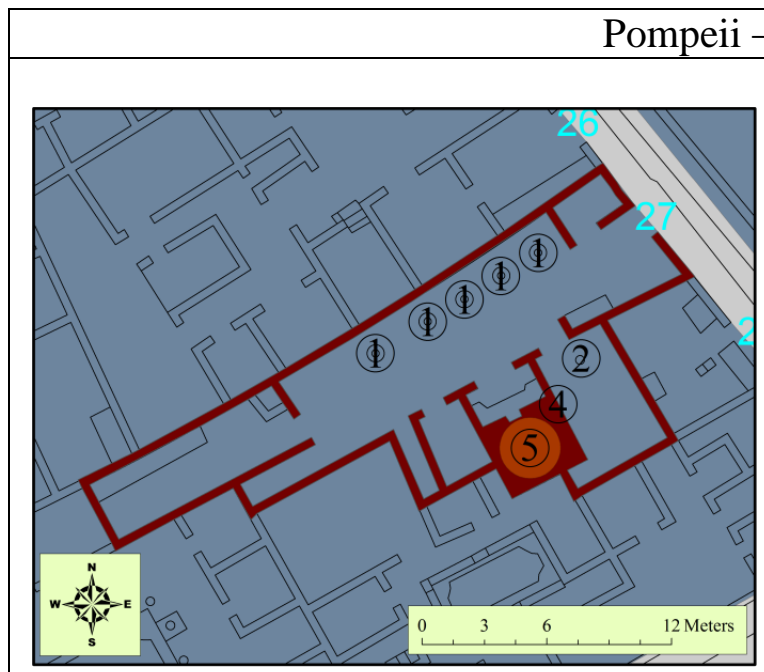

Plan of Bakery Two

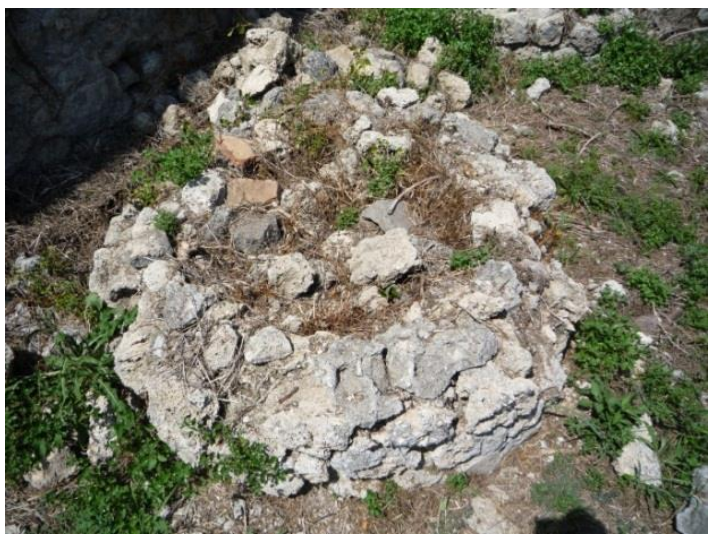

(1) Millstones

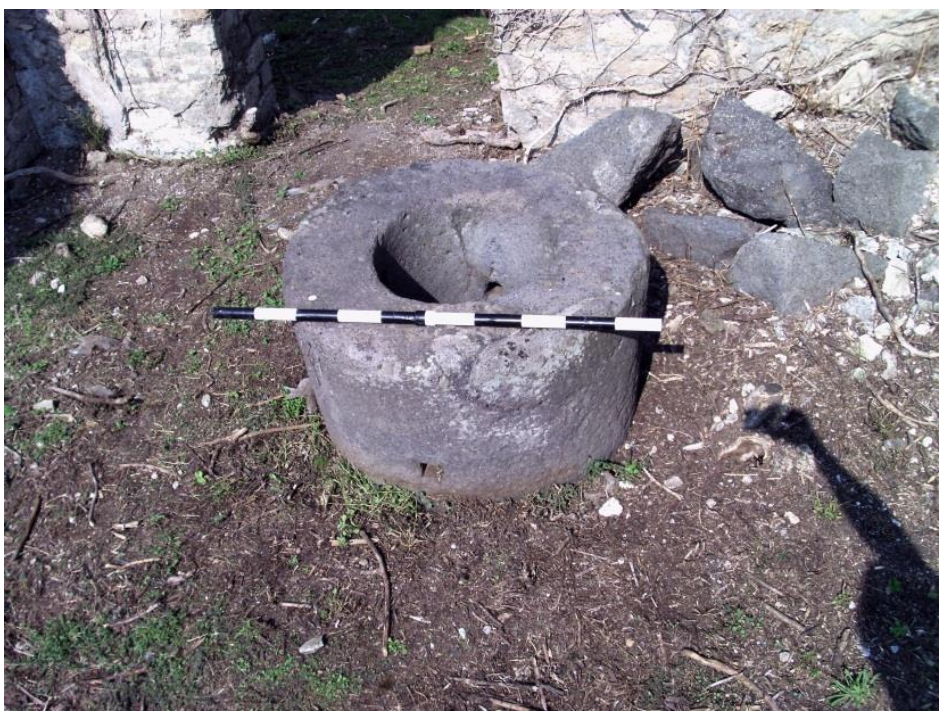

(2) Kneading Machine

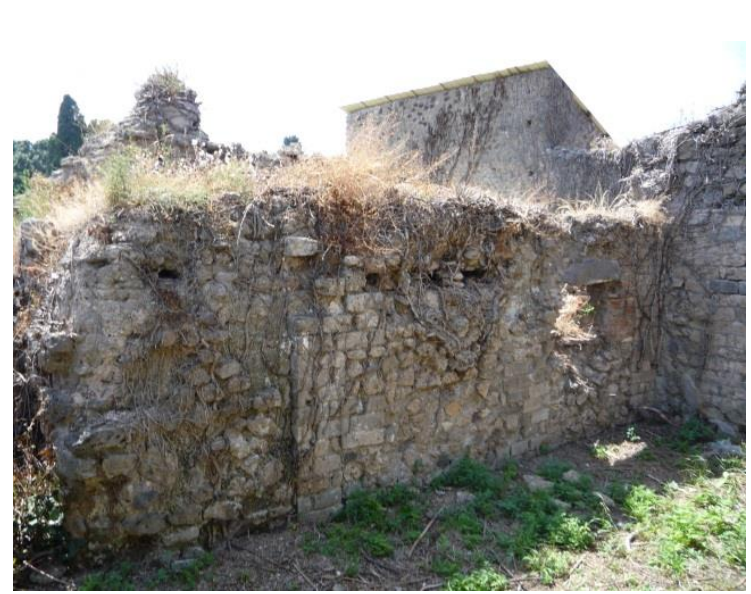

(4) Postholes for Shelves

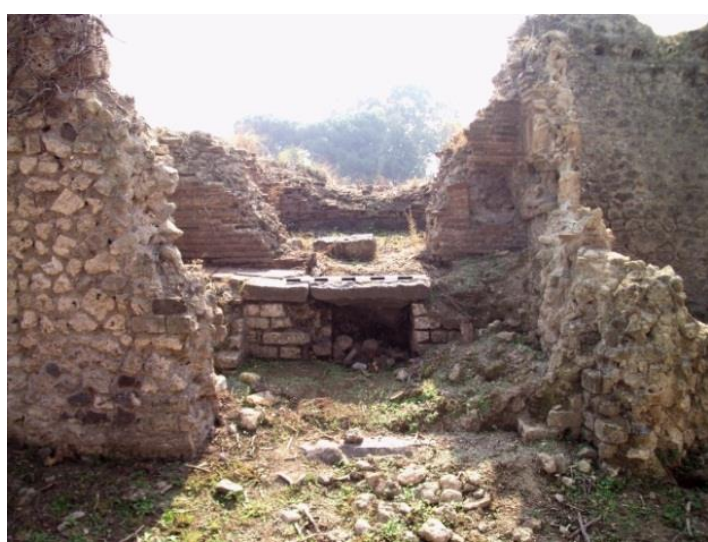

(5) Oven 


\section{Bakery 3 - I.4.12-17}

Bakery three sits at the intersection of via dell'Abbondanza and via Stabiana, which may explain why it has five entrances. The rooms opening onto the two streets contain not baking technologies, except the one accessed through entrance 13, which contains an oven (diameter of $2.0 \mathrm{~m}$ ). The room associated with entrance 16 had a lantern found outside of it with the inscription DIVNI PROQVLI (CIL X 8071), based on which Fiorelli identifies the space as a shop with an owner named D. Iunus Proculus. In the room accessed through entrance 17 , Fiorelli records a series of dolia which contained flour, these are no longer visible. Beyond the rooms lining the streets there is a central chamber with four millstones and a second oven (diameter of $2.4 \mathrm{~m}$ ). In front of the oven there are two catilli. East of the milling chamber is a long rectangular room. The second oven is linked by a chute to the rooms on both its east and west. The room east of the oven contains supports for tables. The two rooms west of the oven also have such supports, but also contain a kneading machine and postholes for shelves.

Bakery three is one of the few in Pompeii with two ovens. It may have been two separate bakeries at some point in its past, as Mayeske suggests, but one subsumed the other. Fiorelli instead asserts that the smaller oven facing via Stabiana was a separate workshop of a pistor dulcarius, again probably because it has no millstones directly associated with the oven. Fiorelli also identifies the long rectangular room east of the mill-room as the stables due to a trough in that space. Mayeske, on the other hand, suggests that the room and trough served to wash the grain before it was milled. 
Fiorelli 1861, 68; Fiorelli 1875, 66-67; Della Corte 1965, 255; Nicollini 1854, 79; Mayeske 1973, 84-86; Pagano and Prisciandaro 2006, 171. 


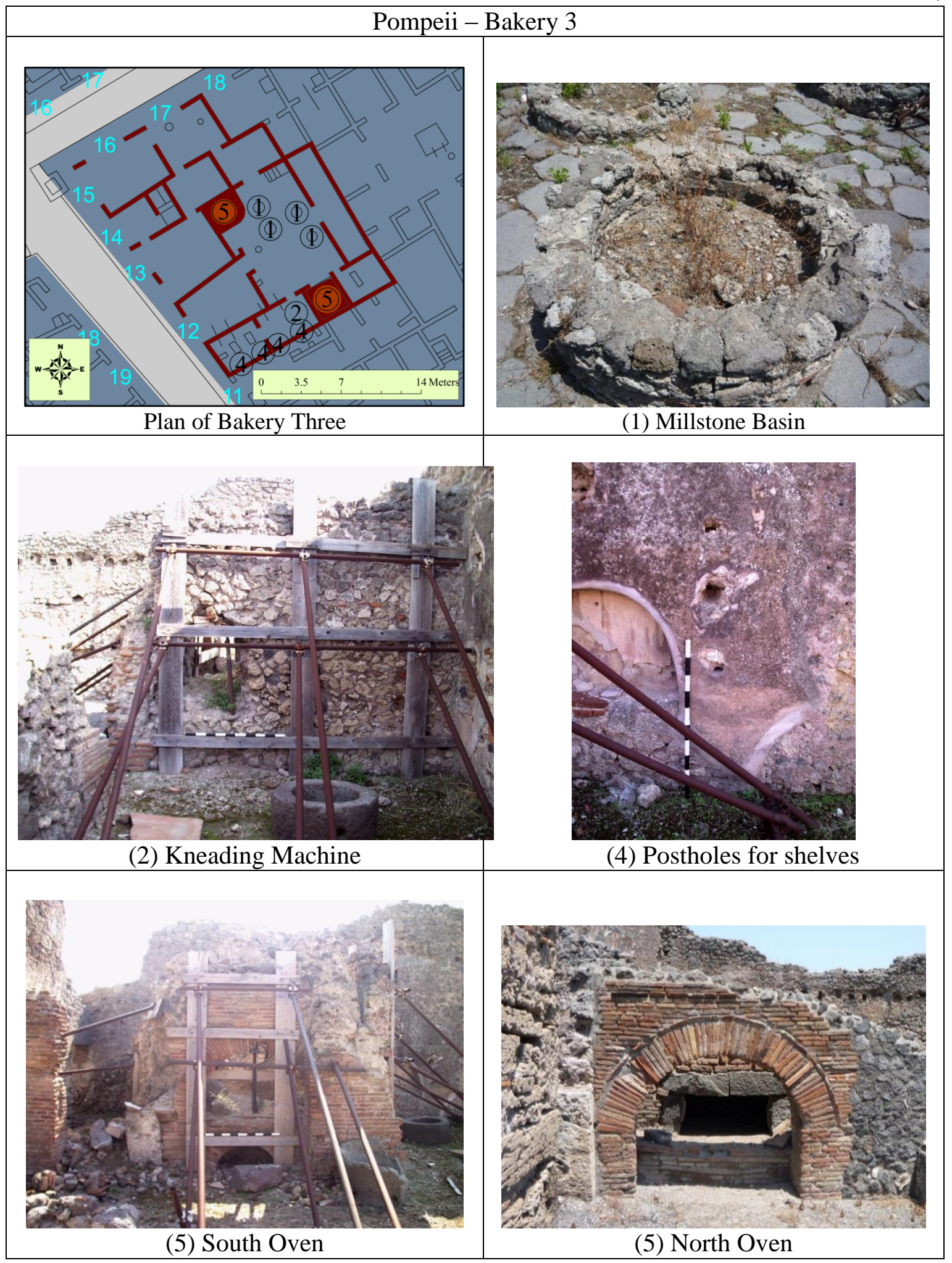


Bakery 4 - I.12.1-2

The so-called Casa del Forno or Pistrinum of Sotericus is one of the most well preserved bakeries in Pompeii. The western half of the establishment is a large house well decorated in fourth style. The eastern half consists entirely of the bakery. The two halves share both entrances one and two. East of the entrance is a large room with four millstones. One of the millstones still has the bottom of the lead canister that ringed the millstone bases, catching the flour. That room leads to a narrow corridor that has two rooms opening on either side. The corridor leads to another large space where the oven is located $(2.4 \mathrm{~m})$. North of the oven, there is a small room with no baking technologies. South of the oven is a well preserved room with white and red plaster, a common decoration for utilitarian spaces. The southern room contains a kneading machine, supports for tables, postholes for shelves, and a chute leading to the oven. The oven still has two iron grates: one to seal it during baking and the other to block off ashes when the oven was cleared.

Della Corte notes two dipinti in front of this house, both of which mention a certain Sotericus, which lead Mayeske to associate ownership of the house and bakery with that name. While the façade was excavated in the $19^{\text {th }}$ century, the interior of both the house and bakery remained unexcavated until 1924. Mayeske identifies the mill-room and suggests the rectangular room to the south of it was probably the stable. She associates the two rooms between the mills and the oven with storage. Mayeske calls the room south of the oven and linked to it by a chute a panificium.

Della Corte 1965, 348; Mayeske 1973, 87-88; Jashemski 1979, 195, Mayeske 1988, 149165; Wallace Hadrill 1994, 34-5 and 72-3; Monteix 2009, 324-33. 


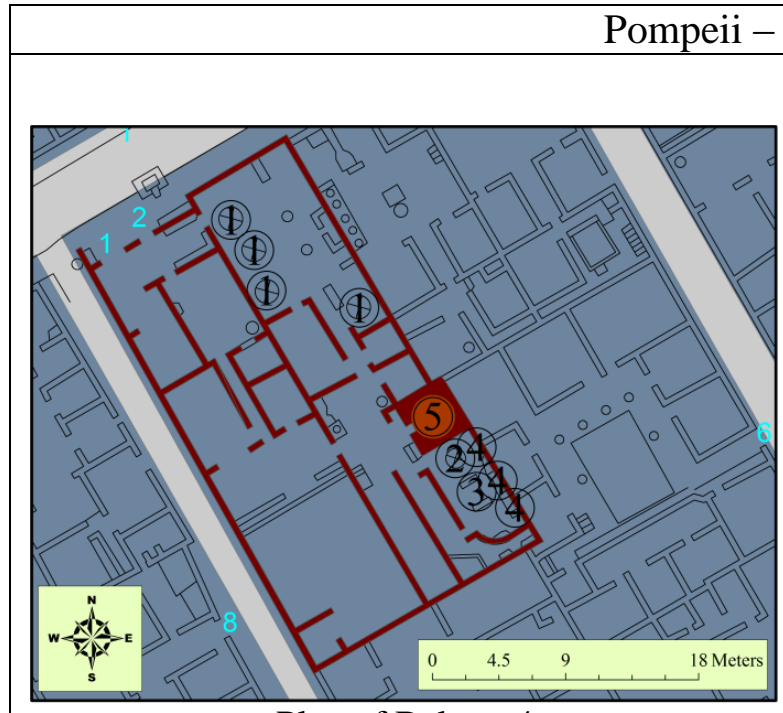

Plan of Bakery 4

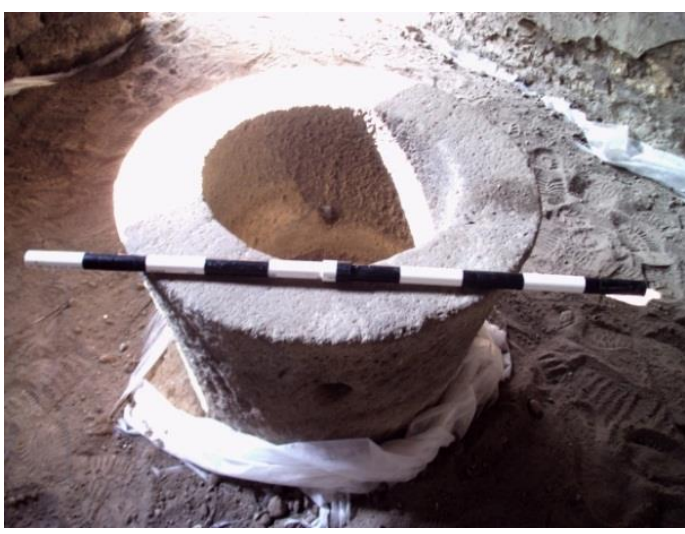

(2) Kneading Machine

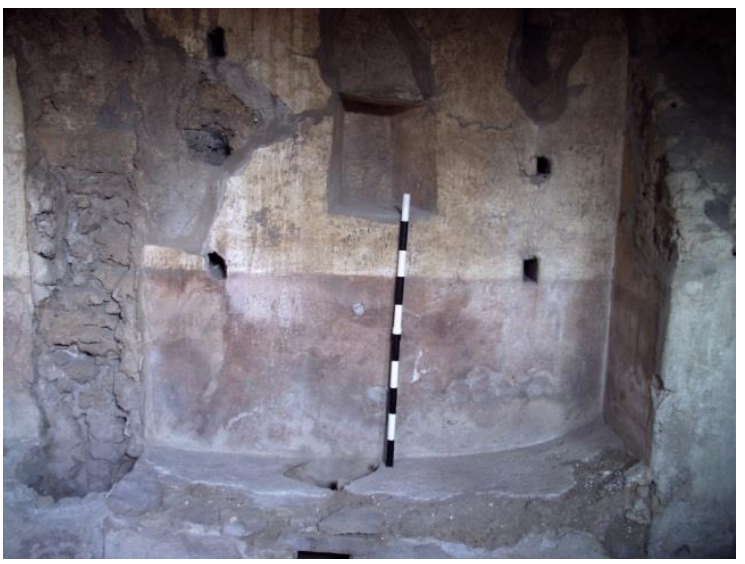

(4) Postholes

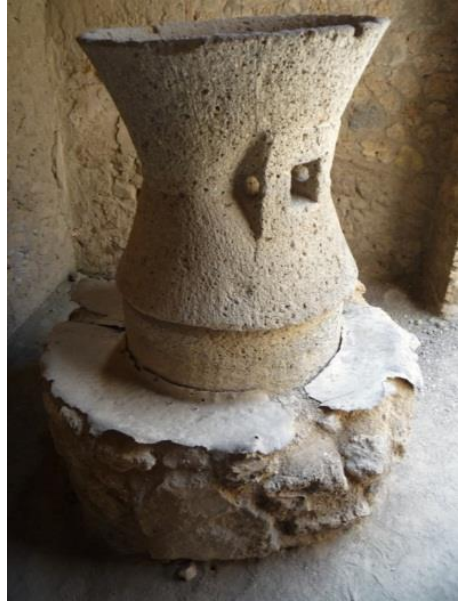

(1) Millstone

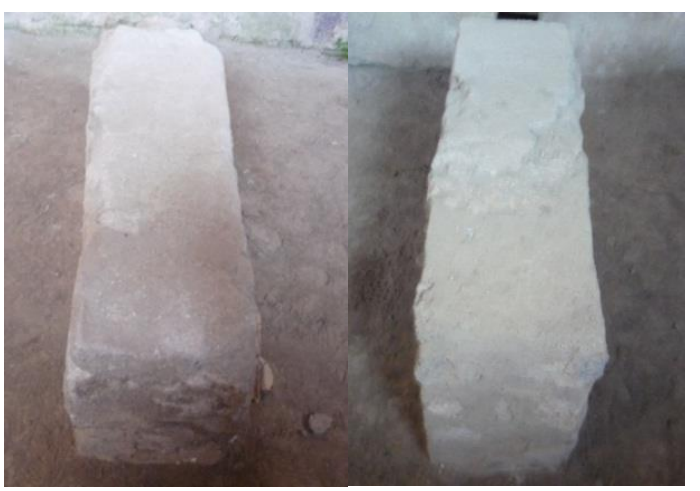

(3) Table supports

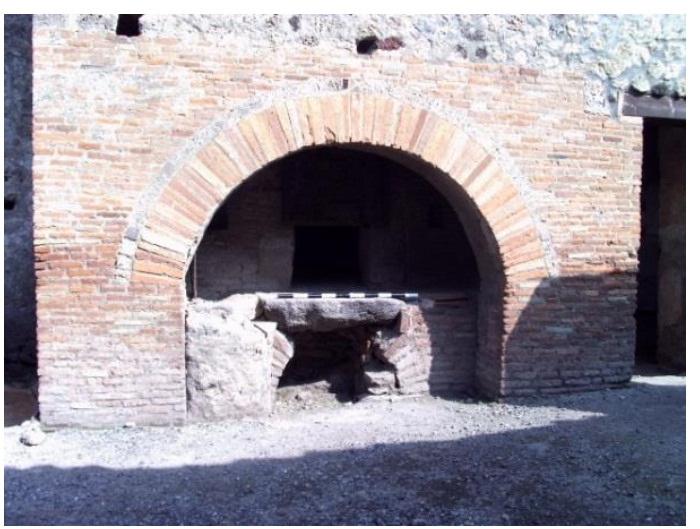

(5) Oven 


\section{Bakery 5 - V.1.14-16}

Bakery five is one of the least preserved in Pompeii. After being excavated in 1875 , it was bombed on September $16^{\text {th }}, 1943$ during World War II. Garcia y Garcia say that the northeast side of the bakery was completely destroyed, but he must mean the northwest side. Early plans show a second oven and a large feature in the northwest corner, neither of which exists today. The extant oven (2.6 m in width and 2.8 in length) is in the far northeast side of the establishment and has a counter in front of it. It may have had a chute linking it to a room to the northeast, which contains supports for tables.

Much of the V.1.14-16 appears reconstructed, casting doubt on any data derived from it. The destroyed oven, as it appears on the old plans, can be estimated at $1.5 \mathrm{~m}$ in diameter. Mayeske calls bakery five a "converted home with two ovens". Della Corte identifies the bakery as an establishment of a pistor dulciarius.

Boyce 32, 1937; Della Corte 1965, 92 and 255; Fulvio 1879, 285; Schefold 1957, 63; Mayeske 1973, 88-89; van der Poel 1986, 70; Garcia y Garcia 2006, 61. 


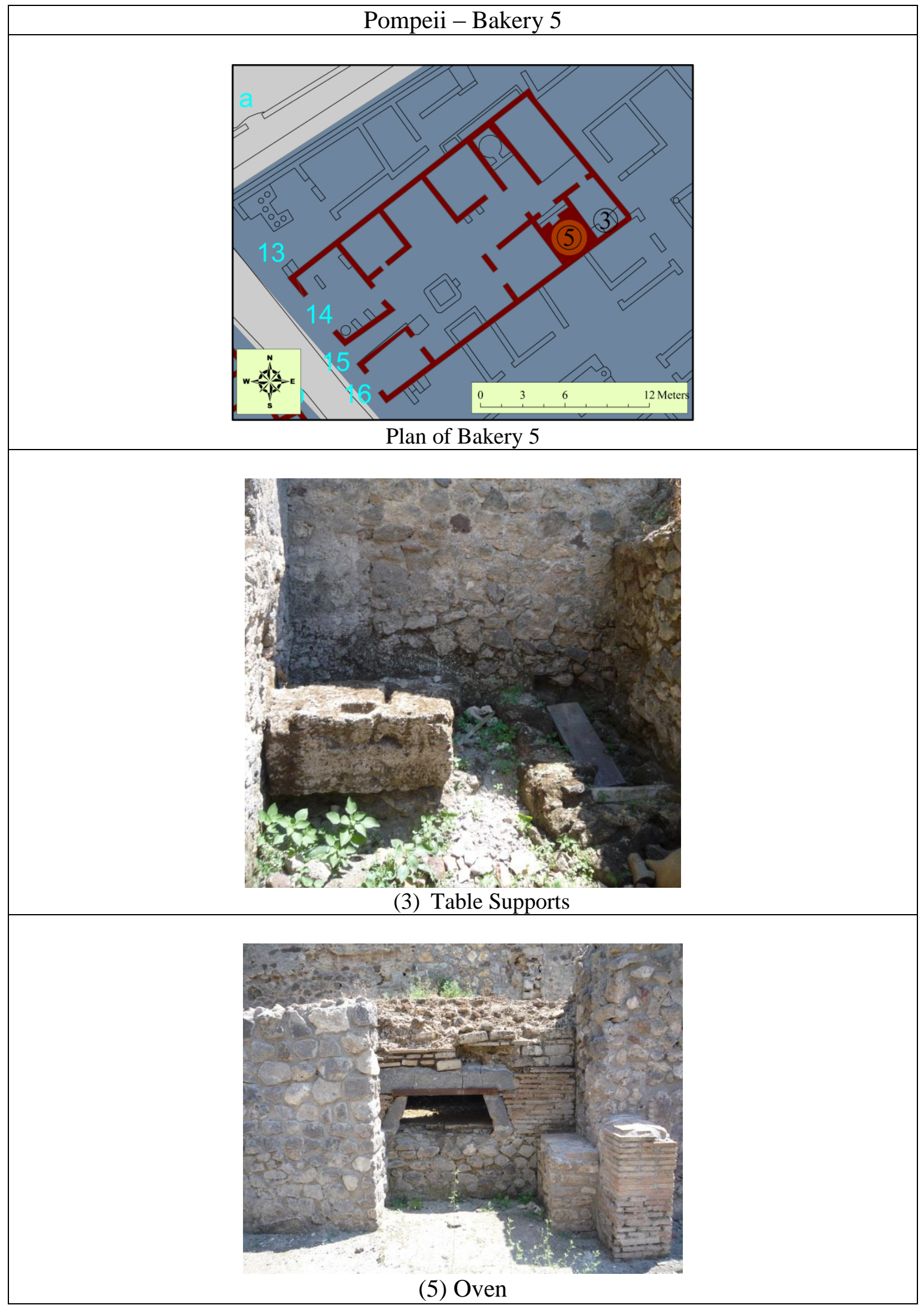




\section{Bakery $6-$ V.3.8}

Excavated in 1901-1902, bakery six was renovated from an atrium-style house. A long fauces leads to an atrium, which was converted into a mill-room, with the bases for two millstones and a third with its meta and catillus in place. Integrated into the impluvium is a kneading machine. In the southeast corner of the atrium is an oven with a diameter of $2.1 \mathrm{~m}$. From the converted atrium, one can access a series of rooms traditionally thought of as cubicula. The room in the southeast corner of the atrium leads to a back room, which links to the front of the oven through a chute. This room contains supports for tables and some indications of postholes for shelves. Returning to the converted atrium, another corridor leads northwest to another series of large rooms, which may be domestic in function.

Mayeske calls V.3.8 a "bakery in a remodeled house". Certainly the atrium reappropriated as a mill-room corroborates that conclusion. Mayeske does not discuss the room behind the oven, which is linked to it by a chute. She does identify the two rooms to the west of the fauces as storage space. She suggests that the three rooms east of the millroom as storerooms and stables. Flohr interprets the placement of the commercial activity at the front as an indication that the domesticity at back of the house was being protected

NSc 1889, 134; NSc 1902, 207-8; Boyce 1937, 38-9; Mayeske 1973, 89-90; Flohr 2007, 139; Monteix 2009, 329. 


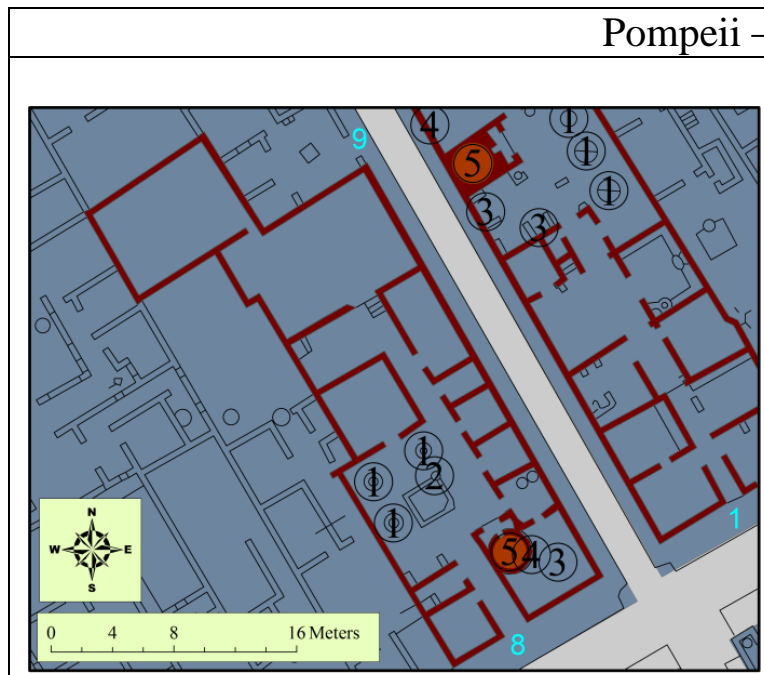

Plan of Bakery Six

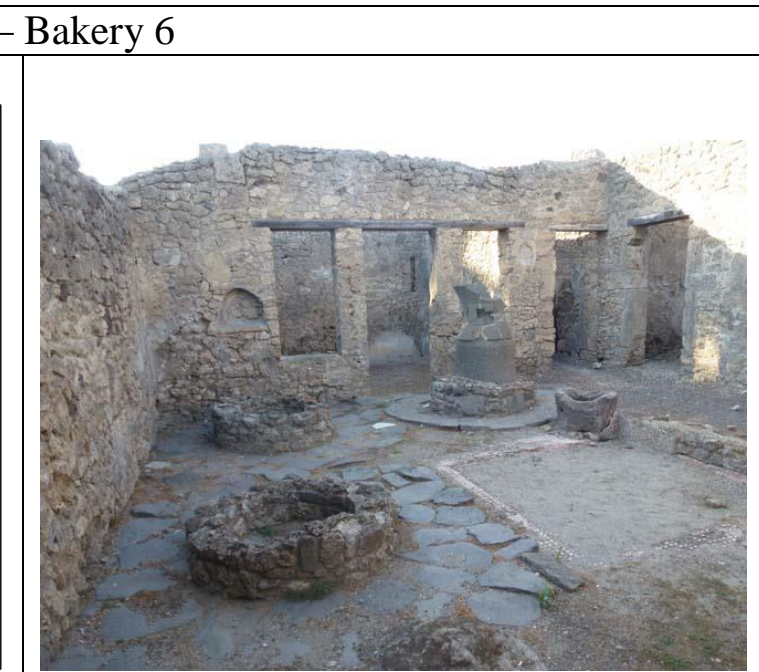

(1) Millstones

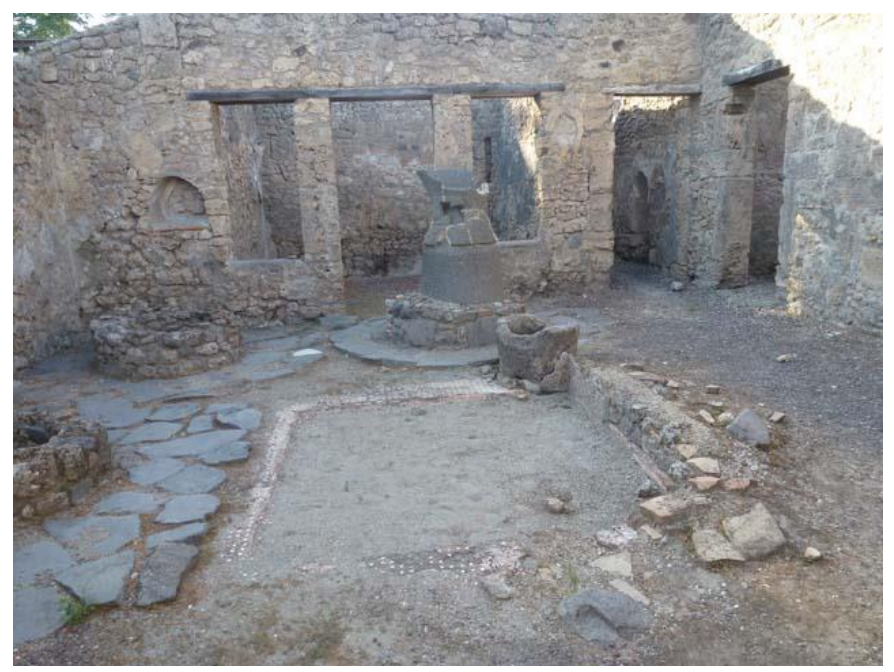

(2) Kneading Machine in converted impluvium

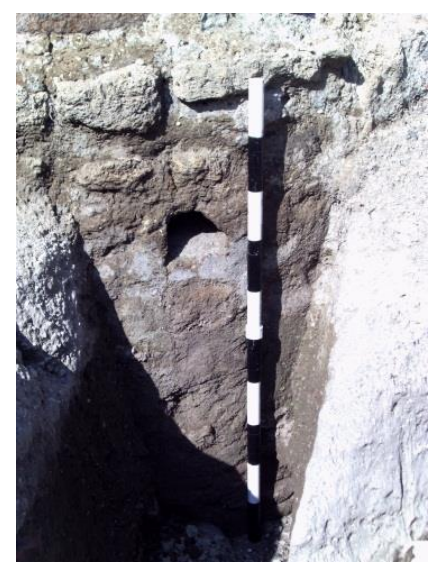

(4) Possible Post-hole

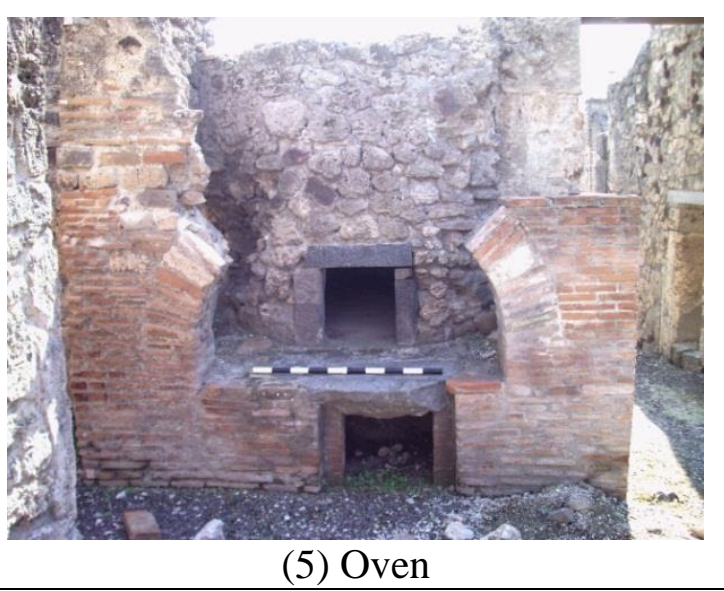




\section{Bakery 7 - V.4.1-2}

Bakery seven, like bakery five, was bombed on September $16^{\text {th }}, 1943$ though the former fared far better than the latter. The two-thirds of the bakery closest to the via di Nola was the hardest hit by the bomb and contains no baking technology except a kneading machine in the front room accessed through entrance two. The kneading machine is clearly out of place and likely repositioned after the bombing. A long corridor the front portion of the bakery leads to a large room in the back, which once had a door onto the vicus to the west, but was blocked off in antiquity. North and east of the large room there is another large space where there are three bases for millstones, one with its meta and catillus. The oven (diameter of $2.6 \mathrm{~m}$ ) opens onto the mill-room. It is linked with a room to the north by a chute. This room contains a table support and postholes for shelves.

Mayeske contrasts bakery seven with bakery eight, referring to it as a "pistrinum with living areas", rather than a home remodeled into a bakery. The decoration in some of the rooms might support this conclusion, though elaborate $4^{\text {th }}$ style wall painting is evident even on the exterior of ovens.

NSc 1889, 133; NSc 1890, 356 and 391-3; NSc 1891, 271; NSc 1901, 255-8; Boyce 1937, 39; Schefold 1957, 83; Mayeske 1973, 90-3; Jashemski 1993, 116; Garcia y Garcia 2006, 62; Monteix 2009, 335 fig. 74. 


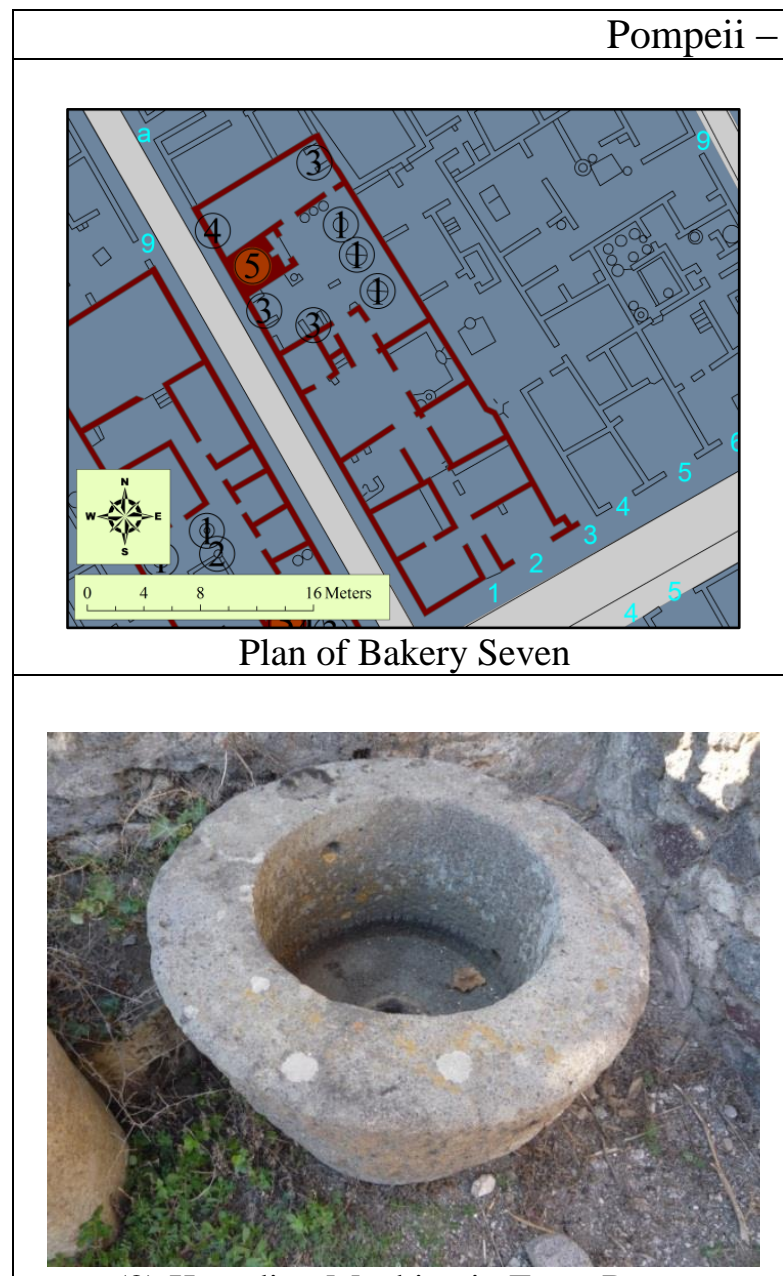

(2) Kneading Machine in Front Room

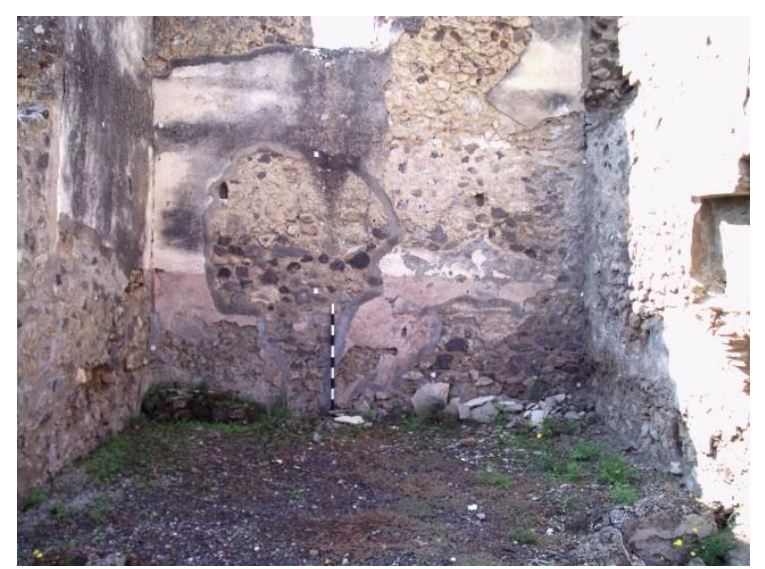

(4) Postholes

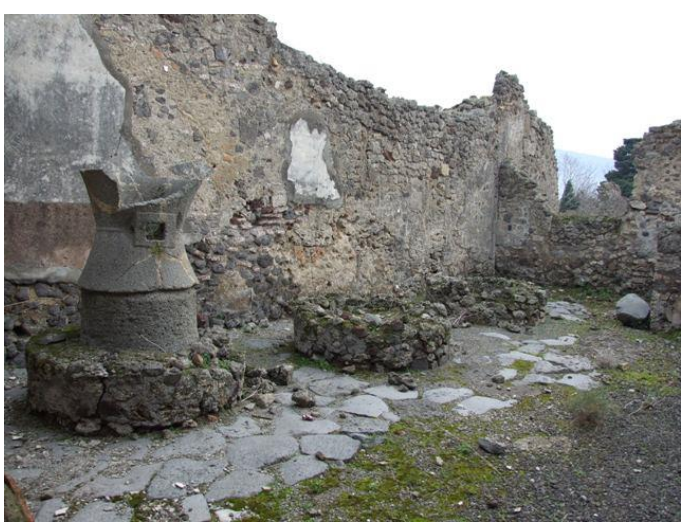

(1) Millstones (Courtesy of the Dunns)

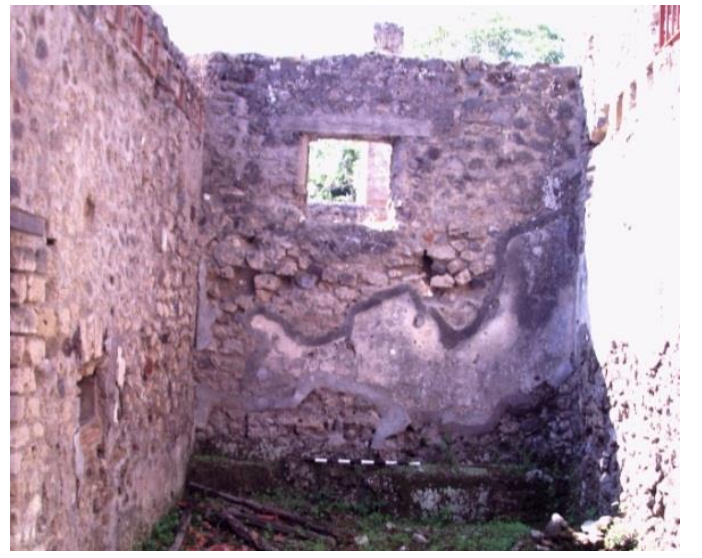

(3) Table Support at Far End of Room

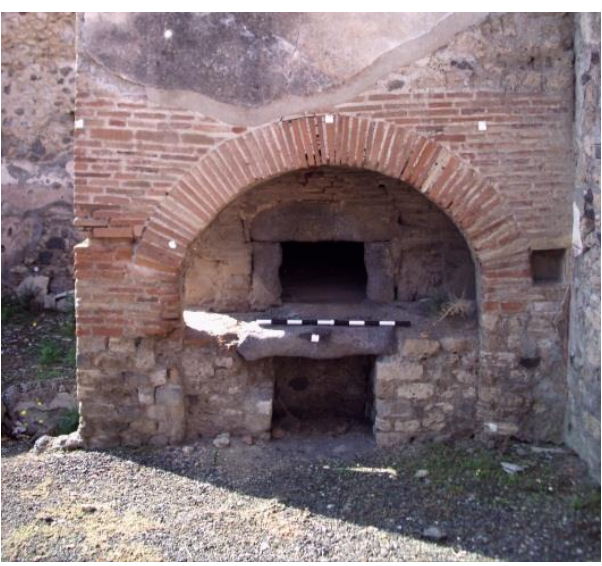

(5) Oven 


\section{Bakery 8 - VI.2.6}

Bakery eight was the earliest excavated of Pompeii’s bakeries (1806-1808). Opening onto via Consulare, the bakery consists of three rooms and an oven. The large room accessed through entrance six contains three millstones. A doorway immediately on the right upon entering the mill-room leads to a nearly square space, which Fiorelli records contained a hearth and a latrine. The oven (diameter of $2.1 \mathrm{~m}$ ) resides at the northeast end of the mill-room, with a chimney extending upward within the praefurnium. A chute in front of the oven leads to table supports on the right side. A small room southeast of the oven contains postholes for shelves.

Fiorelli speculates that the owner of the House of Sallust next door was also the proprietor of bakery eight as well. He also identifies the back room as a storeroom for baked bread, though offers no evidence to support this hypothesis. Mayeske also strongly associates the bakery with its neighbor, which she refers to as the "hotel of A. Cossius Libanus." Currently no access exists between the bakery and the entity next door, whatever its name, nor does a door between the two appear on any of the early plans or in the descriptions of Fiorelli and his contemporaries. Mayeske, on the other hand, reports the presence of a doorway in the room southeast of the mill-room. Hobson suggests that the table supports next to the oven might actually be a latrine.

Nicollini 1854, 79; Helbig 1868, n. 51; Breton 1869, 273-4; Fiorelli 1875, 83;Fulvio 1879, 266; Dyer 1891, 330-339; Moritz 1958, pl. 12; Della Corte 1965, 38-40; Mayeske 1973, 93-4; Zanker 1995, 166; Hobson 2009, 185. 


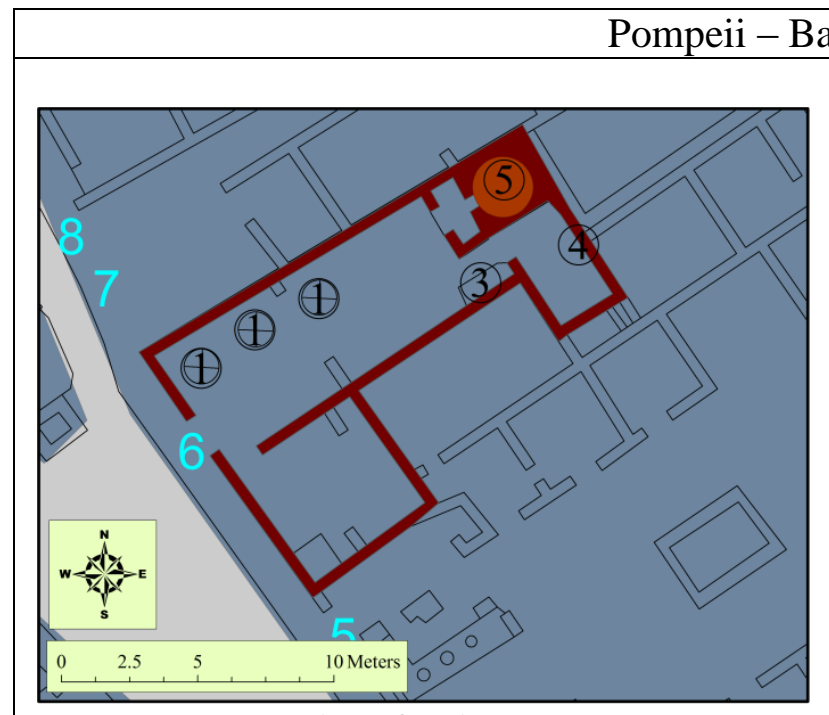

Plan of Bakery 8

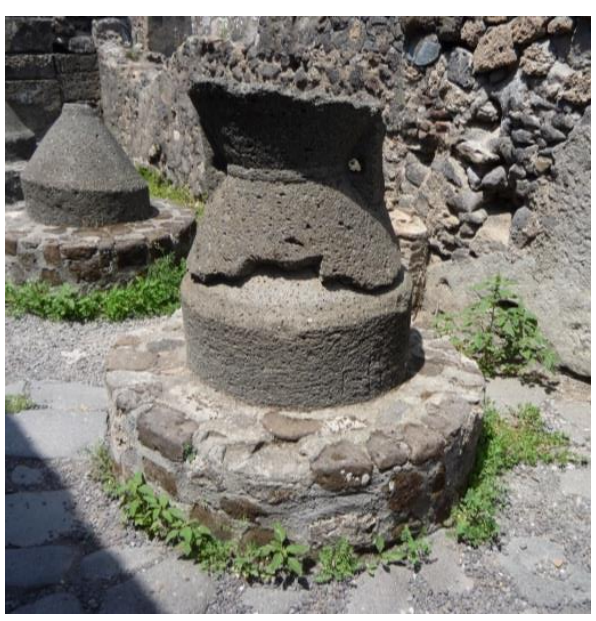

(1) Millstones

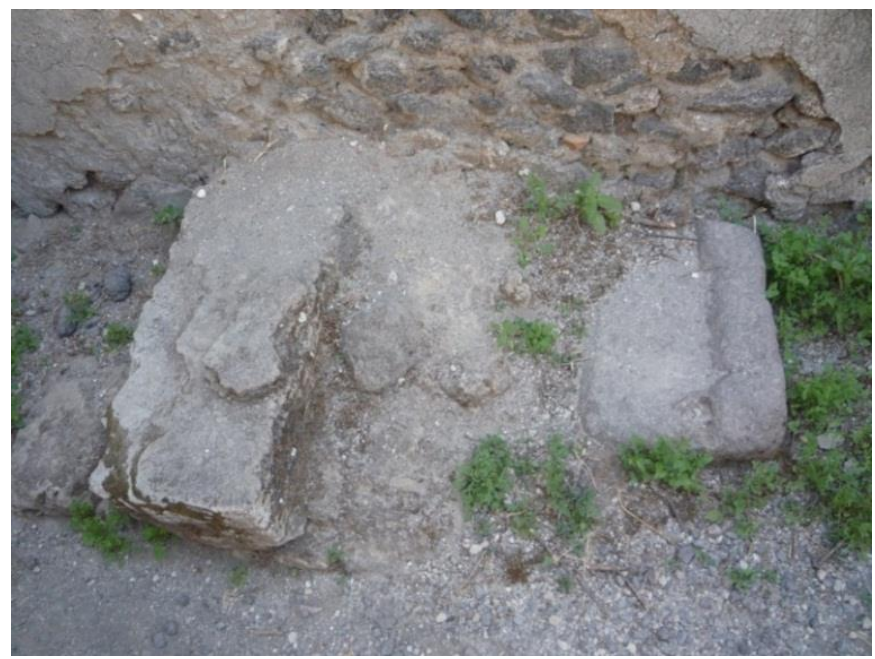

(3) Table Supports south of Oven

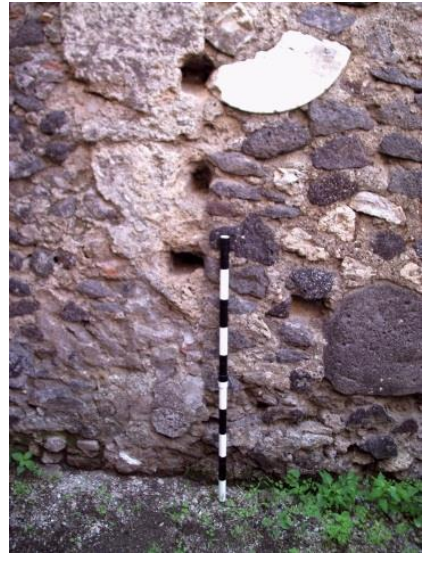

(4) Postholes for shelves in room behind oven

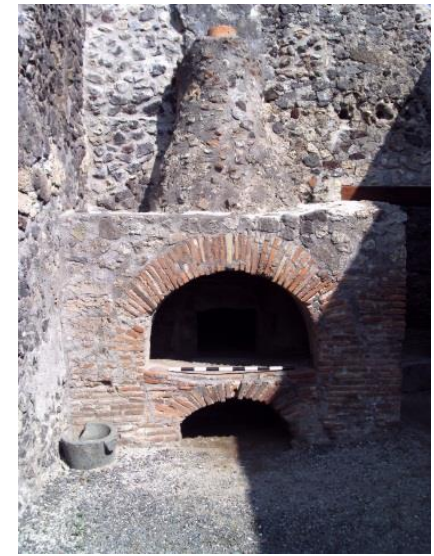

(5) Oven 
Bakery 9 - VI.3.3/27-28

Like bakery six, bakery nine consists of a remodeled atrium-style house. The bakery has three entrances: the main one opening onto via Consulare and two entrances facing vicolo di Modesto. The fauces, atrium, and cubicula surround the central impluvium. , The front room has four masonry pillars that were inserted at the corners of the impluvium. Just south of the fauces, upon entering the house, there is a staircase leading to a second story. The rear half of the house was converted into a bakery. The bakery and the atrium are linked through the tablinum.

The main room of the bakery has direct access to vicolo di Modesto through entrance 27. It also contains four millstones and the oven faces onto it. The oven has a diameter of $2.6 \mathrm{~m}$. North of the large mill-room is a long rectangular room with a long trough and a narrow door to the vicolo. West of the trough-room is a small space with three stepped vats, decreasing in height clockwise around the room. South of mill-room are the oven and another rectangular room, linked by a chute. This room contains postholes for shelves and early maps show supports for a table.

Mayeske speculates that the area of the bakery may have formerly served as the bakery's garden. Breton says that amphorae filled with grain or flour were found in this bakery, as well as carbonized bread. Mazois, who was actually at the excavation of the bakery, only records the amphorae. Flohr argues that the doorway connecting the tablinum and the bakery could be closed off with a door that no longer exists.

Nicollini 1854 ii, 26; Helbig 1868, n. 85; Breton 1869, 205-8; Fiorelli 1875, 92;Fulvio 1879, 286; Dyer 1891, 354; Schefold 1957, 96; Mayeske 1973, 94-7; Zanker 1995, 166; Flohr 2007, 137; Monteix 2009, 330. 

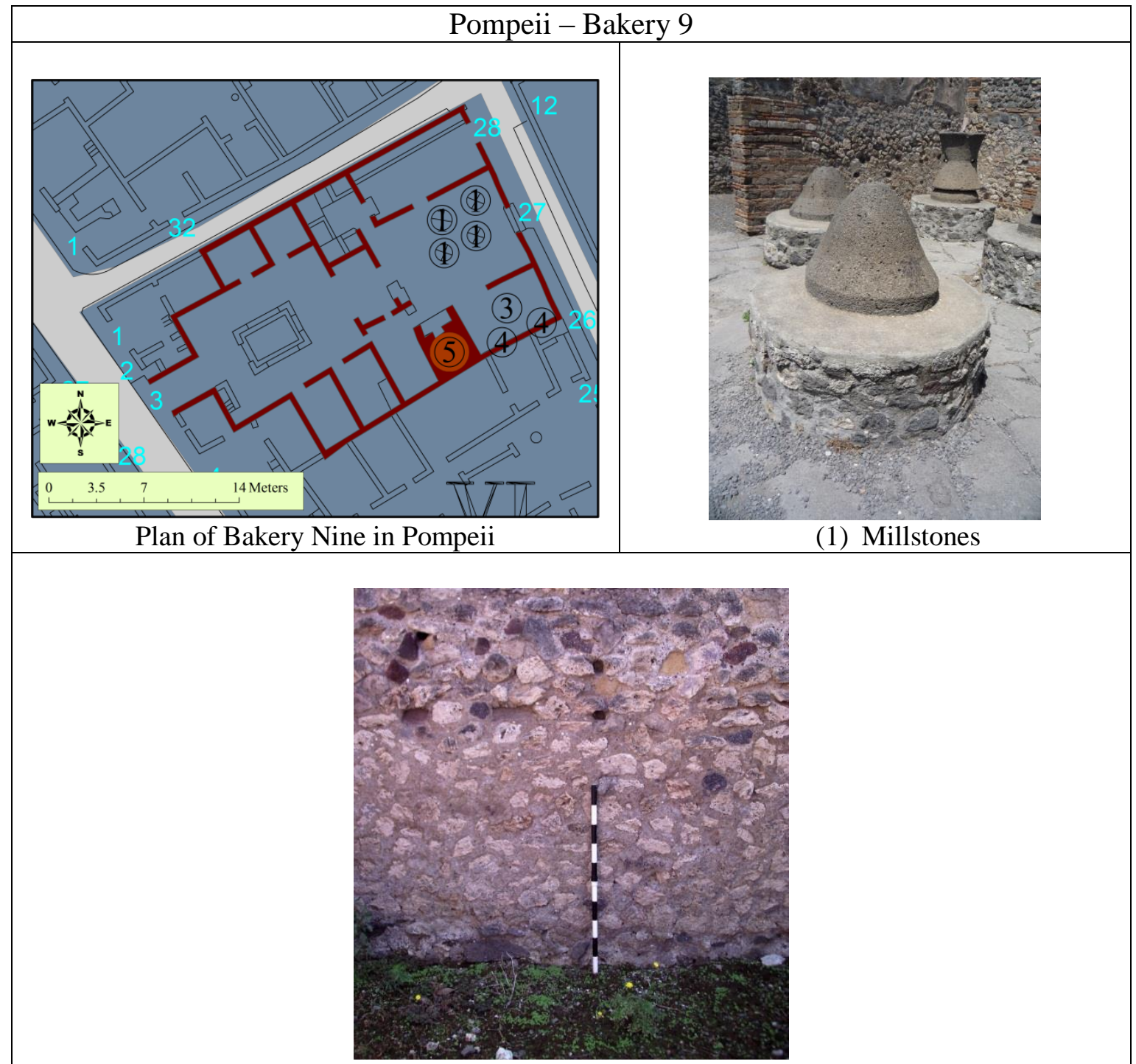

(4) Postholes for Shelves

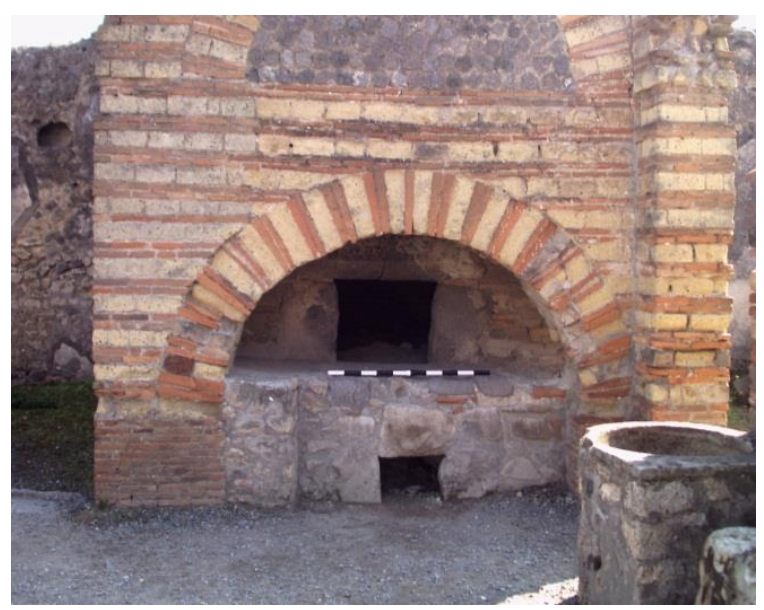

(5) Oven 


\section{Bakery 10 - VI.5.15}

Bakery ten is one of the more peculiar in Pompeii. It is divided into two spaces, connected by a long narrow hallway. The front space consists of a large room with paving stones surrounding two spaces for two mills. Linked to the mill-room are two smaller spaces, one well decorated and the other undecorated. The long corridor leads to a series of spaces, with a latrine immediately on the left upon entering. The next space is delineated by a low wall and a water-basin. Beyond these two spaces to the North, there is an L-shaped space with a kneading machine in front of an oven. Unlike most ovens in Pompeii, the one in bakery ten is of fairly unremarkable construction. The dome is not insulated and the praefurnium (oven-front) lacks a chute. The narrow shape of bakery likely prevented the inclusion of room to either side of the oven, which is $2 \mathrm{~m}$ in diameter. West of the kneading machine is a room, which Fiorelli identifies as the panificio or bread-making room. It has post holes for shelves and early plans show supports for a table. The so-called panificio has two holes in the south wall, which open into the room to the south, cordoned off by the low wall.

Fiorelli identifies the decorated room at the front of the bakery as a shop, which seems probable. He suggests that the shop and the bakery may have had separate proprietors, but Fiorelli misinterprets the paving stones in the mill-room as an extension of the street. His misinterpretation suggests that the two mill fragments currently in the room were placed there sometime after the bakery's excavation, a fact supported by the absence of millstones in the room when Mayeske visited the site in 1971.

Nicollini 1854 ii, 28; Fiorelli 1875, 100;NSc 1876, 27; Mayeske 1973, 97-8. 


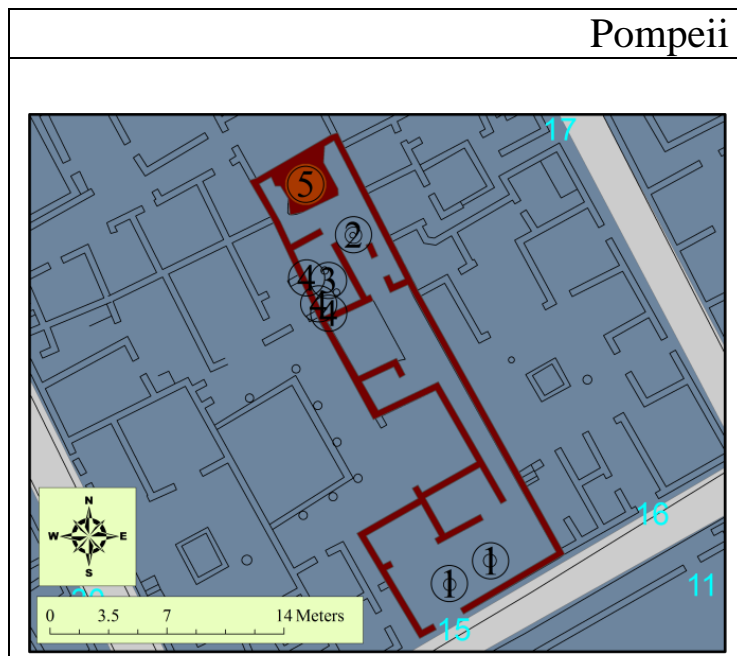

Plan of Bakery Ten

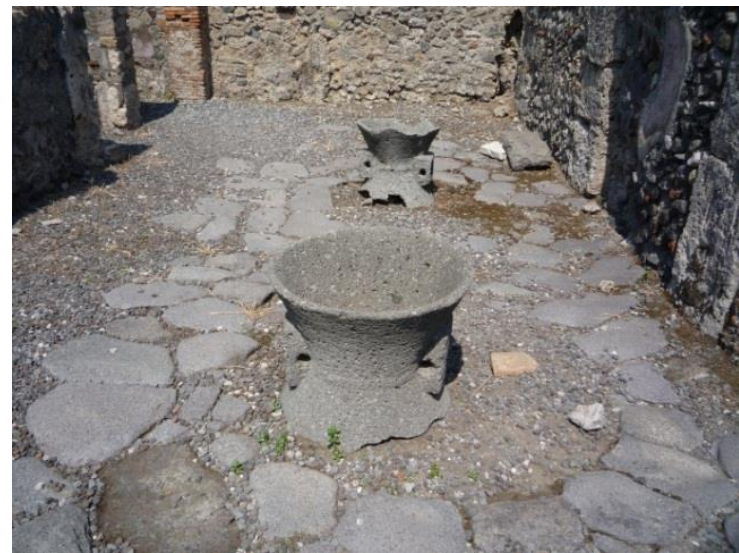

(1) Millstones

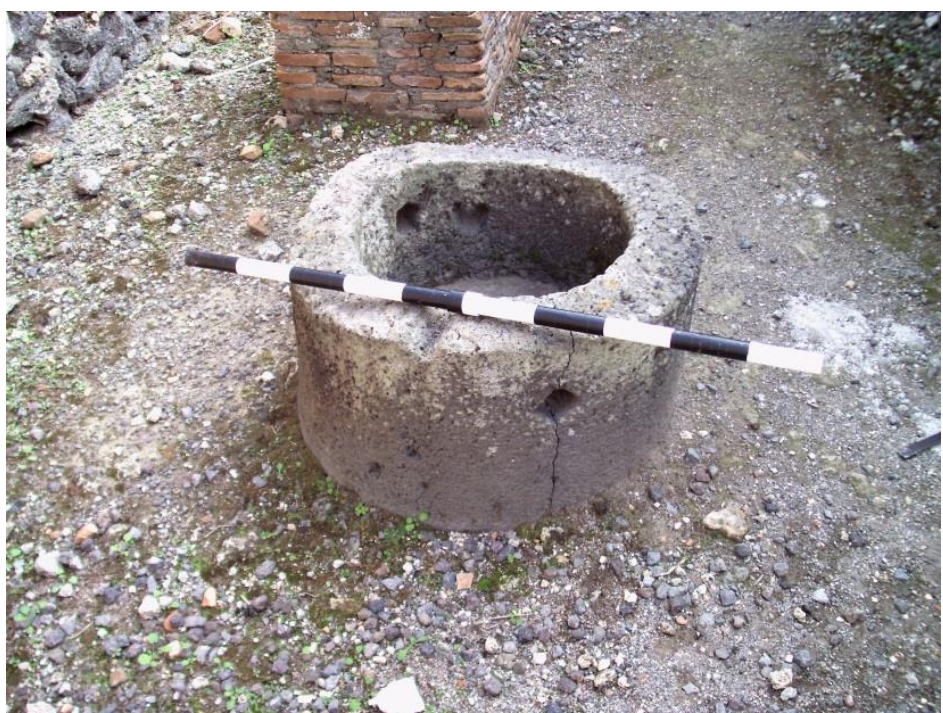

(2) Kneading Machine

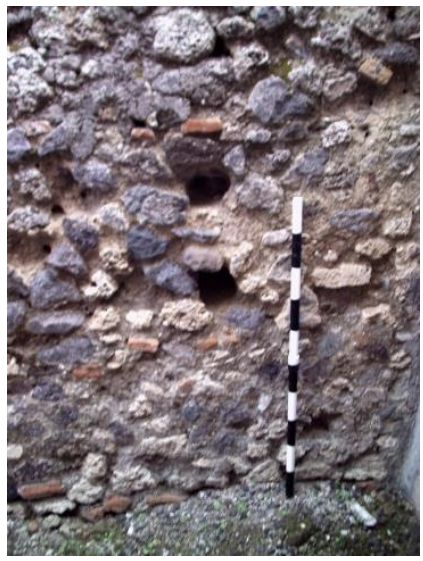

(4) Postholes for Shelves

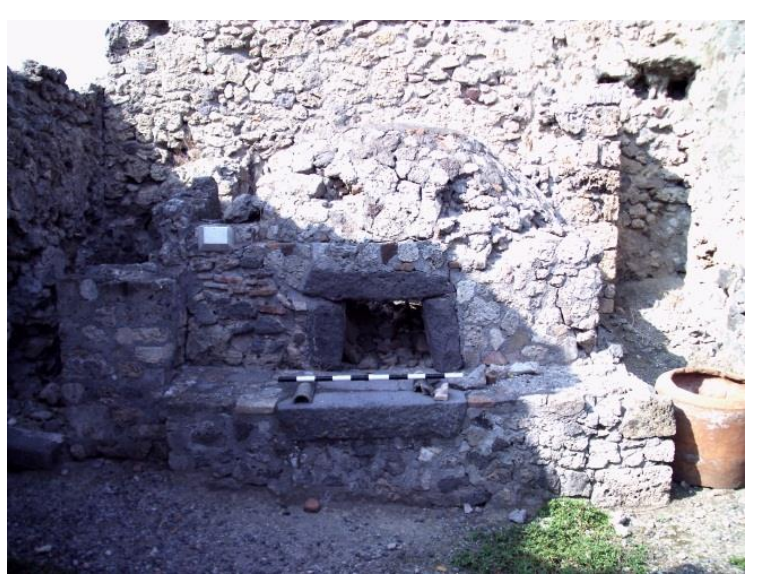

(5) Oven 


\section{Bakery 11 - VI.6.4-5}

Bakery 11 has no millstones and although Fiorelli notes an oven, it no longer remains. Outside the bakery is a political ad for Gaius Iulius Polybius (CIL IV 146). There are two entrances into bakery 11 , both lead to the same room, which contains a staircase to an upper floor. A short corridor leads to a back area; the oven appears to have been located in the room to the west. The early plans and the size of the room (ca. $2.35 \mathrm{~m}$ by $2.2 \mathrm{~m}$ ) suggest an oven diameter of 1.7 and $1.9 \mathrm{~m}$.

On the $14^{\text {th }}$ and $15^{\text {th }}$ of September 1943 three bombs fell on the area of the socalled Casa di Pansa. One of the bombs landed in the eastern part of the atrium, destroying also the bakery described by Fiorelli. What exists is entirely reconstructed, probably before 1971 when Mayeske first visited because her description matches the current state of the space. Mayeske provides little description about the bakery at VI.6.4. She found no evidence for an oven or millstones. Warsher calls the bakery that of a pistor duclarius, as was typical for $19^{\text {th }}$ century scholars when interpreting the bakeries in Pompeii without millstones.

$P A H$ III, 53; Fiorelli 1875, 100; Nicollini 1854 ii, 28; NSc 1876, 27; Mayeske 1973, 98; Garcia y Garcia 2006, 75. 


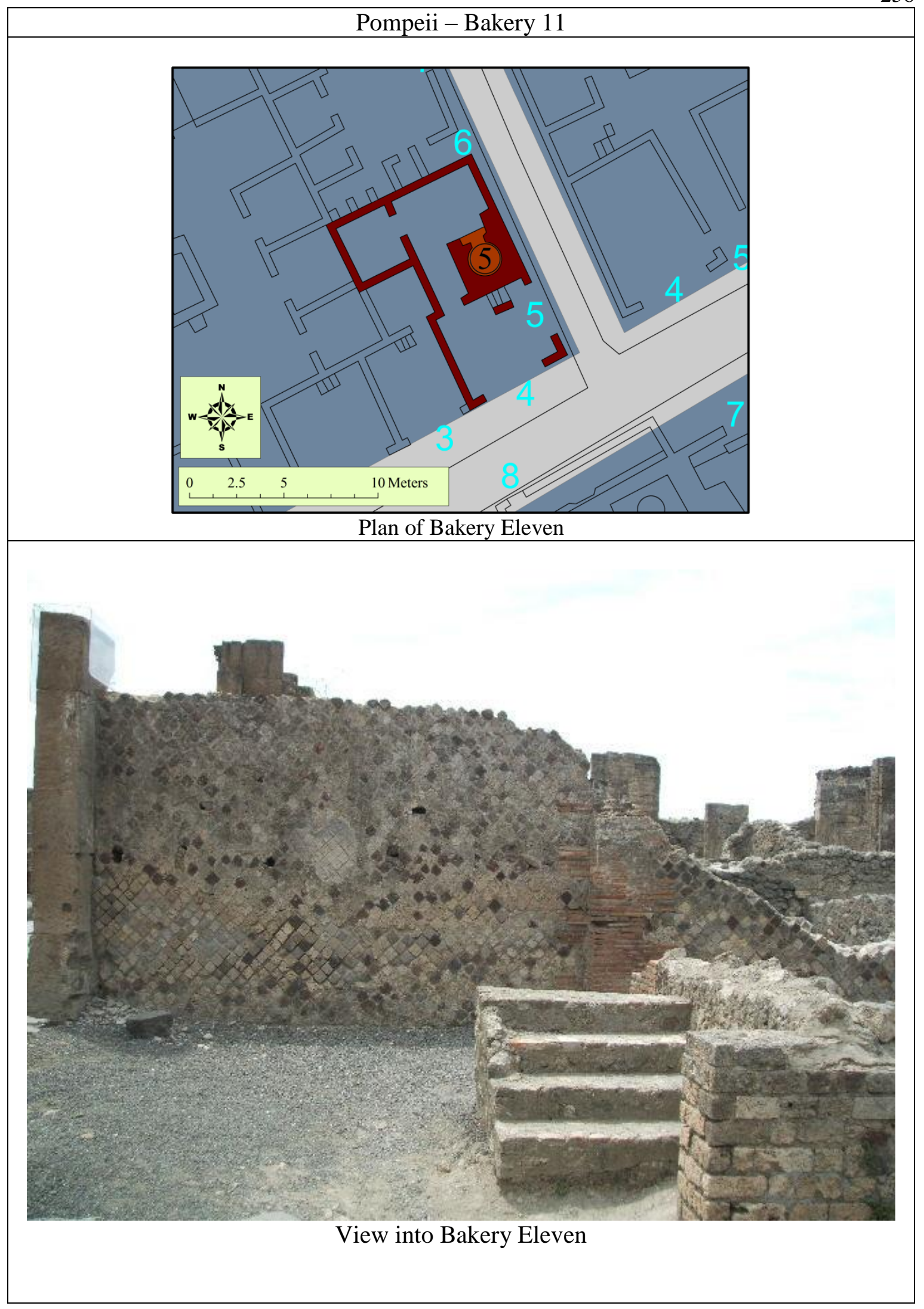




\section{Bakery 12 - VI.6.17,20-21}

Early in the excavation history of Pompeii, bakery 12 was called the Panificio dei Cristiani, the Bakery of the Christians, due to a now vanished depiction of a serpent next to a cross-shaped symbol in the mill-room. The bakery shares walls with the so-called House of Pansa, but does not communicate with it. Entrances 20 and 21 provide access to a front room with shelves, which connects to the back spaces of the bakery though a small room at its northeastern corner. Entrances 18 and 19 provide no access to the bakery; they were stairwells directly linked to the second story. Entrance 17 opens onto a room that links to both the back bakery and a room to the East. The back area of the bakery is dominated by a single large room with three millstones and the oven (diameter of $2.2 \mathrm{~m}$ ). The mill-room communicates with another room to the east which formerly contained a kneading machine, which Mayeske saw in her description of the bakery, but which is no longer present. Also present are supports for a table and a chute linking the room to the front of the oven.

An inscription was found on the exterior of the insula on the southwest corner, near bakery twelve. Della Corte says that it was painted on one of the pilasters in the very corner of the insula. The inscription records the properties on this block available for rent by Gnaeus Alleis Nigidius Maius (CIL IV 138). Robinson interprets this as evidence of a longstanding financial relationship between the patrons of the House of Pansa and their clients to whom they rented workshops.

Mazois1824, 82-7; РAH I, 170; Fiorelli 1875, 104-5; Breton 1869, 247-249; Della Corte 1965, 113; Mayeske 1973, 99-102; Pirson 1997, 165-82; Flohr 2007, 131 fig. 1. 


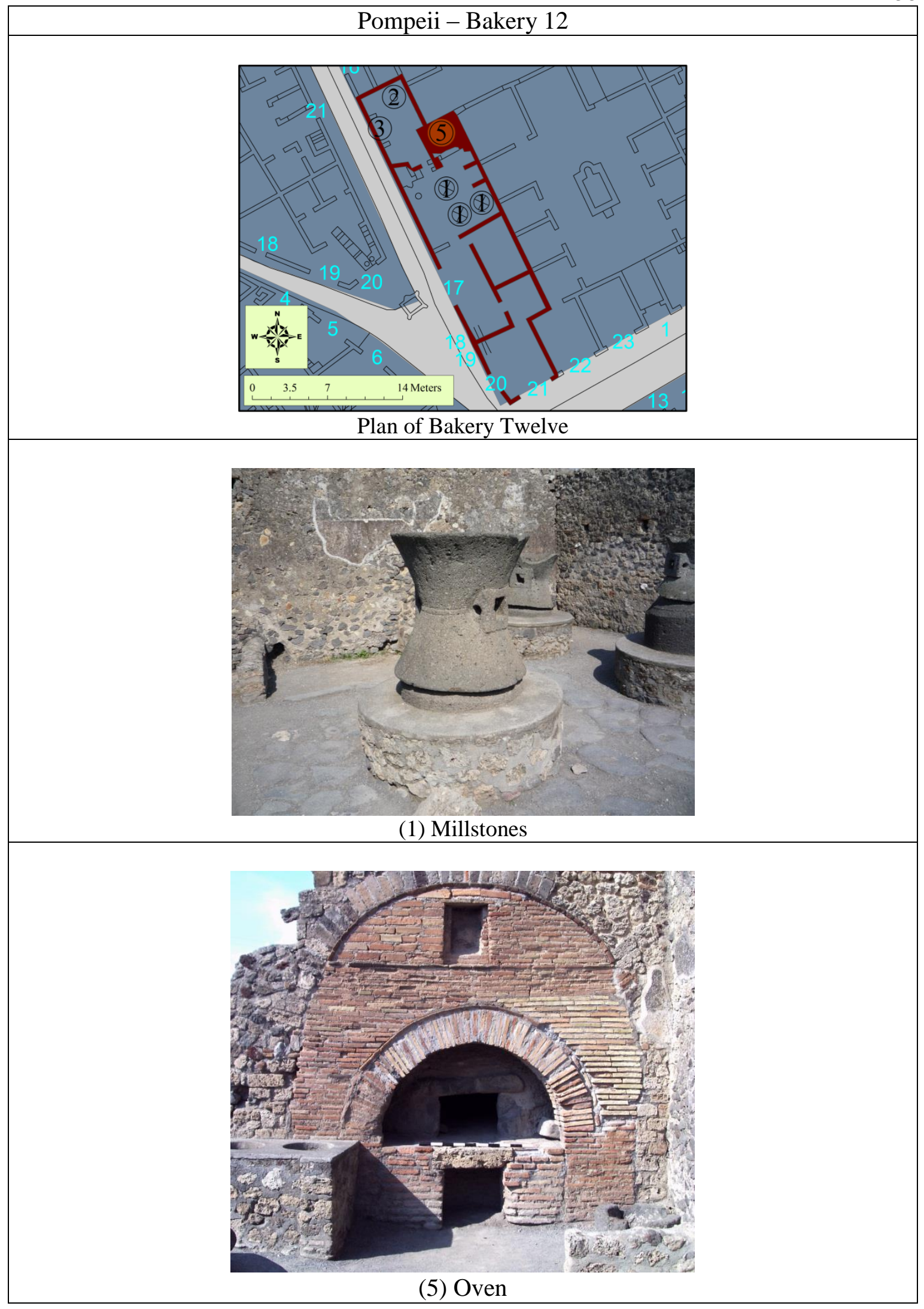


Bakery 13 - VI.11.9

The so-called Casa del Labirinto contains a bakery in its northwestern corner. Unlike bakeries associated with the Casa di Pansa, bakery thirteen is located inside the house. The bakery is accessed through the long corridor from the western atrium. Just south of the mill-room - and accessed through it - is a small well decorated private bath. The main room contains three millstones and three ceramic basins. Strocka postulates the existence of a fourth millstone based on the paving stones. The oven ( $2.3 \mathrm{~m}$ in diameter) opens directly onto the mill-room, but links to the spaces to its east and west through chutes in its praefurnium. In the space west of the oven there is a kneading machine and postholes for shelves. Breton says there was a table in the room west of the oven, though nothing of it remains. West of the oven there is a short hallway that leads to a back room and a narrow space behind the oven.

The bakery in the Casa del Labirinto has always been eclipsed by the house's more attractive attributes. Indeed, Fiorelli fails to mention it entirely and bakery 13 obtained the shortest of all treatments in Mayeske's work. She does suggest that the back room north east of the oven may have served as storage or stables, based on the long trough still evident in that space. Robinson and Wallace-Hadrill cite it as evidence of elite participation in commercial activity.

Fiorelli 1875, 147-8; Breton 1869, 358; Della Corte 1965, 43; Mayeske 1973, 103-4; Strocka 1991, Wallace-Hadrill 1994, 113-5. 


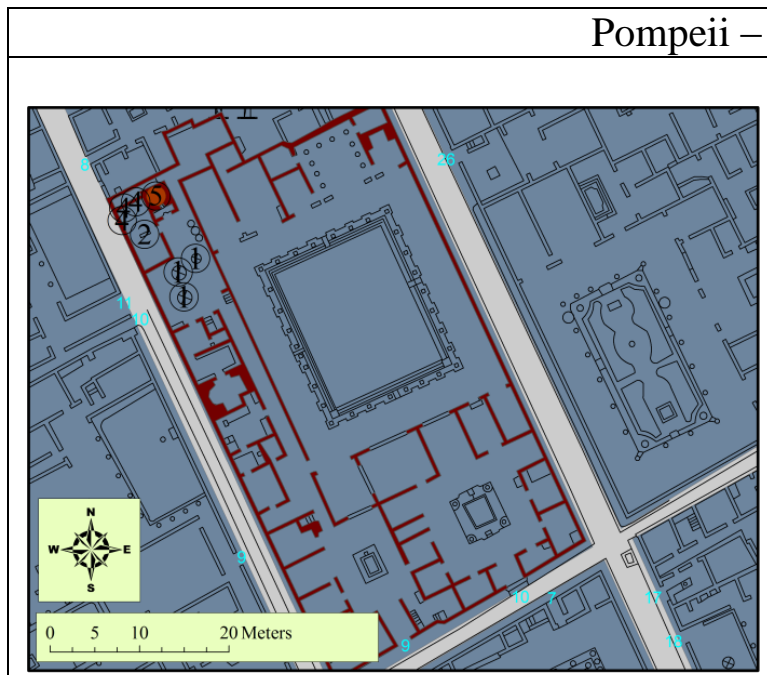

Plan of Bakery Thirteen (Casa del Labirinto)

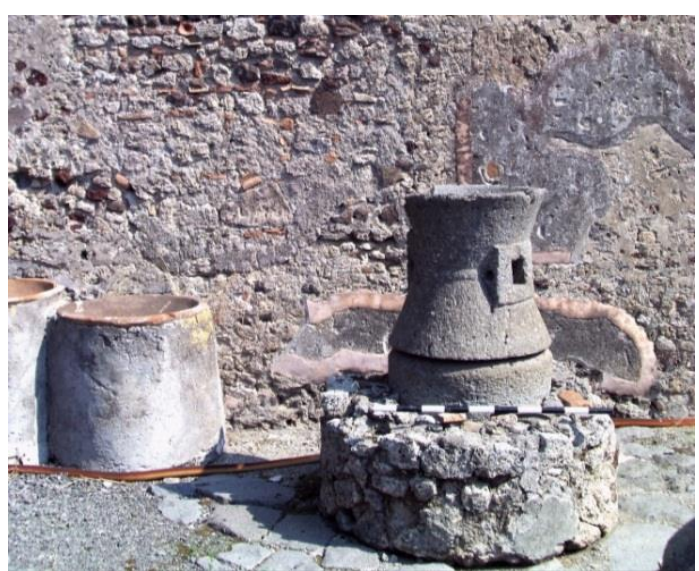

(1) Millstones from the Casa del Labirinto

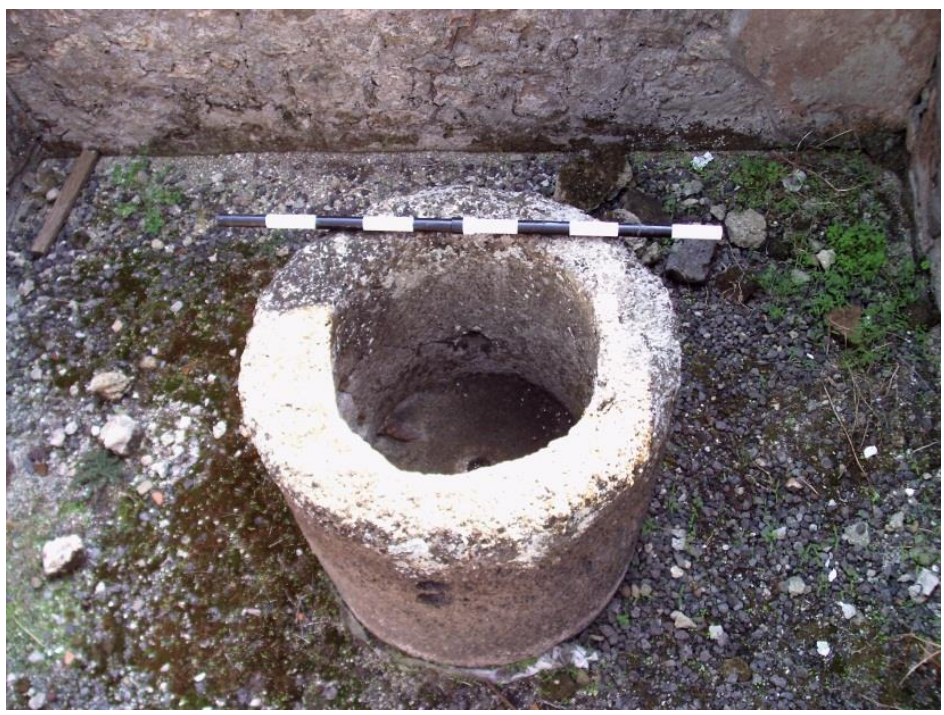

(2) Kneading Machine from the Casa del Laberinto

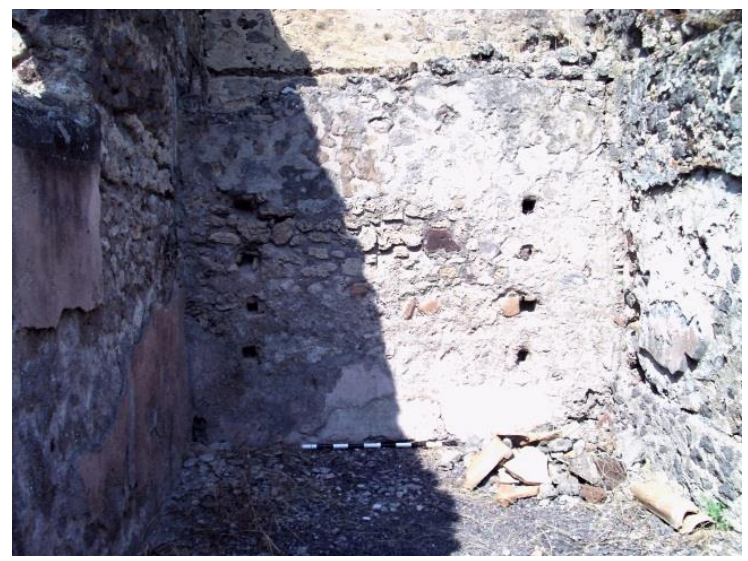

(4) Postholes from the Casa del Laberinto

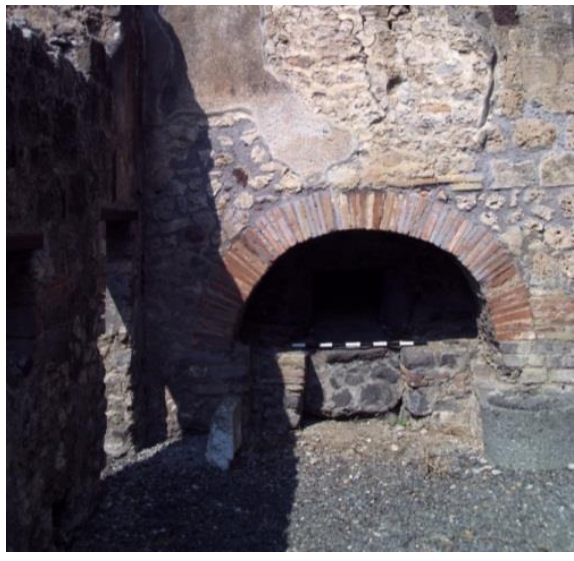

(5) Oven from the Casa del Laberinto 
Bakery 14 - VI.14.28/30-33

Bakery 14 is integrated into the west side of the so-called Casa del Lacoonte, a well decorated home whose fauces opens onto via del Vesuvio at entrance 30.The house has a large stable in the northeast corner. Both the stables and the fauces lead to the atrium, which provides access to the tablinum. South of the tablinum, Jashemski found evidence of a garden. The tablinum links the house with the bakery behind it.

Entrance 33, the door to the bakery, links the mill-room with the vicolo di Mercurio outside. Three millstones are in this room as well as paving stones lining the floor. Mau notes that one of the millstones was inscribed with $\mathrm{C} \Lambda \mathrm{A}$. This room has access to a series of rooms to the west and several rooms to the east that allow for access to the Casa del Lacoonte. South of the mill-room is another chamber that contains the oven (diameter of $2.3 \mathrm{~m}$ ). West of the oven is a narrow space with a vaulted ceiling. East of the oven, and linked to it by a chute, is a small room with supports for a table and a door that provides access to a back room. The west wall in this room retains a small bit of its original decoration. The back room has a kneading machine, supports for a larger table and postholes in the north, south, and west walls. The post holes are carved into wall plaster decorated in $4^{\text {th }}$ style, suggesting that the interior portion of the house was converted to suite commercial activity sometime during the final twenty years before the eruption of Vesuvius.

Mayeske notes that there are two large spaces to either side of the main fauces of the Casa del Lacoonte. The northern entrance she identifies as the stables for the donkeys due to a long counter. The entrance south of the fauces is announced by a ceramic sign depicting a fritillus (gambling cup) flanked by two pairs of phalli. At the threshold of 
entrance 28 was a graffito stating ALIARI ROG(ant), the formulaic beginning to the political ads of Pompeii. Aliari may refer to 'dealers in garlic', as Mau suggests, or to aleari, 'dicemen', as Della Corte suggests. The sign above the shop would support the latter hypothesis.

NSc 1876, 105-7; Mau 1899, 383-4; Della Corte 1965, 90-94; Mayeske 1973, 104-6. Jashemski 1993, 150. 


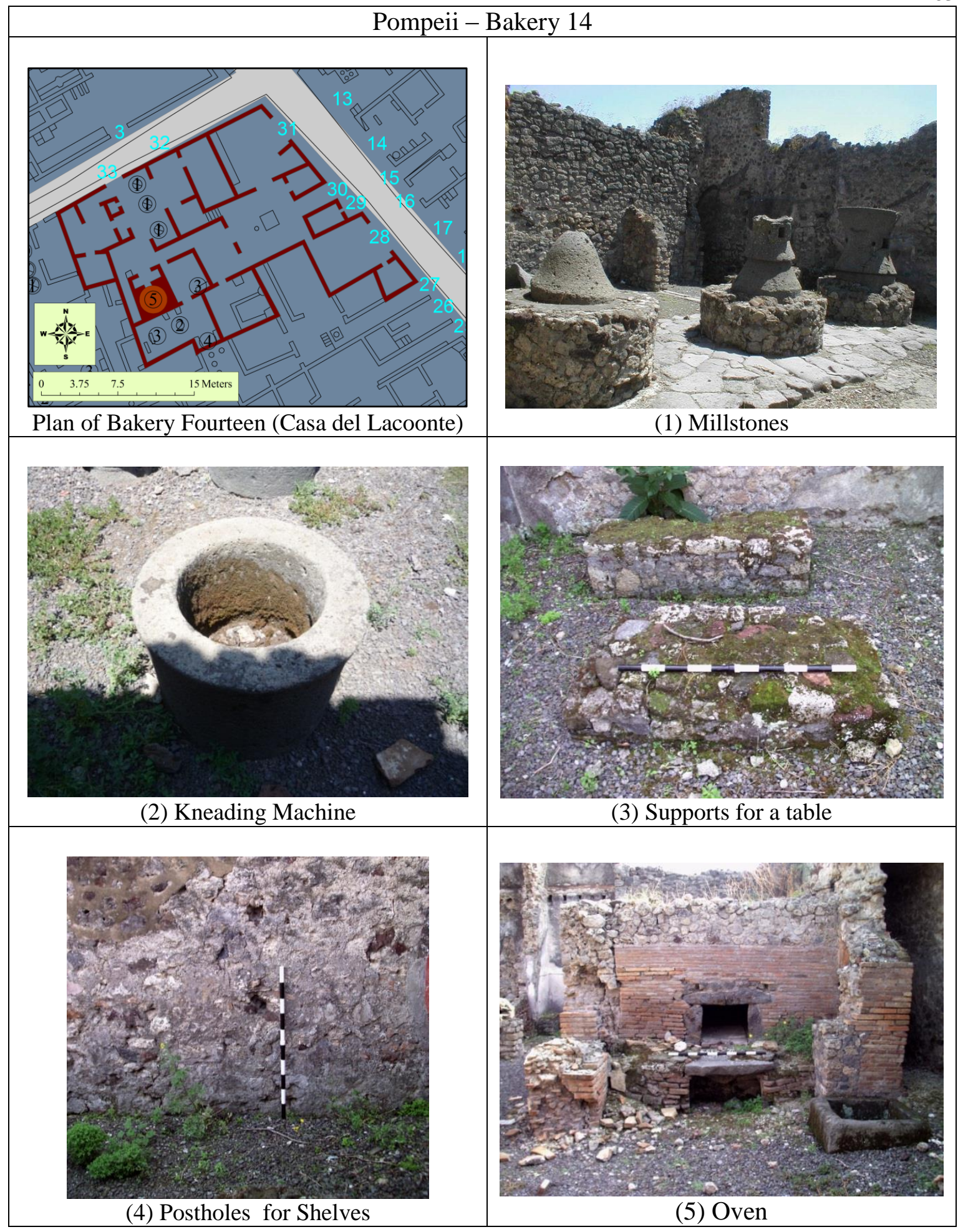




\section{Bakery 15 - VI.14.34}

Bakery fifteen resides on the west side of bakery fourteen. It has two entrances: number 34 and an unmarked door between entrances 33 and 34. The main entrance leads through a fauces to an atrium of fairly standard design. The east half of the residence comprises the bakery. The unmarked entrance leads to a small room, through which one can access the mill-room. The large mill-room has a floor lined with paving stones and it contains the bases for four millstones, which were absent even in 1875 Fiorelli's description of the bakery. The oven (diameter of $2.3 \mathrm{~m}$ ) resides in a space south of the millstone. In front of the oven there is a half-buried basin made of basalt, potentially a reused millstone or kneading machine. The basin is inscribed with the name $\mathrm{C}$. PETRONI SATVRNINI (CIL X 8055). The praefurnium of the oven is linked to the room south of the oven by a chute. The room with a chute contains a very weather kneading machine and supports for a table. At the west end of the room containing the kneading machine is a long narrow space extending westward.

Fiorelli interprets the lack of millstones in the bakery as evidence that the bakery was not milling in 79 AD. The bakery was excavated between 1834 and 1974; if the millroom was excavated early in this period then it may be possible that the stones were present but were robbed out after excavation. Mayeske suggests that the intermediary room between the mills and the vicolo di Mercurio could have served as the stables, though there is no evidence to support this hypothesis other than its proximity to the millroom.

NSc 1877, 105; Boyce 1937, 53; Della Corte 1965, 90-91; Mayeske 1973, 106-7. 


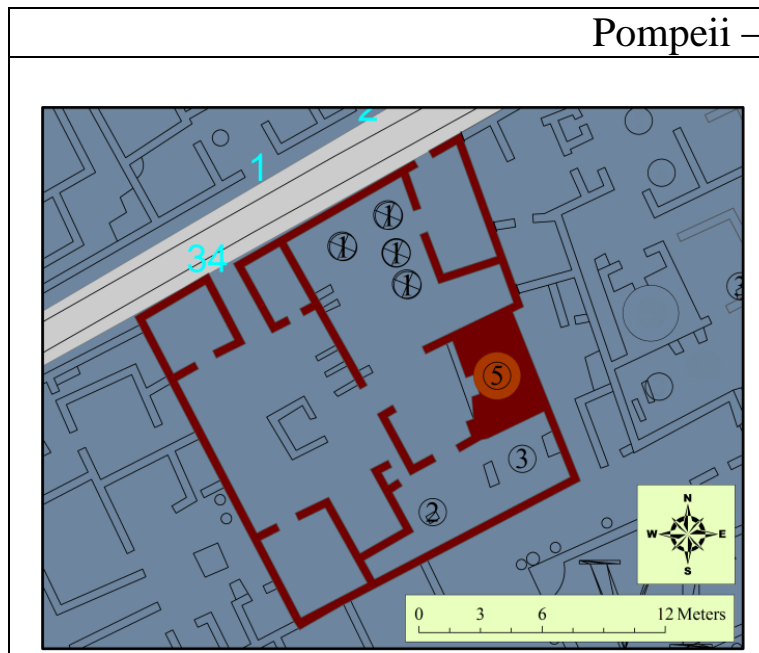

Plan of Bakery Fifteen

\section{Bakery 15}

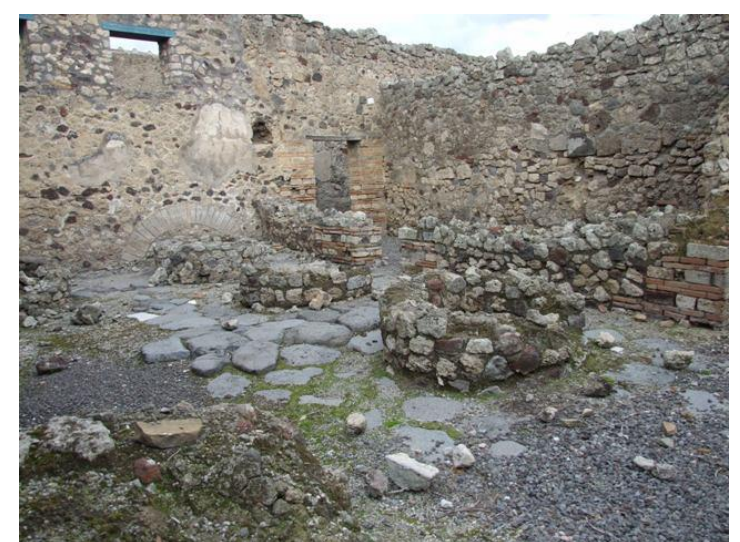

(1) Millstones Basins

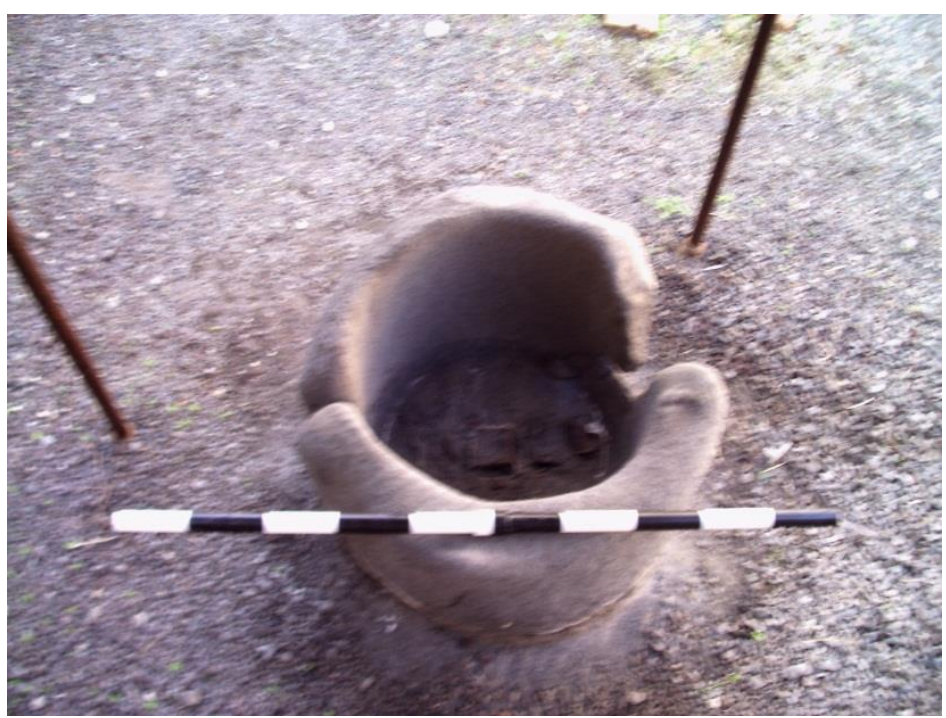

(2) Kneading Machine

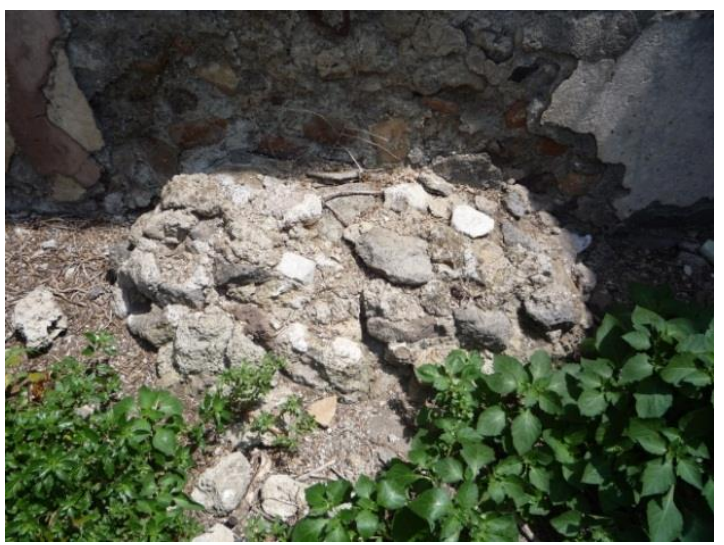

(3) Table Support

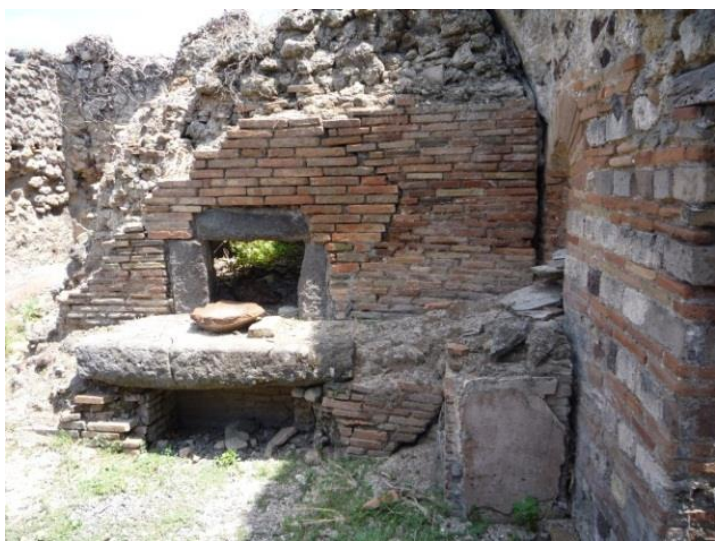

(5) Oven 
Bakery 16 - VII.1.36-37

Excavated in 1866, the so-called Pistrinum of Modestus consists of an atriumstyle house adapted into a bakery. There are two entrances: one through the fauces (n. 36) and the other through a space in the northwest corner of the bakery. Short walls were built around the impluvium to create a water-basin. Southwest of the impluvium is a heavily damaged kneading machine. The attributes associated with bread production are situated in the rear portion of the remodeled house in the areas commonly referred to as the tablinum, triclinia, or oeci. The room in the southeast corner of the bakery contains one complete mill, two metae, and a space for another mill evident in the paving stones aligned on the floor. The intact millstone, along with a catillus on the floor, is unlike the other elongated, hourglass shaped millstones in the city. They are similar in diameter, but are squatter. Millstones of this sort are common in the depiction of milling during the first century $\mathrm{BC}$ and first half of the first century AD. The room in the southwest corner of the bakery has post holes for shelves and a chute in the north wall leading to the front of the oven, in which excavators found 81 loaves of bread. The oven (diameter of $2.55 \mathrm{~m}$ ) is located in what might be called the west ala of the house. Just north of the oven is a staircase that leads above the oven to a second story.

Fiorelli suggests that the space accessed through entrance 27 may be a shop. He further argues that room in the northeastern corner of bakery may have served as the stables, though he cites no evidence to support this conclusion. The bakery became associated with Modestus by Fiorelli, who noted a dipinto outside the bakery MODESTVM AED. Della Corte, on the other hand, notes that the subject of the political 
programmata was LVCIVS, indicating to him that the proprietor would have been named Lucius, not Modestus.

Fiorelli 1875, 171-2; NSc 1877, 105; Boyce 1937, 60; Schefold 1957, 166; Della Corte 1965, 190; Mayeske 1973, 107-10; Bakker 1999, 7. 


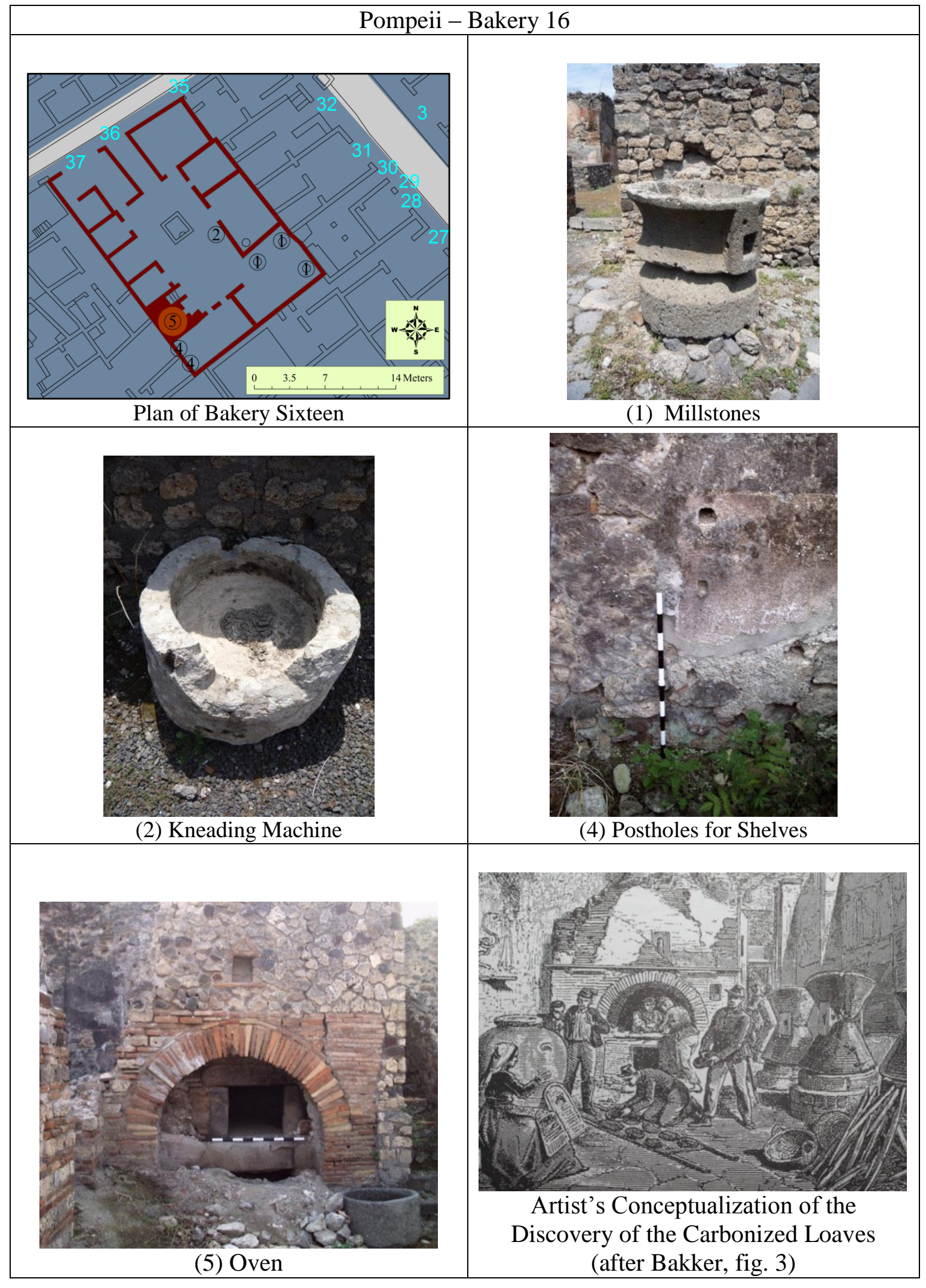




\section{Bakery 17 - VII.2.3\&6}

The so-called House of T Terentius Proculus contains a commercial bakery west of the peristyle in the southern half of the residence. The house is divided into two sections, a series of rooms surrounding the atrium to the North, which opens onto the via stabiana through entrance six. The southern section is dominated by a large peristyle accessed through entrance three. West of the peristyle is a large commercial bakery. A large room linked to the peristyle contains the millstones. Fiorelli records three millstones complete with metae and calilli, but only one with its original lead paneling on the base. He also describes a fourth base with only a meta and a fifth base with no millstones. An oven opens onto the mill-room. The oven (diameter of $2.6 \mathrm{~m}$ ) has a large aperture on its west side and a basin with a wellhead below the opening. Another basin resided just north of the entrance to the mill-room from the peristyle. The room east of the oven - and linked to it by a chute - also has doors connecting it to the mill-room and the peristyle. This room contains supports for a table, postholes for shelves, and two shallow basins now destroyed. South of the mill-room is a large square room.

The house was identified with P. Paqui Proculus by Fiorelli who noted this inscription (CIL IV 920) outside the entrance to the atrium (n. 6): PROCVLE FRONTONI TVO OFFICIVM COMMODA (Proculus, do your duty by your friend Fronto!). A number of Proculi are attested in the inscriptions of Pompeii and Fiorelli narrowed his list of candidates to those who had served as magistrates. He identifies the man from the famous painting of a couple found in the house as Proculus. The young togate man holds a scroll, from which Fiorelli inferred that Proculus must have once served as a magistrate. He then limits his search to the two Proculi that were serving as magistrates in the last 
years of Pompeii: Q. Postumius Proculus and P. Paquius Proculus . Fiorelli selected Paquius Proculus based on a fragmentary graffito found in the peristyle, which he read as PAQVIA (CIL IV 3145). He further associates Proculus with a bakery across the street at IX.3.10-12 based on another inscription: POPIDIVM AED PROCVLVS ROG (CIL IV 3651). Della Corte refutes Fiorelli's attribution, citing a different inscription, CVSPIVM PANSAM AED TERENTIVS NEO ROG (CIL IV 871). From this evidence, Della Corte asserts first that the owners of VII.2.3 were Terentii, second that the Proculus of the bakery at VII.2.3 was Terentius Proculus, and third that the man in the painting was the Terentius Neo from CIL IV 871. Another inscription outside

Two other political dipinti were found outside entrance three. Both urge for the election of C. Julius Polybius as duumvir. The first, C IVLIVS POLYBIVS IIVIR STVDIOSVS ET PISTOR, announces Polybius as a pistor (baker). The second, C IVLIVS POLYBIVS IIVIR O(ro) V(os) F(aciatis) MVLTVM PISTORES ROGANT, states that the bakers (pistores) were politically active.

Fiorelli argues that Proculus bought the house neighboring to the south, combining the two and using the new acquisition as an industrial area. The small rooms north of the peristyle are cordoned off by a low thin wall for reasons that remain unclear. Fiorelli also posits that one of the rooms south of the peristyle served as the stables. Mayeske corroborates this hypothesis, citing a large number of bones found in the room just east of the kitchen/latrin, south of entrance three.. Fiorelli suggests that the space south of the mill-room may have served as the horrea, grain magazine.

Fiorelli 1875, 183; Della Corte 1926, 145-154; Boyce 1937, 61; Schefold 1957, 168; Della Corte 1965, 157-160; Mayeske 1973, 110-113; Adam 1994, 663-4 


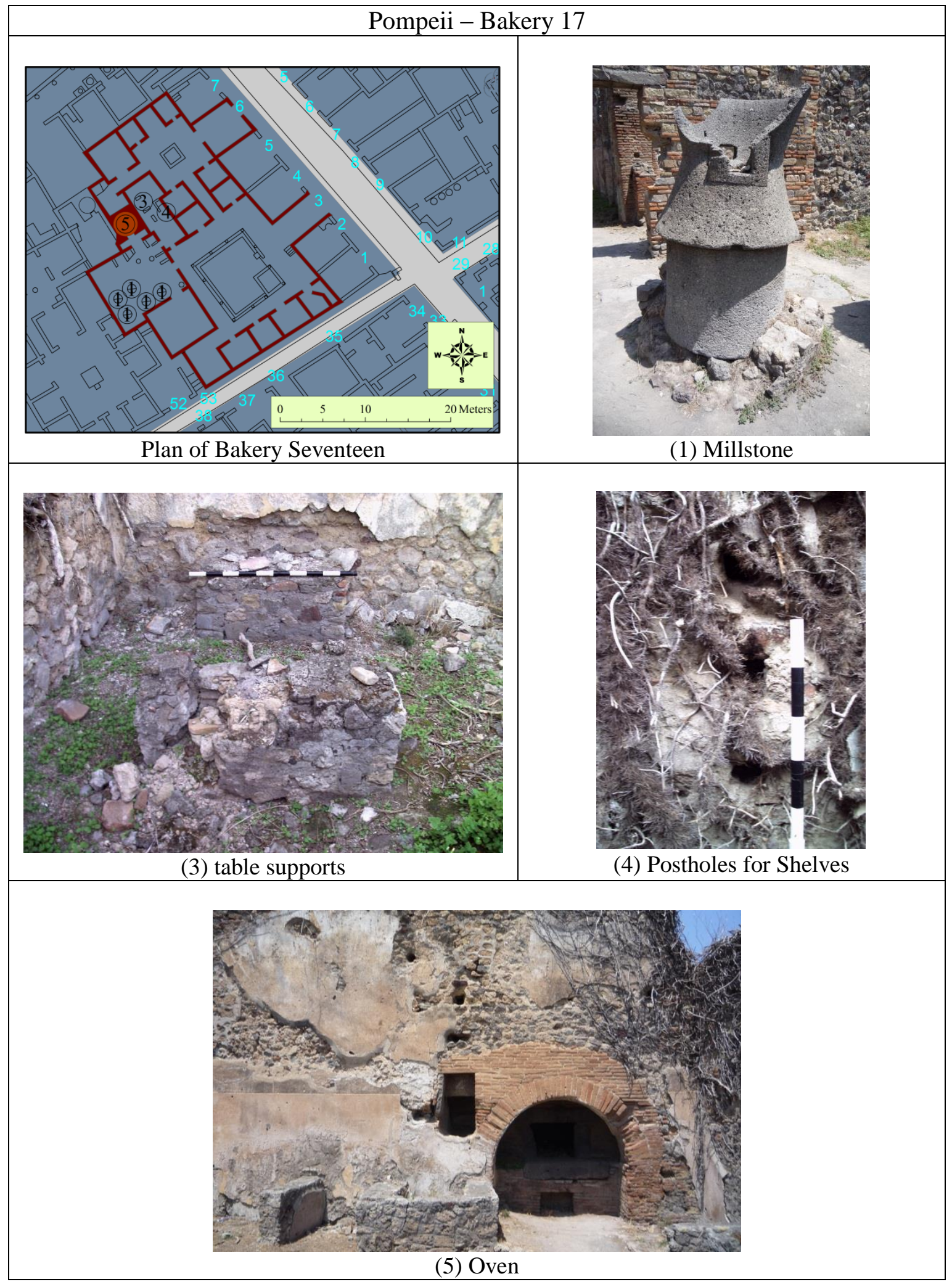




\section{Bakery 18 - VII.2.22}

Mayeske and Robinson both describe this bakery as linked to the so-called House of Popidius Priscus (VII.2.20) through a door at the back wall of the bakery. This door was walled off in antiquity and early photos of the bakery show elaborately decorated stucco covering it. Fiorelli also links the bakery with the house, but states that the door linking the two was found at the top of a paved staircase behind the latrine. The bakery may consist of a remodeled house, as suggested by an impluvium converted into a water basin and the elaborate decoration found at the back of the bakery.

The bakery's sole entrance, at least on the ground floor, is number 22, which opens onto the oven (diameter of $2.6 \mathrm{~m}$ ) and a line of four millstones both their metae and catilli. A fifth and much smaller meta and catillus were found behind the converted impluvium. South of the millstones is a series of supports for a long counter. At the back of the bakery is a small room, delineated by a series of piers, only one of which is extant. The east wall of this room was decorated with fourth style wall painting and a staircase leads upward through the north wall. North and below the staircase there is a latrine. There is a rectangular room containing a kneading machine north of the latrine. North of the oven, and communicating with the room containing a kneading machine, there is another rectangular room that links with the front of the oven through a chute. Mayeske and Fiorelli are in general agreement on the layout of the bakery. They interpret the two rectangular spaces north of the oven and converted atrium as storage spaces.

Fiorelli 1875, 183; Boyce 1937, 61; Schefold 1957, 168; Della Corte 1965, 150-1; Mayeske 1973, 114-15; Robinson 2005, 94; Flohr 2007, 135. 


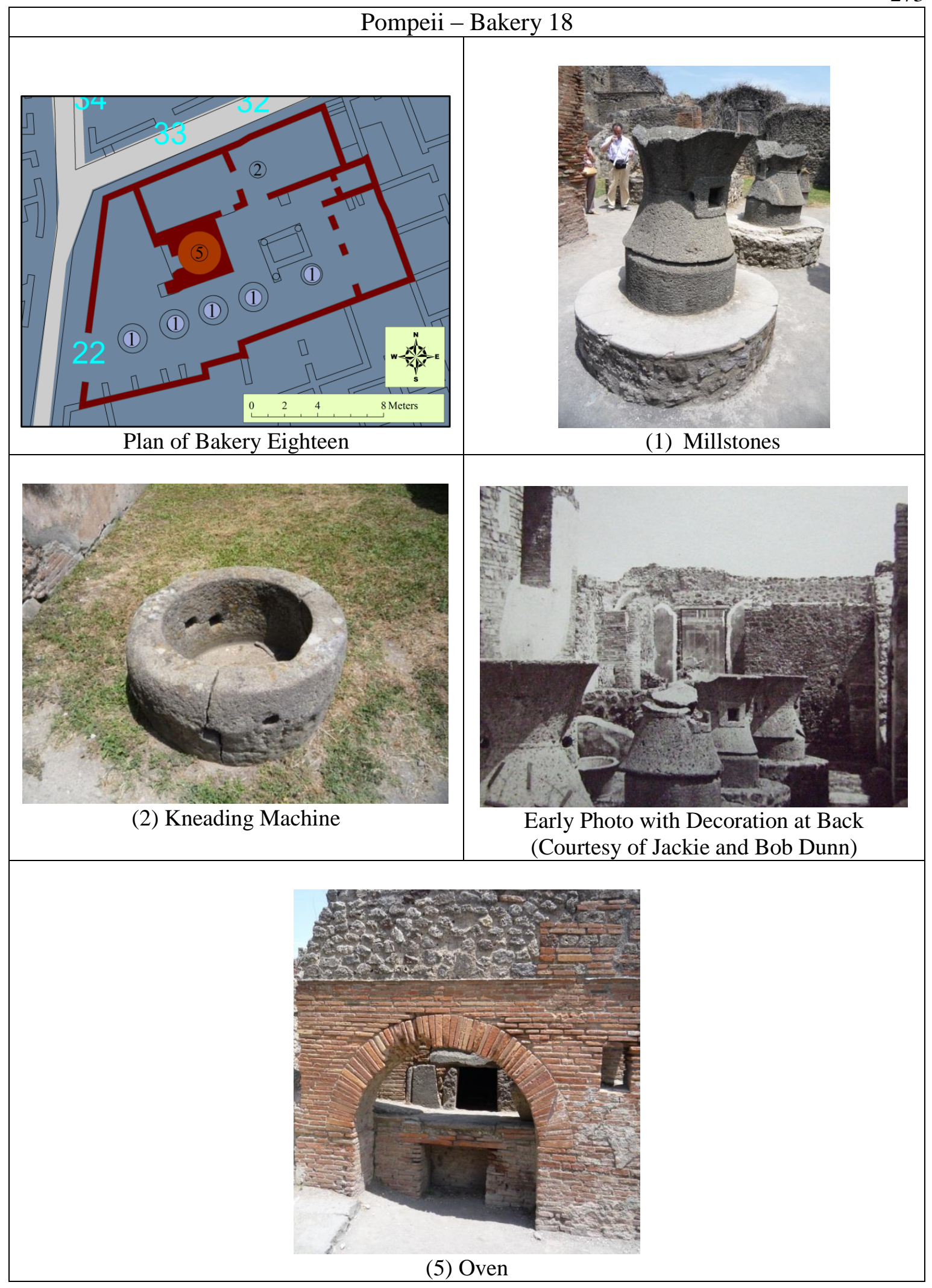




\section{Bakery 19 - VII.2.51}

The so-called House of the Suettii has in its northeastern corner a small oven. The house closely resembles the standard atrium-style house design: A fauces leads to an atrium, which is surrounded by a series of rooms often referred to as cubicula. A tablinum bridges the atrium and the peristyle to the north. The peristyle opens onto two rooms, traditionally called oeci or triclinia. Also accessible from the peristyle is a narrow passageway leading to a backspace, which includes a counter, an oven, and a small space with a recessed floor resembling a bath.

Fiorelli refers to the oven and counter as having a domestic function. Mayeske expresses doubt that the oven could serve in a domestic capacity, but acknowledges that the extent of any commercial activity is impossible to assess. She defines a bakery as anything with an oven, thus compelling her to associate the house with commercial bread production. Robinson includes the house in his study of social organization in Pompeian industries.

Fulvio 1879, 290; Fiorelli 1875, 199-200; Boyce 1937, 63; Della Corte 1965, 181; Mayeske 1973, 116-8; Robinson 2005. 


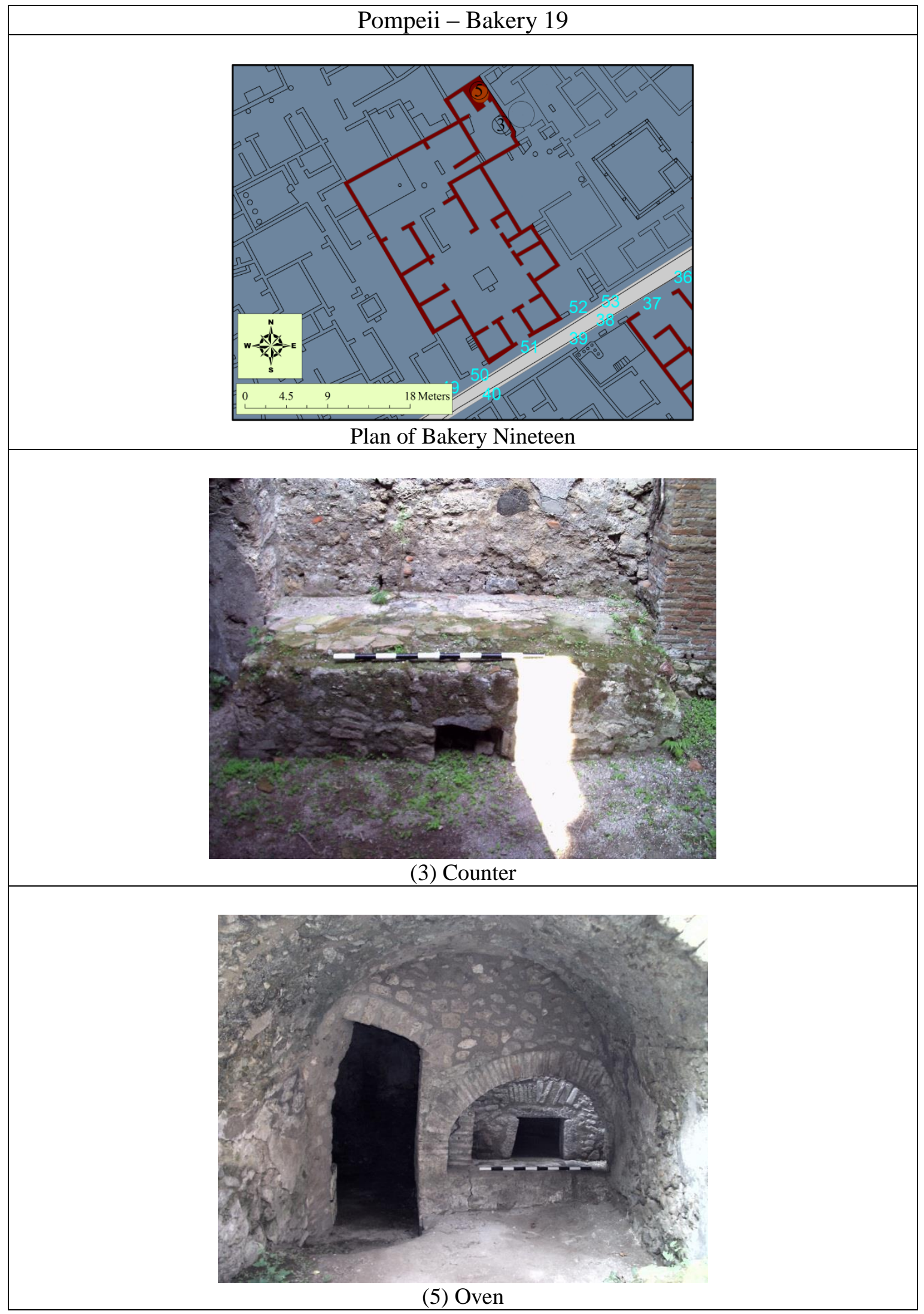




\section{Bakery 20 - VII.4.29}

The Casa dei Capitelli Figurati (VII.4.57) is a large house so-named for two column capitals decorated with figural relief found at the entrance of the fauces. The atrium-style house has a large peristyle garden, which has a passage in its south wall that leads to a back area of small rooms and utilitarian spaces. This back area has its own entrance at VII.4.29. Among the various spaces in the back area of the house is an oven (diameter of $0.75 \mathrm{~m}$ ). In his description of the oven, Fiorelli states that it was divided into two cavities: a lower combustion chamber and an upper space for cooking. He also records the discovery of a pastry mold, with three soldered feet. Breton reports the discovery of some type of small mills (pistrillae), perhaps a hand operated rotary mill which are not uncommon in Pompeii.

Mayeske identifies the back area of the Casa dei Capitelli as a bakery, but unlike in the case of the House of the Suettii, Fiorelli agrees. He classifies it as a workshop of a pistor dulcarius; it is unclear how the Casa dei Capitelli differs from the House of the Suettii for Fiorelli. The bipartite oven, which almost resembles a pottery kiln, is the only one of its kind in Pompeii. Mayeske observes that its design would allow simultaneous combustion and baking.

Fiorelli 1860, 300; Breton 1869, 275; Fiorelli 1875, 217; Fulvio 1879, 282; Mayeske 1973, 118-9. 


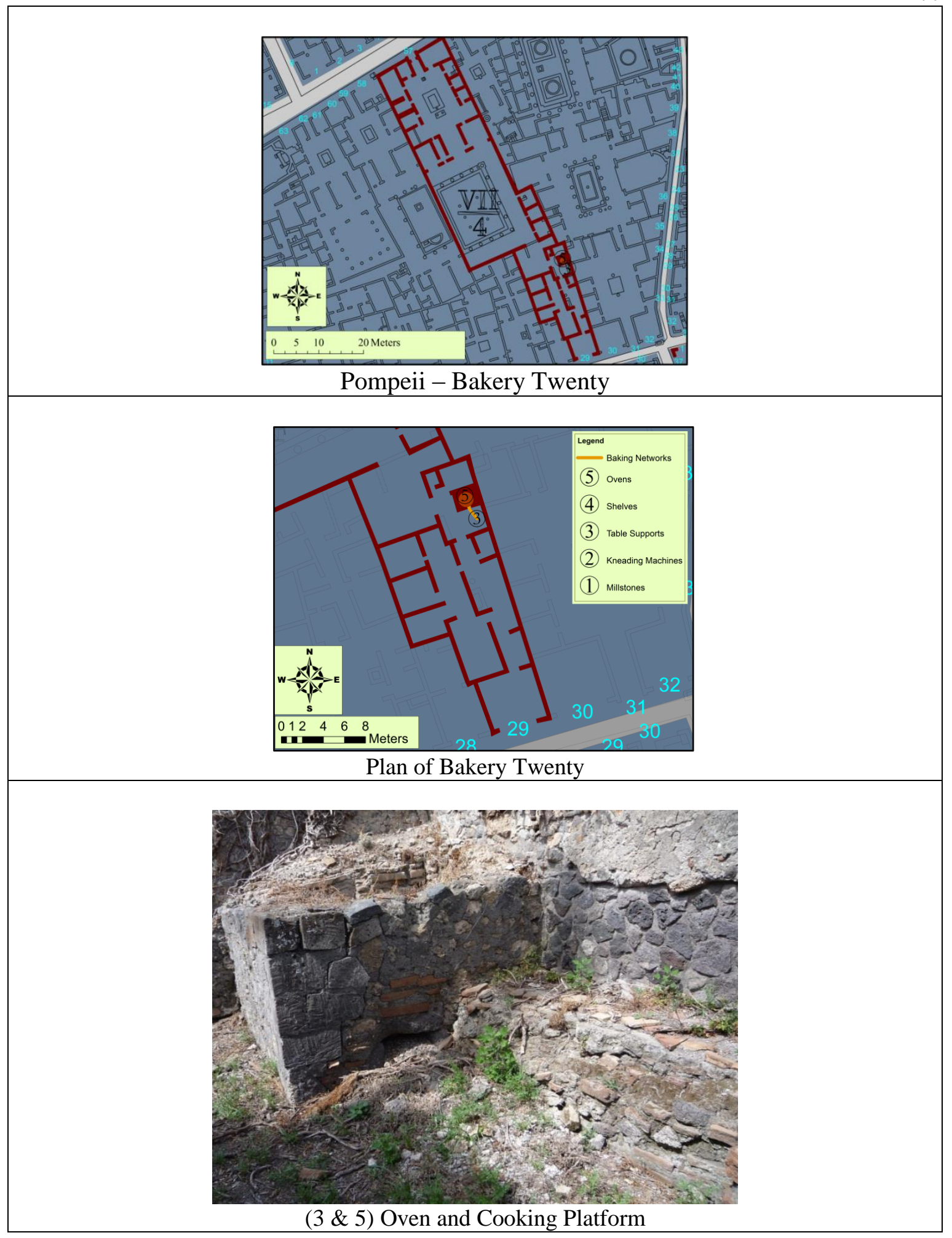




\section{Bakery 21 - VII.12.1-2, 37}

Bakery 21 is a single room establishment linked to the so-called Casa di L. Caecilius Capella. Located on the northwest corner of insula VII.12, the bakery has three entrances each opening onto a single room, which contains a staircase, an oven (diameter of $2.3 \mathrm{~m}$ ), and supports for a table. Fiorelli reports a hearth that no longer exists. Behind the staircase and east of the oven is a doorway to the Casa di L. Caecilius Capella. Fiorelli records a chimney in front of the oven, probably similar to the one in VI.2.6, but it is no longer extant. Della Corte calls the bakery the Pastry Shop of Donatus, because of a political dipinto found near entrance 37 . Fiorelli merely calls it an officina, a workshop. Mayeske follows Della Corte in naming the bakery a pastry shop.

Breton 1869, 275; Fiorelli 1875, 281; Della Corte 1965, 183; Mayeske 1973, 120-1. 


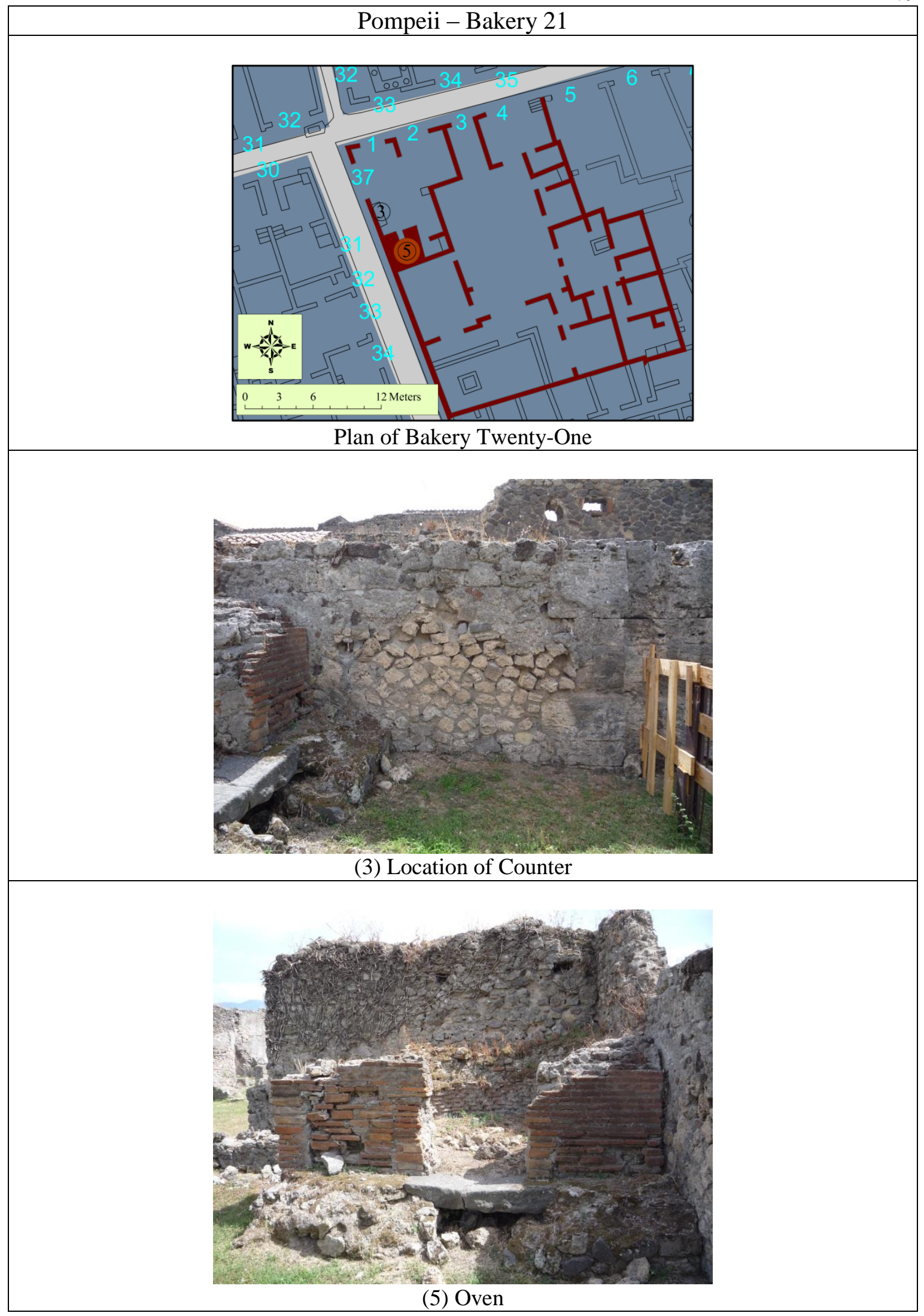


Bakery 22 - VII.12.7

Bakery 22 consists of five rooms. A wide entrance allows access to a front room from the via degli Augustali. Two doorways open onto this room: one leads to a small room and the other forms a passageway to a large oven-room in the back. The oven is heavily damaged, but was low to the ground and oval shaped (diameter of $2.2 \mathrm{~m}$ ). Extending westward from the oven is a long rectangular counter. Fiorelli records an elaborate lararium, now destroyed, overlooking the counter on the south wall. It depicted a Genius standing before a tripod with a patera and a cornucopia in hand, flanked by lares. On one side of the lares stands Vesta holding a scepter and a handful of corn, which a donkey is trying to eat. Mercury stands on the other side with his winged hat and cadauceus. There is a small room in the northwest corner of the oven-room. The third room in the back, north of the oven, contains postholes for shelves in the north wall and was linked to the oven via a chute in the south wall, which is now destroyed but evident in the praefurnium. Fiorelli notes the presence of another counter in this room, as well as a dolium and a some type of vat.

Fiorelli describes bakery 22 as belonging to a pistor dulciarius, as is his wont with bakeries without millstones. He suggests that the front room served as a shop and the room to the southeast served as a dormitory. Both he and Mayeske interpret the small room in the northwest corner of the oven-room as a storage space.

Niccolini 1854 ii, 60; Fiorelli 1875, 282; Helbig 1868, n. 68; Fulvio 1879, 282; Boyce 1937, 70; Mayeske 1973, 121. 


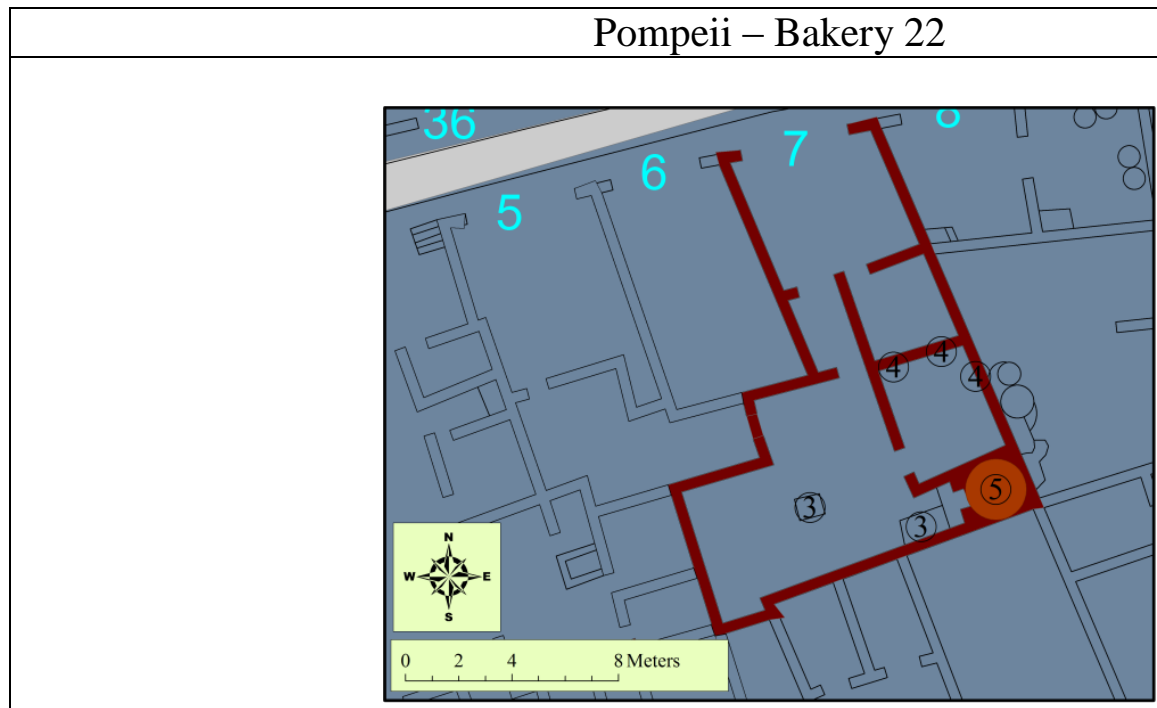

Plan of Bakery Twenty-Two

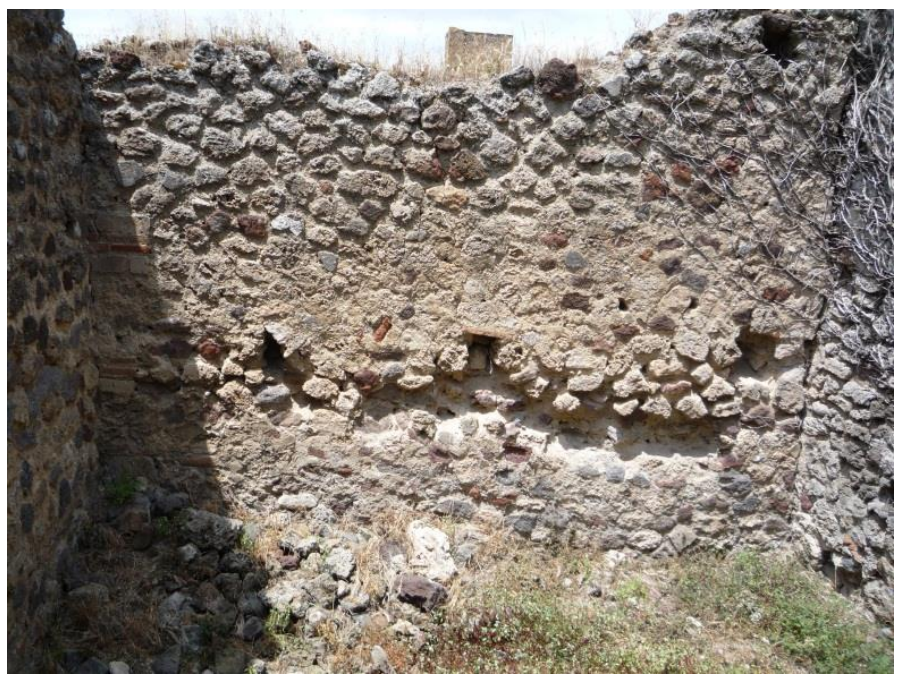

(4) Post holes for shelves

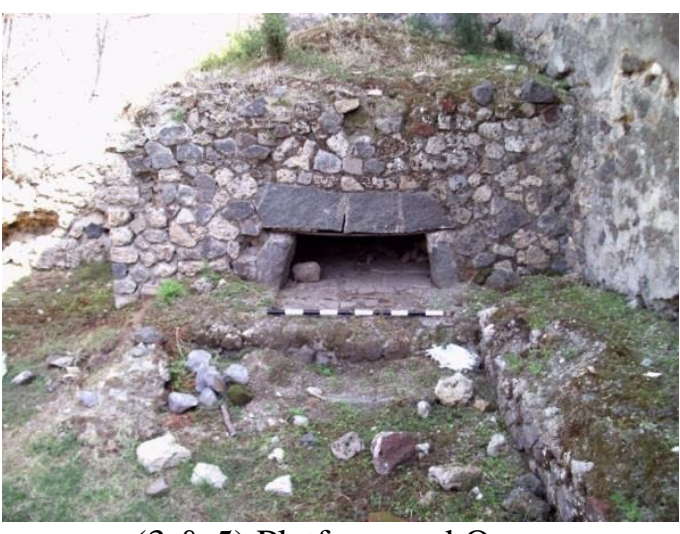

(3 \& 5) Platform and Oven

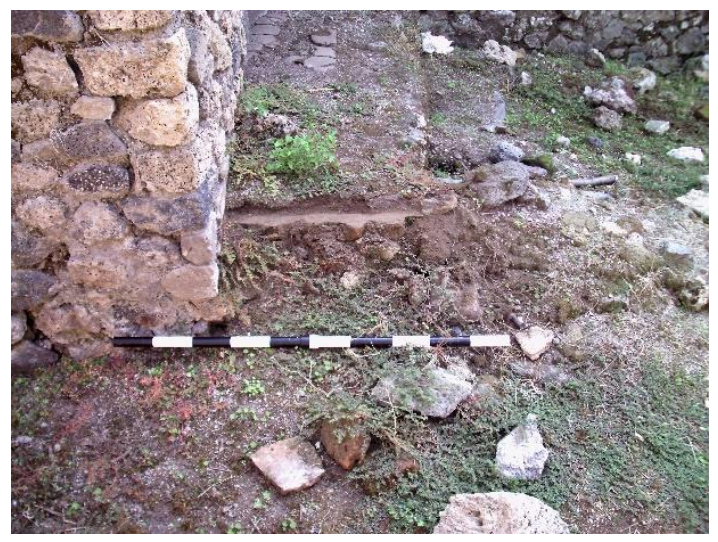

Remnants of Chute 


\section{Bakery 23 - VII.12.11}

Bakery 23 is a long rectangular workshop comprised of two offset rectangular spaces. The first space, opening onto the via degli Augustali has a front room that Fiorelli says contained a staircase, a basin, and a bench. It accesses a corridor on west side and a small room on the east. The corridor leads to the second rectangular space, which has a doorway in its north wall to a trapezoidal room. Just south of the trapezoidal room is a small space formed by a U-shaped wall. The entire space is divided by a room jutting out of the west wall, which has a door and a window that visually link the corridor and the room west of the oven. The east wall of this jutting room is a large lararium depicting a seated genius on a white field holding a patera and a cornucopia. Flanking the genius are two lares holding up garlands above. In a lower register, an altar is flanked by snakes. The oven (diameter of $2.4 \mathrm{~m}$ ) extends outward from the south wall, forming a space on either side. In the eastern space, a niche on the side of the oven contains a lead canister, which has lead pipes leading to and from it. One lead pipe leads to another niche in the front of the oven on its east side. The space west of the oven links to the praefurnium by a chute and contains supports for a table and post-holes for shelves in the south and west walls.

Fiorelli suggests that there may have been mills in bakery 23 , but were removed in antiquity. If the mills existed, he suggests they were located in the corridor linking the front and back of the bakery. In 1971, Mayeske notes a broken catillus in the passage, which may have been the reason for Fiorelli's assertion, but rightly observes that millstones in this space would have blocked access from front to back. Mayeske interprets the various rooms in the back half of the bakery as storage. 
Niccolini 1854 ii, 60; Fiorelli 1875, 283; Helbig 1868, n. 61; Boyce 1937, 70; Mayeske 1973, 122-3; Monteix 2009, 326-34. 


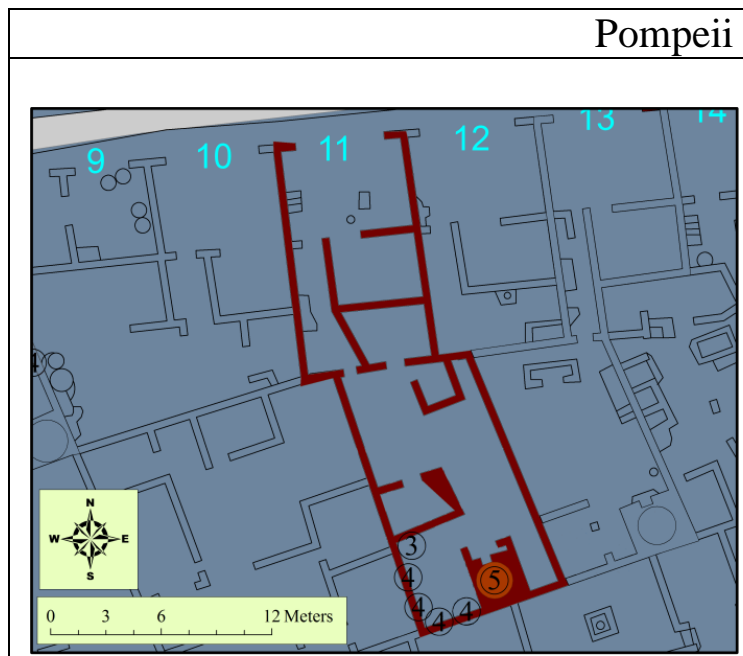

Plan of Bakery Twenty-Three

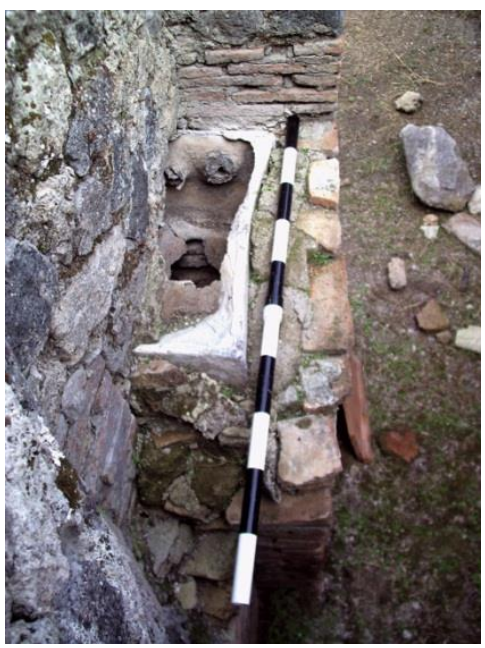

Lead Pipes in Oven
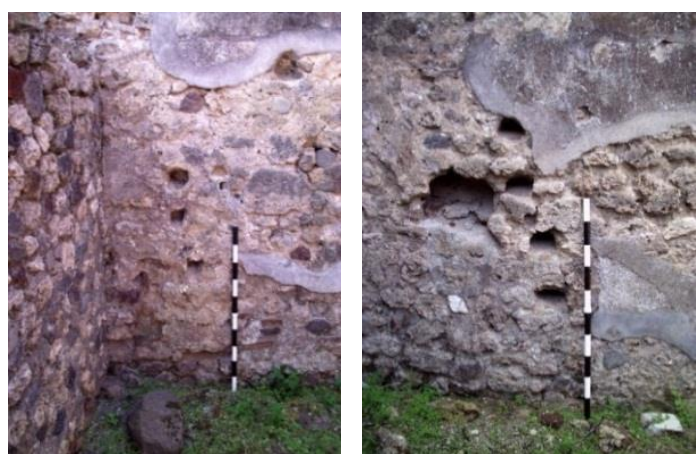

(4) Post Holes for Shelves

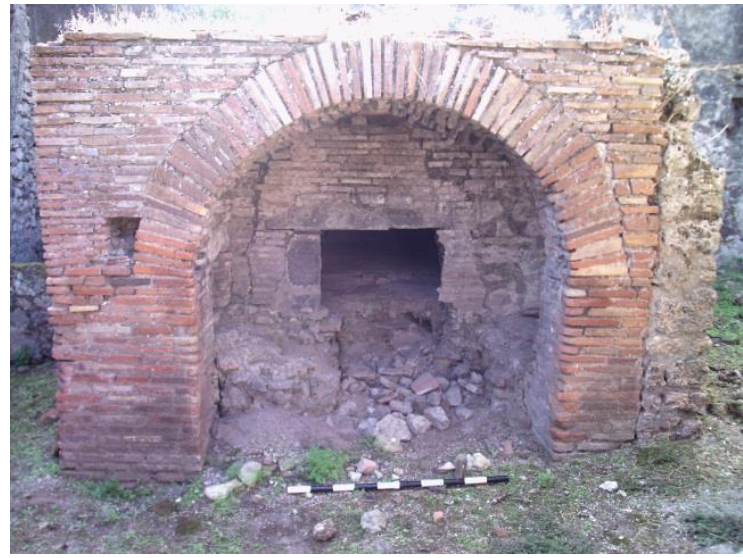

(5) Oven

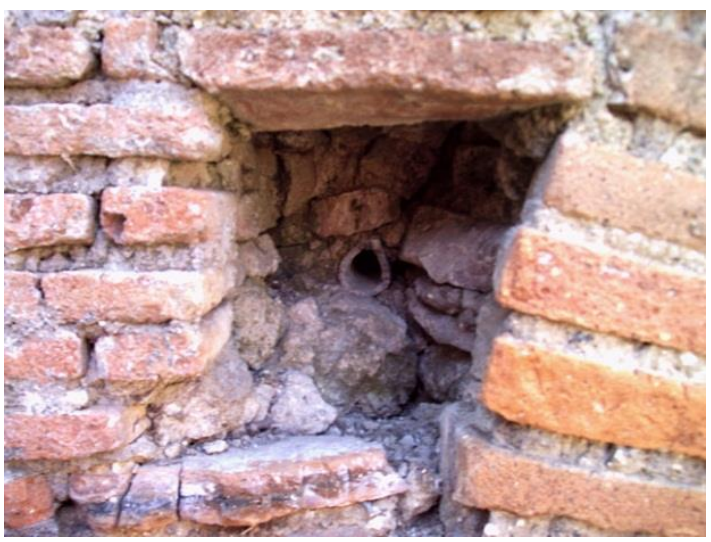

Lead Pipes in Oven 


\section{Bakery 24 - VII.12.13}

Just as with bakeries 22 and 23, bakery 24 is split into two halves. The front half has a wide entrance opening onto the via degli Augustali. This front room has two doorways, the eastern one leading to a small room and the western one forms a corridor leading to the back half of the bakery. The passageway has two counters on its west side. The oven (diameter of $2.6 \mathrm{~m}$ ) resides in the back half of the bakery, in the southeastern corner. The front of the oven is completely destroyed, but its western side - along with a wall jutting from the west wall of the bakery - forms a small room. This room contains a kneading machine and postholes for shelves. Mayeske records table supports in this room in 1971, though they are no longer extant.

Unlike bakeries 22 and 23, Fiorelli suggests that bakey 24 belonged to a pistor who dealt in bread. He also argues that the bakery may have once contained millstones, but they were removed during antiquity. An inscription (CIL IV 629) found outside the bakery, SABINVS CVPIT, leads Della Corte to call the bakery the "Panificio Sabini". Mayeske, straying from Fiorelli's interpretation, calls this bakery a pastry shop. Monteix extensively explores the area of around the oven and determines that the use of heat from the oven in the room west of it suggest leavening and therefore bread production.

Niccolini 1854 ii, 60; Fiorelli 1875, 284; Helbig 1868, n. 62; Boyce 1937, 71;Della Corte 1965, 183; Mayeske 1973, 123-4; Monteix 2009 325-7. 


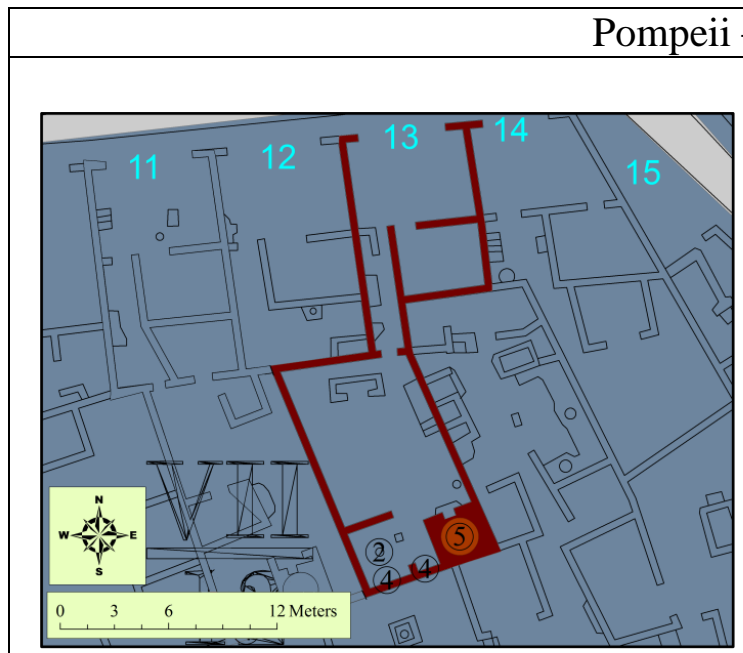

Plan of Bakery Twenty-Four

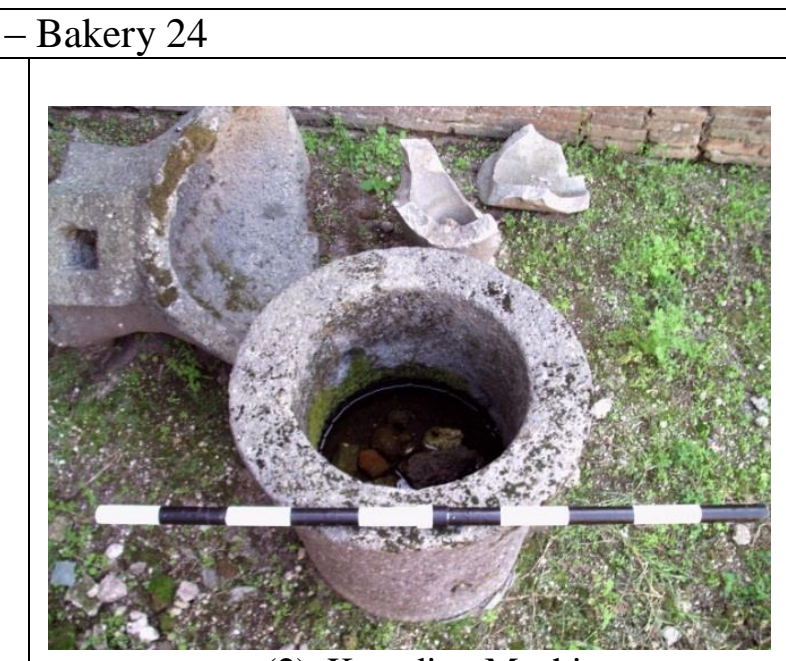

(2) Kneading Machine

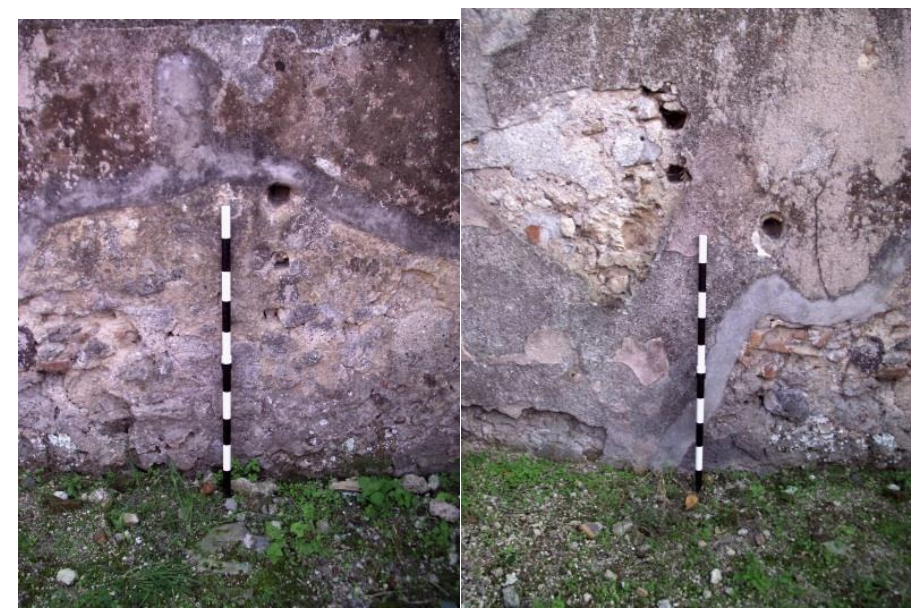

(4) Postholes for Shelves

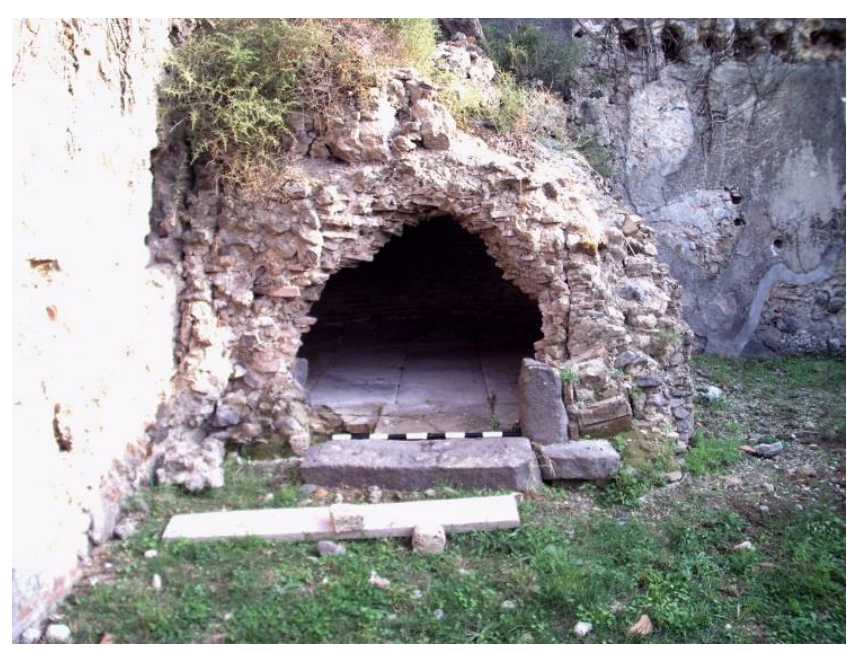

(5) Oven 


\section{Bakery 25 - VII.14.9}

The so-called Casa di V. Popidius, also known as the Casa delle Colombe or the Casa del Scheletro, is an atrium-style house along the via del Abbondanza. The front of the house was excavated early in the modern life of Pompeii, but the interior was excavated later. Beyond the tablinum there is a garden delineated by a series of piers. A narrow doorway west of the garden leads to a series of small rooms. To the North there is a well decorated bath. south of the doorway a small corridor may have served as a staircase. A small oven (diameter of .8) is built into the west wall of the house. North of the oven is a small rectangular space and to its south there is a room with supports for a table and postholes for shelves. Directly in front of the oven there is a shallow basin residing in the corner, south of which there is a broken catillus. Also discovered in this area was a hand operated rotary mill, which may be the one now found in the basin. Near the oven and food preparatory space is a small bath complex in which excavators found a skeleton.

Bakery 25 does not appear in Mayeske's catalog of Pompeii’s bakeries. Fiorelli notes the oven and the millstone, but explains that they were not in use during the final years of Pompeii. He offers no explanation for his conclusion. Breton briefly mentions the house, but only discusses the skeleton, the painting of doves, and the marble impluvium. Much like ovens in the Casa dei Suettii and Casa dei Capitelli Figurati the oven in the so-called Casa di V. Popidius is particularly small compared to the other ovens in Pompeii. Unlike the other houses with small ovens, VII.14.9 contains the additional features and technologies associated with the production of bread. 
Breton 1869, 456 pl. 101; Fiorelli 1875, 302-303. 


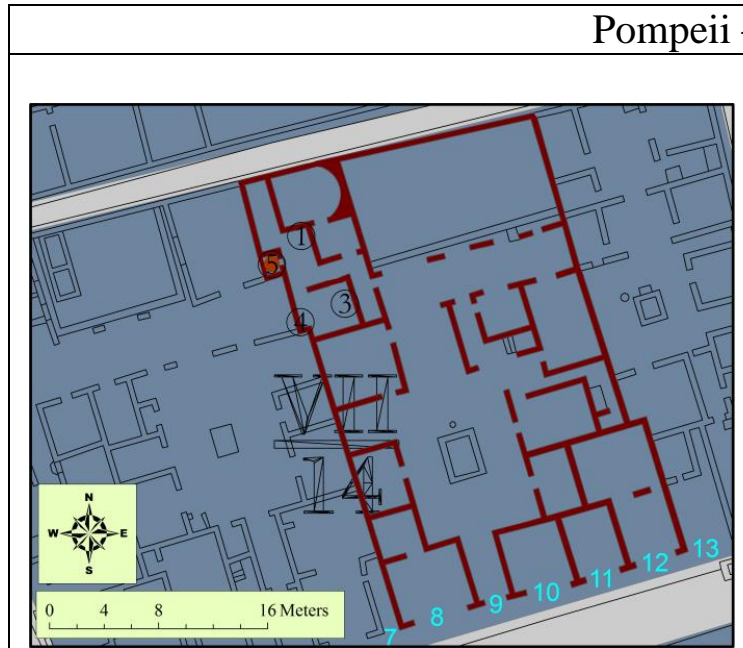

Plan of Bakery Twenty-Five

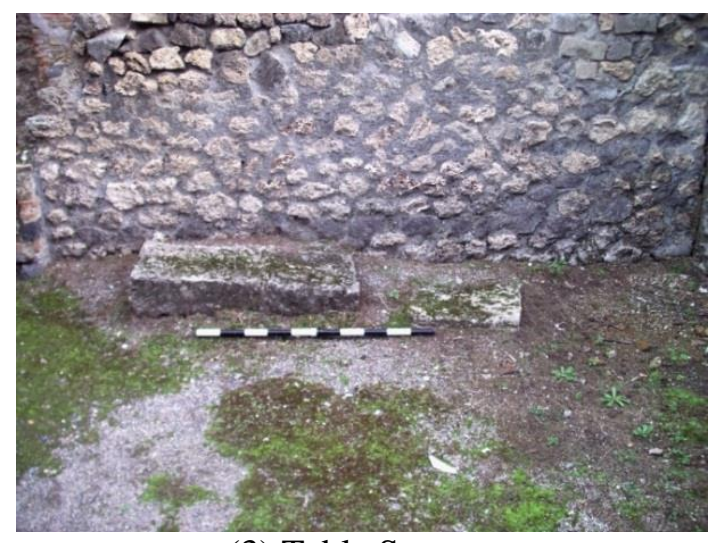

(3) Table Support

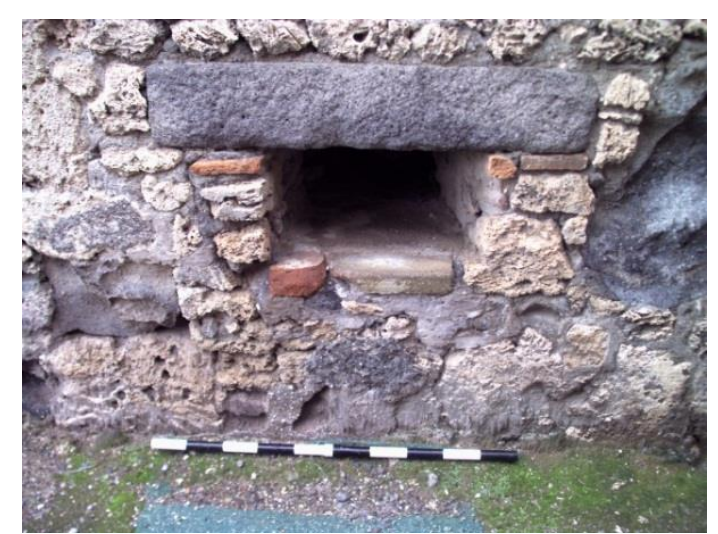

(5) Oven

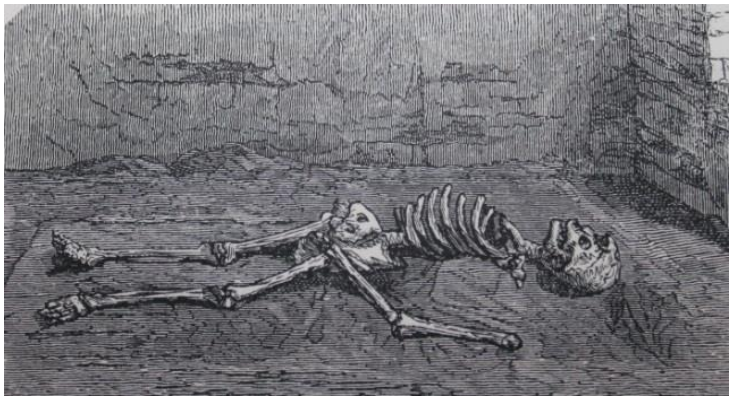

Skeleton Found in Baths near Oven (After Breton, Pl. 101) 


\section{Bakery 26 - VII.15.15}

Bakery 25 resides in a subterranean complex under the Casa del Marinaio. While the main entrance of the house above opens onto the vicolo del Gallo to the South, the entrance of the underground compartments is accessed from the vicolo dei Soprastanti to the North. The spaces is divided into two branches forming an L-shaped corridor. The corridor is lined on either side by compartments. At the nexus of the two branches, at the corner of the $\mathrm{L}$, there is an oven (diameter of $2.2 \mathrm{~m}$ ) at the back of the compartment. This room, unlike the other compartments, is open to the sky. Fiorelli records a broken millstone found in the space in front of the oven, which may be the one now in these store rooms. Communicating with the oven-room is a series of spaces. The first doorway reveals a square room, which may have served as a toilette, though its features are poorly conserved. The second door opens onto a rectangular room with a kneading machine, supports for a table, and postholes for shelves in its southeastern wall. This room is linked to the front of the oven by a chute in its northeastern wall. Behind the oven is a narrow rectangular space. Also communicating with the room with table supports are two back rooms now serving as storage for excavated material.

Bakery 26 does not appear in Mayeske's catalog of the Pompeii’s bakeries. Fiorelli notes the oven and its location, but does not specifically call the oven and its related spaces a bakery, but he interprets the entire subterranean complex as horrea, granaries. Franklin concurs, though he interprets the first compartment on the northeast side of the corridor as a stable for the donkey that turned the millstone. Franklin argues that the inaccessibility of the bakery, deep inside the subterranean complex, suggests that it served the strictly private function of feeding the household above. 
Fiorelli 1875, 305-314; Della Corte 1965, 199; Franklin 1990. Laurence 1994, 57. 


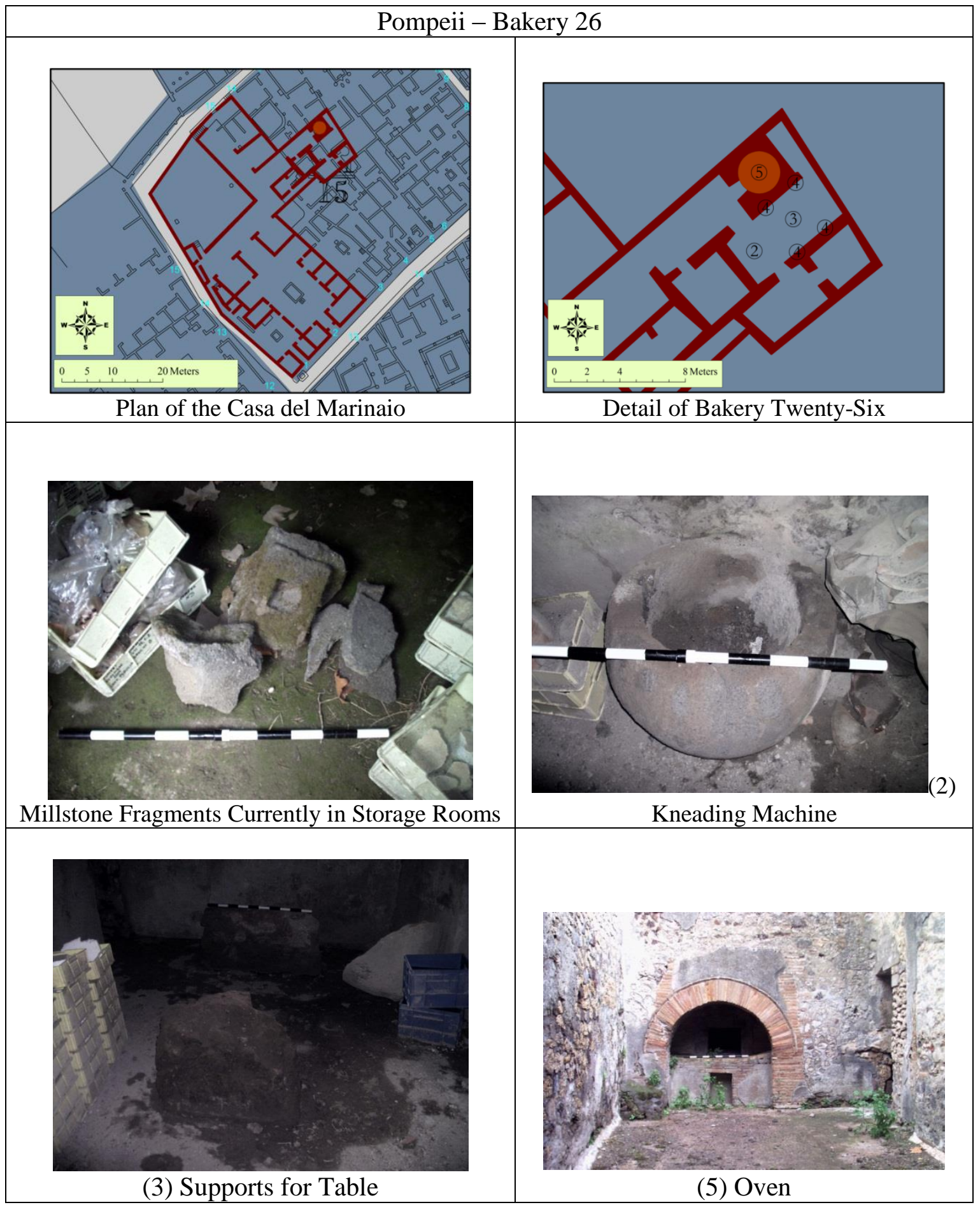




\section{Bakery 27 - VII.16.6\&9 (Insula Occidentalis)}

Excavated in the early $19^{\text {th }}$ century, bakery 26 was mostly destroyed in 1943 by allied bombs. Eschebach describes the address as a two room bakery with an oven, which has now completely disappeared. The oven, based on Eschebach's plan, directly faced the entrance on the vicolo del Gigante (n.9). There is a room north of the oven a doorway south of the oven, leading to the space accessed through the entrance on via Marina (n. 6). The floor of this room is lined with paving stones and has two small millstones. The southern millstones is a rotary mill similar in form to the standard Pompeian mill, but much smaller and closer to the ground. The northern millstone, probably placed there since 1943, is a standard hand operated rotary mill.

Garcia and Garcia state that the entire bakery was destroyed during the bombardment of 1943. The oven is completely gone and the walls around it were rebuilt in 1950 . There is currently a door and a staircase to $\mathrm{n} .10$ that were not originally part of the form of the bakery. Fiorelli says that the room accessed from n. 6 may have at another time contained the millstones for a bakery, which implies that there were none there before the bombing. The paving stones probably compelled him to that conclusion. Fiorelli describes the spaces near entrance n. 9 as separated from the houses around it, though once attached to them, implying that the entrance now found in the bakery - and doubted by Garcia and Garcia - existed but was filled in during antiquity. Fiorelli notes an oven right at the entrance and two rooms adjoining it, one of which he calls a shop.

Fiorelli 1875, 440; Della Corte 1965, 199; Eschenbach 1993, 347; Garcia y Garcia 2006, 131. 


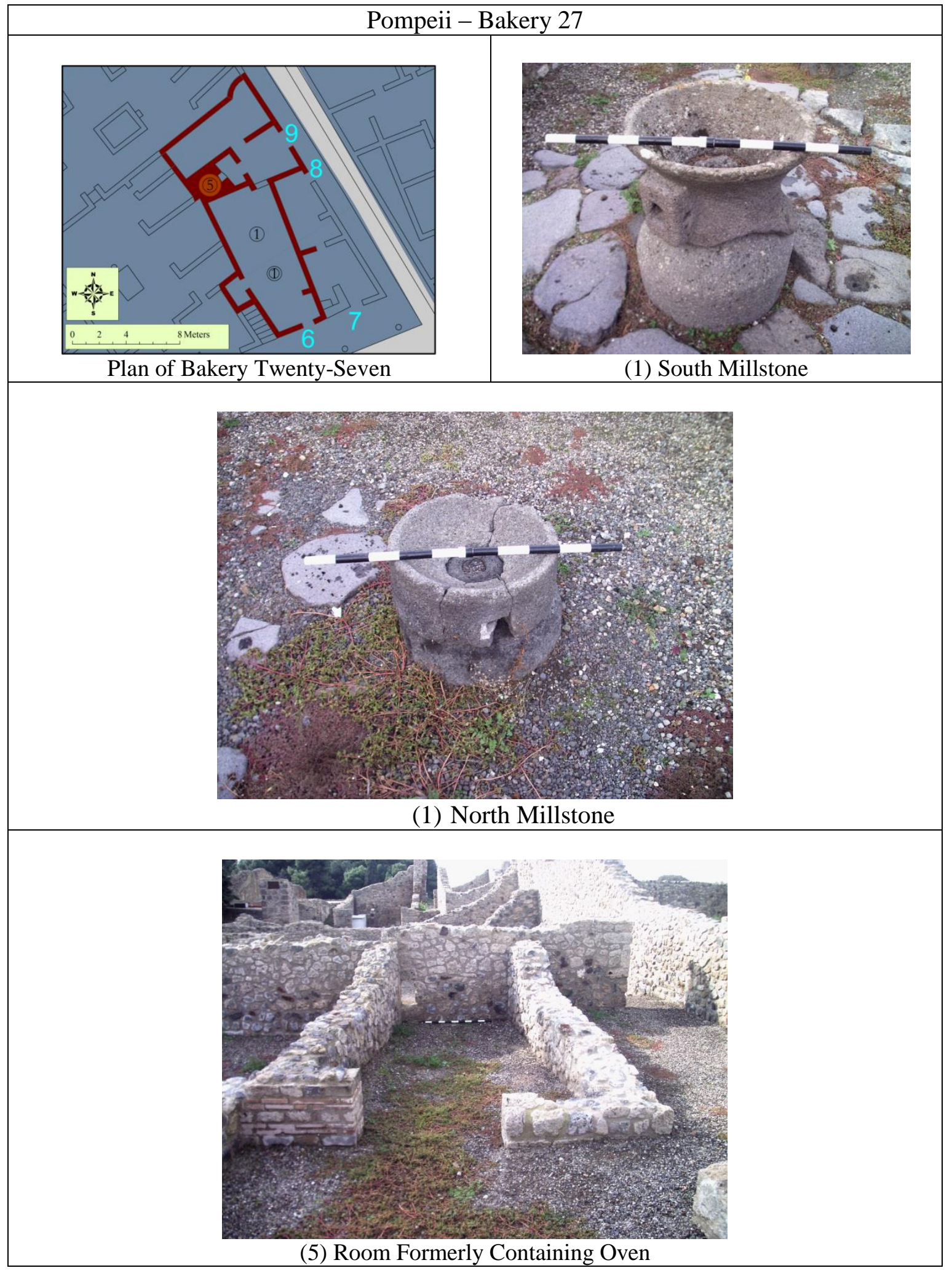


Bakery 28 - VIII.4.26-27 \& 29

Bakery 28, also known as the Bakery of Felix, is located on the west side of the via Stabiana, north of the Temple of Isis and the theater quarter. A painted political program (CIL IV 1008), FELIX ROG, found just south of the main entrance (n. 27), gave the bakery its name. That entrance consists of a wide fauces, linked to a room to the south and a room to the north with its own entrance (n.26). The other end of the fauces opens on to a large space paved with stones. It contains the bases of two millstones and a space in the paving stones for a third. Linked to the mill-room to the West is another room which contains an oven (diameter of $2.1 \mathrm{~m}$ ) situated in the northwestern corner and facing out to mills through the doorway. Fiorelli records a lead basin next to the oven, which Mayeske also saw in 1971. South of the oven and linked to it by a chute is another room in which one finds postholes for shelves. Mayeske records a pipe extending into this room $1.8 \mathrm{~m}$ from the oven wall, but it is no longer extant. The southwest corner of the mill-room provides access through a hallway to a back space dominated by a central peristyle garden. Rooms line both the hallway and the garden and can be accessed from the via del Tempio d'Iside by a back doorway (n. 29).

Mayeske suggests that the room south of the fauces served as the stables for the donkeys that turned the millstones. Both Mayeske and Fiorelli interpret the back spaces as the domicile of the baker and his family. Della Corte posits that the bakery consists of two remodeled houses; the mill-room was once an atrium as was the peristyle in the back.

Fiorelli 1860-62 i, 189; Fiorelli 1875, 343; Boyce 1937, 76; Della Corte 1965, 261-2; Mayeske 1973, 124-5; Pagano and Prisciandaro 2006, 57. 


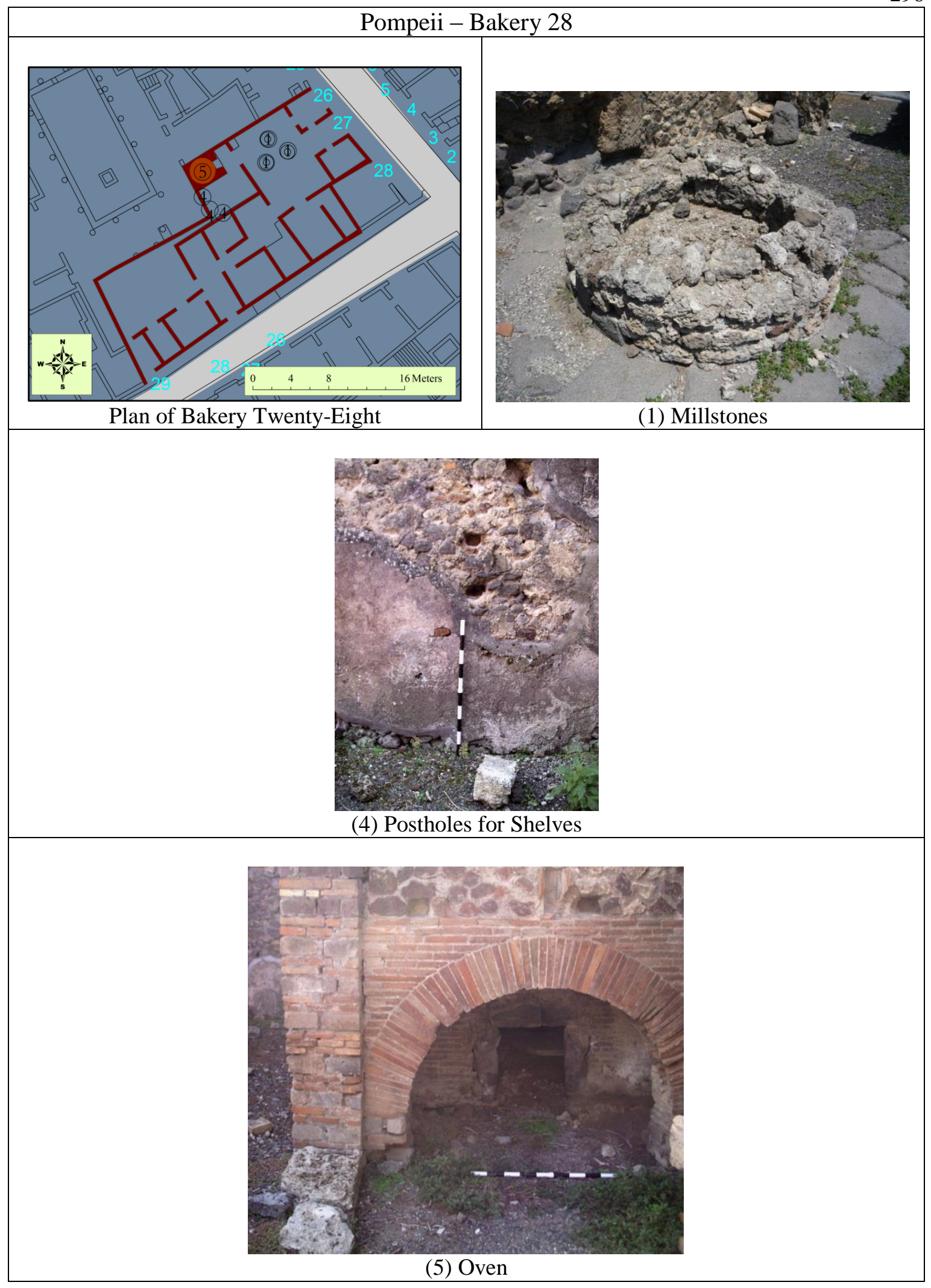




\section{Bakery 29 - VIII.6.1 \& 9-11}

Bakery 29 is located in a large house, the north part of which is a large peristyle in which was found a lead fragment with the inscription P AEMILI GALLICI (CIL X 8339). Below the rooms north of the peristyle there is a cellar, accessed by a staircase. In the cellar was found the skeleton of a woman. The south half of the house is an atrium converted into a mill-room, which is paved with stones with the reconstructed bases for four mills. The actual millstones are no longer in their bases, but several catilli are visible in the mill-room and in the room north of the oven, which also has postholes for shelves in its north, south, and east walls. The oven (diameter of $2.5 \mathrm{~m}$ ), accessed form the millroom, has an arched praefurnium. A chute linked the oven and the room to its south, but a modern repair has filled in the aperture. This room contains supports for a table and postholes for shelves on the north, south and east walls. Excavators found two terracotta basins lined with lead in this room and inscribed with C PETRON SATVRNIN, but they are no longer extant. The postholes are aligned in such a way that the shelves were lining only the east wall. On the south side of the mill-room are two rooms, the first has a platform of the sort commonly found in the kitchens of large Pompeian homes. The trapezoidal space south of the kitchen-like room can provides access to vicolo dei 12 Dei through entrance ten.

Mayeske interprets the north half of the house as the domestic quarters of the baker surrounding a central garden in the peristyle. Jashemsky observes that the supposed garden was actually paved with opus signinum. Eschebach identifies the room west of the mill-room, accessed directly through entrance ten, as a stable. 
NS 1882, 281 \& 399; Della Corte 1965, 261-2; Mayeske 1972, 126; Eschebach 1993, 386; Jashemsky 1993, 219. 


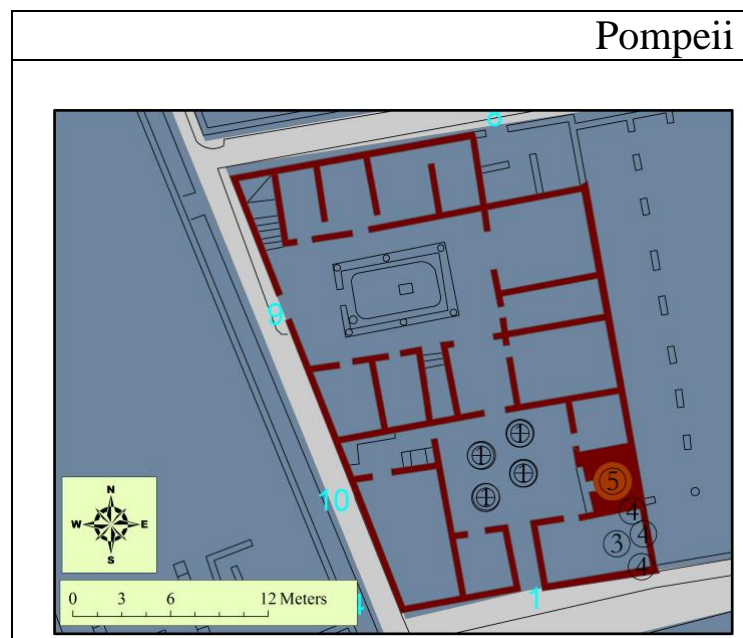

Plan of Bakery Twenty-Nine

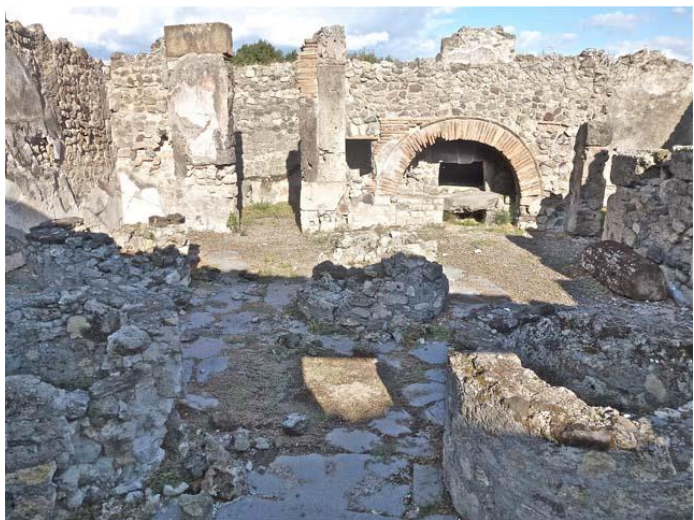

(1) Millstone Bases

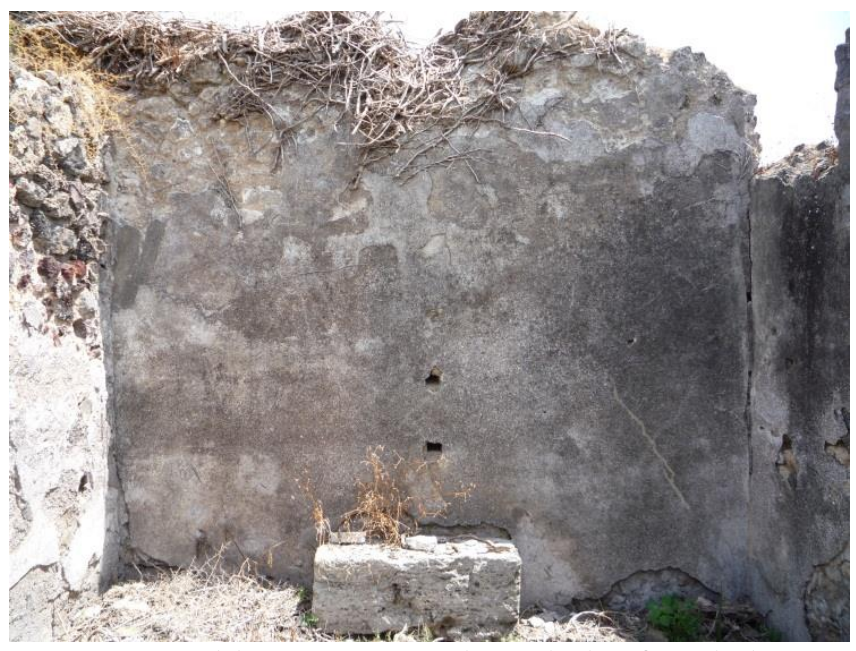

(3 \& 4) Table Supports and Postholes for Shelves

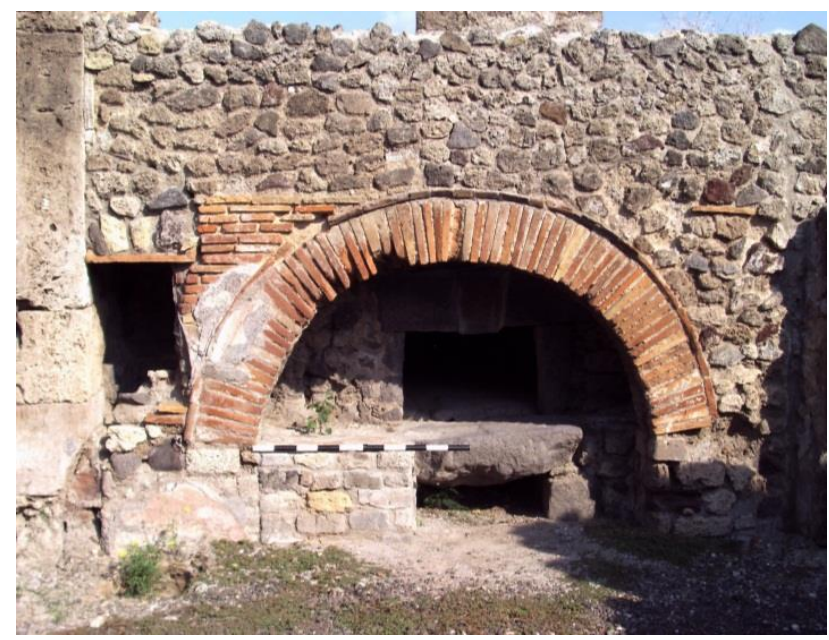

(5) Oven 
Bakery 30 - IX.1.3\&33

Bakery 30 is one of only two in Pompeii with a counter in the front, commonly associated with Pompeii's bars. The L-shaped counter faces onto via Stabiana from a wide entrance (n. 3). Fiorelli records the presence of nine terracotta vessels: three embedded in the counter, five in a platform behind the counter, and one in the floor. Only seven of the original nine remain in the bakery. Fiorelli further says that the five vessels in the platform behind the counter were inscribed with numbers indicating their capacity. The three from the counter are no longer extant and the counter itself appears reconstructed. There are six vessels behind the counter, but only five that are engaged by masonry and pointing. Above these vessels on the south wall of the bakery are postholes for two lines of shelves.

Across from the shelves and the counter there are two doorways, leading to two small square rooms. On the southwest side of the first doorway there is rectangular masonry basin. Northeast of the doorway is the base and the first few steps of a staircase. North of the second entrance there is a stone vessel, similar to the material used for millstones and kneading machines inscribed with the letters SEP. The space south of the stone container has within it three bases for millstones. Fiorelli records that two were complete and the third lacked its catillus. Also in the mill-room there is a broken kneading machine of unknown provenance; it does not appear in the descriptions of Mayeske or Fiorelli. North east of the mill-room one there is a long rectangular room accessed through a doorway to the right of the oven. Across from the oven are two terracotta bowls engaged by masonry podia. Fiorelli records a "nicchia di Penati" above each bowl, but Boyce notes the lack of decoration in the niches indicating religious 
purposes. The oven (diameter of $2.4 \mathrm{~m}$ ) is linked through a chute to a room to the North. This room contains supports for a table and postholes for shelves. Southwest and directly across from the room with the table is a latrine. Both spaces line a corridor that leads to entrance 33 .

The counter is interpreted by both Fiorelli and Mayeske as an indication of commerce. Fiorelli suggests that the vessels behind the counter may have contained flour or grain, implying that the bakery not only sold bread but also flour. It is also possible that the bakery sold items other than grain, flour, and bread, though without evidence for the contents of the vessels such hypotheses remain speculation. Fiorelli also interprets the two rooms north of the counter and mills as bedrooms for the shop-keep and the oven operator. He calls the room south of the oven the stables. Fiorelli labels the room north of the oven the panificio, implying that the space served some function in the production of bread.

Fiorelli 1875, 365; Boyce 1937, 79; Mayeske 1972, 127-9; Pagano and Prisciandaro 2006, 167. 


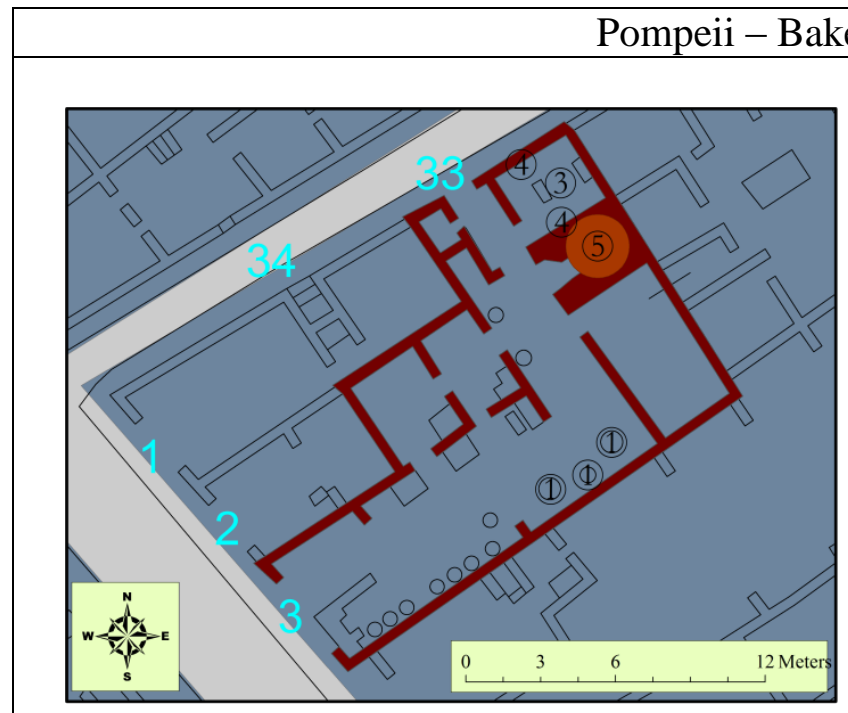

Plan of Bakery Thirty

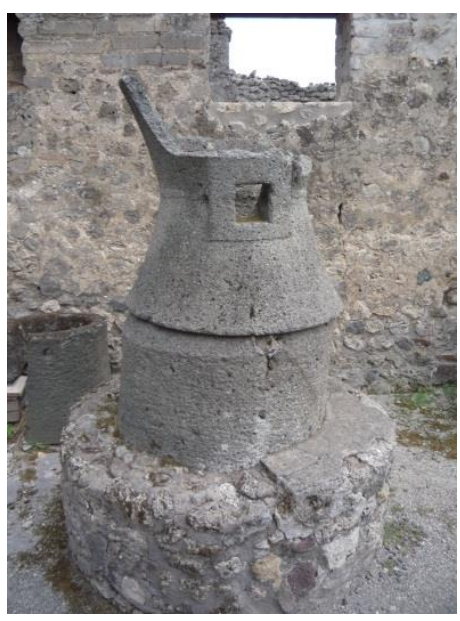

(1) Millstone

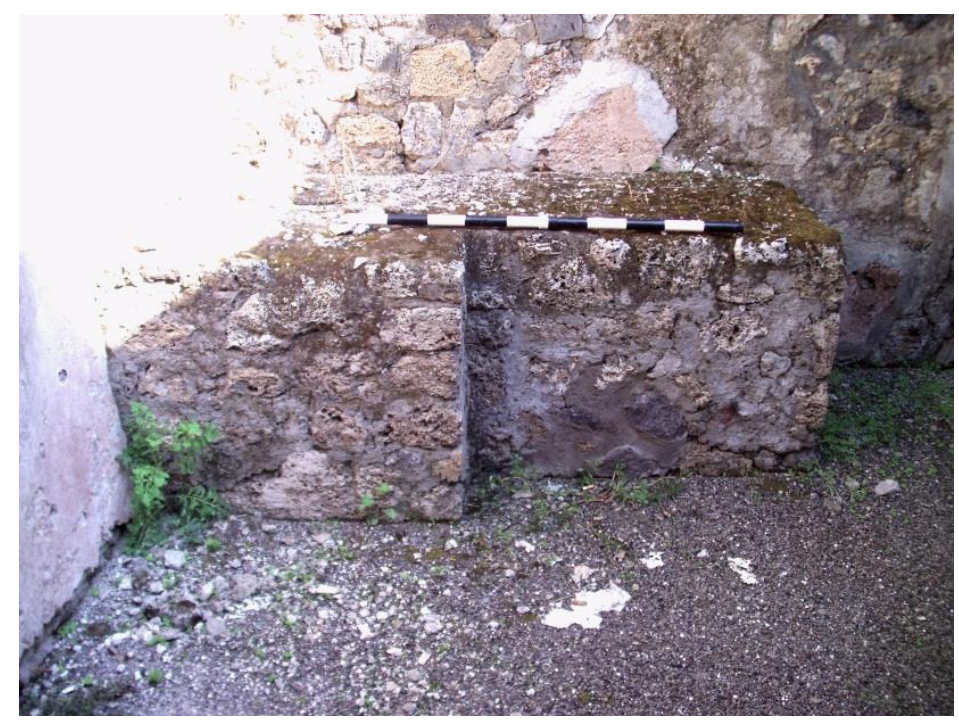

(3) Table Support

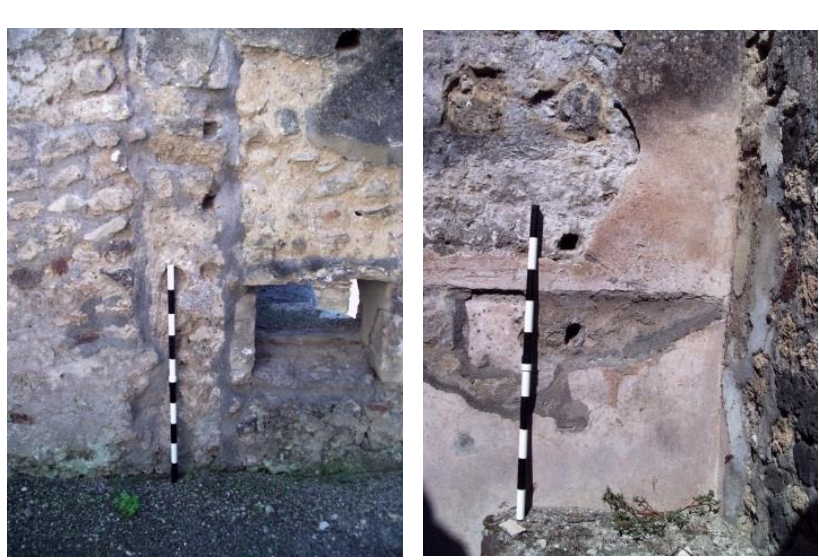

(4) Postholes for Shelves

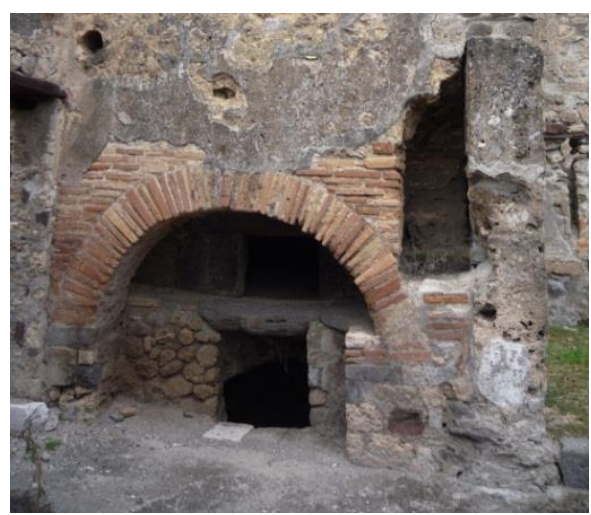

(5) Oven 


\section{Bakery 31 - IX.1.22 \& 29}

The so-called Casa di Epidio Sabino consists of three atrium style homes remodeled into a single large house with a peristyle in the northwestern corner. Two entrances provide access to the house from the via dell' Abbondanza (n. 22) and the vicolo di Tesmo (n. 29). The baking space is located in the northeastern corner of the house, near entrance 29 , which leads to an atrium. This section of the house, surrounding the atrium of entrance 29 , is less opulently decorated than the rest of the house. North of that doorway, another passageway leads to a rectangular room which contains a counter immediately to the East and the oven in the northwestern corner. The oven (diameter of 1.8) has a chute that links it to a room to the West and an aperture into the praefurnium from the oven's face. In front of the oven is a basin made of white stone. Fiorelli records the discovery of animal remains in the main room with the counter and the oven. Wide arched doorways provide access from the main room to two spaces: one east of the oven which contains a broken catillus and another to its west. The western doorway opens onto a hallway which leads to an arched niche at its western extent and to the room linked with the oven to the North. Inside the niche, next to the south pier of the arch, is a wellhead. The room linked to the oven contains a broken catillus or a millstone and has postholes in the western wall.

Mayeske does not include bakery 31 in her catalog and Fiorelli only mentions the oven and a panificio, which must be a reference to the room west of the oven, though it is not clear. Della Corte calls the house by another name, the Domus Cuspiorum, Pansae et Proculi, derived from a series of inscriptions found at the front of the entrance (CIL IV 1067, 1068, \& 1071). Fiorelli identifies the owner of the house as Epidius Sabinus, but 
does not elaborate on his reasoning. The well-known inscription found at IX.1.19, which exhorts Epidius Sabinus as a worthy young man and an ideal candidate for duumvir, may have provided the evidence for Fiorelli's attribution (CIL IV 1059). A rare retrograde graffito, found outside entrance 29, repeats the names Sabino, Emilio, and Curvio (CIL IV 2400):

\section{SVIVRVC ONIBAS SVNIBAS OIVRVC SAL SVIVRVC OIILIMEA SAL SVILIMEA CVRVIO SAL}

The repeated use of the name Sabinus, combined with the size of the house and its proximity to the inscription at IX.1.19, may have compelled Fiorelli to make the attribution. Recent excavations below the $79 \mathrm{AD}$ levels have shown the urban development on the insula of IX.1. Similar to other places in Pompeii, the so-called Casa di Epidio Sabino systematically subsumed other houses around it, though the bakery after the merger.

Fiorelli 1875, 375-376; Della Corte 1965, 244-5; Gallo 2001; Gallo 2010. 


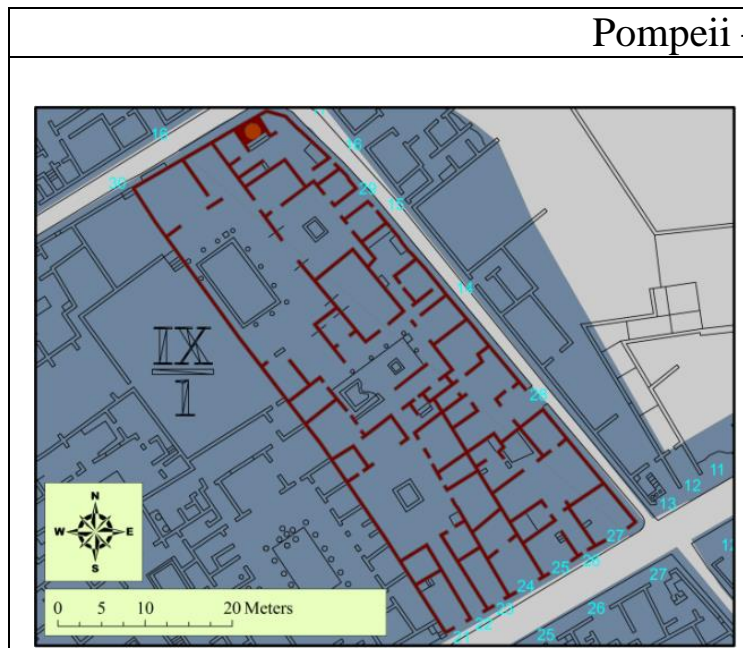

Plan of the House of Epidius Sabinus

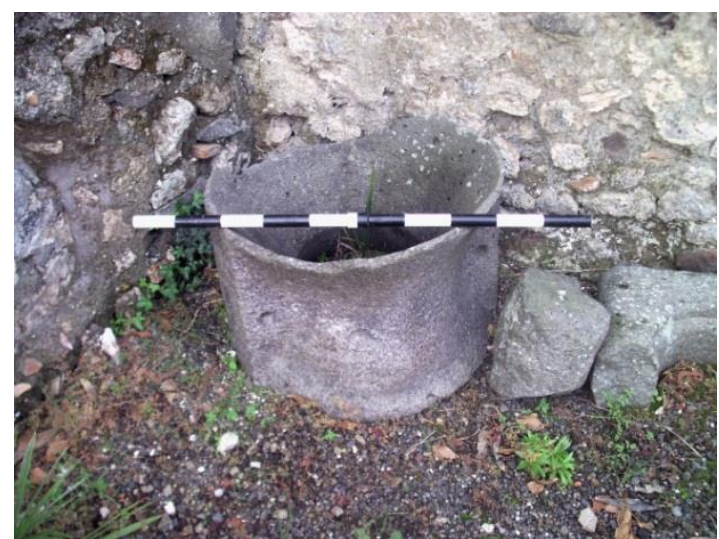

(1) Millstone

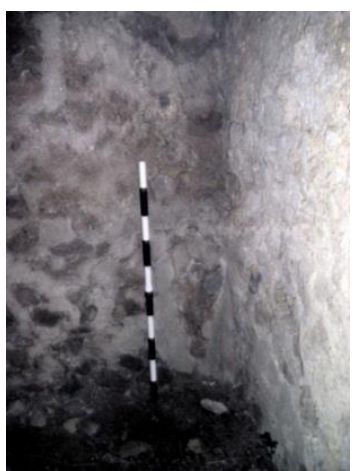

(4) Postholes for shelves

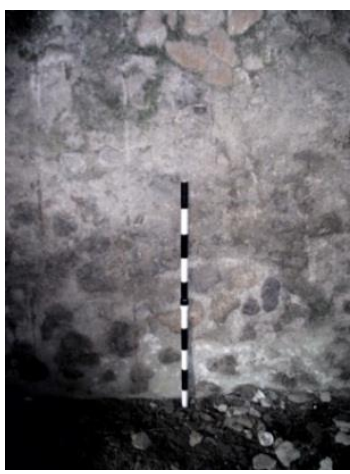

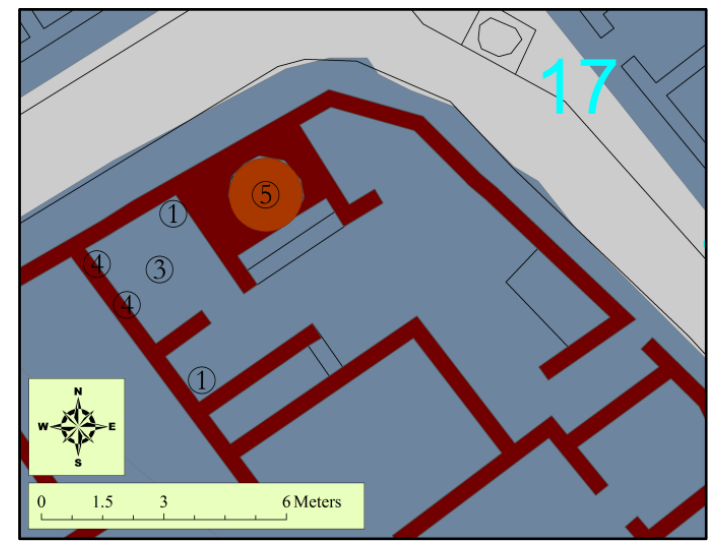

Detail of Bakery Thirty-One

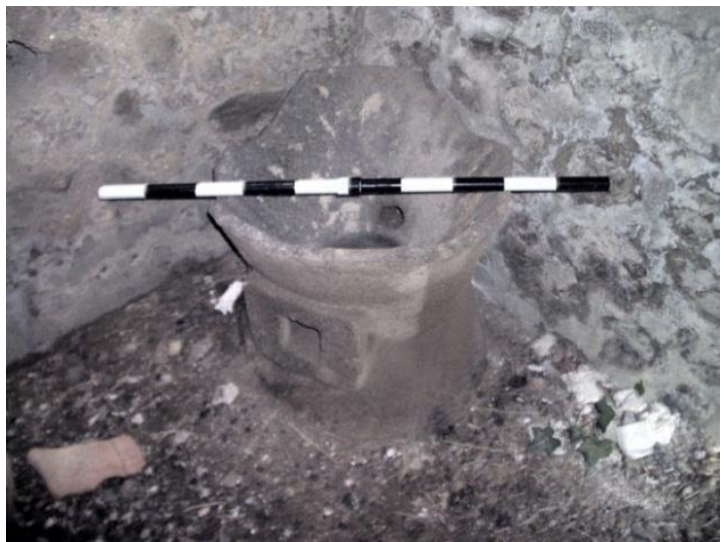

(1) Millstone

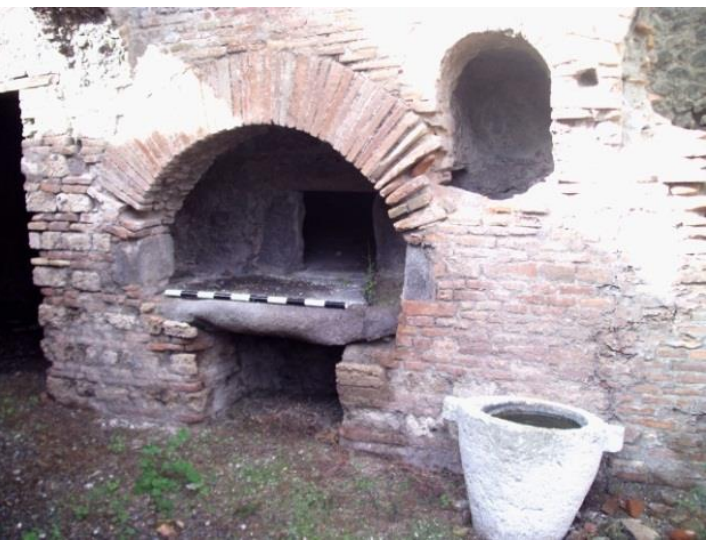

(5) Oven 


\section{Bakery 32 - IX.3.10-12}

The so-called bakery of T. Terentius Proculus resides at the intersection of via Stabiana and an unnamed vicolo which would be the natural extension of via degli Augustali. The bakery has three entrances, one opening onto via Stabiana (n. 10) and the other two onto the vicolo (n. 11\&12). Entrances 10 and 11 provide access to a front space with an L-shaped counter, making it one of only two in Pompeii with such a feature. There are terracotta vessels integrated into masonry behind the counter. Originally there were four, but only two remain extant. Behind the counter and next to the vessels is a doorway to a small room. Northeast of the front room there is a similarly sized space with the bases for four millstones, none of which contain the metae or catilli, though early photographs show millstones still in their bases. There are two catilli that were found half buried flanking the oven (diameter of $2.3 \mathrm{~m}$ ), which resides just north of the mill-room. Boyce records the existence of a lararium scene painted on the pilaster across from the oven, which depicted the family Genius at an altar robed as a priest with a cornucopia. A snake coiling around the altar extends to the left. To the right, a boat sails toward the Genius. Beyond the pilaster there is a long rectangular transitional space with several counters at the north end. West of the transitional space is a large room. North of the oven is a rectangular room with postholes for shelves and supports for tables. Early photographs of this room and the oven show them linked by a chute, which was not preserved in the reconstruction of the oven-façade. In the northern most part of the bakery, there are two spaces, the smaller Fiorelli calls a triclinium and the other a viridarium or garden. 
Positioned across the via Stabiana from the so-called House of T. Terentius

Proculus (Bakery 17, VII.2.3\&6), Della Corte argues that the two establishments were part of the combined commercial enterprises of Terentius Proculus. He supports his assertion with an inscription found between entrances 11 and 12, in which Proculus proclaims his support for Popidius for aedile (CIL IV 3651). Fiorelli takes no position on the ownership of the bakery, but he suggests that the front shop may have sold flour, probably due to four vessels found near the counter (following the same logic he used for the bakery at IX.3.33). He also interprets the large room west of the oven and transitional space as the stables and calls the room north of the oven the panificio.

Niccolini 1854 ii, 74; NSc 1870, 45; Fiorelli 1875, 395; Della Corte 1926,145-154; Boyce 1937, 83; Della Corte 1956, 158; Mayeske 1972, 129-31; Fröhlich 1991, 295. 


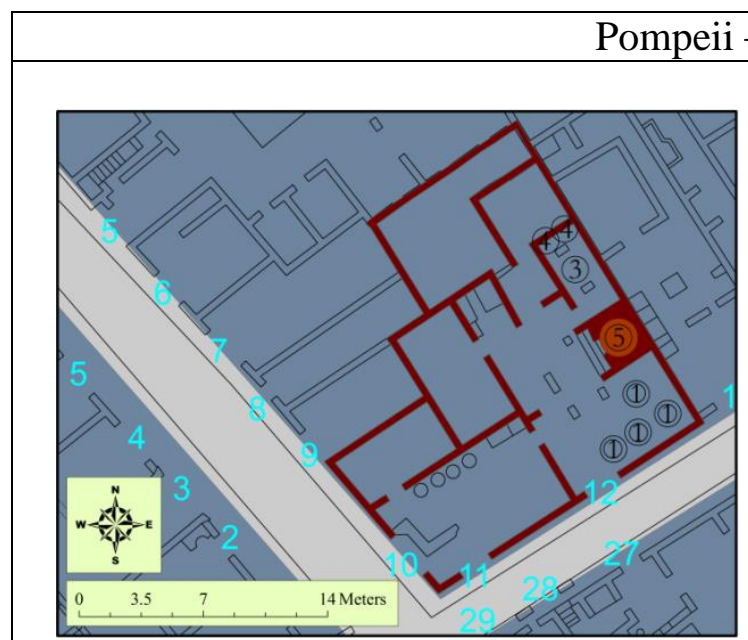

Plan of Bakery Thirty-Two

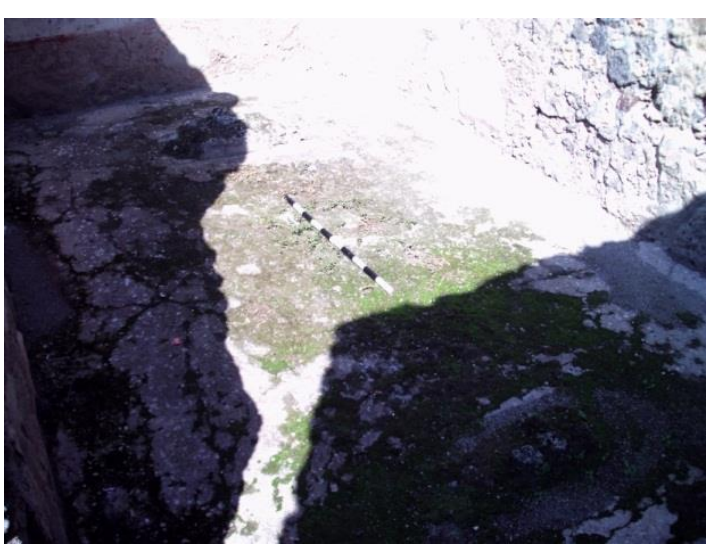

(3) Supports for Tables

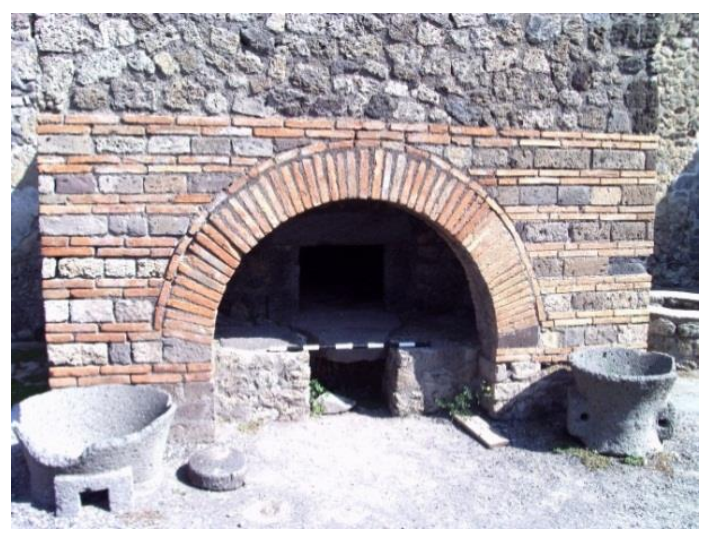

(5) Oven

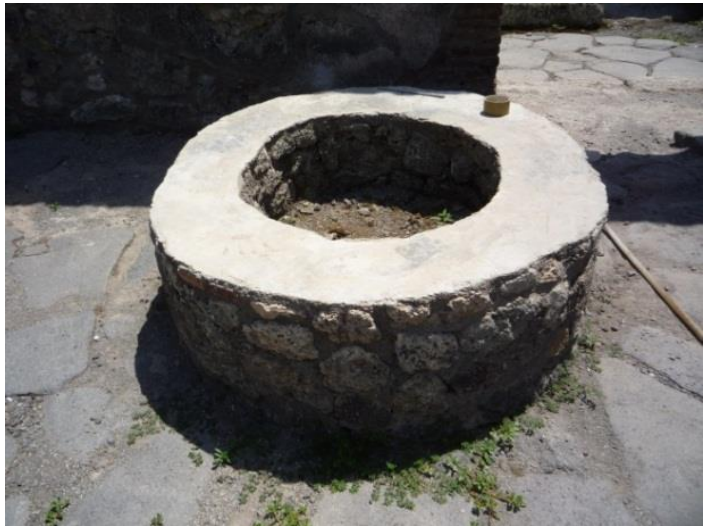

(1) Millstones

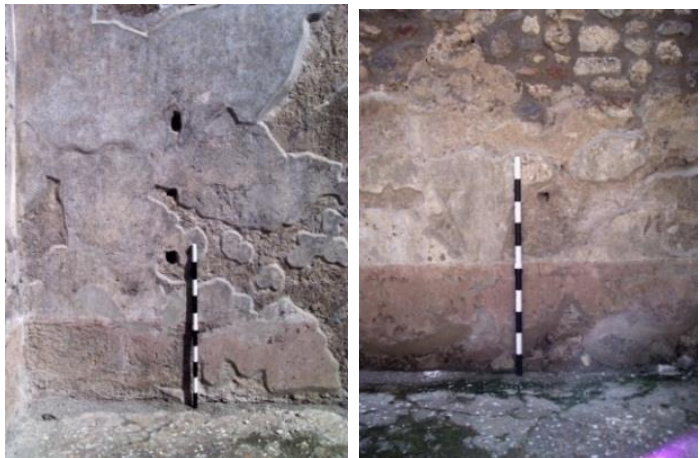

(4) Postholes for Shelves

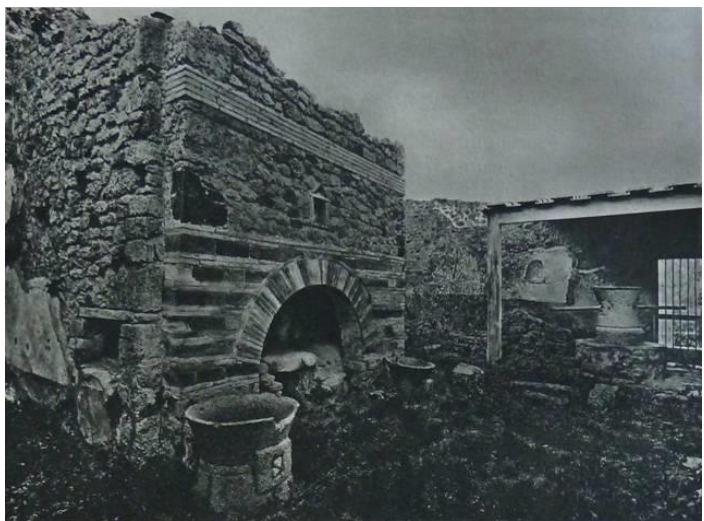

Photo of Oven before Restoration (Courtesy of Jackie and Bob Dunn) 


\section{Bakery 33 - IX.3.19-20}

Although not an atrium-style house, the so-called Taberna di T. Genialis is

probably better considered a house with a bakery in it. The wide main entrance (n. 19) provides access to a large room with postholes for shelves on its eastern wall. East of the front room are two rooms elaborately decorated in $4^{\text {th }}$ style wall painting, which Fiorelli describes as triclinia. A wide doorway on the east side of the northern wall leads to a square room, now filled with rubble. A narrower doorway in the same wall links the front room with mill-room in the back through a long corridor. The mill-room is lined with paving stones and contains the bases of four millstones, two of which are complete with their metae and catilli. A third millstone base has just its meta and the fourth contains neither the meta or catillus. At the center of the millstones a brick column was discovered, which Warsher suggests may have supported a special roof.

An oven (diameter of $2.1 \mathrm{~m}$ ) resides north of the mill-room, with adjoining rooms to its east and west. The eastern room is currently filled with rubble, but Mayeske records the presence of a staircase against the south wall and a raised platform. The room west of the oven is linked to it by a chute. Mayeske describes supports for a table in this room, but they are no longer visible. Another room extends westward and contains two terracotta basins engaged by a masonry platform. Fiorelli says that the basins were lined with lead and a broken kneading machine resides in the southwest corner.

There are two doorways in the west wall of the mill-room. The southern doorway leads to a square room. The northern doorway leads to a rectangular space where Fiorelli describes the discovery of two features apparently collapsed from the second storey, one of which may be the upside down meta in the northeast corner of this room. West of this 
room there is a garden room with water features, an elaborate lararium scene, and a staircase. The west, north, and east walls of the room are lined by a low podium, which may be a water feature. At the center of the room is a labrum (a birdfeeder-like basin). An elaborate lararium was painted on the west wall depicting a coiled serpent approaching an altar and a personification of the River Sarno, in the typical reclining pose.

Fiorelli calls bakery 33 the Taberna di T. Genialis, due to an inscription between entrances 18 and 19, in which T. Genialis Infantio asks that L. Albucius Celsus be made aedile. The association of Genialis with the bakery and house epitomizes the inherent problems presented by attributing ownership to names found in political programmata and graffiti. There were two other dipinti found between entrances 18 and 19. In the first, a group of men and women, Pyramus, Olympionica, and Calvos, asks for the election of M. Casellius Marcellus to aedile. The second records the support of two women, Statia and Petronia, for Casellius and a certain L. Albucius for aedile. It seems as though any of these names could also have been the owner. Della Corte recognizing this dilemma interprets the many names cited by Fiorelli as participants in the baking process, which must be incorrect. He discovers the owner's name, Papirius Sabinus, in a remarkable graffito found across from entrance 20 at IX.6.2 (CIL IV 5065):

\section{HIC DOMVS PAPIRIV SABINIVM}

Despite the seemingly direct information offered by this inscription, its location makes it difficult to ascertain to which house it actually refers. Mayeske misreads the locations of all the inscriptions. The inscriptions recorded by Fiorelli were found outside the bakery, not inside of it. She also states that the CIL IV, 5065 was found on the steps leading to 
the second floor, but fails to recognize that Della Corte is talking about "(VI.2) l'ingresso a contare dall'angolo occidentale. Caupona, col solito bano di vendita e due ambienti per ospitare gli avventori."

Della Corte clearly does not think it could be the caupona (IX.6.2) next to which it was found. But other possibilities exist, such as the so-called House of Pyramus (IX.6.4) and the very nearby domus at (IX.6.3).

Both Fiorelli and Mayeske identify the room east of the oven as the stables. Fiorelli calls the two spaces west of the oven the 'panificio', suggesting that the terracotta basins lined with lead held the water necessary for the "manipolazione del pane." He further suggests that the collapsed features in the space between the mill-room and the garden may have served to wash the grain.

Niccolini 1854 ii, 74; NSc 1871, 134-5; Fiorelli 1875, 397-9; Boyce 1937, 84; Della Corte 1956, 192-193; Mayeske 1972, 131-4; Monteix 2009, 326-329.. 


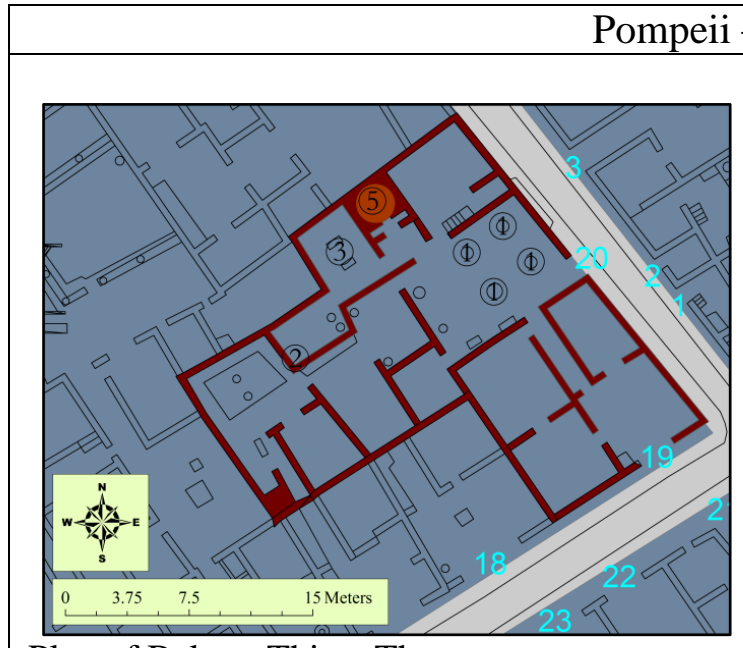

Plan of Bakery Thirty-Three

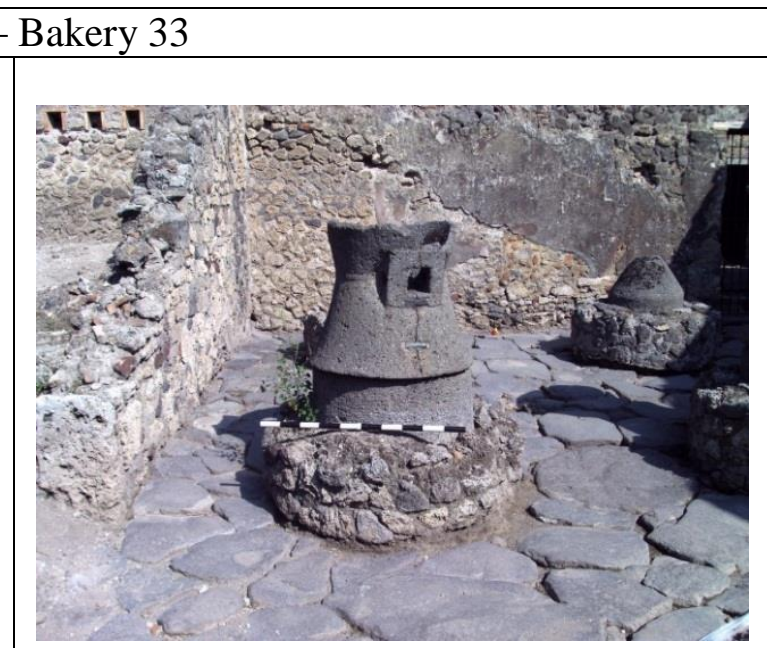

(1) Millstones

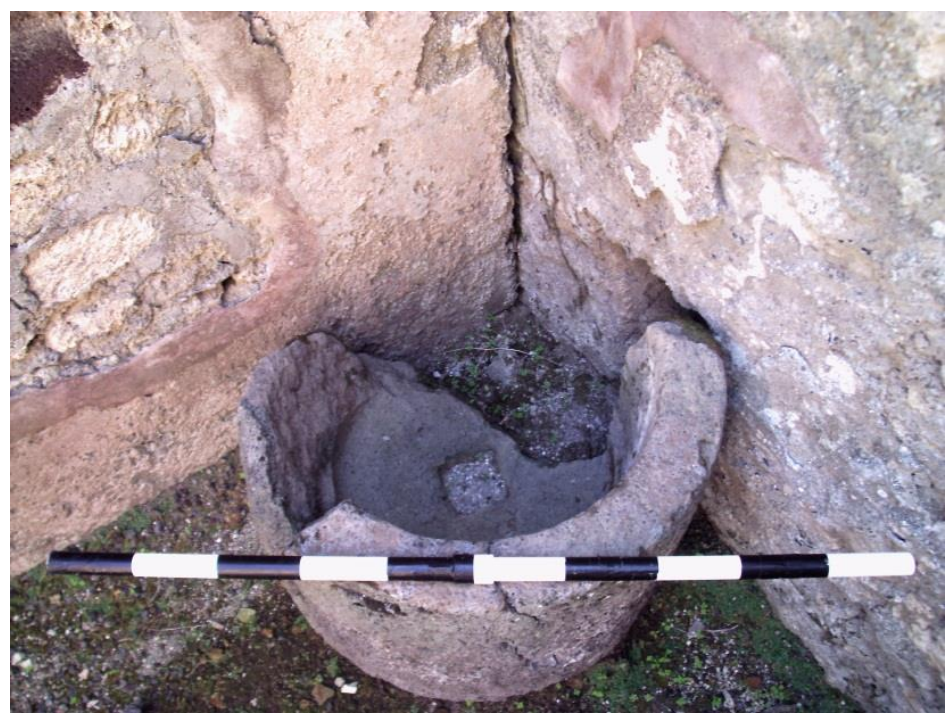

(2) Fragmentary Kneading Machine

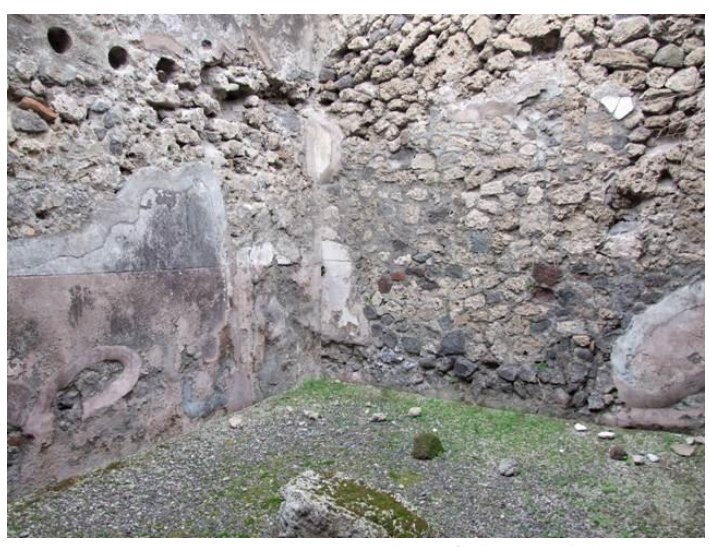

(3) Room Formerly of the Table

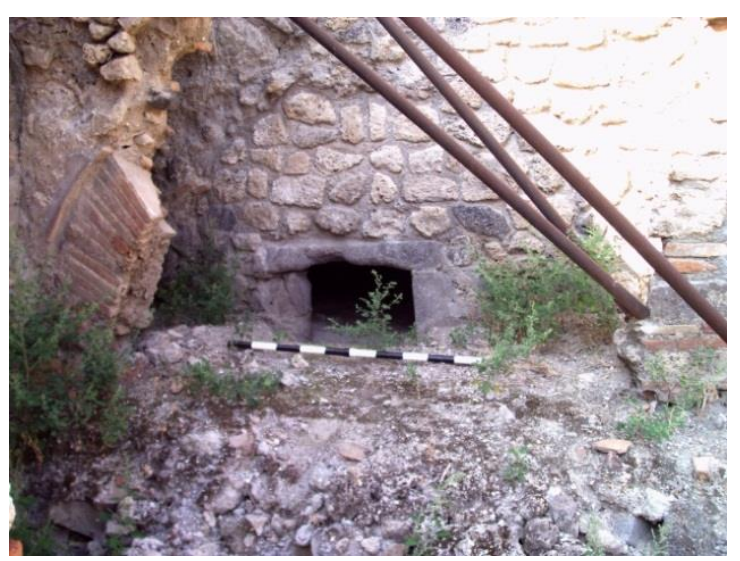

(5) Oven 


\section{Bakery 34 - IX.5.4}

Bakery 34 has a single entrance accessed from the vicolo delle Nozze d'Argento. The front room was decorated simply with plaster, divided into two registers. The next space, a large room, is lined with paving stones and the bases for four millstones, but only one contains a meta. Around the bases there are catilli scattered, broken, and in some cases half buried. The rest of the bakery is divided into two sections. The first section leading from the mill-room from the east consists of two rooms. The first space is delineated from the mill-room by two piers and contains a broken catillus in the northwest corner. The second contains a kneading machine and two broken catilli, one in the southeast corner and one in the northwest corner, which was used as a stand for a terracotta basin. Both the south and east walls have postholes for shelves. The south wall of the room also has a niche below the shelves and a chute linking the room to the front of the oven.

The second section of the bakery, leading from the mill-room on the west, consists of a long corridor leading to two large spaces in the very back of the bakery. The front of the oven opens onto the corridor. There are two half buried terracotta basins in front of the oven. The oven (diameter of $2.1 \mathrm{~m}$ ) is peculiar for Pompeii. It is inserted into a room, but not fully integrated into the masonry of the walls. It lacks the typical curvilinear dome shape, instead consisting of a rectilinear exterior and a cylindrical interior with a flat top.

Excavated in 1877 , the discovery of the bakery occurred too late to appear in Fiorelli's description of Pompeii. Mayeske calls it a bakery without living quarters and categorizes the two large rooms in the south of the bakery as workrooms. These rooms 
did contain counters, but the first contained a lararium, of which only a single Lar holding a bucket was visible in 1971 when Mayeske conducted her research. Moreover, the fourth style wall painting in the southern most room might suggest some domestic functions in the back room. Some part of the back rooms may also have served as stables, suggested by the lack of other spaces available to serve that function.

NSc 1878, 338; Fulvio 1879, 286; Boyce 1937, 85; Schefold 1957, 253; Mayeske 1972, 134-5. 


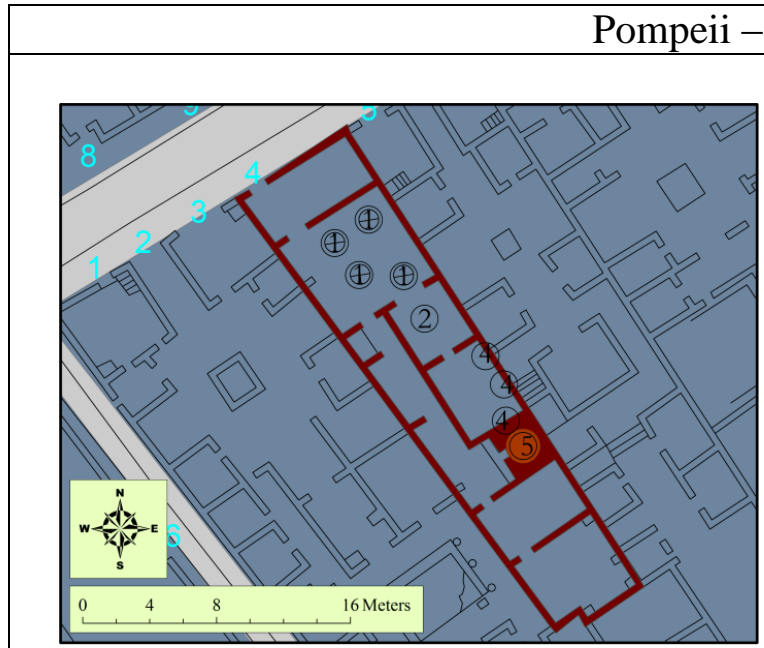

Plan of Bakery Thirty-Four

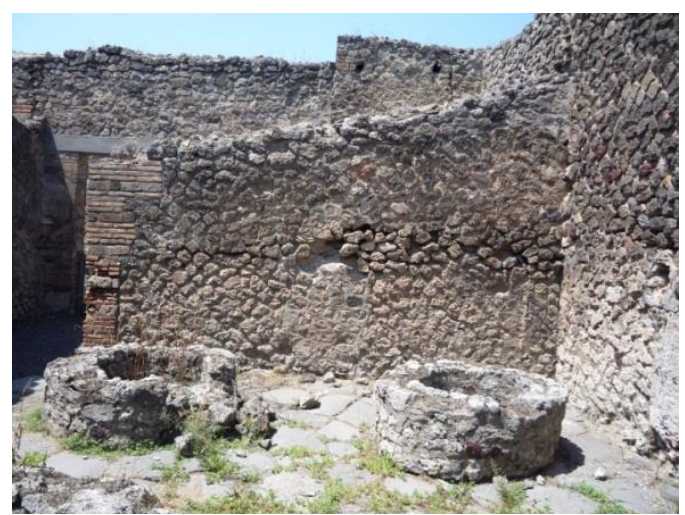

(1) Millstone Basins

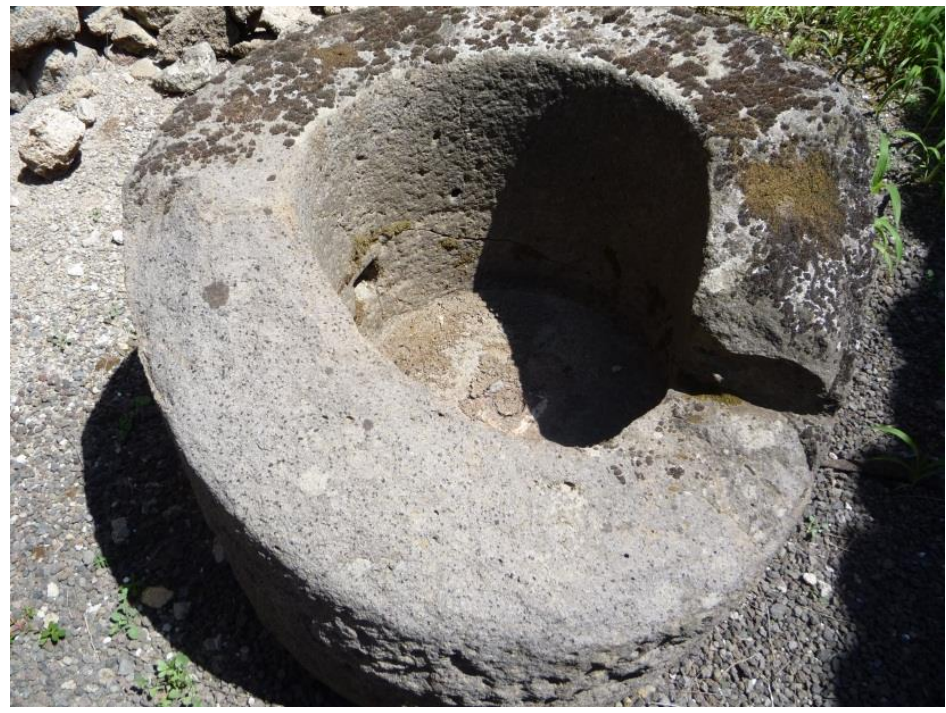

(2) Kneading Machine

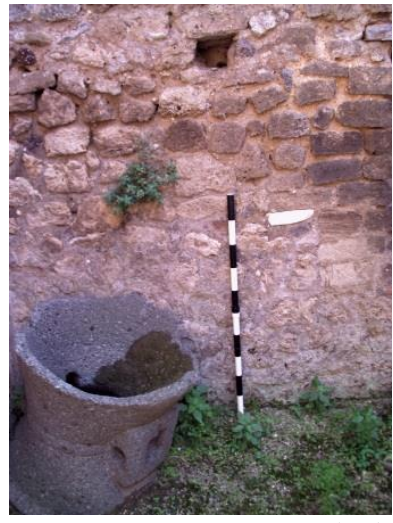

(4) Postholes for Shelves

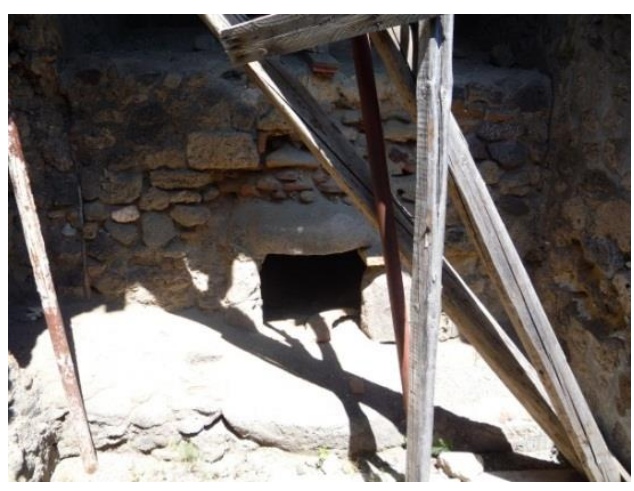

(5) Oven 
Bakery 35 - IX.12.6-7

The so-called Casa dei Casti Amanti contains the most recently excavated and best preserved bakery in Pompeii. It has two entrances, one on the via dell'Abbondanza (n.6) and another as of yet unnumbered entrance on the unnamed vicolo between insulae 12 and 13 of region 9. The main entrance on via dell'Abbondanza provides access to two small front rooms. The first, with access to the back rooms, is plastered with two registers, the lower one a light pink and the upper register white. It contains a beginning of a staircase in the northeast corner. The second room, to the east, has a barrel vault ceiling and is finely decorated in $3^{\text {rd }}$ style wall painting.

The two front rooms lead to a large central space. Four complete millstones are located in the northwest corner of the central room. The millstones have lead sheets covering their bases, though the sheets were once directed upwards to form a canister to catch the output of the mills. The wall north of the millstones has a doorway to an undecorated square room and a small decorated panel with inserted tesserae. The oven (diameter of $2.2 \mathrm{~m}$ ) is integrated into the walls just south of the mills.. The front of the oven is flanked by two basins, one made from an overturned meta and the other by a catillus. A kneading machine and two terracotta basins couched in masonry are situated across from the oven. A chute links the praefurnium with a room south of the oven. The room south of the oven contains supports for a table and postholes for shelves, as well as a small painted panel showing Venus and Cupid.

In the northeast corner of the main room there are two doorways. The northern doorway leads to a small room with a large feature in the southwest corner, perhaps a staircase. The three doorways in this room each lead to a finely decorated room. The 
eastern room is a long rectangular room richly painted in third style, with red panels framed by attenuated columns. In the center of each wall is occupied by a black panel with a small scene of a convivium, except in the south wall where there is a window looking out onto the water feature in the room across the hallway.

The eastern doorway in the northeast corner of the mill-room leads to a hallway. To the south there is a space with a water feature and a lararium. The window into the convivial room is on the right. The hallway leads to a room on the right where one finds a latrine as well as a wellhead comprised of a broken catillus and a hollow marble cylinder shaped like a column. Across from the latrine and well, there is a stable, with the skeletons of five donkeys where are still in the stables. There is a terracotta vessel still above one of the skeletons. The second entrance to the bakery is located in the north wall of the stables. One of the skeletons is partially out the door.

Ciarallo 1993; Ciarallo and Lippi 1993, 110-6; Sica et al. 2002, 179-84. 


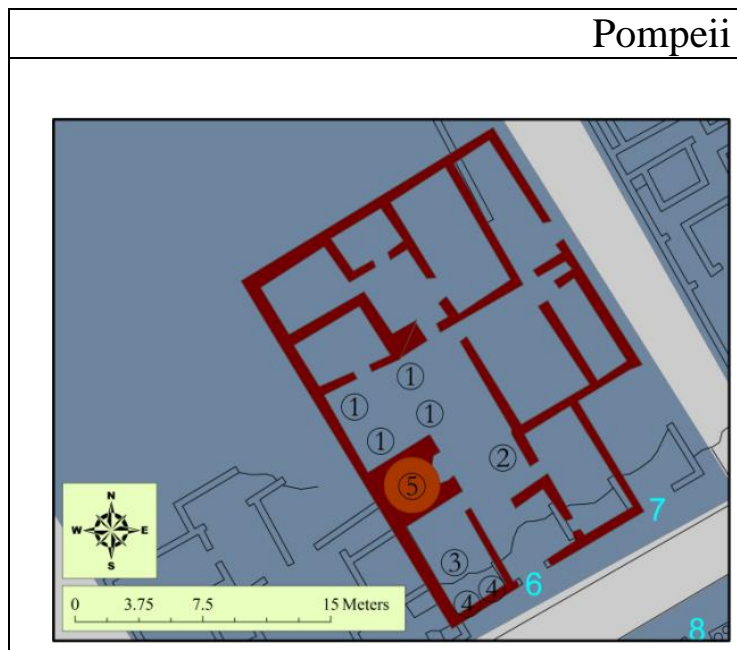

Plan of the Casa dei Casti Amanti

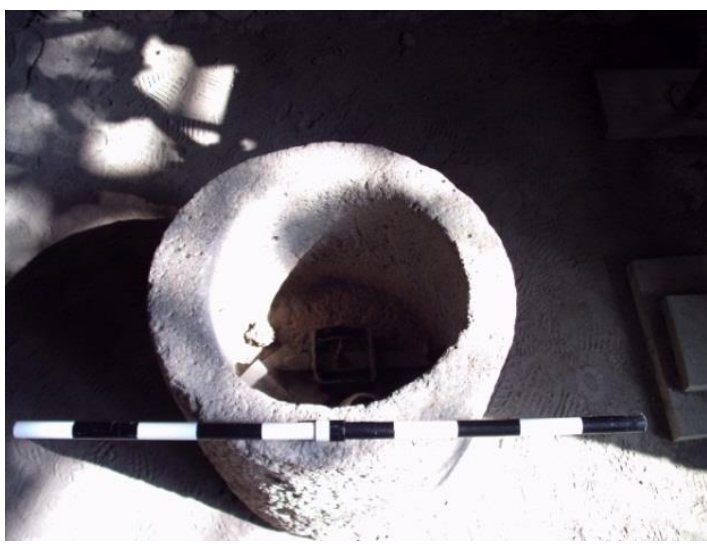

(2) Kneading Machine

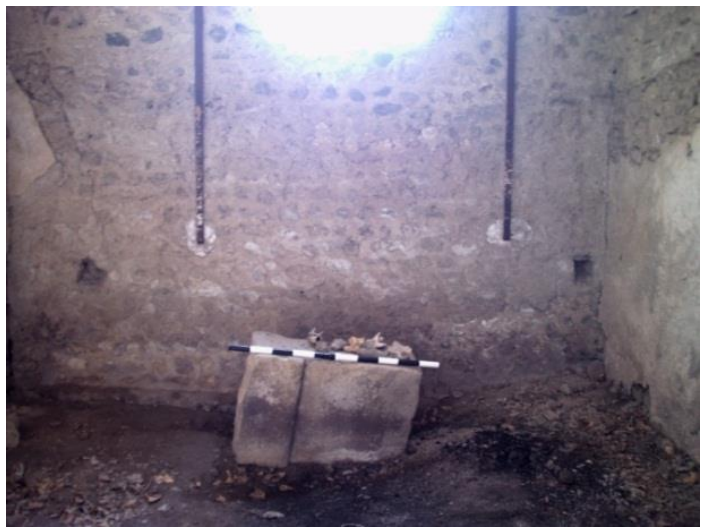

(4) Postholes for Shelves

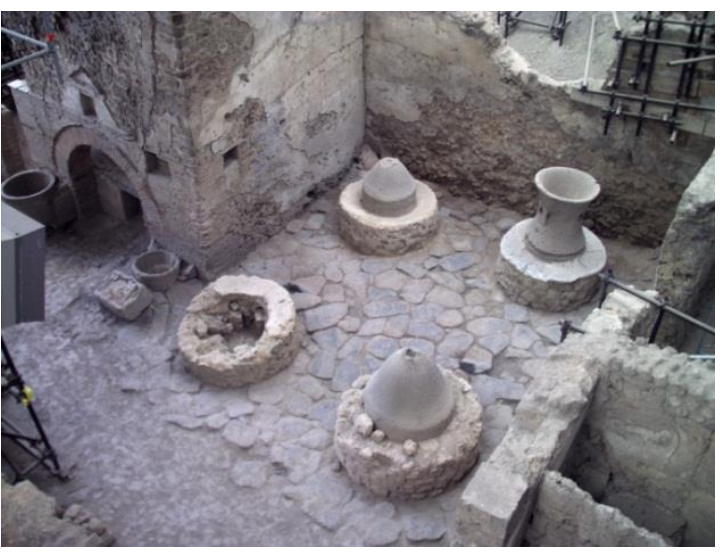

(1) Millstones

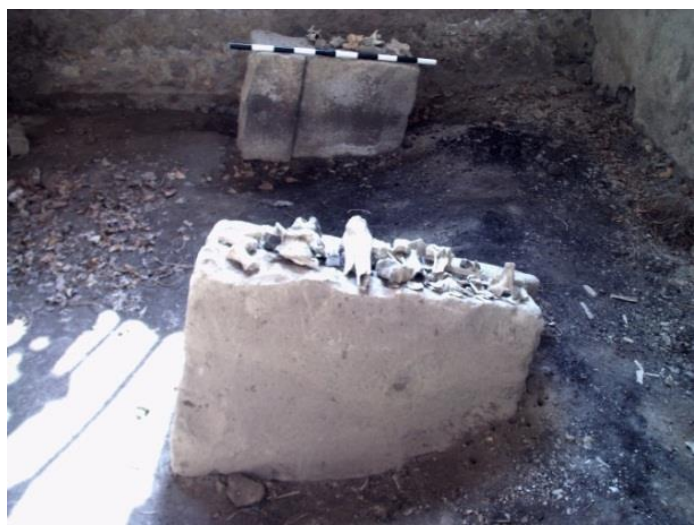

(3) Supports for a Table

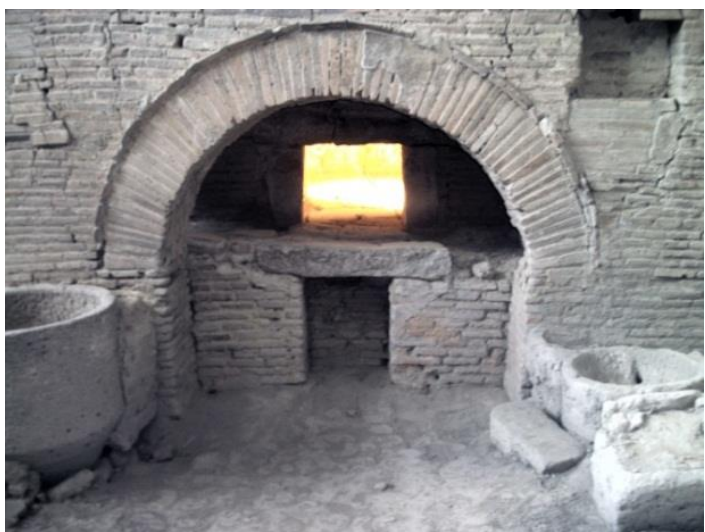

(5) Oven 


\section{Herculaneum}

\section{Bakery 1 - Insula Orientalis II.8}

The so-called Pistrinum of Sextus Patulcus Felix consists of four rooms. There are two millstones in the room that opens directly onto Cardo V. A sigil stamp, the namesake of the bakery, was found in the front room as well. Two doorways link the mill-room to a back room, where 25 circular baking tins were found. They range from $13 \mathrm{~cm}$ to $50 \mathrm{~cm}$, but the bulk of them are between 20 and $31 \mathrm{~cm}$. A small door northeast of the milling room leads to a series of back rooms. The first room contains an oven, with a diameter of $1.8 \mathrm{~m}$. Above the aperture of the oven, two apotropaic phalloi are built into the dome. The space northeast of the oven-room is less well conserved, but Maiuri records a terracotta plaque in the southeastern wall depicting a phallus with legs, supports for a table, and a clay shelves.

Maiuri identifies the patron of bakery one as Sextus Patulcus Felix due to the discovery of the sigil, which may be a bread or wax stamp. He further suggests that the baker of this establishment was a pistor placentarius, due to the baking tins, despite the fact that the tin display a range of sizes. Maiuri identifies the millstones as molae manuariae, or human operated millstones. Indeed, the bakery lacks the paving stones commonly lining the mill-rooms of Pompeii. Nevertheless, the height and size of the catilli would suggest a greater force than humans can apply, probably the work of donkeys.

Maiuri1958, 456-61; Deiss 1989, 123-4; Wallace-Hadrill 2011, 276-7. 


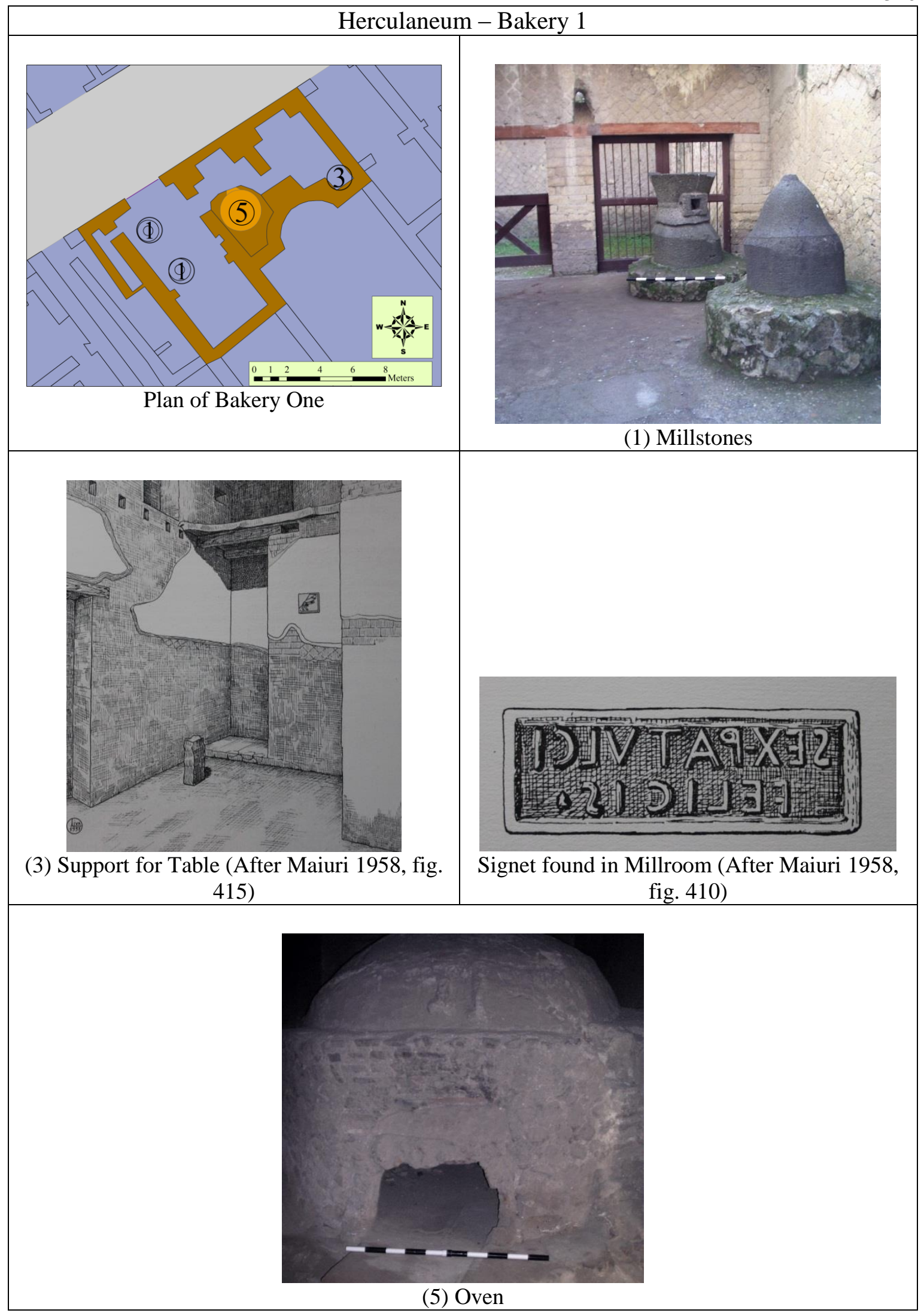




\section{Bakery 2 - Insula Orientalis II.1a \& 3}

Bakery two is part of a large complex with an entrance on Cardo V (n. 2) and another entrance off of a side alley (n. 1a). The side entrance gives access to a large room with an oven in the southern most corner and two millstones, next to which was found the skeleton of a donkey. Its two millstones and a partly destroyed oven ( $2.4 \mathrm{~m}$ in diameter) are in a room that opens directly onto a narrow street perpendicular to Cardo V. A long room, probably a bathroom, resides to the northwest of the mill-room. To the northeast, the mill-room links to a long room with post-holes for shelves and a half-buried stone vat in the northern corner, maybe a catillus. Beyond the north wall of the mill-room there is a long latrine with two entrances, potentially indicative of a separation of space based on gender or status.

The fine decoration of the complex, combined with its unconventional form, present some difficulties for interpretation. Maiuri and Esposito agree that the complex was once an "abitazione signorile", but transformed into a bakery at a later date. Based on the $4^{\text {th }}$ style decoration, Esposito hypothesizes that the conversion occurred in the final years of the city's life in antiquity. Maiuri notes that the door between the mill-room and the well-decorated rooms to the south was not part of the complex's original construction. Wallace-Hadrill suggests that bread from the bakery may have been sold out of entrance 1a or in the shop at entrance 2, though the shop does not communicate with the bakery.

Maiuri 1958, 451-54; Deiss 1989, 122-3; Wallace-Hadrill 2011, 275; Guidobaldi et al. 2012, 183-9. 


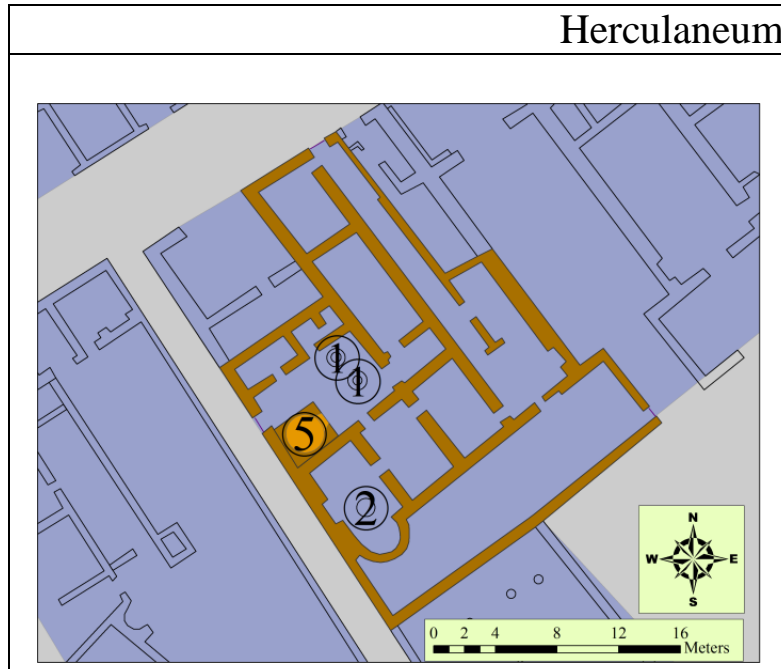

Plan of Bakery Two

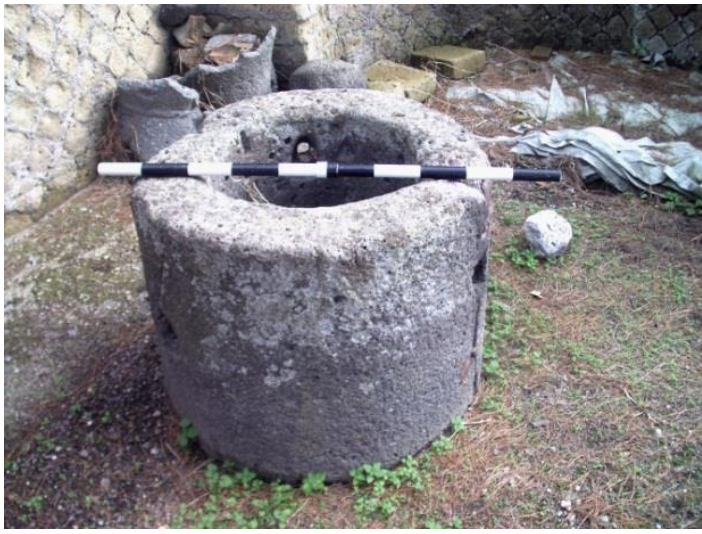

(2) Kneading Machine

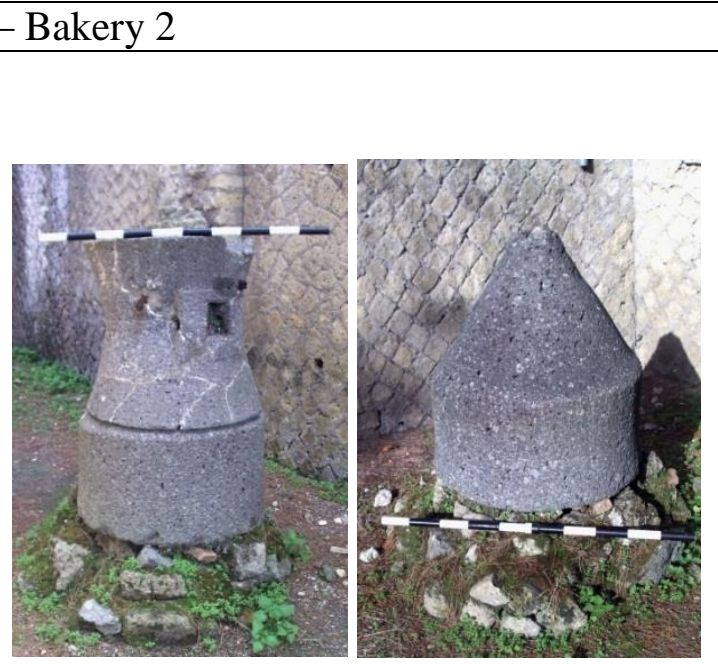

(1) Millstones

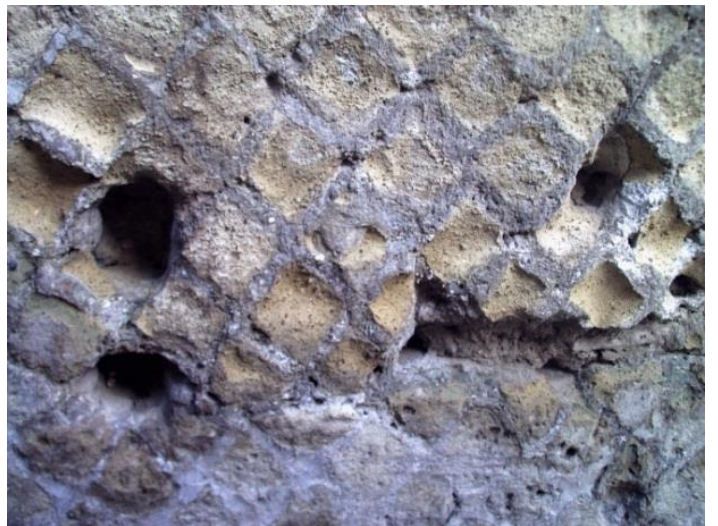

(4) Post-holes for Shelves

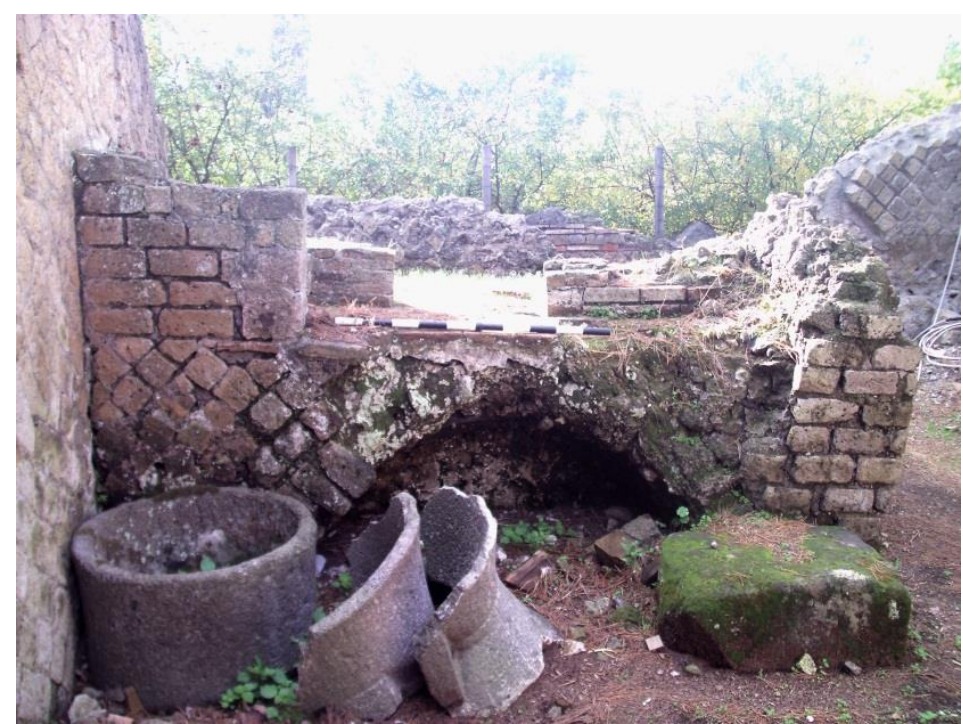

(5) Oven 


\section{Ostia}

\section{Bakery 1 - I.II.2\&6}

The so-called the Caseggiato del Balcone Ligneo, along with its neighbor the Caseggiato del Pantimimo Apolausto, was excavated during WWI by Roberto Paribeni, who was director of Excavations at Ostia from 1914 to 1924 . The bakery originally consisted of a large house dating to the early part of Hadrian's principate, later subdivided into two smaller spaces. Brick-stamps found beneath the oven dating from 161 to $176 \mathrm{AD}$ suggest that the remodeling of the house and the installation of the bakery occurred during the principate of Marcus Aurelius (CIL XV 622). A fauces and a shop entrance give access to the bakery from the via di Diana; two other entrances open onto the so-called piazza dei Lari, at the center of which stands Ostia's best preserved compitum, or public shrine. The fauces leads to a central space paved with lava stones. A cylindrical object was found in this room, which Paribeni describes as a mill, but which Bakker suggests may be a kneading machine. A small fragment of a kneading machine still found in this area may be that object.

The central room divides the bakery into two halves, providing access to both the east and the west. To the west, a rectangular room contains a large oven (W: $5 \mathrm{~m}, \mathrm{~L}: 5.2$ $\mathrm{m})$. North of the oven room, there is a line of three rooms. The first, directly north of the oven room, is floored with paving stones. The other two once had entrances onto the via di Diana, but they were blocked off and paved with basalt stones, probably around the same time the oven was installed and the bakery split off from the rest of the previous house. On western wall of the first converted shop Paribeni found plaster painted white and decorated in red with a stylized depiction of a cantharus and vignettes, probably a 
vestige of the decoration from the first domestic phase of the structure. In fact, the beam holes for an inserted upper floor disrespecting the fresco suggest that the floor preserved the decoration. Paribeni notes the discovery in both converted shops of small fragments of objects, potentially the remains of millstones or kneading machines, but his description does not warrant a clear attribution. The eastern half of the bakery consists of another courtyard space which links to a square shop-like room to the north and another room to the east, which contains postholes low to the ground and troughs. The central courtyard space contains a staircase to an upper floor, a wellhead, basins, and a basalt paved floor.

Bakker interprets the baking complex as a public space accessed from the piazza dei Lari, but lined with shops of which the bakery is only one. He cites the paving stones and the thresholdstones with indications of locking mechanisms on the lintels even within interior doorways. Paving stones might indicate an inside access node linking the piazza dei Lari with a series of shops within, but they are also the customary flooring for all of Ostia's bakeries. Moreover, not all of the interior doorways have thresholds with locking mechanisms and those that do may be reused spolia from previous constructions. The obvious stables across the courtyard from the oven would suggest that the entire space was a single establishment. In terms of production, Bakker argues that milling and kneading occurred in the two converted shops north of the oven, with the loaves baked into dough in the large oven.

NSc 1914, 70; NSc 1916, 411-22; Blake 1973, 170; Heres 1982, 369-371; Bakker 1999, 90-4. 


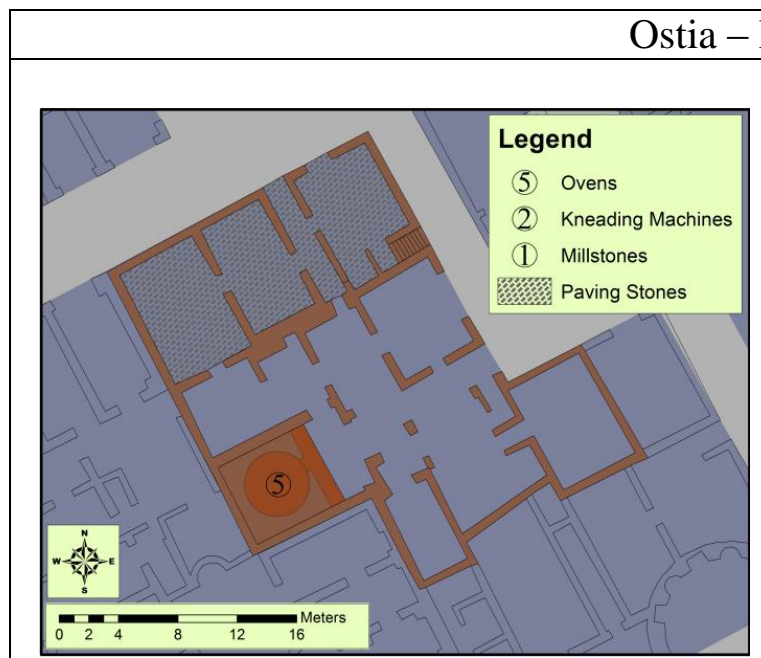

Plan of Bakery 1

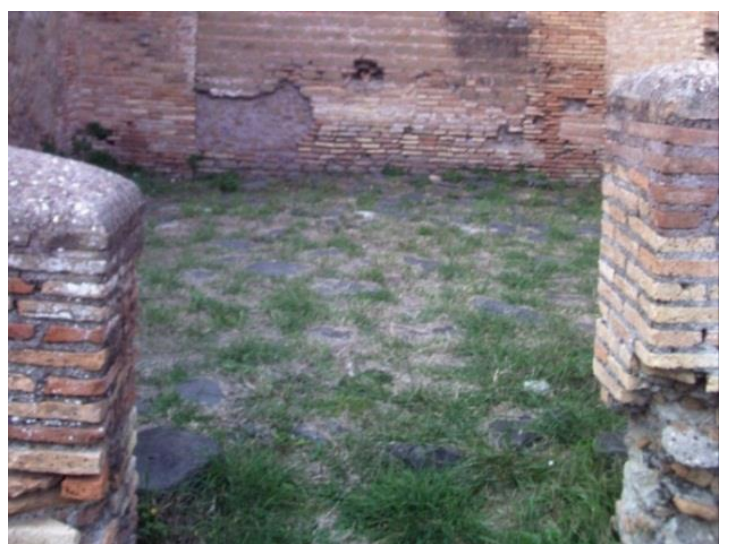

Paving stones

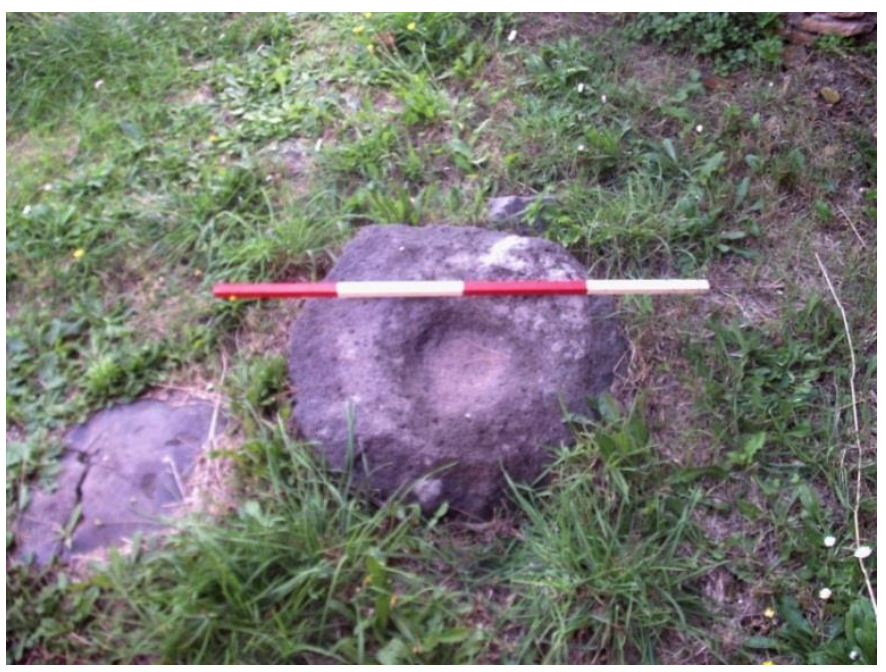

Fragment of Kneading Machine

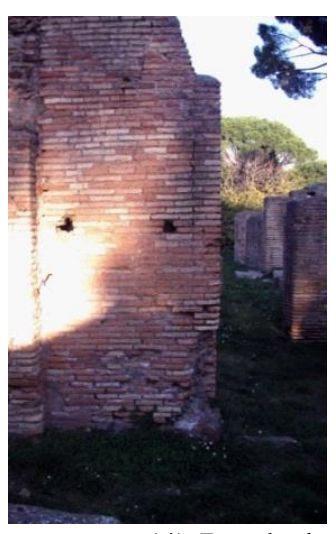

(4) Postholes for Shelves

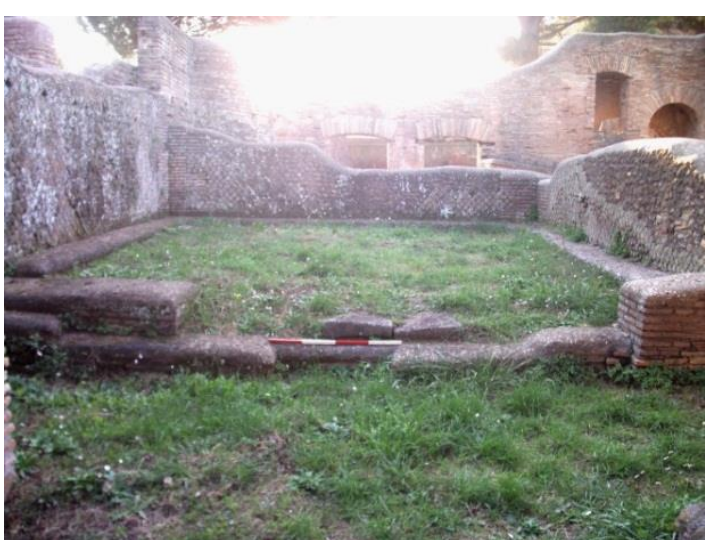

(5) Oven 


\section{Bakery 2 - I.III.1}

Excavation of the so-called Caseggiato dei Molini began in 1870, but was put on hold during the Risorgimento. Work on the bakery restarted in 1913 and completed in 1916 by Raffaele Finelli and Guido Calza. During the interim, much of the bakeries features were disturbed and in some cases stolen. In terms of area, it is the second largest bakery in Ostia and one of the best preserved. The bakery consists of three zones. The first zone is a series of spaces lining the via Molini and the via di Diana; they provide access the bakery and are primarily floored with opus signinum, except the room just south of the derelict oven, which is paved with basalt street stones. The second zone is a long central space subdivided in to five spaces by four long arches. The floor of the long central space consists entirely of basalt paving stones, in which millstones are set. There are six metae integrated into the floor, four with catilli, and the fragments of millstones strewn about the room. In this area were found a large number of metal objects, including sheets of bronze with gods and constellations in relief. Also among the objects were statuettes of gods, a lar, a scorpion, and a child of African descent. North of the millroom is another space also paved with basalt stones, into which are fixed five kneading machines, all with a $0.55 \mathrm{~m}$ radius and depth. The third zone is a long corridor paved with opus spicatum along the west side of the bakery. In the corridor there are two basins or table supports, which lack the typical water proof plaster. At the south end of the corridor is a shrine or lararium. At the north end of the corridor there are post holes for shelves cut into the corner of the east and north walls. Across from the postholes there is a doorway flanked by two apertures angles towards the oven entrance. The doorway leads 
to a room with a large oven, with a length of $4.8 \mathrm{~m}$ and a width of $4.6 \mathrm{~m}$. The dome of the oven is masonry on top of a course of stone blocks, which bear wear marks in lines.

The excavators of the bakery report indications of fire on the walls and a great number of coins under the rubble from the upper stories, the latest of which date to dominate of Probus. Bakker suggests that the bakery was destroyed by a fire in the fourth quarter of the third century. The basic structure was built in the Hadrianic period, but consisted of shops lining via Molini. Based on the construction of certain walls, Bakker further argues that the bakery was installed in the Severan period. Certainly the current form of the bakery dates to this time. The bakery may have been installed in the late second century, as indicated by the derelict oven in the room east of the main oven. In fact, a brick stamp in the fabric of the derelict oven, Q.OPPI.VERECUNDI, dates to 123 $\mathrm{AD}$ in the principate of Hadrian (CIL XV 273). The date provides only a terminus post quem, but significant additions and renovations occurred under the Antonines. The complex of shops may have been renovated into the bakery in the late second century only to be modified later in the fourth century, accounting for the derelict oven and the clearly multiphasic nature of the bakery.

NSc 1913, 184; NSc 1915, 249; NSc 1917, 323; Blake 1973, 171-5; Bakker et al. 1999, 16-60. 


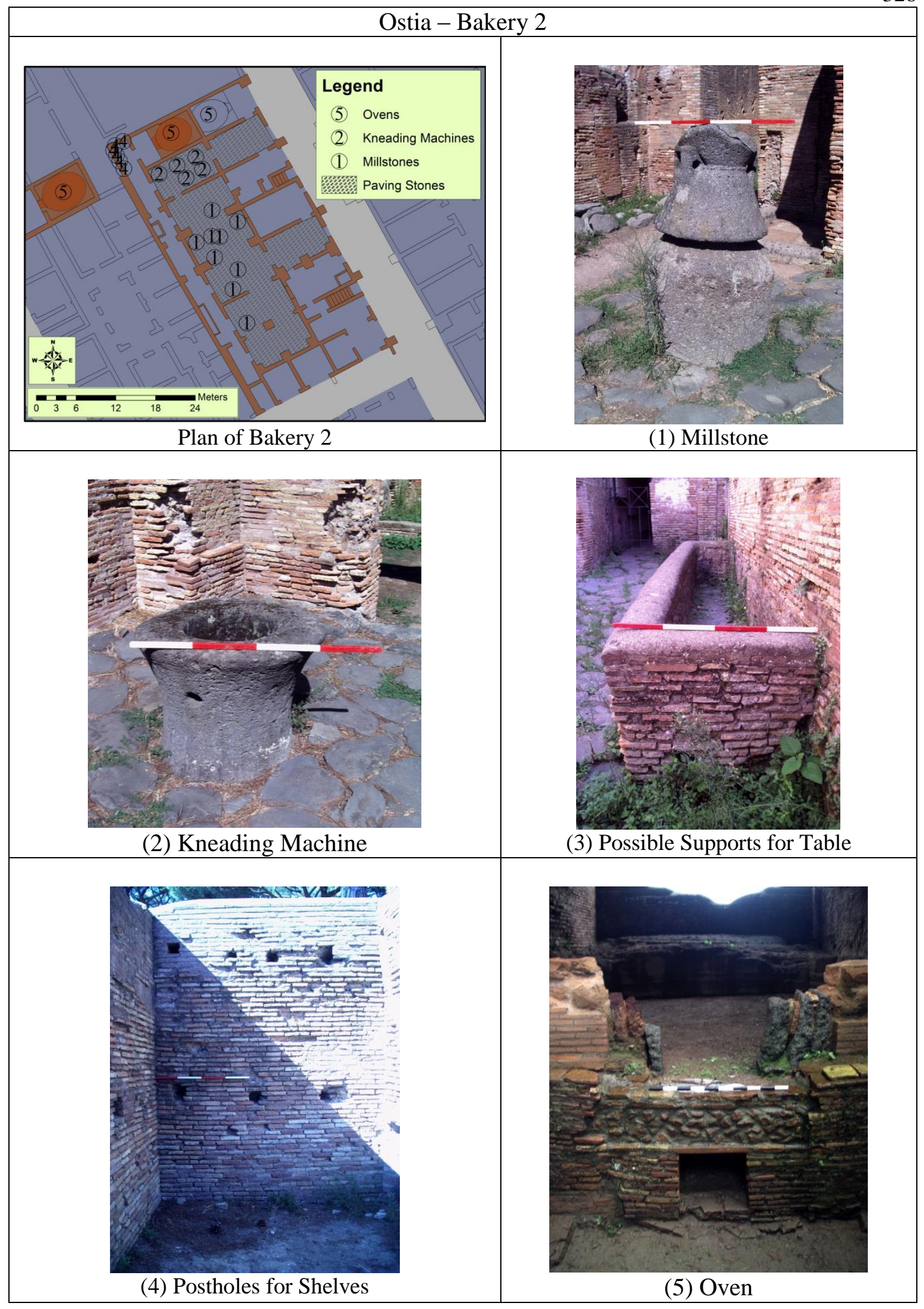




\section{Bakery 3 - I.III.5}

Bakery three is a small two-room establishment on via dei Balconi, excavated from 1931 to 1934. A hole was created in the northeast wall of the front room into the back room, which consists entirely of the oven $(5.5 \mathrm{~m}$ in length and $5.05 \mathrm{~m}$ in width). The room with the oven once had a doorway in its east wall, but it was blocked sometime in antiquity, probably when the oven was inserted into the room. The location of the oven is particularly interesting because it aligns with both the main oven and the defunct oven in bakery two. This may suggest that they were part of the same complex at some point, in which case the oven was reoriented to face the west rather than the (explaining the hole cut into the wall for access to the oven). Bakker does not include this establishment in his work on the city's bakeries, but he does address it elsewhere. He concludes that the function of the oven is unclear and indeed it is significantly larger than most ovens in the city, but it also shares many traits with Ostia's other ovens. The peculiar stone blocks lining the side of the oven with the two lines of grooves are also present in bakery three's oven. An oven of this sort could not produce the temperatures necessary to fire pottery nor was it well suited for smelting or glass blowing, but the oven could have served any number of cooking purposes, including the preparation of meats.

NSc 1917, 180; Bakker et al. 1999, 34; Oome 2004, 12-21; Oome 2007, 233-46. 


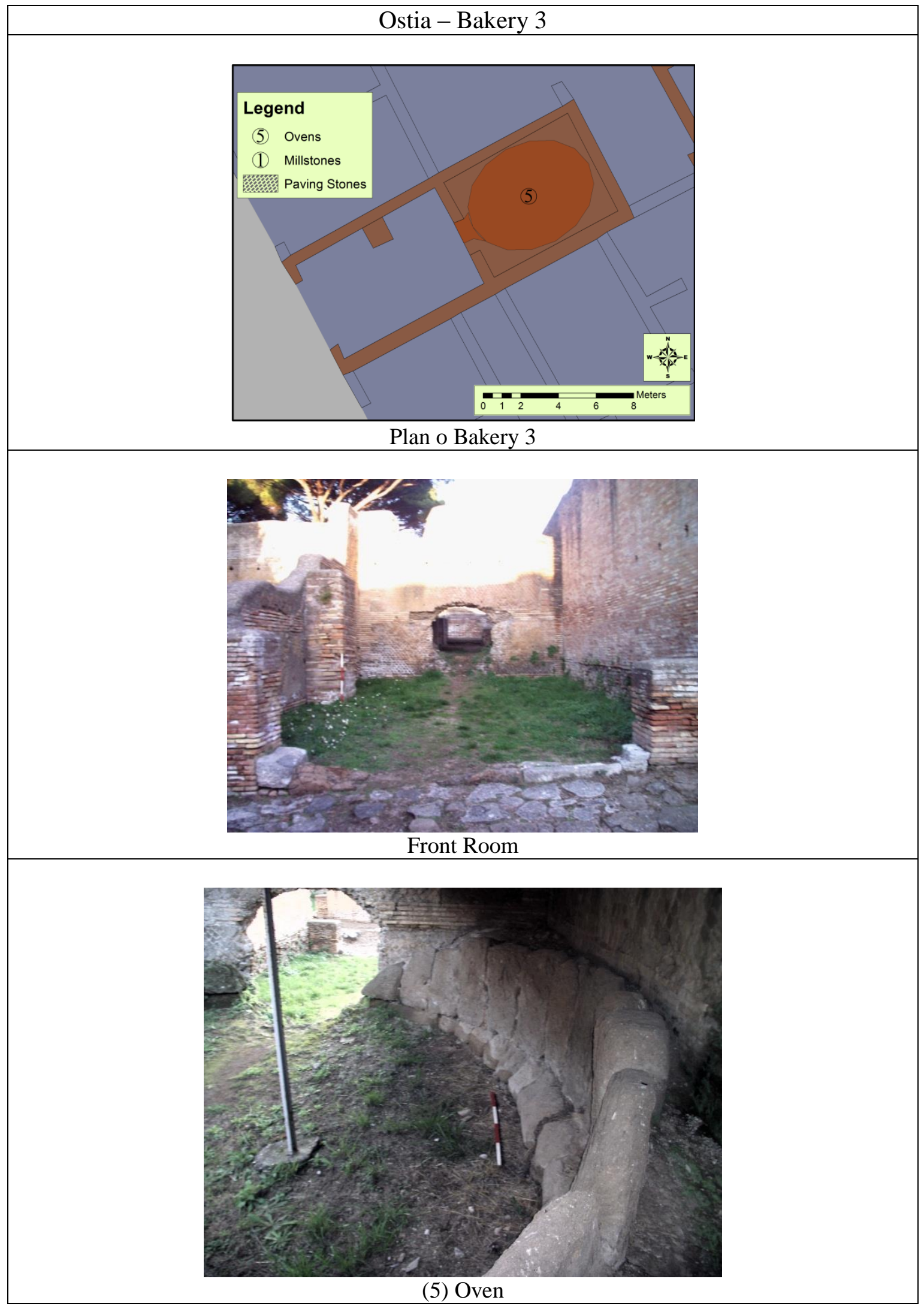




\section{Bakery 4 - I.IX.2}

The caseggiato at I.IX.2 resides at the intersection of via delle Casette Repubblicane and via del Larario. The excavation of the bakery occurred sometime before 1923 when Guido Calza published a description of it. The bakery is divided into a north and south half by a line of piers. The north half is subdivided into four compartments by the piers. The center two compartments are paved with basalt stones, the floor level of which is $0.7 \mathrm{~m}$ above the current floor level of the other spaces in the bakery. On Calza's plan of the bakery there are three spaces in the paving stones, which may have accommodated the bases of millstones. The southern half of the bakery is similarly divided into four compartments by the piers. Calza's plan shows a basin on the far western compartment and a now vanished well in the far eastern compartment of the southern half of the bakery. The eastern compartment also has a doorway to a trapezoidal room to the south, which contains an oven and postholes for shelves on the south and west walls. Calza's plan indicates some sort of counter or table below the shelves. The diameter of the nearly circular oven is $3.35 \mathrm{~m}$.

Based on construction techniques, Bakker and Heres suggest a third or fourth century date for the installation of the oven and the anomalous construction of the oven in terms of size and material supports this hypothesis. The form of the bakery, with the various compartments delineated by piers, leads Bakker to suggest the structure was originally built for shops. The unpaved floors are currently ca. $0.7 \mathrm{~m}$ lower than the other rooms, but the foundations between piers in these rooms are at the same level as the rooms with the paving stones, implying that the excavators dug through the floors. Bakker takes the paving stones as an indication of milling, which is corroborated by the 
three to four gaps for millstone bases in the pavement. Bakker finds it difficult to identify the function of the rooms to the south, including the oven room.

SO I, 235; NSc 1923 182-3; Bakker et al. 1999, 95-6. 


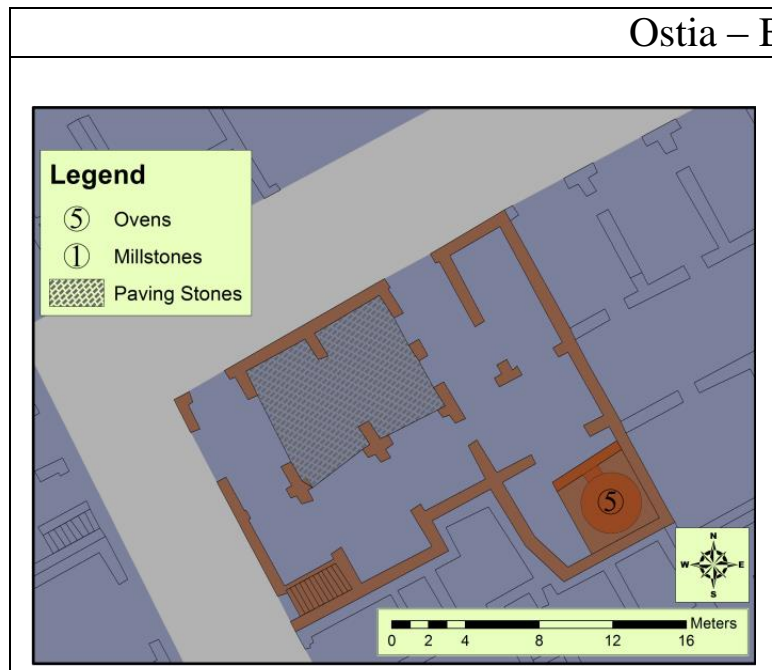

Plan of Bakery 4

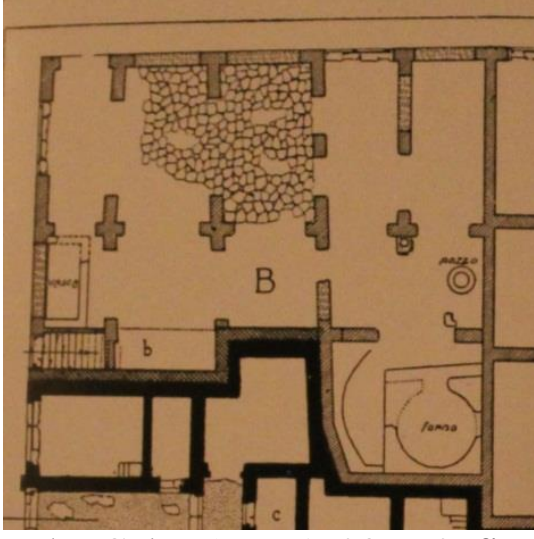

Plan by Calza (NSc 1923, t. 2, fig. 1)

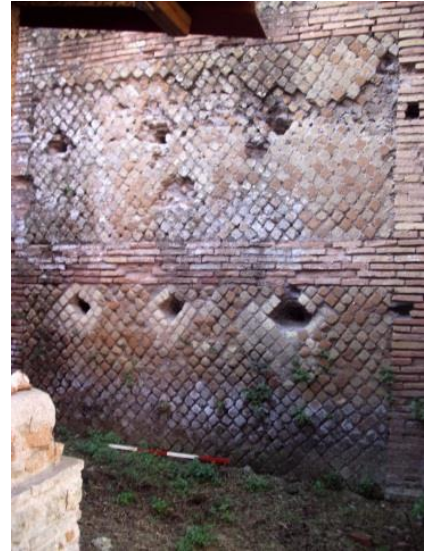

(4) Postholes for Shelves

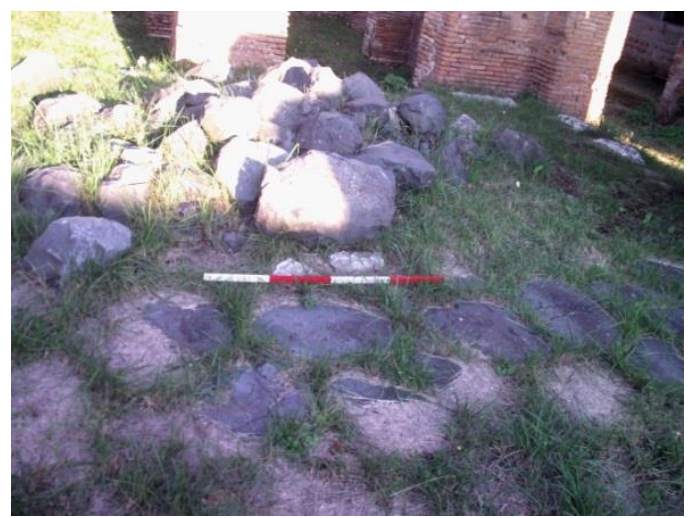

Paving Stones

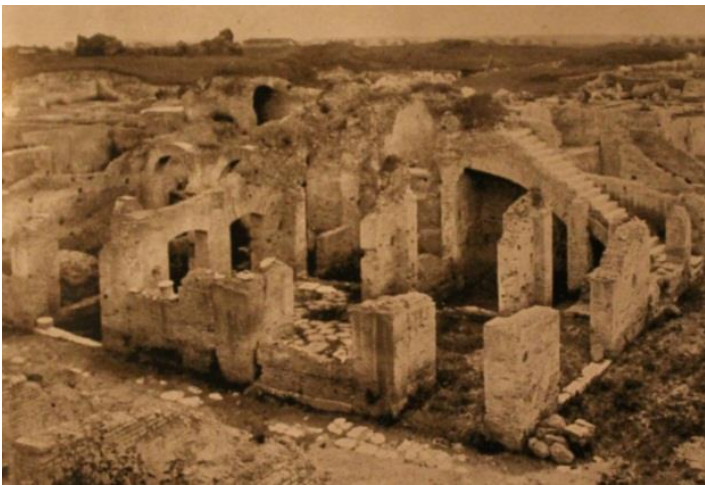

Photo Just after Excavation (NSc 1923, t. 3, fig. 1)

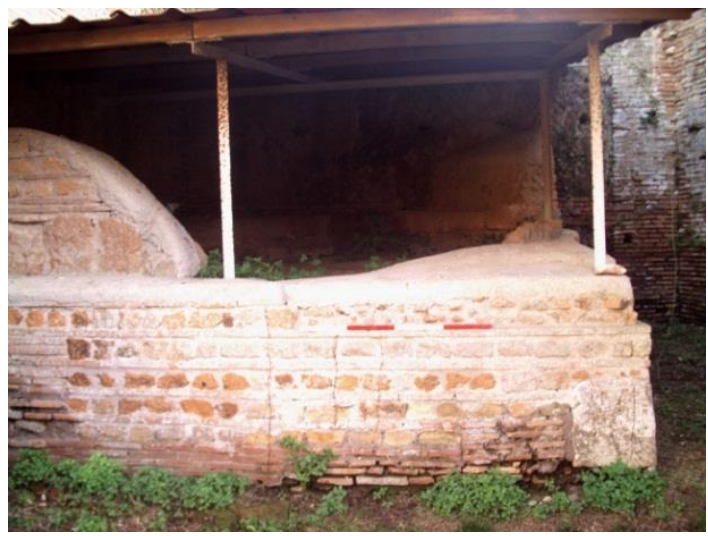

(5) Oven 


\section{Bakery 5 - I.XII.4}

The so-called Caseggiato della Cisterna is a large complex of diverse spaces at the intersection of the Decumanus and Semita dei Cippi. Nine liminal spaces, commonly called shops, provide access from the Semita dei Cippi. A broken fragment of a kneading machine was found in the shop-space just east of the oven. A group of cisterns and basins in the southern end of the complex give the establishment its name. Other rooms, paved with stones and displaying hoofmarks were discovered under the exedra to the north, but built over in antiquity. Gaps in the paving stones suggest millstones or kneading machines were once located in the area of the exedra. Just south of the exedra basalt paving stones comprise the floors of the rooms that surround a large oven with a diameter of 4 by 4.2 meters built into a semicircular niche, a vestige of the Hadrianic bath complex.

The Caseggiato della Cisterna contains the most problematic bakery in Ostia, in terms of both date and interpretation. The earliest construction evident in the caseggiato dates to the principate of Hadrian, but seems to have been a bath or some type of monumental architecture. Heres dates the elements pertaining to bread production to the end of the $2^{\text {nd }}$ century $\mathrm{AD}$ based on construction technique. Excavations by the Italian Soprintendenza found paving stones with hoof marks below the floor of the exedra north of the bakery. The exedra as well as the Foro della Statua Eroica date to the middle of the fourth century AD. The bakery in the Caseggiato della Cisterna had apparently ceased to function by that time or had significantly changed form, perhaps reducing its scale to new economic realities. Bakker presents the possibility of a waterwheel in the area of the cisterns, which would have been fed by the aqueduct only a short distance away, but he 
also finds such a phenomenon based on a lack of direct evidence and the absence of such an innovation anywhere else in the city.

SO I, 132; Blake 1973, 176; Heres 1982, 386-92; Bakker et al. 1999, 97-9. 


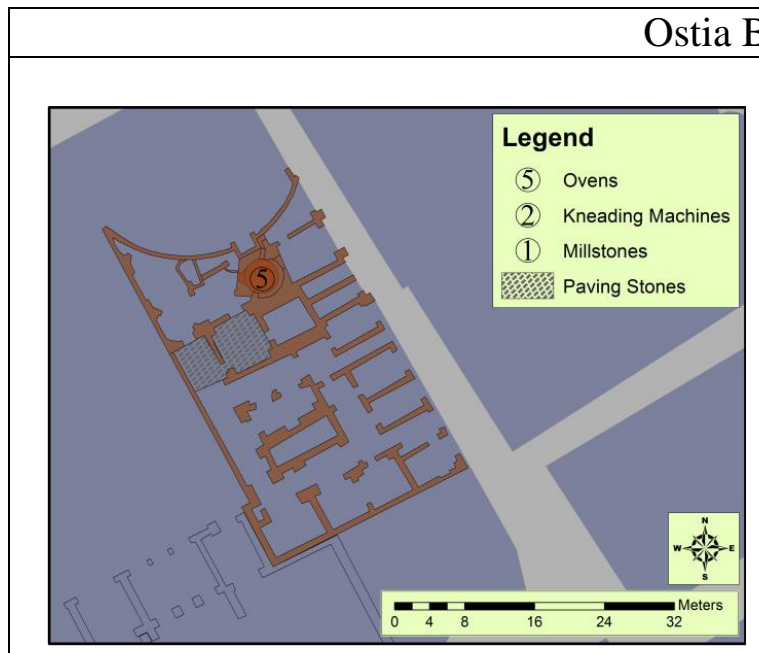

Plan of Bakery 5

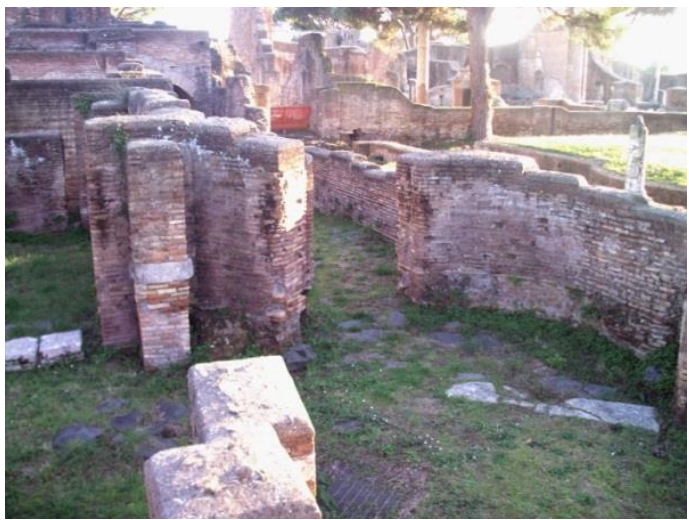

Paving Stones

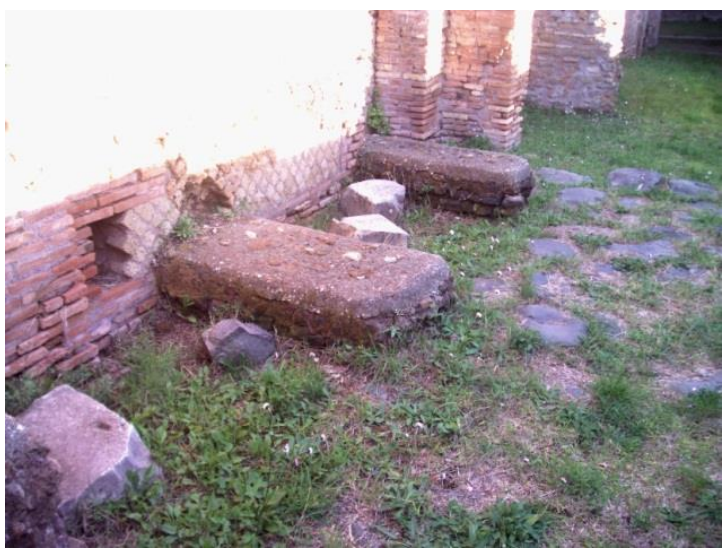

(3) Possible Table Supports and Paving Stones

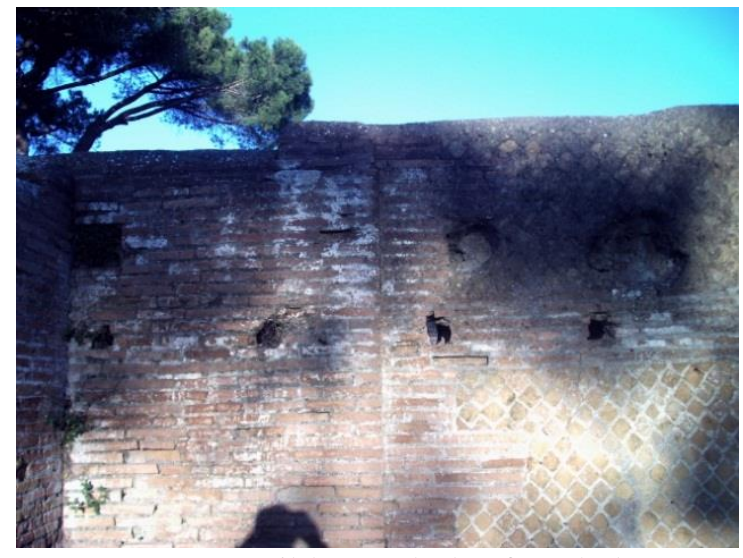

(3) Possible Postholes for Shelves

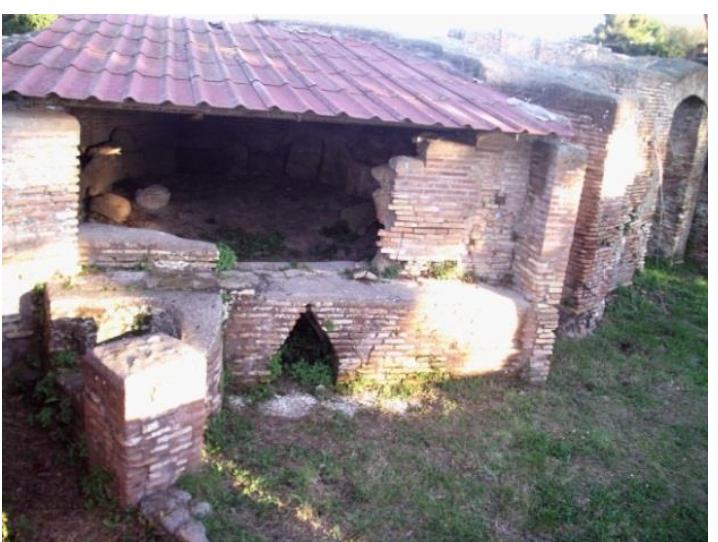

(5) Oven 


\section{Bakery 6 - I.XIII.4}

Located in a triangular insula wedged between Semita dei Cippi and the Cardo Maximus, the so-called Molino is the largest bakery in Ostia. It contains six - maybe seven - simultaneously operating millstones, four kneading machines, and a single large oven. There are eight shop-like spaces, four lining each street. Among the shops, wide fauces lead to the bakeries interior. The interior of the bakery consists of two spaces. The first space is a large sala with three aisles delineated by piers. The millstones and kneading machines reside in the aisles, conveniently offset in the intervals between the piers. The northwestern aisle contains the four kneading machines. Six millstones inserted into the floor and a seventh in fragments reside in the central aisle. A number of bronze objects were found in this area, including typical vessels, a Dionysian mask, and several candelabra. Bakker found holes in the original masonry for beams to support a platform above the millstones. The southeastern aisle aligns with the two fauces and contains several large basins, one of which has its own staircase descending to its bottom. Another staircase southwest of the basins leads to an upper floor. On the south side of the bakery there is a long rectangular room with a large oven installed in the west end. It has an average oven diameter of $5.0 \mathrm{~m}$. The walls of the room consist of piers like those that delineate the aisles, but the intervals are filled in with brickwork. The oven surface is lined with tiles, one of which has a brick stamp with the words: OPVS DOLIARE EX PRAEDIS AVG N; C COMINI SABINIANI. The brick stamp is dated to 161-168 AD.

The Molino was excavated from 1934 to 1938 under an initiative by Musolini. Bakker dates only small portions of the bakery to the first century AD. The bulk of the bakery was built in two phases from 100 to 125 AD. Additions and repairs continue until 
the $5^{\text {th }}$ century AD. The brick stamp in the oven's surface implies a date for the current form of the oven sometime after $161 \mathrm{AD}$. The wall dependent on the oven (thus later than it) just to the west daters to the early $3^{\text {rd }}$ century, thus the oven in its current form was installed sometime between the third quarter of the second century and the first quarter of the third. This does not, however, preclude a previous form of the oven. The phases of construction do suggest a long duration of use as a bakery, from the initial design in the first quarter of the second century to repairs around AD 400, nearly 300 years of use.

The initial design of the structure required few alterations to operate as a bakery. The millstones and kneading machines are conveniently placed at intervals with the piers; the oven room is part of the early construction phases. The suitability leads Bakker to hypothesize that the Molino may have been specifically designed to serve in that function at its inception in the first quarter of the second century. Such a hypothesis is corroborated by the second floor platform built into the early second century masonry above the mills and kneading machines, which Bakker interprets as storage. The platform probably also served as a superstructure to support the rope and pulley systems that would have been needed to lift catilli from their metae.

The shop-like spaces lining both the Cardo Maximus and the Semita dei Cippi lead Bakker to suggest that the bakery served as a pistrinum privatum, a privately owned commercial bakery serving the local consumers of Ostia. Certainly the bakery has ample and perfect space for shops and is ideally located on two main streets near the forum, the Terme del Foro, the Terme del Filosofo, and the Terme del Faro. It is also conveniently located near the horrea at V.I.2 and I.XII.1, suggesting potential sources of the bakery's grain. 
SO I, 38, 125, 134, 153, 198, and 237; SO VIII, 10; Lugli 1957, 604; Packer 1971, 14; Meiggs 1973, 274; Blake 1973, 157 and 177; Steinby 1975, 42-43; Heres 1982, 386-92; Heres 1988, 37; Bakker et al. 1999, 61-79. 


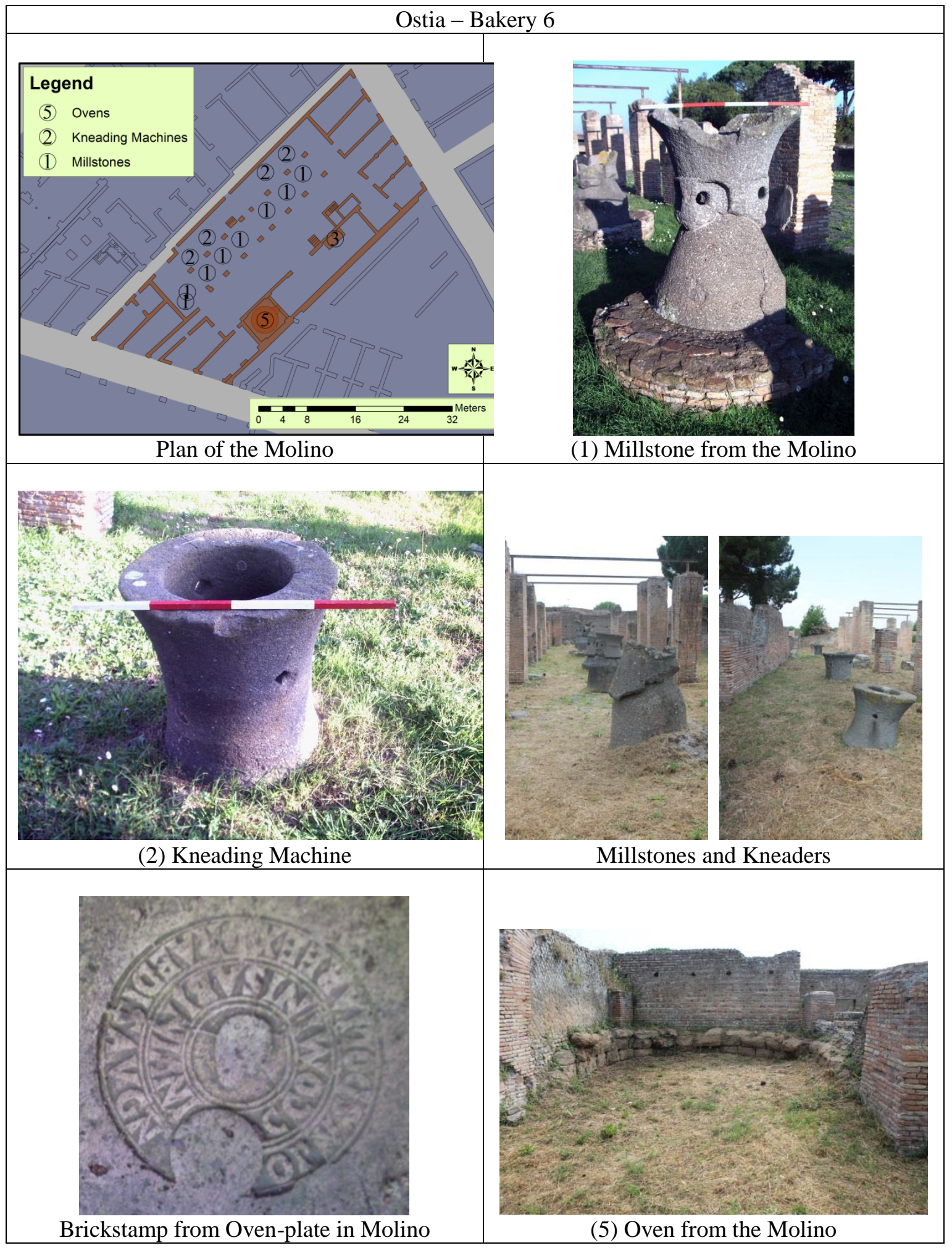




\section{Bakery 7 - I.XVII.1}

The so-called Caseggiato con Fornace per Laterizi shares walls with a series of small spaces to the south and the Terme di Mitra to the north. The one-room establishment contains a large oven against the back wall. A large number of roof tiles were found next to the oven. The oven is $5.4 \mathrm{~m}$ wide and $5.8 \mathrm{~m}$ in length and displays many of the same attributes as the city's other ovens, such as the stone blocks lining the side of the oven and the two lines of wear marks on those stones.

The caseggiato was excavated between 1939 and 1940, in tandem with the Terme di Mitra. The tiles led many early scholars to suggest that the oven was actually a kiln. This may explain why the caseggiato does not appear in Bakker's tome. The size of the aperture and the volume of the baking chamber preclude the oven serving as a kiln. Other possibilities include recent repairs or a re-appropriation of the space in new functions, perhaps as storage. The size of the oven is anomalous, as is the absence of evidence for the other processes such as milling and kneading, possibly suggesting a function other than baking. The oven in bakery seven could accommodate as many as 417 loaves at a time, allowing it to produce between 3320 and 5530 loaves a day.

SO I, Tav. XIV, 4; Heres 1982, 428 fig. 77 


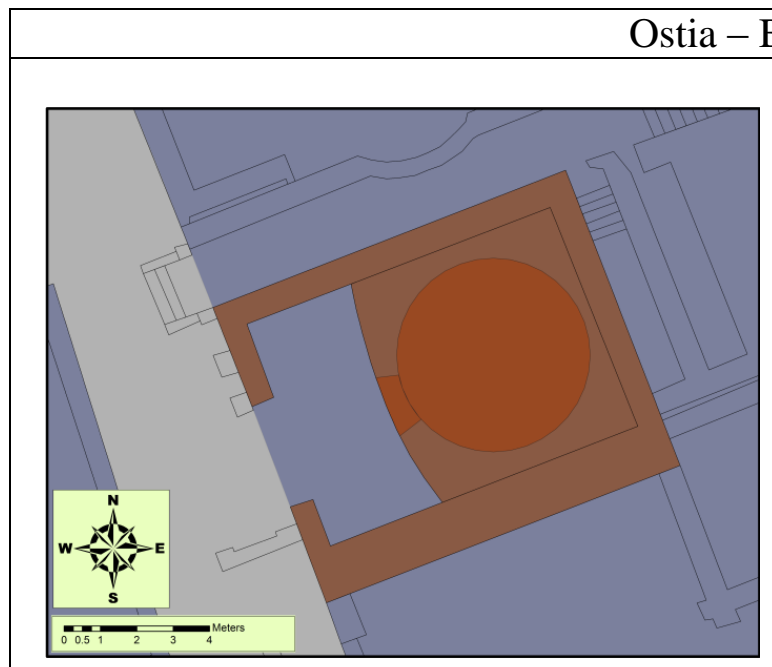

Plan of Bakery Seven

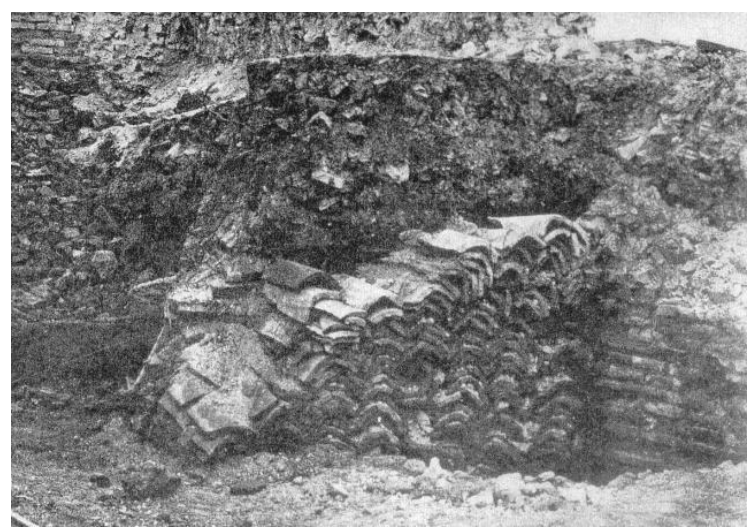

Tiles Found in Front of Oven

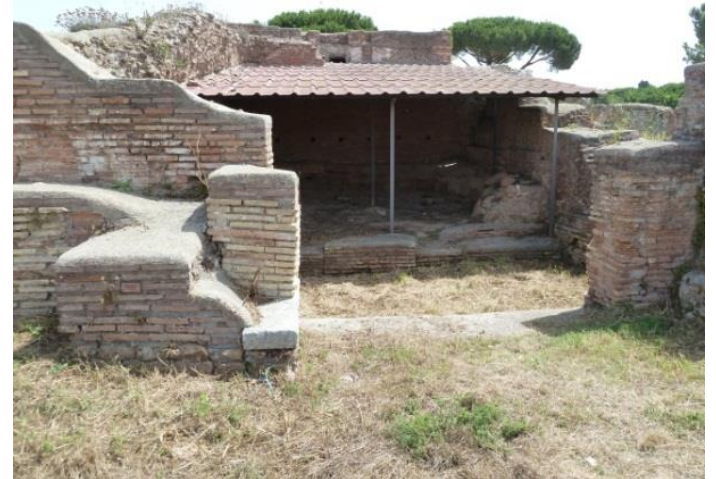

View from Street

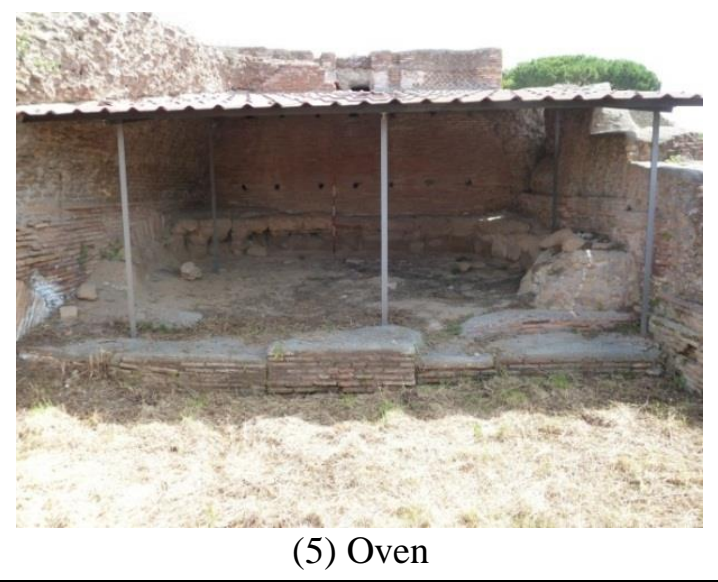

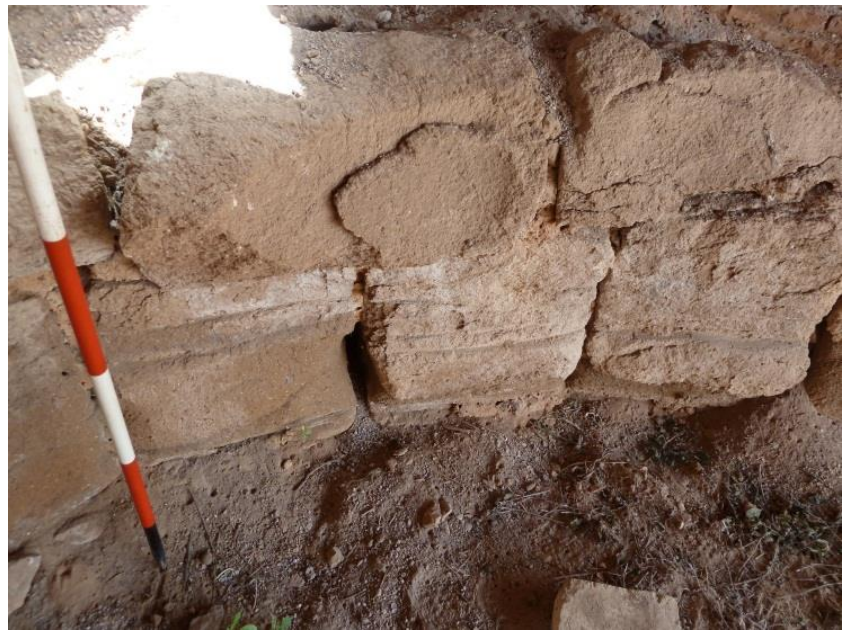

Interior of Oven 


\section{Bakery 8 - II.VI.7}

The so-called Caseggiato delle Fornaci resides at the north end of a long narrow insula between via delle Corporazioni and via della Fontana. It has entrances on both streets, as well as onto via della Fullonica to the north and a covered alley to the south. The initial excavation of the bakery began in 1888 during the exploration of the Caserma dei Vigili, but the Caseggiato delle Fornaci remained unexcavated until 1907 when part of the oven room was excavated. Full excavation of the bakery did not occur until 1912 when Finelli and Vaglieri began recording the findings.

The bakery consists of two lines of compartments extending down the length of the establishment. One line faces of compartments provides access to via delle Corporazioni, while the other line is blocked from street access. The southern end of the bakery is delineated by a covered alley, in which a lime kiln was installed at a late date. Just north of the alley there are two rooms with access to both the via delle Corporazioni and a staircase leading to a second story. The next few entrances from via delle Corporazioni access a long sala, subdivided by piers supported with masonry reinforcements. The sala is paved with basalt stones. East of the sala are three rooms. The southernmost room is a narrow space with walls similarly supported by masonry reinforcements. The next two rooms are also paved with basalt stones. The first of the two rooms has a basin, installed at the end of the $3^{\text {rd }}$ century or later. The northern portion of the bakery, consisting of six spaces, is accessed through the rooms east of the sala. The three rooms with access to the via delle Corporazioni are paved with basalt stones. The central room has a large basin of a late date. The eastern three spaces are also paved with basalt stones. A broken kneading machine was found in the first of these three rooms. 
The northern room contains the remains of two large ovens, which are poorly preserved. The western oven is $3.6 \mathrm{~m}$ in width and $3.8 \mathrm{~m}$ in length and the second oven is $2.5 \mathrm{~m}$ in diameter. The surfaces of both ovens consists of sesquipedali tiles, on one of which Vaglieri records the discovery of the following brickstamp (CIL XV 847):

\section{EX FIG Q ASINI MARCELLI D OP F C NVNFORTVNA Q ART PAE ET APRONA COS}

Dalen, Bakker, and Heres date the installation of the bakery into II.VI.7 to the second or third quarters of the $2^{\text {nd }}$ century, when the doors between the oven-room and the room to the west were blocked. The brickstamp found in one of the ovens, dating to $123 \mathrm{AD}$, is consistent with that interpretation, though it may suggest a slightly earlier date. The fortification of the walls and piers in most rooms also dates to this period, which Bakker suggests may have served to support an upper story weighted with grain. The upper story may have also housed a pulley system to lift and place the millstones.

Bakker suggests that milling occurred in the rooms lined with paving stones on the west side of the bakery. He further indicates that similarly paved rooms to the east may have housed kneading and kneading machines, a hypothesis supported by the discovery of a kneading machine fragment in that area. Bakker tentatively assigns loafformation and leavening to the space between the potential kneading rooms and the ovenroom, but there are no postholes or tables to corroborate that conclusion. He also suggests that sieving occurred in the rooms in front of the oven, but sieving would have occurred before kneading but after milling meaning. 
NSc 1907 212-214; NSc 1912, 388-389; NSc 1913, 122-127; Blake 1973, 174; Bakker et al. 1999, 80-89. 


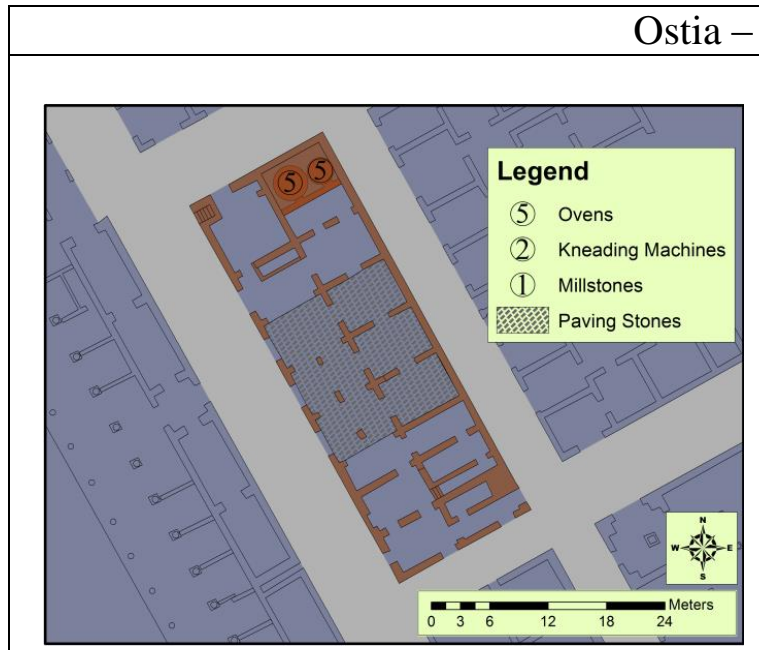

Plan of Bakery Eight

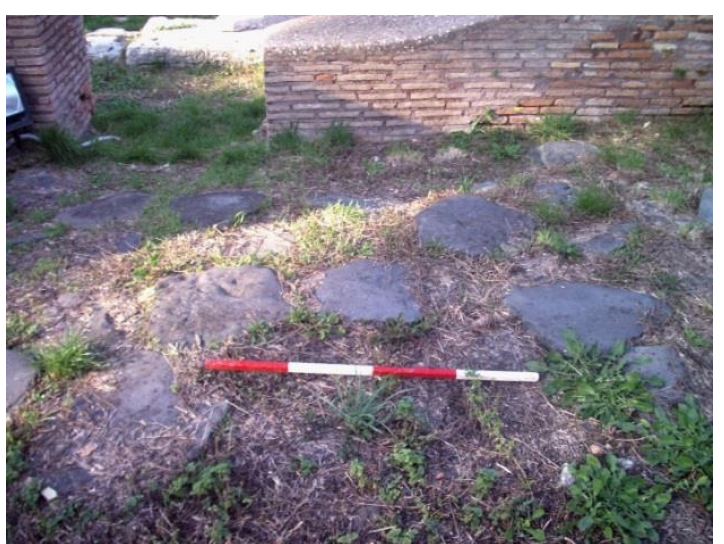

Paving Stones

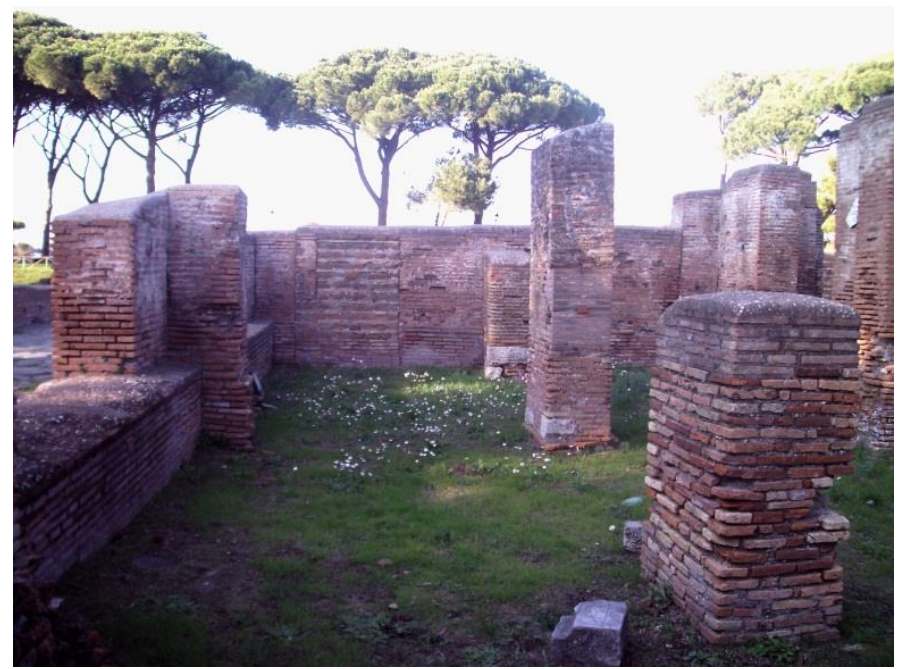

Area of Paving Stones

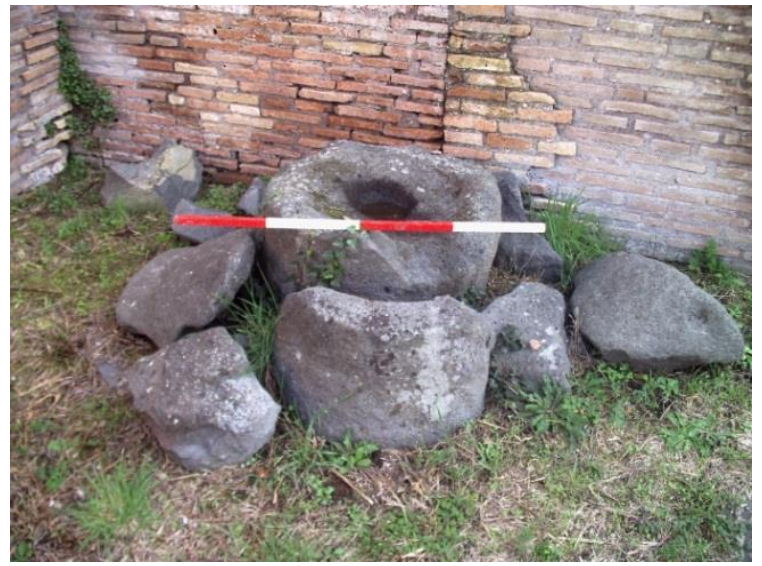

Broken Kneading Machine

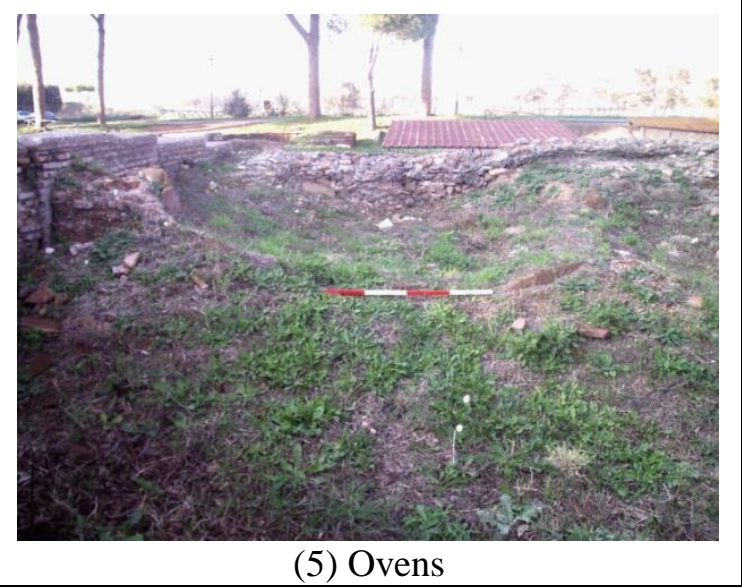




\section{Italica}

\section{Bakery_1}

Excavated in during the first half of the twentieth century, bakery one in Italica is located in the Nova Urbs, or 'New City', the portion of Italica expanded in the first century AD. The bakery is associated with - and on the same insula as - the so-called House of the Birds. It consists of one room with a masonry oven placed directly on the floor. There are no indications of millstones, kneaders, tables, or shelves.

The bakery is almost entirely reconstructed. The walls separating the bakery fromt he House of the Birds are reconstructed, but there is no indication in the actual remains of a door between the house and the workshop. Antonio Caballos Rufino says that the only parts of the oven that are original are the base plate, which is directly on the floor, and the first few courses of the dome. The oven itself is oval-shaped, with a length of $2.1 \mathrm{~m}$ and a width of $1.9 \mathrm{~m}$. Its opening faces the street.

Caballos Rufino 1999, 70; Caballos Rufino 2010, 90 fig. 7.7 


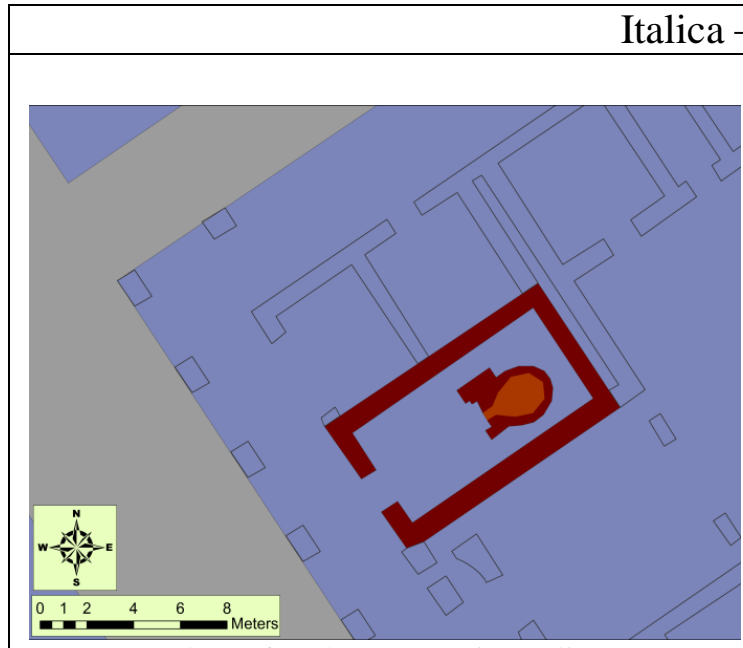

Plan of Bakery One in Italica

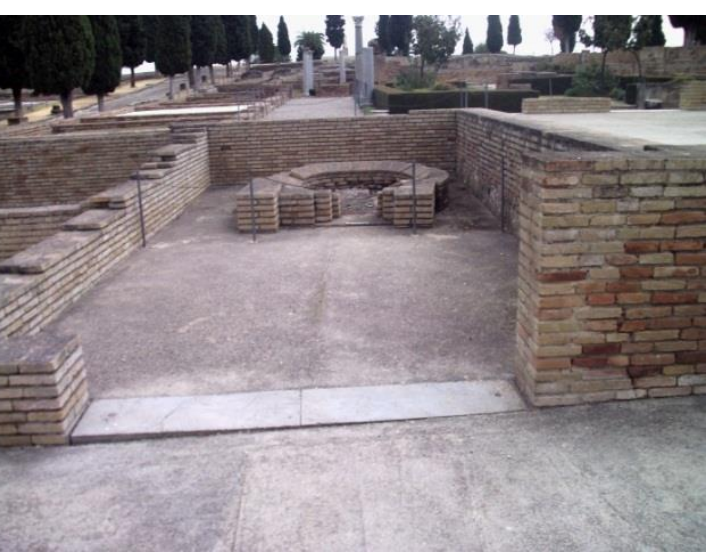

Bakery From the Street

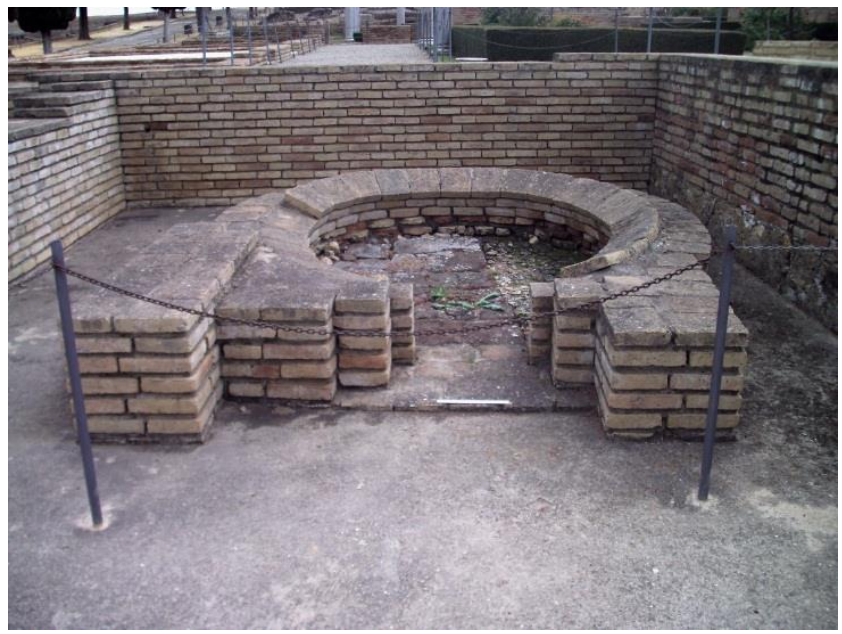

Oven from the Front

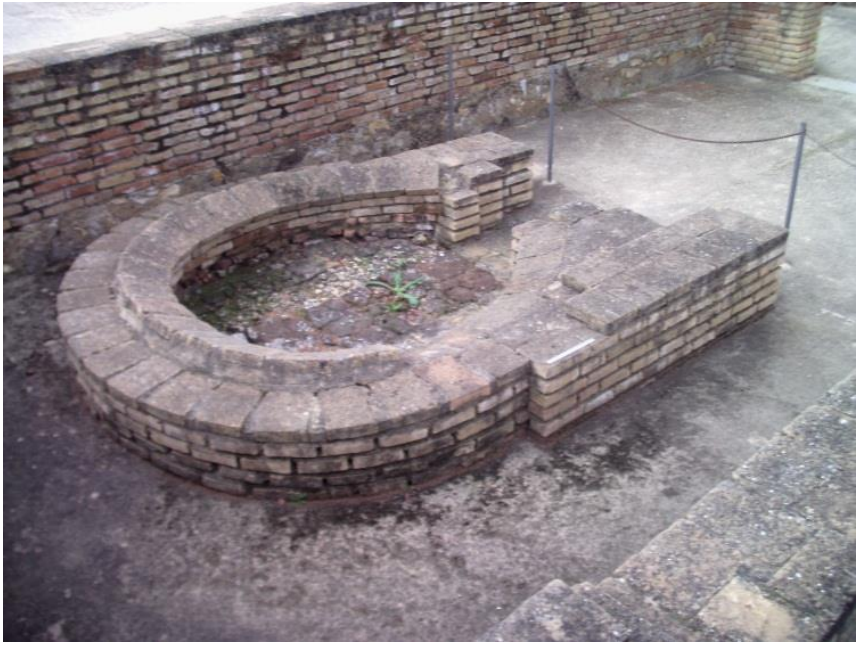

Oven from Behind 


\section{Bakery 2}

Bakery two in Italica resides on the same insula as the House of the Planetarium, though it does not communicate with the domus. The workshop is located in the "new city': the portion of Italica that was expanded to the northwest during the first century AD. The insula on which the bakery is situated was excavated during the 1970s, when a fervent of archaeological activity occurred on the site.

The bakery consists of two rooms, both with direct access to the street. The northwest room is paved with terracotta tiles. The tiles extend along the north and west sides of the room. The north side of the south room is similarly tiled, but it also contains two ovens. The north oven is ?? in diameter. The south oven is ??. The two ovens have been considerably reconstructed and it is difficult to discern which parts of them are ancient and which are modern.

Luzon 1982; Caballos Rufino 2010, 89-90. 


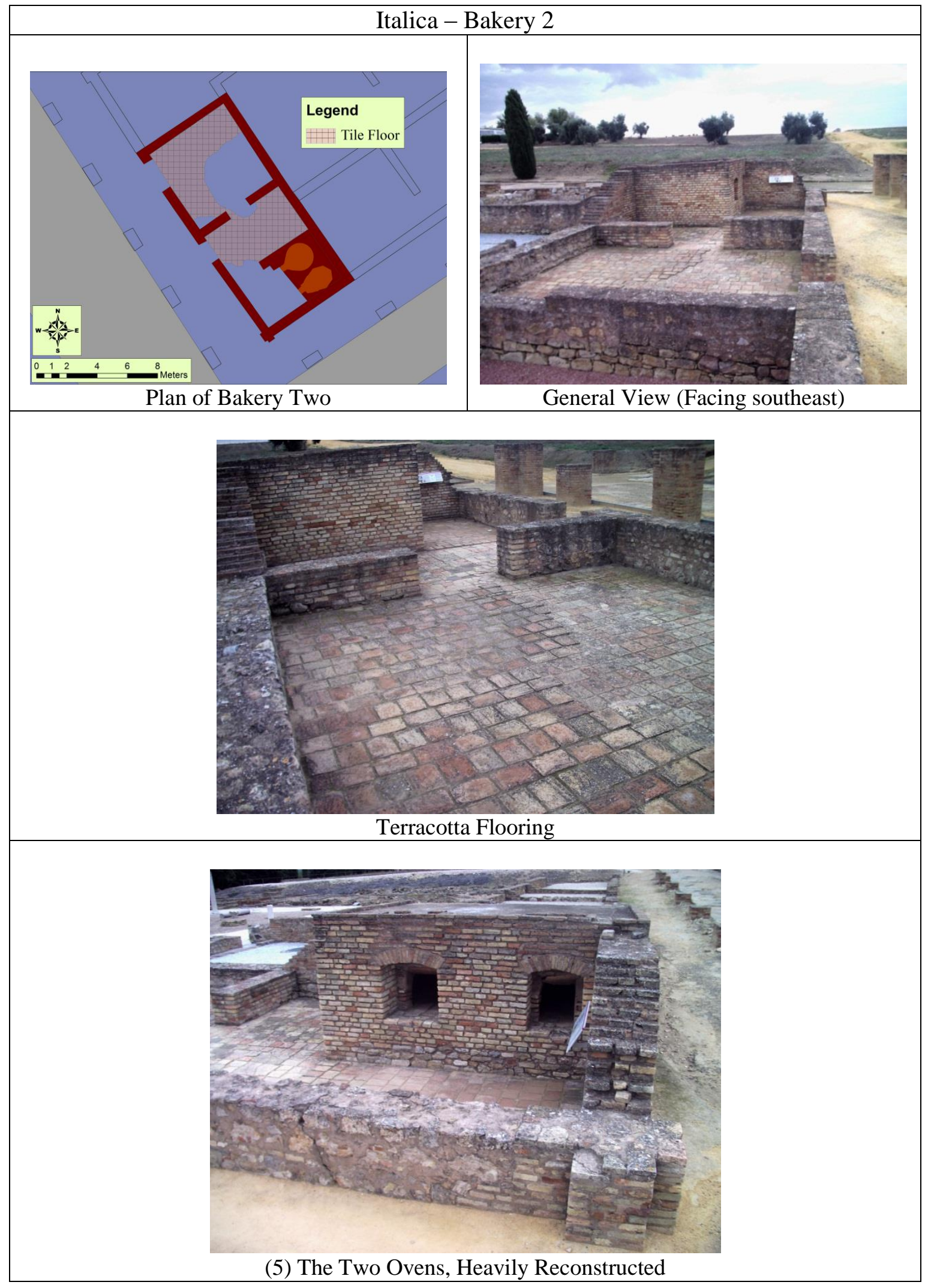


Volubilis

\section{Bakery 1}

The bakery in Insula 10, at the eastern extent of the city, is located next door to an olive press. It opens to the south, onto an unexcavated street. The bakery consists of four spaces: the main room opening onto the street, a passage between rooms and two back

rooms. There is one millstone in the northeastern back room. The passage space links the mill-room to the second back room, which may have had a doorway to the street to the north. The rear of the oven and the wall to the north of the oven form a corridor linking the passage room and the main room. In this corridor was found a kneading machine 45 $\mathrm{cm}$ in diameter and $50 \mathrm{~cm}$ deep. The main room contains the oven which faces out onto the street. The oven, of which only the floor remains extant, is $2.4 \mathrm{~m}$ in diameter.

Leduc 2008; Leduc 2011. 


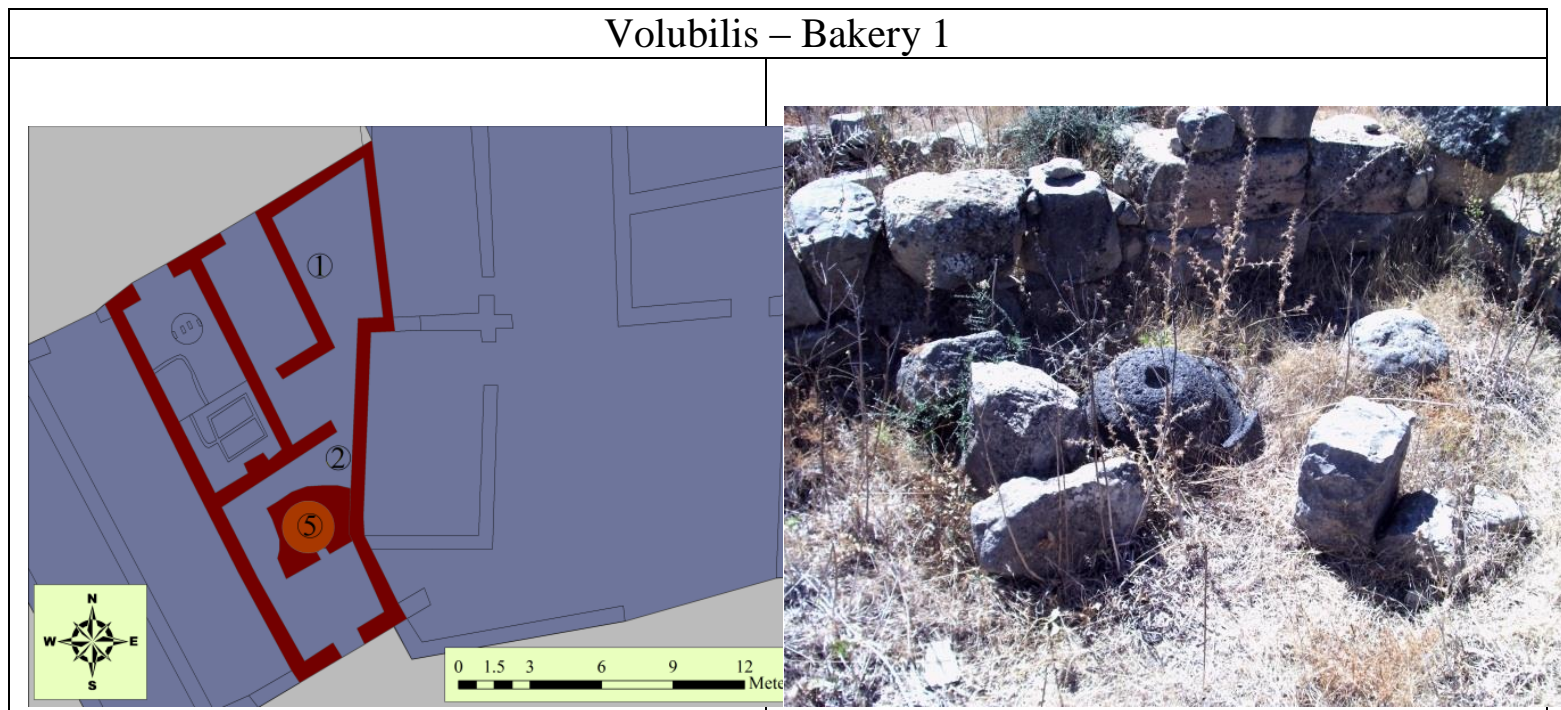

Plan of Bakery One (1) Millstone

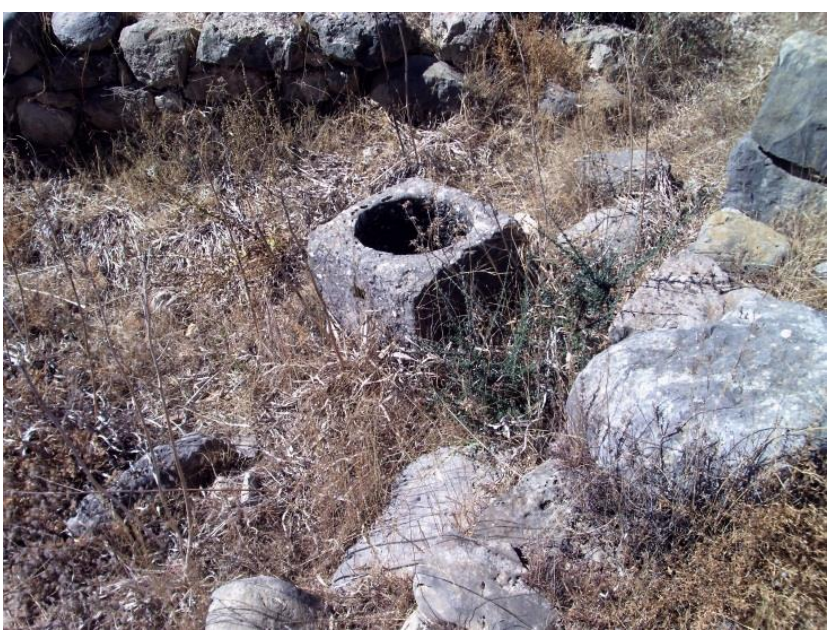

(2) Kneading Machine

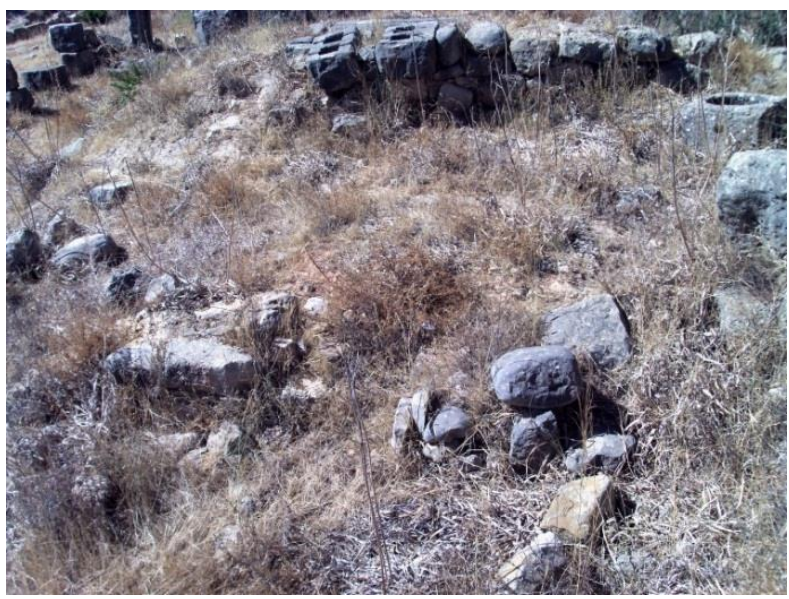

(5) Oven 


\section{Bakery 2}

The bakery in Insula 18 consists of three main spaces: one facing onto the street, the area of the oven, and a back space to the west. The back space is very long and it contains a millstone in its western half. A kneading machine found in the establishment next door may have originated in the eastern half of the long backroom. The oven resides at the nexus of the front and back spaces, facing toward the entrance. The oven is $2.6 \mathrm{~m}$ in diameter.

Leduc describes the area of Volubilis in which bakery two resides as "un quartier populaire, le Quartier Meridional, où aucun plan d'urbanisme ne semble avoir ete etabli et où la chronologie des batiments, tout comme la destination des pieces, est parfois obscure." Certainly the remains are poorly preserved, making the identification of function to various rooms difficult. Leduc hypothesizies that milling likely occurred in the backroom, west of the oven and progressed toward the oven and was sold in the room at the front of the oven. Leduc further suggests that the kneading machine found in the space next door may have originally been located between the millstone and the oven.

Langlois 2000, fig. 10; Leduc 2008, Leduc 2011, 186 and fig. 4-5. 


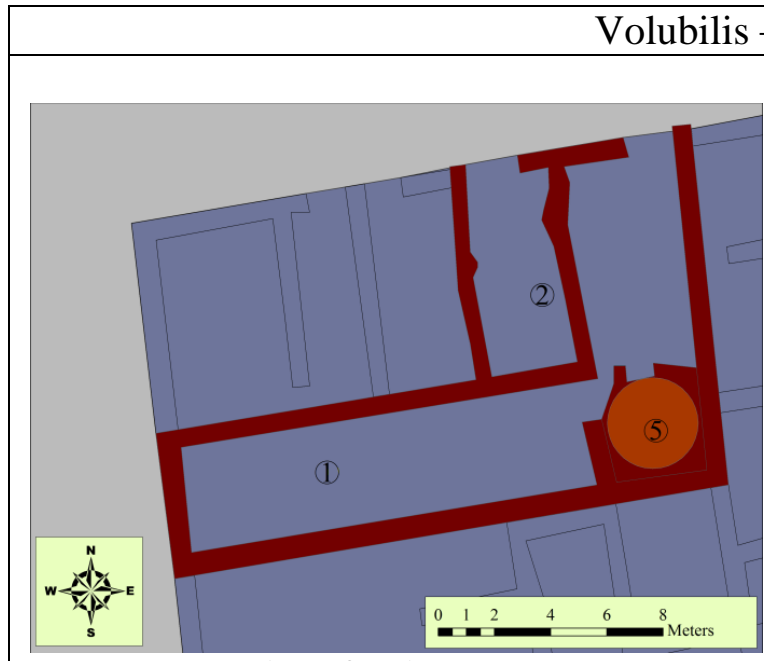

Plan of Bakery Two

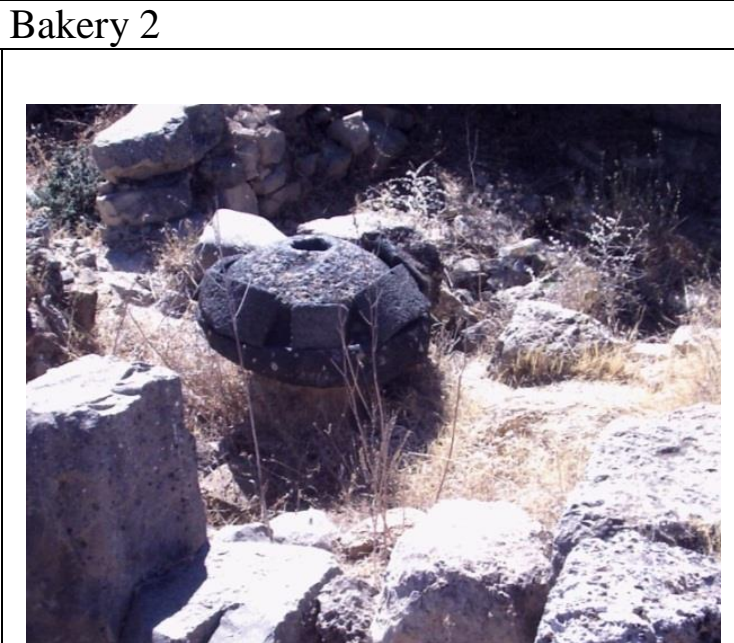

(1) Millstone

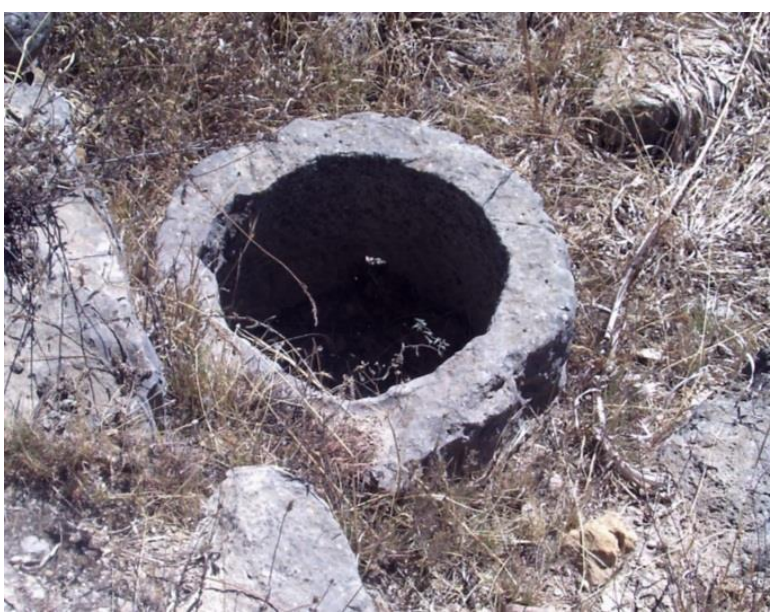

(2) Kneading Machine

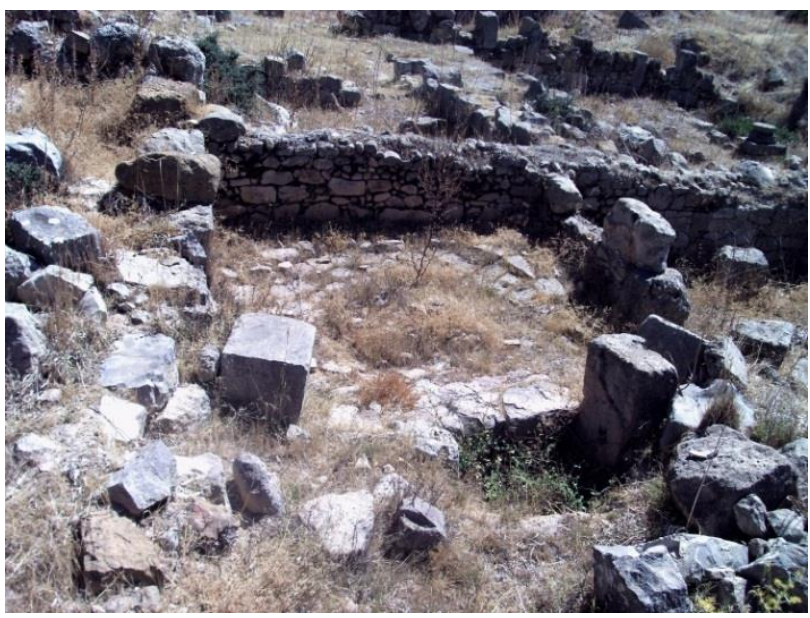

(5) Oven 


\section{Bakery 3}

The so-called Forum Bakery is the best preserved bakery in Volubilis. It has two rooms: the western room contains two millstones and there are two kneading machines in the eastern room. An oven is located on the far eastern side of the bakery, at the entrance. The walls tend to be no more than a meter high, so post holes for shelves are no longer extant and features like table supports are rare. The millstones are much closer to the ground than those of Pompeii with a smaller ring-shaped catillus, the upper portion of the Roman millstone.

In addition to its superior preservation, the so-called Forum Bakery is the most well studied of Volubilis' bakeries. Luquet quantifies the capacity of the oven at 150 loaves, though he provides no explanation for this estimate. He also identifies the house to the west as the potential residence of the baker.

Luquet 1966, 312-6; Leduc 2008; Leduc 2011. 


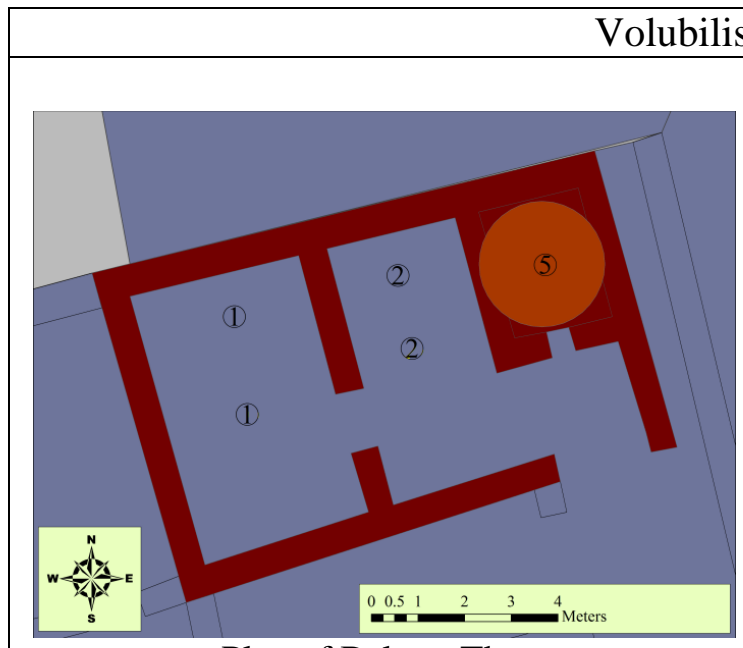

Plan of Bakery Three

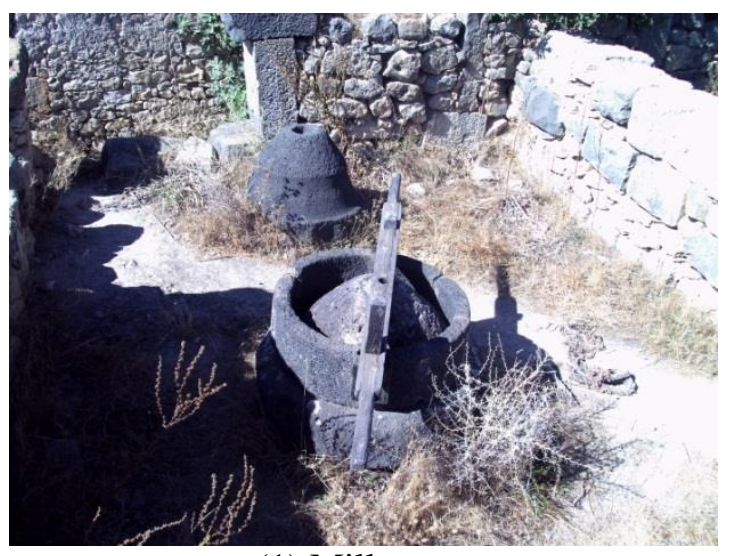

(1) Millstones

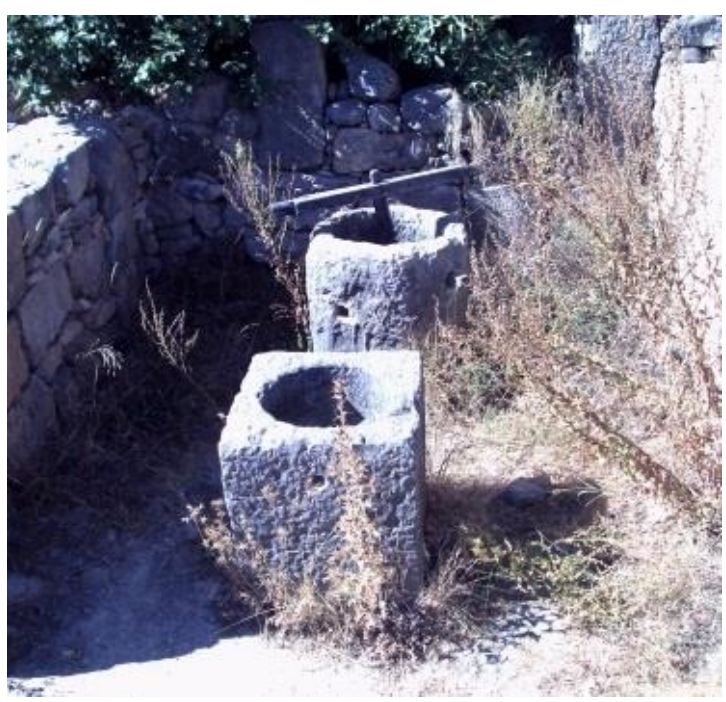

(2) Kneading Machines

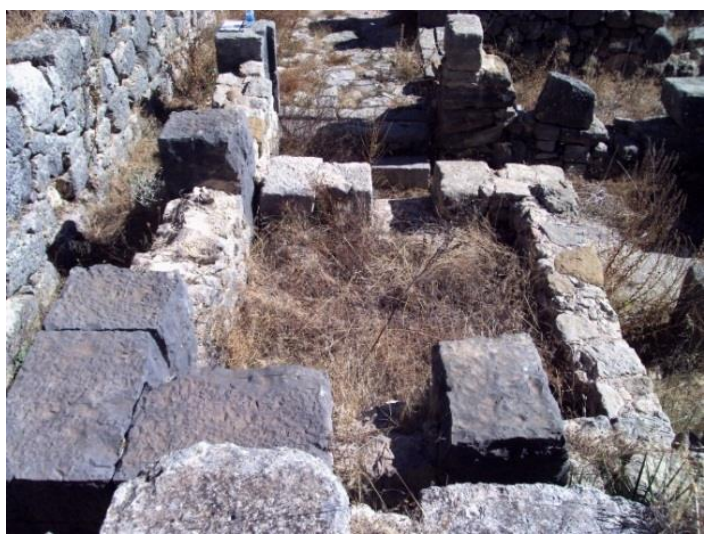

(5) Oven 


\section{Bakery 4}

The bakery associated with the Maison a la Citern is the largest of Volubilis bakeries, but due to several wall collapses, the oven and other technologies are no longer visible. The only entrance to the bakery resides on the north side of the bakery. A small room at the entrance provides access to another small room to the east. To the south, the transitory space leads to a large space subdivided by two piers. The two piers, along with the walls on either side, supported three vaulted doorways. The east half of the large space provided direct access to the oven, which is inserted into a narrow room. West of the oven rooms is another room in which were found a kneading machine and a millstone of the annular type. Ettiene's plan of the House of the Cistern indicates an oven with a diameter of $2.45 \mathrm{~m}$.

Etienne 1960, 159; Zehnacker and Hallier 1964a; Zehnacker and Hallier 1964b, 392; Leduc 2008; Leduc 2011, 184. 


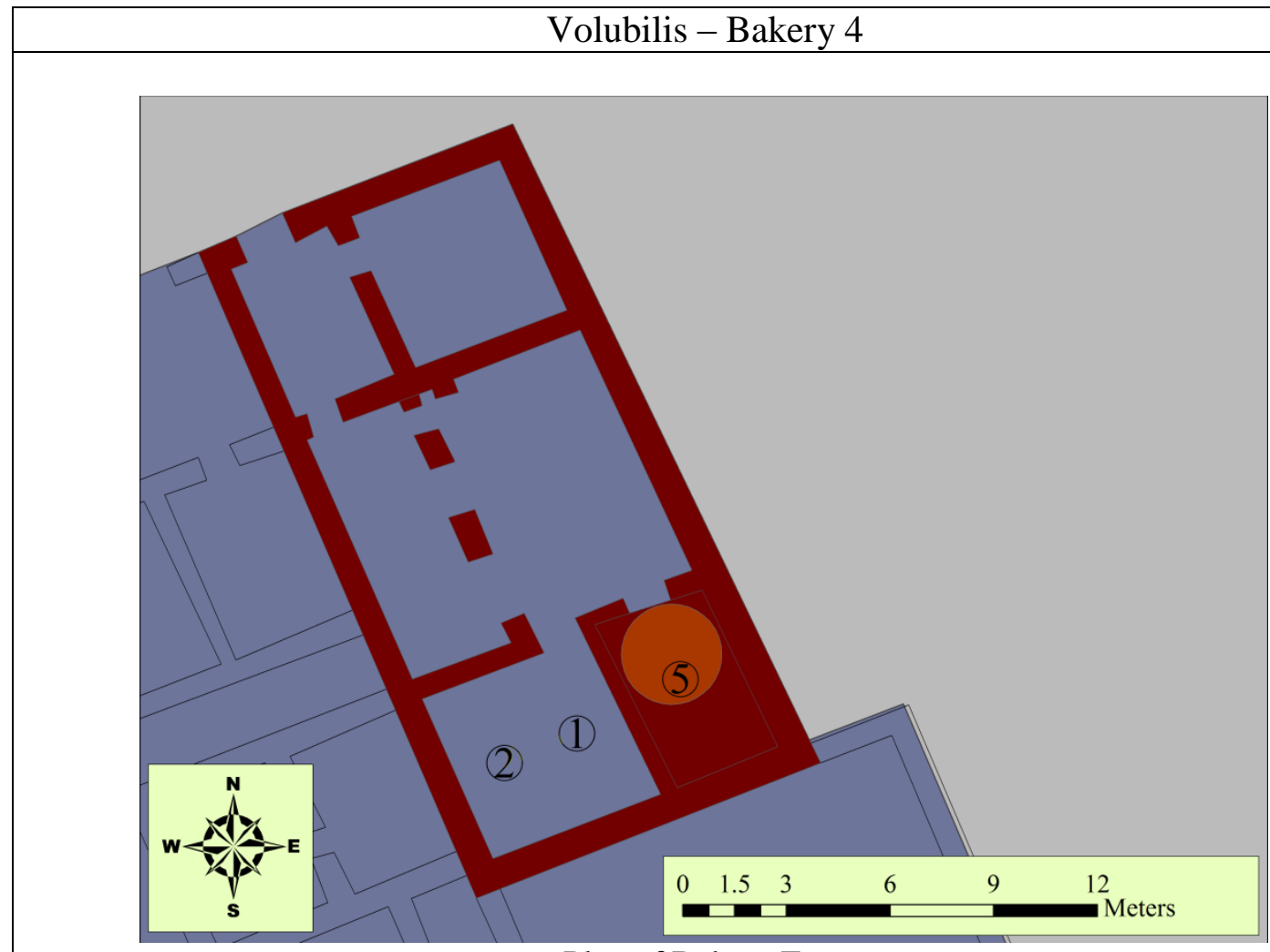

Plan of Bakery Four

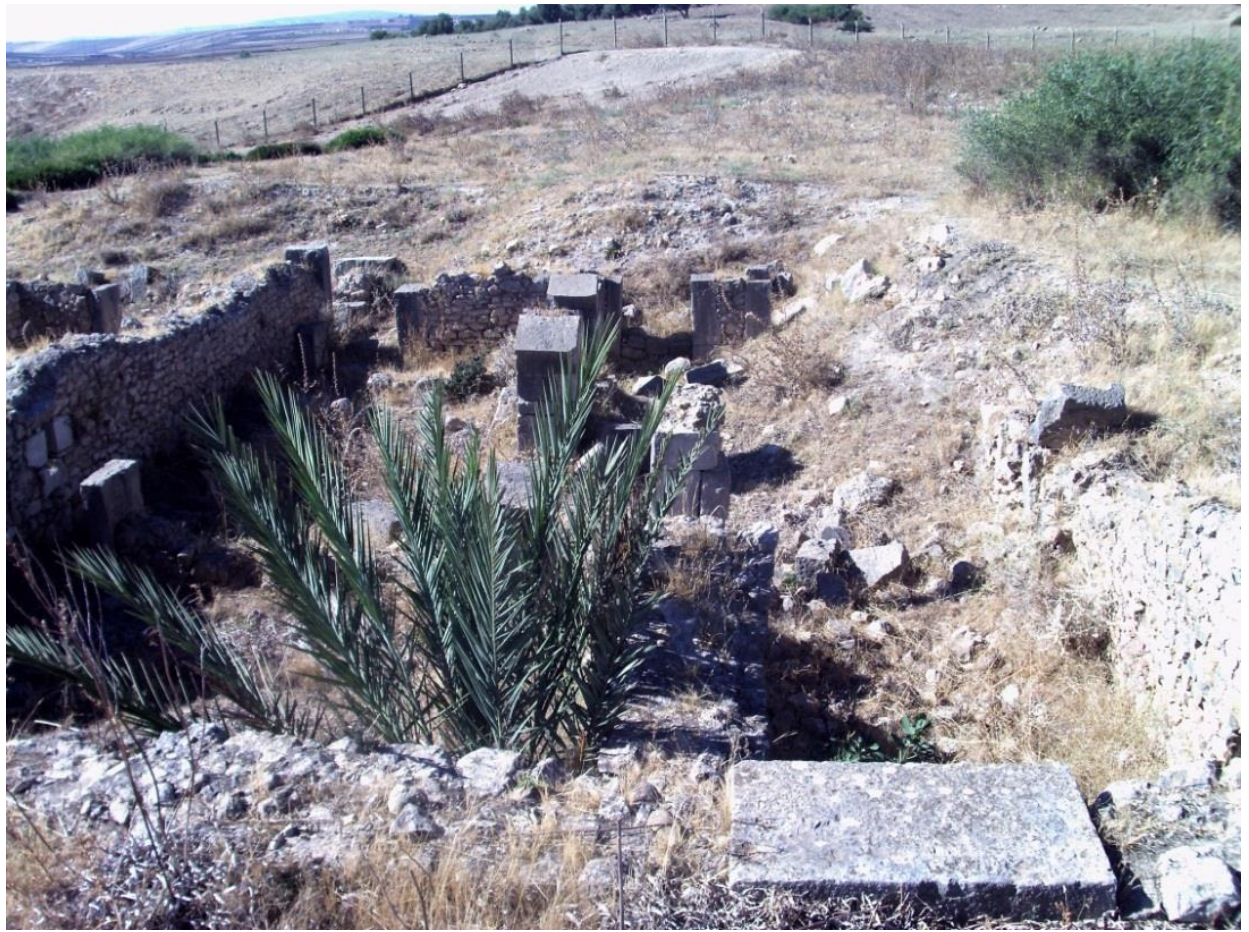




\section{Bakery 5}

The bakery associated with Maison aux Colonnes resides in a series of rooms separate from the house and accessed from the alley to the west of the insula. The entrance leads to a square room that provides access to a large central space. The central space is surrounded by five smaller rooms: two to the north, two to the south, and one to the west. The oven (2.3 $\mathrm{m}$ in diameter) resides in the western room on the south side of the central space. No millstones were found associated with this bakery, but a kneading machine now resides in an unassociated shop south of the bakery, facing onto the main cardo. The kneading machine may have originated in the bakery, potentially in the room east of the oven.

Etienne 1960, 159; Leduc 2008; Leduc 2011. 


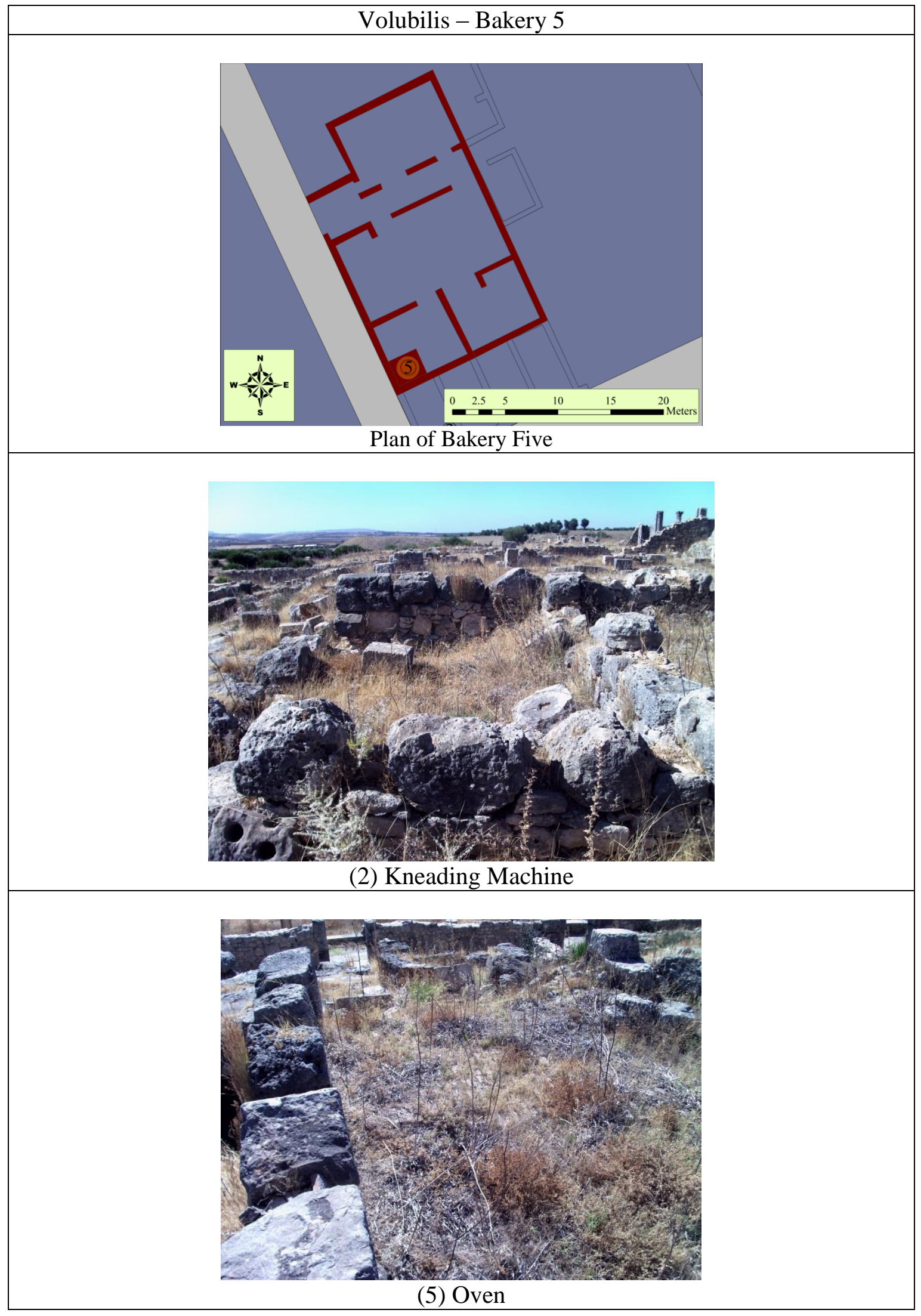




\section{Bakery 6}

If the Forum Bakery is the best preserved in the city, the bakery associated with the Maison au Buste de Bronze is a close second. The bakery consists of three spaces: a large front room, an oven space, and a back room. The front room contains two kneading machines. In the same room there are two stacks of stones that may have been structural piers, but may also have served as table supports. East of the supports are three millstones: three metae and two catilli, all of the annular type. A corridor, extending southeast of the front room, leads first to the oven (diameter of $2.55 \mathrm{~m}$ ) and then to another space in the southeast corner of the bakery.

Bakery six's association with the large house next door is dubious. Etienne's plan of the bakery shows a door between the two, but Leduc notes that no such link exists. Leduc infers from the locations of the millstones and kneading machines that milling and kneading took place in the front room and that the loaf-formation and baking occurred in the space in front of the oven. The back room, according to Leduc, served as storage.

Etienne 1960, 80-1 and 159; Leduc 2008; Leduc 2011. 


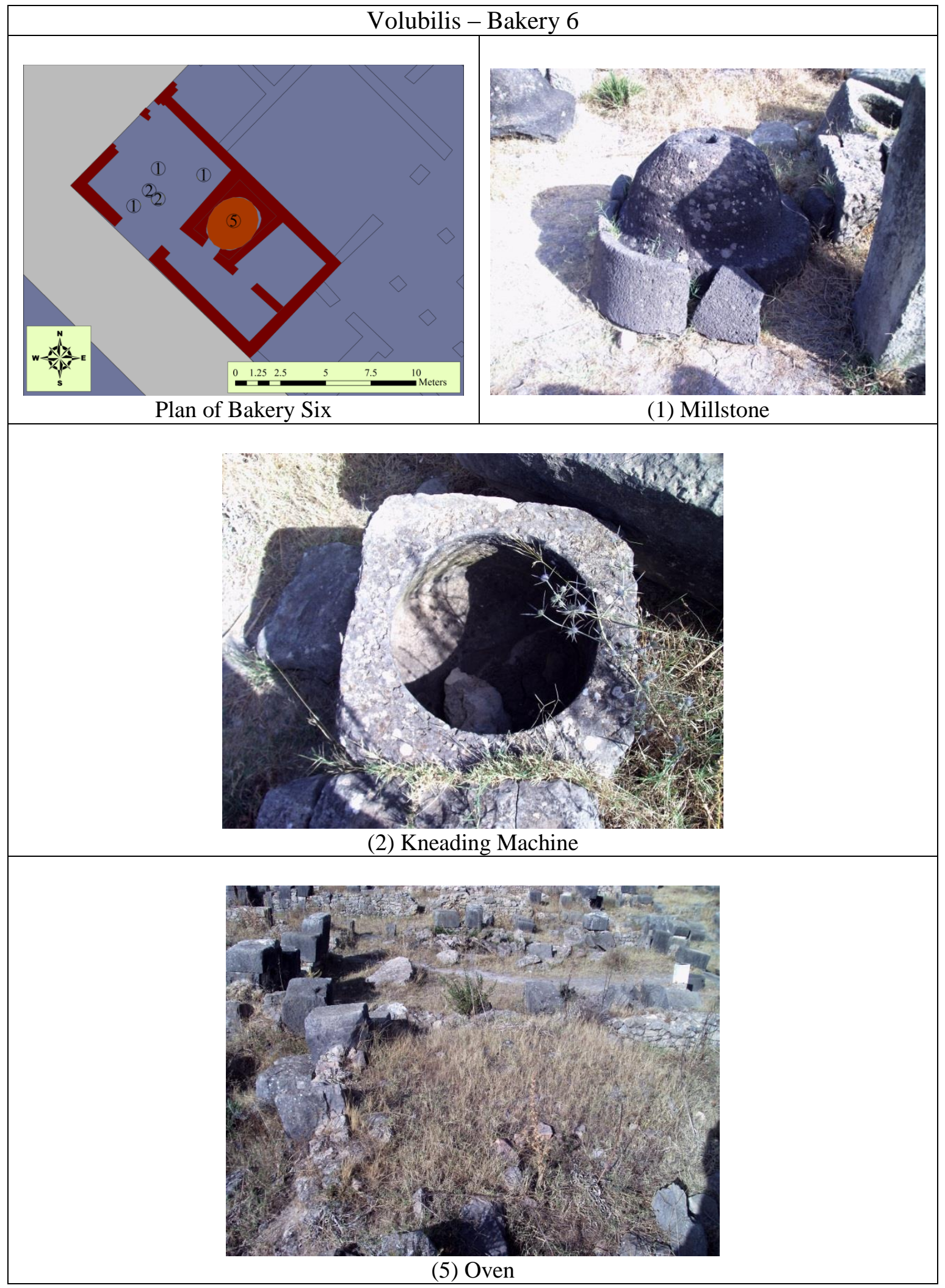




\section{Bakery 7}

The bakery associated with the Maison a la Monnaie d'Or is accessed from a dead end alley, much like bakery three. The bakery itself is poorly conserved. It is long and consists of two spaces. The front space has one millstone of an unusual type and a kneading machine. The machine has a cavity with a $46 \mathrm{~cm}$ diameter and a $46 \mathrm{~cm}$ depth. The eastern room has another millstone, of the same sort, and the oven (diameter of $2.3 \mathrm{~m})$, which rests on a raised platform with a base plate of terracotta tiles and a lining of stones. Although it appears as part of the Maison a la Monnaie d'Or in Ettiene's plan, the bakery is distinctly separate from it.

Etienne 1960, 53, 159 Pl LVII, 2; Leduc 2008; Leduc 2011, 186-7. 


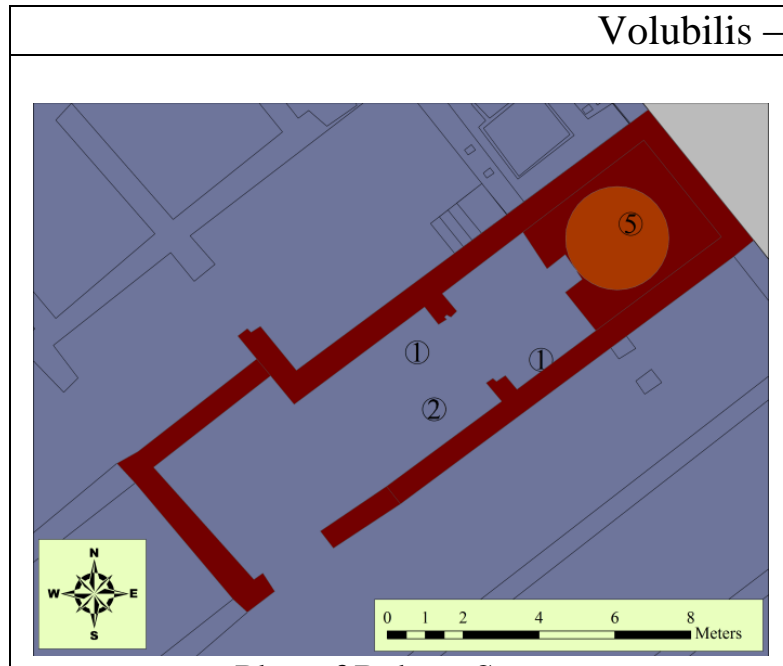

Plan of Bakery Seven

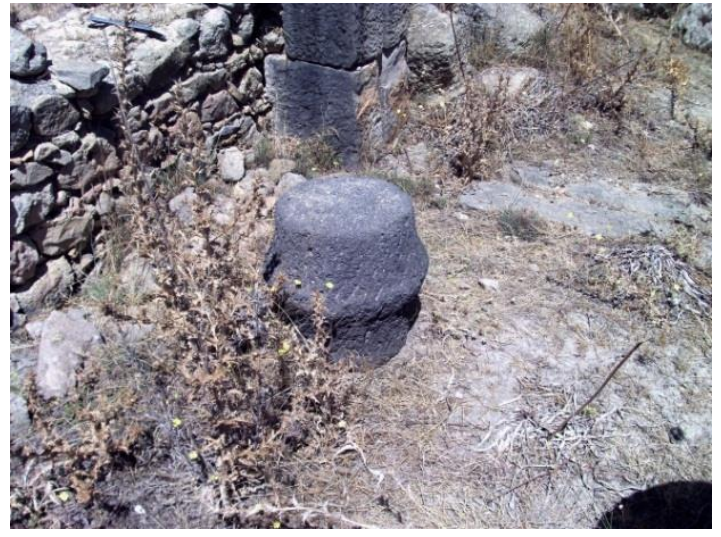

(1) Millstone

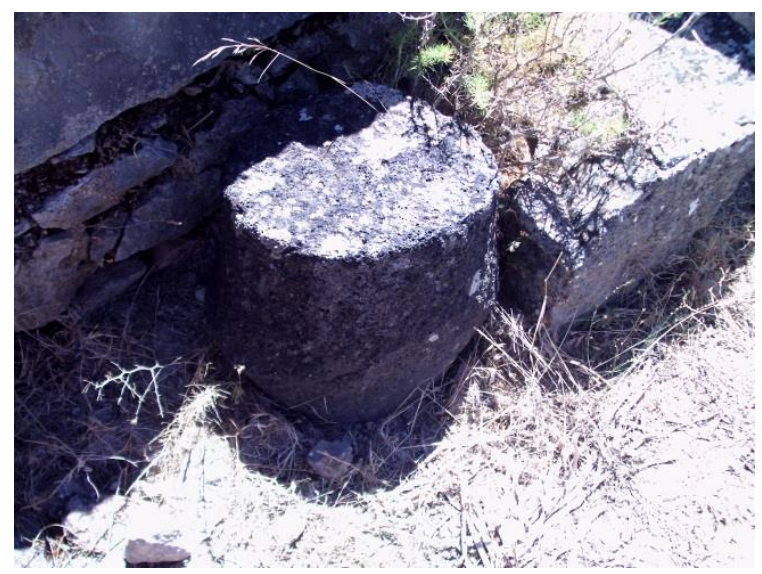

(1) Millstone

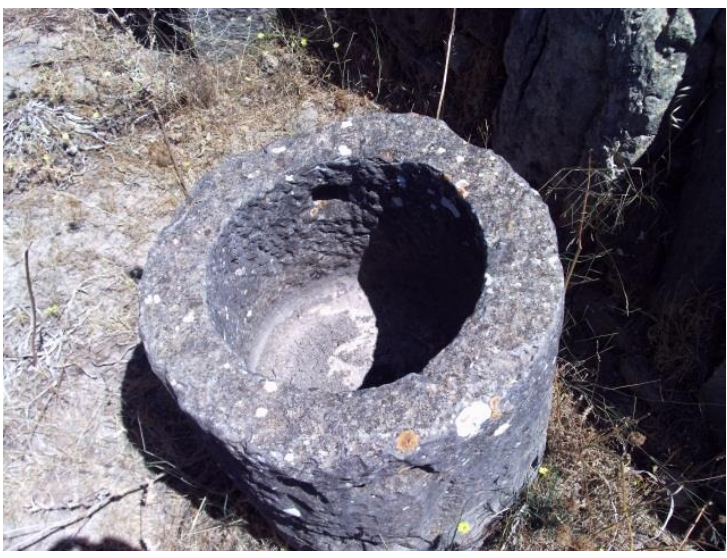

(2) Kneading Machine

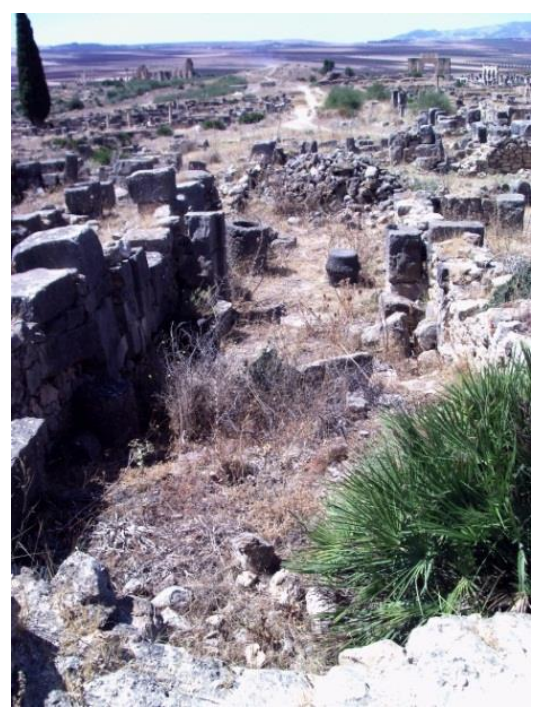

(5) View of Oven from Behind 


\section{Bakery 8}

The bakery associated with the Maison au Bassin Tréflé consists of two small rooms in the northwest corner of the insula. Its entrance from the street to the north leads to a small room in which a kneading machine was found. The other room to the east contains the oven (diameter of $2.5 \mathrm{~m}$ ), of which only the baseplate of terracotta tiles remains. Etienne's plan of the city shows a link between bakery eight and the Maison au Bassin Tréflé, though the remains of the walls are so badly preserved that they retain no indications of such a doorway.

Etienne 1960, 74 and 159; Leduc 2008; Leduc 2011. 


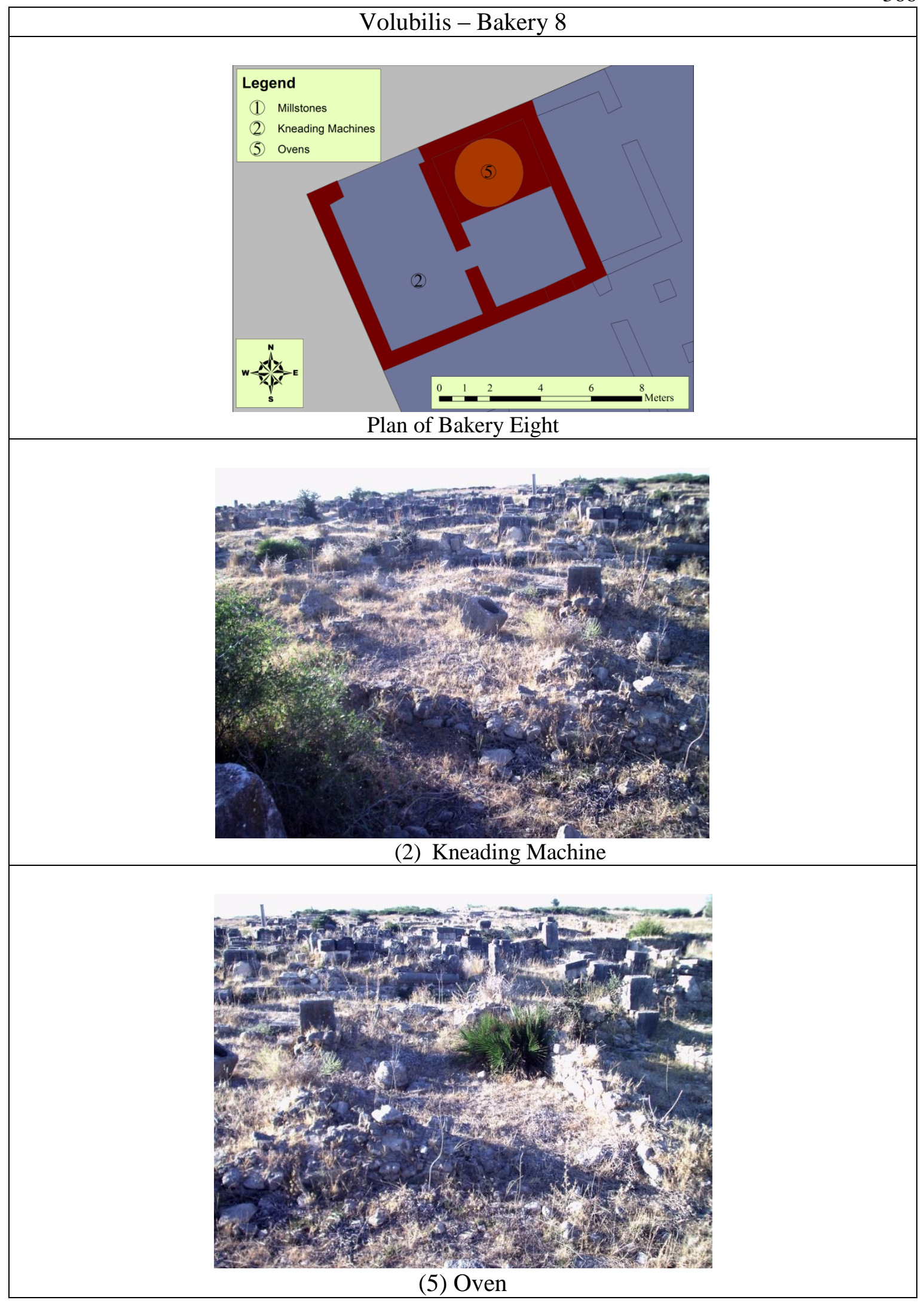




\section{Augusta Raurica}

\section{Bakery 1}

Bakery one at Augusta Raurica was excavated between 1965 and 1967. North of the Augustan-age theater, the city's defining attribute, excavators found a series of commercial spaces, several of which contain the remains ovens. The only extant oven was found in bakery one, in a room opening directly onto the street. The ground floor of the bakery was subdivided by thatched walls. The very back of the space offered access to a second floor. The rubble from the collapse of the second story contained some prestige goods, including bronze figurines of a religious nature and militaria of various metals. There was also high concentrations of chicken bones and tools of a functional or domestic character.

The structure of the bakery dates to the late second century AD, but the oven was not added until the third quarter of the third century AD. Excavations below the floor of the workshop revealed the remnants of a hypocaust system, suggesting that the space may have previously been part of a bath complex. Just west of the main oven, there is a smaller oven. Sandra Ammann and Peter-Andrew Schwarz interpret the oven and the animal bone assemblages, evidence from the structures final phase, as indications that the workshop was not exclusively engaged in bread production but may in fact have been more of a tavern than a bakery. The building collapsed towards the end of the third century AD and was not rebuilt.

Berger 1977; Ammann and Schwarz 2010. 


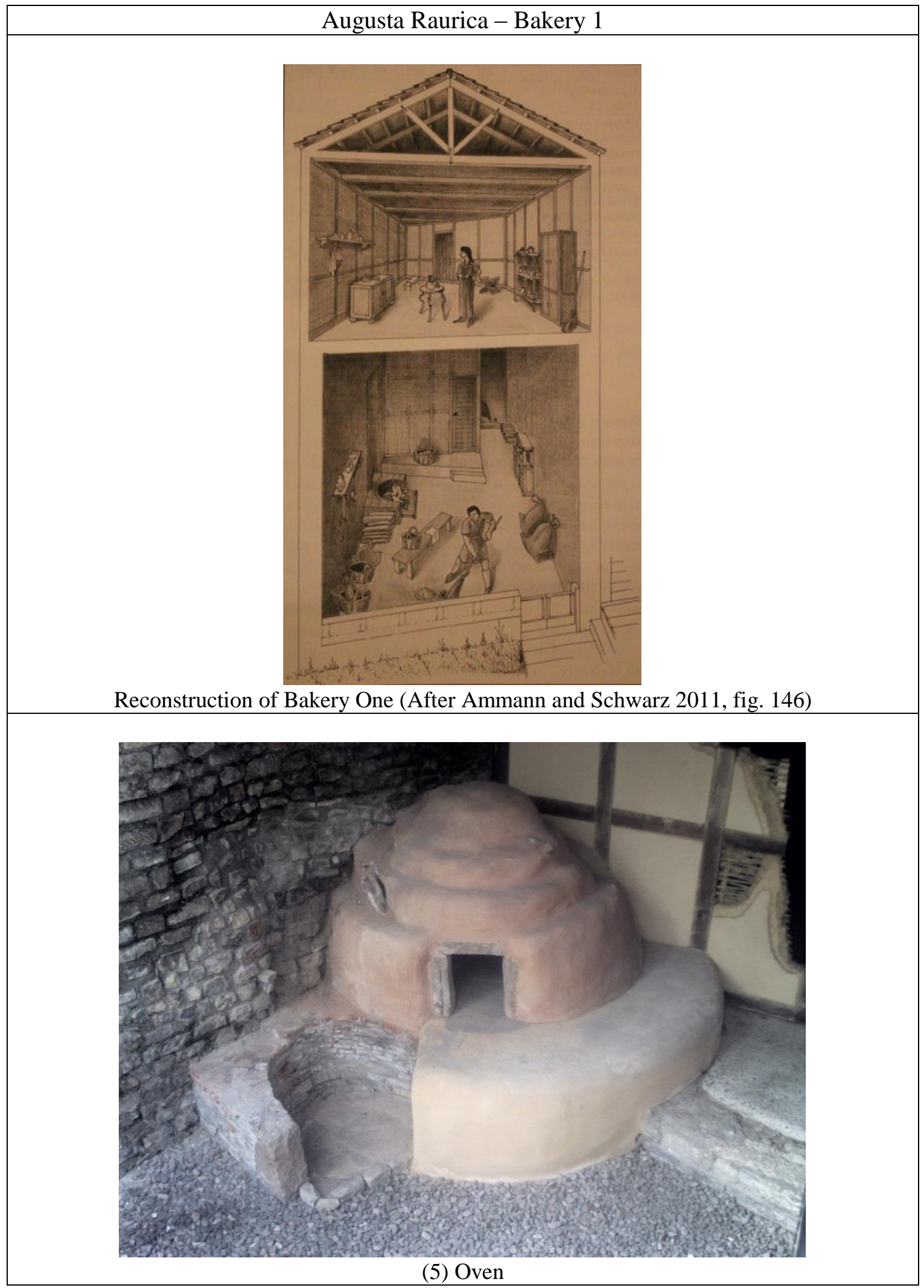




\section{FIGURES}

*Unless otherwise indicated, all photographs and plans are my own.

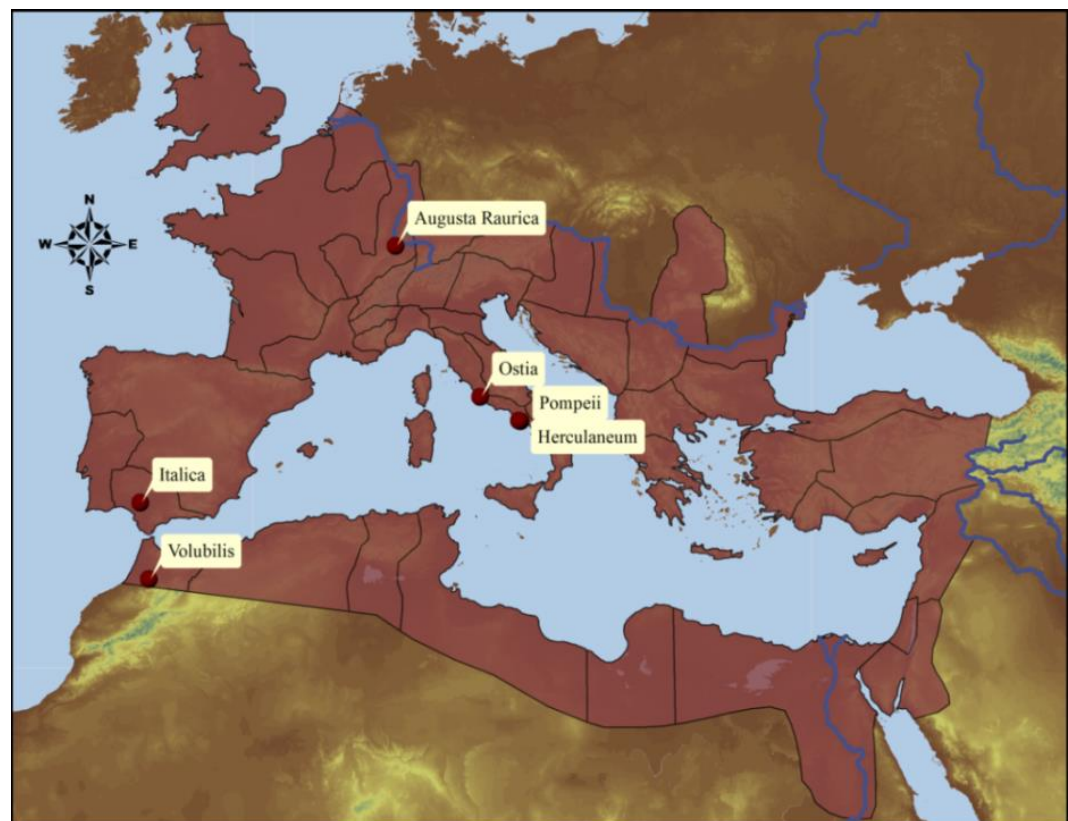

Fig. 1 - The Location of Roman Cities in this Dataset with the Remains of Bakeries

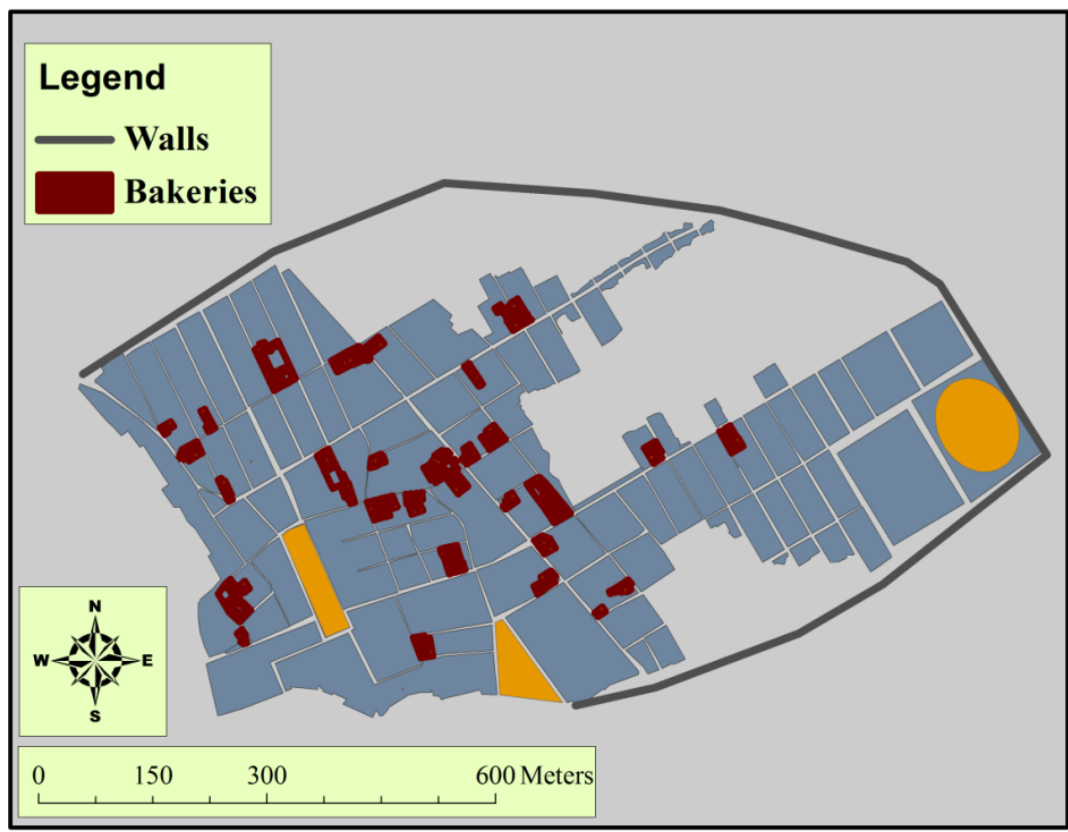

Fig. 2 - The Distribution Bakeries in Pompeii 


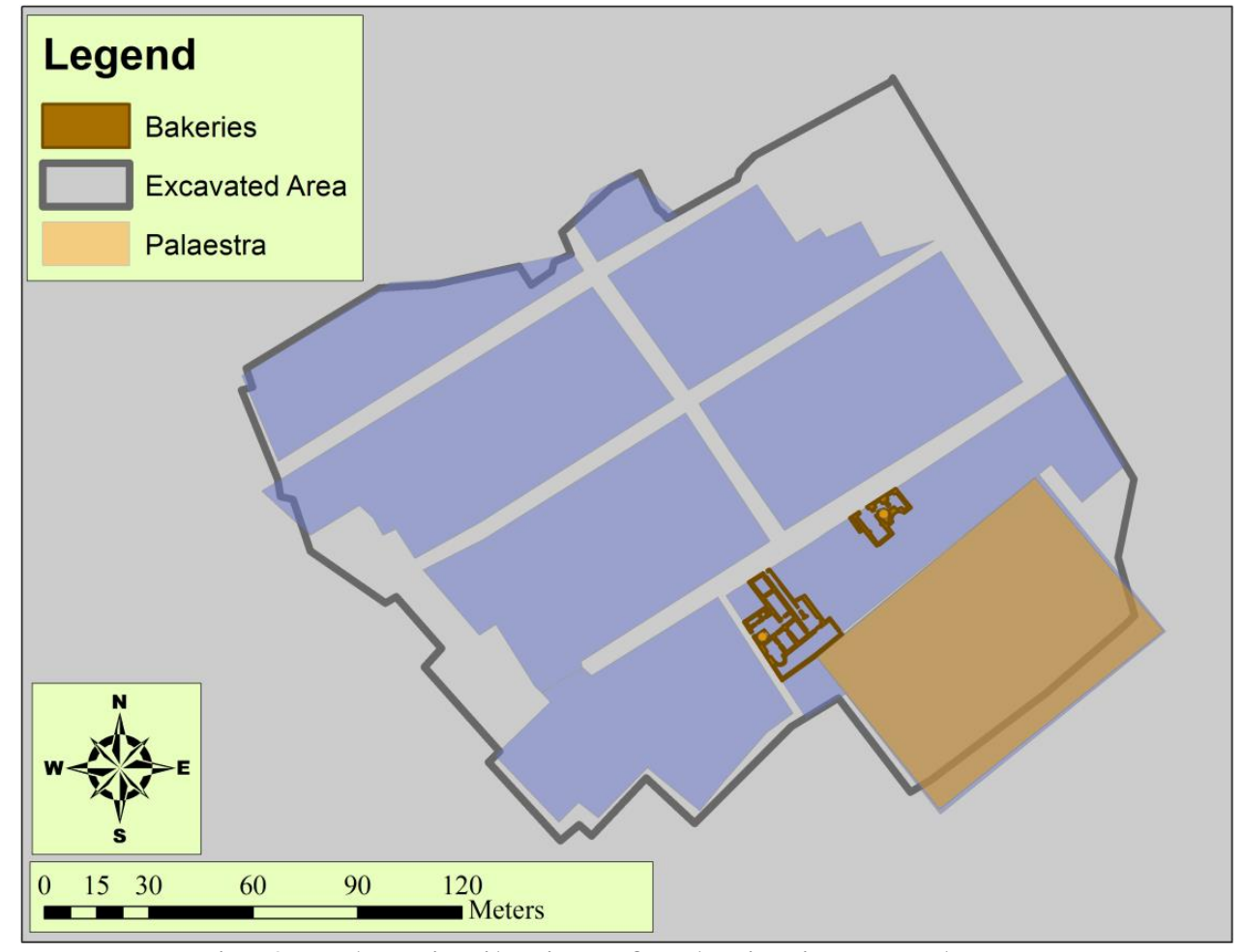

Fig. 3 - The Distribution of Bakeries in Herculaneum

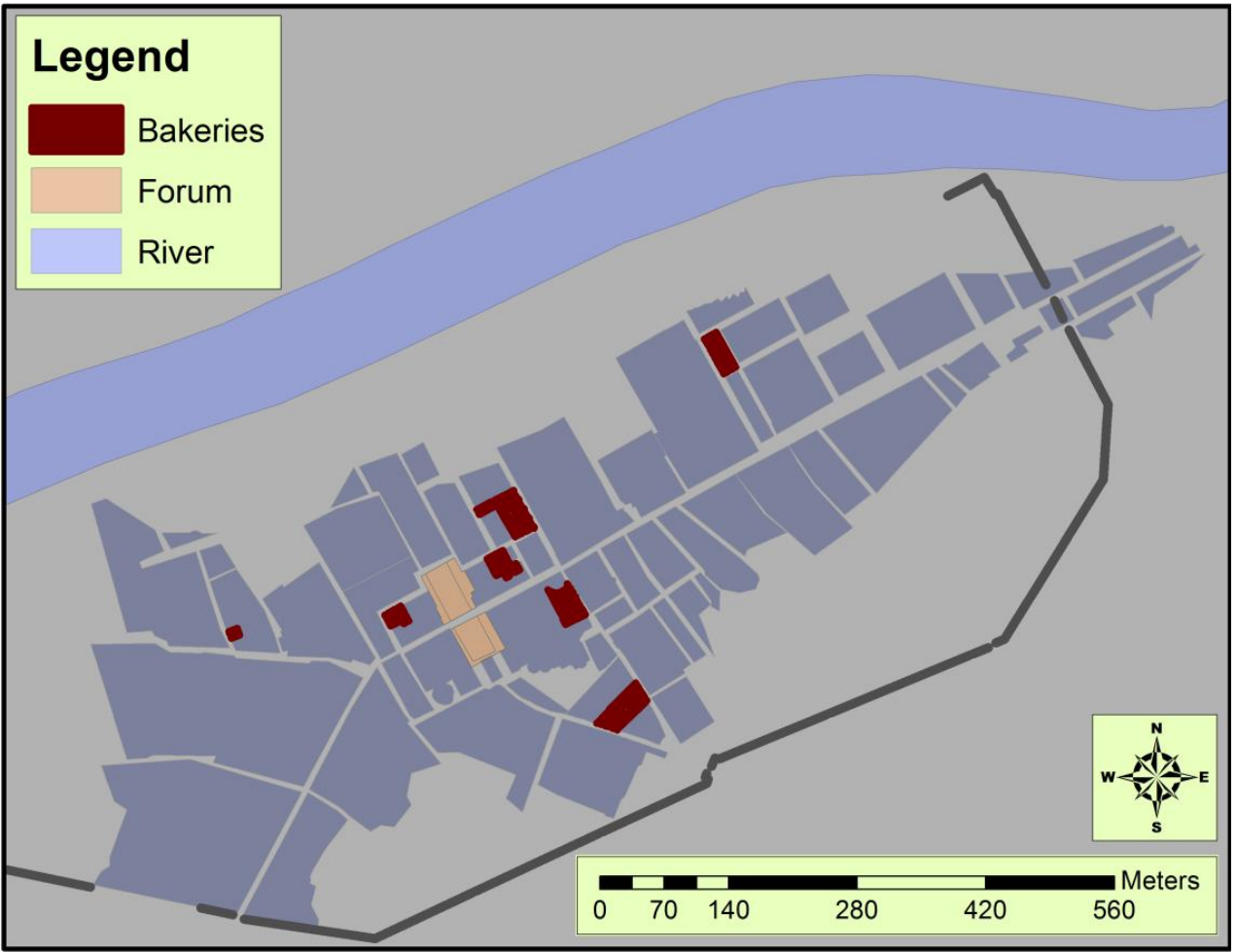

Fig. 4 - The Distribution of Bakeries in Ostia 


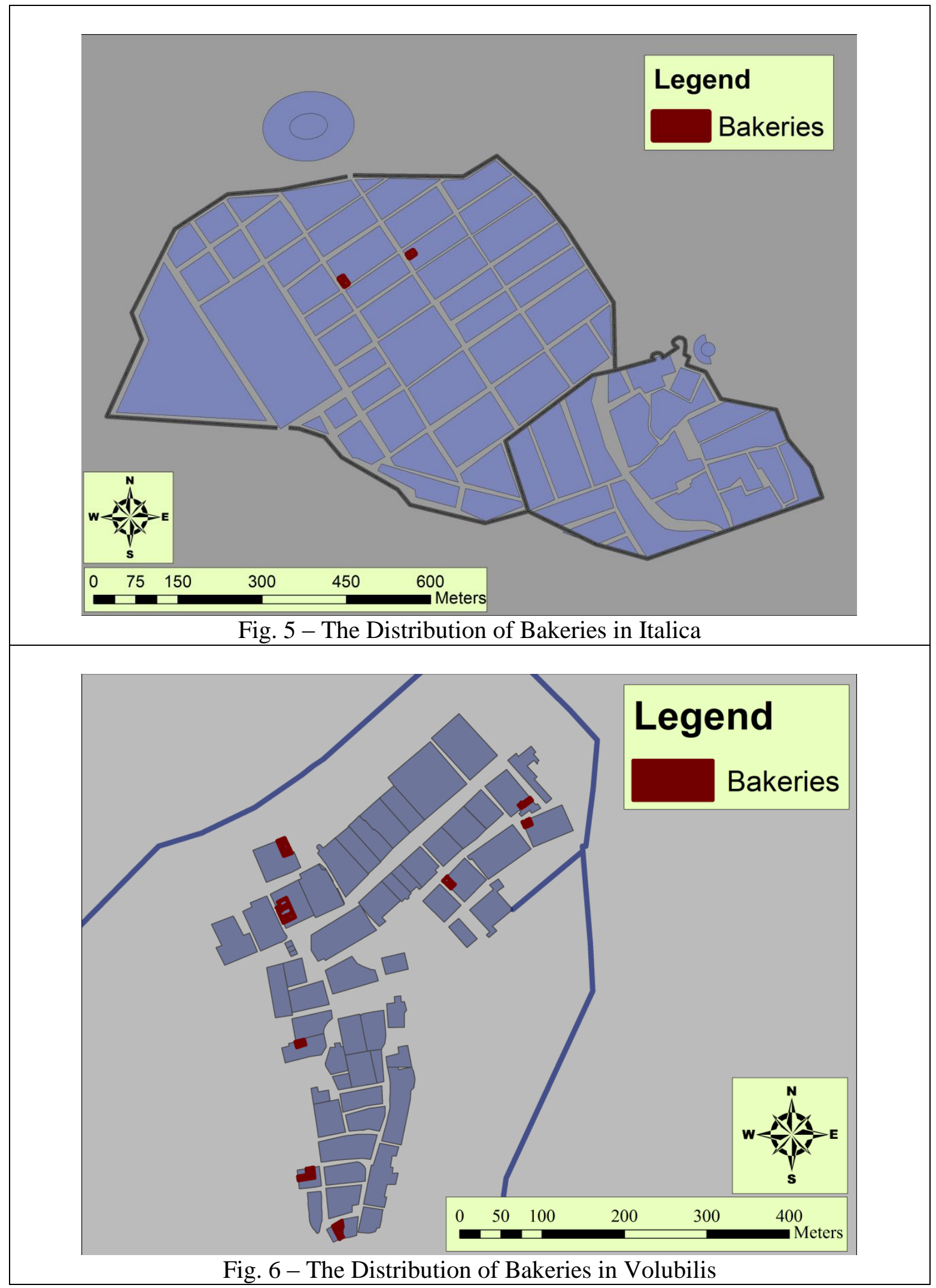




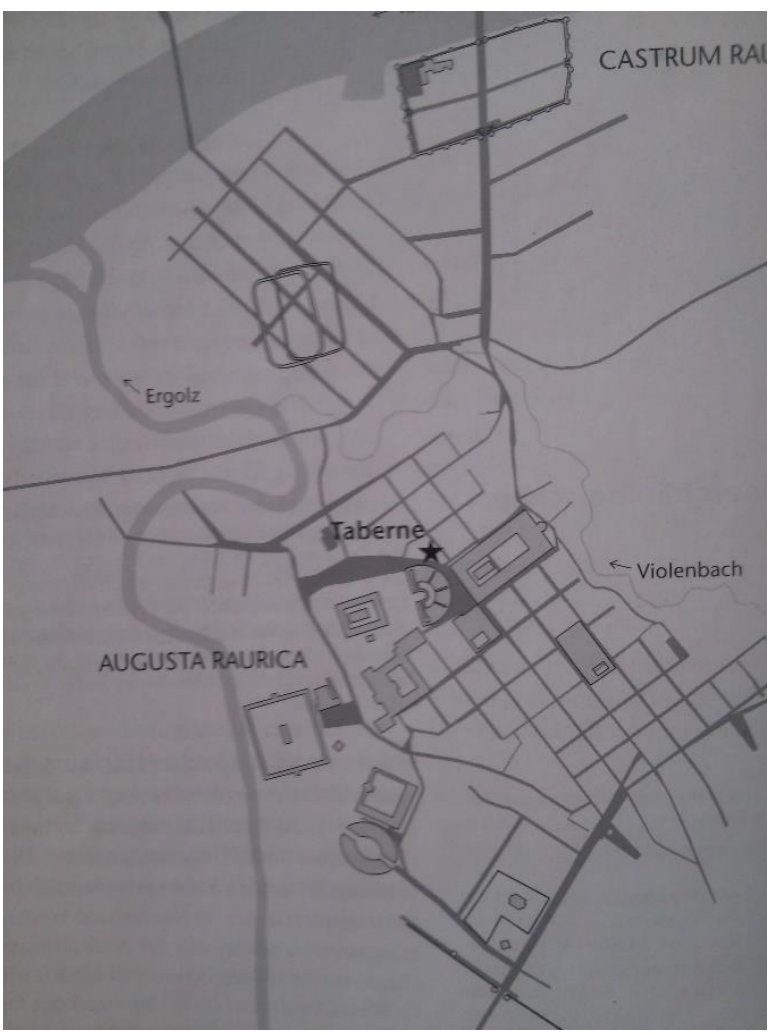

Fig. 7 - Plan of Theater at Theater at Augusta Raurica and Location of Bakery (Taberne) (After Amman and Schwarz 2011, abb. 1) 


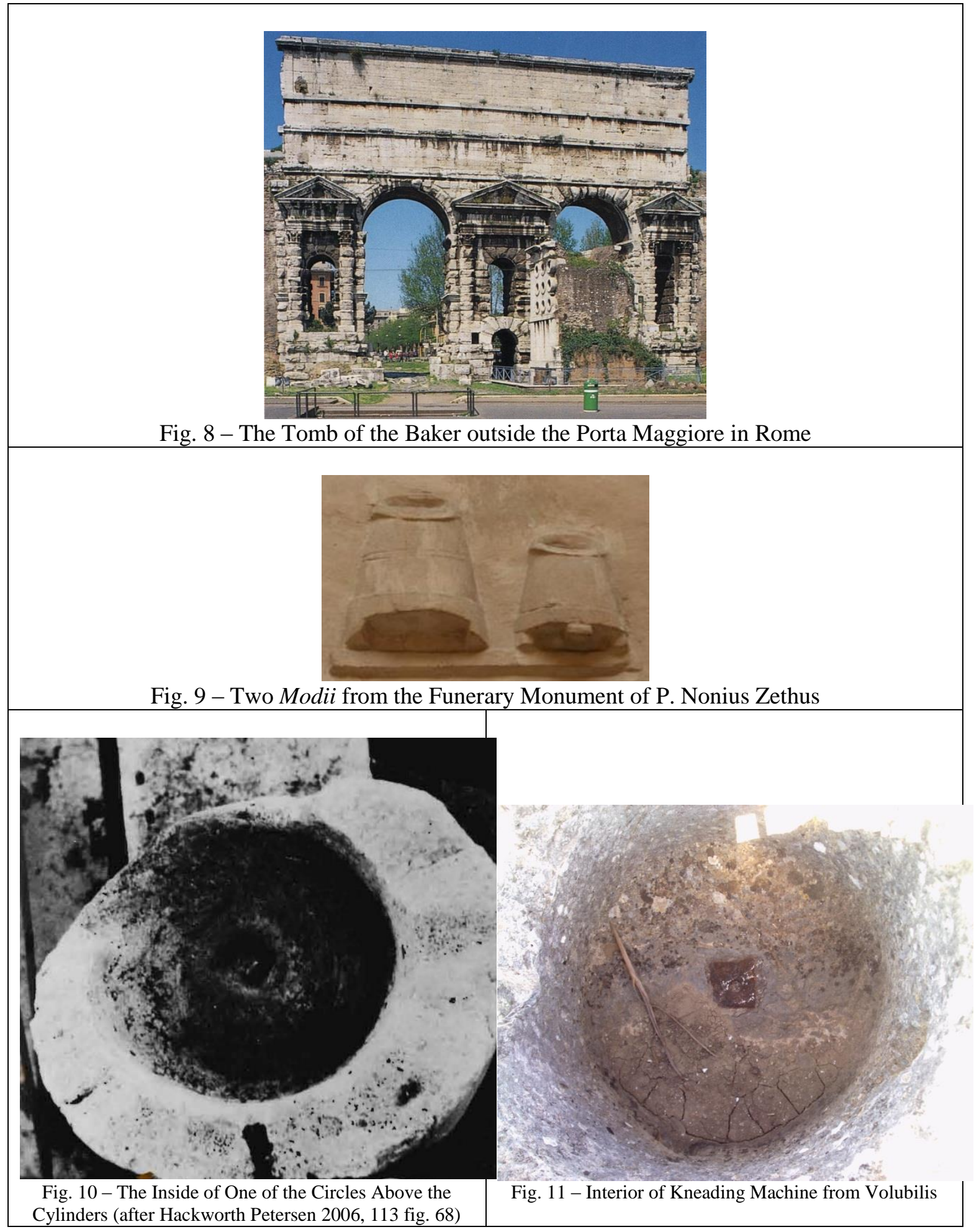




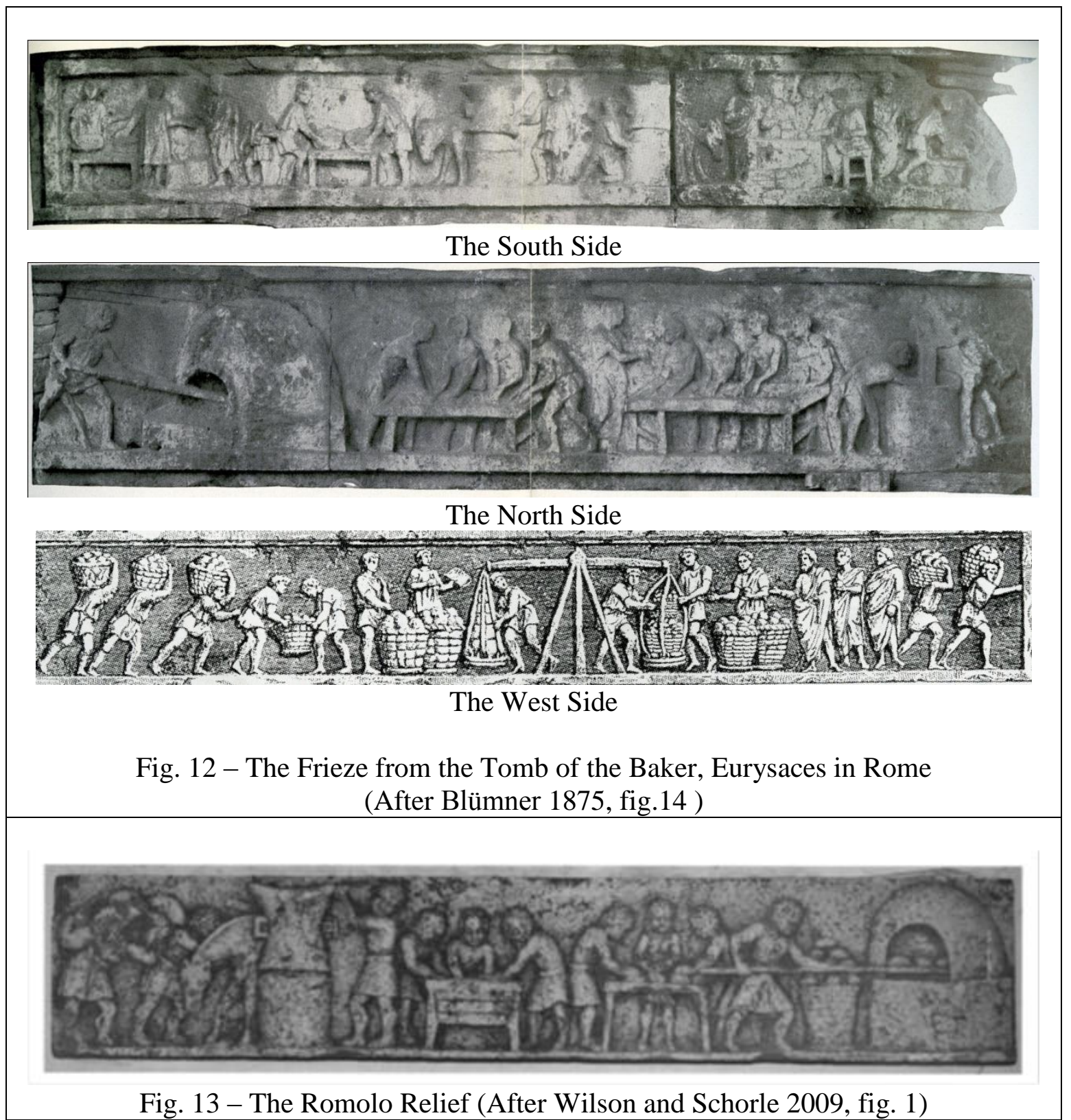




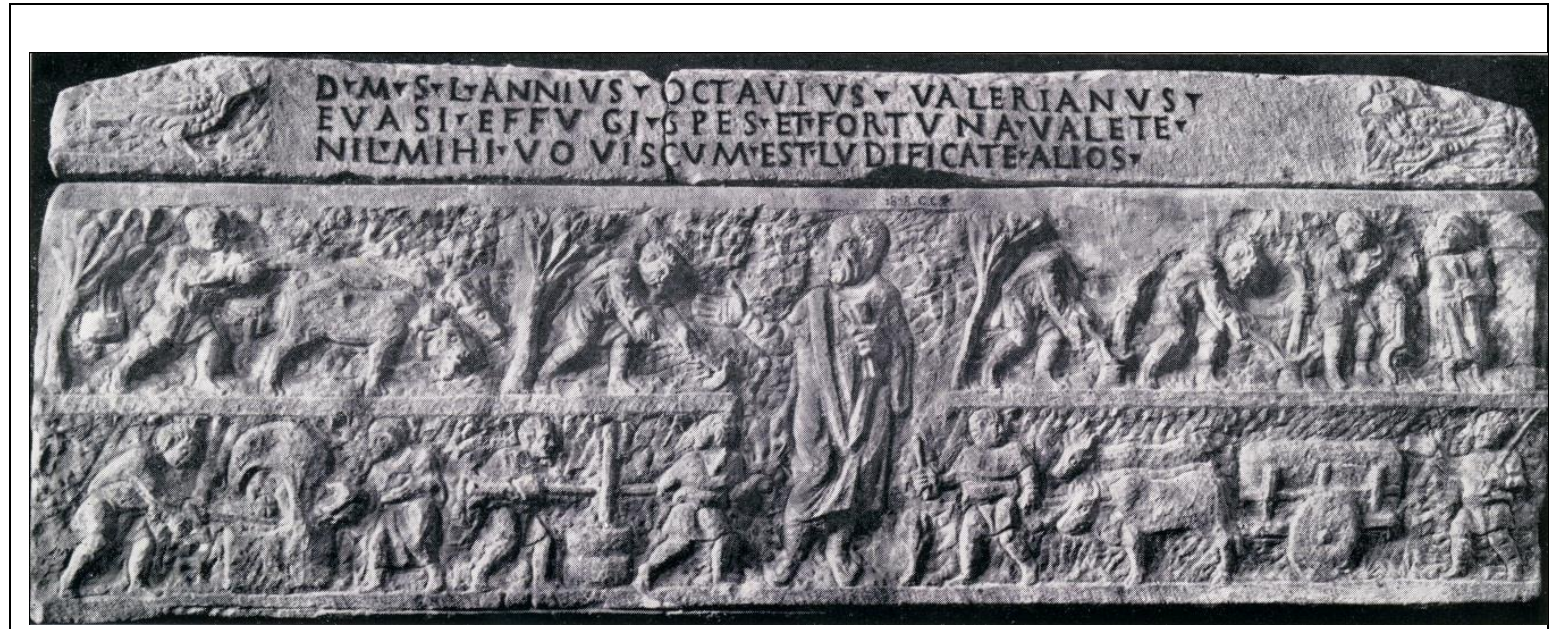

Fig. 14 - Sarcophagus of Lucius Annius Octavius Valerianus (After Moritz 1958, fig 9)

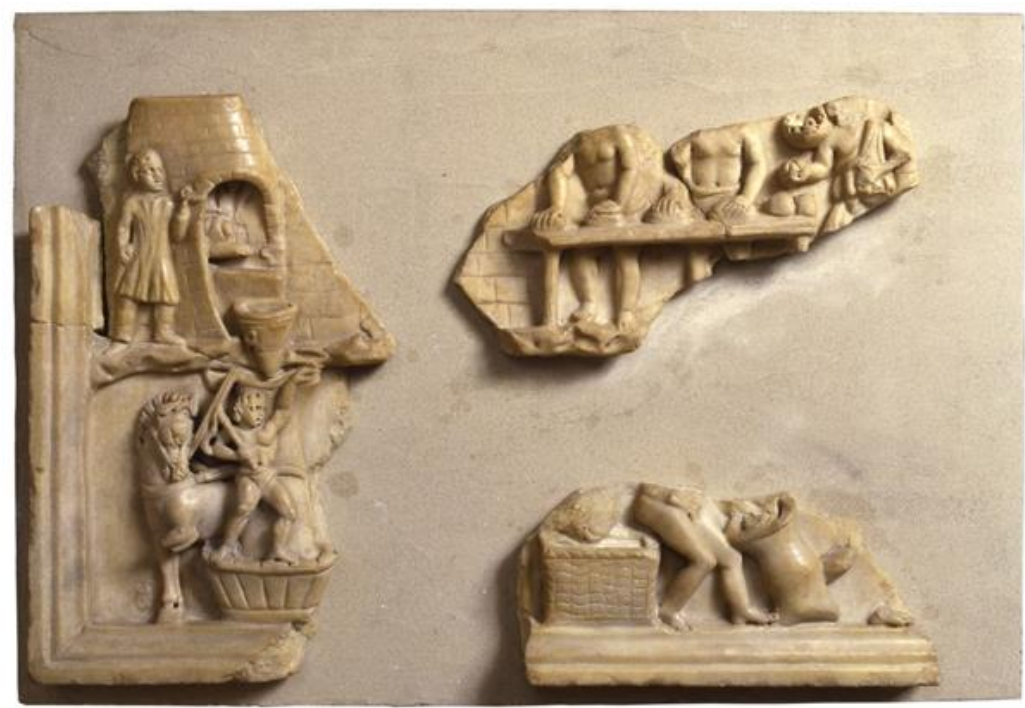

Fig. 15 - Marble Plaque from Bologna (After Cullin-Mingaud 2010, fig. 214)

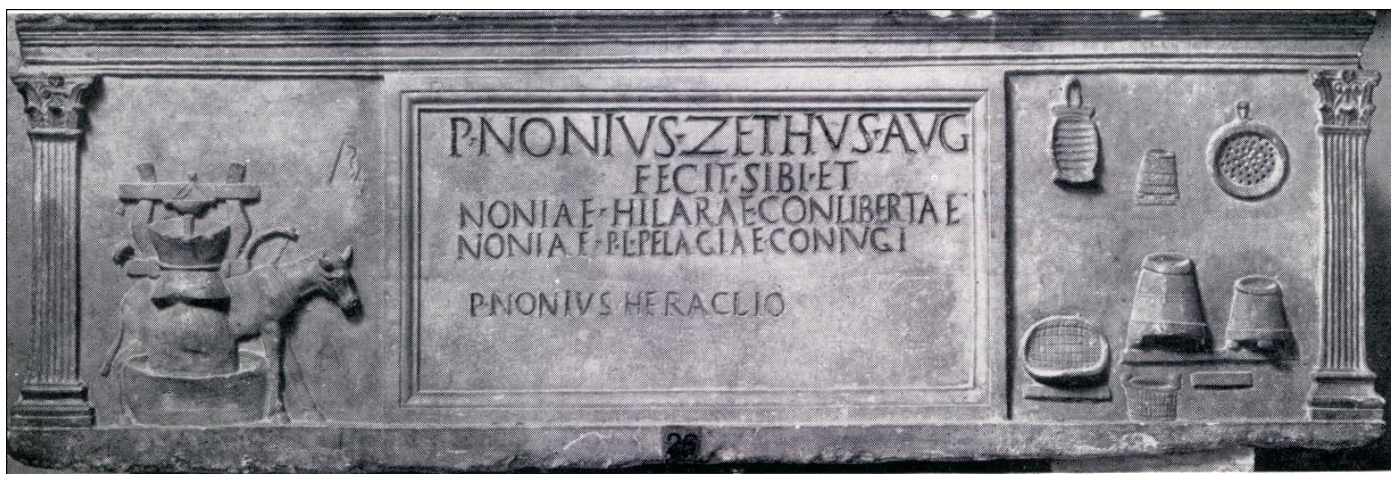

Fig. 16 - Funerary Monument of P. Nonius Zethus (After Blümner 1875, fig. 17) 


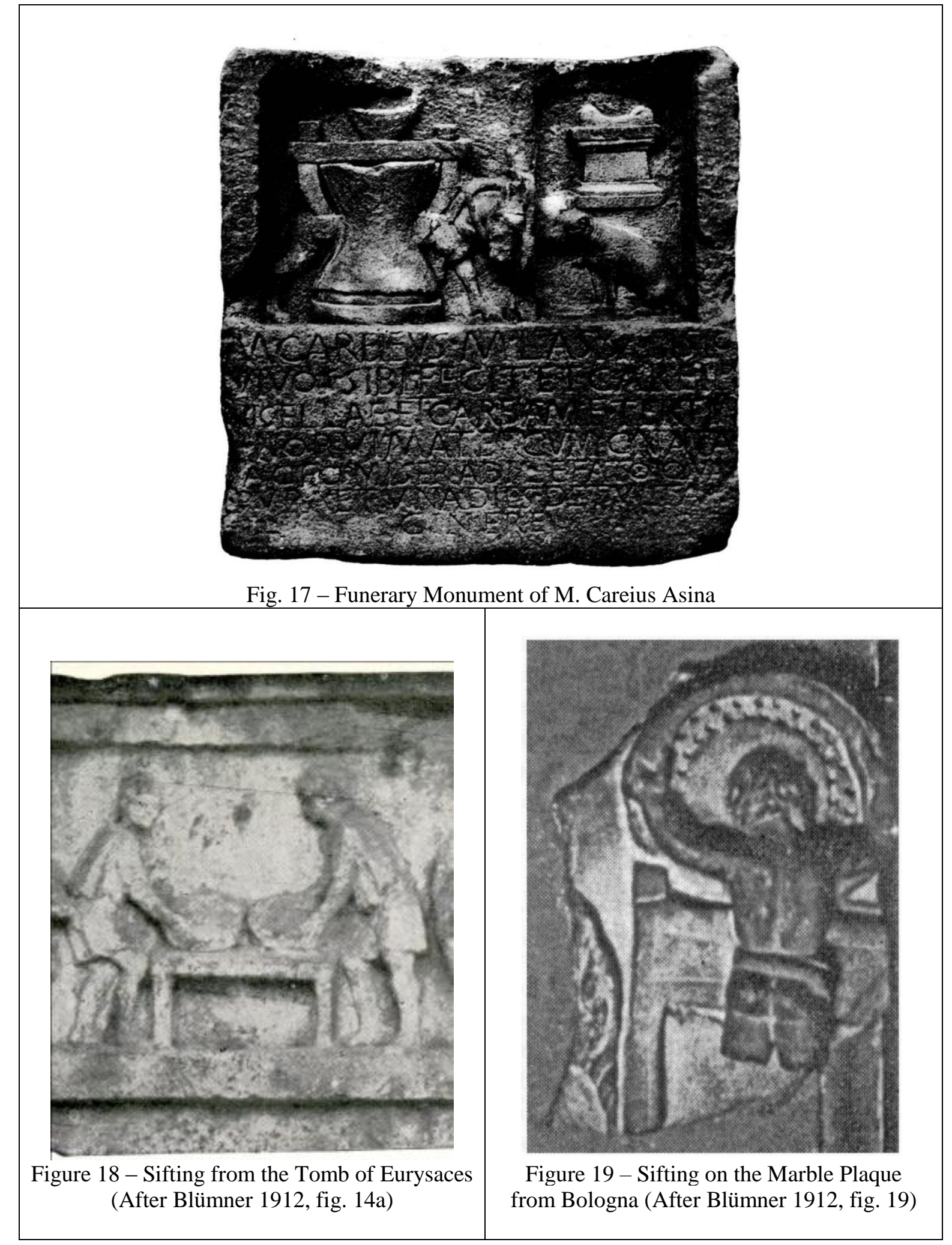




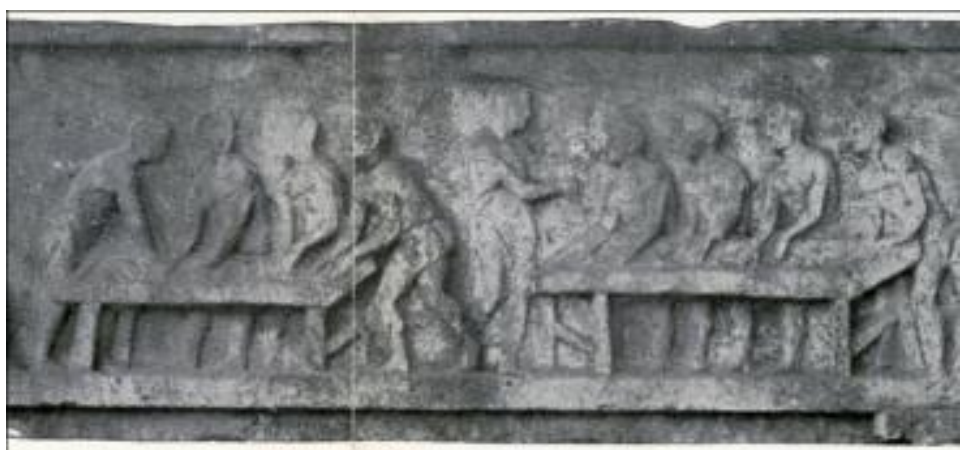

Figure 20 - Image of Loaf-Formation from the Tomb of Eurysaces, in Rome (After Blümner 1912, fig. 14)

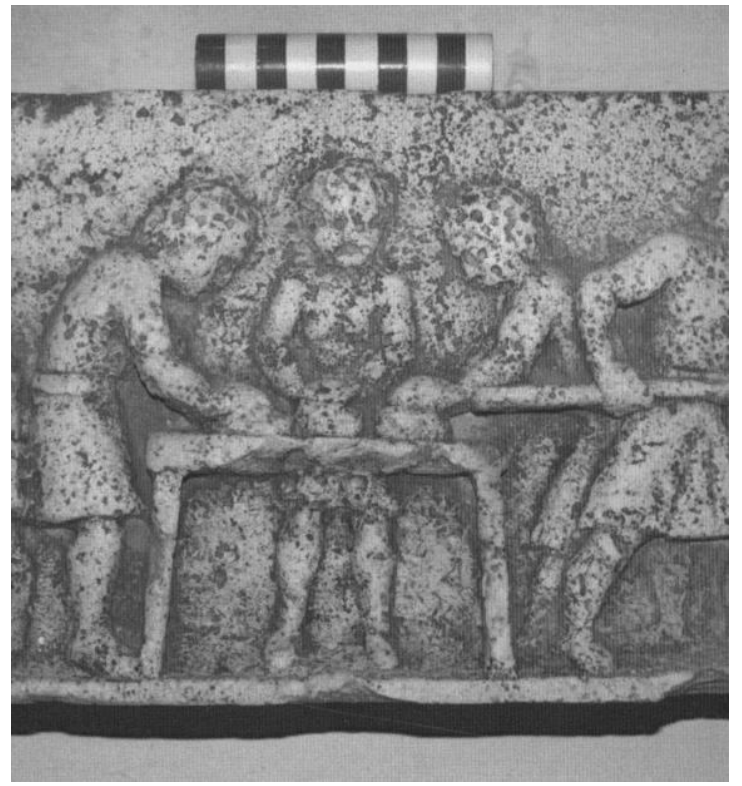

Figure 21 - Image of Loaf-Formation from the Romolo Relief, in Rome (After Wilson and Schorle 2009, fig. 5)

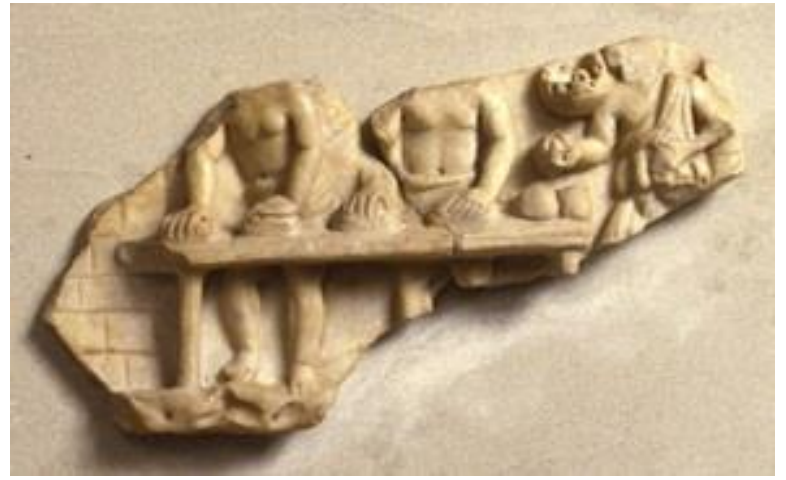

Figure 22 - Kneading from the Marble Plaque from Bologna (After Cullin-Mingaud 2010, fig. 214) 


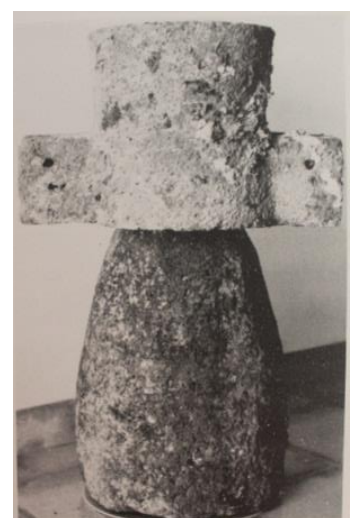

Figure 23 -Millstone from Sec Wreck (After Arribas 1987)

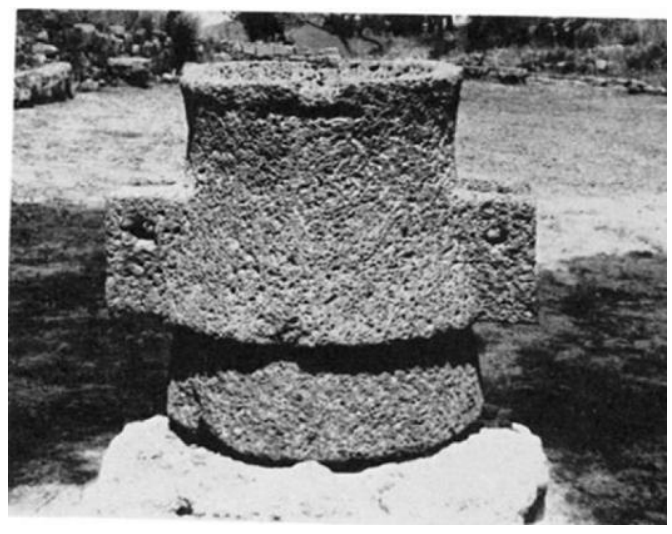

Figure 24 - An Early Rotary Millstone Morgantina (After White 1963, fig. 6)

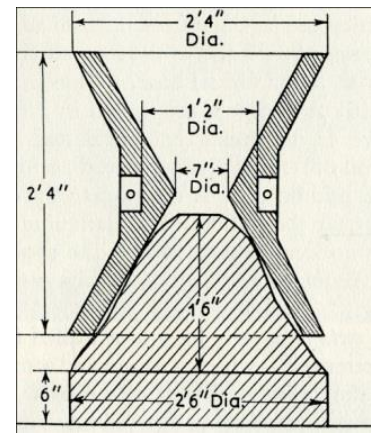

Figure 25 - Diagram of a Pompeii-style millstone (after White 1963, fig. 10).

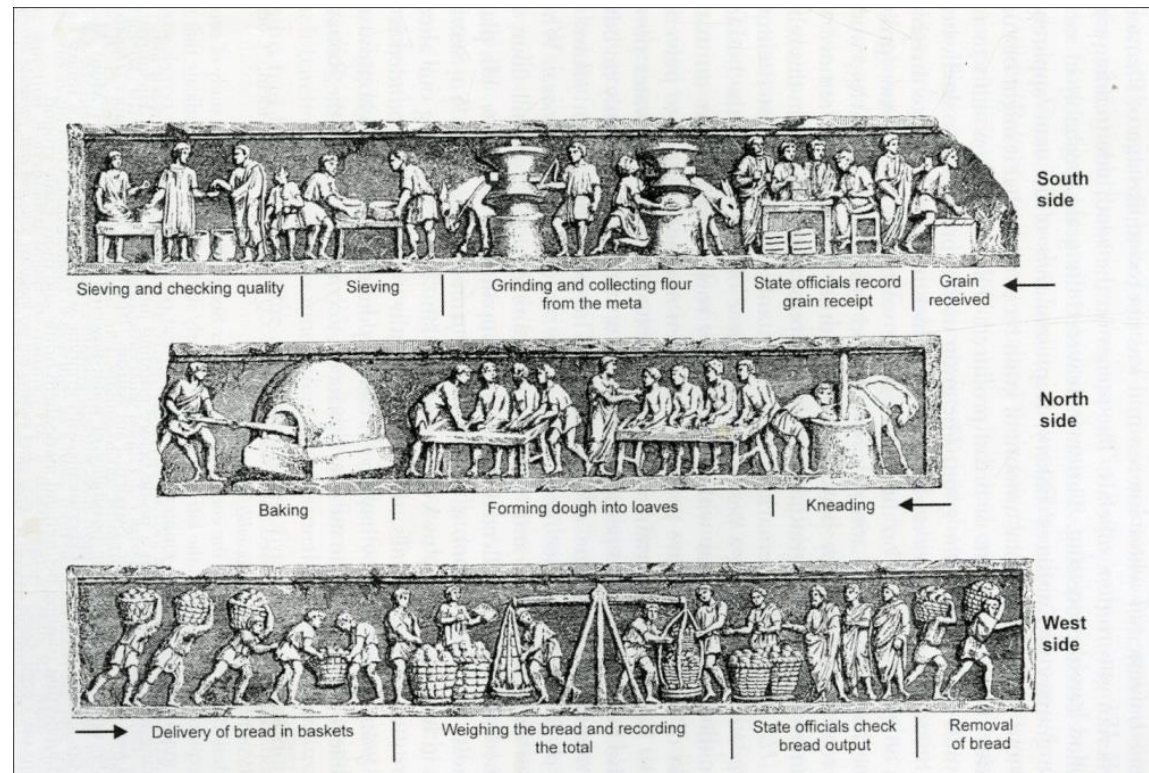

Figure 26 - Frieze From the Tomb of the Bakery, Eurysaces, Late First Century BC, Rome (After Curtis, fig. 28) 


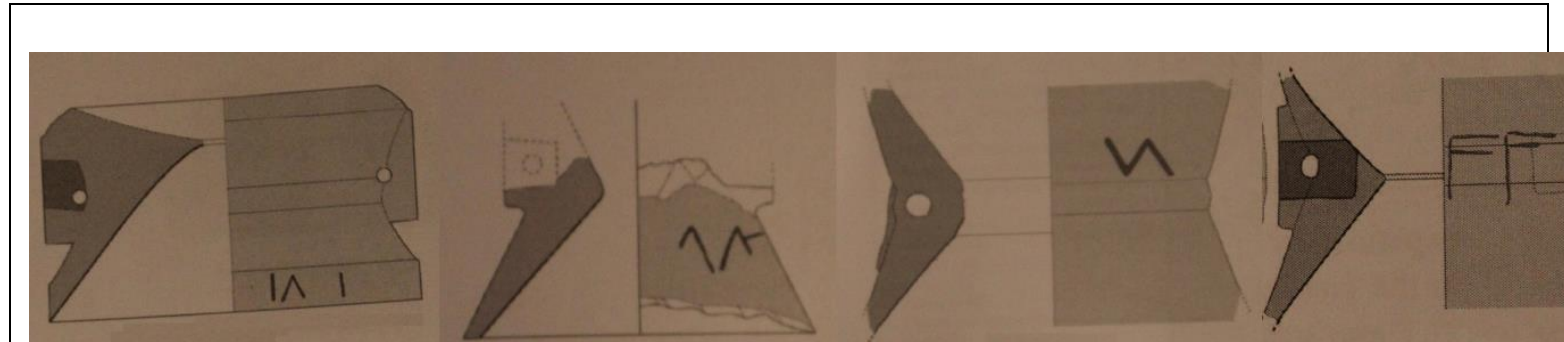

Figure 27 - Drawings of Leucite-Bearing Volcanic Rock Catilli from Southeast France (After Jaccottery and Longepierre 2011, fig. 13-16)

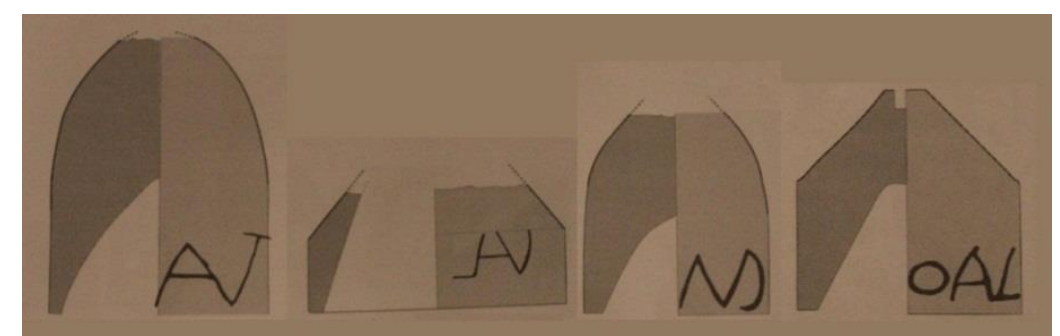

Figure 28 - Drawings of Leucite-Bearing Volcanic Rock Metae from Southeast France (After Jaccottey and Longepierre 2011, fig. 18)
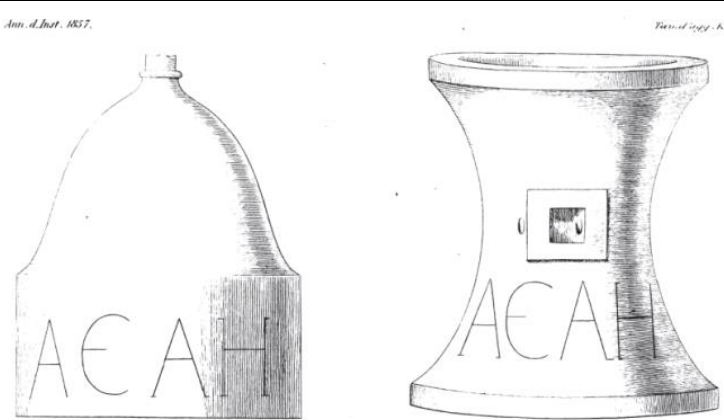

Figure 29 - Roman Millstones with Inscriptions from the Aventine in Rome (After de Rossi 1857, Plate K)

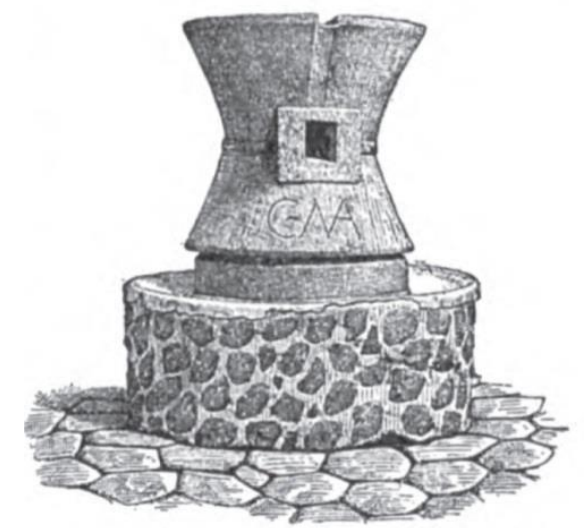

Figure 30 - Roman Millstone with Inscription, Catillus Now Missing, Bakery 9 in Pompeii, VI.3.3/27-28 (After Mau 1899, Figure 210) 


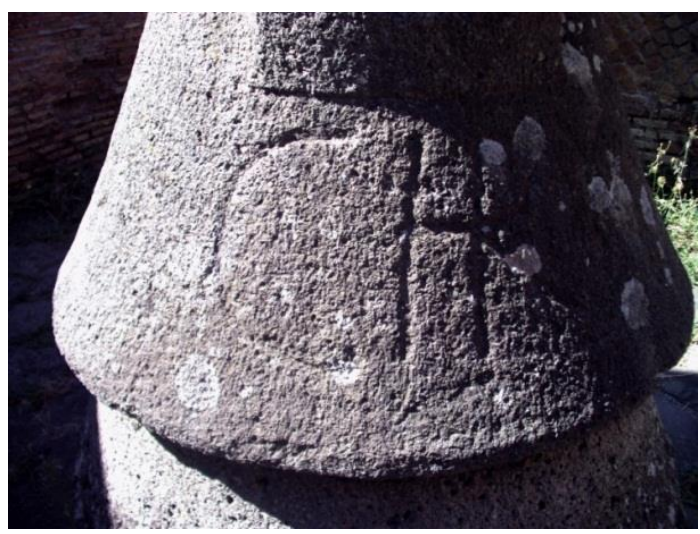

Figure 31 - Bottom of Catillus with Makers Mark, Ostia, Bakery 2, I.III.1

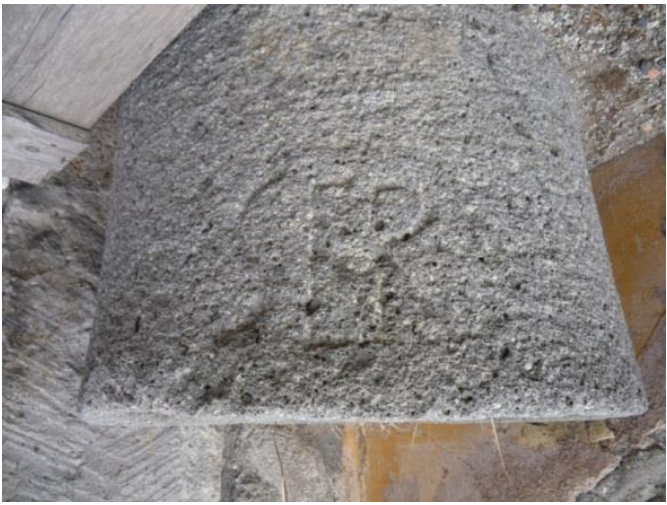

Figure 32 - Meta with Makers Mark, Pompeii, Bakery 30, IX.1.3/33 (Upside Down)

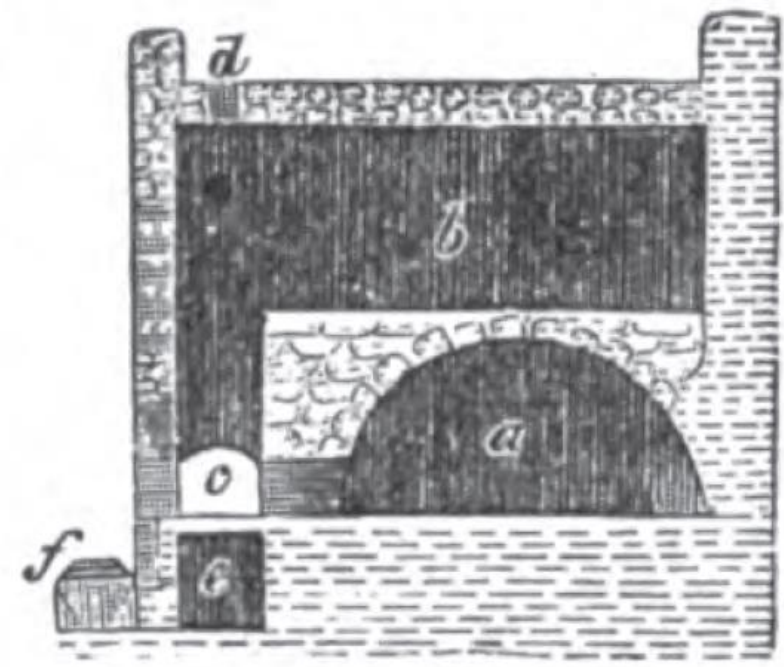

Figure 33 - Section Diagram of a Pompeian Oven (After Mau 1899, 383) a: oven b: cavity above oven c: chute d: flu e: fuel storage below praefurnium 

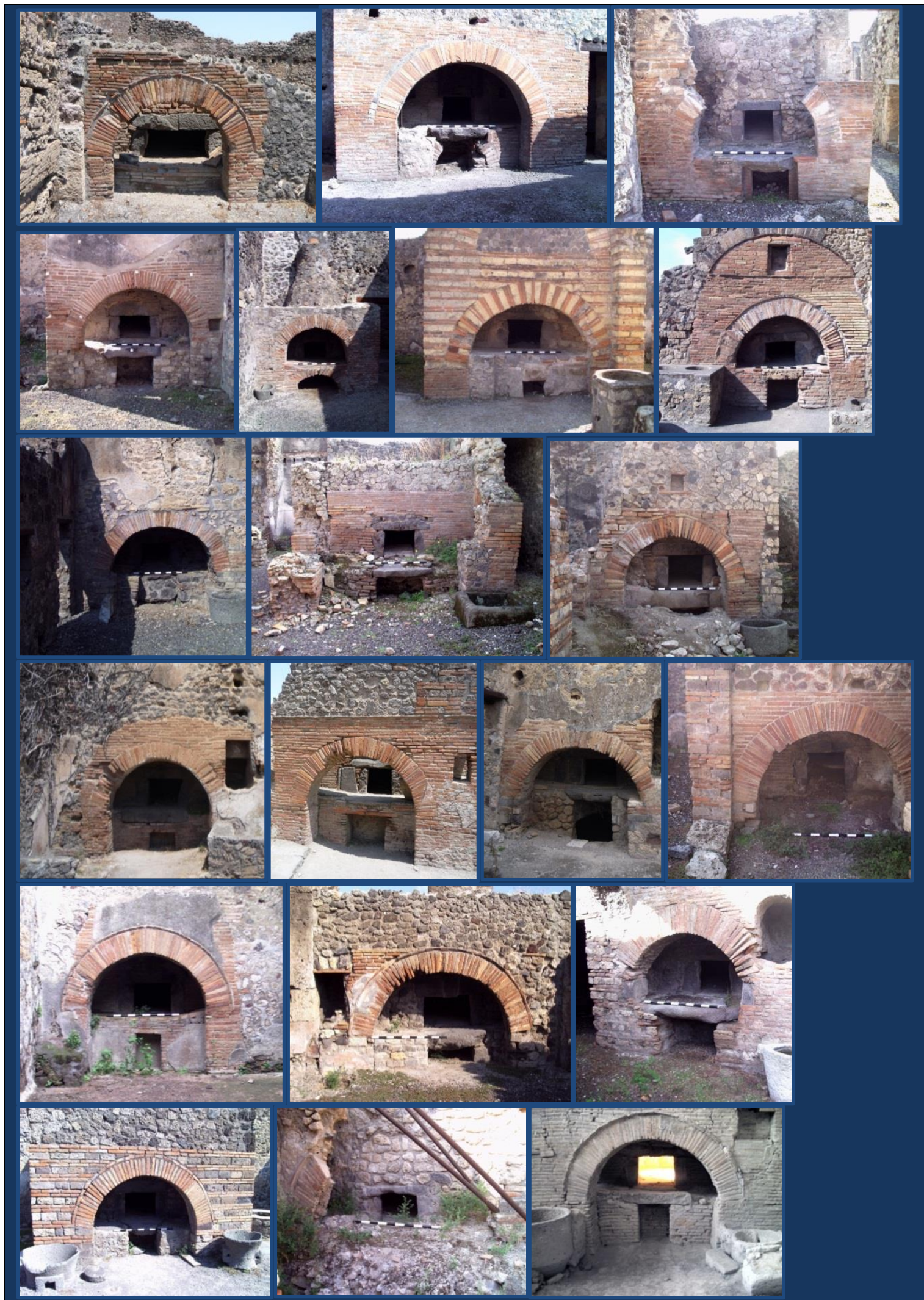

Figure 34 - The Twenty-One Standardized Ovens in Pompeii 


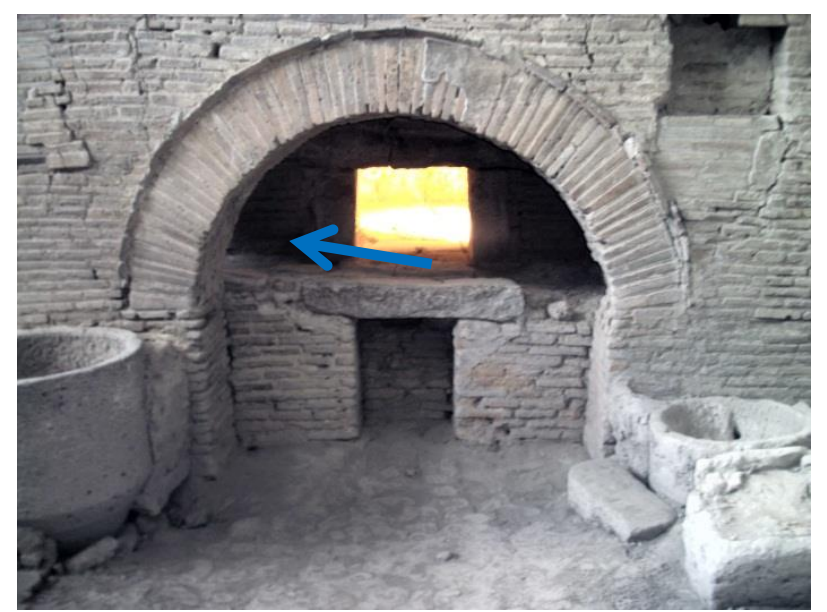

Figure 35 - Oven from Bakery 35 in Pompeii, Casa dei Casti Amanti (IX.12.6-7) Arrow Indicates Direction of Chute

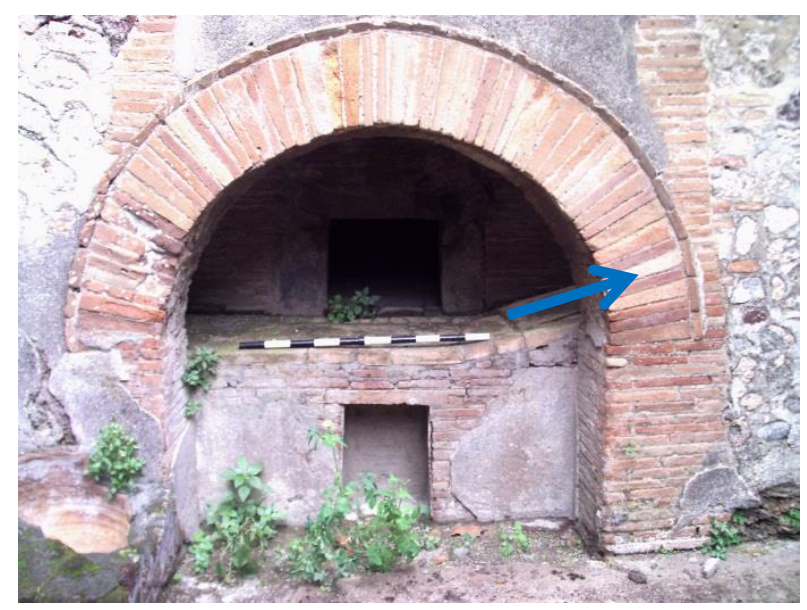

Figure 36 - Oven from Bakery 4 in Pompeii, Casa del Forno or Pistrinum of Sotericus (I.12.1-2) Arrow Indicates Direction of Chute

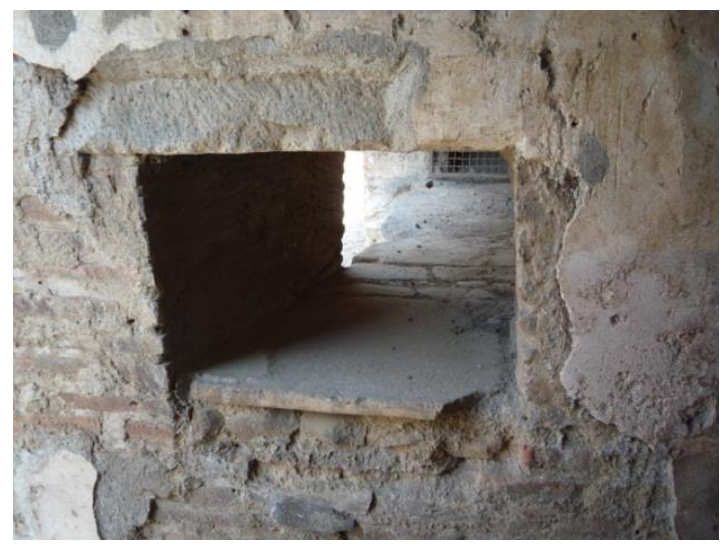

Figure 37 - Chute in Bakery 4 in Pompeii, Casa del Forno or Pistrinum of Sotericus (I.12.1-2) 


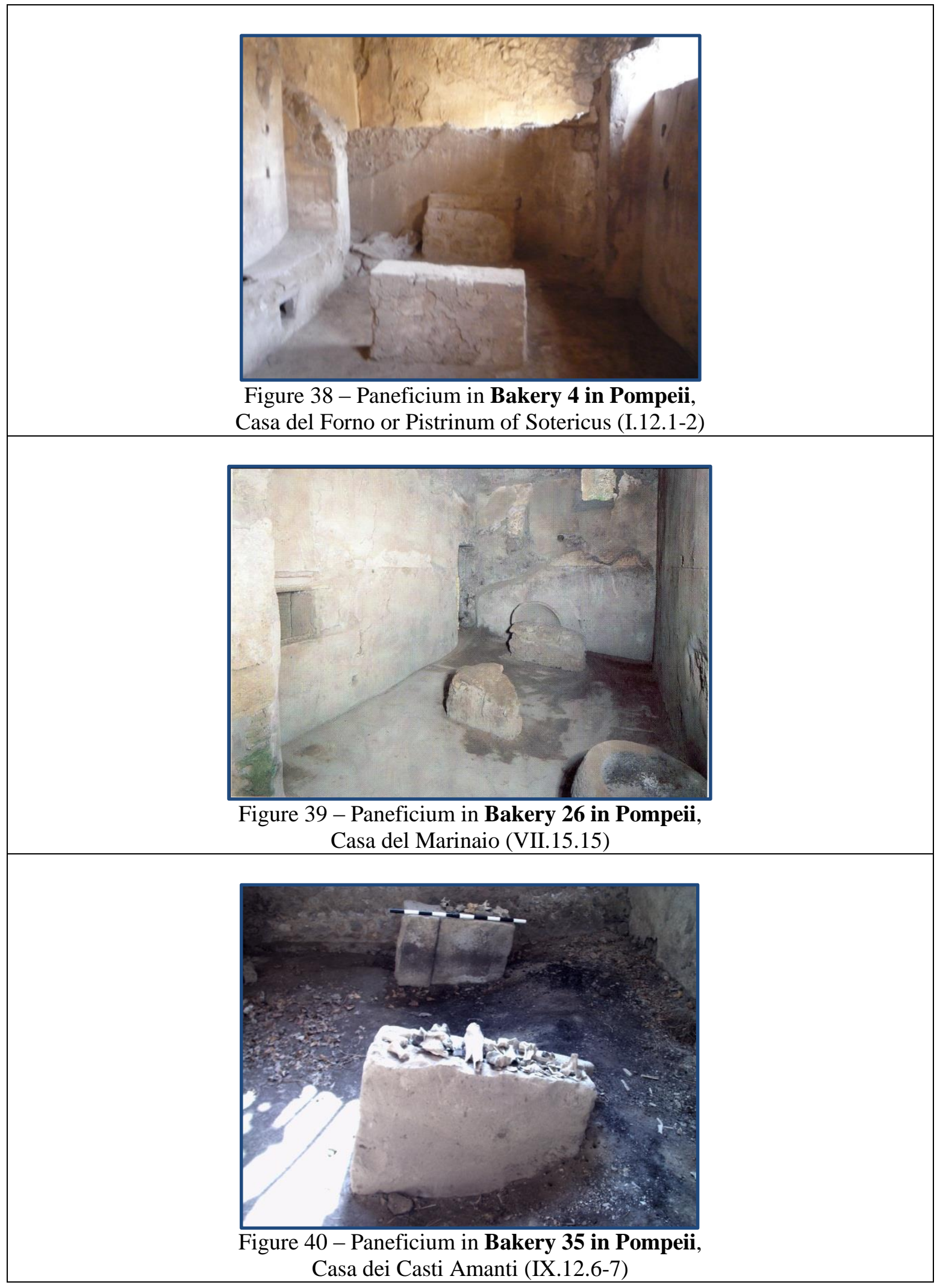




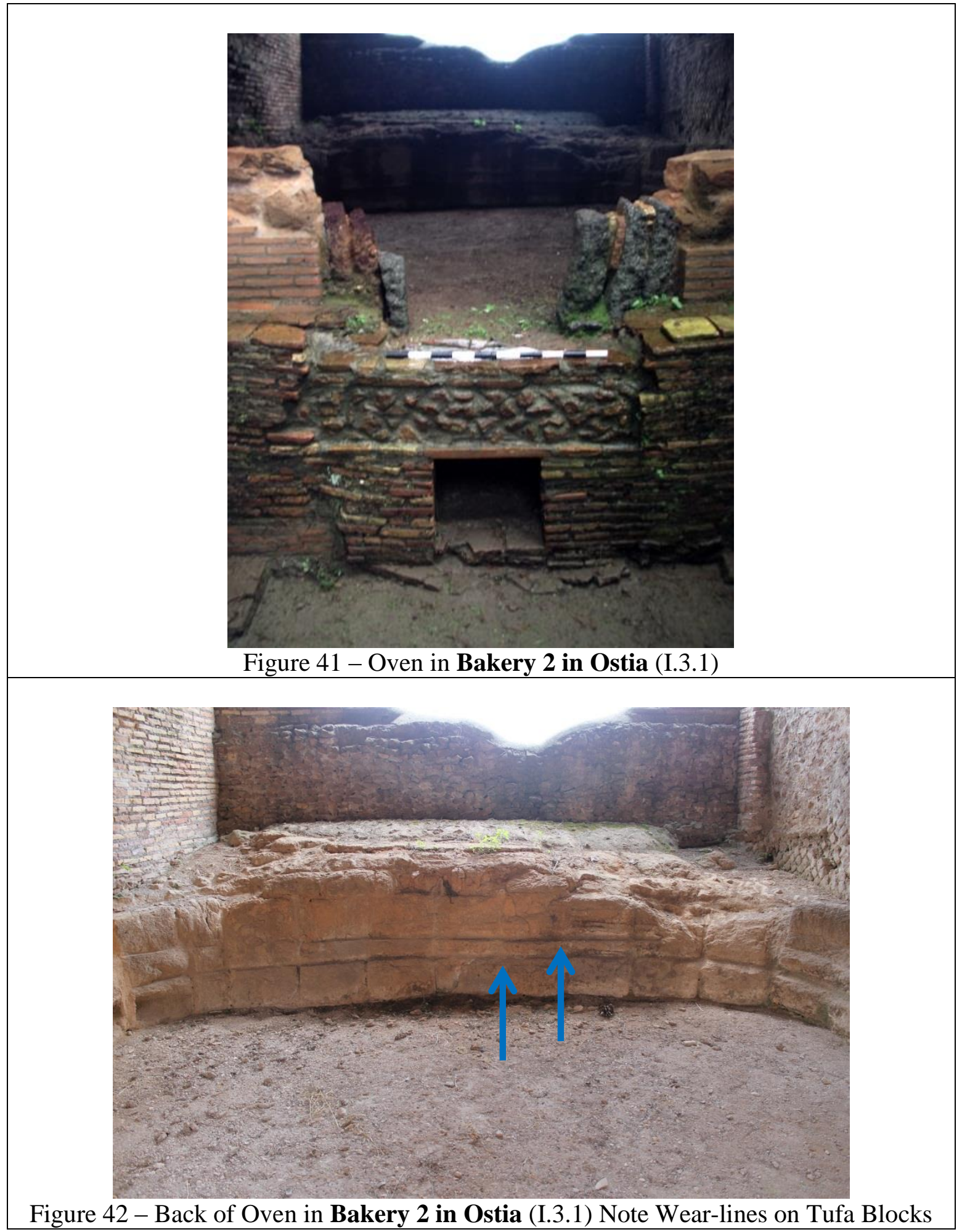




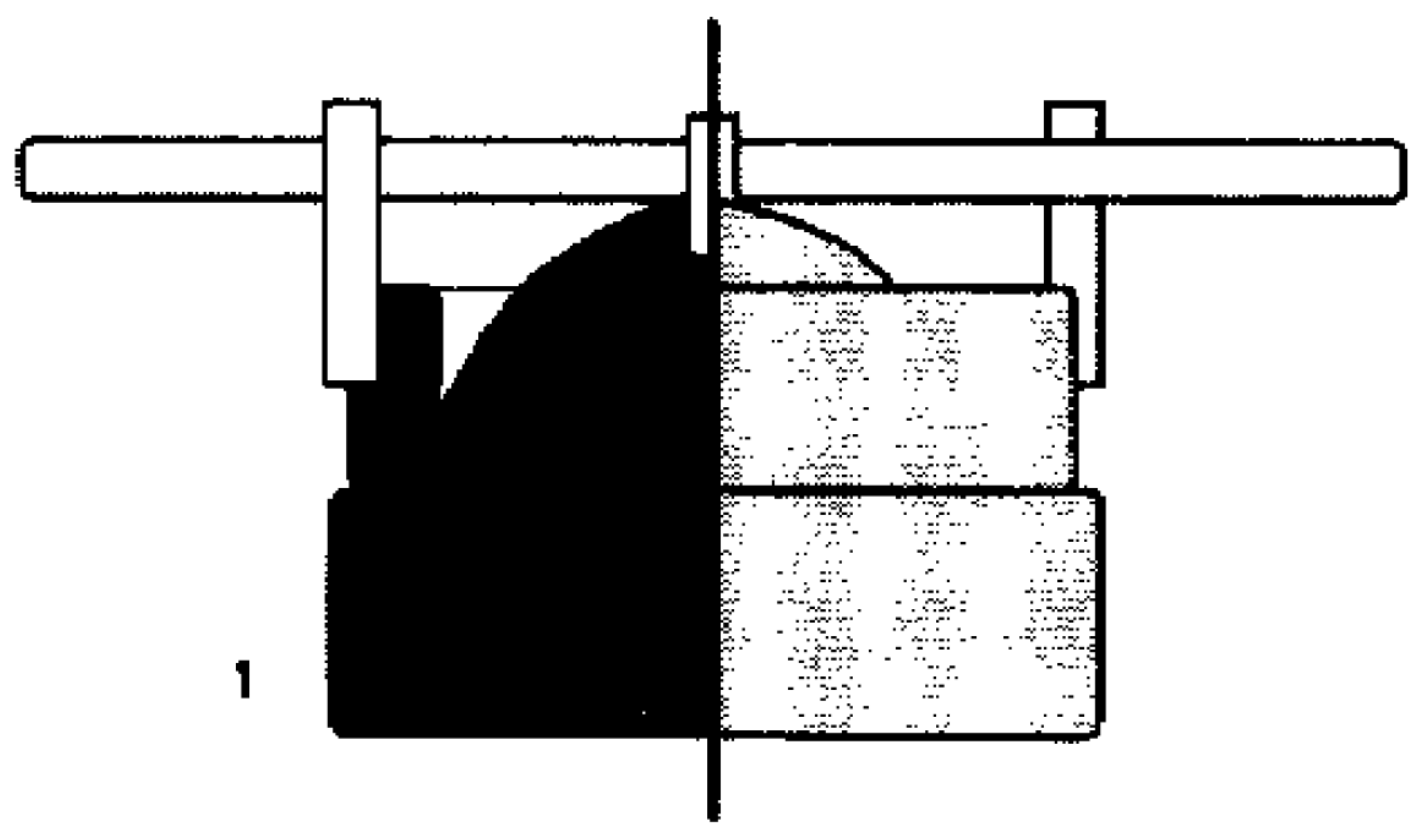

Figure 43 - Diagram of an Annular Millstone from Volubilis (After Leduc 2007, fig. 2)

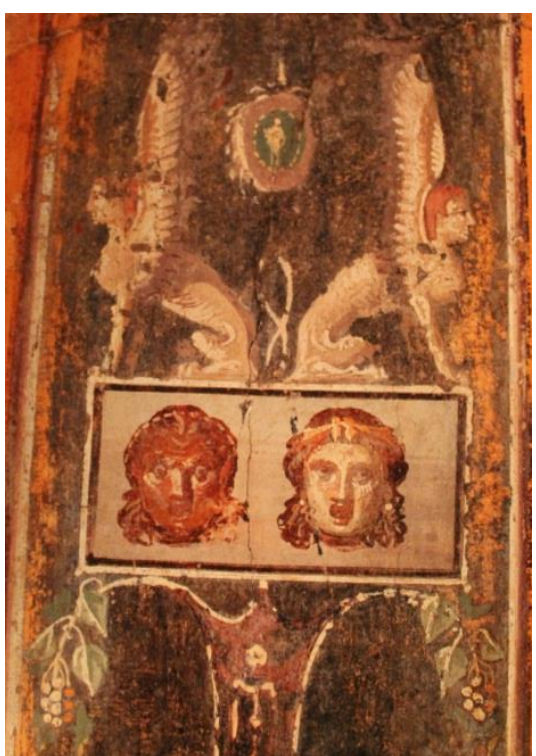

Figure 44 - Decoration in Bakery 2 in

Herculaneum (After Guidobaldi and Esposito 2012, 187)

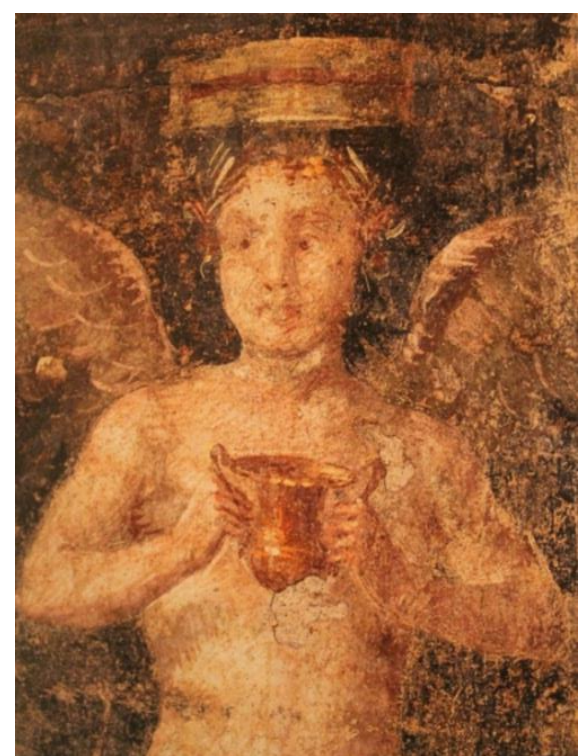

Figure 45 - Decoration in Bakery 2 in Herculaneum (After Guidobaldi and Esposito 2012, 186) 


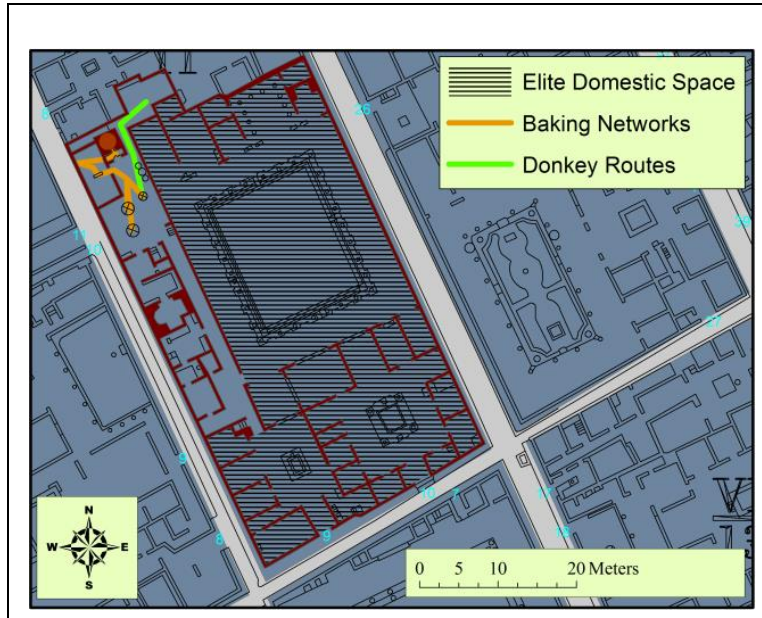

Figure 46 - Casa di Labirinto (VI.11.9)

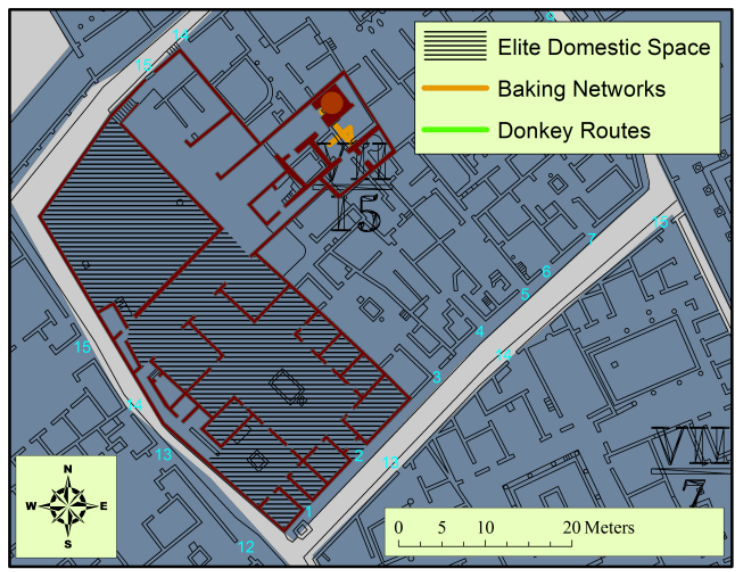

Figure 48 - Casa del Marinaio (VII.15.15)

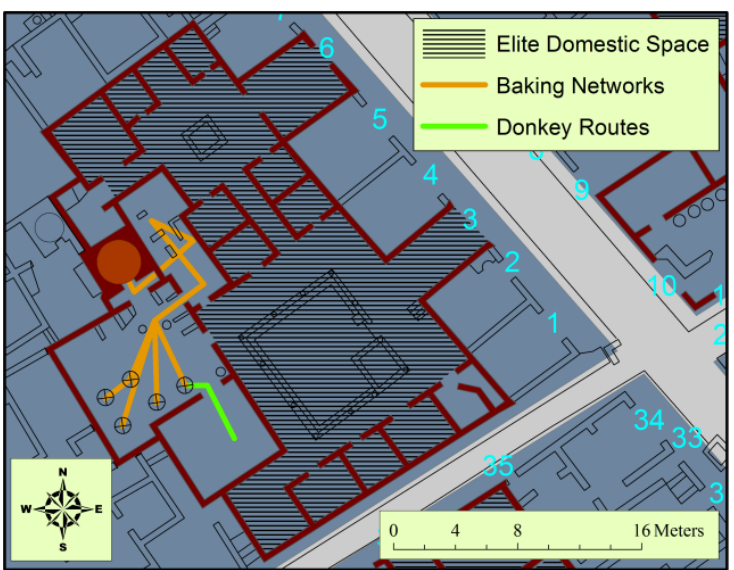

Figure 47 - Casa di Procolo (VII.2.3)

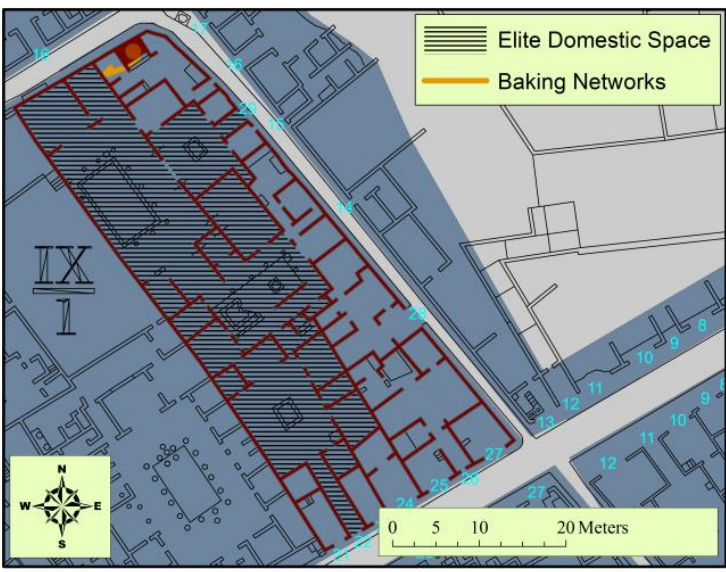

Figure 49 - Casa di Epidio Sabino (IX.1.22)

Type One Bakeries: Operating Sequences and Indications of Elite Domestic Space 


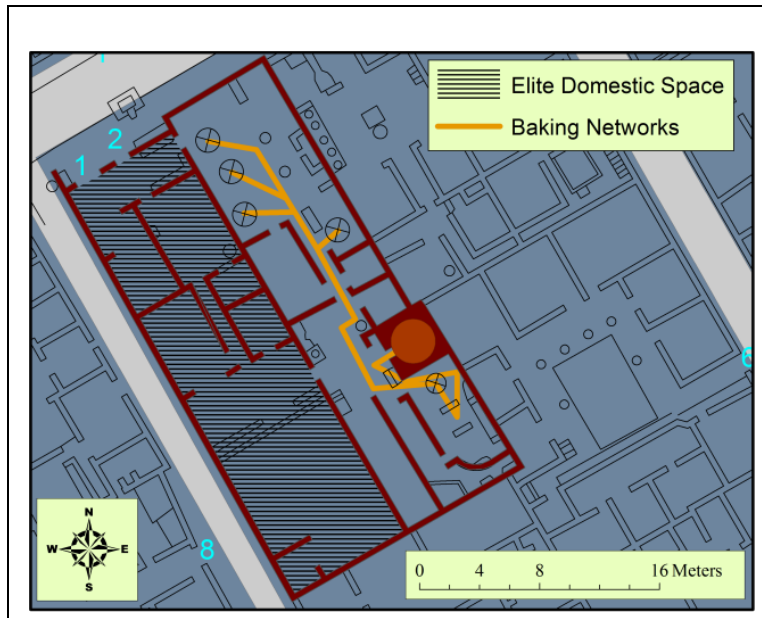

Figure 50 - Casa del Forno in Pompeii (I.12.1)

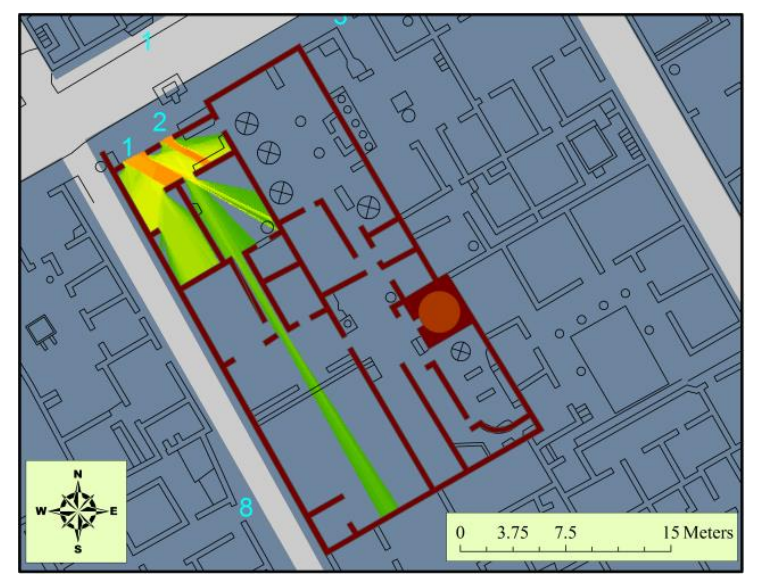

Figure 51 - Casa del Forno in Pompeii (I.12.1)

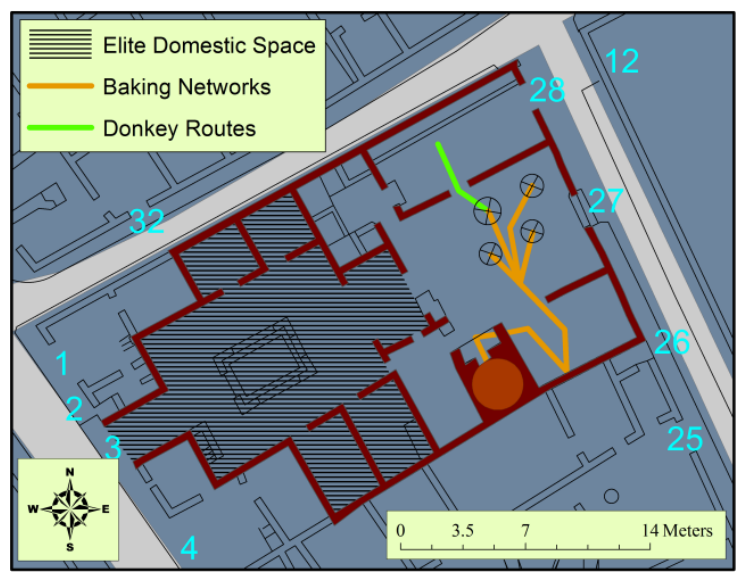

Figure 52- Bakery Nine in Pompeii (VI.3.3)

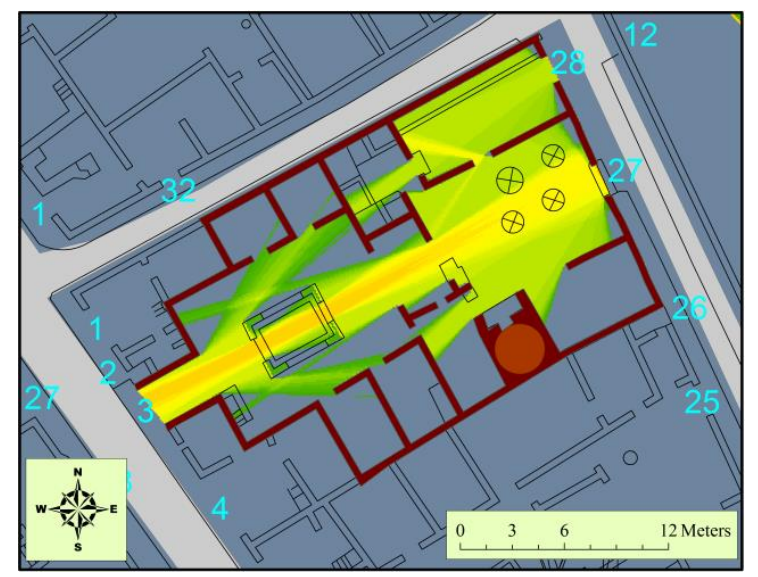

Figure 53 - Bakery Nine in Pompeii (VI.3.3)
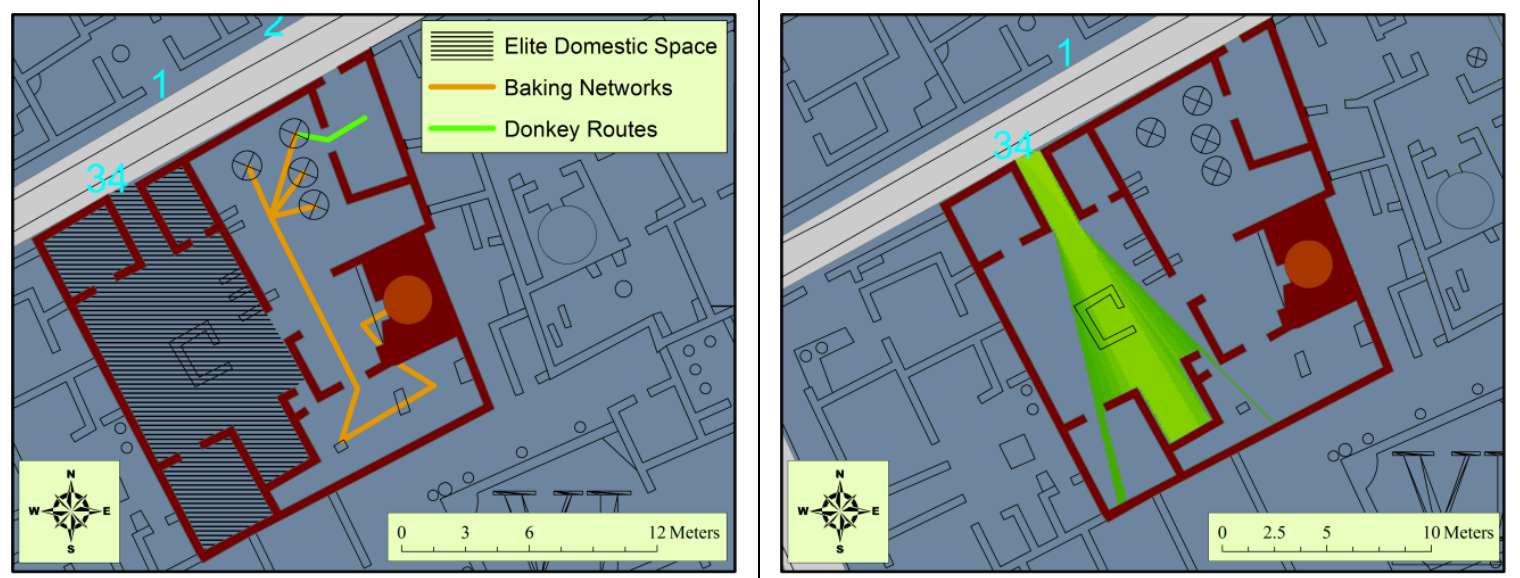

Figure 54 - Bakery 15 in Pompeii (VI.14.34)

Figure 55 - Bakery 15 in Pompeii (VI.14.34) Type-Two Bakeries: Operating Sequences and Indications of Elite Domestic Space on the Left and Viewsheds on the Right 


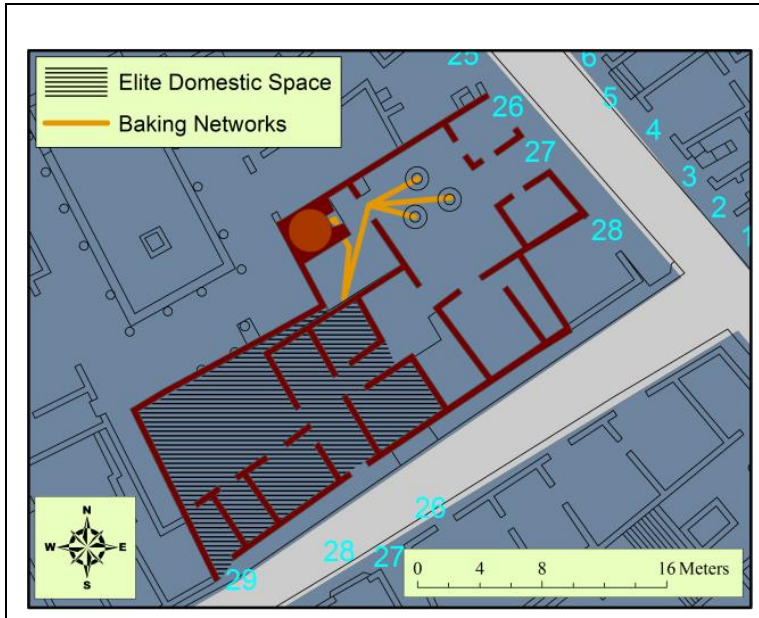

Figure 56 - Bakery 28 in Pompeii (VIII.4.26)
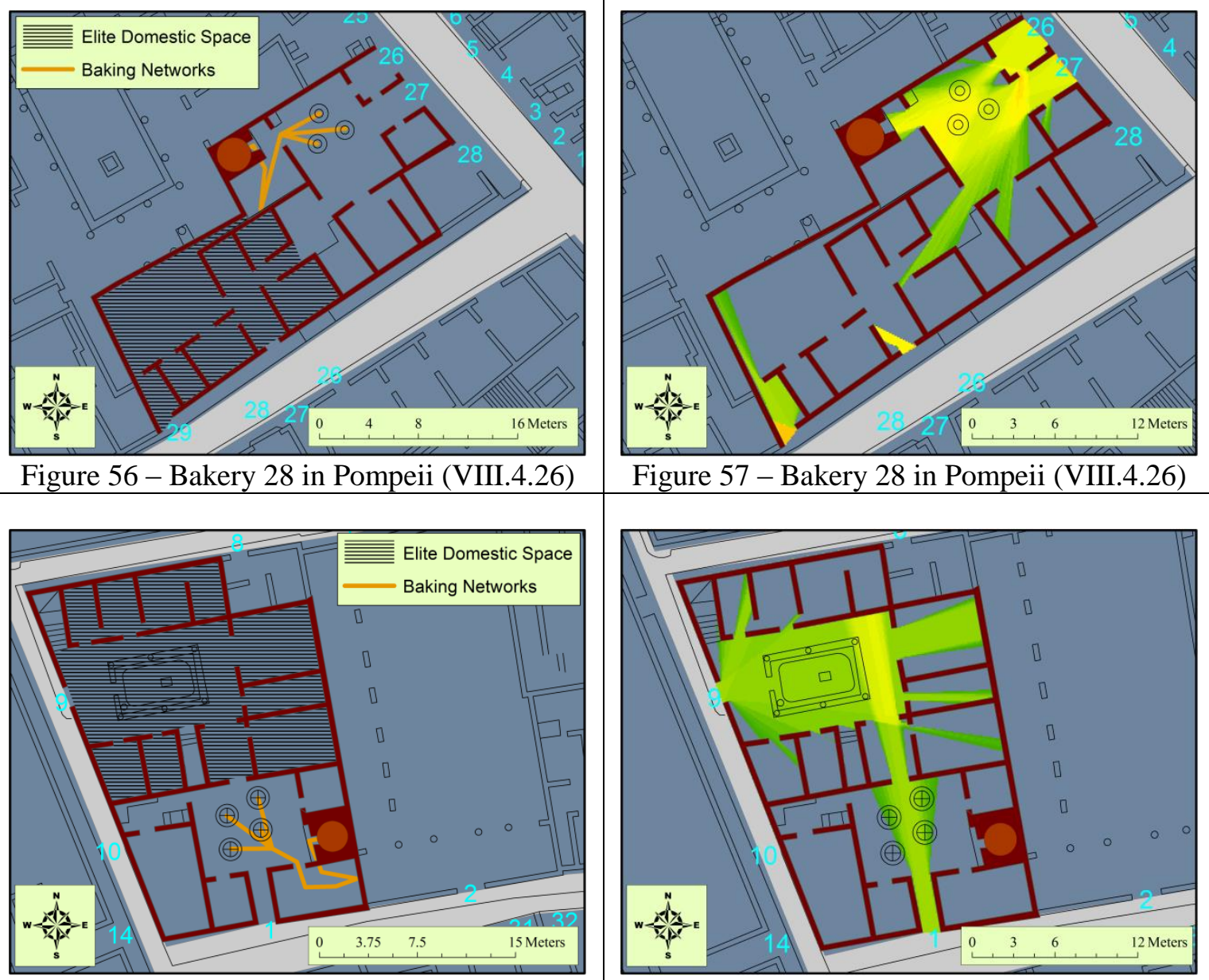

Figure 58 - Bakery 29 in Pompeii (VIII.6.1)

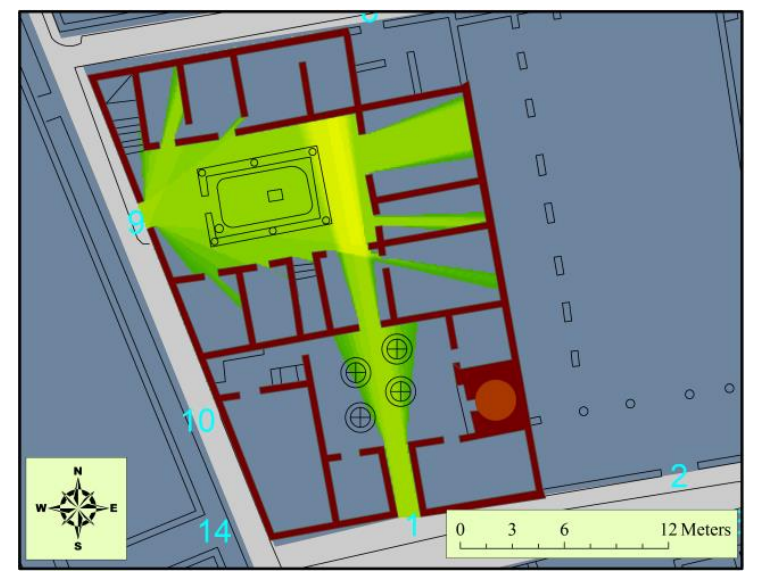

Figure 59 - Bakery 29 in Pompeii (VIII.6.1)

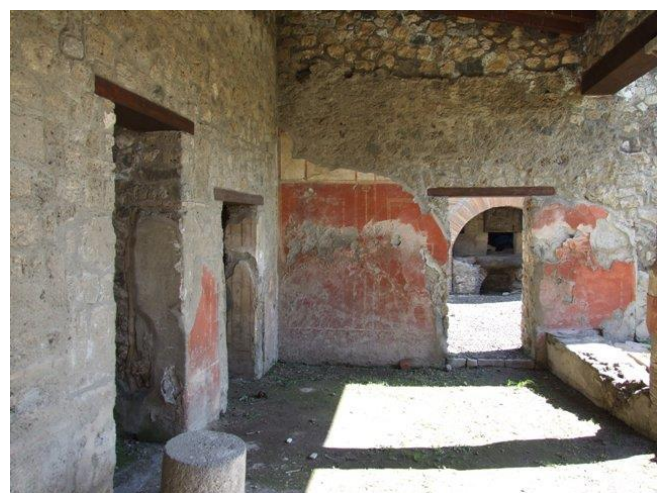

Figure 60 - I.12.1: Decorated Walls Looking from Garden into Bakery (facing east) (Courtesy of Jackie and Bob Dunn)

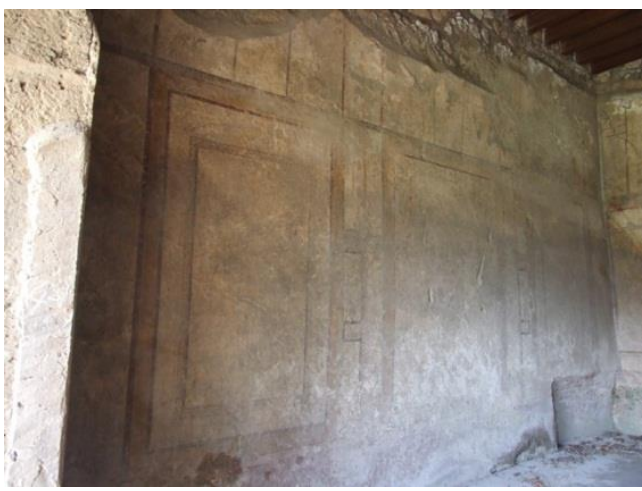

Figure $61-$ I.12.1: Decorated walls in Oecus (facing northwest)

(Courtesy of Jackie and Bob Dunn)

Type-Two Bakeries: Operating Sequences and Indications of Elite Domestic Space on the Left and Viewsheds on the Right 


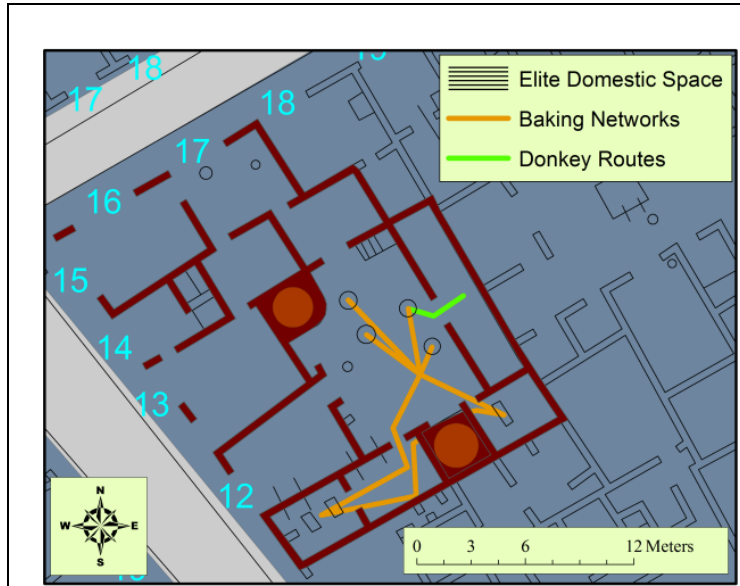

Figure 62 - Bakery 3 in Pompeii (I.4.12)

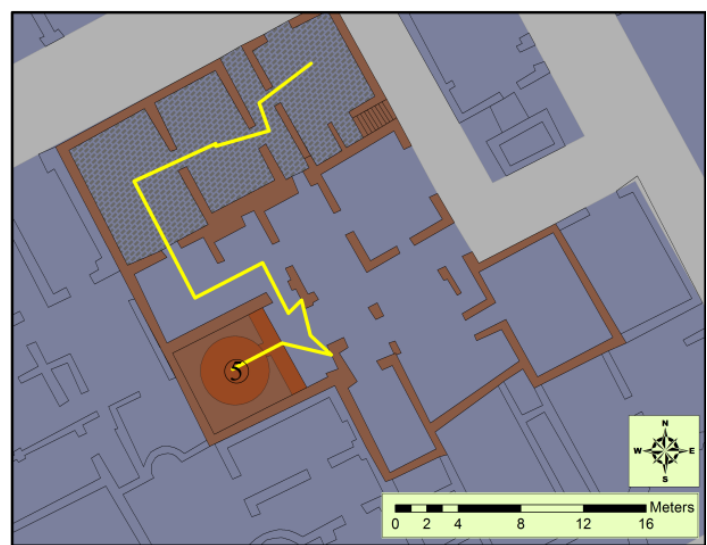

Figure 64 - Bakery 1 in Ostia (I.II.2\&6)

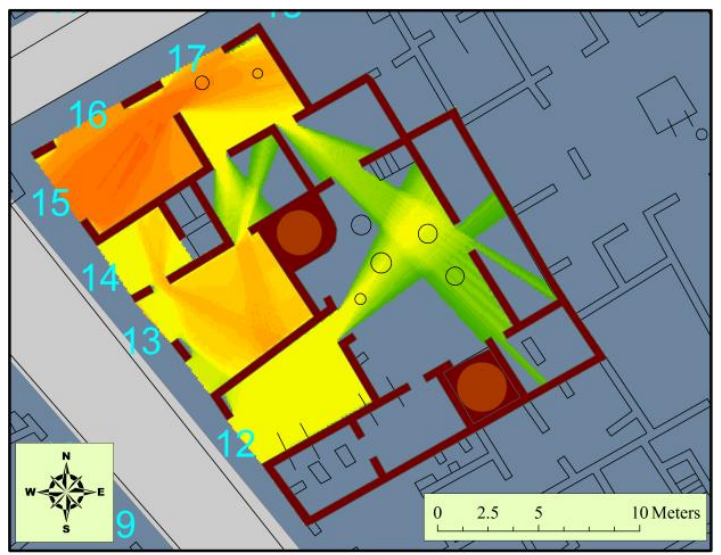

Figure 63 - Bakery 3 in Pompeii (I.4.12)

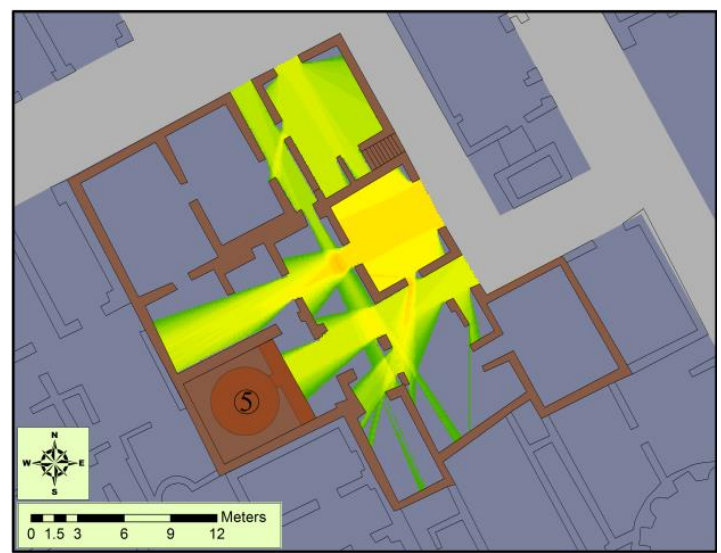

Figure 65 - Bakery 1 in Ostia (I.II.2\&6)

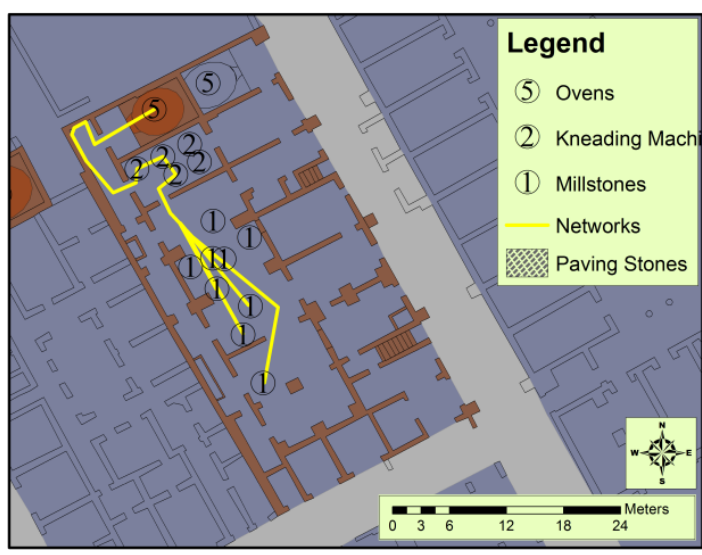

Figure 66- Bakery 2 in Ostia (I.III.1)

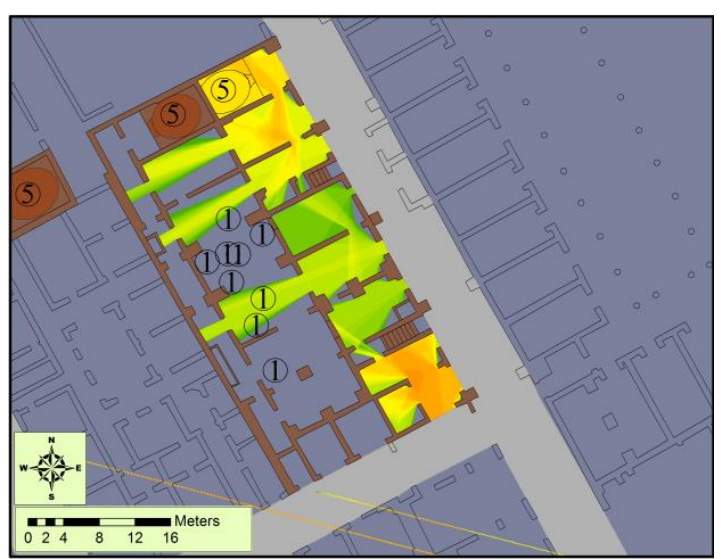

Figure 67 - Bakery 2 in Ostia (I.III.1)

Type-Five Bakeries: Operating Sequences and Indications of Elite Domestic Space on the Left and Viewsheds on the Right 


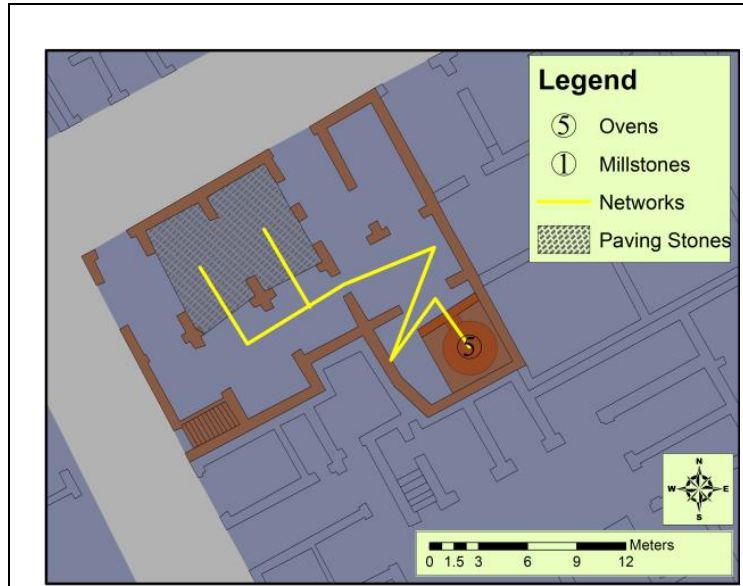

Figure 68 - Bakery 4 in Ostia (I.IX.2)

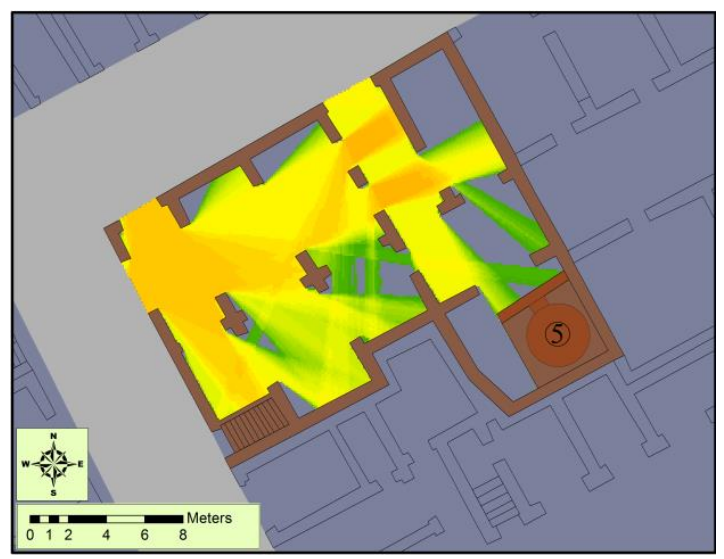

Figure 69 - Bakery 4 in Ostia (I.IX.2

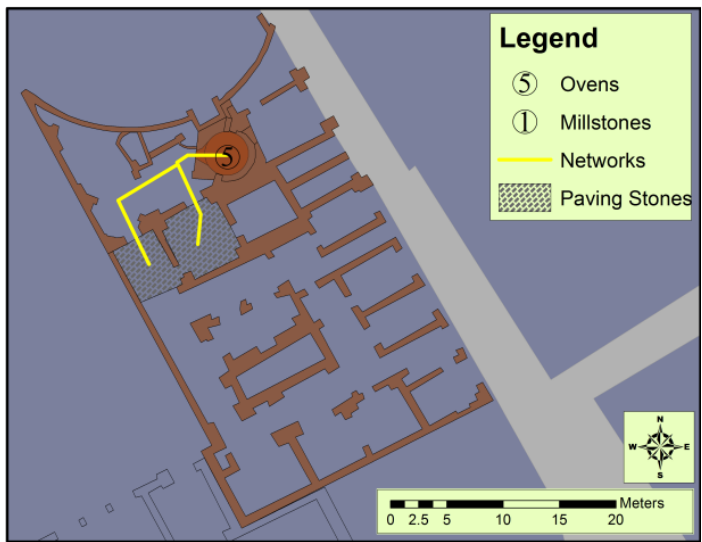

Figure 70 - Bakery 5 in Ostia (I.XII.4)

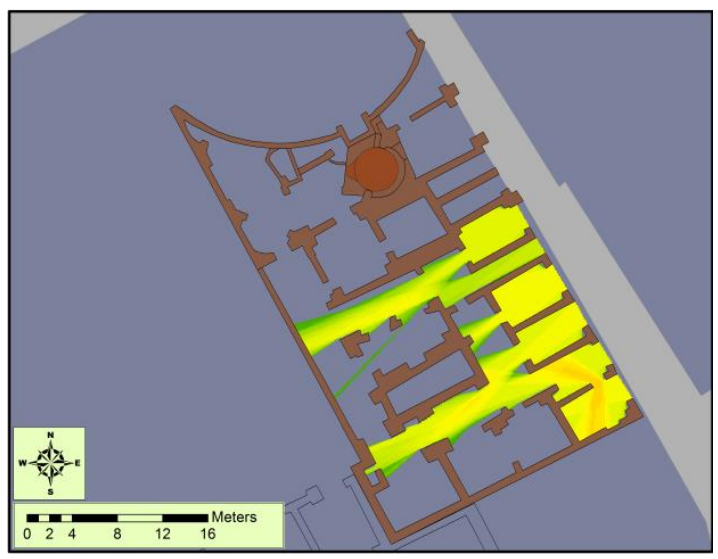

Figure 71 - Bakery 5 in Ostia (I.XII.4)

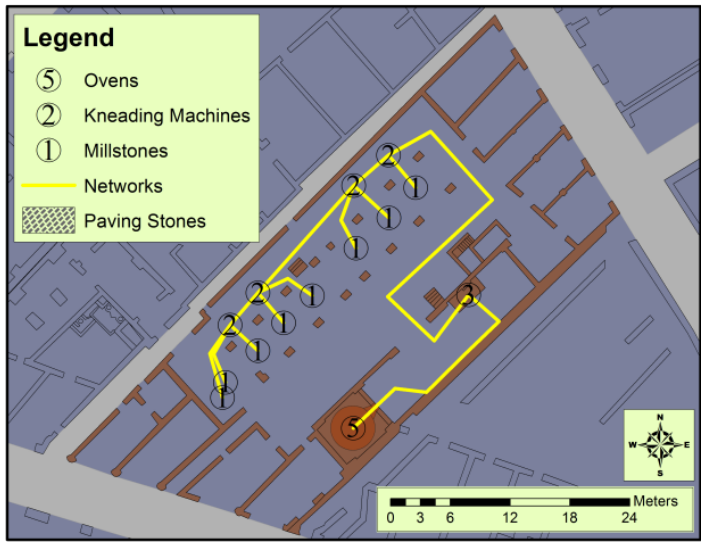

Figure 72 - Bakery 6 in Ostia (I.XIII.4)

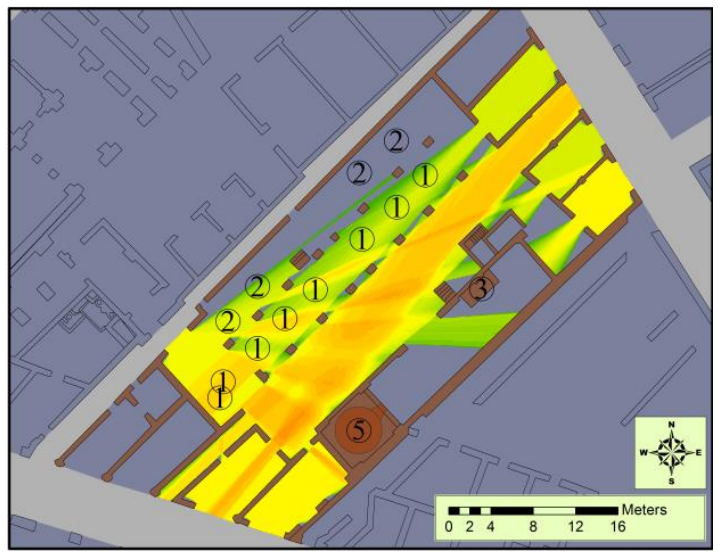

Figure 73 - Bakery 6 in Ostia (I.XIII.4)

Type Five Bakeries: Operating Sequences and Indications of Elite Domestic Space on the Left and Viewsheds on the Right 


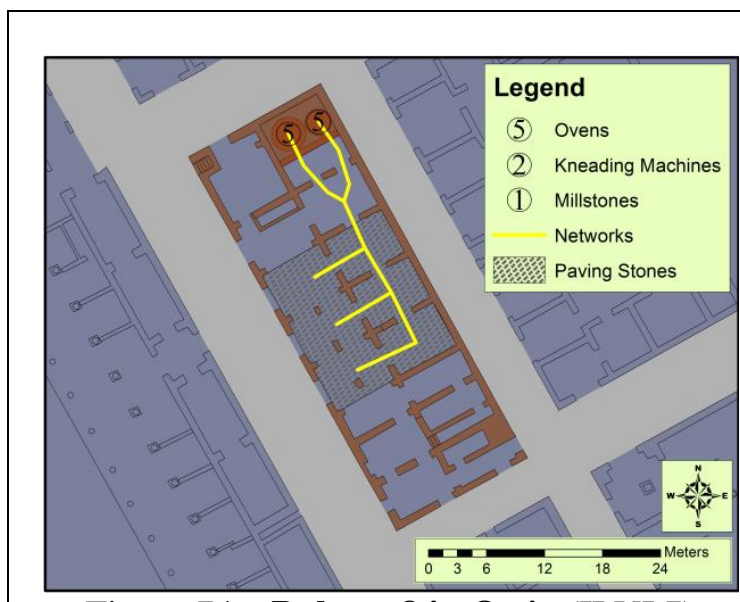

Figure 74 - Bakery 8 in Ostia (II.VI.7)

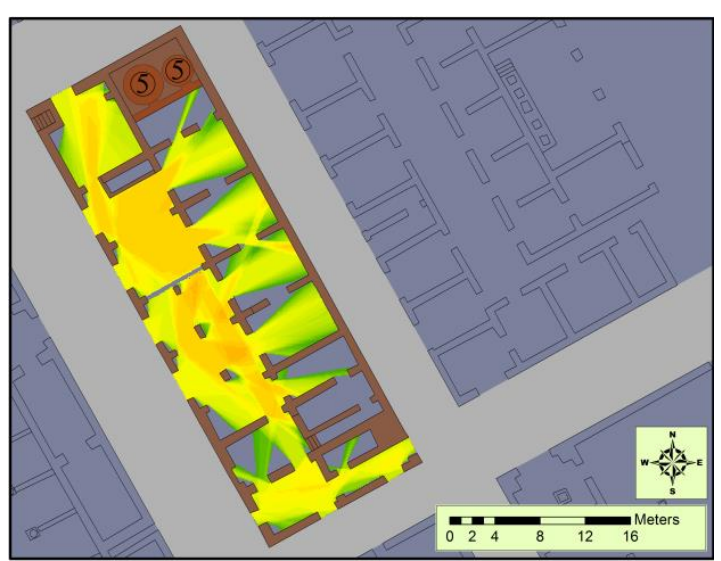

Figure 75 - Bakery 8 in Ostia (II.VI.7)

Type Five Bakeries: Operating Sequences and Indications of Elite Domestic Space on the Left and Viewsheds on the Right 


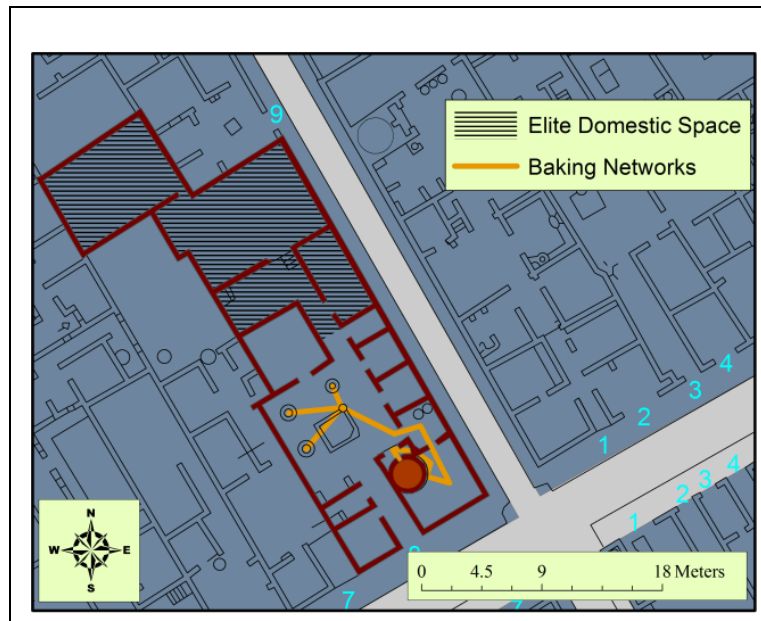

Figure 76 - Bakery Six in Pompeii (V.3.8)

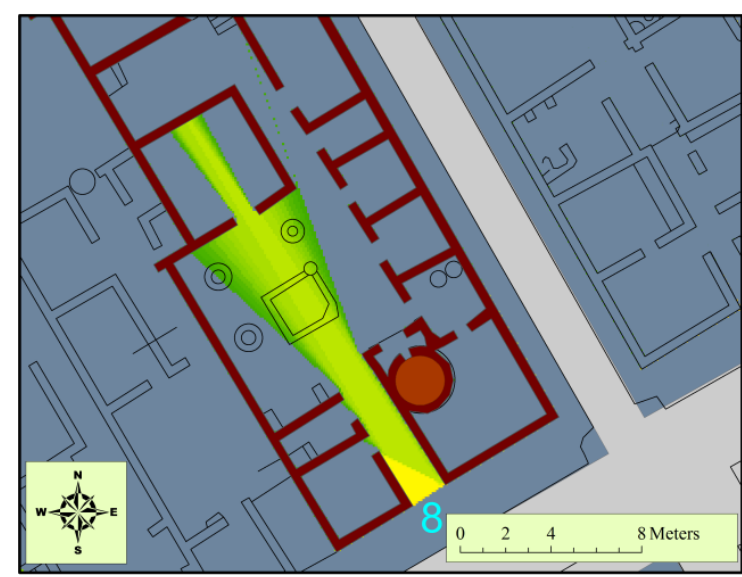

Figure 77 - Bakery Six in Pompeii (V.3.8)

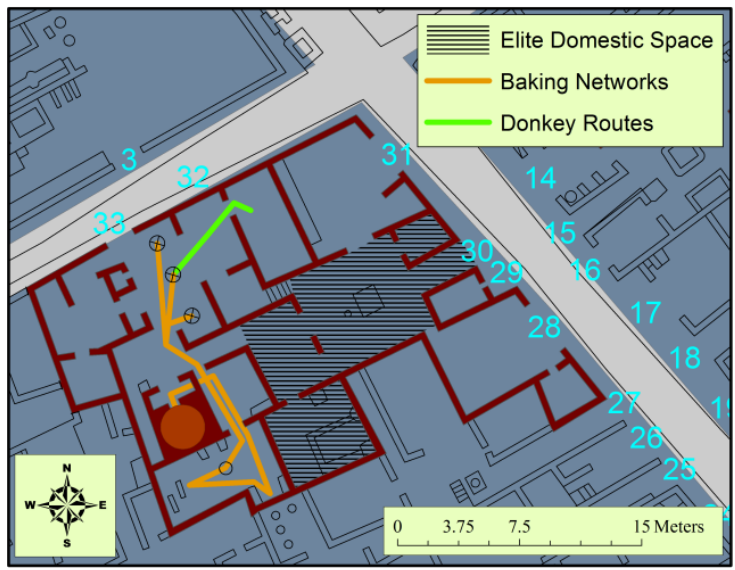

Figure 78 - Casa del Lacoonte (VI.14.28)

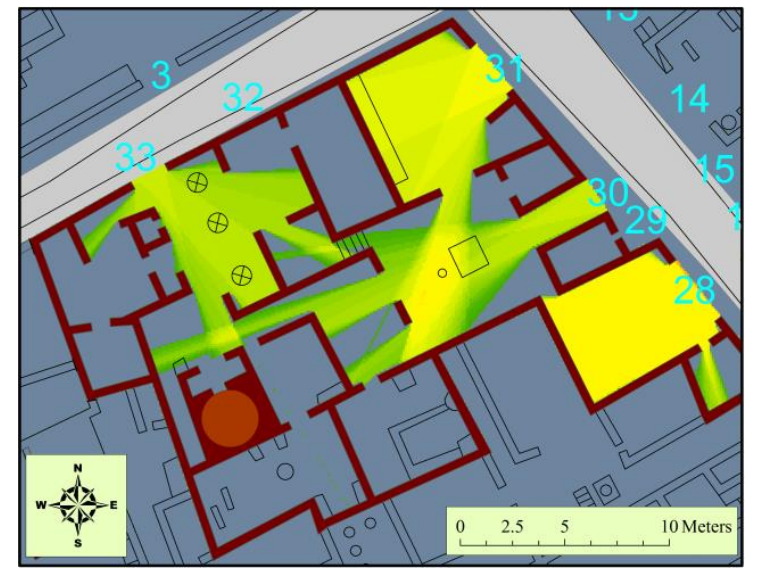

Figure 79 - Casa del Lacoonte (VI.14.28)
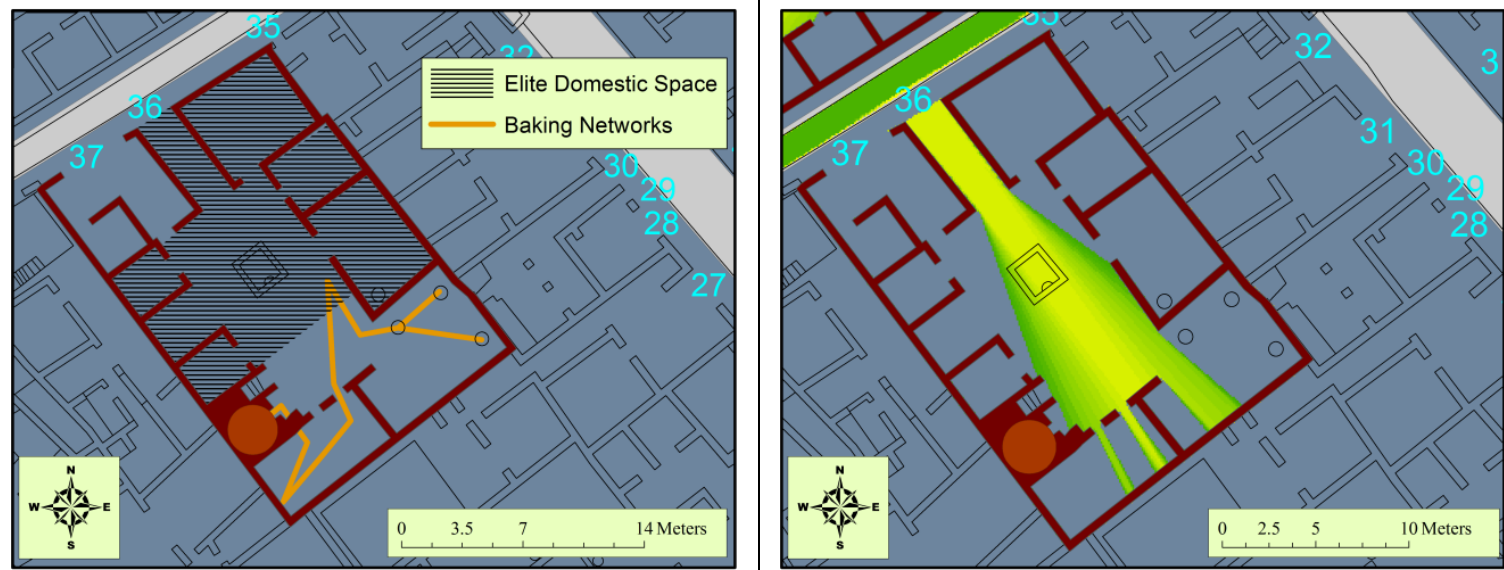

Figure 80 - Pistrinum of Modestus (VII.1.36)

Figure 81 - Pistrinum of Modestus (VII.1.36) Type Three Bakeries: Operating Sequences and Indications of Elite Domestic Space on the Left and Viewsheds on the Right 


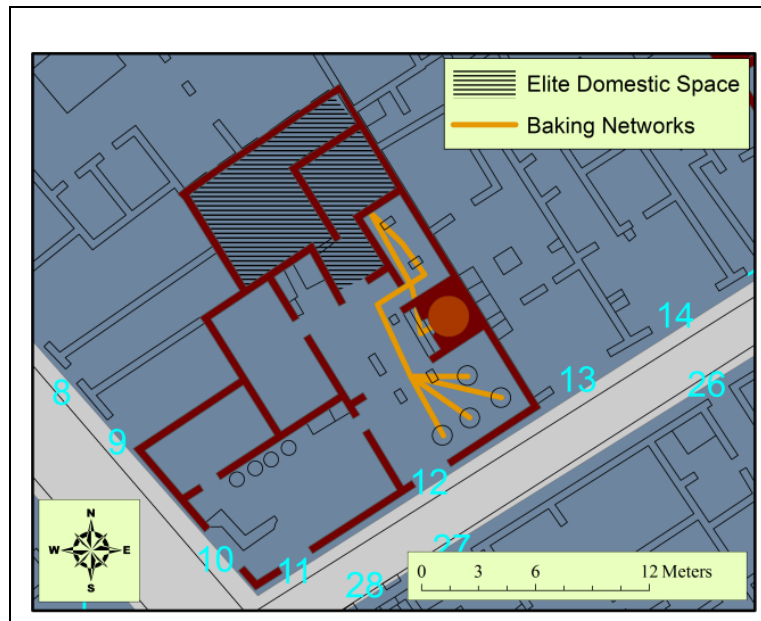

Figure 82 - Bakery 32 in Pompeii (IX.3.10)

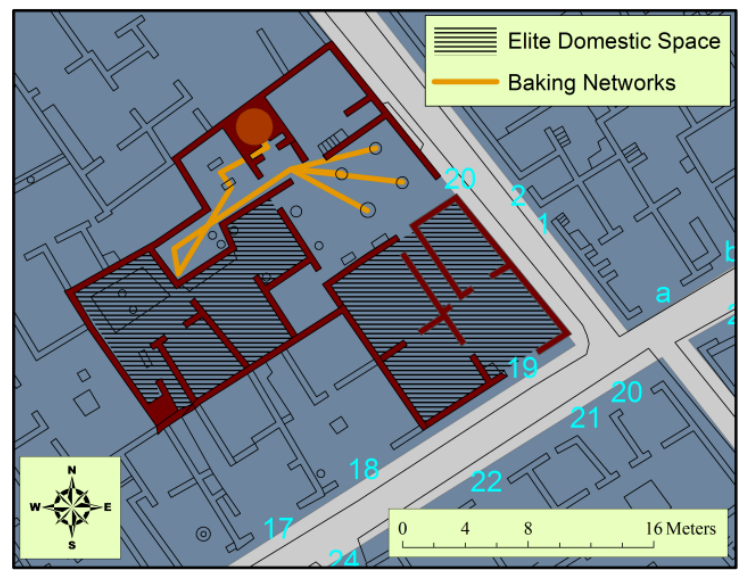

Figure 84 - Bakery 33 in Pompeii (IX.3.19)

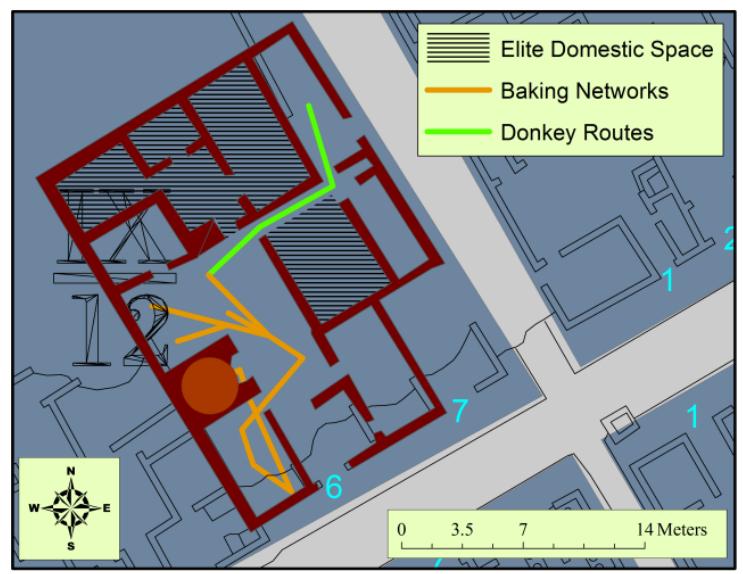

Figure 86 - Bakery 35 (IX.12.6)

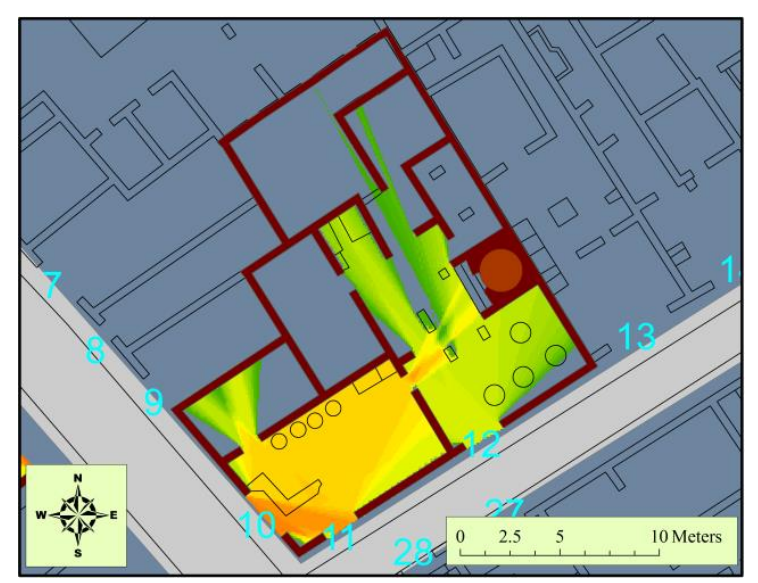

Figure 83 - Bakery 32 in Pompeii (IX.3.10)

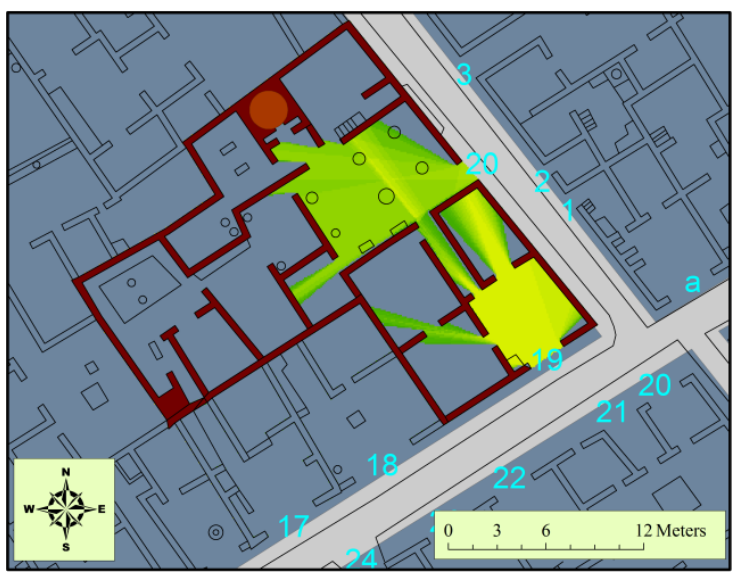

Figure 85 - Bakery 33 in Pompeii (IX.3.19)

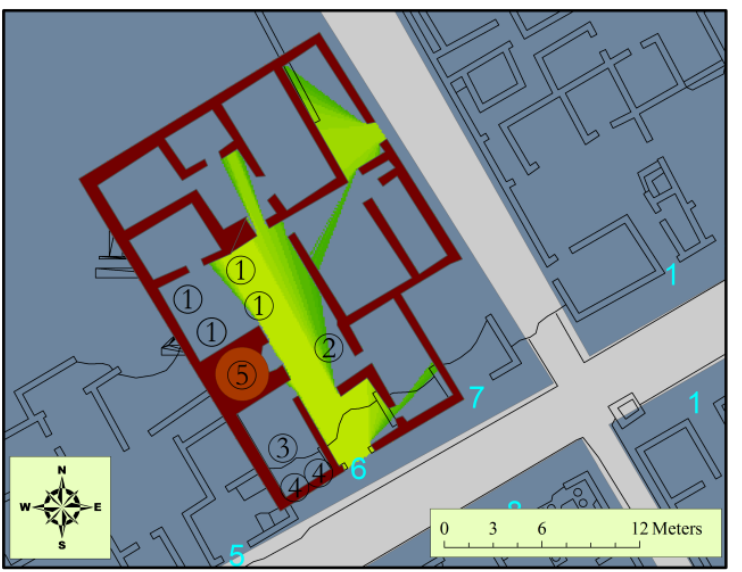

Figure 87 - Bakery 35 (IX.12.6)

Type Three Bakeries: Operating Sequences and Indications of Elite Domestic Space on the Left and Viewsheds on the Right 


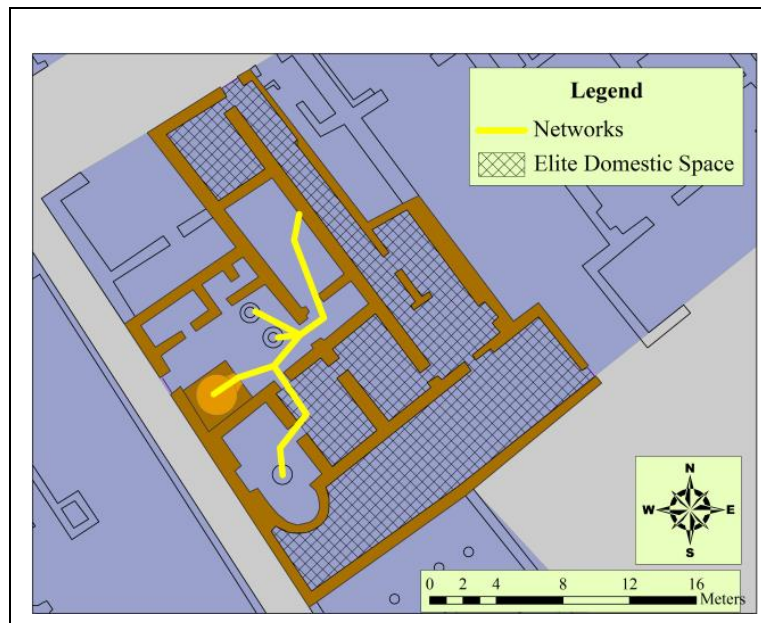

Figure 88 - Bakery 2 in Herculaneum

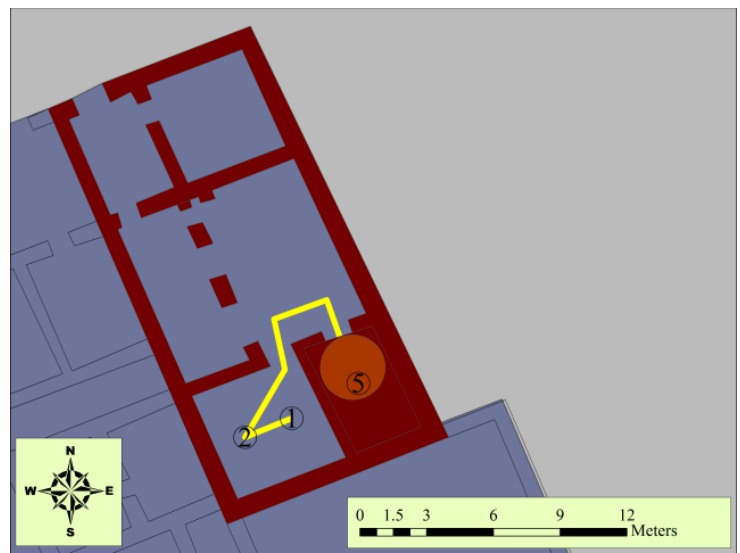

Figure 90 - Bakery 4 in Volubilis

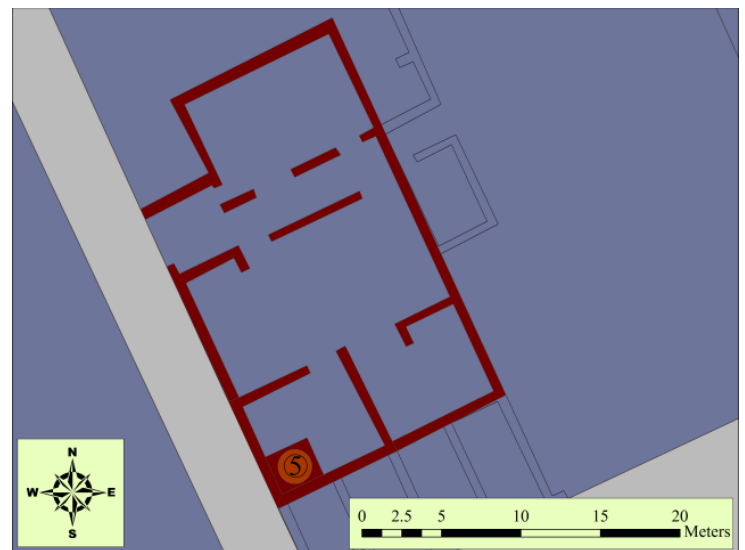

Figure 92 - Bakery 5 in Volubilis

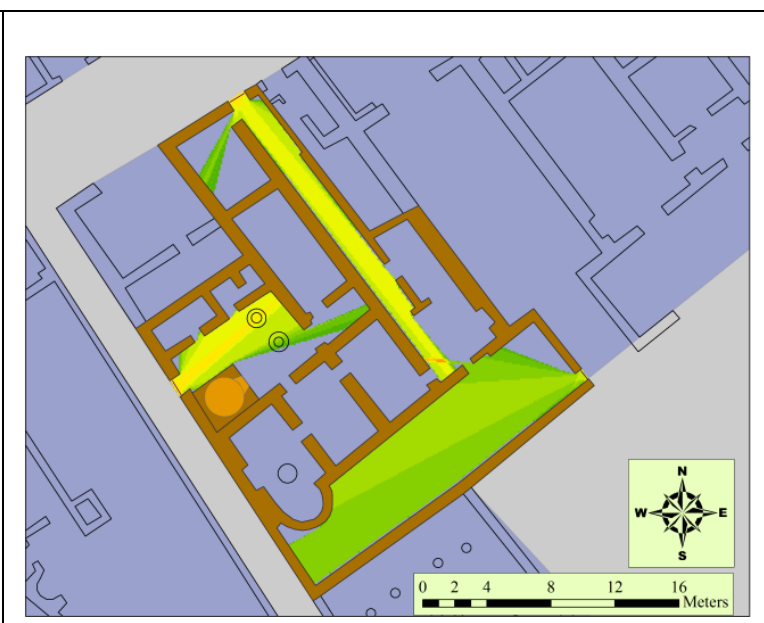

Figure 89 - Bakery 2 in Herculaneum

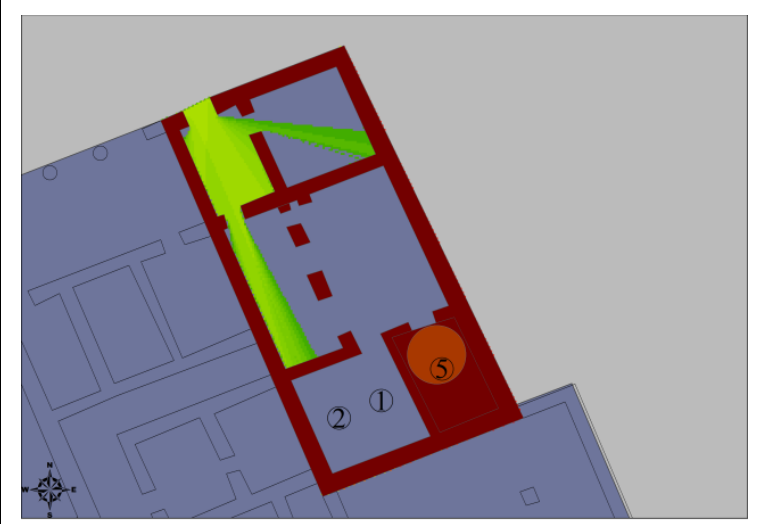

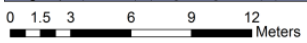

Figure 91 - Bakery 4 in Volubilis

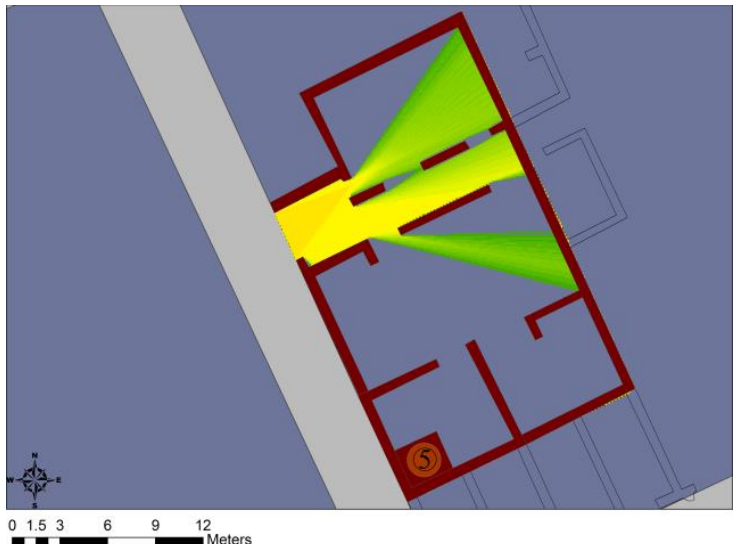

Figure 93 - Bakery 5 in Volubilis

Type Three Bakeries: Operating Sequences and Indications of Elite Domestic Space on the Left and Viewsheds on the Right 


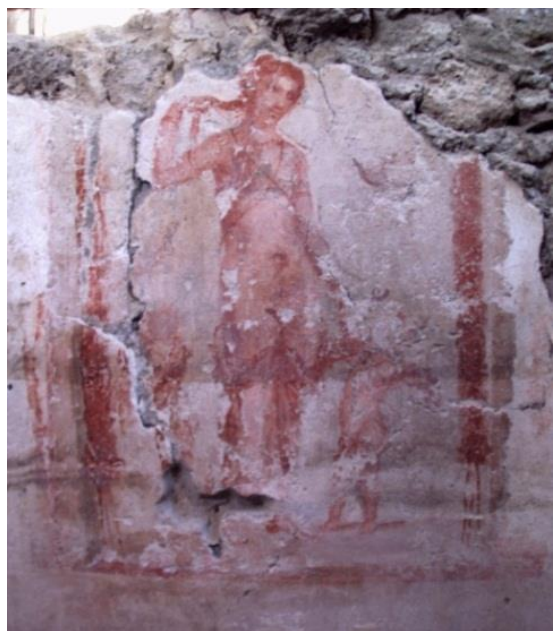

Figure 94 - Depiction of Venus and Cupid From the Paneficium of The Casa dei Casti Amanti (IX.12.6)

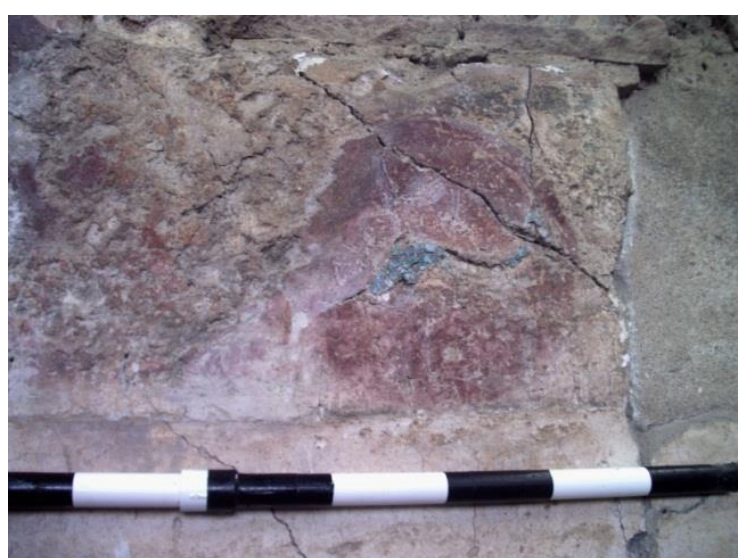

Figure 95 - Tessellated Fresco North of the Millstones in the Casa dei Casti Amanti 


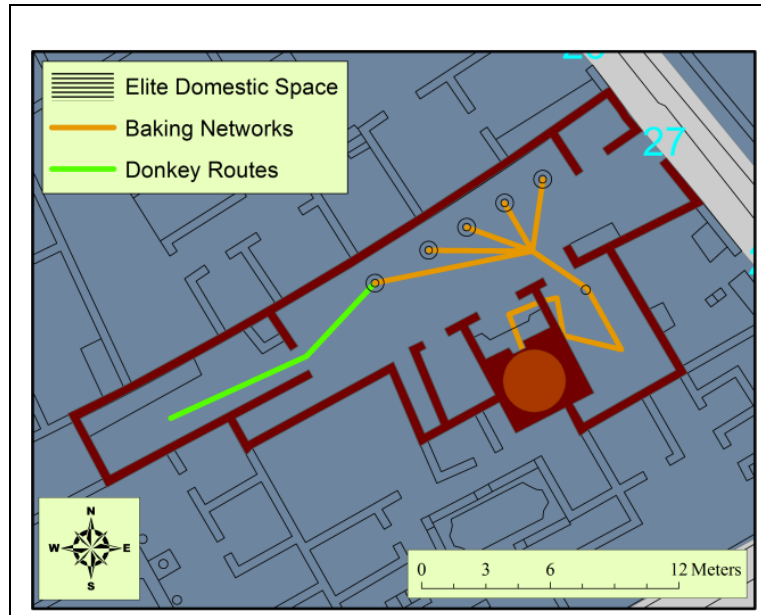

Figure 96 - Bakery 2 in Pompeii (I.3.27)

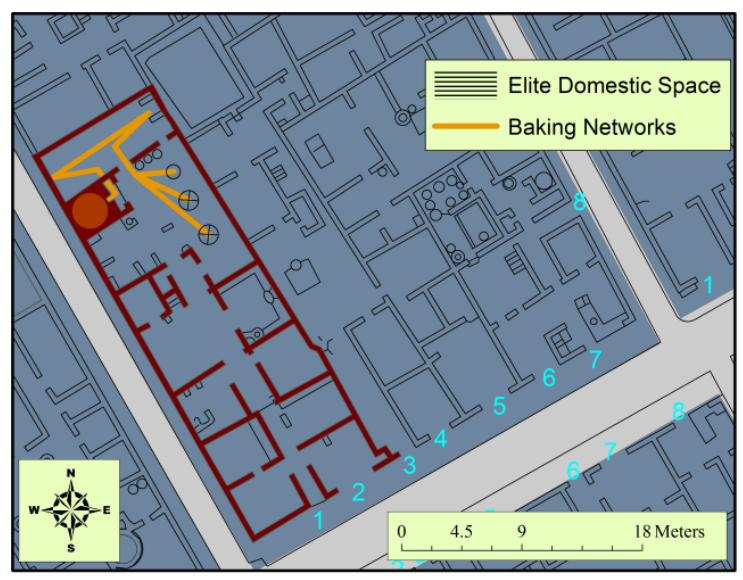

Figure 98 - Bakery 7 in Pompeii (V.4.1)

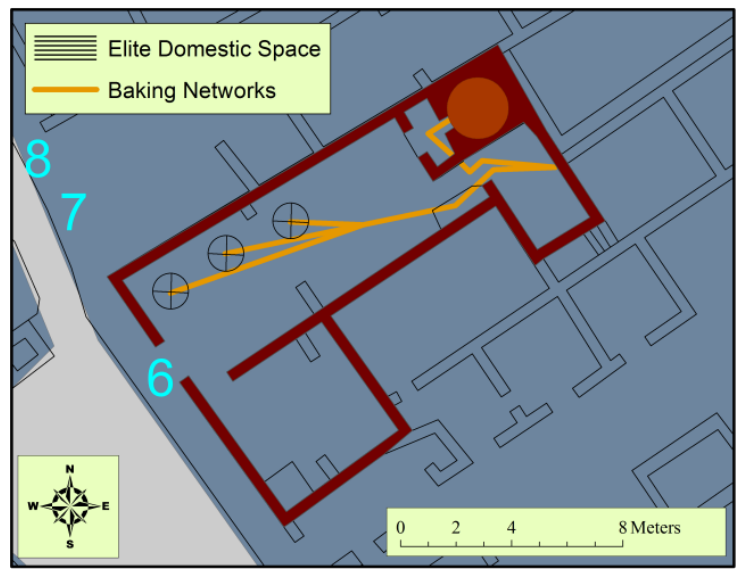

Figure 100 - Bakery 8 in Pompeii (VI.2.6)

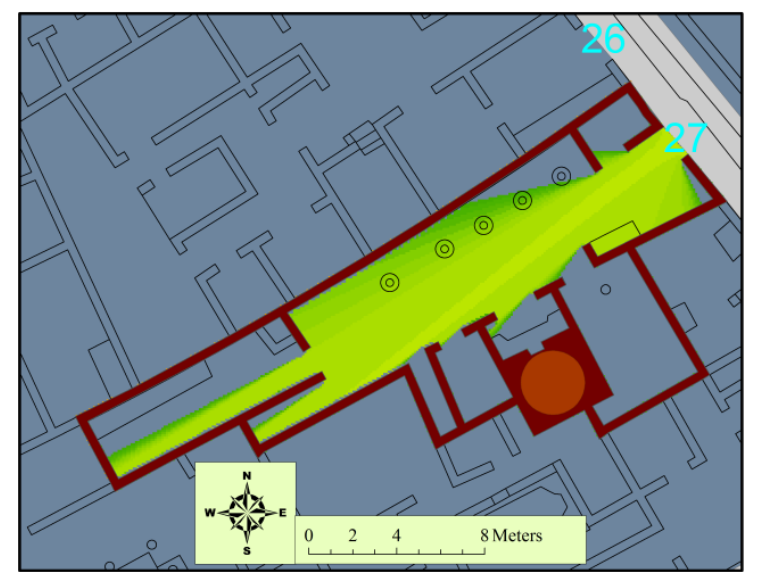

Figure 97 - Bakery 2 in Pompeii (I.3.27)

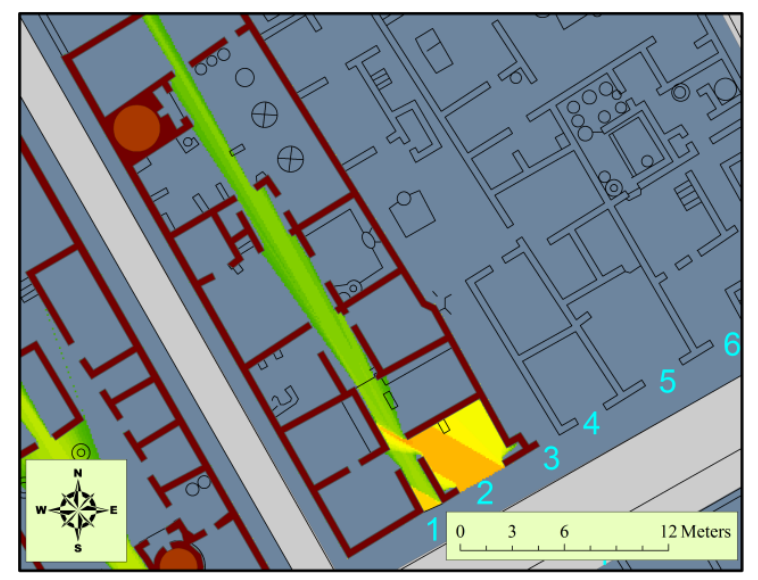

Figure 99 - Bakery 7 in Pompeii (V.4.1)

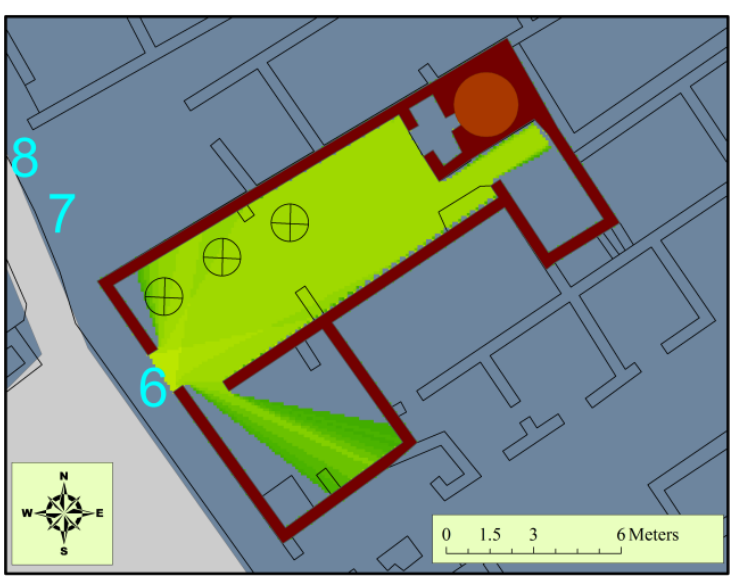

Figure 101 - Bakery 8 in Pompeii (VI.2.6)

Type Four Bakeries: Operating Sequences and Indications of Elite Domestic Space on the Left and Viewsheds on the Right 


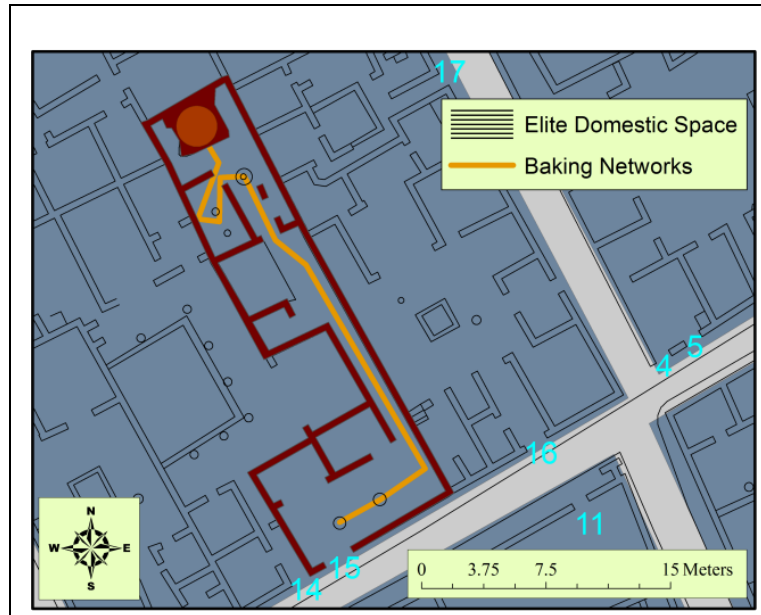

Figure 102 - Bakery 10 in Pompeii (VI.5.15)

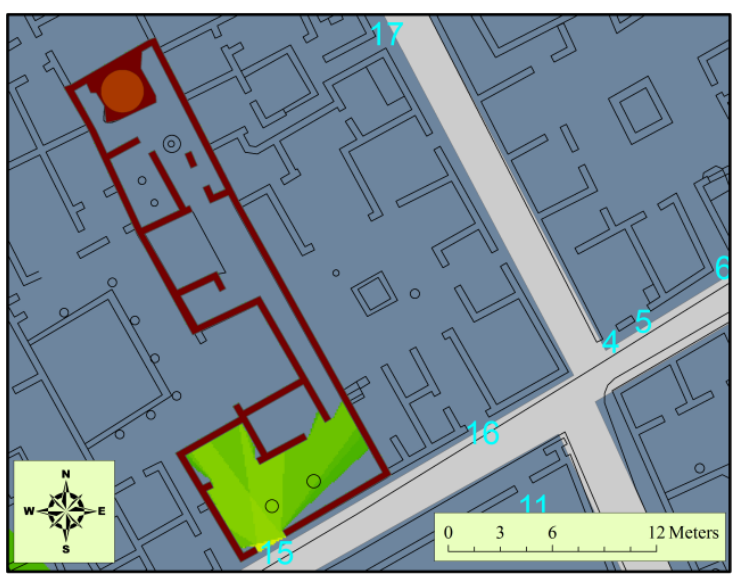

Figure 103 - Bakery 10 in Pompeii (VI.5.15)

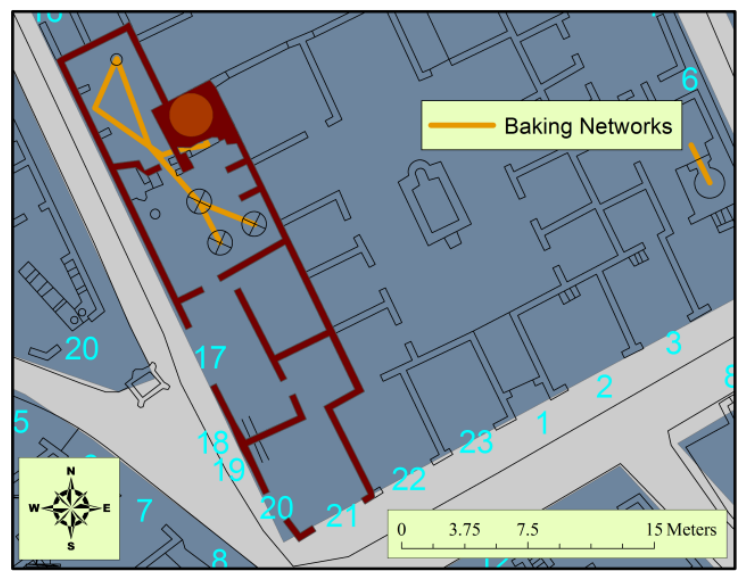

Figure 104 - Bakery 12 in Pompeii (VI.6.17)
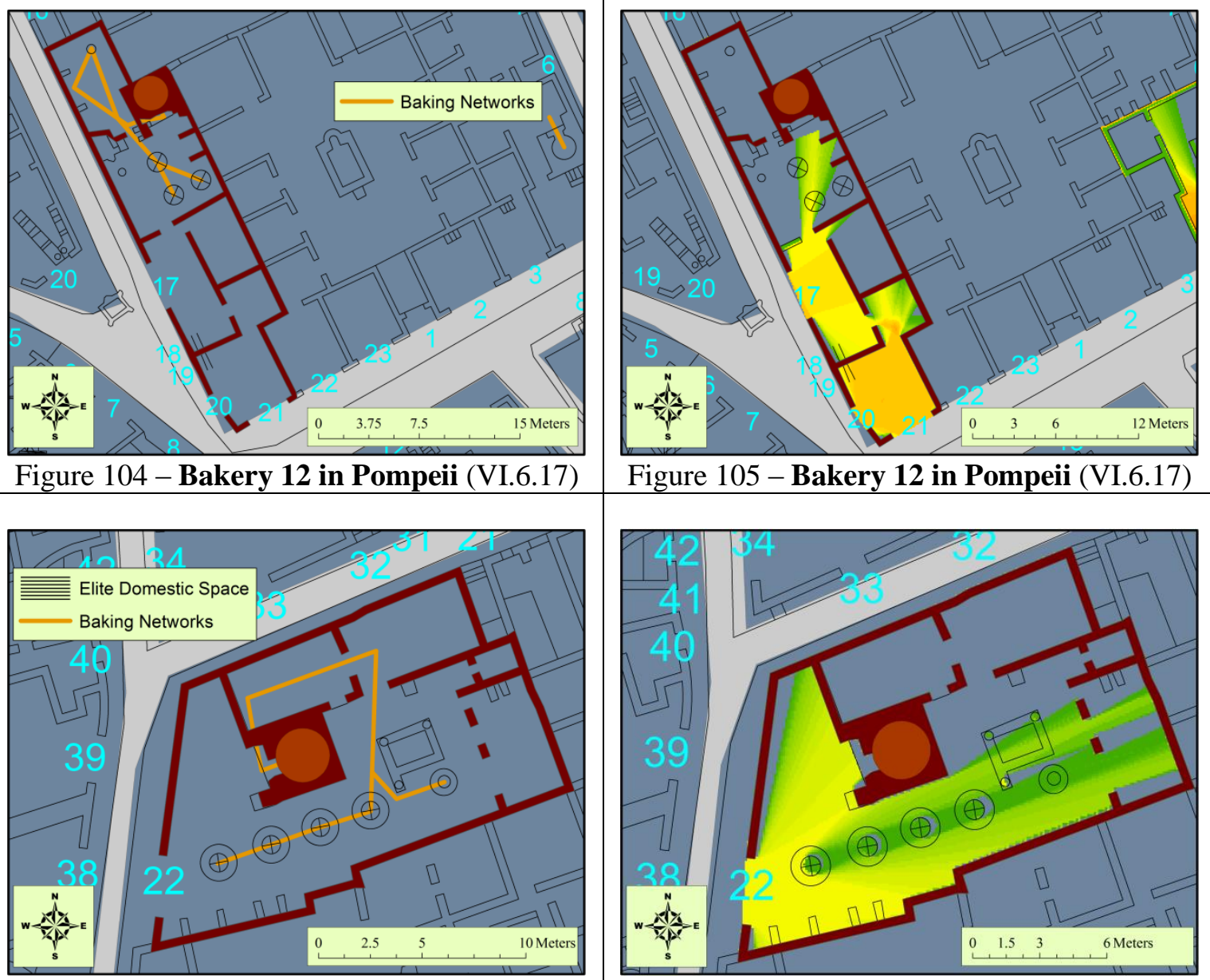

Figure 106 - Bakery 18 in Pompeii (VII.2.22)

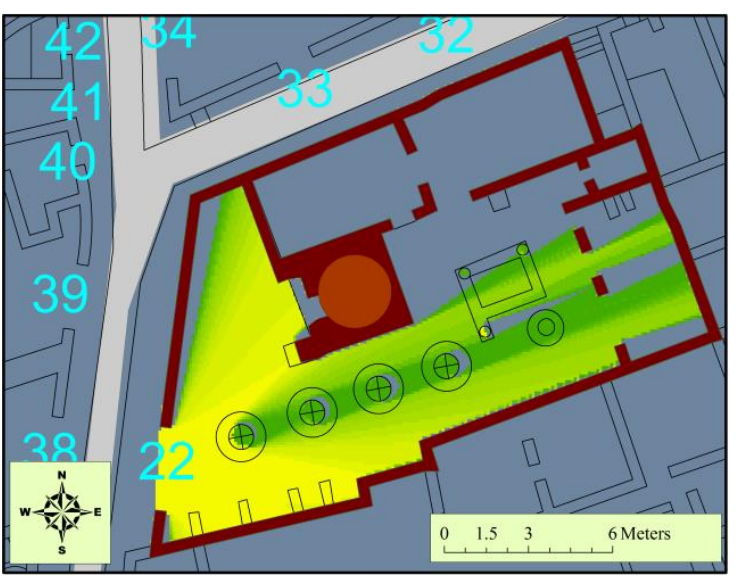

Figure 107 - Bakery 18 in Pompeii (VII.2.22)

Type Four Bakeries: Operating Sequences and Indications of Elite Domestic Space on the Left and Viewsheds on the Right 


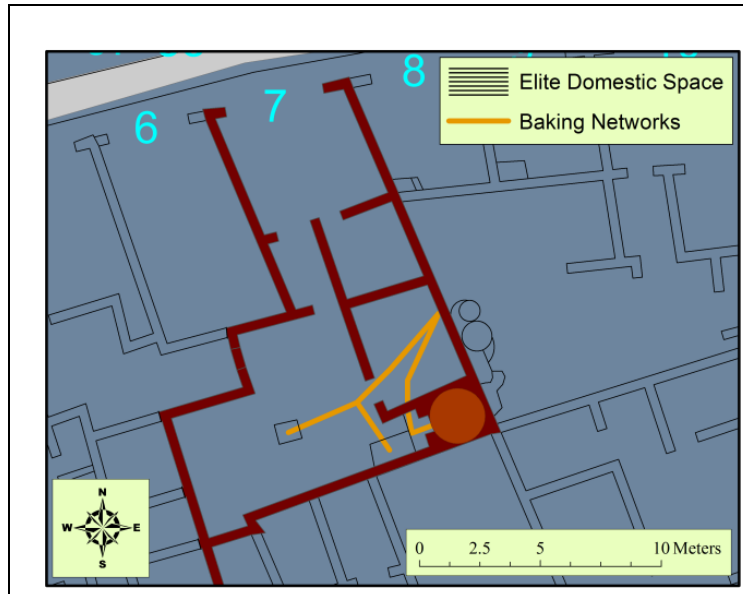

Figure 108 - Bakery 22 in Pompeii (VII.12.7)

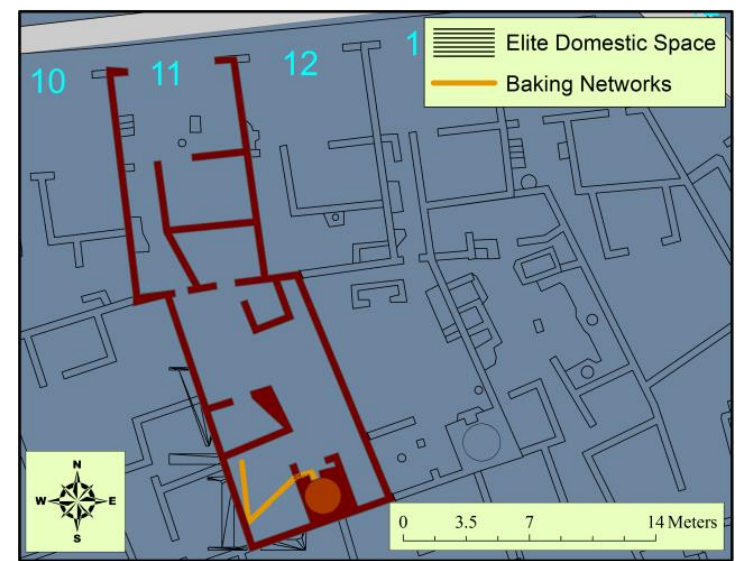

Figure 110 - Bakery 23 in Pompeii (VII.12.11)

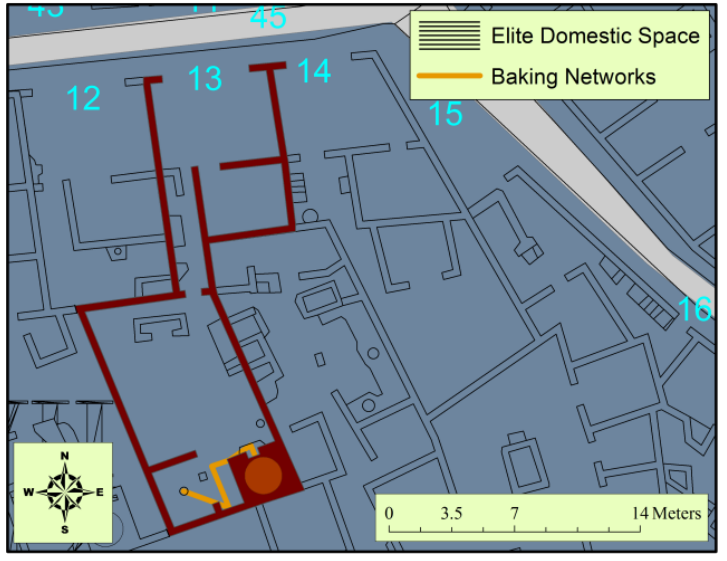

Figure 112 - Bakery 24 in Pompeii (VII.12.13)

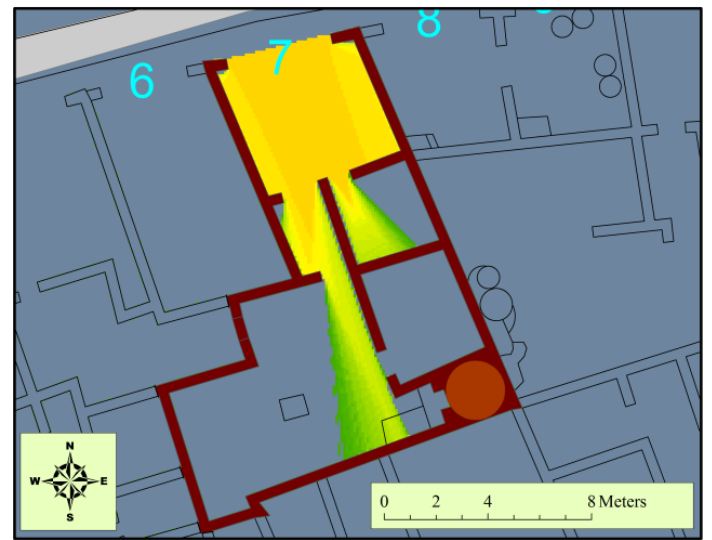

Figure 109 - Bakery 22 in Pompeii (VII.12.7)

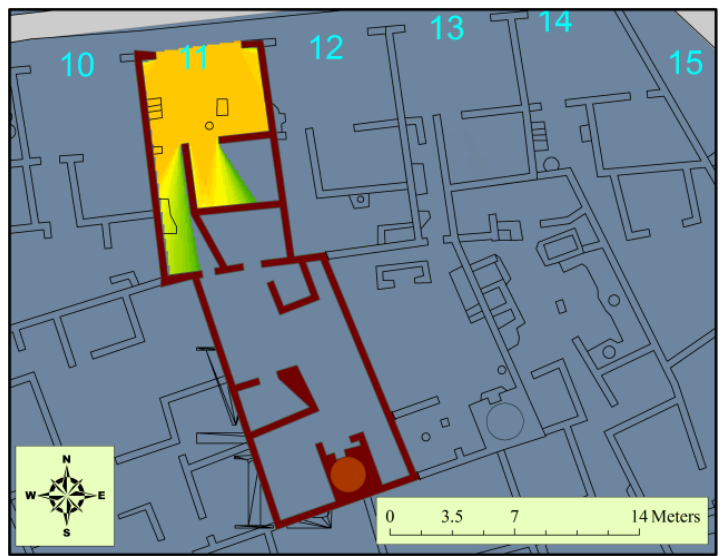

Figure 111 - Bakery 23 in Pompeii (VII.12.11)

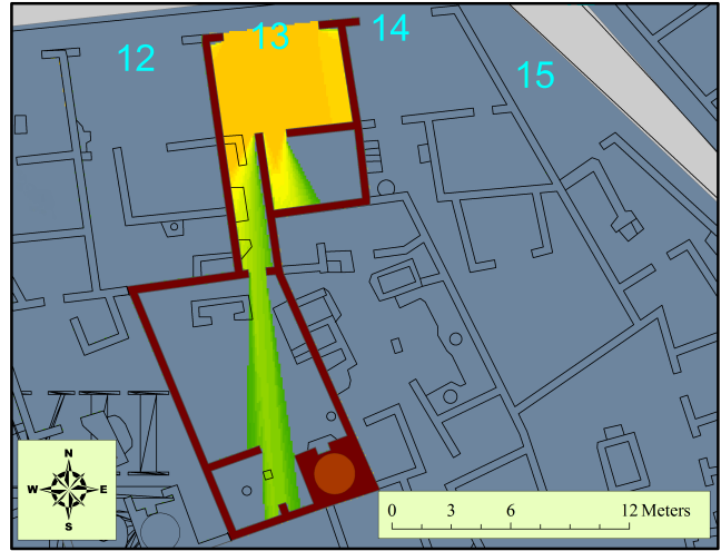

Figure 113 - Bakery 24 in Pompeii (VII.12.13)

Type Four Bakeries: Operating Sequences and Indications of Elite Domestic Space on the Left and Viewsheds on the Right 


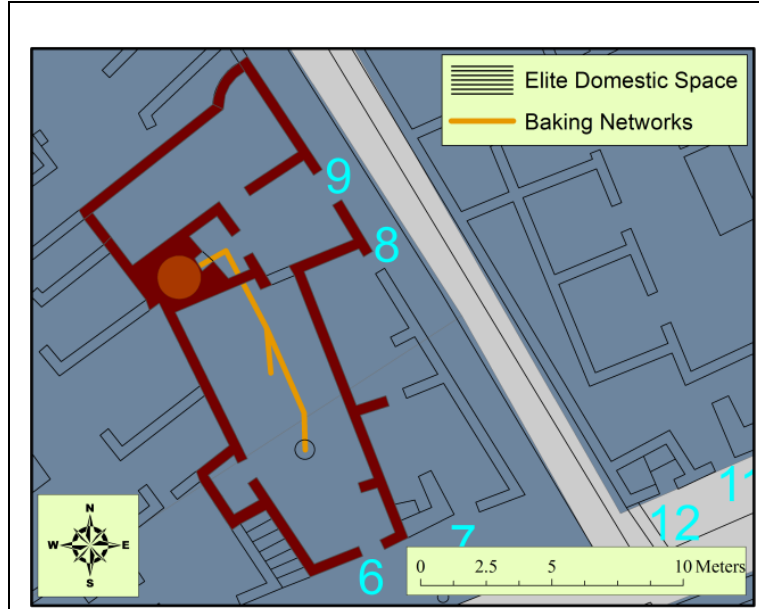

Figure 114 - Bakery 27 in Pompeii (VII.16.6)

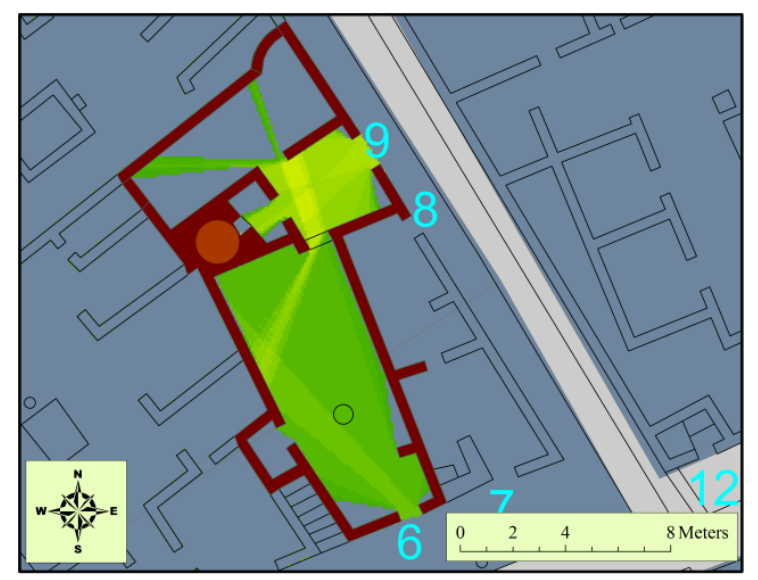

Figure 115 - Bakery 27 in Pompeii (VII.16.6)

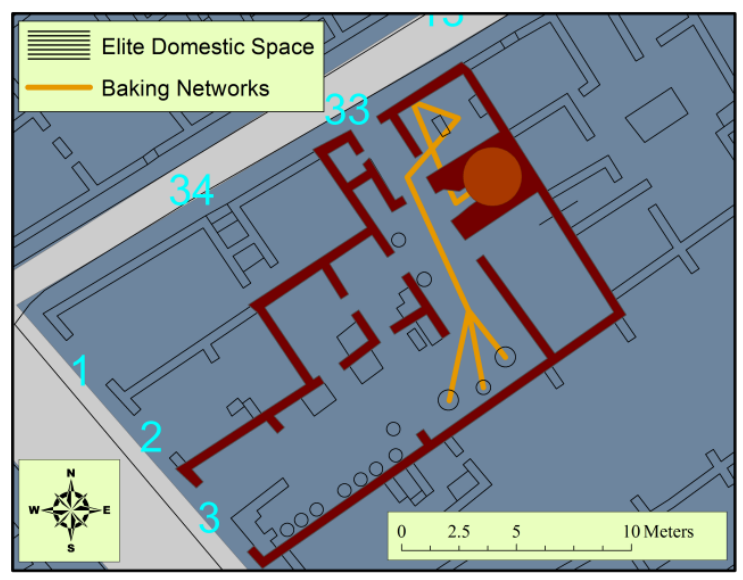

Figure 116 - Bakery 30 in Pompeii (IX.1.3)

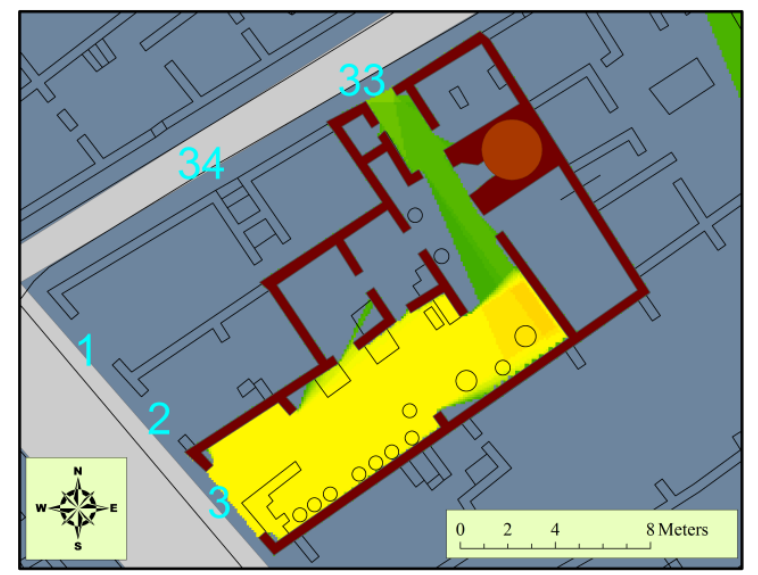

Figure 117 - Bakery 30 in Pompeii (IX.1.3)

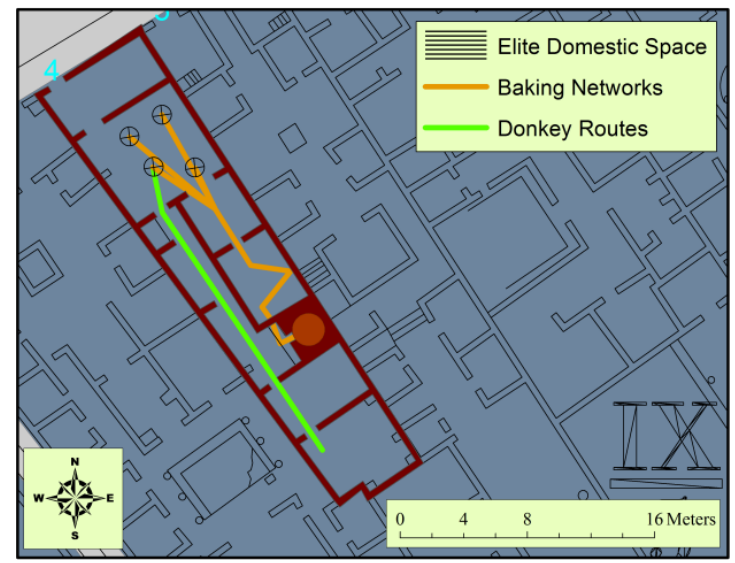

Figure 118 - Bakery 34 in Pompeii (IX.5.4)

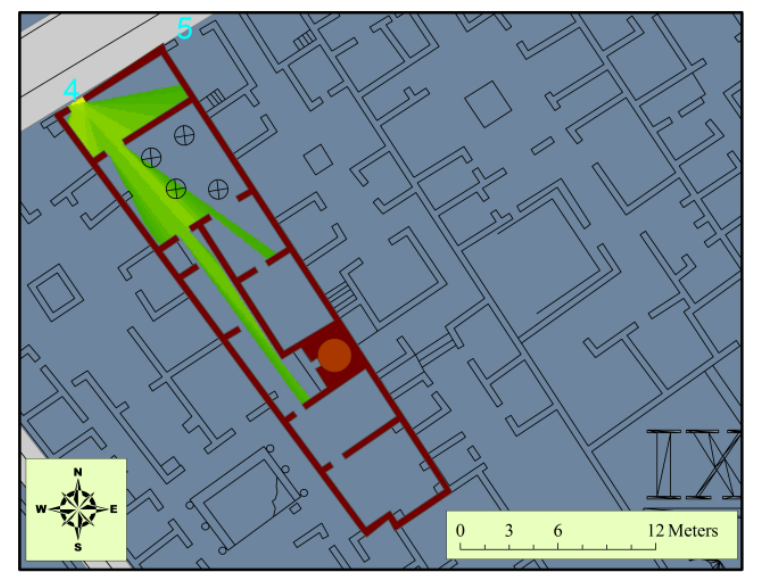

Figure 119 - Bakery 34 in Pompeii (IX.5.4)

Type Four Bakeries: Operating Sequences and Indications of Elite Domestic Space on the Left and Viewsheds on the Right 


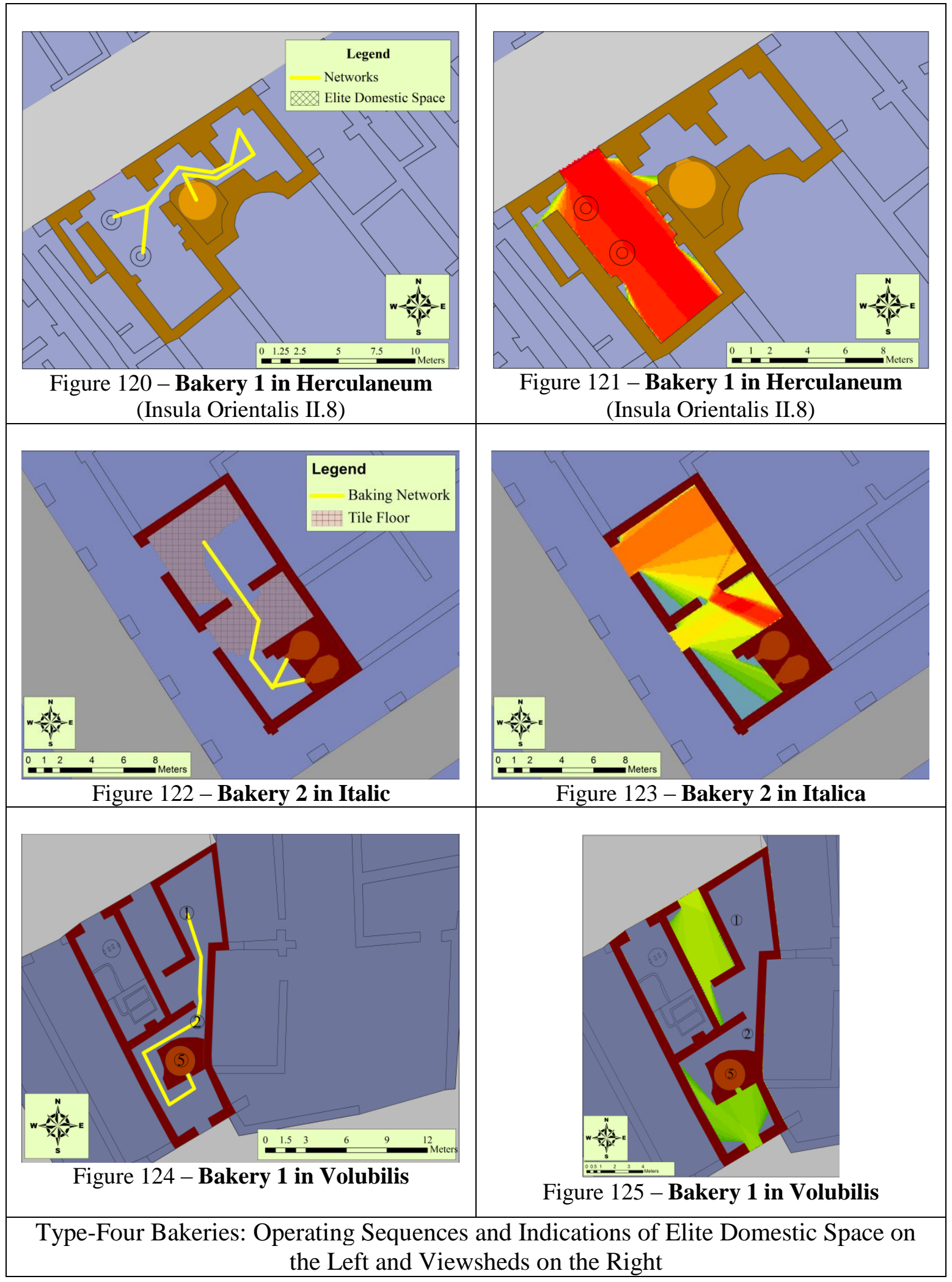




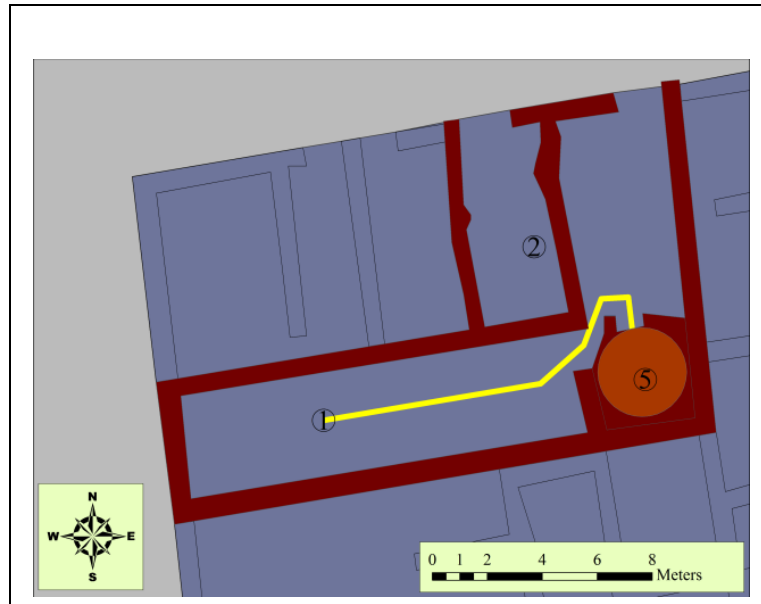

Figure 126 - Bakery 2 in Volubilis

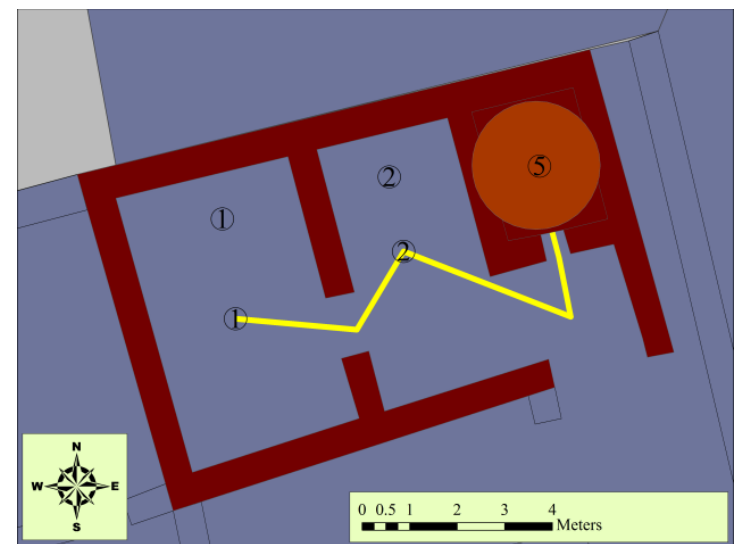

Figure 128 - Bakery 3 in Volubilis

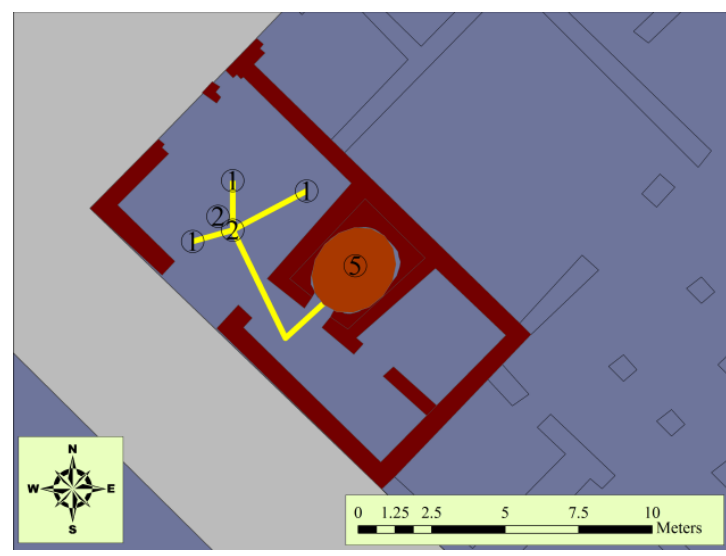

Figure 130 - Bakery 6 in Volubilis

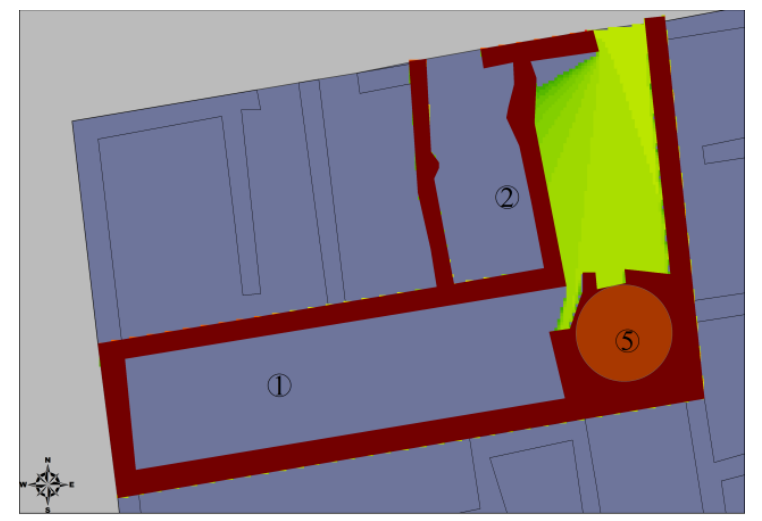

$0.12 \quad 4 \quad 6 \quad 8$ Meters

Figure 127 - Bakery 2 in Volubilis

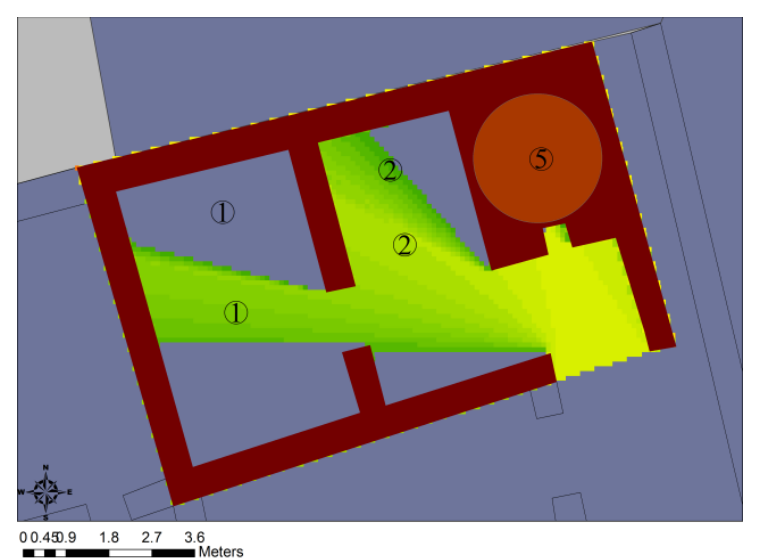

Figure 129 - Bakery 3 in Volubilis

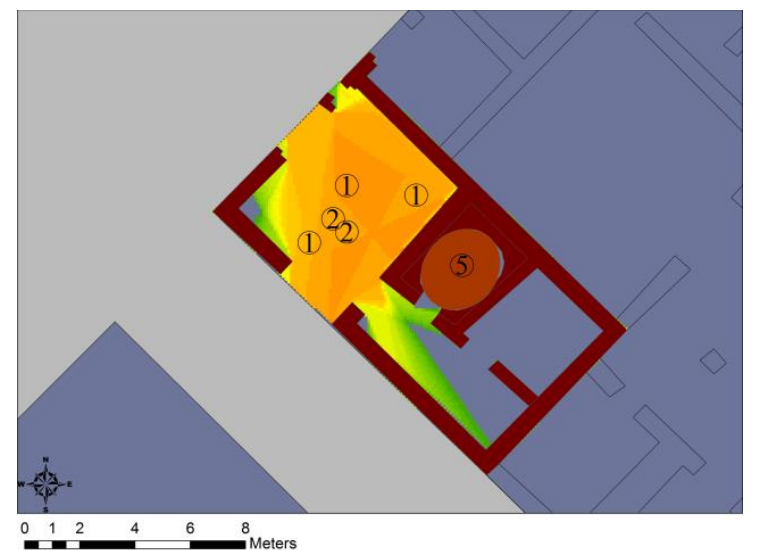

Figure 131 - Bakery 6 in Volubilis

Type-Four Bakeries: Operating Sequences and Indications of Elite Domestic Space on the Left and Viewsheds on the Right 


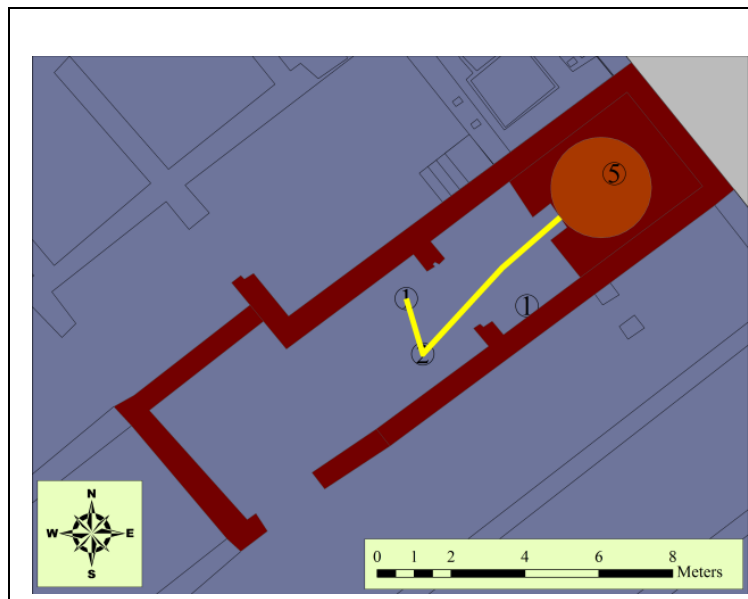

Figure 132 - Bakery 7 in Volubilis

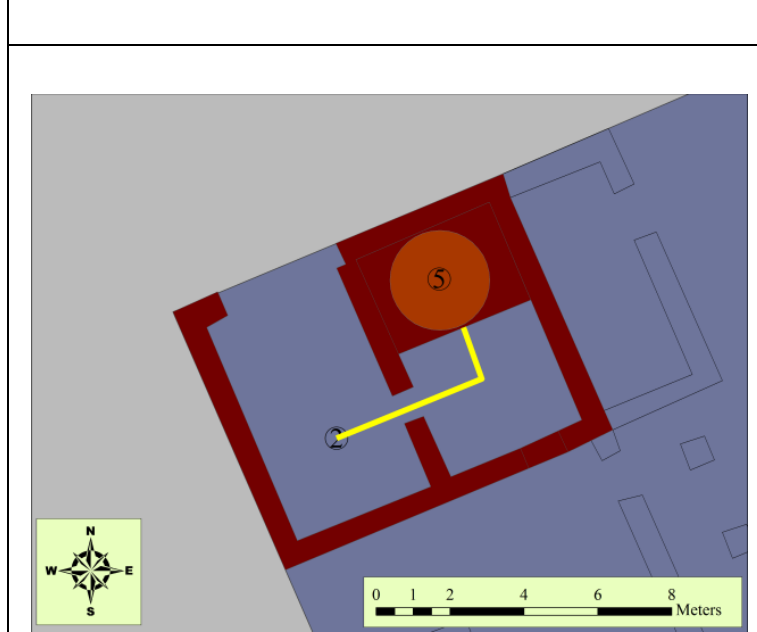

Figure 134 - Bakery 8 in Volubilis

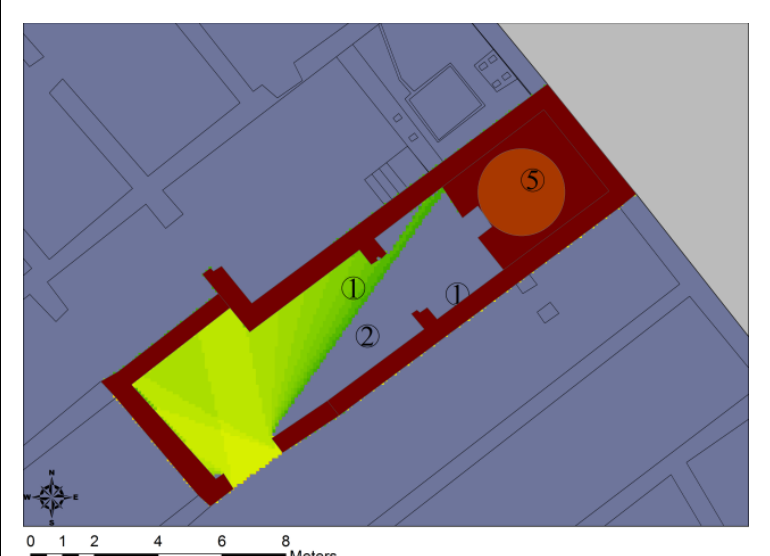

\begin{tabular}{llllll}
0 & 1 & 2 & 4 & 6 & 8 \\
\hline & - & & & &
\end{tabular}

Figure 133 - Bakery 7 in Volubilis

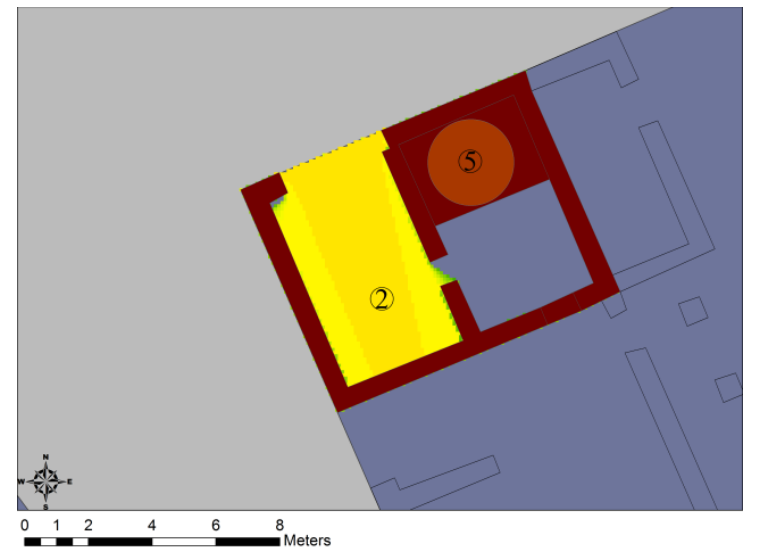

Figure 135 - Bakery 8 in Volubilis

Type Four Bakeries: Operating Sequences and Indications of Elite Domestic Space on the Left and Viewsheds on the Right 


\begin{tabular}{|c|c|}
\hline $\begin{array}{l}\text { Figure } 136 \text { - Fornax on Eurysaces' Tomb, } \\
\text { Rome (After Blümner 1912, fig. 14) }\end{array}$ & $\begin{array}{c}\text { Figure } 137 \text { - Fornax on Romolo Relief, Rome } \\
\text { (After Wilson and Schorle 2009, 6) }\end{array}$ \\
\hline $\begin{array}{l}\text { Figure } 138 \text { - Fornax on Sarcophagus of } \\
\text { Octavius Valerianus, Rome. } \\
\text { (After Moritz 1958, Pl. 8) }\end{array}$ & $\begin{array}{l}\text { Figure } 139 \text { - Fornax on Sarcophagus } \\
\text { from Villa Sassi, Rome } \\
\text { (After Blümner 1912, fig. 15c) }\end{array}$ \\
\hline $\begin{array}{c}\text { Figure } 140 \text { - Image of Oven in the Marble } \\
\text { Plaque from Bologna } \\
\text { (After Cullin-Mingaud 2010, fig. 214) }\end{array}$ & $\begin{array}{l}\text { Figure 141 - Fornax from Rustic Calendar, } \\
\text { Saint-Romain-en-Gal . } \\
\text { (After Dunbabin 1999, fig. 80) }\end{array}$ \\
\hline
\end{tabular}




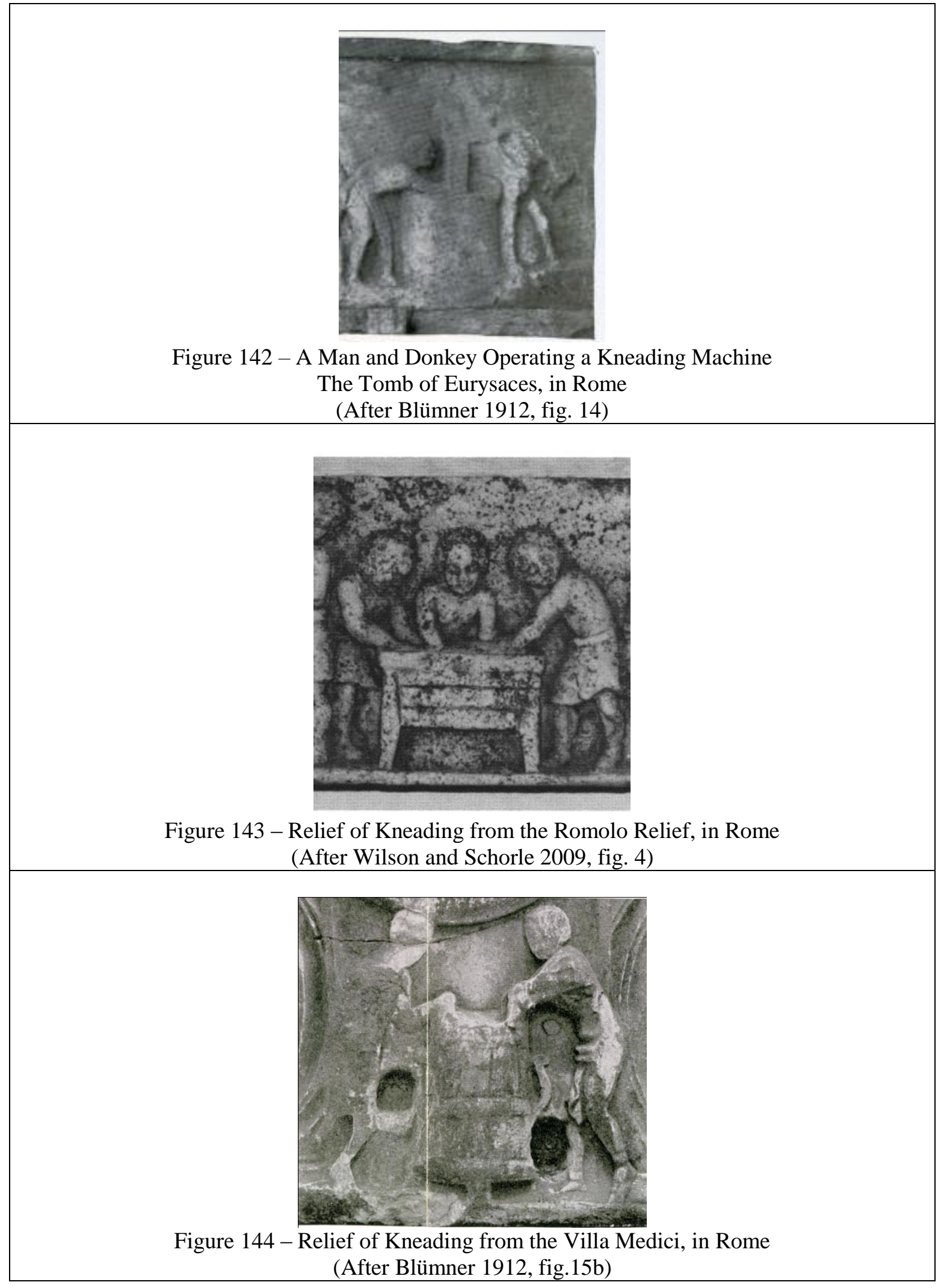




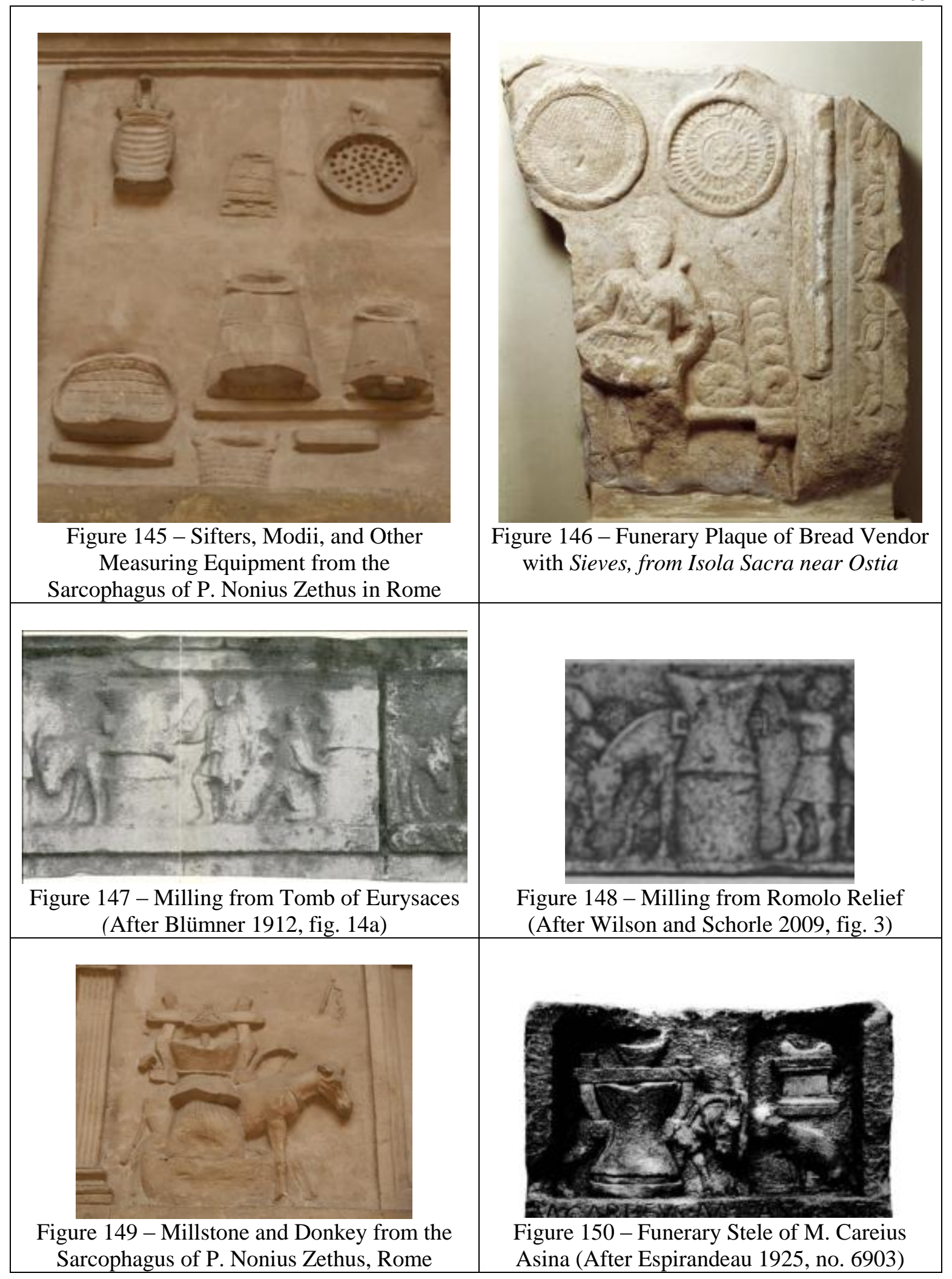




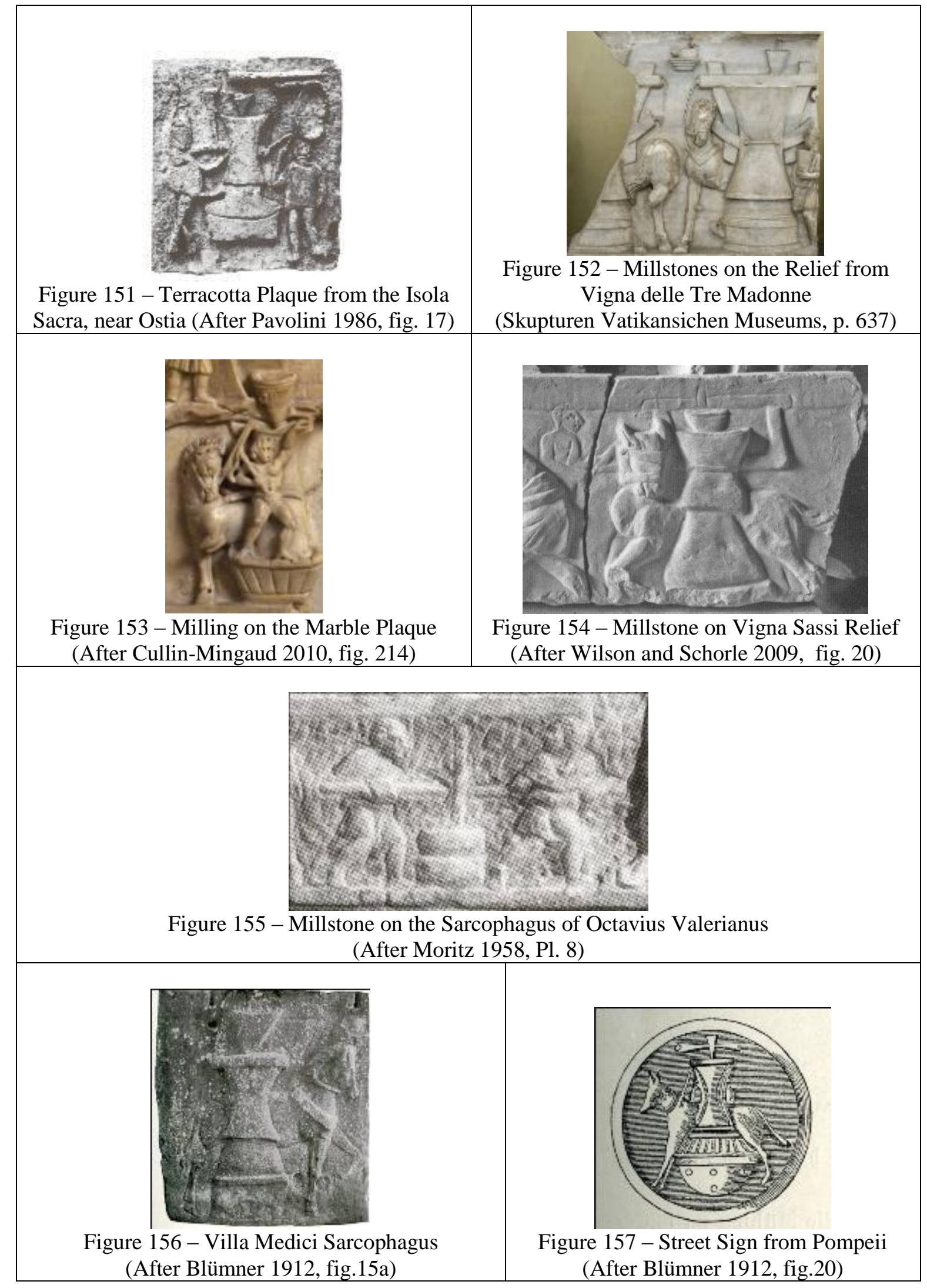




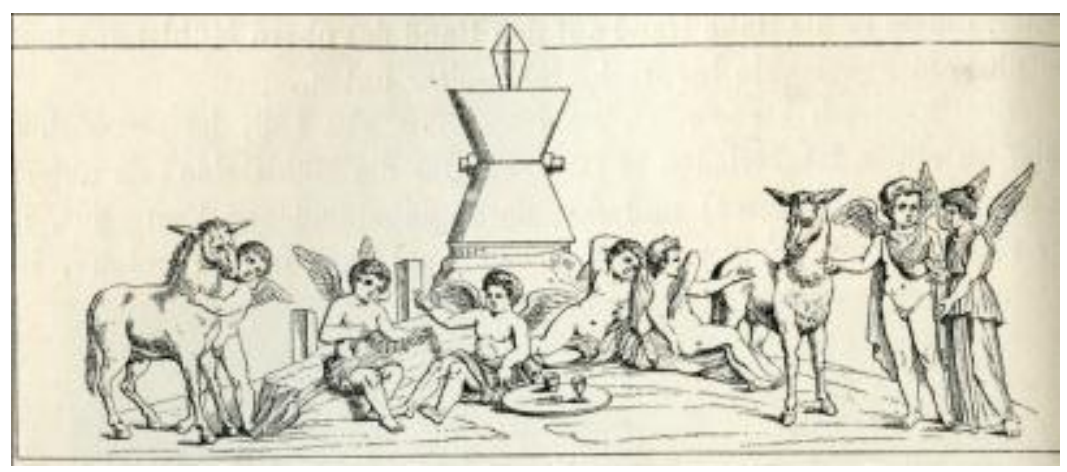

Figure 158 - So-Called Vestalia Scene, from Macellum in Pompeii (After Blümner 1912, fig.23)

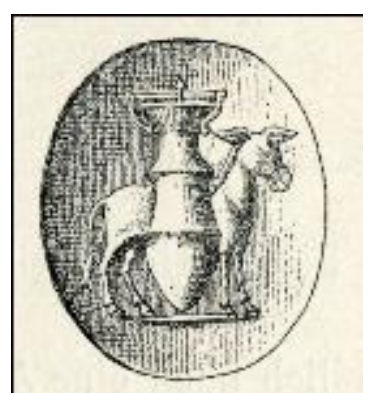

Figure 159 - Signet Ring with Donkey and Mill (After Blümner 1912, fig.21)

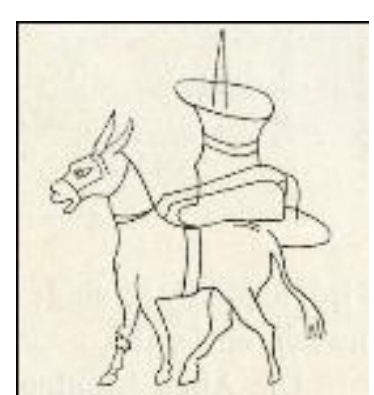

Figure 160 - Grafitto from Palatine, Rome (After Blümner 1912, fig. 22) 


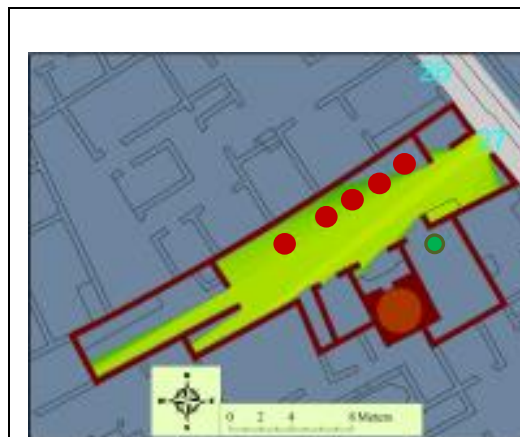

Fig. 161 - Bakery 2 in Pompeii

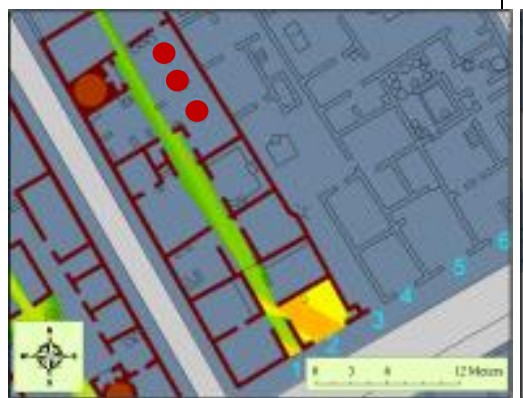

Fig. 164 - Bakery 7 in

Pompeii

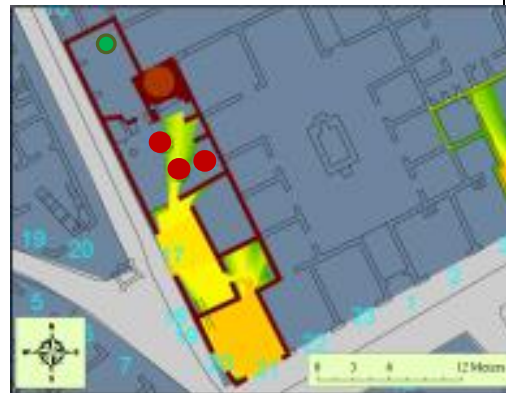

Fig. 167 - Bakery 11 in

Pompeii

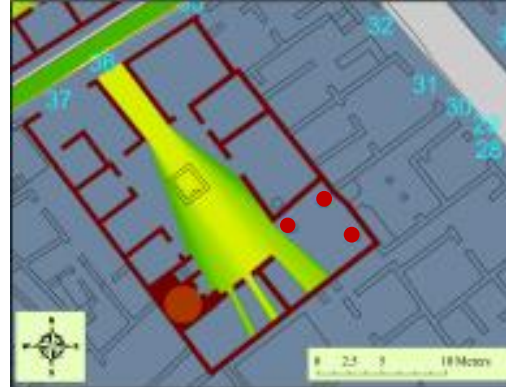

Fig. 170 - Bakery 16 in

Pompeii

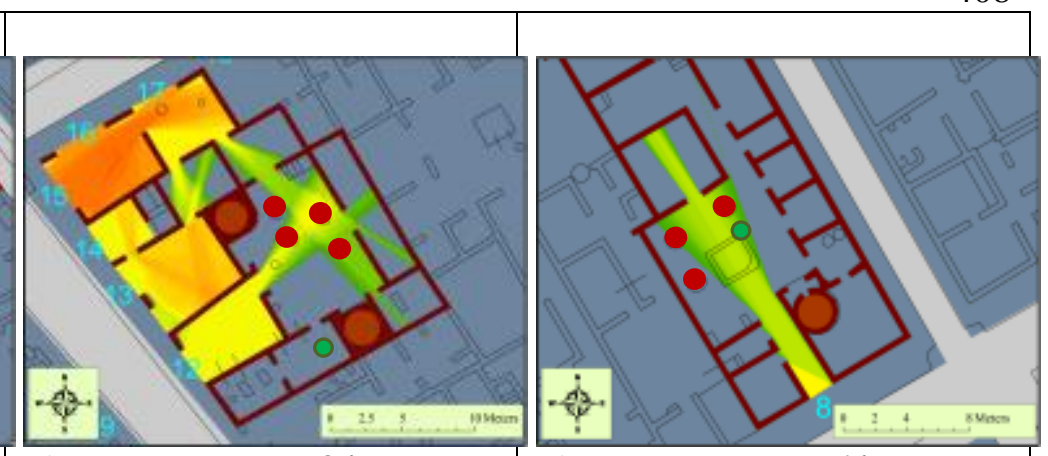

Fig. 162 - Bakery 3 in Pompeii

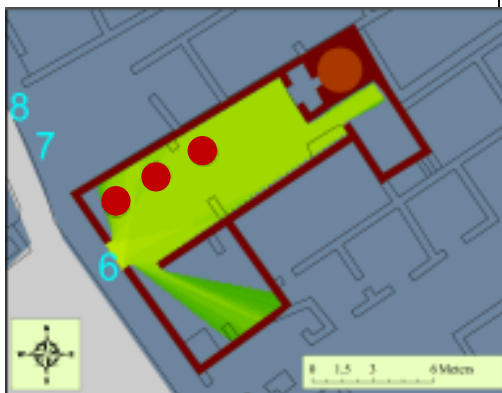

Fig. 165 - Bakery 8 in

Pompeii

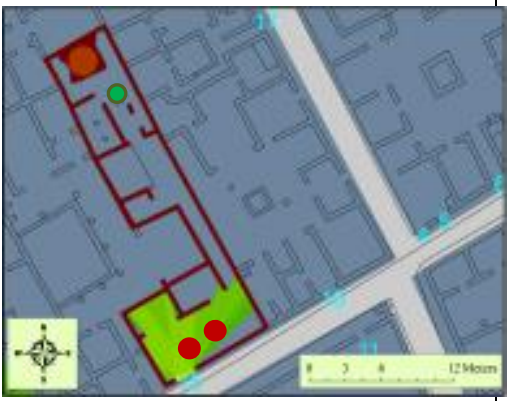

Fig. 168 - Bakery 12 in

Pompeii

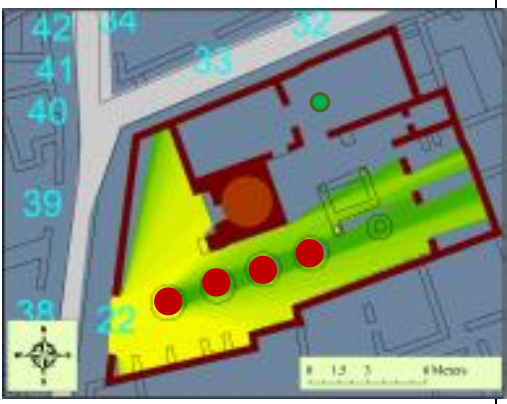

Fig. 171 - Bakery 18 in

Pompeii
Fig. 163 - Bakery 6 in Pompeii

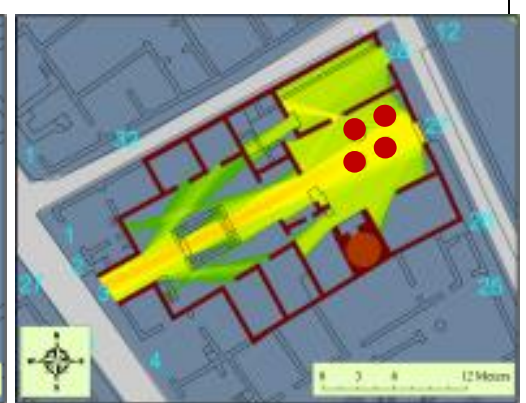

Fig. 166 - Bakery 9 in Pompeii

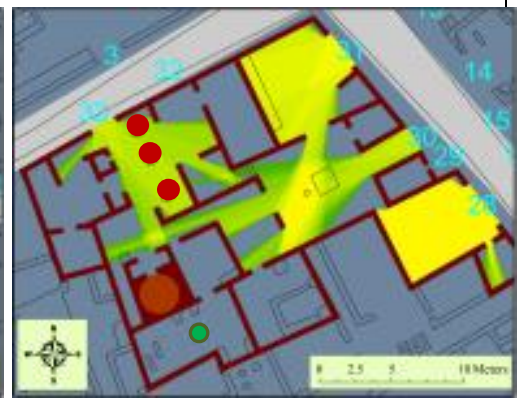

Fig. 169 - Bakery 14 in Pompeii

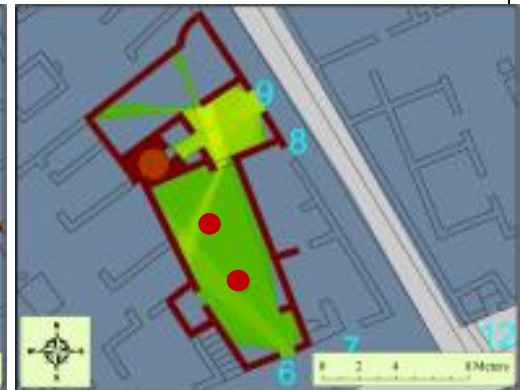

Fig. 172 - Bakery 27 in

Pompeii

The red dots are millstones, the green dots are kneaders, and the orange circles are the ovens. 


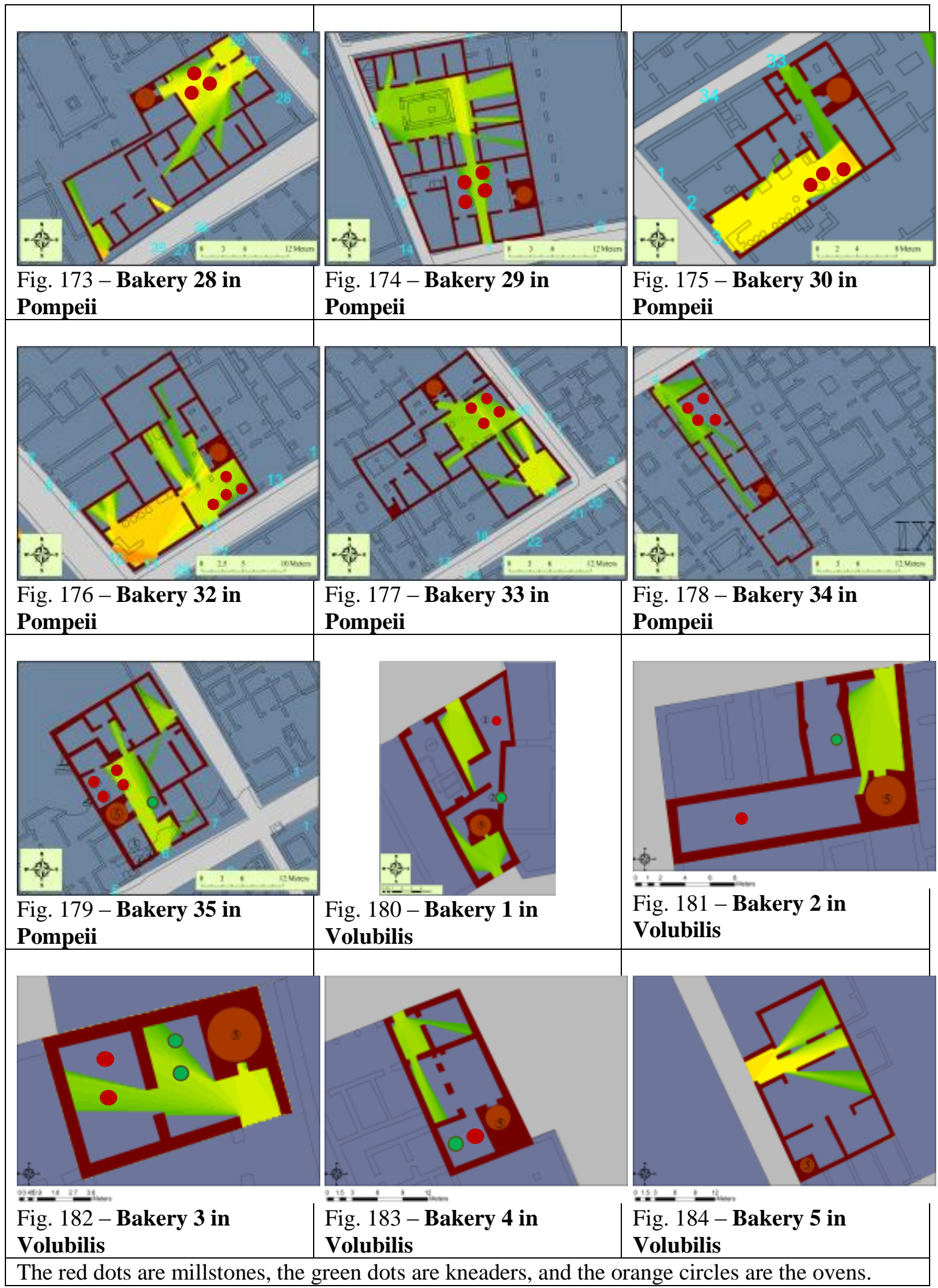




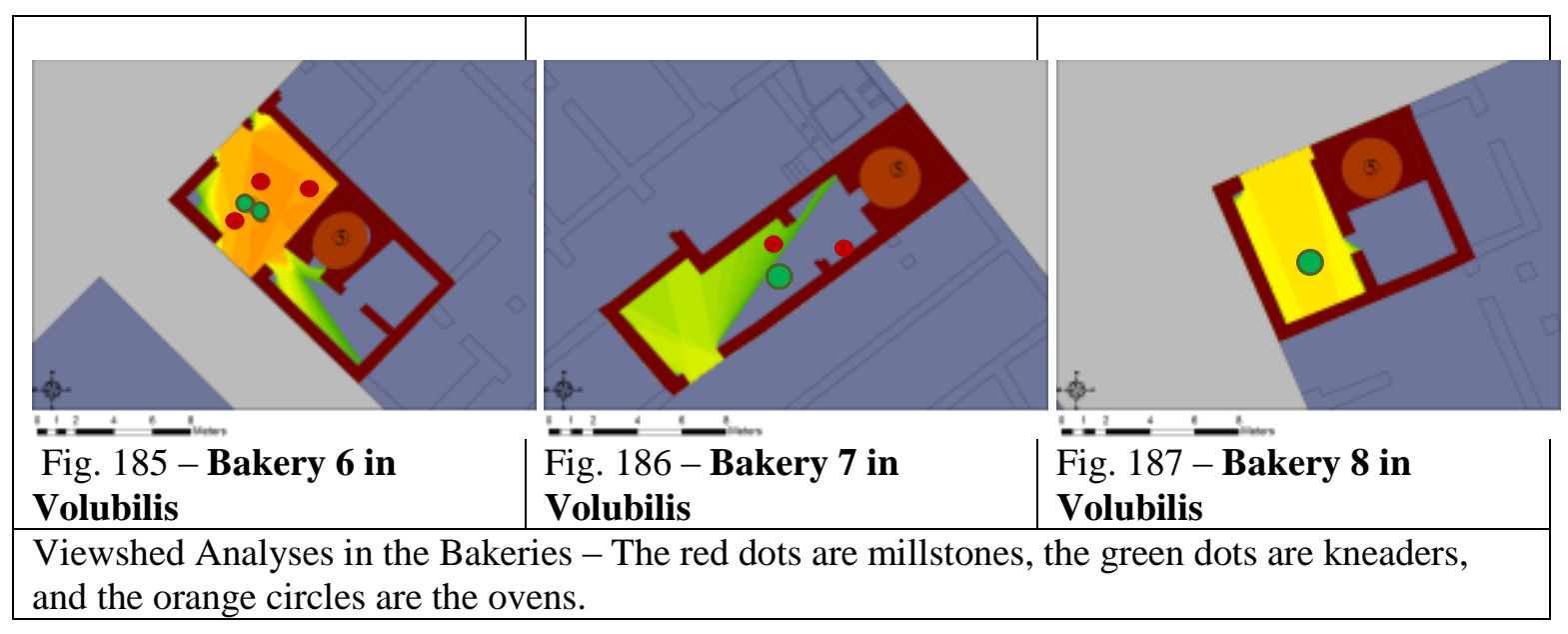




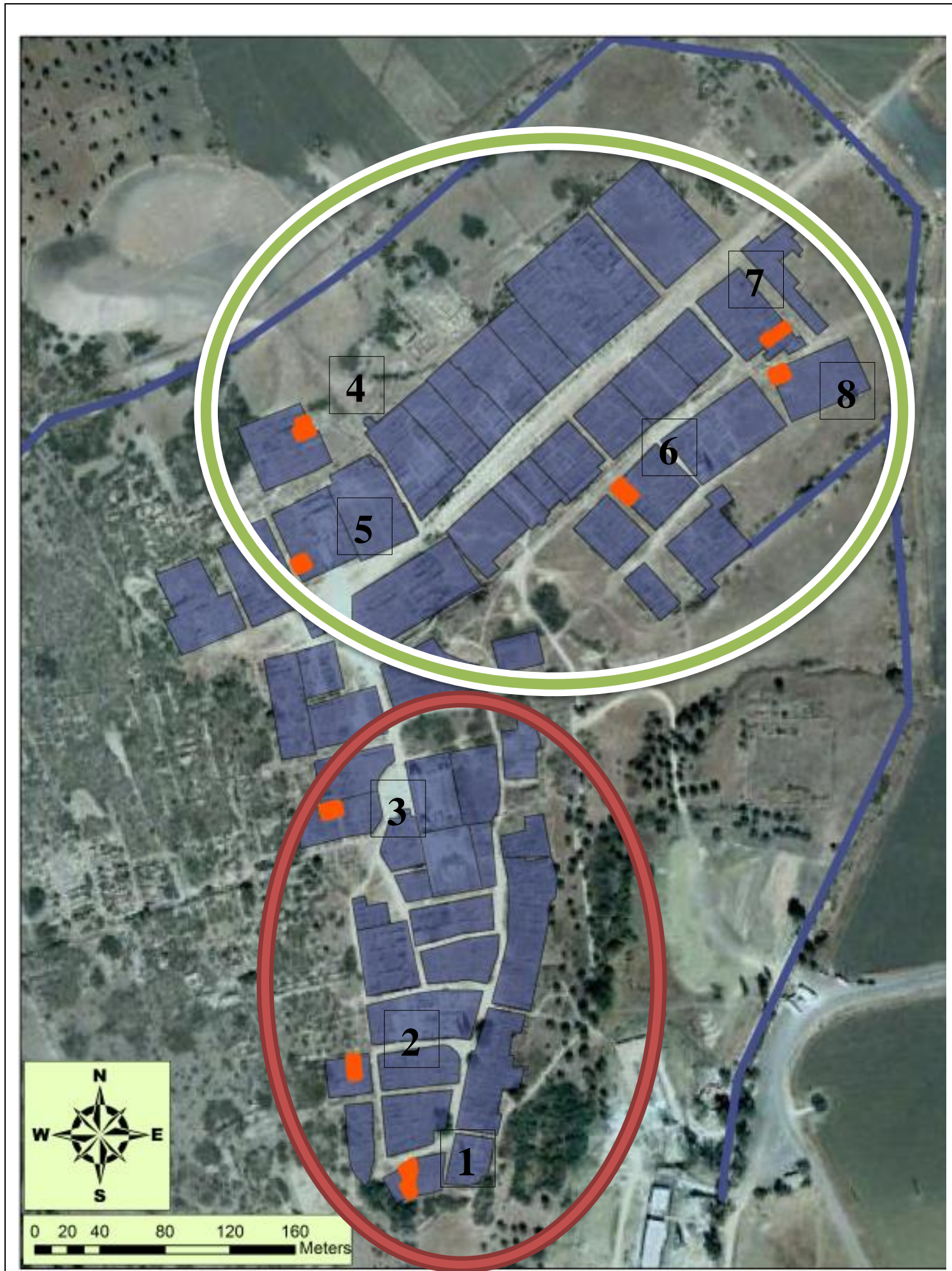

Figure 188 - Plan of Volubilis with Bakeries Identified. The green circle indicates the bakeries in which millstones are the most visible. The red circle indicates the bakeries in which ovens are the most visible. 


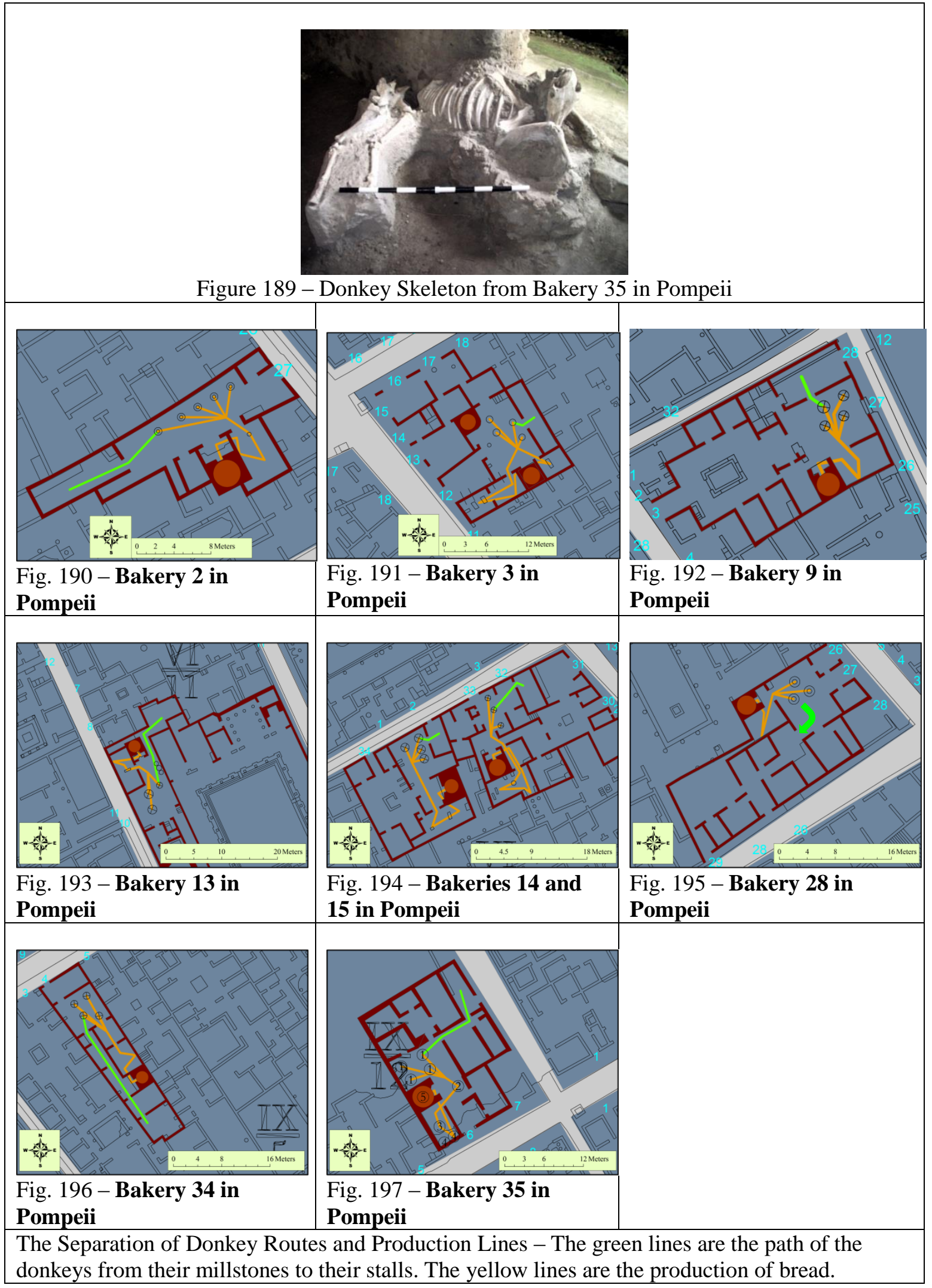




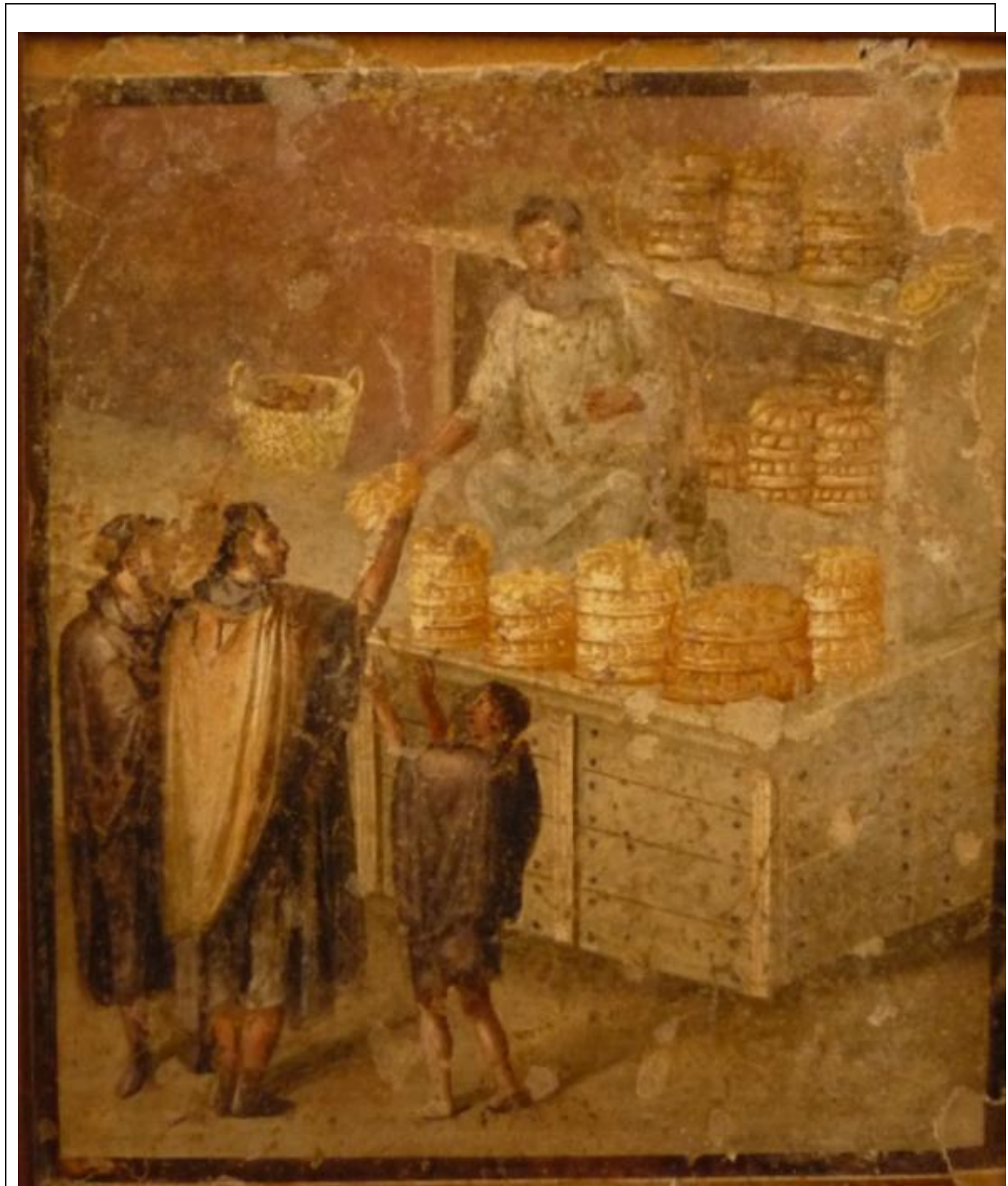

Figure 198 - Distribution of Bread from the Tablinum in the Pompeian House at VIII.3.30 


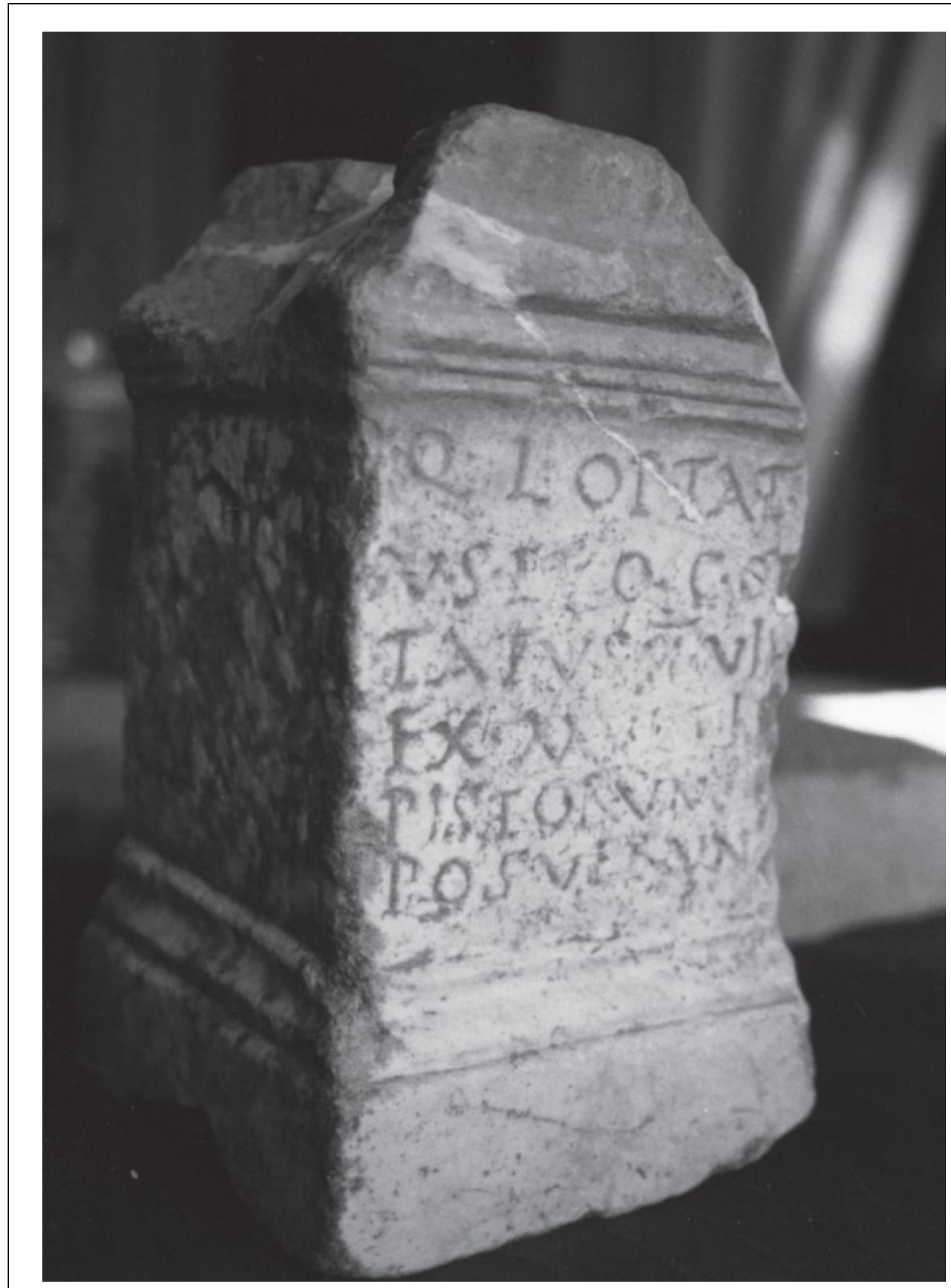

Figure 199 - Inscription Commemorating the Exaction of a Fine from the Pistores (After Ordóñez \& Chamizo 2009, 199) 


\section{BIBLIOGRAPHY}

1. Adam, Jean Pierre. 1994. Roman Building: Materials and Techniques. Bloomington: Indiana University Press.

2. Alexander, C. 1964. Notes on a Synthesis of Form. Cambridge: Harvard University Press.

3. Allison, P. 1999. The Archaeology of Household Activities. Routledge: New York.

4. Alonso, N, M Aulinas, M T Garcia, F Martin, G Prats, and S. Vila. 2011. "Manufacturing rotary querns in the 4th century BC fortified settlement of ElsVilars." In Bread for the People: The Archaeology of Mills and Milling: Proceedings of a Colloquium Held in the British School at Rome, 4th-7th November 2009, edited by D. F. Williams and David Peacock, 55-66. Oxford: Archaeopress.

5. Ammann, Sandra, and Peter-Andrew Schwarz. 2010. Eine Taberna in Augusta Raurica: Ergebnisse der Grabungen 1965-1967 und 2002 in Insula 5/9. Augst BL: Römermuseum Augst.

6. Andreau, J. 1974. Les affaires de Monsieur Jucundus. Rome: École Française de Rome.

7. Andreau, J. 2002. "Twenty Years after Moses I. Finley's The Ancient Economy.” In The Ancient Economy, edited by Walter Scheidel and Sitta von Reden, 3349. Edinburgh University Press: Edinburgh.

8. Antonelli, F., G. Nappi, and L. Lazzarini. 2000. "Sulla 'pietra da mole' della regione di Orvieto. Caratterizzazione petrografica e studio archeometrico di macine storiche e protostoriche dall'Italia centrale." In Atti del I Congresso Nazionale di Archeometria, 195-207. Bologna: Pàtron.

9. Arribas, Antonio. 1987. El Barco de El Sec (Calvià, Mallorca): estudio de los materiales. Mallorca: Exm. Ajuntament de Calvià.

10. Aubert, J. J. 1993. "Workshop Managers." In The Inscribed Economy: Production and Distribution in the Roman Empire in the Light of instrumentum domesticum: The Proceedings of a Conference Held at the American Academy in Rome on 10-11 January, 1992, edited by William V. Harris. Ann Arbor, MI: University of Michigan.

11. Aubert, Jean-Jacques. 1994. Business managers in ancient Rome: a social and economic study of Institores, 200 B.C.-A.D. 250. Leiden: E.J. Brill.

12. Ausbüttel, Frank M. 1982. Untersuchungen zu den Vereinen im Westen des Römischen Reiches. Kallmünz: M. Lassleben. 
13. Bakker, Jan Theo. 1999. The Mills-Bakeries of Ostia: Description and Interpretation. Amsterdam: J.C. Gieben.

14. Bandelli, G. 2002. "La Colonizzazione Romana della Penisola Iberica da Scipione Africano a Bruto Callaico." In Hispania terris omnibus felicior: premesse ed esiti di un processo di integrazione: atti del convegno internazionale, Cividale del Friuli, 27-29 settembre 2001, edited by Gianpaolo Urso, 10542. Pisa: ETS.

15. Beloch, Julius. 1898. Le città dell'Italia antica.

16. Berger, Ludwig. 1977. "Ein gut erhaltener Backofen in Augusta Raurica". Regio Basiliensis. 28-40.

17. Bird, H. W. 1994. Sextus Aurelius Victor: Liber de Caesaribus. Liverpool: Liverpool University Press.

18. Biscottini, Maria Valentina. 1966. "L’Archivio di Tryphon, tessitore di Oxyrhynchos." Aegyptus vol. 46, no. 1: 60-90.

19. Blegen, C. W. 1950. “A Mycenaean Breadmaker.” Annuario della Scuola Archeologica di Atene e delle Missioni Italiane in Oriente vol. 24: 13-16.

20. Blümner, Hugo. 1875. Technologie und Terminologie der Gewerbe und Künste bei Griechen und Römern. Leipzig: B.G. Teubner.

21. Bowman, A. and A. Wilson. 2009. Quantifying the Roman Economy: Methods and Problems. Oxford: Oxford University Press.

22. Boyce, George K. 1937. Corpus of the lararia of Pompeii. Rome: American Academy in Rome.

23. Bradley, Keith R. 1991. Discovering the Roman family: Studies in Roman Social History. New York: Oxford University Press.

24. Bradley, Keith R. 1985. "Child Labour in the Roman World.” Historical Reflections/Reflexions Historiques vol. 12, no. 2, Summer 1985: 311-30.

25. Bradley, M. 2002. "It All Comes out in the Wash: Looking Harder at the Roman Fullonica." Journal of Roman Archaeology 15: 21-44.

26. Brandt, Olle. 1993. "Recent Research on the Tomb of Eurysaces." Opuscula Romana 19, no. 2: 13-17.

27. Bransbourg, G. 2012. "Rome and the Economic Integration of the Empire." ISAW Papers, 3. http://dlib.nyu.edu/awdl/isaw/isaw-papers/3/

28. Broekaert, W. 2011. "Partners in Business: Roman Merchants and the Potential Advantages of being a collegiatus." Ancient Society 41: 221-256.

29. Brumfiel, Elizabeth M., and Timothy K. Earle. 1987. Specialization, Exchange, and Complex Societies. Cambridge: Cambridge University Press. 
30. Buckler, William Hepburn. 1923. "Labour disputes in the Province of Asia". Anatolian Studies Presented to W. M. Ramsay.

31. Bustard, Wendy J. 1996. Space as Place: Small and Great House Spatial Organization in Chaco Canyon, New Mexico, A.D. 1000-1150. Ph.D. diss., University of New Mexico.

32. Caballos Rufino, Antonio, and Pilar León Alonso. 2010. Itálica-Santiponce: Municipium y Colonia Aelia Augusta Italicensium. Roma: L'Erma di Bretschneider.

33. Caballos Rufino, Antonio, Jesús María Marín Fatuarte, and José M anuel Rodríguez Hidalgo. 1999. Itálica arqueológica. Sevilla: Universidad de Sevilla.

34. Carvalho, Susana, Eugénia Cunha, Cláudia Sousa, and Tetsuro Matsuzawa. 2008. "Chaînes opératoires and resource-exploitation strategies in chimpanzee (Pan troglodytes) nut cracking". Journal of Human Evolution. 55 (1): 148163.

35. Ciarallo, A., and M. Mariotti Lippi. 1993. "The Garden of 'Casa dei Casti Amanti' (Pompeii, Italy)." Garden History 21, no. 1: 110-116.

36. Ciarallo, A., and M. Mariotti Lippi. 1993. "The Garden of 'Casa dei Casti Amanti' (Pompeii, Italy)". Garden History. 21 (1): 110-116.

37. Clarke, John R. 1991. The Houses of Roman Italy, 100 B.C.-A.D. 250: Ritual, Space, and Decoration. Berkeley: University of California Press.

38. Coates-Stephens, Robert. 2004. Porta Maggiore, Monument and Landscape: Archaeology and Topography of the Southern Esquiline from the Late Republican Period to the Present. Rome: L'Erma di Bretschneider.

39. Cooley, Alison, and M. G. L. Cooley. 2004. Pompeii: A Sourcebook. London: Routledge.

40. Cooley, Alison. 2003. Pompeii. London: Duckworth.

41. Coupaye, L. 2009. "Ways of Enchanting and the Chaine operatoire." In Prehistoric Britain, edited by J. Pollard, 160-176. Oxford: Blackwell.

42. Cresswell, R. 1976. "Avant-Propos." Techniques et Culture 1: 5-6.

43. Cubberley, A. L., J. A. Lloyd, and P. C. Roberts. 1988. "Testa and Clibani: The Baking Covers of Classical Italy" Papers of the British School at Rome 56: 98-119.

44. Curtis, Robert I. 2001. Ancient Food Technology. Leiden: Brill.

45. Dark, K. R. 1996. External Contacts and the Economy of Late Roman and PostRoman Britain. Woodbridge, Suffolk, UK: Boydell Press.

46. D'Arms, John H. 1981. Commerce and Social Standing in Ancient Rome. Cambridge: Harvard University Press. 
47. David, Nicholas and Carol Kramer. 2001. Ethnoarchaeology in Action. New York: Cambridge University Press.

48. De Robertis, Francesco Maria. 1971. Storia delle corporazioni e del regime associativo nel mondo romano. Bari: Adriatica editrice.

49. De Rossi, Giovanni Battista. 1857. Utilità del metodo geografico nello studio delle iscrizioni cristiane. Iscrizione cristiane di Tropea in Calabria. Napoli: G. Minervini.

50. Deiss, Joseph Jay. 1989. Herculaneum: Italy's Buried Treasure. Malibu: J. Paul Getty Museum.

51. Della Corte, M. 1926. "Publius Paquius Proculus." The Journal of Roman Studies 16: $145-54$.

52. Della Corte, Matteo. 1965. Case ed abitanti di Pompei. Napoli: Faustino Fiorentino.

53. Desportes, F. 1999. "Food Trades." In Food: A Culinary History from Antiquity to the Present, edited by Jean Louis Flandrin, Massimo Montanari, and Albert Sonnenfeld, 275-86. New York: Columbia University Press.

54. Diehl, Ernst. 1930. Pompeianische Wandinschriften und Verwandtes. Berlin: W. De Gruyter \& Co.

55. Dobbins, John J. 1994. "Problems of Chronology, Decoration, and Urban Design in the Forum at Pompeii". American Journal of Archaeology. 98 (4): 629-694.

56. Dobbins, John J. and Pedar William Foss. 2007. The world of Pompeii. London: Routledge.

57. Duhoux, Y. 1974. "Le boulanger et son pain: l'etymologie d'artokopos et d' artos." L'Antiquite Classique XLIII: 321-24.

58. Dunbabin, Katherine M. D. 1999. Mosaics of the Greek and Roman World. Cambridge: Cambridge University Press.

59. Duncan, J. S. 1981. "From Container of Women to Status Symbol: The Impact of Social Structure on the Meaning of the House." In Housing and Identity: Cross-Cultural Perspectives, edited by J. S. Duncan, 36-59. London: Croom Helm.

60. Duncan-Jones, Richard. 1974. The Economy of the Roman Empire: Quantitative Studies. Cambridge: Cambridge University Press.

61. Duncan-Jones, Richard. 1990. Structure and Scale in the Roman Economy. Cambridge: Cambridge University Press.

62. Dunlop, Olive Jocelyn. 1912. English Apprenticeship and Child Labour, a History. New York: Macmillan.

63. Durkheim, E. 1965. Reprint. The Elementary Forms of the Religious Life. Chicago: University of Chicago Press. 1915. 
64. Durkheim, E., and M. Mauss. 1963. Reprint. Primitive Classification. Chicago: University of Chicago Press. 1903.

65. Dyer, Thomas Henry. 1891. Pompeii. London.

66. Elkins, J. 2008. "On Some Limits of Materiality in Art History." 31: Das Magazin des Instituts fur Theorie 12: 25-30.

67. Eschebach, Liselotte, and Jürgen Müller-Trollius. 1993. Gebäudeverzeichnis und Stadtplan der antiken Stadt Pompeji. Köln: Böhlau.

68. Escurac, Henriette Pavis d', and Henriette Pavis. 1976. La préfecture de l'annone: service administratif impérial d'Auguste à Constantin. Rome: Palais Farnèse.

69. Espérandieu, Émile. 1925. Recueil général des bas-reliefs de la Gaule romaine 93. Paris: Nationale.

70. Etienne, Robert. 1960. Le quartier nord-est de Volubilis. Paris: E. de Boccard.

71. Fathy, H. 1986. Natural Energy and Vernacular Architecture. Chicago: University Chicago Press.

72. Fentress, E., H. Limane, and G. Palumbo. 2001. "The Volubilis Project, Morocco. Excavation, Conservation and Management Planning." Archaeology International 5: 36-39.

73. Finley, M. I. 1999. The Ancient Economy. Berkeley: University of California Press.

74. Fiorelli, Giuseppe, Umberto Pappalardo, and Mario Grimaldi. 2001. La descrizione di Pompei per Giuseppe Fiorelli (1875): con una cronistoria per immagini e la lettera alla Guardia Nazionale del distretto di Castellammare di Stabia. Napoli: Massa Editore.

75. Fiorelli, Giuseppe. 1860-62. Pompeianarum Antiquitatum Historia.

76. Fiorelli, Giuseppe. 1861. Giornale degli scavi di Pompei. Napoli: Stamperia della R. Università.

77. Fiorelli, Giuseppe. 1875. Descrizione di Pompei. Napoli: Tipografia Italiana.

78. Fitch, J. M., Branch, D. P. 1960. "Primitive Architecture and Climate." Scientific American 203, no. 6: 134-44.

79. Flannery, K. 1968. "Archaeological Systems Theory and Mesoamerica.” In Anthropological Archaeology in the Americas, edited by B. J. Meggers, 6787. Washington DC: Anthropological Society of Washington.

80. Flohr, Miko. 2007. "Nec quicquam ingenuum habere potest officinal? Spatial contexts of urban production at Pompeii, AD 79." BABesch 82: 129-148.

81. Flohr, Miko. 2013a. The World of the Fullo. Oxford: Oxford University Press. 
82. Flohr, Miko. 2013b. "Review: E. Mayer. The Ancient Middle Classes. Urban Life and Aesthetics in the Roman Empire." Journal of Roman Studies 103: 3089 .

83. Foss, P.W. 1994. "Kitchens and Dining Rooms at Pompeii: The Spatial and Social Relationship of Cooking to Eating in the Roman Household." Ph.D. Diss., University of Michigan.

84. Frank, Tenney, and Allan Chester Johnson. 1933. An Economic Survey of Ancient Rome. Vol. 4. Baltimore: The Johns Hopkins Press.

85. Frankel, Rafael. 2003. "The Olynthus Mill, Its Origin, and Diffusion: Typology and Distribution." American Journal of Archaeology 107, no. 1: 1-21.

86. Franklin, James L. 1990. Pompeii: The "Casa del marinaio" and its History. Rome: L'Erma di Bretschneider.

87. Fröhlich, Thomas. 1991. Lararien-und Fassadenbilder in den Vesuvstädten: Untersuchungen zur 'Volkstümlichen' pompejanischen Malerei. Mainz am Rhein: Philipp von Zabern.

88. Fujisawa, A. 1995. "I 'Pistores' nel Primo Impero.” Acme 48, 2: 169-181.

89. Fulvio, L. 1879. Delle fornaci e dei forni pompeiani.

90. Fusco, Ugo, and Gian Luca Gregori. 1996. "A proposito dei matrimoni di Marcella minore e del monvmentvm dei suoi schiavi e liberti". Zeitschrift Für Papyrologie Und Epigraphik.111: 226-232.

91. Gallo, Alessandro. 2001. Pompei: l'Insula 1 della regione IX: settore occidentale. Rome: L'Erma di Bretschneider.

92. Gallo, Alessandro. 2010. Pompei: scavo stratigrafico nel settore orientale dell'Insula IX, 1: campagne 2004 e 2006: l'area sacra arcaico-ellenistica, l'occupazione dei lotti abitativi. Pompeii (Naples): Associazione internazionale Amici di Pompei.

93. García y García, Laurentino. 2006. Danni di guerra a Pompei: una dolorosa vicenda quasi dimenticata: con numerose notizie sul Museo pompeiano distrutto nel 1943. Rome: L'Erma di Bretschneider

94. Gardiner, E. Norman. 1930. Athletics of the Ancient World. Oxford: Clarendon Press.

95. Gibbs, M. 2011. "Trade Associations in Roman Egypt: Their raison d'être." Ancient Society 41: 291-315.

96. Godelier, Maurice. 1986. The Mental and the Material: Thought Economy and Society. Translated by Martin Thom. London: Verso.

97. Gosden, Chris. 1994. Social Being and Time. Oxford: Blackwell Publishers. 
98. Gosselain, O. 2000. "Materializing Identities: an African Perspective." Journal of Archaeological Method and Theory 7: 187-217.

99. Graves-Brown, P. 2000. Matter, Materiality and Modern Culture. London: Routledge.

100. Green, C. 2011. "Hertfordshire Puddingstone Querns: Working With a Difficult Rock." In Bread for the People: The Archaeology of Mills and Milling: Proceedings of a Colloquium Held in the British School at Rome, 4th-7th November 2009, edited by D. F. Williams and David Peacock, 123-30. Oxford: Archaeopress.

101. Guidobaldi, Maria Paola, Domenico Esposito, and Luciano Pedicini. 2012. Ercolano: colori da una città sepolta. San Giovanni Lupatoto (Verona): Arsenale.

102. Hamon, C., and V. Le Gall. 2011. "Ethnography. Les meules en pays Minyanka (Mali): Étude des carrières et techniques de production actuelles." In Bread for the people: The Archaeology of Mills and Milling: Proceedings of a Colloquium Held in the British School at Rome, 4th-7th November 2009, edited by D. F. Williams and David Peacock, 19-28. Oxford: Archaeopress.

103. Harl, Kenneth W. 1996. Coinage in the Roman Economy, 300 B.C. to A.D. 700. Baltimore: Johns Hopkins University Press.

104. Hasegawa, Kinuko. 2005. The familia urbana During the Early Empire: a Study of Columbaria Inscriptions. Oxford: Archaeopress.

105. Hasegawa, Shuichi. 2012. "Olynthus Millstones in the Southern Levant: The Backdrop to the Maritime Trade of Olynthus Millstones." Palestine Exploration Quarterly, 144, no. 2: 102-114.

106. Helbig, Wolfgang, and Otto Philipp Donner-von Richter. 1868. Wandgemälde der vom Vesuv verschütteten städte Campaniens. Leipzig: Breitkopf und Härtel.

107. Heres, T. L. 1982. Paries, A Proposal for a Dating System of Late-Antique Masonry Structures in Rome and Ostia. Amsterdam: Rodop.

108. Heres, T. L. 1988. "The Building History of the Caseggiato dei Molini (Reg. I iii 1) at Ostia: A Preliminary Study." Mededeelingen van het Nederlands Historisch Instituut te Rome: Antiquity 48: 37-74.

109. Hobson, Barry W., Helen Molesworth, and Kate Trusler. 2009. Pompeii, Latrines and Down Pipes: A General Discussion and Photographic Record of Toilet Facilities in Pompeii. Oxford: John and Erica Hedges Ltd.

110. Hodder, I. 2003. Reading the Past: Current Approaches to Interpretation in Archaeology. $3^{\text {rd }}$ edition. Cambridge: Cambridge University Press.

111. Holleran, Claire. 2012. Shopping in Ancient Rome: The Retail Trade in the Late Republic and the Principate. Oxford: Oxford University Press. 
112. Hope, Valerie M. 2007. Death in Ancient Rome: A Source Book. London: Routledge.

113. Hopkins, Keith. 1978. Conquerors and Slaves. Cambridge: Cambridge University Press.

114. Hugh-Jones, C. 1979. From the Milk River: Spatial and Temporal Processes in Northwest Amazonia. Cambridge: Cambridge University Press.

115. Ingold, Tim. 2007. "Materials against materiality". Archaeological Dialogues. 14 (1): 1-16.

116. Jashemski, Wilhelmina F. 1993. The Gardens of Pompeii: Herculaneum and the Villas Destroyed by Vesuvius. Vol. 2. New Rochelle, N.Y.: A.D. Caratzas.

117. Jasny, Naum. 1944. The Wheats of Classical Antiquity. Baltimore: Johns Hopkins Press

118. Jodry, F. 2011. "Roman First-Century Querns of the Roman Army, in the Light of Modern Texts." In Bread for the People: The Archaeology of Mills and Milling: Proceedings of a Colloquium Held in the British School at Rome, 4th-7th November 2009, edited by D. F. Williams and David Peacock, 8592. Oxford: Archaeopress.

119. Jongman, Willem. 1988. The Economy and Society of Pompeii. Amsterdam: J.C. Gieben.

120. Kehoe, Dennis P. 2007. "The Early Roman Empire: Production." In The Cambridge Economic History of the Greco-Roman World, edited by Walter Scheidel, Ian Morris, and Richard P. Saller, 541-569. New York: Cambridge University Press.

121. Kelley, J. H. and M. P. Hanen. 1988. Archaeology and the Methodology of Science. Albuquerque: University of New Mexico Press.

122. Kent, S. 1984. Analyzing Activity Areas: An Ethnoarchaeological Study of the Use of Space. Albuquerque: University of New Mexico Press.

123. Kirschenbaum, Aaron. 1987. Sons, Slaves, and Freedmen in Roman Commerce. Jerusalem: Magnes Press, Hebrew University.

124. Kleiner, Fred S. 2007. A History of Roman Art. Victoria: Thomson/Wadsworth.

125. Knappett, C. 2012. "Materiality." In Archaeological Theory Today, edited by Hodder, 188-207. Malden, MA: Polity Press.

126. Knowles, R. 1974. Energy and Form: An Ecological Approach to Urban Growth. Cambridge: Massachusetts Institute of Technology Press.

127. Langlois, H. 2000. Etude architeecturale et statigraphique de l'insula 18 de Volubilis, Memoire de maitrise dactylographie. Rouen: universite de Rouen. 
128. Laurence, Ray. 1994. Roman Pompeii: Space and Society. London: Routledge.

129. Lawrence, D. L., and S. M. Low. 1990. "The Built Environment and Spatial Form." Annual Review of Anthropology 19: 453-505.

130. Leduc, M. 2008. "Les Pistrina Volubilitains, Temoins Majeurs du Dynamisme Economique Municipal." In L'Africa Romana. Le Ricchezze dell'Africa Risorse, Produzioni, Scambi. Atti del XVII Convegno di Studio. Sevilla, 1417 Dicembre 2006. Rome: Carocci.

131. Leduc, M. 2011. “L'artisanat au Coeur de la ville: l'exemple des pistrina de Volubilis." In La ville au quotidien: regards croisés sur l'habitat et l'artisanat antiques: Afrique du Nord, Gaule et Italie: actes du colloque international, Maison méditerranéenne des sciences de l'homme, Aix-enProvence, 23 et 24 novembre 2007, edited by Souen Fontaine, Stéphanie Satre, and Amel Tekki, 181-9. Aix-en-Provence: Publications de l'Université de Provence.

132. Lefebvre, H. 1991. The Production of Space. Translated by D. Nicholson-Smith. Oxford: Blackwell.

133. Lemonnier, P. 1992. "Elements for an Anthropology of Technology." Anthropological Papers of the Museum of Anthropology 88. Ann Arbor: University of Michigan Press.

134. Leroi-Gourhan, A. 1964. Le geste e la parole. Sciences d'aujourd'hui. Paris: Michel.

135. Ling, Roger. 2007. Pompeii: History, Life and Afterlife. Stroud: Tempus.

136. Liu, Jinyu. 2008. "Pompeii and Collegia: A New Appraisal of the Evidence." The Ancient History Bulletin 22.1-2: 53-69.

137. Liu, Jinyu. 2009. Collegia centonariorum: The Guilds of Textile Dealers in the Roman West. Boston: Brill.

138. MacMullen, Ramsay. 1963. "A Note on Roman Strikes.” The Classical Journal 58, 6: 269-271.

139. MacMullen, Ramsay. 1974. Roman Social Relations, 50 B.C. to A.D. 284. New Haven: Yale University Press.

140. Magie, David. 1932. The Scriptores historiae Augustae. Cambridge: Harvard University Press.

141. Maiuri, Amedeo. 1958. Ercolano: i nuovi scavi (1927-1958). Rome: Istituto poligrafico dello Stato, Libreria della Stato.

142. Mankiw, N. Gregory. 2007. Macroeconomics. New York: Worth Publishers.

143. Mayer, Emanuel. 2012. The Ancient Middle Classes: Urban Life and Aesthetics in the Roman Empire, 100 BCE-250 CE. Cambridge: Harvard University Press. 
144. Mayeske, Betty Jo B. 1973. Bakeries, Bakers, and Bread at Pompeii: A Study in Social and Economic History. Ann Arbor: University of Michigan Microfilms.

145. Mazois, F. 1824. Les Ruines de Pompei 1-2. Paris: Didot.

146. Meiggs, Russell. 1973. Roman Ostia. Oxford: Clarendon Press.

147. Merkelbach, Reinhold. 1978. Zeitschrift für Papyrologie und Epigraphik. Bonn: Rudolf Habelt Verlag.

148. Miller, D. 1998. Material Cultures: Why Some Things Matter. Chicago: University of Chicago Press.

149. Miller, D. 2005. "Materiality: An Introduction.” In Materiality, edited by D. Miller, 1-50. Durham, NC: Duke University Press.

150. Milligan, George. 1910. Selections from the Greek Papyri. Cambridge: Cambridge University Press.

151. Moeller, Walter O. 1966. "The 'Lanifricarius' and the 'Officinae Lanifricariae' at Pompeii." Technology and Culture 7, no. 4: 493-6.

152. Moeller, Walter O. 1976. The Wool Trade of Ancient Pompeii. Leiden: Brill.

153. Mommsen, Theodor, Paul Krueger, and Alan Watson. 1985. The Digest of Justinian. Vols. 1-3. Philadelphia: University of Pennsylvania Press.

154. Monteix, Nicolas. 2009. "Pompei, Pistrina: Recherches sur les Boulangeries de l'Italie Romaine.” MEFRA 121, 1: 322-335.

155. Morgan, L. H. 1965. Reprint. Houses and House-Life of the American Aborigines. Chicago: University of Chicago Press. 1881.

156. Morgan, M. H. 1960. Vitruvius: The Ten Books on Architecture. New York: Dover Publications.

157. Moritz, L. A. 1958. Grain-Mills and Flour in Classical Antiquity. Oxford: Clarendon Press.

158. Mouritsen, Henrik. 1988. Elections, Magistrates, and Municipal Elite: Studies in Pompeian Epigraphy. Rome: L'Erma di Bretschneider.

159. Mouritsen, Henrik. 2011. The Freedman in the Roman World. Cambridge: Cambridge University Press.

160. Mrozek, Stanisław. 1975. Prix et rémunération dans l'Occident romain, 31 av. n.è.250 de n.è. Gdańsk: Zakład Narodowy im Ossolińskich, Oddział w Gdańsku.

161. Niccolini, Fausto, and Felice Niccolini. 1854. Le Case ed i monumenti di Pompei. Naples. 
162. Nijf, Onno van. 1997. The Civic World of Professional Associations in the Roman East. Amsterdam: J.C. Gieben.

163. Nissen, Heinrich. 1877. Pompeianische Studien zur Städtekunde des Altertums. Leipzig: Breitkopf und Härtel.

164. Norman, A. F. 1992. Libanius: Autobiography and Selected Letters. Cambridge: Harvard University Press.

165. O’Connell, James. 1995. "Ethnoarchaeology Needs a General Theory of Behavior." Journal of Archaeological Research 3: 205-255.

166. Oliver, P. 1969. "Part I.” In Shelter and Society, edited by P. Oliver, 7-29. London: Barrie and Rockliff.

167. Oome, N. 2004. "Il Caseggiato del mitreo di Lucrezio Menandro (I iii 5): een casestudie van wandschilderkunst in Ostia." TMA 31: 12-21.

168. Oome, N. 2007. "The Caseggiato del mitreo di Lucrezio Menandro (I iii 5). A Casestudy of Wall Painting in Ostia." BABesch 82: 233-246.

169. Ordóñez Agulla, Salvador and José Carlos Saquete Chamizo. 2009. "Una Dedicacion Votiva EX MVLTIS PISTORVM hallada en la Betica." HABIS 40: 197-204.

170. Packer, J. E. 1967 "Housing and Population in Imperial Ostia and Rome." Journal of Roman Studies 57: 80-95.

171. Pagano, Mario, and Raffaele Prisciandaro. 2006. Studio sulle provenienze degli oggetti rinvenuti negli scavi borbonici del Regno di Napoli: una lettura integrata, coordinata e commentata della documentazione. Naples: $\mathrm{N}$. Longobardi.

172. Parker Pearson, Michael, and Colin Richards. 1994. Architecture and Order: Approaches to Social Space. London: Routledge.

173. Parton, H. 2011. "The Hand-Mills of Olymbos: An Ethnographical Study of their Form, Function and Role in a Greek Village." In Bread for the People: The Archaeology of Mills and Milling: Proceedings of a Colloquium Held in the British School at Rome, 4th-7th November 2009, edited by D. F. Williams and David Peacock, 29-42 Oxford: Archaeopress.

174. Peacock, D. P. S. and L. Cutler. 2011. "The Earliest Rotary Querns in Southern England." In Bread for the People: The Archaeology of Mills and Milling: Proceedings of a Colloquium Held in the British School at Rome, 4th-7th November 2009, edited by D. F. Williams and David Peacock, 77-80. Oxford: Archaeopress.

175. Peacock, D. P. S. 1980. “The Roman Millstone Trade: A Petrological Sketch.” World Archaeology 12, no. 1, 1980: 43-53. 
176. Peacock, D. P. S. 1982. Pottery in the Roman World: An Ethnoarchaeological Approach. London: Longman.

177. Peacock, D. P. S., and D. F. Williams. 1986. Amphorae and the Roman Economy: An Introductory Guide. London: Longman.

178. Pearson, R. A., and M. Ouassat. 1996. "Estimation of the Liveweight and Body Condition of Working Donkeys in Morocco." The Veterinary Record. 138, no. 10: 229-33.

179. Petersen, Lauren Hackworth. 2006. The Freedman in Roman Art and Art History. New York: Cambridge University Press.

180. Pharr, Clyde. 1952. The Theodosian Code and Novels, and the Sirmondian Constitutions. Princeton: Princeton University Press.

181. Pirson, F. 1997. "Rented Accommodation at Pompeii: The Evidence of the Insula Arriana Polliana VI 6." Journal of Roman Archaeology-Supplementary Series 22: 165-182.

182. Poste, E. A. Whittuck, A. H. J. Greenidge, and Francis De Zulueta. 1904. Gai Institutiones, or, Institutes of Roman Law. Oxford: Clarendon Press.

183. Poste, Edward. 1890. Gaius: Elements of Roman Law. Oxford: Clarendon Press.

184. Preziosi, D. 1979a. The Semiotics of the Built Environment: An Introduction to Architectonic Analysis. Bloomington: University of Indiana Press.

185. Preziosi, D. 1979b. Architecture, Language, and Meaning. New York: Mouton Publishers.

186. Preziosi, D. 1983. Minoan Architectural Design: Formation and Signification. New York: Mouton.

187. Prussin, L. 1969. Architecture in Northern Ghana: A Study of Forms and Functions. Berkeley: University of California Press.

188. Rapoport, A. 1969a. House Form and Culture. Englewood Cliffs, NJ: PrenticeHall.

189. Rapoport, A. 1969b. "The Pueblo and the Hogan: A Cross-Cultural Comparison to Two Responses to an Environment." In Shelter and Society, edited by P. Oliver, 66-79. New York: F.A. Praeger.

190. Ratti, Niccola. 1825. "Dissertazione sopra una antica iscrizione rinvenuta nel territorio di Cività-Lavinia spettante alla citta di Lanuvio, Dissertazioni della Pontificia Accademia romana di archeologia." Atti dell'Accademia romana di archeologia 2: 435-462.

191. Renfrew, Colin, and Kenneth L. Cooke. 1979. Transformations: Mathematical Approaches to Culture Change. New York: Academic Press. 
192. Renzulli, A., P. Santi, G. Nappi, M. Luni and D. Vitali. 2002. "Provenance and Trade of Volcanic Rock Millstones from Etruscan-Celtic and Roman Archaeological Sites in Central Italy." European Journal of Mineralogy 14: 175-183.

193. Robinson, D. 2005. "Re-thinking the Social Organisation of Trade and Industry in First Century A.D. Pompeii.” In Roman Working Lives and Urban Living, edited by Ardle MacMahon and Jennifer Price, 88-105. Oxford: Oxbow Books.

194. Rolfe, John C. 1913. Suetonius. Cambridge: Harvard University Press.

195. Rossetto, Paola Ciancio. 1973. Il sepolcro del fornaio Marco Virgilio Eurisace a Porta Maggiore. Rome: Istituto di studi romani.

196. Rostovtzeff, Michael Ivanovitch, and J. D. Duff. 1926. A History of the Ancient World. Oxford: Clarendon Press.

197. Rostovtzeff, Michael Ivanovitch. 1957. The Social and Economic History of the Roman Empire. Oxford: Clarendon Press.

198. Roth, Jonathan P. 2012. The Logistics of the Roman Army at War (264 B.C.-A.D. 235). Leiden: Brill.

199. Russell, J.C. 1977. "The Population and Mortality at Pompeii." Bulletin of the International Committee on Urgent Anthropological and Ethnological Research 19: 107-14.

200. Saller, Richard. 2012. "Human Capital and Economic Growth." In The Cambridge Companion to the Roman Economy, edited by Walter Scheidel, 71-86. Cambridge: Cambridge University Press.

201. Schefold, Karl. 1957. Die Wände Pompejis: topographisches Verzeichnis der Bildmotive. Berlin: DeGruyter.

202. Scheidel, W. 2004. "Prices and Other Monetary Valuations in Roman History: Ancient Literary Evidence." http://www.stanford.edu/ sscheidel/NumKey.htm

203. Scheidel, W. 2006. "Stratification, Deprivation and Quality of Life." In Poverty in the Roman World, edited by M. Atkins and R. Osborne, 40-59. Cambridge University Press: Cambridge.

204. Scheidel, W. 2009. "In Search of Roman Economic Growth." Journal of Roman Archaeology 22: 46-70.

205. Schiffer, M. B., and J. M. Skibo. 1997. "The Explanation of Artifact Variability." American Antiquity 62: 27-50.

206. Schneider, Helmuth. 2007. "Technology." In The Cambridge Economic History of the Greco-Roman world, edited by Walter Scheidel, Ian Morris, and Richard P. Saller, 144-72. New York: Cambridge University Press. 
207. Sebesta, Judith Lynn, and Larissa Bonfante. 1994. The World of Roman Costume. Madison: University of Wisconsin Press.

208. Sica, M., S. Aceto, A. Genovese, and L. Gaudio. 2002. "Analysis of Five Ancient Equine Skeletons by Mitochondrial DNA Sequencing." Ancient Biomolecules 4, no. 4: 179-184.

209. Sigurdsson, Haraldur, Stanford Cashdollar and Stephen R. J. Sparks. 1982. "The Eruption of Vesuvius in A. D. 79: Reconstruction from Historical and Volcanological Evidence" AJA 86, 1: 39-51.

210. Sirks, Adriaan Johan Boudewijn. 1991. Food for Rome: The Legal Structure of the Transportation and Processing of Supplies for the Imperial Distributions in Rome and Constantinople. Amsterdam: J.C. Gieben.

211. Skibo, M., and M. B. Schiffer. 2008. People and Things: A Behavioural Approach to Material Culture. New York: Springer.

212. Skydsgaard, J. E. 1983. "Public Building and Society." In Città e architettura nella Rome Imperiale, edited by K. de Fine Licht, 223-237. Odense.

213. Smith, Richard Horton. 1904. “A Well-Known Epitaph.” In Notes and Queries 10: 444-445. London: Oxford University Press.

214. Smits, Wendy, and Thorsten Stromback. 2001. The Economics of the Apprenticeship System. Cheltenham, UK: E. Elgar.

215. Sprecht, Eckhardt. 2013, 18 October. "The Best Known Packings of Equal Circles in a Circle." http://hydra.nat.uni-magdeburg.de/packing/cci/cci.html

216. Starace, Pia. 2006. Lo statuliber e l'adempimento fittizio della condizione: uno studio sul favor libertatis fra tarda Repubblica ed età antonina. Bari: Cacucci Editore.

217. Strocka, Volker Michael. 1991. Casa del Labirinto (VI 11,8-10). München: Hirmer.

218. Tchernia, A. 1968. "Premiers resultants des fouilles de juin 1968 sur l'epave 3 de Planier." Aix-en-Provence 3: 51-82.

219. Temin, Peter. 2006. "The Economy of the Early Roman Empire." Journal of Economic Perspectives 20, 1: 133-151.

220. Temin, Peter. 2013. The Roman Market Economy. Princeton: Princeton University Press.

221. Tilley, Christopher. 2004. "The Materiality of Stone." In Explorations in Landscape Phenomenology, Edited by Tilley, Christopher, and Wayne Bennett. New York: Berg.

222. Toren, Christina. 1999. Mind, Materiality, and History: Essays in Fijian Ethnography. New York: Routledge. 
223. Van der Leeuw, S. 1993. "Giving the Potter a Choice: Conceptual Aspects of Pottery Techniques." In Technological Choices: Transformation in Material Cultures Since the Neolithic, edited by Pierre Lemonnier, 238-88. New York: Routledge.

224. Van der Leeuw, S. 2009. “The Long-Term Evolution of Social Organization.” In Complexity: Perspectives in Innovation and Social Change, edited by D. Lane, S. van der Leeuw, D. Pumain \& G. West, 85-116. Dordrecht: Springer.

225. Van der Poel, Halsted B., and Laurentino García y García. 1986. Corpus Topographicum Pompeianum. Pars 3 A, Pars 3 A. Rome: Ed. dell'Elefante.

226. Verboven, Koenraad. 2002. The Economy of Friends: Economic Aspects of Amicitia and Patronage in the Late Republic. Brussels: Editions Latomus.

227. Wailes, B. 1996. "V. Gordon Childe and the Relations of Production." In Craft Specialization and Social Evolution: In Memory of V. Gordon Childe, edited by B. Wailes, 3-16. Philadelphia: University of Pennsylvania Museum of Archaeology and Anthropology.

228. Wallace-Hadrill, A. 1994. Houses and Society in Pompeii and Herculaneum. Princeton: Princeton University Press.

229. Wallace-Hadrill, A.1995. "Public Honour and Private Shame: The Urban Texture of Pompeii." In Urban Society in Roman Italy, edited by Cornell, Tim, and Kathryn Lomas, 39-62. New York: St. Martin's Press.

230. Wallace-Hadrill, A. 2008. Rome's Cultural Revolution. Cambridge: Cambridge University Press.

231. Wallace-Hadrill, A. 2011. Herculaneum: Past and Future. London: Frances Lincoln Limited.

232. Waltzing, Jean Pierre. 1895. Étude historique sur les corporations professionelles chez les Romains depuis les origines jusqu'à la chute de l'Empire d'Occident.

233. Ward-Perkins, Bryan. 2005. The Fall of Rome: And the End of Civilization. Oxford: Oxford University Press.

234. Warsher, Tatiana. 1937-1957. Codex topographicus Pompejanus.

235. Wefers, S. 2011. "Still Using Your Saddle Quern? A Compilation of the Oldest Known Rotary Querns in Western Europe." In Bread for the People: The Archaeology of Mills and Milling: Proceedings of a Colloquium Held in the British School at Rome, 4th-7th November 2009, edited by D. F. Williams and David Peacock, 67-76. Oxford: Archaeopress.

236. White, D. 1963. “A Survey of Millstones from Morgantina.” American Journal of Archaeology 67, 2: 199-206. 
237. Wikander, Ö. 2008. "Sources of Energy and Exploitation of Power." In The Oxford Handbook of Engineering and Technology in the Classical World, edited by John Peter Oleson, 136-157. Oxford: Oxford University Press.

238. Williams, R.S., and D. P. S. Peacock. 2011. "A Note on Pompeian Style Mills in Britain." In Bread for the People: The Archaeology of Mills and Milling: Proceedings of a Colloquium Held in the British School at Rome, 4th-7th November 2009, edited by D. F. Williams and David Peacock, 117-22. Oxford: Archaeopress.

239. Williams-Thorpe, O., and R. S. Thorpe. 1990. "Millstone Provenancing Used in Tracing the Route of a Fourth-Century BC Greek Merchant Ship." Archaeometry 32, no. 2: 115-137

240. Williams-Thorpe, O., and R. S. Thorpe. 1991. "The Import of Millstones to Roman Mallorca." Journal of Roman Archaeology 4: 152-159.

241. Williams-Thorpe, O., and R.S. Thorpe. 1993. "Geochemistry and Trade of Eastern Mediterranean Millstones from the Neolithic to Roman Periods." Journal of Archaeological Science 20: 263-320.

242. Wilson, A. 2006. "The Economic Impact of Technological Advances in the Roman Construction Industry." In Innovazione tecnica e progresso economico nel mondo romano. Atti degli Incontri capresi di storia dell'economia antica. Capri 13-16 aprile 2003, edited by Elio lo Cascio, 225-236. Bari : Edipuglia.

243. Wilson, A. 2011. "City Sizes and Urbanization in the Roman Empire." In Settlement, Urbanization, and Population, edited by Alan K Bowman and Andrew Wilson, 161-95. Oxford: Oxford University Press.

244. Wilson, A., and K. Schorle. 2009. “A Baker's Funerary Relief from Rome." Papers of the British School at Rome 77: 101-23.

245. Wing, Daniel, and Alan Scott. 1999. The Bread Builders: Hearth Loaves and Masonry Ovens. White River Junction, VT: Chelsea Green.

246. Zehnacker, Hubert, and Gilbert Hallier. 1964a. "Les premiers thermes de Volubilis et la Maison à la Citerne.” Mélanges d'archéologie et d'histoire, 77: 87152.

247. Zehnacker, Hubert, and Gilbert Hallier. 1964b. Les premiers thermes de Volubilis et la maison à la citerne. Paris: Boccard.

248. Zimmer, Gerhard. 1982. Römische Berufsdarstellungen. Berlin: Mann. 